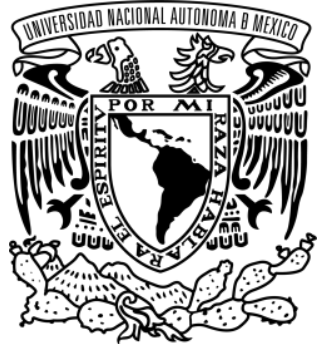

UNIVERSIDAD NACIONAL AUTÓNOMA DE MÉXICO

ESCUELA NACIONAL DE TRABAJO SOCIAL

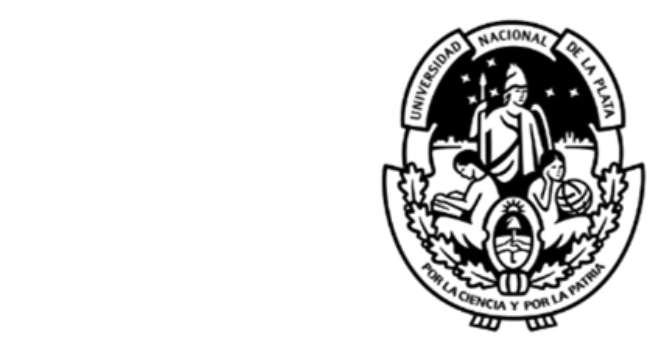

UNIVERSIDAD NACIONAL DE LA PLATA

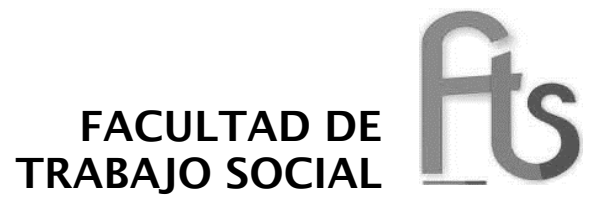
TRABAJO SOCIAL

$\mathrm{s}$

\title{
Del dispositivo de la intervención al proceso de acompañamiento social
}

El Trabajo Social y su implicación con la niñez en condición de institucionalización

\section{PRESENTA:}

\section{CARMEN GABRIELA RUÍZ SERRANO}

Programa de Doctorado en Trabajo Social

DIRECTORA:

DRA. BERENICE PÉREZ RAMÍREZ

ENTS-UNAM

CODIRECTORA:

DRA. CELESTE HERNÁNDEZ

FTS-UNLP 


\section{RESUMEN}

La presente tesis analiza las categorías subjetivación, episteme e institución, como los elementos constituyentes del dispositivo de la intervención que posibilita el ejercicio profesional de las trabajadoras sociales dedicadas a la atención de la niñez en condición de institucionalización. Ha sido realizada con fundamento en la metodología de enfoque cualitativo y teórico de la analítica del poder.

El estudio ha logrado desvelar la intersección de los elementos que dan cuerpo al dispositivo de la intervención, evidenciando la manera en cómo se entrelazan y retroalimentan dialéctica y no linealmente.

Entre los resultados más relevantes, está la propuesta de "enfoque de reconocimiento de la niñez”, que la emplaza como la experiencia humana dinámica, relacional y contextual de los primeros años de vida, resultante de un recorrido histórico que supone un proceso de humanización. De igual forma, resignifica la intervención profesional e invita a un desplazamiento hacia la construcción de procesos de "acompañamiento social", de encuentro horizontal, en donde convergen las voces del profesional que acompaña y el sujeto de decisión que se hace acompañar, cuyo encuentro, desencadena la posibilidad de transformación de trayectorias.

Los resultados, aportes y reflexiones plasmados en este documento, aspiran a contribuir en la manera en cómo las y los trabajadores sociales nos situamos en el escenario operativo y definimos encuentros que viabilizan geografías tendientes al reconocimiento de las y los otros, desde el respeto de las identidades, la dignidad y la esperanza. 


\section{Dedico esta tesis:}

A las personas niñas, quienes me han enseñado a colocarme en el mundo, desde los territorios de la esperanza, el amor y la rebeldía.

A las personas adultas que cuidan de las personas niñas, disponiéndose a hospedar sus realidades, y con ello, contribuir a una sociedad menos injusta y desigual.

A mi persona niña favorita, Naatak. 


\section{Agradecimientos}

El documento que las y los lectores tienen en sus manos representa en mí, más que un instrumento de carácter académico resultado de un vasto proceso de investigación, una posibilidad para dar voz a todas aquellas personas que han determinado mi forma de estar y vivirme en el mundo. Especialmente, dedico este trabajo y agradezco, a las niñas y los niños cuyas historias de abuso y maltrato han fisurado mi alma, y al mismo tiempo, han revelado resistencias y quienes son el motivo principal para luchar día a día por un mundo menos violento, injusto y desigual; esto en la aspiración de cuidar, acoger y acompañar a todas las personas niñas.

Ofrezco una disculpa por los desatinos, omisiones y fallas que esta investigación pueda tener, asumo la responsabilidad plenamente, al estar consciente de que, cada línea escrita se encuentra trazada por mi ser "sentipensante", que se apasiona, se trastoca, se confunde y se implica.

Empezaré agradeciendo a mi clan: gracias Naatak por tu presencia en mi vida, por darme la oportunidad de cuidar de ti, en colectivo, en manada, en el encuentro; por tu paciencia, tus enseñanzas, tu mirada, que cada amanecer, me confirma que siempre vale la pena luchar. A mi compañero de vida Paco por la complicidad, la fuerza, los sueños construidos, la entrega y la utopía que apunta a construir un mundo, donde quepan muchos mundos. A mis padres, con quienes he compartido la vida y mi proyecto más importante, el cuidado de "nuestro niño". A mis hermanos por ser los mejores cómplices de vida. Infinitas gracias, sin ustedes, imposible haber llegado hasta aquí.

Agradezco a todas mis colegas y particularmente a las trabajadoras sociales de Casa Cuna Coyoacán, que generosas me recibieron y enseñaron en los primeros años, cuando el universo de las violencias y la niñez me descolocaban y cegaban los caminos. A ti Maru Sandoval, por ser inspiración y fuerza. A mis compañeras y amigas que, desde sus conocimientos psicológicos, jurídicos y médicos, me ayudaron a entender la condición humana, a ti mi querida Jacquie.

A mis estudiantes de la práctica de especialización "Trata de personas y maltrato infantil" y especialmente a las y los integrantes del proyecto académico "Problemáticas de la

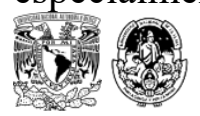


niñez en el México contemporáneo”, profesionistas en formación cuya mirada, escucha y palabra motiva la construcción de nuevos caminos.

A las y los profesionales en ejercicio de las instituciones gubernamentales y organizaciones de la sociedad civil que brindaron sus experiencias, definiendo universos de reflexión. A las y los periodistas que, valientes señalan, visibilizan y se comprometen en la construcción de “otras formas" para enunciar la realidad: Kenia Velázquez, Raymundo Sandoval y Alejandro Hernández.

A mi directora Berenice Pérez Ramírez y codirectora María Celeste Hernández, ambas acompañaron con sus saberes, su presencia e infinita generosidad. Berenice, colega, modelo y amiga, guía determinante en este proceso. Este documento es el resultado de las conversaciones, las coincidencias, los encuentros y desencuentros.

A la Universidad Nacional Autónoma de México y la Escuela Nacional de Trabajo Social, mi "alma mater", geografía plural que promueve posicionamientos críticos y reflexivos en sus aulas, jardines, pasillos. A las autoridades académicas que impulsaron la formación de Doctoras y Doctores en Trabajo Social. A la Maestra Leticia Cano, cuyo ejemplo y entrega, es inspiración.

A la Universidad Nacional de La Plata y la Facultad de Trabajo Social que, a través de sus profesoras y profesores, me permitieron entrar al mundo contemporáneo del Trabajo Social, a los debates que emergen desde nuestra Patria grande y a su vez me desafiaron para la construcción del conocimiento científico disciplinar, Dra. Margarita Rosas y Dr. Alfredo Carballeda.

Al Sistema Nacional para el Desarrollo Integral de la Familia, institución que me formó en el quehacer profesional y me abrió las puertas para la realización de este estudio, a las autoridades Claudia Navarro, Gloria Tokunaga y Oscar Isidro, que han confiado en cada propuesta, investigación e iniciativa, encaminada a la consolidación de las trabajadoras sociales dedicadas a la atención de la niñez receptora de maltrato.

A todas las personas capaces de indignarse frente a la injusticia y la violencia.

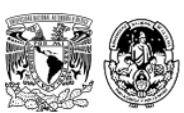




\section{ÍNDICE}

GLOSARIO DE ABREVIATURAS 10

INTRODUCCIÓN Mirarse hacia adentro: del andar profesional al andar analítico 11

Mirar ahí: los Centros de Asistencia Social, el escenario investigativo 13

Niñez en condición de institucionalización: implicación y planteamiento 16 metodológico de la investigación

Una niñez situada: niñez receptora de maltrato, sin cuidados parentales y 18 en condición de institucionalización

Del contenido: situándonos en el desarrollo de la investigación 19

JUSTIFICACIÓN CAPÍTULO I

UN ENFOQUE CUALITATIVO PARA COMPRENDER LA INTERVENCIÓN DEL TRABAJO SOCIAL CON LA NIÑEZ RECEPTORA DE MALTRATO, SIN CUIDADOS PARENTALES Y EN CONDICIÓN DE INSTITUCIONALIZACIÓN: RECORRIDO METODOLÓGICO

Prefacio 31

$1.1 \quad$ Pregunta de investigación 32

1.2 Objetivo General 32

1.3 Objetivos específicos 32

1.4 Supuesto hipotético 32

1.5 Enfoque metodológico 33

$\begin{array}{lll}1.6 & \text { Técnicas } & 36\end{array}$

$\begin{array}{lll}1.7 & \text { Instrumentos } & 40\end{array}$

1.8 Herramientas 41

CAPÍTULO II LA ANALÍTICA DEL PODER: APROXIMACIONES PARA EL 42 ANÁLISIS DE LA INTERVENCIÓN DESDE EL TRABAJO SOCIAL

Prefacio $\quad 45$

2.1 La analítica del poder y sus postulados teóricos 46

2.1.1 Poder y elementos constituyentes 48

2.1.2 Subjetivación: la construcción del sujeto 50

2.1.3 Dispositivo: de lo dicho y lo no dicho 52

2.1.4 Episteme: los constructos de la ciencia 54

2.1.5 Agenciamiento: fenómenos de individuación 55

2.1.6 El sujeto institucional: la otra cara de la intervención 56

2.2 De otros estudios sobre la niñez contemporánea y la intervención $\quad 58$ del Trabajo Social desde la analítica del poder

CAPÍTULO III EPISTEMES DE LA NIÑEZ: DEL INFANTE SUJETO DE 62 PROTECCIÓN A LA NIÑEZ COMO CONSTRUCTO DINÁMICO, RELACIONAL Y CONTEXTUAL

$\begin{array}{ll}\text { Prefacio } & 69\end{array}$

3.1 Epistemes de la niñez: categoría conceptual, resultado de un 71 devenir histórico 
3.1.1 Historización de la niñez desde la mirada de la Europa 72 occidental

3.1.2 Historización de la niñez en México 77

3.1.2.1 El México prehispánico: entre el Tepochcalli 78 y el Calmécac

3.1.2.2 La época colonial: un nuevo ordenamiento 80

3.1.2.3 Los movimientos independentista y 81 revolucionario en México: entre segregación, violencia y abandono

3.1.2.4 El nuevo Estado-nación: el nuevo ciudadano

3.2 Conocimientos y saberes en torno a la niñez en una perspectiva 88 contemporánea: construyendo una episteme en el contexto de los derechos del Niño

3.2.1 De los diversos campos en el estudio de la niñez

3.2.2 Los derechos de niñas $y$ niños en el marco

88 internacional y nacional: dispositivo en el ordenamiento jurídico

90

$\begin{array}{lll}\text { 3.3 La niñez en el contexto capitalista-neoliberal } & 97\end{array}$

3.3.1 La psicología promovente de una episteme

97 individualizante: ritmos y modalidades convenientes al capitalismo

3.3.2 La niñez como sujeto relacional en un contexto capitalista neoliberal

3.3.3 Los dos polos de la niñez en el capitalismo: 101 consumidor y consumible.

3.4 Propuestas epistemológicas y de enfoque para la comprensión de 106 la niñez

3.4.1 Nueva mirada de la infancia: por una categoría 107 relacional

$\begin{array}{lll}\text { 3.4.2 Por una Cultura de la infancia } & 109\end{array}$

3.4.3 Una mirada sociológica y antropológica 110 deconstructiva de la infancia

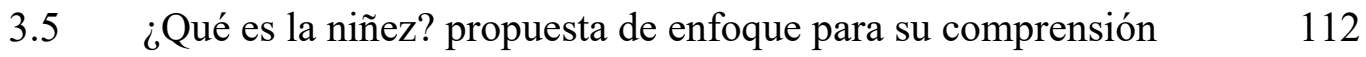

\begin{tabular}{ll} 
Epílogo & 113 \\
\hline & 116
\end{tabular}

CAPÍTULO IV LAS EPISTEMES DE LA INTERVENCIÓN DESDE EL TRABAJO 116 SOCIAL FRENTE A UNA NIÑEZ SITUADA

Prefacio

4.1 Las epistemes de la intervención: de la filantropía vigilante a la 121 operación institucionalizada

4.1.1 La Reconceptualización: entre la encomienda 125 funcionalista y el principio emancipador

4.1.2 El reconocimiento de la niñez como sujeto de 130 intervención social en el capitalismo neoliberal

4.1.3 La niñez en condición de institucionalización y la 131 intervención desde el Trabajo Social: tensiones e imprecisiones 
4.2 La intervención desde el Trabajo Social contemporáneo: algunas propuestas latinoamericanas

CAPÍTULO V

Epílogo

136

143

CUIDADO ALTERNATIVO: ESTRATEGIA PARA LA ATENCIÓN DE LA NIÑEZ RECEPTORA DE MALTRATO

Prefacio

5.1 Niñez y violencias estructurales: cuando el afuera determina el

5.2 Niñez y violencias domésticas: cuando el adentro determina el

154 afuera

5.3 Acogimiento residencial: la institucionalización como estrategia de restitución de derechos de la niñez receptora de maltrato

5.4 La asistencia social en México en materia de protección a la niñez: $\quad 160$ responsabilidad del SNDIF

5.4.1 De la Procuraduría Federal de Protección de Niñas, 164 Niños y Adolescentes

5.5 Niñas, niños y adolescentes en condición de institucionalización: cifras, motivos y afectaciones

5.5.1 Motivos de ingreso de la niñez a los espacios de cuidado alternativo

5.5.2 Del desprendimiento familiar al encierro institucional: efectos, implicaciones y grietas

5.5.3 Trastornos psicológicos y psiquiátricos asociados con la institucionalización de niñas y niños en CAS

5.5.4 Afectaciones al desarrollo derivadas de la 188 institucionalización en la niñez

CAPÍTULO VI

Epilogo

CENTROS DE ASISTENCIA SOCIAL: "ESPACIOS DE RIESGO", UNA INVISIBLE REALIDAD

Prefacio

192

6.1 Centros de Asistencia Social identificados en el territorio nacional como "espacios de riesgo"

6.1.1 Cronología de las geografías de violencia: violaciones

206 a derechos de la niñez en CAS en México

Epílogo

6.1.2 El cuidado en CAS: una responsabilidad en tensión

227

228

CAPÍTULO VII

SISTEMA NACIONAL PARA EL DESARROLLO INTEGRAL DE

LA FAMILIA, INSTITUCIÓN RECTORA EN MATERIA DE ASISTENCIA SOCIAL EN MÉXICO

Prefacio

7.1 De los Centros de Asistencia Social del Sistema Nacional para el Desarrollo Integral de la Familia

7.1.1 Modelo Tipo de Atención y Protección Integral de CAS para Niñas, Niños y Adolescentes

7.1.2 Marco operacional de actuación del Trabajo Social 
7.2 Subjetivación-episteme-institución y su expresión en el campo operativo (desarrollo, procesamiento y descripción de los resultados del trabajo de campo)

7.2.1 La construcción del sujeto (categoría subjetivación)

7.2.2 De los constructos de la ciencia (categoría: episteme)

7.2.3 El rostro institucional (categoría institución)

7.2.4 Categorías y Subcategorías del dispositivo: intervención 262 Epílogo

\section{CAPITULO VIII}

\section{EL DISPOSITIVO DE LA INTERVENCIÓN}

Prefacio

269

8.1 Entramado subjetivación-episteme-institución, elementos

270

constitutivos del dispositivo intervención (discusión y análisis)

8.1.1 CAS y cuidado alternativo, estrategia para la atención de la niñez receptora de maltrato, sin cuidados parentales y en condición de institucionalización, resultado de un proceso histórico

8.1.2 La intervención del Trabajo Social frente a la niñez en condición de institucionalización: refuncionalización del dispositivo en el contexto neoliberal

8.1.3 Las epistemes de la niñez y la intervención, procesos tensionados en el escenario institucional: entre la práctica tradicional y la realidad contemporánea

8.1.4 Tecnologías del poder que subjetivan: diagnósticos, etiquetas y discursos

8.1.5 Otras formas de situar y acompañar la realidad, procesos que favorecen la desubjetivación

8.2 "Enfoque de acompañamiento social": propuesta exploraciónruptura para la transformación de trayectorias

8.2.1 Situar el territorio, situar los sujetos 301

8.2.2 La reflexividad en el acto de hospedar 304

8.2.3 Enfoques para la transformación de trayectorias 305 Epílogo

ÍNDICE

IMÁGENES

ÍNDICE DE

TABLAS

REFERENCIAS 


\section{GLOSARIO DE ABREVIATURAS}

\begin{tabular}{|c|c|}
\hline CAS & Centro de Asistencia Social \\
\hline CDMX & Ciudad de México \\
\hline CDNNU & Comité de los Derechos del Niño de las Naciones Unidas \\
\hline CIDN & Convención Internacional de los Derechos del Niño \\
\hline CNMAIC & $\begin{array}{l}\text { Centro Nacional Modelo de Atención, Investigación } \\
\text { Capacitación }\end{array}$ \\
\hline CNMAIC-CCC & $\begin{array}{l}\text { Centro Nacional Modelo de Atención, Investigación } \\
\text { Capacitación Casa Cuna Coyoacán }\end{array}$ \\
\hline CNMAIC-CCT & $\begin{array}{l}\text { Centro Nacional Modelo de Atención, Investigación } \\
\text { Capacitación Casa Cuna Tlalpan }\end{array}$ \\
\hline CNMAIC-CAHONI & $\begin{array}{l}\text { Centro Nacional Modelo de Atención, Investigación } \\
\text { Capacitación Casa Hogar para Niñas }\end{array}$ \\
\hline CNMAIC-CAHOVA & $\begin{array}{l}\text { Centro Nacional Modelo de Atención, Investigación } \\
\text { Capacitación Casa Hogar para Varones }\end{array}$ \\
\hline $\mathrm{CNDH}$ & Comisión Nacional de los Derechos Humanos \\
\hline CTA & Centro de Terapia de Apoyo a Víctimas de Delitos Sexuales \\
\hline DH & Derechos Humanos \\
\hline DGIS & Dirección General de Integración Social \\
\hline DIF & Desarrollo Integral de la Familia \\
\hline ENTS & Escuela Nacional de Trabajo Social \\
\hline LGDNNA & Ley General de los Derechos de Niñas, Niños y Adolescentes \\
\hline NNA & Niñas, Niños y Adolescentes \\
\hline $\mathrm{OSC}$ & Organizaciones de la Sociedad Civil \\
\hline PFPNNA & $\begin{array}{l}\text { Procuraduría Federal de Protección de Niñas, Niños } \\
\text { Adolescentes }\end{array}$ \\
\hline REDIM & Red por los Derechos de la Infancia en México \\
\hline SNDIF & Sistema Nacional para el Desarrollo Integral de la Familia \\
\hline $\mathrm{TS}$ & Trabajo Social \\
\hline UNAM & Universidad Nacional Autónoma de México \\
\hline UNICEF & Fondo de las Naciones Unidas para la Infancia \\
\hline
\end{tabular}




\section{INTRODUCCIÓN}

\section{Mirarse hacia adentro: del andar profesional al andar analítico}

Para muchos pueblos latinoamericanos de referente indígena el pasado está adelante y el futuro mira atrás, metáfora que incita la construcción de una mirada profunda respecto de quiénes somos a partir de lo que hemos sido, y ello, posibilita resistencias y terrenos de transformación. Los saberes ancestrales, enfatizan que eso que hemos sido se coloca de frente, y que lo que anhelamos ser, está por fuera de nuestro campo visual, por tanto, en la recuperación del pasado está la posibilidad de trazar nuevos caminos.

El texto que tienen en sus manos es resultado de un proceso que recoge -entre otras cosasmi camino y trayectoria de más de 20 años de implicación profesional desde el Trabajo Social (TS). Nace como una necesidad personal por profundizar en la manera en cómo me he situado en el acompañamiento de personas en condición de vulnerabilidad y mi anhelo por comprender cómo el maltrato en la niñez repercute en la forma en que nos relacionamos y significamos el mundo.

En el año 2007, como Jefa de departamento de TS, tenía la responsabilidad de conducir los planes de tratamiento enfocados a la atención de la población albergada en una Casa Hogar (hoy Centro de Asistencia Social ${ }^{1}$ ) y eso me desafiaba, me instalaba un espejo que, para aquel entonces, resaltaba mis carencias teóricas derivadas de una incipiente formación académica (que sentía tener) y la inexperiencia propia, de una profesionista recién egresada de la formación de licenciatura, que traía como único equipaje, el ejercicio profesional a nivel técnico obtenido 10 años atrás (1997) y que me había hecho transitar otras geografías posibles. La búsqueda teórica y metodológica emerge en mí, desde una necesidad e interés personal y profesional -al ser la responsable de conducir las acciones de intervención dentro

\footnotetext{
${ }^{1}$ Centro de Asistencia Social (CAS). "Establecimiento, lugar o espacio de cuidado alternativo o acogimiento residencial para niñas, niños y adolescentes sin cuidado parental o familiar que brindan instituciones públicas, privadas y asociaciones" (Ley General de los Derechos de Niñas, Niños y Adolescentes, 2014: 20).
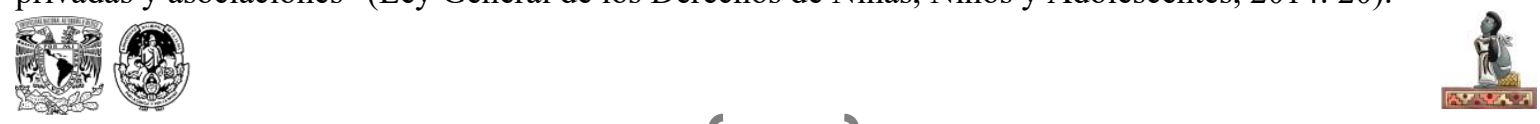
del CAS- y eso motivó mis estudios de maestría ${ }^{2}$ en el año 2011. En este proceso académico me involucré intuyendo los efectos sociales y emocionales que el permanente contacto con las niñas y los niños receptores de maltrato me implicaba en lo individual y lo colectivo, es decir, cómo esa realidad determinaba mi relación con quienes interactuaba de forma multidisciplinar, al interior del departamento de TS y con el resto de las y los profesionales de las áreas médica, jurídica, psicológica e incluso administrativa, mismas que conformaban el equipo profesional del Centro de Asistencia Social (CAS).

"Jefatura de departamento de Trabajo Social de Casa Cuna Coyoacán"” se inscribía en la puerta de mi oficina por aquel entonces, encargada de un equipo de 10 trabajadoras sociales de importante trayectoria institucional y que duplicaban mi edad. Ahí, en mi encuentro con ellas, aprendí la pasión, el amor, la entrega y también el miedo y la frustración que ofrece el campo operativo. Fue particularmente mi coincidencia con Elvia, trabajadora social y terapeuta familiar, lo que me empujó a construir caminos trazados con conocimientos diversos (emanados de las disciplinas de la psicología, la antropología y la ciencia jurídica), fortaleciendo así, el terreno de lo social y sumergiéndome en el campo del quehacer terapéutico, en el afán de andar reconociendo que las historias profundamente dolorosas y quebrantadas de las niñas y los niños, me conectaban con quién era y quería llegar a ser.

Fue, casi al finalizar la tesis de maestría que llegó a mis manos La muerte sin llanto de Nancy Scheper (1997), un estudio antropológico profundo y denso, que relata la pobreza y muerte infantil en las favelas del Brasil, dando cuenta del papel de la investigadora desde el "estar ahí”. Su lectura marcó un parteaguas a partir de las resonancias que se instalan en mi mente y cuerpo después de implicarme en su texto. Influencia que inspira la investigación que tienen en sus manos.

\footnotetext{
${ }^{2}$ El grado de Maestra en Terapia Familiar lo obtuve en 2014, con la investigación "Vínculo establecido entre niñeras de Casa Cuna Coyoacán y las niñas y niños asistidos" (quienes se interesen por conocer con mayor profundidad este estudio, pueden recurrir a los artículos: "Familia Comunal Institucionalizada: deconstruyendo la institucionalización" (2015) de acceso libre en internet o al texto "Cuando el hogar expulsa, la institución... ¿hospeda? Vínculos, intersubjetividades y entramados institucionalizados" -2021- que forma parte del libro "Desafíos del Trabajo Social para la intervención social con familias")

${ }^{3}$ El lector encontrará entrecomilladas las expresiones textuales a lo largo del documento.

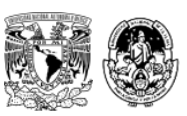


¿Qué significa el "estar ahí”? ¿Cómo se inscribe un mapa profesional a partir no sólo del "estar ahí", sino el "ser ahí"? ¿De qué forma los elementos relacionales construyen subjetividad y definen la manera de estar y ser para la niñez y sus familias? Estas incógnitas que se abrieron en la conclusión del estudio de maestría son el antecedente de esta investigación que, ahora, se interesa en profundizar e intentar dar respuesta a la pregunta: ¿De qué manera el entramado subjetivación-episteme-institución configura los elementos de un dispositivo que posibilita la intervención de las trabajadoras sociales dedicadas a la atención de la niñez receptora de maltrato, sin cuidados parentales y en condición de institucionalización?

\section{Mirar ahí: los Centros de Asistencia Social, el escenario investigativo}

Lo que se describe en cada uno de los capítulos desarrollados en esta tesis, no aspira, en definitiva, a ser un estudio de corte antropológico, sin embargo, sí deriva de mi proceso de "reflexividad" triangulado con otras técnicas de estudio de enfoque cualitativo, que permiten el análisis desde un claro lugar: "ser, estar y acompañar".

En cada capítulo se narran historias verdaderas que dan vida y rostro a niñas y niños que padecen en el anonimato y se matriculan para un control institucional, ya sea jurídico o de asistencia social. Ellas y ellos son albergados en paredes inquebrantables que promueven imaginarios irreales e incitan, la mayoría de las veces, miradas lastimosas, criminalizantes o nulas, que construyen y fortalecen estigmas sociales, instaurando la idea de que, la restitución de derechos de niñas y niños vinculados con el maltrato se expresa "cabalmente", tras el acto de ingresarles en un CAS, sin prestar suficiente atención a las formas de cuidado que al interior se les brinda.

El espacio para este estudio ocupa una geografía de relevancia e impacto nacional, se trata de la institución más importante en materia de atención a la niñez en México, rectora de la asistencia social, que gobierna las niñeces, diseña y operacionaliza estrategias de política pública en materia de atención de este sector poblacional y sus contextos familiares: el 
Sistema Nacional para el Desarrollo Integral de la Familia (SNDIF), a través de sus cinco CAS, ubicados en la Ciudad de México (CDMX).

Esta institución fue mi escenario profesional por casi 10 años (2007-2016), en un primer momento implicada profesionalmente en una de las cinco de sus Casas Hogar: el Centro Nacional Modelo de Atención, Investigación y Capacitación Casa Cuna Coyoacán (CNMAIC-CCC), como "jefa del área de Trabajo Social” y después como responsable de la supervisión a nivel nacional de los CAS de Niñas, Niños y Adolescentes (NNA) y Centros Gerontológicos. Esta participación profesional me ha permitido "estar y ser ahí", inscribirme y tener la posibilidad hoy, de explorar desde otro ámbito -el académico- y de alguna manera, atreverme a escudriñar en las entrañas que por mucho tiempo me alojaron y que ahora vivo con una particular legitimidad, a la par de una necesaria distancia, desde un proceso de extrañamiento, que posibilita volver "insólito" lo familiar y así generar reflexiones para conocer.

Por otra parte, los encuentros, las conversaciones y el trabajo colaborativo que he realizado en el SNDIF a partir de mi incursión como profesora e investigadora de la Escuela Nacional de Trabajo Social (ENTS) de la Universidad Nacional Autónoma de México (UNAM) (2016 a la fecha), ha soportado la construcción de conversaciones genuinas de franca curiosidad y posición "del no saber", en el reconocimiento de que las expertas en sus trayectorias profesionales, son ellas, las colegas que en el día a día, se construyen, deconstruyen e involucran en el actuar profesional. Este posicionamiento ha contribuido favorablemente para la realización de esta investigación, en donde soy yo, quien les incito a que me entreguen sus narrativas, encontrando un sólido eco, resultado -probablemente- del proceso empático y de respeto de identidades que se forjó, en gran medida, tras mi ejercicio profesional.

El SNDIF es una institución pública y descentralizada, de carácter nacional, en donde cada estado de la república cuenta con su propio Sistema para el Desarrollo Integral de la Familia (DIF), lo que le delimita una función rectora y sin atribuciones respecto de las decisiones estatales. Para su operación cuenta con dos unidades de atención: la de Población Vulnerable y la de Asistencia e Integración Social, que a su vez funcionan con las siguientes siete
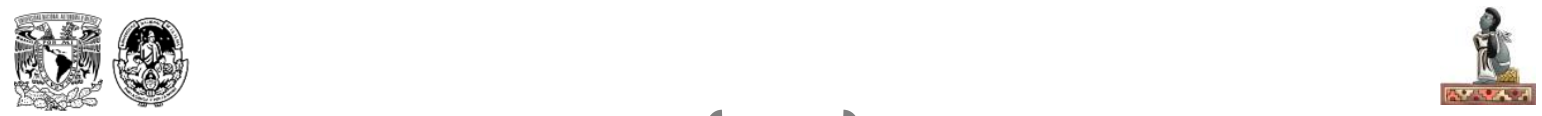
direcciones generales: Alimentación y Desarrollo Comunitario, Integración Social, Profesionalización de la Asistencia Social, General Jurídica y de Enlace Institucional, Recursos Materiales y Servicios Generales, Programación, Organización y Presupuesto y Enlace Interinstitucional; todas ellas encargadas de diseñar y operar acciones de política pública tendientes al fortalecimiento de las familias y la niñez en el territorio nacional y cuyo atributo de vigilancia y rectoría, les permite coadyuvar para que las entidades estatales generen e implementen acciones armonizadas con lo estipulado por ellas. ${ }^{4}$

Es la Dirección General de Integración Social (DGIS) la responsable de la construcción de los marcos normativos de actuación frente a la atención de la niñez en condición de institucionalización. A nivel operativo, cuenta en la CDMX con cinco CAS, los cuales se dividen por rango etario y sectorial (edad y sexo) y albergan fundamentalmente a menores de edad vinculados con "carpetas de investigación"s que han sido víctimas de delitos o problemáticas entre las que se enuncian: el maltrato físico, psicológico y/o sexual, la omisión de cuidados, la carencia de recursos económicos y familiares, la niñez migrante no acompañada ${ }^{6}$ o aquella vinculada con delitos como la trata de personas.

Los CAS pertenecientes al SNDIF son: el Centro Nacional Modelo de Atención, Investigación y Capacitación Casa Cuna Tlalpan (CNMAIC-CCT) que alberga a niñas $\quad$ y niños recién nacidos a los 4 años 11 meses; el Centro Nacional Modelo de Atención, Investigación y Capacitación Casa Cuna Coyoacán (CNMAIC-CCC) que atiende a niñas y niños de los 5 a los 8 años 11 meses; la Subdirección del Centro Amanecer para Niños, que solo atiende al género masculino de los 9 a los 12 años 11 meses; el Centro Nacional Modelo

\footnotetext{
${ }^{4}$ El organigrama del SNDIF, que describe puntualmente la organización y distribución por áreas disciplinares, se expone en el capítulo 5, numeral 5.4, Imagen 25.

${ }^{5}$ La "carpeta de investigación" es el conjunto de registros de diligencias y actos de investigación que realiza el Ministerio Público en la investigación de los delitos, para recabar los datos de prueba suficientes, pertinentes e idóneos que sustenten sus determinaciones ministeriales.

${ }^{6}$ El fenómeno migratorio proveniente del Triángulo Norte de Centroamérica (Guatemala, Honduras y el Salvador), representa un desafío nacional dada la cantidad de niñas, niños y adolescentes que transitan por nuestro país de forma irregular y no acompañada. Para 2017 "las autoridades migratorias identificaron 18,300 menores de edad en el territorio nacional, quienes lo hacen en total desamparo y soledad" (Fuentes, 2019: 84). El SNDIF, tiene la obligación de acoger a esta niñez, y para ello, además de la firma de convenios de colaboración con organizaciones de la sociedad civil, ocupa sus CAS como espacio de resguardo y atención, en tanto se define su situación migratoria.
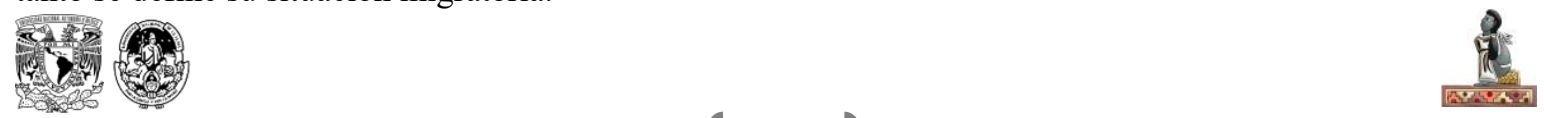
de Atención, Investigación y Capacitación Casa Hogar para Niñas (CNMAIC-CAHONI) solo al género femenino de los 9 a 18 años y el Centro Nacional Modelo de Atención, Investigación y Capacitación Casa Hogar para Varones (CNMAIC-CAHOVA), que atiende niños de los 13 a 18 años.

Como he mencionado, estos centros albergan fundamentalmente a NNA residentes de la CDMX o vinculados con el fenómeno migratorio y actualmente registran un aproximado de 150 (número que no corresponde a toda la niñez albergada en CAS en el país, pues como ya se dijo también, cada estado de la República tiene sus propios espacios de acogimiento residencial $^{7}$, y para ello, se tienen centros públicos, sociales y privados). Al respecto es necesario enfatizar que, de acuerdo con la información vertida por la Red por los Derechos de la Infancia en México (REDIM) para 2020 "9 de cada 10 niñas y niños en condición de institucionalización, son atendidos por Organizaciones de la Sociedad Civil (OSC)", lo que coloca al SNDIF en un rol, sustancialmente normativo, si consideramos que se calcula un aproximado de 30,000 NNA en estos espacios y a lo largo de todo el territorio nacional (discusión que forma parte de este documento).

\section{Niñez en condición de institucionalización: implicación y planteamiento metodológico de la investigación}

La presente investigación profundiza en la intervención profesional desde el TS que se realiza con la niñez albergada en los CAS del SNDIF, cuyas condiciones familiares les expulsaron del sistema de origen para delegar su protección en espacios de acogimiento residencial. Es importante aclarar que, se recuperan experiencias que involucran a CAS de carácter "social o privado" con el fin de ampliar el espectro de la realidad nacional en torno al cuidado alternativo, pero se sitúa en la comprensión de los procesos de intervención del TS en lo

\footnotetext{
7 “Acogimiento que brindan las instituciones públicas, sociales o privadas a la niña, niño o adolescente en situación de desamparo" (Ley de Cuidados Alternativos para Niñas, Niños y Adolescentes en el Distrito Federal, 2015).

${ }^{8}$ Los CAS de carácter "social o privado" están contemplados en la LGDNNA (2014) y engloban a aquellas OSC que proveen de acogimiento residencial a NNA, bajo las figuras de: Asociación Civil (A.C.), Albergue, Fundación o Institución de Asistencia Privada (IAP), que no operan con recurso gubernamental o este se proporciona de forma parcial. El capítulo seis aborda lo concerniente a este rubro.
} 
concerniente a la experiencia operativa de los CAS en el SNDIF, que es el principal escenario de análisis de esta tesis.

Se plantea como objetivo general analizar subjetivación, episteme e institución, como los elementos constituyentes del dispositivo de la intervención que posibilita el ejercicio profesional de las trabajadoras sociales dedicadas a la atención de la niñez receptora de maltrato, sin cuidados parentales y en condición de institucionalización, a partir de la recuperación de sus narrativas para con ello contribuir a la reflexión ontológica de la profesión.

Para lograrlo, se sumerge en la identificación y descripción del entramado de estas tres categorías de análisis, desvelando y examinando su intersección, partiendo del supuesto hipotético de que la intervención del TS se encuentra constreñida por el dispositivo que se configura en la interrelación de las categorías expuestas.

Se trata de un estudio realizado en la triangulación de técnicas de enfoque cualitativo que, como veremos en el capítulo uno (recorrido metodológico) recupera por un lado, mi proceso de "reflexividad" que se expresa a través de la narración de historias de vida que acompañé durante mi implicación profesional (las lectoras y lectores, hallarán una serie de relatos que dan cuenta de pasajes de vida de algunas niñas y niños albergados en CAS y lo que ello me significó a nivel personal y disciplinar), revelando mi proceso de subjetivación; y por otro, las narrativas de profesionistas del TS, que operan en los CAS del SNDIF, así como en organizaciones gubernamentales vinculadas a la restitución de derechos de NNA y de las OSC.

La información se construyó a partir de entrevistas informales, recorridos institucionales donde se realizó observación de tipo participante y no participante, además de la implementación de talleres grupales con las trabajadoras sociales adscritas al CNMAIC-CCT y la recopilación de notas periodísticas. Los hallazgos se registraron en instrumentos como el diario de campo, las guías de entrevista y de observación, y la toma de fotografías. 
El análisis de los resultados se construye recuperando el caminar conceptual de Michel Foucault respecto de la «analítica del poder» y sus principales postulados como: los discursos, el dispositivo, el agenciamiento y el poder -entre otros-; se retoman sus ideas en relación al análisis crítico que desarrolló respecto de las instituciones como mecanismos disciplinarios y los elementos de subjetivación que se implican ante estrategias carcelarias que aprisionan sujetos, vigente en el manto protector de la niñez en condiciones institucionalizadas.

Esta propuesta teórica resulta pertinente dado el supuesto hipotético planteado y la necesidad por desvelar el ejercicio disciplinar colocado, entre otras, en un andamiaje de saberes, técnicas y discursos científicos que se forman y entrelazan con la práctica del poder, en donde el ejercicio profesional "queda en muchos casos atrapado en esta encerrona discursiva que requiere de su separación para operar en el hiato, en la distancia. En ese aparataje burocráticoadministrativo-jurídico-político-económico-corporativo, que cobra forma en las instituciones y en donde las mismas están en falta y en distancia entre la norma y su aplicación" (Zelmanovich, 2012: 41).

\section{Una niñez situada: niñez receptora de maltrato, sin cuidados parentales y en condición de institucionalización}

Considero importante advertir que, a lo largo de la tesis, se usa frecuentemente "niñez receptora de maltrato, sin cuidados parentales y en condición de institucionalización". Se trata de un constructo conceptual no azaroso que reconoce las particularidades de estas personas niñas y desvela el entramado que resulta de las condiciones adversas y frecuentemente empobrecidas, en sus contextos institucionales, sociofamiliares, y personales.

La adjetivación "receptores de maltrato" resulta de la tensión y resistencia que me lleva a dar la espalda a construcciones generalizadas que, enuncian a niñas y niños como "víctimas" o "sobrevivientes" y que sugieren entes pasivos, de huellas imborrables con poca o casi nula capacidad de transformación. Desde mi perspectiva, el campo narrativo que les ubica como

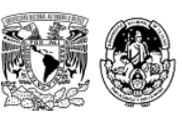


"receptores", permite darles otro lugar y externalizar el maltrato9 que se perpetra en contra de sus cuerpos. "Sin cuidados parentales" obedece al marco jurídico referencial en México, mismo que no expone una condición de orfandad sino que apunta al concepto legal para referir el desprendimiento de la familia de origen y el cuidado en manos del Estado ${ }^{10}$; finalmente "condición de institucionalización", habrá de insinuar un estado transitorio que confronta el uso del estereotipo "niño institucionalizado" (frecuentemente referido por disciplinas como la jurídica y/o psicológica), que instaura una forma de estar en el mundo usualmente peyorativa- y del que es muy difícil escapar.

Esta singular niñez y las y los trabajadores sociales, responsables de su intervención, ocupan un escenario disciplinar de tradición histórica en donde la implicación profesional hoy se tensa frente a la complejidad de las problemáticas sociales, en donde las violencias estructurales como la pobreza, la marginalidad, la corrupción y la impunidad, atraviesan las comunidades y el mundo íntimo familiar, expresándose en el maltrato del que son objeto y transgrediendo sus derechos fundamentales, dejando un impacto en el trayecto de su vida presente y futura.

\section{Del contenido: situándonos en el desarrollo de la investigación}

La tesis está organizada en siete capítulos además de esta introducción. En el primero se exponen las elecciones metodológicas que forjaron la investigación desde un enfoque cualitativo. Se presenta allí el ejercicio de reflexividad realizado como investigadora y tras la experiencia del acompañamiento de la niñez receptora de maltrato, sin cuidados parentales y en condición de institucionalización, sus familias y sus contextos comunitarios. Así como también se describen las técnicas que posibilitaron recuperar las narrativas de las trabajadoras sociales dedicadas a la intervención en los CAS (las adscritas al CNMAIC-CCT principal,

\footnotetext{
${ }^{9}$ UNICEF (2000) define como "maltrato hacia niñas y niños, a los actos de violencia física, sexual o emocional, sea en el grupo familiar o en las instituciones sociales".

${ }^{10}$ Se refiere de este modo a "niñas, niños y adolescentes que han sido separadas/os de su familia de origen, nuclear y/o extensa o de sus referentes afectivos y/o comunitarios por haber sido dictada una medida de protección excepcional de Derechos" (Fondo de las Naciones Unidas para la Infancia, 2018).
}

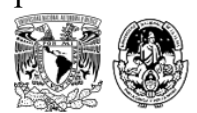


aunque no exclusivamente) del SNDIF, instituciones gubernamentales y OSC vinculadas a la atención de este grupo poblacional.

El capítulo dos desarrolla la perspectiva teórica adoptada y ahonda en la comprensión de las categorías de análisis que permitirán estudiar los datos empíricos construidos. Se profundiza en los elementos desarrollados por Michel Foucault sobre la "analítica del poder", misma que bordea la investigación y a la cual se recurre para comprender el ejercicio profesional en la atención de la niñez albergada en los CAS. Al finalizar este apartado se retoman algunas investigaciones que, de igual forma, recuperaron los postulados "Foucoltianos" para describir y analizar fenómenos vinculados con NNA, y se constituyen en antecedentes del uso de este enfoque para el análisis de este campo avalando su pertinencia.

En el tercer capítulo se desvelan algunas de las percepciones y construcciones teóricas realizadas en torno a la niñez en un proceso histórico-geográfico, cultural y social, en permanente transformación. Se define el desarrollo de diversas epistemes de referencia que nos encaminan a concebir a la niñez (en el contexto actual) como "sujetos de derecho". Dicho recorrido inicia con la recuperación de la perspectiva occidentalizada, se retoman experiencias latinoamericanas significativas y culmina en lo relativo a México, destacando la episteme, instaurada socialmente, que entiende a las niñas y los niños como sujetos “pasivos, maleables y a la espera de la vida adulta". El capítulo se cierra con la definición de una "propuesta de enfoque para el entendimiento de la niñez" que sugiere trascender de la idea exclusiva de que, las niñas y los niños son individuos que transitan un rango etario de ciertas características biopsicosociales. Apuesta por un desplazamiento, en donde lo relacional y contextual cobra relevancia, construye las consideraciones para la comprensión de una "niñez situada" en sus singularidades y contextos sociales concretos.

El desarrollo de las epistemes de la intervención del TS se abordan en el capítulo cuatro, referenciando momentos históricos relevantes -a nivel latinoamericano y nacionalintentando tejer un entramado con el ejercicio disciplinar que se enmarca epocalmente en las políticas públicas definidas para la atención de la niñez en México. 
Tomando como base esta historicidad, definiremos el carácter de la niñez como "sujeto de intervención social" en el contexto económico capitalista en su fase neoliberal, que provoca tensiones y problemáticas sociales específicas, en donde confluyen las violencias, desigualdades y el maltrato al interior de los sistemas de familia, que son los motivos más frecuentes de la institucionalización de la niñez. En este apartado se pone en discusión la situación nacional ante la falta de referencias y estadísticas de las y los menores de edad que se albergan en los CAS (ya sean públicos, sociales o privados) y la distancia con las epistemes de la intervención del TS contemporáneo, como una disciplina de las ciencias sociales tendiente a la transformación de trayectorias, colocando la revisión de algunas propuestas de intervención latinoamericanas.

Seguidamente, en el capítulo cinco, trascendemos de la dimensión cuantitativa -expuesta en el apartado anterior- para implicarnos en el estudio de los factores socio-estructurales y familiares que hacen proclive la institucionalización, enunciando los motivos de ingreso (enmarcados en la legislación nacional) y los efectos e implicaciones que genera la vida al interior de los CAS, en el desarrollo integral de estas "personas niñas".

El capítulo seis exhibe desde una georreferencia nacional y tocante a la última década, los espacios que han sido investigados -gracias al periodismo- y catalogados -por organismos internacionales y nacionales de defensa de los Derechos Humanos (DH)- como "espacios de riesgo", lugares -aparentemente- creados para la protección y el cuidado de quienes han padecido el maltrato familiar, y en donde, se ha transgredido ese rol al ejercer sobre sus identidades, violencias como: la trata de personas (en sus fines de adopción ilegal, explotación sexual y/o laboral, mendicidad forzada y tráfico de órganos), además del abuso físico, psicológico y sexual.

En esta parte de la tesis se describen las características en tiempo, ubicación geográfica y descripción de las vejaciones ejecutadas. Se redactó con la finalidad de visibilizar, por un lado, las diversas realidades que se expresan en el cuidado alternativo a través de la institucionalización en México y las profundas amenazas que representa el hecho de que el Estado ignore su función de rectoría y vigilancia; y, por otro lado, para poner en evidencia

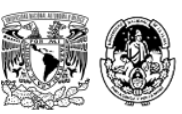


que el carecer de profesionistas capaces de intervenir sobre la base del conocimiento y la sensibilidad, resulta indispensable para la atención esta niñez.

En lo tocante al capítulo siete, se muestra otra geografía posible: la concerniente a los CAS del SNDIF, que convocan a un ejercicio profesional congruente con las exigencias de la realidad contemporánea, así también, se explican los enfoques y modelos diseñados para la atención de esta población. Aquí se hace la descripción de CAS en ubicación geográfica, perfil etario y sectorial de la población que recibe y los marcos jurídico-normativos que regulan e indican el tipo de atención proporcionada. En la segunda parte del capítulo se muestran los datos recabados del trabajo de campo en los CAS del SNDIF, relativos a la exploración de las categorías de análisis subjetivación, episteme e institución, datos que se construyen con base en los hallazgos empíricos y que se organizan según las categorías planteadas y las subcategorías construidas del trabajo de campo.

El capítulo ocho recoge los resultados construidos, los organiza y reflexiona sobre ellos a la luz de la analítica del poder. Esto permite dar cuenta del cumplimiento de los objetivos investigativos y representa, la plataforma sobre la que se erige la propuesta con que se cierra el documento. Así, el "Acompañamiento social", como se ha llamado a este enfoque, abre nuevos interrogantes, viabilizando "otras formas" de implicación para el TS situado en los procesos de NNA receptores de maltrato, sin cuidados parentales y en condición de institucionalización

Finalmente, en el apartado de conclusiones se exponen de forma resumida los resultados de la investigación en congruencia con los objetivos planteados, el regreso al supuesto hipotético, la pertinencia del enfoque teórico y metodológico, así como las limitaciones, problemáticas investigativas y las nuevas interrogantes que hacen factible la continuidad del estudio.

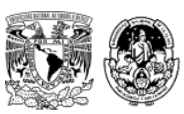




\section{JUSTIFICACIÓN}

Aquel que hospeda debe enfrentarse a su propio desamparo, su propia incompletud [...] la hospitalidad se ofrece, o no se ofrece, al extranjero, a lo extranjero, a lo otro. Y lo otro, en la medida misma en que es lo otro, nos cuestiona, nos pregunta. Nos cuestiona nuestros supuestos saberes, en nuestras certezas, en nuestras legalidades.

(Stolkiner, 2013)

La historia, la identidad y el quehacer del TS como disciplina han ocupado la reflexión y el análisis histórico que, desde algunas posturas, plantea su génesis en acciones "caritativofilantrópicas de carácter eclesiástico" -desarrolladas en Mendoza Rangel (1986), Evangelista Ramírez (1998) y Vélez Restrepo (2005)-.

Por otra parte, hay quienes sustentan que el TS es la construcción técnica de profesionistas creadas (os) para ejecutar y legitimar políticas sociales dirigidas a paliar los efectos de un modelo económico capitalista que agudiza las desigualdades, en donde la individualidad se promueve y apunta hacia la descomposición del tejido social, al ser altamente efectiva en la conservación de la homeostasis de una economía global. Para Míguez (2017: 164) el TS como disciplina "fue creado para sustentar el saber médico configurándose una formación de tipo asistencialista de relación sujeto-objeto ocupado de resolver las dificultades de la gente

pobre, una profesión al servicio de los intereses del Estado y su estrecha relación con la consolidación del modelo capitalista". Este teórico asegura que el TS

[...] aparece, por un lado, como una disciplina científica a través de la cual se genera conocimiento en lo social desde y para intervenir lo social. Pero a su vez reproduce, cuando el deber ser institucional se impone, técnicas homogeneizantes, disciplinares y controladoras que ubican al sujeto "otro" en una relación asimétrica en el pensarse como sujeto que parte de su historia singular y colectiva (Míguez 2017: 168). 
Por su parte Netto sostiene que la disciplina del TS "se constituye en el marco de un nuevo enfoque, de un nuevo tratamiento, en donde la materia prima son las expresiones y las manifestaciones de la cuestión social" (2011: 21). Para él las prácticas "caritativofilantrópicas" constituyen, más que una continuidad una ruptura y ofrece una reflexión soportada en que el TS es un "campo de conocimientos y prácticas que responden a las demandas sociales y se convierten en un espacio históricamente construido y por tanto sujeto al contexto". Plantea, como un importante desafío profesional, una mayor cualificación en la formación profesional para ampliar los procesos teóricos, metodológicos y políticos, en donde el ejercicio profesional habrá de situarse dentro de un contexto de mediación institucional que incida directamente en los problemas sociales.

A diferencia de Netto, Villela Iamamoto advierte que el TS "actúa en la realidad mediando las relaciones del Estado y la sociedad civil en el proceso de reproducción de las relaciones sociales" (2005:11). Para ella, la profesión no tiene una dependencia para operar bajo el cobijo o determinante institucional, sino que se articula como una profesión inscrita en la división sociotécnica del trabajo que parte de la intervención en la realidad poniendo en juego la acumulación del conocimiento, producido por otras ciencias y aplicándolo a la realidad.

Hoy día el ámbito académico a nivel internacional y nacional busca fortalecer el carácter científico profesional del TS, de la producción y organización del conocimiento teóricometodológico para la investigación, el diagnóstico y los planes de tratamiento, sobre la base de que estos elementos, se reflejan y determinan la intervención profesional.

Sin embargo, impresiona que en el campo operativo las y los profesionales en TS, no logran distanciarse significativa y consistentemente de una práctica paliativa y asistencial para consolidarse desde la intervención crítica y generadora de procesos de transformación social. Hoy día sigue prevaleciendo, en muchos ámbitos, la idea de que se trata de profesionales operarios de un sistema económico que interviene para paliar los efectos de ese mismo modelo. 
Esta idea se fortalece en escenarios profesionales en donde nuestra presencia es prácticamente incuestionable: la escuela, el hospital, la asistencia social en la atención de grupos en condición de vulnerabilidad y frente a los que parece poco relevante o necesario cuestionar la práctica profesional, pues su engranaje y simbiosis, legitima -casi irrefutablemente- nuestra acción.

En lo relativo al espectro de la violencia doméstica y el maltrato infantil, que se interviene desde los CAS, se funda el entendimiento de que estas violencias son un asunto del ámbito doméstico, privativo del sistema familiar y cobran relevancia sólo cuando derivan en la institucionalización de niñas y niños, que han quedado sin cuidados parentales.

Como he destacado antes, durante casi diez años y hasta el año 2016, me dediqué a supervisar y dar acompañamiento a trabajadoras y trabajadores sociales de los CAS del SNDIF y de las OSC encaminadas a la protección de la niñez receptora de maltrato, en estos espacios me encontré frecuentemente con profesionistas del TS que, en su mayoría, cuentan con una permanente capacitación en distintos niveles de profundidad (cursos, diplomados, maestrías y doctorados) que pone de manifiesto la incorporación de propuestas de capacitación disciplinar, planteadas por teóricos como Netto (2011), en relación a que, ampliar los procesos teórico-metodológicos y políticos, incrementara la cualificación de las y los trabajadores sociales en el campo operativo de actuación y ello derivara en intervenciones más eficaces.

A partir de mi experiencia profesional pude identificar prácticas desarrolladas en un modelo de atención centrado fundamentalmente en la asistencia e internamiento de las y los menores de edad, que faculta la incidencia gubernamental ante posibles contextos de maltrato en contra de NNA y que no sólo legitima sino obliga su separación del sistema familiar de origen para su internamiento en CAS.

Esta estrategia de intervención del Estado, con respecto a la atención de la niñez vinculada con el maltrato, tiene su antecedente en el período posrevolucionario, específicamente en la época Cardenista (1934-1940), momento histórico de consolidación de las instituciones y la

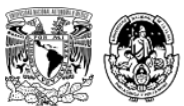


asistencia social que, en el marco del Estado benefactor, aspiró a dar respuesta al ejercicio de los derechos humanos en su primera generación y las garantías de igualdad social en México.

Uno de los señalamientos disciplinares más relevantes de esta época se circunscribe en la necesidad del Estado por contar con operarios profesionales, donde el TS ha jugado un papel protagónico como puente articulante entre las problemáticas sociales y la estrategia de intervención gubernamental.

En la década de los ochenta Donzelot (1977: 112) se sumerge en el "histórico mundo institucional y a partir del análisis de la actuación de los Tribunales para menores de la Francia del siglo XVIII y XIX, identifica la intrusión del Estado en la autonomía familiar a partir del reclutamiento de menores abandonados, difíciles o problemáticos en internados".

El Estado determinaba (para estas niñas y niños) la permanencia o no dentro de la familia de donde provenían, sobreponiéndose al papel de la Iglesia en este campo de actuación. "El antiguo mercado de la infancia estaba organizado mediante técnicas conventuales y militares, conectado con la autoridad familiar y religiosa, policial y judicial. El nuevo busca sus métodos en la medicina, la psiquiatría, la pedagogía: trata de aprovisionarse por sus propios medios: la selección escolar, la prospección por los trabajadores sociales” (Donzelot, 1977: 107).

Han transcurrido más de cuatro décadas desde que el antropólogo francés desafiaba y cuestionaba la ontología disciplinar.

¿Qué es el Trabajo Social? ¿Es un freno a la brutalidad de las sanciones judiciales centrales, mediante intervenciones locales, mediante la suavidad de las técnicas educativas?, o bien, ¿es el desarrollo incontrolado del aparato del Estado que, con la disculpa de la prevención, extendería su control sobre los ciudadanos hasta su vida privada; ¿llegaría a marcar de forma suave, aunque no menos estigmatizante, a los menores que no hubieran cometido el menor delito? (Donzelot, 1977:101). 
Hoy a la distancia, sus cuestionamientos a la disciplina en este campo aparecen más vigentes que nunca. Donzelot (1977) colocó la intervención del TS como un elemento técnico profesional de las instituciones enfocado a la atención de las clases menos favorecidas, específicamente con la "infancia en riesgo"11, aquella que no se ha beneficiado de todos los cuidados de crianza y de educación proporcionados por la familia de origen, describe el papel de las y los trabajadores sociales, como el de una institución jurídica externa, que ejerce su poder sobre la vida privada del niño y su familia.

En este orden de ideas Foucault (1981) desveló en la familia "un instrumento privilegiado para el gobierno de la población a la cual habría que disciplinar y controlar desde el Estado y para ello las instituciones juegan un papel fundamental" (Castel, Donzelot, Foucault, Gaudamar, Grignon y Muel, 1981:22).

Para Foucault (1976) la institución se constituye como un dispositivo de control, que vigila y castiga el actuar en donde se insertan los profesionales como operarios.

Los dispositivos disciplinarios han secretado una "penalidad de la norma", que es irreductible en sus principios y su funcionamiento a la penalidad tradicional de la ley. El pequeño tribunal que parece actuar permanentemente en los edificios de la disciplina, y que a veces adopta la forma teatral del gran aparato judicial, no debe engañar: no prolonga, excepto por algunas continuidades formales, los mecanismos de la justicia criminal hasta la trama de la existencia cotidiana, o al menos no es lo esencial; las disciplinas han fabricado — apoyándose en toda una serie de procedimientos, por lo demás muy antiguos - un nuevo funcionamiento punitivo, y es éste el que poco a poco ha revestido el gran aparato exterior que parecía reproducir modesta o irónicamente (Foucault, 1976: 214).

¿Cómo estos planteamientos pueden ser vigentes hoy en un marco de actuación profesional soportado en la construcción científica del conocimiento, heredada fundamentalmente por el

\footnotetext{
${ }^{11}$ Por niños en riesgo Osorio y Arteaga (2012: 215) entienden a "infantes que han sido abandonados, viven o trabajan en las calles, se hallan en estado de orfandad o han sido maltratados". Dichos autores les llaman así porque bajo el discurso institucional de ciertas autoridades actuales, son sujetos altamente proclives a ser delincuentes o adquirir conductas antisociales si no se les atiende.

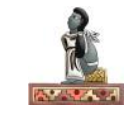


movimiento de Reconceptualización del TS? ¿Qué elementos se interseccionan de cara a un discurso internacional y nacional que privilegia el "interés superior del niño ${ }^{12}$ " frente a la intervención profesional que se expresa distante de una incidencia y contribución en la transformación de trayectorias?

Por otra parte, las inquietudes respecto a la intervención con niñas y niños receptores de maltrato, han provocado en mí desde hace algunos años, la necesidad de explorar la actuación de las y los profesionales en estos contextos y fue así como en el año 2014, me aproximé al ejercicio profesional de niñeras (cuidadoras primarias de los niños y las niñas albergadas en el CNMAIC-CCC), a través de una investigación cualitativa cuyo objetivo estuvo centrado en conocer la percepción del vínculo establecido con los menores de edad.

Aquella investigación de maestría (en el campo de la Terapia Familiar) partía del supuesto hipotético de que las niñeras “desarrollaban un vínculo con las niñas y los niños, pero que al tener que negarse en aras de un hacer profesional con distancia emocional, se entorpecía su desempeño profesional, manifestándose en prácticas ambivalentes de cuidado y atención que se tensaban entre la protección y el maltrato". Los hallazgos confirmaron en importante medida la existencia de una relación intersubjetiva que se manifiesta en un "apego con estrategia de afrontamiento de tipo ambivalente" 13 por parte de las cuidadoras, inserto en un marco institucional que delimita la correspondencia entre los actores y un relato de vida personal que ejerce una importante influencia en su actuación (Ruíz, 2014).

Este antecedente investigativo, con relación a la atención de la niñez en condición de institucionalización, me brindó otras miradas que me ayudan a comprender, con mayor amplitud, la realidad que viven las niñas y los niños al interior de los CAS del SNDIF, y en continuidad a ese interés científico, es que la presente investigación busca profundizar en la intervención del TS, enmarcada en una serie de premisas y conocimientos que no sólo se

\footnotetext{
${ }^{12}$ Para la Convención de los Derechos del Niño (1989), se entiende por "interés superior del niño" al conjunto de acciones y procesos enfocados en garantizar un desarrollo integral y una vida digna.

13 "El Apego con estrategia de afrontamiento de tipo ambivalente, se da frente a la separación con angustia intensa y mezcla comportamientos de apego con expresiones de protesta, enojo y resistencia, [...] los niños con este tipo de apego no tienen expectativas de confianza respecto al acceso y respuesta de sus cuidadores" (Bowbly, 1986). 
sitúan en la operacionalización teórico-metodológica, sino que se instalan en aquello que se dispone a manera de dispositivo.

Foucault afirma que el dispositivo:

[...] es un conjunto decididamente heterogéneo, que comprende discursos, instituciones, instalaciones arquitectónicas, decisiones reglamentarias, leyes, medidas administrativas, enunciados científicos, posiciones filosóficas, morales, filantrópicas, en resumen: los elementos del dispositivo pertenecen tanto a lo dicho como a lo no dicho. El dispositivo es la red que puede establecerse entre estos elementos (1976: 128).

Es así como este estudio se plantea el objetivo central de analizar los elementos subjetivación, episteme e institución como aquellos que configuran e instauran un dispositivo, posibilitando la intervención de las trabajadoras sociales dedicadas a la atención de la niñez receptora de maltrato, sin cuidados parentales y en condición de institucionalización. 


\section{- CAPÍtUlo I}

\section{UN ENFOQUE CUALITATIVO PARA COMPRENDER LA INTERVENCIÓN DEL TRABAJO SOCIAL CON LA NIÑEZ RECEPTORA DE MALTRATO, SIN CUIDADOS PARENTALES Y EN CONDICIÓN DE INSTITUCIONALIZACIÓN: RECORRIDO METODOLÓGICO}

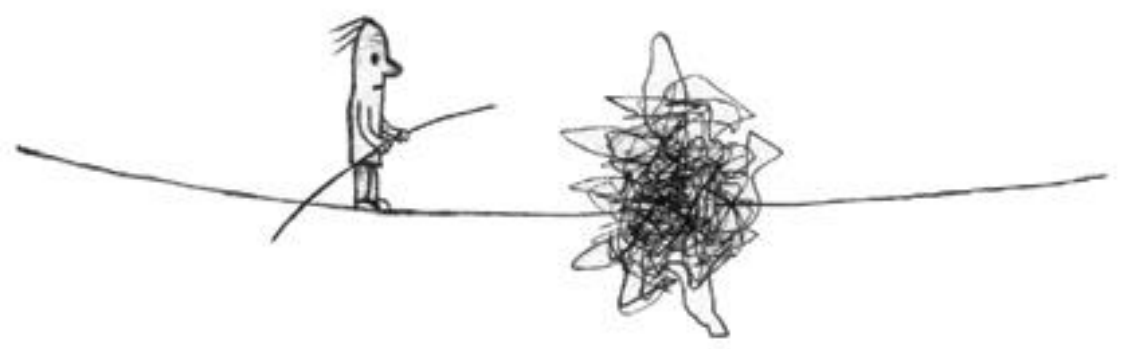

Troche, G. (2016). [Ilustración]. Recuperada de: http://www.good2b.es/los-dibujos-invisibles-de-gervasiotroche/?fb_comment_id=933396286747579_1708844759202724

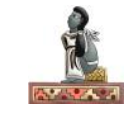


Cuca estaba realmente perdida en su soledad cuando el DIF decidió que no sería buena madre y le quitó al hijo. Fue entonces cuando se rebeló con su locura.

Las voces le dijeron que el niño seguía siendo suyo y empezó a vivir en un mundo paralelo donde tenía los apellidos de la familia de sus patrones de crianza. Supo también, por las voces, que el niño fue a la escuela y está esperando, como ella, el juicio final.

(Tinajero, 2019).

\section{Prefacio}

A lo largo del presente capítulo se expondrá el recorrido metodológico diseñado para la investigación y, a través de éste, se describirán: la pregunta de investigación, los objetivos, el supuesto hipotético, los enfoques a nivel metodológico, las técnicas empleadas, los instrumentos y las herramientas.

Se recurre al enfoque cualitativo para sumergirnos en el mundo íntimo de la intervención de las trabajadoras sociales dedicadas a la atención de la niñez receptora de maltrato, sin cuidados parentales y en condición de institucionalización, albergada en los CAS del SNDIF y se lleva a cabo a partir de las categorías de análisis: subjetivación, episteme e institución, con fundamento en el enfoque teórico de la analítica del poder desarrollada en Foucault.

A continuación, se precisan los elementos metodológicos que dan cuerpo a la investigación:

\subsection{Pregunta de investigación}

¿De qué manera el entramado subjetivación, episteme e institución, configuran los elementos de un dispositivo que posibilita la intervención de las trabajadoras sociales dedicadas a la atención de la niñez receptora de maltrato, sin cuidados parentales y en condición de institucionalización?

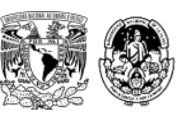




\subsection{Objetivo General}

Analizar subjetivación, episteme, e institución como los elementos constituyentes del dispositivo de la intervención que posibilita el ejercicio profesional de las trabajadoras sociales dedicadas a la atención de la niñez receptora de maltrato, sin cuidados parentales y en condición de institucionalización, a partir de la recuperación de sus narrativas para con ello contribuir a la reflexión ontológica de la profesión.

\subsection{Objetivos Específicos}

- Identificar y describir subjetivación, episteme e institución como los elementos de la intervención que posibilitan el ejercicio profesional de las trabajadoras sociales dedicadas a la atención de la niñez receptora de maltrato, sin cuidados parentales y en condición de institucionalización.

- Desvelar y examinar la intersección de subjetivación, episteme e institución como elementos de la intervención que posibilitan el ejercicio profesional de las trabajadoras sociales dedicadas a la atención de la niñez receptora de maltrato, sin cuidados parentales y en condición de institucionalización.

\subsection{Supuesto hipotético}

La intervención profesional de las trabajadoras sociales dedicadas a la atención de la niñez receptora de maltrato, sin cuidados parentales y en condición de institucionalización, se encuentra constreñida por la intersección de tres elementos: subjetivación-epistemeinstitución, que al interaccionar se instalan como el dispositivo que determina la intervención social, desafiando la idea de que el TS, en el campo operativo, obedece únicamente a procedimientos, conocimientos científicos disciplinares y metodologías sobre la base de la objetividad profesional. 


\subsection{Enfoque metodológico}

La presente investigación es desarrollada desde un enfoque metodológico cualitativo, al centrarse en explorar el mundo íntimo de la intervención profesional del TS en los CAS, entendiendo la intervención como aquel proceso que indica la transformación de la realidad social, a partir de acciones que inciden e irrumpen desde un hacer intencional y fundado en el conocimiento.

Para ello se recupera información emanada de técnicas e instrumentos polifacéticos de procesos e inmersión diferenciada, es decir, técnicas y estrategias investigativas diversas que tienen como antecedente, y a su vez fuente de información, mi desempeño profesional desde el ámbito operativo como Jefa de Departamento de Trabajo Social en el CNMAIC-CCC (2007-2016) y Jefa de Departamento de Trabajo Social de los CAS a nivel nacional, que al ser revisitada desde las inquietudes de la investigación, es analizada y viabiliza datos para esta tesis, desarrollando -para ello- el método de la "reflexividad", propuesto por Guber (2004).

El trabajo investigativo expuesto en esta tesis, toma como referente mi ejercicio como profesora-investigadora a partir del proyecto "Problemáticas de la niñez en el México contemporáneo" (PNMC), que se lleva a cabo desde el año 2016 a la fecha, ubicando como escenario el SNDIF. Esta labor detonó el intercambio de conocimientos y saberes y arrancó la construcción de un diagnóstico social en 2016, que en adelante profundiza en la intervención profesional desde la articulación académica propuesta por la ENTS de la UNAM, a partir de la incursión de grupos de práctica de especialización dedicados al estudio de la niñez y su vinculación con las violencias estructurales y el maltrato, tomando como interlocutoras fundamentales a las profesionistas del Trabajo Social y cuya periodicidad abarca hasta el año 2020. 


\section{Reflexividad}

Para Guber "la reflexividad es el proceso de interacción, diferenciación y reciprocidad entre la reflexividad del sujeto cognoscente -sentido común, teoría, modelo explicativo de conexiones tendenciales- y la de los actores o sujetos de investigación" (2004:50), implica una toma de conciencia más inmediata, continua, dinámica y subjetiva, en donde el proceso analítico se sitúa en el posicionamiento del o la investigadora y no del sujeto que se investiga.

La autora De la Cuesta-Benjumea reconoce que no se cuenta con una prescripción establecida que detalle cómo hacer la reflexividad, sino en "la necesidad por exponerla y sensibilizar sobre las decisiones, las alternativas y las limitaciones que conlleva el proceso de investigación" (2011: 165).

Desarrolla cinco modelos para llevarla a cabo:

1. Introspección individual: aquí la reflexividad se entiende como un relato confesional sobre la metodología o un examen de las reacciones personales posiblemente inconscientes.

2. Examen de las interacciones mutuas: se examina la dinámica de las relaciones con los participantes.

3. Reflexividad en la investigación colaborativa: los participantes, como investigadores que son, se implican en ciclos de reflexión y experiencia.

4. Crítica social: destacan prácticas coercitivas de las instituciones. Particularmente, los investigadores que usan este modelo de reflexividad les preocupa cómo manejar el desequilibrio de poder entre el investigador y los participantes.

5. Reflexividad como una desconstrucción: irónica surge de un paradigma posmoderno; aquí se entiende que el mundo es como un parloteo con muchas voces que compiten, ninguna de ellas con un estatus privilegiado. El investigador, por lo tanto, tiene que desenmascarar la retórica de ser "una voz autorizada", permitiendo así que se escuchen las múltiples voces.

Para efectos de este estudio, se recurre al uso de los modelos 1 y 5: "Introspección individual" y "Reflexividad como una deconstrucción", que se desarrollan y se verán expresados en las narraciones, documentación de casos y epílogos (las narraciones y documentación de casos

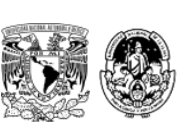


se encuentran de forma transversal y los epílogos se redactan al concluir cada apartado de la tesis). Las experiencias recuperadas están vinculadas -fundamental, aunque no exclusivamente- con mi ejercicio profesional en la intervención con las niñas y los niños receptores de maltrato, sin cuidados parentales y en condición de institucionalización.

El ejercicio reflexivo lo realicé distanciada en temporalidad y espacio, cada una de las narraciones que aparecen a lo largo de este documento, las redacté fuera de la implicación en procesos de intervención social, y toman como fuente informativa los informes sociales y las notas de diario de campo de mi archivo personal; se escriben sobre el análisis de los sucesos, actores y procesos desde el TS que, en un primer momento, redacté a manera de "viñetas" y que pretendían ser utilizadas como recurso didáctico para mi quehacer docente, en ellas, identificaba modelos, estrategias, técnicas y metodologías puestas en marcha durante la “intervención individualizada"14. Este ejercicio me permitió reconocer y nombrar las emociones, percepciones e inquietudes, en una conexión con mi historia personal, trascendiendo de un ejercicio didáctico a un proceso de reflexividad desde los modelos $1 \mathrm{y}$ 5, propuestos por De la Cuesta-Benjumea (2011).

El escribir las historias de vida de las niñas y los niños que por casi 10 años acompañé desde el proceso de intervención, me posibilitó cobrar conciencia sobre la influencia de las emociones en la toma de decisiones y construcción de planes desde el TS, desvelando y confrontando la "objetividad de la intervención" como el camino para la eficiencia profesional y esto me permite, a su vez, implicarme en el estudio de la subjetivación y su vinculación con la intervención.

La triangulación de técnicas enriquece la obtención de información y da mayor fiabilidad a los resultados, es por ello por lo que, para efectos de la presente investigación, se recurre al uso de entrevistas informales de encuentro individual, técnicas aplicadas en grupo a través de talleres y otras como la observación de carácter participante y no participante.

\footnotetext{
${ }^{14} \mathrm{La}$ "intervención individualizada" en México, es utilizada como sinónimo de la "metodología tradicional de caso". 
A continuación, se describen las técnicas, los instrumentos y las herramientas utilizadas durante el proceso investigativo, mismas que se implementaron con trabajadoras sociales adscritas a los diferentes CAS del SNDIF y que se diseñaron sobre la base de las categorías de análisis subjetivación, episteme, institución, encauzando los encuentros hacia la obtención de información que diera cuenta de la influencia subjetiva e intersubjetiva, los conocimientos disciplinares y las determinantes institucionales, que influyen en el ejercicio profesional.

\subsection{Técnicas}

Las técnicas investigativas se implementaron de 2017 a 2019, siendo esto posible gracias a la vinculación interinstitucional establecida entre el SNDIF y la ENTS, en donde el primero (SNDIF) funge como escenario de proximidad profesional para la realización de la Práctica de especialización "Trata de personas y maltrato infantil" 15 dirigida a profesionistas del TS en formación (pertenecientes a la ENTS) y de la cual soy responsable (como he mencionado con anterioridad).

De esta forma, se desarrollan:

a) Entrevistas informales. Encuentros conversacionales con trabajadoras sociales adscritas a los CAS y demás equipo multidisciplinario que involucra a las y los responsables de cada centro, así como, profesionistas en las áreas médica, psicológica y jurídica, desde una genuina implicación de reconocimiento de su quehacer profesional situado en la atención de la niñez albergada.

b) Observación participante, no participante y recorridos institucionales. Consistió en realizar visitas periódicas de encuentro con la población albergada, sus familias y demás profesionistas que favorecieron un encuentro permanente, a través del cual, se

\footnotetext{
${ }^{15}$ La Práctica de especialización es una asignatura que forma parte del Plan de estudios vigente en la ENTSUNAM, se imparte en el $8^{\circ}$ y $9^{\circ}$ semestre y puede desarrollarse en instituciones públicas, privadas o en OSC. Actualmente -y desde 2016- está a mi cargo la Práctica de especialización: "Trata de personas y maltrato infantil".

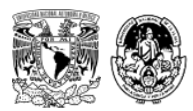


observan las diversas acciones definidas institucionalmente para la restitución de los derechos de NNA.

c) Encuentros conversacionales y observación participante con periodistas que documentaron los casos de maltrato institucional, cuyo acercamiento se dio incluyéndome en acciones de tipo operativo y académico que se documentaron en diario de campo.

Para lo que ocupó el trabajo de campo en grupo, se utilizaron las técnicas: Trayectoria laboral, Mapas conceptuales y Línea del tiempo, realizadas con la finalidad de incitar el intercambio que pone en juego: conocimientos profesionales, percepciones y saberes individuales y colectivos (base del proceso de intersubjetividad y subjetivación), así como la recuperación de lineamientos institucionales para el ejercicio profesional. Se determina como un escenario central el CNMAIC-CCT ${ }^{16}$, a través de sus informantes clave, que fueron 6 trabajadoras sociales adscritas al mismo y se ejecuta en el año 2017.

\section{d) Trayectoria laboral.}

Para Longa (2010:10) la trayectoria es "una técnica de exploración biográfica que consiste en identificar las transiciones específicas que han ocurrido en la vida de un sujeto, en relación directa con el problema de investigación. La importancia está puesta en el pasaje de un espacio de socialización al otro en virtud de la temática estudiada”.

El análisis de las trayectorias de los sujetos nos permite entender los diferentes tipos de desplazamientos, desde geográficos hasta profesionales, escolares y/o políticos. Según este enfoque, las transiciones vividas por los individuos están siempre inscritas en trayectorias que les dan una forma y un sentido distintivos. Cuando se habla de trayectoria se mencionan los esquemas de movilidad definidos por la o el investigador a los que se incorpora un individuo. Lo que importa son los diferentes momentos a través de los cuales

\footnotetext{
${ }^{16}$ La selección de este centro se colocó en: la viabilidad para desarrollar el trabajo de campo, la trascendencia del impacto de las acciones de intervención del TS y con el fin de delimitar algunas informantes clave. 
se construyen las trayectorias. Las trayectorias están permeadas por instituciones sociales tales como la educación, el servicio militar, las posibilidades de empleo, así como las particularidades del actor tales como su edad, su sexo, sus antecedentes laborales, etc.

Recuperar la subjetivación respecto del ejercicio profesional de las trabajadoras sociales a partir de la trayectoria, supone encontrar elementos discursivos en un corte epocal y de identidad personal en relación con las y los otros.

Esta técnica investigativa se situó en la exploración del recorrido profesional que cada trabajadora social había experimentado antes y durante su adscripción institucional vinculada con sus propias experiencias de vida. Se diseña para explorar la categoría de análisis subjetivación.

\section{e) Mapas conceptuales.}

Los mapas conceptuales, de acuerdo con la propuesta metodológica de Joseph Novak (1988), consisten en la exposición esquemática de un concepto que se tiene, permitiendo al que lo elabora, visualizar una jerarquización de ideas y desarrollar lo que se piensa.

Para la elaboración de un mapa conceptual se debe elegir un concepto clave o central del tema de estudio a desarrollar, esto permitirá que las personas muestren todos los conceptos y relaciones que puedan conectar con dicho concepto, esto con la intención de tener una idea mucho más profunda y sorprendente de hasta qué punto se conoce, se están entendiendo, desarrollando y diferenciando ciertos temas (Novak, 1988:4-18).

Esta técnica es pertinente en tanto permite identificar y analizar los referentes teóricometodológicos, jurídicos y técnicos, con los que cuentan las trabajadoras sociales.

Los mapas buscaron explorar en los conocimientos disciplinares adquiridos e implementados en el ejercicio profesional, desde la propuesta de la intervención individualizada y los diversos modelos, enfoques y técnicas implementadas con la población albergada y sus sistemas de familia y comunitarios. Se define para explorar la categoría de análisis episteme. 
f) Línea del tiempo. La línea de tiempo como técnica permite "conocer la situación sobre una temática o problemática a fin de poder actuar casi de inmediato o tratar de predecir o anticipar la evolución de la temática o de un riesgo" (Márquez, 2009: 2-5). La línea del tiempo brinda diversas oportunidades, tales como:

- Desarrollar series de acontecimientos, reforzando la capacidad de organizar hechos en secuencias coherentes.

- Evaluar su capacidad de recordar sucesos en orden.

- Profundizar en un período de tiempo determinado, al detallar y articular los hechos que lo componen (Márquez, 2009: 2-5).

De acuerdo con Judith Licea (2007), esta técnica obedece a diferentes momentos donde se les pide a los participantes que relaten en detalle cómo se condujeron en una situación problemática e indicar las dudas que les surgieron a cada paso.

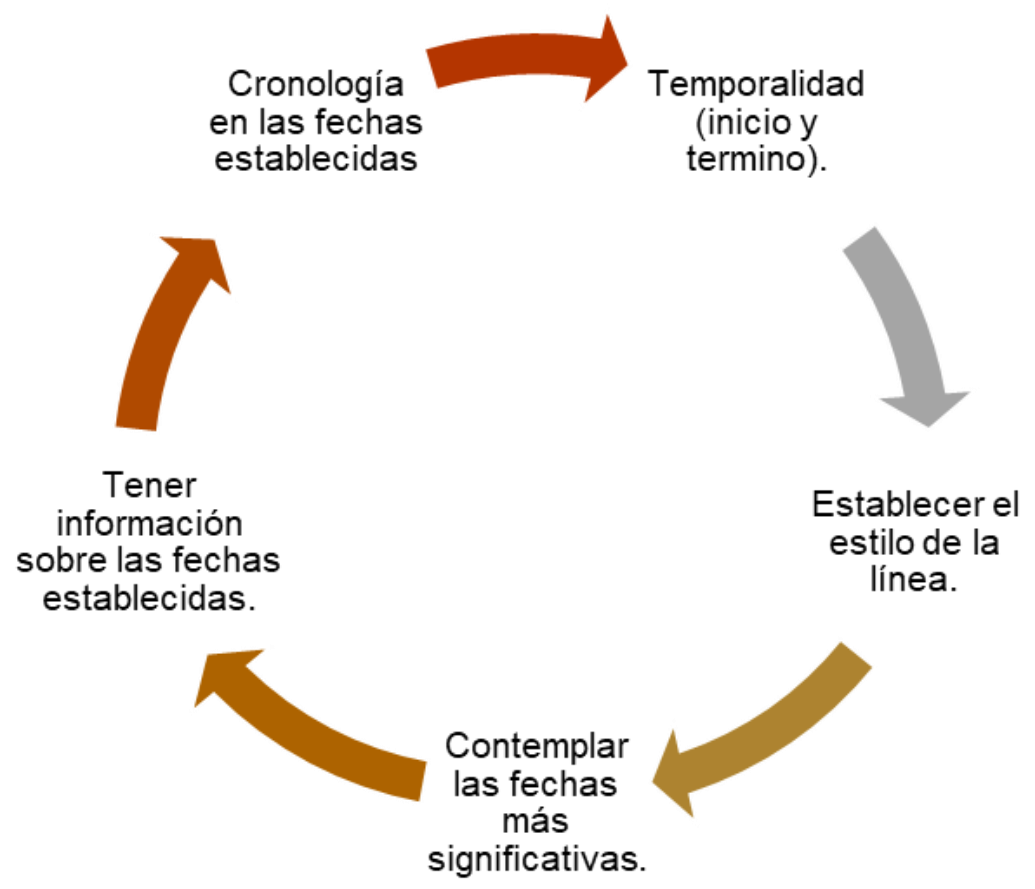

Imagen 1. Taller DIF a través del tiempo Fuente: Elaboración propia para el desarrollo del taller DIF a través del tiempo (2017).

Se efectúa incitando la identificación de momentos de cambio trascendentes en términos de la implicación profesional en la asistencia social, concretamente en lo concerniente a las transformaciones internas del SNDIF (del año 2005 al año 2017) y sus consecuentes 
adecuaciones en los marcos normativos de actuación, en congruencia con las estrategias de política pública definidas por el Estado para la atención de la niñez en condición de institucionalización. Se define para explorar la categoría de análisis institución.

\subsection{Instrumentos}

Los instrumentos para el registro de la información ocuparon propuestas diferenciadas, que permitieron ordenar y organizar la información emanada del campo. A continuación, se describen aquellos que fueron utilizados:

a) Diarios de campo. Instrumento personal que favorece, a partir del análisis del registro, la recuperación profunda de las situaciones y la percepción de los eventos.

b) Guía de observación y guía de entrevista. Instrumento de registro de información relevante durante los recorridos y encuentros institucionales.

c) Informes de caso y notas informativas. A través de los cuales consta y se evidencia mi ejercicio disciplinar. Fueron elaborados de forma permanente como trabajadora social operativa e investigadora.

d) Correos electrónicos. Medio de comunicación que favoreció el intercambio de información, ideas y pensamientos respecto al ejercicio profesional.

e) Notas periodísticas. Textos informativos de carácter nacional e internacional, a través de los cuales, se recuperó información relativa a la atención prestada a través de los CAS (enunciados como "espacios de riesgo"), no pertenecientes al SNDIF y que expresaron condiciones inadecuadas de alojamiento, cuidado y restitución de derechos de NNA en el territorio nacional. 


\subsection{Herramientas}

Finalmente se describen las herramientas utilizadas en el trabajo de campo, que implicaron el diseño de estrategias lúdicas, de accesible comprensión y factibilidad, encaminadas a la obtención de la información.

a) Evidencia fotográfica. Permite documentar e interpretar espacios, actividades, acciones, en torno a una actividad, acción o hacer. A lo largo de la tesis se observarán, gracias a la evidencia fotográfica, los espacios arquitectónicos, las reglamentaciones y la vida al interior de los CAS del SNDIF, de los CAS de carácter social o privado, así como de encuentros interinstitucionales y actividades diversas de implicación en campo.

b) Álbum fotográfico. Rescata el proceso de subjetivación respecto de la práctica profesional en un ejercicio de registro fotográfico vinculado a su trayectoria profesional y personal. Este álbum fue creado para operacionalizar la técnica de la "Trayectoria laboral".

c) Guía de conectores. Sirven como puentes articulantes para identificar las epistemes profesionales (conocimientos, saberes y métodos del TS) a los que se recurre en la práctica operativa. Esta guía fue diseñada para operacionalizar la técnica de "Mapas conceptuales".

d) Preguntas detonadoras. Incitan la expresión de vivencias con relación a la pertenencia a la institución en y frente a las transformaciones internas de ésta. Las preguntas fueron diseñadas para operacionalizar la técnica "Línea del tiempo".

Los elementos del planteamiento metodológico descritos permitieron la implicación en campo y la obtención de información para la construcción de datos, incitando la reflexión y el análisis profundo para con ello alcanzar el objetivo general de esta investigación. 


\section{- CAPítulo II}

\section{LA ANALÍTICA DEL PODER: APROXIMACIONES PARA LA REFLEXIÓN DE LA INTERVENCIÓN DESDE EL TRABAJO SOCIAL}

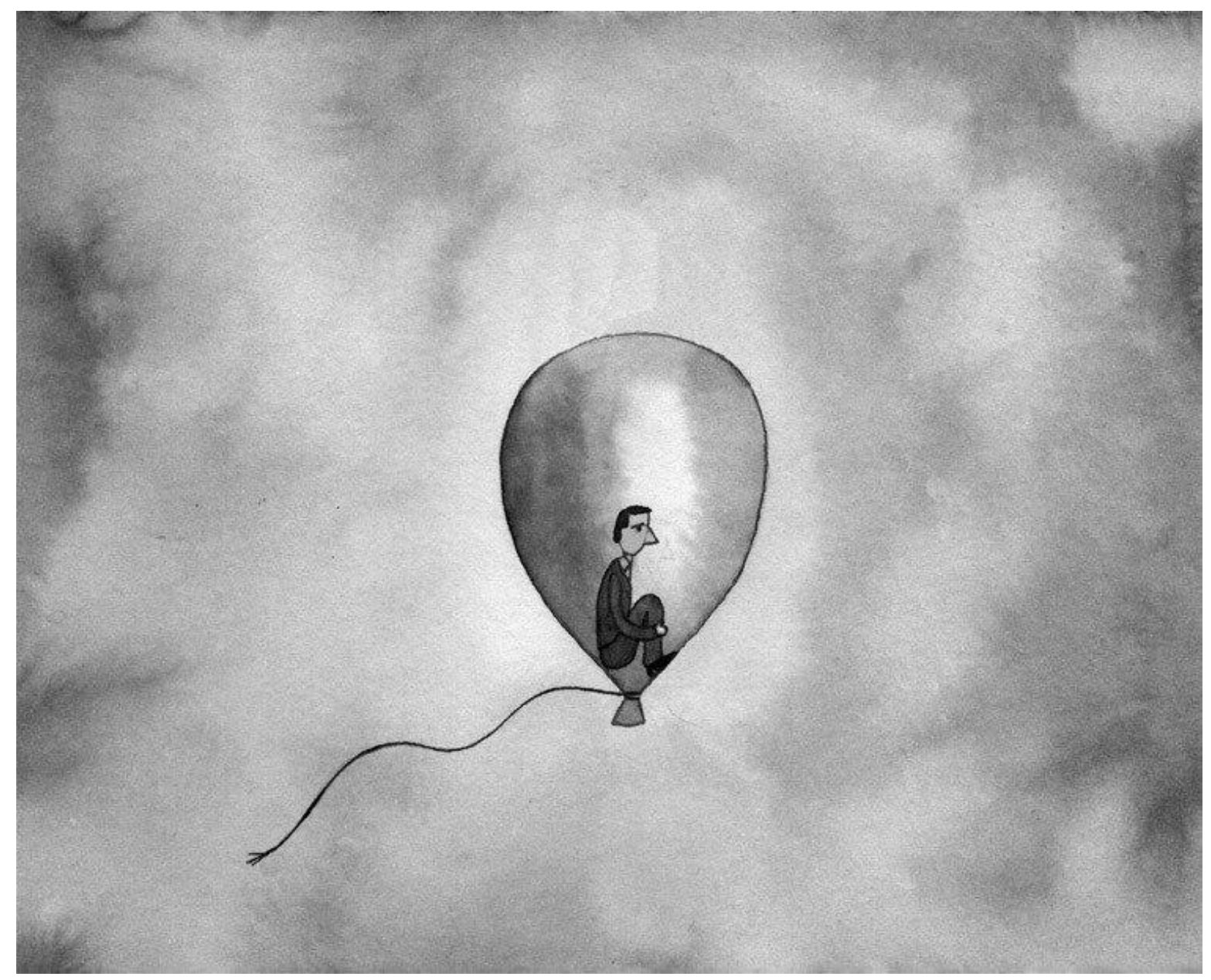

Troche, G. (2014). [Ilustración]. Recuperada de: http://portroche.blogspot.com/2014/

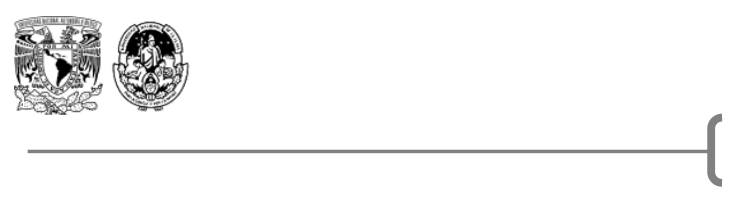


Una mañana nos regalaron un conejo de Indias. Llegó a casa enjaulado. Al mediodía, le abri la puerta de la jaula.

Volví a casa al anochecer y lo encontré tal como lo había dejado: jaula adentro, pegado a los barrotes, temblando del susto de la libertad.

(Galeano, 2014)

María $^{17}$

(2008)

Cuando María llegó al Hospital Pediátrico en la CDMX contaba con dos años. El diagnóstico médico la reportaba como grave, presentando quemaduras de tercer grado consecuencia del incendio en su improvisada vivienda ubicada en un tiradero de basura donde su abuela y madre se dedicaban a "pepenar"18. Según el relato que obra en el expediente médico se sabe que tres niñas estaban solas en el domicilio cuando una veladora cayó al suelo y de inmediato se extendió el fuego que envolvió a las tres menores de edad, sin que éstas pudieran hacer nada.

Su historia familiar es incierta y opaca. Se sabe que tenía dos hermanas, una mayor que ella y una menor (quienes también llegaron al nosocomio), la más pequeña murió un par de días después de haber sido ingresada y la mayor, con dificultades, logró recuperarse y ser egresada con su madre unas semanas más tarde.

María permaneció meses en el hospital, la recuperación fue lenta, costosa y muy difícil. Durante su estancia el pronóstico fue reservado. No sólo se trataba de las quemaduras externas, sino de las complicaciones que presentaba en el resto de sus órganos internos.

\footnotetext{
${ }^{17}$ Las narraciones respecto de las historias de niñas y niños receptores de maltrato que habrán de leerse a lo largo de esta tesis se inspiran en casos reales, se han cambiado sus nombres para conservar el anonimato y proteger su privacidad y han sido redactadas con el mayor cuidado y exactitud posible, recurriendo a los instrumentos de registro con los que se cuenta: diario de campo, informes sociales, notas de expediente y correos electrónicos.

18 "Pepenar" es una expresión que alude al acto de recoger del suelo o de la basura, objetos o alimentos que han sido desechados para consumo personal.

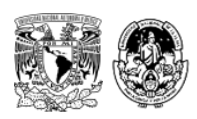


Tras una serie de intervenciones, cirugías, tratamientos y terapias, se determinó su "alta". Ahora su mayor problema no era médico, sino familiar.

Una vez estable de salud, se encontraba en orfandad -tras el abandono de su madre-, de quien poco se supo durante la estadía hospitalaria y cuya localización posterior fue imposible. Esta situación motiva su ingreso a un CAS, cuyo proyecto institucional se centra fundamentalmente en resolver su situación jurídica e integrarla lo más pronto posible, ya fuera a la familia biológica extensa o a una familia de condición adoptiva; proyecto congruente con la encomienda institucional de fungir como un hogar transitorio de corta permanencia.

Las trabajadoras sociales adscritas a la instancia jurídica y luego las del CAS, iniciaron una búsqueda incesante sin éxito, por lo que la investigación en torno al paradero de la familia de origen se abortó para dar paso a un proceso judicial que pronto designó a la niña como candidata de adopción, dejándola jurídicamente en posibilidades de ser integrada a una familia por esta vía.

Desafortunadamente ese proyecto cada día se vislumbraba más distante. Las parejas aprobadas para adoptar no deseaban asumir la responsabilidad del cuidado y crianza de una niña con las características de María. Argumentos como: "no estamos en condiciones", "nosotros pedimos una niña sana”, "no tenemos dinero para atender sus necesidades”, “¿qué va a pasar cuándo crezca, va a poder tener hijos?”, eran la constante.

Mientras estos intentos fallidos de asignación frustraban el proyecto institucional, al interior del centro cuidadoras, enfermeras, profesionales y el resto de las niñas y niños albergados le ofrecían un ambiente seguro. De sus cuidadoras se escuchaba decir "es una gran niña", "es tan obediente y disciplinada", "cuando vamos al hospital nunca se queja", "que linda es María, no cuesta ningún trabajo quererla", "es una gran hija".

Los años pasaron por ella, hoy día es una adolescente que sigue albergada en el CAS, en donde no sólo se le ha proveído de sus necesidades instrumentales, económicas y materiales; el apego de sus pares y cuidadoras se observa claramente en el sentido de pertenencia que

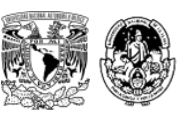


esta ha desarrollado: "a mí me gusta mucho estar aquí, antes quería papás, pero ahora ya no, no quiero que me separen de mis mamás y mis hermanos” (Ruíz, 2019: 19).

Fue en el año 2017 cuando por primera vez conté públicamente la historia de María, una niña especialmente significativa en mí, cuyo encuentro me dejó importantes fisuras derivadas del vínculo que establecí con ella y del que por años me sentí culpable, sumado a la profunda frustración por no haber conseguido "mi encomienda profesional" de lograr su integración a una familia de condición adoptiva, que por el año 2008 (cuando la conocí) experimentaba como casi la única manera de repararle y hacerle valer su derecho a vivir en familia.

Así, al terminar mi conferencia -que inicia con el relato de María- en un encuentro en la Facultad de Filosofía y Letras de la UNAM denominado: "Taller de aplicación de textos literarios al entorno social”, el coordinador Maurice Biriotti, discípulo de Jacques Derrida, se mostró parco a la vez que contundente y me dijo: “el tuyo, un relato Kafkiano Gabriela, que esconde detrás de la historia de María, la emocionalidad propia. Se quiebra tu voz y eso se hace evidente. Déjala emerger... ${ }^{19}$ ".

Esta experiencia, provoca en mí la necesidad por conectar emocionalmente con María, tomar distancia de la intervención como únicamente una encomienda profesional y reconocer el proceso de subjetivación que se detonó y del cual no tenía cabal conciencia hasta el momento de su redacción.

\section{Prefacio}

Implicarse en el análisis y reflexión del ejercicio disciplinar de las y los trabajadores sociales situados en la atención de niñas y niños receptores de maltrato, sin cuidados parentales y en condición de institucionalización, supone un necesario posicionamiento sustentado en un marco teórico referencial, en el entendido de que el bordeo teórico aportará la base sobre la cual se comprenderán las prácticas de la intervención.

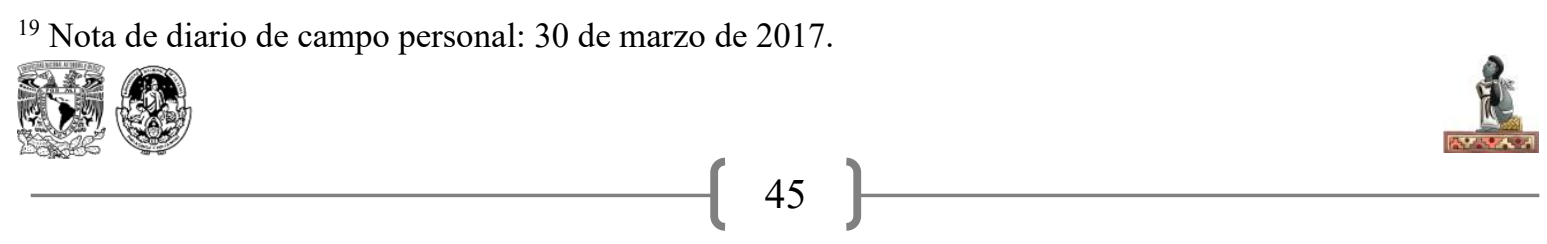


A lo largo de este capítulo se construye el enfoque teórico para el abordaje del fenómeno de investigación. El mismo, expone algunos elementos inscritos en el transitar conceptual de la analítica del poder desarrollada por Michel Foucault y sus principales seguidores. En su construcción se profundizan las categorías de poder, subjetivación, dispositivo, episteme, agenciamiento, sujeto institucional, entre otras, así como los elementos para el análisis crítico contemporáneo respecto de las instituciones como mecanismos disciplinarios.

Al final del apartado se recuperan algunos estudios y/o investigaciones en materia de niñez, que han recurrido al planteamiento "Foucaultiano", que sirven, como un pertinente referente al ofrecer campos de análisis que vinculan los fenómenos que aquejan a la niñez, vinculados con categorías teóricas como el proceso de subjetivación, episteme e institución.

\subsection{La analítica del poder y sus postulados teóricos}

En términos de enfoque teórico, la presente investigación recurre a algunas aproximaciones de la filosofía desarrolladas en la analítica del poder de Michel Foucault y de estudiosos que recuperan sus postulados para interpretarlo o analizar realidades concretas, como: Giorgio Agamben, Gilles Deleuze, Jacques Donzelot, Roberto Espósito y Ariadna Estévez; intentando con ello disponer un análisis disciplinar en consideración de la serie de elementos que se imbrican y las determinantes del sujeto, el poder, los discursos, las prácticas, las legislaciones, las instituciones, etc.

No se trata entonces, de la búsqueda de determinantes que ejemplifiquen los planteamientos "Foucaultianos", sino del uso de nociones desarrolladas en la obra de dicho autor, sus seguidores y los elementos que de estas emanan para el análisis del ejercicio profesional.

A decir verdad, reflexionar la intervención del TS en el escenario de la asistencia social, no ocupa un hallazgo nuevo, ni se trata de una propuesta extraordinaria, el mismo Foucault por el año 1972 participó en una mesa de discusión al lado de sus contemporáneos: el sociólogo Jacques Donzelot, conocido especialmente por La policía de las familias (1990), Paul Virilio, arquitecto que escribe sobre tecnología y sociedad y otros participantes como el sociólogo

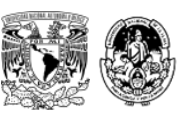


Philippe Meyer y Jeane René Tréaton (el último era entonces director de la Revue Française de Sociologie), el historiador Jacques Julliard y el escritor René Pucheu, así como el director Jean-Marie Domenach y el editor jefe, Paul Thibaud, de Esprit (Chambon, Irving, Epstein, 2001: 169-182).

A esta mesa la denominaron “¿Por qué el trabajo social?” Entre otros elementos Domenach dirige la discusión planteando que:

El trabajo social aumenta constantemente su campo de acción. Habiendo partido del apoyo benévolo a una acción de erradicación de la tuberculosis y las enfermedades venéreas, ha pasado por la asistencia profesional en medio del subproletariado o para-proletario. Hoy se encuentra ampliamente plantado en las empresas y la administración. Su evolución más reciente le lleva a encargarse de la animación colectiva de la población corriente, sobre todo en las ciudades (Chambon, Irving, Epstein, 2001: 174).

Este último se plantea las preguntas:

¿Piensan ustedes que este crecimiento y esta evolución del trabajo social tiene una relación con la naturaleza y la evolución de nuestro sistema económico?

¿Existe realmente una continuidad entre el trabajo social surgido del tratamiento policial, psiquiátrico, reeducativo de los desviados y la acción social en la masa de la población? (Chambon, Irving, Epstein, 2001: 174).

Ya en este encuentro, se cuestionaban el rol e intervención que llevan a cabo las y los profesionales del TS en un sistema económico capitalista que procura el aislamiento de grupos e individuos para optimizar su función. Al respecto discutían:

[...] estos trabajadores sociales no solo serán productores de socialidad, como se hace creer oficialmente, sino que soterradamente reforzarán el proceso de atomización y de disgregación del tejido social, y esto es lo que parece más catastrófico, independientemente del papel de control social que puedan jugar a través de esta transmisión de una nueva ley (Chambon, Irving, Epstein, 2001: 175).

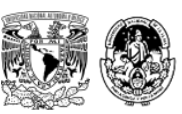


Recuperando la obra de Foucault y otros pensadores, en esta tesis se interpreta la intervención en el escenario concreto de los CAS del SNDIF, a partir de la premisa de que el ejercicio profesional contemporáneo no dista significativamente de lo que por la década de los setenta ya se cuestionaban los pensadores de la época: el papel del TS, como una disciplina enfocada a paliar los efectos de la desigualdad, sin concretar acciones de transformación social.

\subsubsection{Poder y sus elementos constituyentes}

Si bien para Castro (2004: 2014) Foucault "no hizo una teoría del poder, sí se aventuró a desarrollar una filosofía analítica del mismo, que no intenta definirlo sino establecer cómo funciona y cómo somete a los sujetos". El poder en el francés no se posee, se ejerce y permite influir y determinar formas de pensamiento y actuación en los sujetos.

Para Foucault (1991: 166) "no es el poder sino el sujeto lo que constituye el tema general de su investigación y al mismo tiempo reconoce su imbricación y la necesidad por ampliar las dimensiones de una definición de poder al reconocer que el humano se halla situado en relaciones (de poder) extremadamente complejas". Para este autor, el término poder designa relaciones entre partes, se trata de un juego que se da entre individuos y grupos al identificar que es posible su emerger, sólo a partir del encuentro, en donde uno se instaura sobre otro. La tesis fundamental expone cómo es que se ejerce este poder. Explica:

El ejercicio del poder no es simplemente una relación entre distintas partes, individuales o colectivas; es una forma en la que ciertas acciones modifican a otras. Lo cual equivale a decir, claro está, que ese algo llamado poder, con o sin mayúscula, que se supone existe universalmente de forma concentrada o difusa, no existe. El poder existe únicamente cuando es puesto en acción, incluso si, desde luego, está integrado a un campo desigual de posibilidades llevadas a actuar sobre estructuras permanentes. Esto significa además que el poder no es una función del consentimiento. No es en sí mismo, una renuncia a la libertad, una transferencia de derechos, el poder de todos y cada uno delegado a unos pocos (lo cual impide que la posibilidad del consentimiento pueda ser una condición para la existencia y el mantenimiento del poder); la relación de poder puede ser el resultado de un consentimiento

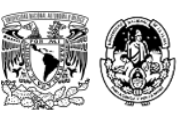


previo y permanente, pero no es por naturaleza, la manifestación de un consenso (Foucault, 1991:180).

Estos planteamientos habrán de colocar el carácter del poder como una acción que se ejerce y modifica las formas de actuar, ya sea en lo individual o en lo colectivo, al instaurarse en la interacción, definiendo así las formas de comportamiento en reciprocidad. Afirma que "lo que define una relación de poder es que constituye un modo de acción que no actúa directa o inmediatamente sobre otros. Actúa por el contario sobre acciones existentes o sobre aquellas que puedan seguir en el presente o en el futuro" (Foucault, 1991: 180).

En esta línea de interpretación para Estévez, el poder consiste en conducir conductas, es decir, no actúa sobre las personas, sino sobre sus acciones, induciéndolas, facilitándolas, dificultándolas, limitándolas o impidiéndolas. Para dicha autora, "las relaciones de poder se vuelven de dominación cuando son bloqueadas con técnicas que permiten dominar la conducta de los otros. Desde esta filosofía, el vehículo ideal del poder es el discurso, el cual es el conjunto de elementos o bloques de tácticas en las relaciones de fuerza, los cuales determinan subjetividades y tienen efectos de verdad, es decir, establecen objetos y saberes que dividen lo falso de lo verdadero" (Estévez, 2018: 11). Por su parte García (2011:2) define que:

Los discursos se hacen prácticas por la captura o pasajes de los individuos, a lo largo de su vida, produciendo formas de subjetividad; los dispositivos constituirán a los sujetos inscribiendo en sus cuerpos un modo y una forma de ser [...] lo que inscriben en sus cuerpos son un conjunto de praxis, saberes, instituciones, cuyo objetivo consiste en administrar, gobernar, controlar, orientar, dar un sentido que se supone útil a los comportamientos, gestos y pensamientos de los individuos.

Articular los discursos cobra relevancia en tanto se trata de prácticas producidas que construyen identidades individuales y colectivas y gracias a textos como Las palabras y las cosas (1966), se pone el acento en cómo los discursos median, se enredan y construyen verdad, pues en realidad como sujetos no tenemos acceso directo a la realidad, sino a partir de la articulación de enunciados y objetos discursivos. 
En Foucault (1991) "el poder se ejerce sobre la inmediata vida cotidiana que categoriza al individuo, lo marca con el sello de su propia individualidad, lo ata a su propia identidad, impone sobre él una ley de verdad que él debe reconocer y que los demás tienen que reconocer en él. Es una forma de poder que transforma a los individuos en sujetos" (1991:170).

$\mathrm{Al}$ respecto, brota un elemento constituyente del poder o, mejor dicho, el proceso a través del cual el sujeto se vuelve el engranaje por el que pasa el poder, se perpetua y desarrolla en su configuración: el proceso de subjetivación.

\subsubsection{Subjetivación: la construcción del sujeto}

En Foucault un proceso de subjetivación es el modo en que el sujeto hace la experiencia de sí mismo al interior de un juego de verdad en el que está en relación consigo. "De esa experiencia de sí mismo, de esa relación consigo, surge un otro que se inserta en relaciones de poder a la vez que reacciona ante ellas y las reformula" (1984: 942). Toda relación de poder requiere esos dos elementos indispensables; reclama que "ese 'otro' (sobre quien se ejerce una acción de poder) debe ser enteramente reconocido y mantenido hasta el fin como una persona que actúa; y que, ante una relación de poder, se abra todo un campo de respuestas, reacciones, resultados y posibles invenciones" (Foucault, 1991: 253).

De ahí que para la interpretación de Vignale (2014: 7):

[...] el sujeto no es constituyente, sino constituido. El mismo dispositivo que constituye los diversos objetos, sea la locura, la criminalidad, la sexualidad, produce también al yo como sujeto. Cuando en Vigilar y castigar Foucault dice que la disciplina fabrica individuos, el cuerpo se presenta como la superficie sobre la cual se imprime el lenguaje reglado de lo permitido y de lo prohibido. El poder produce al sujeto a partir de determinados hábitos, posiciones, prohibiciones, vestiduras, gestos, tiempos. Y lo vuelve un individuo productivo, una pieza en un engranaje. Ahora bien, en muchos casos, la respuesta a esta perspectiva fue la de considerar la filosofía de Foucault como una filosofía pesimista, reprochándosele negar la libertad y la acción de los individuos, como si solo estuviesen encadenados a los 
dispositivos y fuesen incapaces de transformar el discurso. Pero se trata de una lectura simplista, que no considera la cuestión de la libertad y no alcanza a comprender el tipo de trabajo que Foucault realiza, que consiste en "un escepticismo sistemático respecto de todos los universales antropológicos" lo cual de ninguna manera implica negar la libertad de los individuos.

En su libro Vigilar y castigar, Foucault (1976: 250) subraya que "la hermosa totalidad del individuo no está amputada, reprimida, alterada por nuestro orden social, sino que el individuo se halla en él cuidadosamente fabricado, de acuerdo con toda una táctica de las fuerzas y de los cuerpos".

En las "sociedades de normalización" la disciplina constituye la forma mediante la cual el objeto sobre el que recae el poder -el individuo- no es meramente pasivo, sino que requiere toda una actividad en el juego de las fuerzas que lo sujetan a determinadas normas. Si bien el poder disciplinario, con sus técnicas y dispositivos, se constituye en un ejemplo paradigmático al hablar de los modos de sujeción, se hace necesario comprender que "hay dos significados de la palabra sujeto: por un lado, sujeto a alguien por medio del control y de la dependencia y por otro, ligado a su propia identidad por conciencia y autoconocimiento. Ambos significados sugieren una forma de poder que subyuga y sujeta (Foucault 1991: 250).

De ahí que la subjetivación se ve atravesada por los juegos de poder; es el proceso constituyente del sujeto a partir de los discursos y prácticas con los que se mira y le miran, dejando poco o prácticamente nada al ejercicio de la subjetividad en voluntad, pues esta para él, es inexistente. Para ello la subjetivación se configura desde el entramado de discursos y el poder. En esta línea de pensamiento Agamben sostiene que:

El hombre se constituye como persona, adquiere una identidad social, a través del reconocimiento (Anerkennung) de los otros, lo cual está en la base de la personalidad jurídica que le sobreañade. La lucha por el reconocimiento sería así una lucha por una máscara que coincide con la personalidad que la sociedad reconoce a cada individuo. De allí que el reconocimiento de la propia persona haya sido por milenios la posesión más significativa para los sujetos (2009: 71-72).

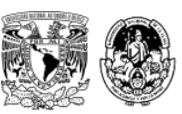


La subjetivación es, por tanto, la manera en cómo el sujeto expresa su subjetividad que resulta de la intersección de los discursos, pensamientos, atribuciones que los otros tienen de él y su propio reconocimiento, de ahí entonces que ningún elemento tiene una esencia nata, nada es lo que en sí, sino en función de su relación con otro(s) elementos(s). Los "modos de subjetivación" o "procesos de subjetivación" del ser humano corresponden en realidad a dos tipos de análisis: por un lado, los modos de objetivación que transforman a los seres humanos en sujetos, lo que significa que sólo se puede ser sujeto al objetivarse y que los modos de subjetivación son, en ese sentido, prácticas de objetivación. Por otro lado, "la manera como nos relacionamos con nosotros mismos, a través de una serie de técnicas de sí, nos permite constituirnos como sujetos de nuestra propia existencia” (Revel, 2009: 128).

De ahí que en García (2011: 2) "los discursos se hacen prácticas por la captura o pasaje de los individuos a lo largo de su vida, por los dispositivos produciendo formas de subjetivación; los dispositivos constituirán a los sujetos inscribiendo en sus cuerpos un modo y una forma de ser".

\subsubsection{Dispositivo: de lo dicho y lo no dicho}

"El poder produce a través de una transformación técnica de los individuos lo real, adquiriendo así legitimidad" (Foucault, 2001:11). Es aquí donde emergen otras categorías que plantean dicho ejercicio de poder y para ello su obra desentraña el dispositivo como:

[...] un conjunto decididamente heterogéneo, que comprende discursos, instituciones, instalaciones arquitectónicas, decisiones reglamentarias, leyes, medidas administrativas, enunciados científicos, posiciones filosóficas, morales, filantrópicas, en resumen: los elementos del dispositivo pertenecen tanto a lo dicho como a lo no dicho. El dispositivo es la red que puede establecerse entre estos elementos (Foucault, 1976:128).

"Los dispositivos surgen, primeramente, como respuesta a una urgencia, como tentativa de resolución pragmática, como forma política de solucionar lo que se percibe como un problema de orden práctico. De lo cual se sigue que la emergencia de un dispositivo obedece

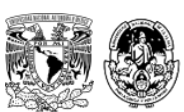


a una función estratégica dominante" (Heredia, 2012:87), configuran campos de actuación y se imponen a manera de prácticas instauradas en el sujeto, sin que este se dé cuenta de ello. Para García (2011: 2):

Uno de los equívocos más generalizados que existen con relación al uso que Michel Foucault le asigna al término dispositivo consiste en utilizarlo como sinónimo de institución. Sin embargo, de una lectura atenta de los textos Foucaultianos se deduce claramente que lo que define como dispositivo es la relación o red de saber/poder en la que se inscriben la escuela, el cuartel, convenio, hospital, cárcel, fábrica y no cada uno de ellos de forma separada. Un dispositivo seria entonces, una relación entre distintos componentes o elementos institucionales que también incluirían los discursos, instalaciones arquitectónicas, decisiones reglamentarias, leyes, medidas administrativas, enunciados científicos, filosóficos, morales y/o filantrópicos, que circulan dentro de dicha relación; específicamente aclara que el dispositivo mismo es la red que se establece entre estos elementos.

El dispositivo es el espacio de saber/poder donde se procesan tanto las prácticas discursivas como no discursivas, no hay circularidad ni interacción, ni mucho menos una basesuperestructural ya que las formaciones discursivas producen los objetos de los que hablan (dominio de la arqueología del saber) en tanto los regímenes de enunciación organizan las posibilidades de la experiencia (genealogía del poder) de acuerdo a unas condiciones de posibilidad que se definen en la historicidad (a priori histórico) del acontecimiento. "No es que saber y poder son la misma cosa o dos cosas distintas exteriores la una a la otra sino elementos constituyentes de las prácticas sociales cuya relación debe ser explicada en su singularidad" (García, 2001: 4).

En el texto ¿Qué es un dispositivo? Giorgio Agamben resume tres puntos con relación a él:

1.- El dispositivo se trata de un conjunto heterogéneo que incluye virtualmente cada cosa, sea discursiva o no; discursos, instituciones, edificios, leyes, medidas policiacas, proposiciones filosóficas. El dispositivo, tomado en sí mismo, es la red que se tiende entre estos elementos. 
2.- El dispositivo siempre tiene una función estratégica concreta, que siempre está inscrita en una relación de poder.

3.- Es algo general, un reseau, una "red", porque incluye en sí la episteme, que es para Foucault, aquello que en determinada sociedad permite distinguir lo que es aceptado como un enunciado científico de lo que no es científico (2011:1).

\subsubsection{Episteme: los constructos de la ciencia}

Al analizar las formas discursivas se integran los elementos epistemológicos que las ciencias atribuyen a constructos concretos y que de una u otra forma, determinarán el abordaje técnico de representaciones en las ciencias.

Por episteme se entiende, el conjunto de las relaciones que pueden unir, en una época determinada, las prácticas discursivas que dan lugar a unas figuras epistemológicas, a unas ciencias, eventualmente a unos sistemas formalizados; el modo según el cual en cada una de esas formaciones discursivas se sitúan y se operan los pasos a la epistemologización, a la cientificidad, a la formalización; la repartición de esos umbrales, que pueden entrar en coincidencia, estar subordinados los unos a los otros, o estar desfasados en el tiempo; las relaciones laterales que pueden existir entre figuras epistemológicas o unas ciencias en la medida en que dependen en prácticas discursivas contiguas pero distintas. La episteme no es una forma de conocimiento o un tipo de racionalidad que, atravesando las ciencias más diversas, manifestará la unidad soberana de un sujeto de un espíritu o de una época dada; es el conjunto de las relaciones que se pueden descubrir, para una época dada, entre las ciencias cuando se las analiza al nivel de las regularidades discursivas. La episteme no es una figura inmóvil, que, aparecida un día, estaría destinada a desvanecerse no menos bruscamente: es un conjunto indefinidamente móvil de escansiones, de desfases, de coincidencias que se establecen y se deshacen (Foucault, 1979:322-324).

Saber y episteme jugarán entonces una dualidad casi indisoluble, pues se interseccionan para producir cierto tipo de sujeto colocado así en el poder y el deseo, en donde no hay campos únicos de conocimiento y, por tanto, esta episteme habrá de legitimar el agenciamiento de quienes operan ese saber. 


\subsubsection{Agenciamiento: fenómenos de individuación colectivos e impersonales}

Hasta ahora, se ha planteado que el dispositivo es la red, el entramado y la interrelación que opera desde las prácticas discursivas y no discursivas, legislaciones, constructos teóricos, etc., expresándose de forma instaurada en el sujeto. Con relación al agenciamiento, desarrollado por Deleuze (1993), se entenderá como el:

[...] conjunto de relaciones cofuncionales entre elementos heterogéneos y dichos rasgos son análogos a los de la noción de Dispositivo (una red de elementos heterogéneos discursivos y no discursivos, etc.) [...] el agenciamiento colectivo de enunciación busca captar los procesos de individuación colectiva de enunciados y daría lugar a una formalización de expresión [...] y a la vez, no remite a la intención de un individuo o de una misteriosa causalidad estructural, sino a individuaciones psicosociales, es decir fenómenos de individuación colectivos e impersonales que movilizan un conjunto infinito de potencias y singularidades preindividuales y que se actualizan en el proceso real encarnando agenciamientos concretos y finitos: agenciamientos maquínicos de efectuación (régimen de cuerpos, de acciones y de pasiones) y agenciamientos colectivos de enunciación (régimen de signos, consignas-actos y contraseñas) (Heredia, 2012: 96).

Por tanto, el agenciamiento formalizará las relaciones y dará potestad para la transmisión e implementación de categorías dadas, legitimándose en espacios concretos de actuación - tales como la institución- en donde el espacio configura un elemento sustancial, pero no el espacio como un lugar exclusivamente físico, sino como una geografía que determina relaciones. Todo agenciamiento es en primer lugar territorial. "El territorio crea agenciamiento. El territorio excede a la vez el organismo y el medio, la relación entre ambos: por eso el agenciamiento va más allá también del simple comportamiento" (Deleuze, 2002: 513).

De ahí que el agenciamiento influye y determina a los sujetos que en él convergen, se identifican y construyen sus relaciones.

La unidad real mínima no es la palabra, ni la idea o el concepto, ni tampoco el significante.

La unidad real mínima es el agenciamiento. Siempre es un agenciamiento el que produce los

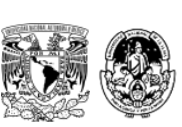


enunciados [...] El agenciamiento es el cofuncionamiento, la "simpatía", la simbiosis. [...] En la simpatía no hay ningún juicio, lo único que hay son convivencias entre cuerpos de cualquier naturaleza. [...] Agenciar es eso: estar en el medio, en la línea de encuentro de un mundo interior y un mundo exterior (Deleuze y Parnet, 1980: 61-62).

Es así como el sujeto desarrolla puntos de coincidencia determinados por el territorio que a la vez configuran procesos anudados congruentes con las reglamentaciones, los discursos y la subjetivación, hasta ahora expuestos.

\subsubsection{El sujeto institucional: la otra cara de la intervención}

La obra Vigilar y castigar estudia la presencia de las relaciones de poder, las tecnologías de control, y la microfísica de poder. Es en este texto en donde Foucault profundiza sobre el castigo como mecanismo y función social compleja, métodos punitivos que recurren a espacios de encierro de los anormales y en donde claramente se ejerce el poder:

El panóptico es el espacio cerrado, recortado, vigilado en todos sus puntos, donde los menores movimientos se controlan, los acontecimientos se registran, en el que un trabajo ininterrumpido de escritura une el centro y la periferia, en el que el poder se ejerce por entero, de acuerdo con una figura jerárquica continua, en el que cada individuo está constantemente localizado, examinado y distribuido entre otros individuos. Este aparato arquitectónico es una máquina que crea y sostiene las relaciones de poder, que fabrica efectos de poder. El panóptico es un lugar privilegiado que hace posible la experimentación sobre los hombres (Foucault, 1984:203).

En estos espacios de encierro (la cárcel, el hospital psiquiátrico, los hospicios), se cuenta con operarios que ejercen el poder entre la agencia y la estructura, a partir de la episteme de su hacer profesional y con lugares constreñidos que les facultan dicho ejercicio que habrá de dictaminar al final, la subjetivación de ese otro anormal. Para Giraldo:

La medicina, la psicología, la psiquiatría ocupan un lugar central, porque constituyen un saber que vincula la acción científica y la técnica política de la intervención tanto sobre el cuerpo como sobre la población. Sobre el cuerpo individualmente considerado historial clínico, pero

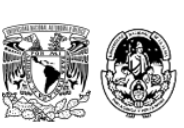


al mismo tiempo también intervención masiva sobre la población. Es un poder-saber, para Foucault la otra cara del poder es el saber, que actúa sobre ambos, el cuerpo individual y el cuerpo social, y por tanto tiene efectos disciplinarios sobre cada cuerpo individual como efectos de regulación sobre las poblaciones consideradas globalmente (2006:116).

Los espacios de encierro habrán de estructurar a la sociedad contemporánea y se configuran como instituciones que subjetivan, construyen y alojan sujetos institucionales. Ahí no se habla entonces "de cualquier sujeto, sino de aquel que fue construido, modelado y connotado por una o varias instituciones, formaciones que asumieron características propias [...] en donde institución y disciplina se dan conjuntamente, una requiere de la otra, es causa y efecto de la otra. La disciplina es una técnica del ejercicio del poder que tiene como objetivo conformar los cuerpos de los sujetos y absorber y ritmar su tiempo de vida, ya sea de manera parcial o total" (García, 1995: 187188).

En el texto Vigilar y castigar (1976), Foucault nos habla de todas estas técnicas que han ido haciendo al sujeto disciplinado a partir de las tecnologías del poder. En esa misma línea de pensamiento, García sostiene que:

Llevado al extremo el sometimiento de este tipo de sujetos, podemos constatar que su actividad comenzó a disminuir convirtiéndose en sujetos profundamente pasivos, infantilizados, anonadados, sin capacidad de respuesta. Este sujeto pasivo, sin voz ni reflejos reactivos, se caracteriza por su estatismo, su inmovilidad. Esto ha provocado la emergencia de una nueva subjetividad en Occidente, con su correspondiente sensibilidad; es decir, ha nacido un nuevo tipo de sujeto que ya no responde a las disquisiciones teóricas ni a las formulaciones explicativas que se hicieron de él, ya sea como sujeto disciplinado o como institucional (1995: 192).

Para efectos de la presente investigación, se hace indispensable cruzar el análisis con relación a la forma en cómo, no sólo las niñas y los niños en condición de institucionalización se ven atravesados por este espacio reglamentado que configura su proceso de subjetivación, sino las propias profesionales se ven marcadas y determinadas por los discursos, las técnicas y las reglamentaciones que se fortalecen con el encuentro de su agenciamiento profesional, objeto central del análisis de esta tesis. 
Hasta aquí, hemos realizado un breve recorrido conceptual por los preceptos desarrollados en Foucault desde la analítica del poder (tal como se señaló al inicio de este capítulo). De igual forma, han sido muchas y muchos estudiosos, quienes han hecho uso de su obra para aproximarse al entendimiento de las realidades que se manifiestan en la sociedad contemporánea, en donde el foco se coloca en la niñez en condición de maltrato y su consecuente intervención institucional.

\subsection{De otros estudios sobre la niñez contemporánea y la intervención del Trabajo Social. Un análisis desde la analítica del poder}

Uno de los textos más importantes que inspiran la presente investigación, se encuentra en $L a$ policía de las familias de Jacques Donzelot, obra escrita en 1977 y en donde es el mismo Deleuze quien a manera de epílogo reflexiona sobre esta, denunciando cómo se observa una clara diferenciación entre las clases más desfavorecidas y en donde el abandono de los hijos derivado de la mala economía los lleva al abandono como posibilidad de refuncionamiento social.

Específicamente en el capítulo cuatro, Donzelot se sumerge en el Tribunal de Menores, desvelando la red de los poderes legales, la agencia disciplinar de las y los trabajadores sociales, en esa intromisión del ámbito íntimo en donde lo privado se vuelve público desde las prácticas de enjuiciamiento y normalización de aquellos niños difíciles de tratar, abriéndose expedientes, haciéndose uso de valoraciones psicológicas y valoraciones de su ámbito familiar, echando mano de interrogatorios y verificaciones del mundo familiar.

Atrapada en esta doble red de tutores sociales y de técnicos, la familia aparece como colonizada. Ya no hay dos instancias frente a frente: la familia y el aparato, sino una serie de círculos concéntricos en torno al niño: el círculo familiar, el círculo de los técnicos, el círculo de los tutores sociales. Paradójico resultado de la liberación de la familia, del nacimiento del derecho de un/a niño/a, del reajuste hombre-mujer: cuanto más proclamados estos derechos, más estrecho alrededor de la familia pobre, el cerco de un poder tutelar. El patriarcalismo familiar sólo es destruido al precio de un patriarcado de Estado (Donzelot, 1977; 107).

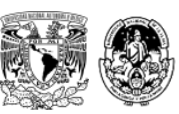


Entender el papel que juegan las y los especialistas y técnicos en la intervención familiar no resulta menor, al analizarse una atención disciplinaria que representa un estudio ético, ontológico, a la vez que la única posibilidad para deconstruir dichas prácticas.

La reflexión respecto de la construcción de la intervención proporcionada por el Estado a través de sus instituciones lleva a Osorio y Arteaga (2012) a desarrollar el texto De la disciplina al control: niños en riesgo y dispositivos asistenciales en el centro de México.

Este trabajo analiza algunos de los dispositivos manejados por ciertas instituciones públicas asistenciales del centro de México para atender a los llamados niños en riesgo, desde 1960 hasta la primera década del siglo XXI. Partiendo de los conceptos de racionalidades políticas y tecnologías de gobierno, aborda las transformaciones que han experimentado y que dan cuenta del tránsito inacabado que ha llevado de una forma de atención disciplinaria (representada por una asistencia masiva, indistinta y asistencialista) a otra de control (representada por una asistencia gerencial y menos terapéutica), lo cual ha derivado en un creciente proceso de desamparo estatal hacia estos niños, al tiempo de criminalizar a algunos grupos de ellos (Osorio y Arteaga: 2012: 213).

Entre sus ideas concluyentes más relevantes está la de una intervención que desde principios del año 2000, está alentando el uso entre las instituciones públicas de nuevas tecnologías para la atención y la prevención sistemática de riesgos ${ }^{20}$. "Esas tecnologías son presentadas como una herramienta para mejorar la atención de los niños, pero que al final alientan la homogeneización y la deshistorización de estos, pues las distintas problemáticas y características que presentan pretenden ser reducidas a un conjunto de variables preestablecidas para, posteriormente, definir a los sujetos de atención" (Osorio y Arteaga, 2012: 235). La atención parcializada, selectiva, se observa en los mecanismos institucionales que colocan el foco de atención en la niñez en riesgo, separándola del sistema familiar y

\footnotetext{
${ }^{20}$ Osorio y Arteaga (2012) ofrecen un análisis que -entre otras condicionantes- concluye que hay espacios que se configuran como escenarios de encierro tendientes a promover una atención alienante y masificada. "Entre estos espacios enuncian: los Centros de readaptación para menores de edad, los hospitales de índole psiquiátrica y los hospicios, que son, el antecedente histórico de los Centros de Asistencia Social, como recintos de atención para la niñez en condición de orfandad o riesgo social, administrados por el Estado".
}

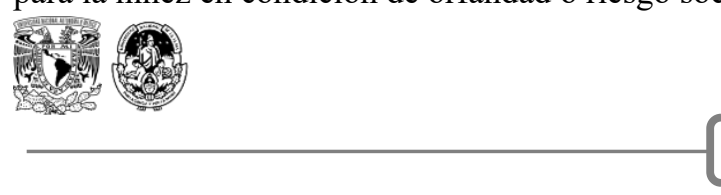


dando poca importancia al contexto social, que obligan la separación de las y los menores de edad e integrándolos en un juego dicotómico de inclusión-exclusión.

Esta dualidad es trabajada por Bauman (2013) quien expone que "la tecnología de vigilancia actual se desarrolla en dos frentes y sirve a dos objetivos estratégicamente opuestos: por un lado, el del confinamiento (o "mantener dentro de la valla"), y por el otro, el de la exclusión (o "mantener más allá de la valla"). La aparición entre las masas globales de exiliados, refugiados, demandantes de asilo — o de pan y agua — podría incluso estimular ambos tipos de tecnología de la vigilancia" (Bauman y Lyon, 2013: 37). Estas ideas se enmarcan, en la definición de "cuerpos desechables" que hacen funcionar al sistema, que a su vez les expulsa por encontrarse fuera de la norma, no advirtiendo que han sido las condiciones desiguales y de marginalidad, las que les construyen y desde la propuesta de Foucault $(1976,1984,1991)$ con relación a la subjetivación, encuentran una inminente intersección.

Otro estudio que ha servido como importante influencia para la presente investigación, es el realizado por Perla Zelmanovich y Mercedes Minnicelli (2012: 39-50): "Instituciones de infancia y prácticas profesionales: entre figuras de segregación y dispositivos de inscripción simbólica", texto que recupera consideraciones sobre cómo entendemos la operación subjetiva y el sostén colectivo de la "Institución de Infancia" y su distinción con respecto a las instituciones, en tanto organizaciones concretas que se ocupan del trabajo con las niñas y los niños. Ambas autoras sitúan luego su relación con las prácticas profesionales, cuando se ubican "entre" figuras de segregación y dispositivos de inscripción simbólica, a partir del análisis de los emergentes que identificaron en los trabajos presentados en el III Simposio Internacional Infancia, Educación, Derechos de niños, niñas y adolescentes. Las prácticas profesionales en los límites del saber y la experiencia, realizado en la ciudad de Mar del Plata durante 2011.

Se destaca su reflexión respecto de la "responsabilización de los profesionales a partir de no dejarse capturar acríticamente por los significantes circulantes, como partícipes activos en la construcción de los problemas que están llamados a tratar" (Zelmanovich y Minnicelli, 2012: 45); instan a que dichos profesionales no se dejen atrapar o capturar de manera irreflexiva o

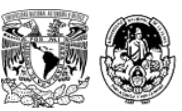


critica por los discursos que imponen las estructuras jurídicas, normativas y/o institucionales, que promueven una atención colocada en "des-identificarlos" y a abordarlos sólo como "sujetos de intervención" derivado de su "vulnerabilidad".

Por otra parte, y para destacar algunos estudios realizados desde el Trabajo Social con el enfoque teórico propuesto y la intervención profesional, me gustaría señalar la investigación realizada por la Dra. Mancinas Espinoza: “Intervención de Trabajo Social con familias. Interpelaciones y propuestas", en donde plantea una investigación de carácter cuantitativo, cuyo objetivo es analizar la conceptualización de familias en trabajadores sociales que laboran en distintos ámbitos (servicios sociales, educación, salud mental y atención a adicciones) del Área Metropolitana de Monterrey, así como las tácticas empleadas durante su intervención con estas. Esta autora llega a conclusiones que aluden a la construcción de acciones que son sustentadas en la premisa neoliberal de que los sujetos son los principales responsables de su bienestar en términos de educación, salud y previsión social (Montaño, 2005). De esta manera, el neoliberalismo desplaza la competencia reguladora del Estado hacia los individuos (Balibar, 2013).

Finalmente se recuperan los planteamientos de Sandoval (2018), quien ante el caso Ciudad de los Niños en Guanajuato ${ }^{21}$, expone en Necropolítica y violencia de género la marginación, el anonimato, el control y la violencia a la que estaban (están) sometidas niñas, niños y adolescentes de Ciudad de los Niños a la que coloca como un "lugar de muerte", donde se administra su dolor, la orfandad y la pobreza, concluyendo entre otras cosas que dicho caso se puede entender desde la necropolítica, ya que permite asimilar el albergue como dispositivo de administración del dolor y la violencia a la que son sometidas niñas, niños y adolescentes. Fundamenta desde la necropolítica recuperando a Mbembe (2018), quien señala que la proliferación de armas y la existencia de mundos de muerte (lugares donde la gente se encuentra tan marginada que en realidad vive como muerto viviente) son un

\footnotetext{
${ }^{21}$ Ciudad de los Niños es un Centro de Asistencia Social que operaba bajo la figura de Asociación Civil en México, vinculado con el fenómeno del maltrato institucional, “a partir de una denuncia anónima en 2016 que le acusa por malversación de fondos y maltrato infantil [...] funcionarios del Sistema para el Desarrollo Integral de la Familia (DIF) acudieron y encontraron menores de edad en mal estado y a una niña de siete años con las manos quemadas por haber robado plastilina, castigo ejercido por una de las monjas que colaboran en el sitio" (Velázquez, 2017), lo que ocupo la constitución de una observación (32VG/2020) en el año 2020.
}

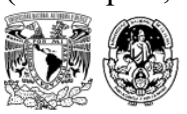


indicador de que existe una política de la muerte (necropolítica) en lugar de una política de la vida (biopolítica), como la entiende Foucault (1981).

\section{Epílogo}

Si recordamos el relato de María -registrado al inicio de este capítulo-, que da fe del testimonio "antes quería familia, pero ya no" encontraremos una poderosa narrativa que desvela la manera en cómo la institución produce subjetivaciones a partir de diversas tecnologías como los discursos y el poder. Al concluir aquel encuentro con Maurice Biriotti, me enfatizó esta conclusión de la historia sin dar mayor explicación. Hoy me queda claro que él habría logrado identificar lo que yo no: el consistente proceso de subjetivación que coexistía en María, y hacía de esta, una niña institucional construida, modelada y dependiente del ritmo que marcaba el CAS que, tras la fallida posibilidad de situarla en un contexto de familia tradicional, le inscribía la institucionalización como su realidad.

¿De qué manera las profesionales en TS influimos en la subjetivación de niñas y niños como María? ¿Esta relación recíproca, en dónde hospedamos su realidad, sus dolores y fisuras, trastocan nuestra propia identidad y nos subjetivan?

Por su parte, las trabajadoras sociales, montadas en la agencia disciplinar y respondiendo al dispositivo reglamentario y la episteme de las niñeces en condición de institucionalización, aspirábamos a su asignación en un contexto adoptivo, como si esta conclusión en una línea recta de causalidad, fuera la única posibilidad de restitución de derechos, lo que limitó la construcción de otros mecanismos y desde una episteme de la intervención configurada con una perspectiva reduccionista, fortalecida por el discurso de que las niñas y los niños en orfandad, serán felices si se les encuentra una familia.

La institucionalización se transforma así, en una fallida intervención, configurando el dispositivo de control que atraviesa los cuerpos y se materializa en una niña cuya “discapacidad fenotípica” (las cicatrices del incendio en la improvisada vivienda) fue el 
motivo por el cual no pudo ser adoptada. Trazan el sujeto constituyente y enrutan al camino de la desechabilidad.

¿Es posible que el dispositivo opere en la medida que responde a las determinantes estructurales atrapadas en marcos reglamentarios que instruyen procesos de historización individual y colectiva? ¿Define una forma de estar en el mundo desde la gubernamentalidad de espacios de encierro y disciplina? Lo que para Heredia (2012) son los agenciamientos maquínicos de efectuación (régimen de cuerpos, de acciones y de pasiones) y agenciamientos colectivos de enunciación (régimen de signos, consignas-actos y contraseñas).

Lo que no podemos ignorar es que, en esta trampa biopolítica, las trabajadoras sociales también formamos parte de los agenciamientos maquínicos de efectuación y de enunciación, que se instauran y operan de forma inconsciente en el ejercicio profesional, "el tuyo, un relato Kafkiano Gabriela, que esconde detrás de la historia de María, la emocionalidad propia. Se quiebra tu voz y eso se hace evidente", palabras que resuenan en mí, cobran sentido y se colocan en este estudio.

El planteamiento teórico de categorías como el poder, el sujeto y los discursos, enmarcadas en otras tecnologías planteadas por Foucault, que se implantan en el sujeto para influir la forma en cómo este actúa y piensa, me resultan útiles para acercarme a la lectura de la realidad, me inquietan en comprender la interseccionalidad de prácticas discursivas con los procesos subjetivos, que exhiben la subjetivación construida a partir de lo que los otros nos atribuyen en un contexto histórico determinado y en convergencia con nuestras propias experiencias de vida.

A lo largo del capítulo hemos realizado un recorrido teórico-conceptual de la analítica del poder desarrollada en la obra de Michel Foucault y se sostiene cómo este enfoque teórico no es nuevo para la comprensión del ejercicio profesional en el campo de lo social y en un modelo capitalista en su fase neoliberal. La irrupción de las y los trabajadores sociales y su intervención con grupos humanos excluidos y precarizados económicamente desde la década de los setenta, ha sido colocada sobre la mesa de la discusión, examinando su participación

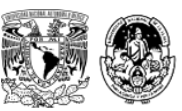


en procesos de socialidad a la vez que de atomización y de disgregación del tejido social, reflexiones que le reconocen como un elemento del engranaje estructural, una tecnología más del ejercicio del poder, que soportado en la construcción epistemológica y en su agenciamiento profesional forman parte del proceso de subjetivación de sujetos institucionales que instalados desde la gubernamentalidad en espacios de encierro, la disciplina y el control instauran una microfísica del poder, al constreñirse en espacios íntimos de encuentro que reducen a ellos, los desposeídos, a la vez que a los profesionales agenciados, en una trampa biopolítica (Foucault, 1977; Donzelot, 1981).

Así es como el poder hace posible la construcción de dispositivos, esos entramados heterogéneos que involucran tanto lo dicho como lo no dicho, la red intangible que no es la suma sino el encuentro de elementos tales como: los discursos, instituciones, instalaciones arquitectónicas, decisiones reglamentarias, leyes, medidas administrativas, enunciados científicos, posiciones filosóficas, morales, filantrópicas, que implican la red saber/poder y en donde la construcción epistemológica atribuye formas de pensamiento que la ciencia asigna.

La presente investigación hará uso de la categoría de poder, no como algo que se posee, sino que se ejerce. Se trata de una acción que transforma la manera de actuar en forma individual y/o colectiva, instaurándose en la interacción de los sujetos, definiendo formas de comportamiento en reciprocidad, pero sin colocarse en una relación asimétrica de propiedad con respecto a quienes lo poseen sobre los que no, es más bien, el resultante de una interacción en donde las tecnologías de poder construyen campos de acción. A través de los discursos, las agencias, la episteme, los procesos de subjetivación, es que el poder se transversaliza, opera y fortalece en un entramado constituyente, configurando los dispositivos como el espacio en donde este se ejerce.

La instauración de verdades y enunciados que se establecen como discursos coloca un filtro a la realidad, cobra relevancia al definir identidades que se experimentan en la vida cotidiana en un contexto histórico-social determinado, cuando los discursos trascienden la esfera íntima, se articulan los saberes científicos, formalizándose desde la episteme de la ciencia los

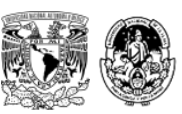


saberes que producen un objeto y que al estar formalizado determinan formas de actuar con y en él.

Por su parte, la episteme homogeniza y regula, construyendo la agencia para incorporar dichos saberes de forma irrefutable al tiempo que estructura, garantizado una trama ejecutoria colectiva que atraviesa a las y los individuos desde la construcción de signos, consignas, actos, en un territorio anudado a las reglas, las normas y los preceptos que detonan procesos de subjetivación, dejando claro que el sujeto no es constituyente sino constituido a partir de la relación que establece con los otros. Así, la subjetivación habrá de ser la manera en cómo se expresa la subjetividad resultante de la intersección de discursos, pensamientos y atribuciones que hacen converger el pensamiento propio y los atributos asignados por los otros.

Poder, subjetivación, agencia, episteme, discursos, panóptico, gubernamentalidad, biopolítica, son sólo algunos de los referentes teóricos que a manera de mandatos construyen el dispositivo, cuya función es tan estratégica como invisible: ser el espacio de saber/poder creando una red, un engranaje que intersecciona y juega una permanente reciprocidad. 


\section{- CAPÍtUlo III •}

\section{EPISTEMES DE LA NIÑEZ: DEL INFANTE SUJETO DE PROTECCIÓN A LA NIÑEZ COMO CONSTRUCTO DINÁMICO, RELACIONAL Y CONTEXTUAL}

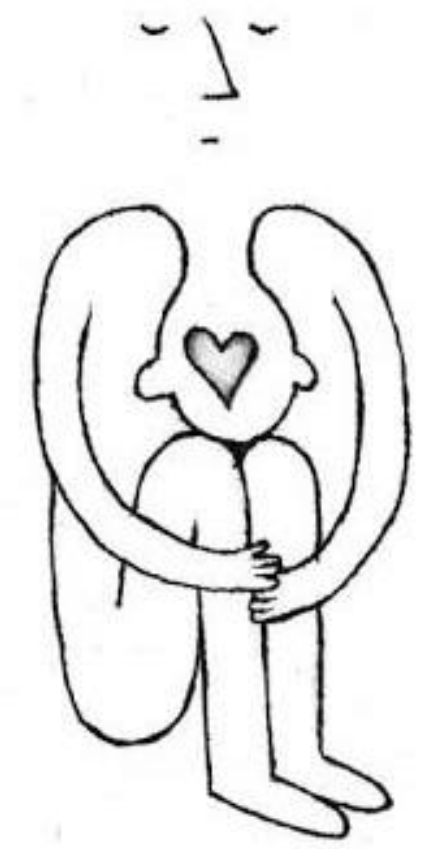

TROCHE 
El sujeto... no es algo que pueda ser alcanzado directamente como una realidad sustancial presente en alguna parte; por el contrario, es aquello que resulta del encuentro cuerpo a cuerpo con los dispositivos en los cuales ha sido puesto -si lo fue- en juego... la historia de los hombres no es quizá otra cosa que el incesante cuerpo a cuerpo con los dispositivos que ellos mismos han producido: antes que ninguno el lenguaje... la subjetividad se muestra y resiste con más fuerza en el punto en que los dispositivos la capturan y la ponen en juego. Una subjetividad se produce cuando el viviente, encontrando en el lenguaje y poniéndose en juego en él sin reservas, exhibe un gesto de irreductibilidad a él.

(Stolkiner, 2013)

Mario

(1995)

Las puertas de la sala de emergencia golpeteaban advirtiendo que algo fuera de lo común sucedía. El ruido de las sirenas, cada vez más cercano, taladraba mi cabeza anunciando una llegada en tanto yo llenaba los formatos del ajetreo cotidiano. Pasados unos minutos escuché la voz del médico decir: ¡rápido que venga la trabajadora social y haga algo con esto!

En la cama de revisión: un niño de apenas dos años. No había que hacer demasiadas preguntas. Su cuerpo moreno, pequeño y delgado tenía incrustados los registros del descuido y el maltrato: moretones y marcas de la dentadura que se había encajado en pecho, piernas y cuello sugerían que no se trataba de un evento pueril provocado en un parque, la escuela o el hogar de forma accidental. La madre, una adolescente de 18 años me miraba estupefacta, su miedo en la mirada se encajaba en la estampilla de salubridad bordada en la parte frontal de mi filipina blanca, insignia de estatus que me acreditaba para una estricta vigilancia. "No sé cómo sucedió señorita" - se precipitó a advertirme sin que yo hubiera hecho pregunta alguna"andaba jugando en la bicicleta y se cayó". Fue la abuela quien interrumpió y en tono de reproche e indignación contradijo la versión: "debes decirles la verdad, debes decir que fue tu marido quien lo violó, le pegó y quemó las manos a la bebé” (la hermanita del niño quien a su vez dormía en la cama contigua y que no rebasaba el año de vida). 
Aquello que mis ojos miraban y el terrible testimonio se sumergieron en lo más profundo y contactaron con mi propia historia de maltrato, una historia coexistente e inconsciente que no requería más punto de intersección que el sentimiento de vulnerabilidad que me espejeaba y con el cual, me debatía en la creencia de que sólo la "objetividad" (o lo que yo en ese momento entendía como distancia emocional) haría de mí una "profesional responsable" (eso que a los estudiantes tan jóvenes se nos queda grabado como ley irrefutable). La experiencia se instauraba a manera de tatuaje indeleble, algo que muchos años después reconocí como una huella mnémica ${ }^{22}$ profesional que cobraba fuerza con las huellas instauradas de mi ser, experiencias que se alojan en la profundidad del self y determinan de forma atemporal quiénes somos.

Me dirigí a pedir ayuda al departamento jurídico de la institución que, dicho sea de paso, carecía de conocimiento en el manejo de los casos relacionados con la violencia doméstica, pues generalmente realizaban trámites administrativos de usuarios adultos mayores o mujeres dedicadas al hogar que requerían una superficial orientación para asuntos de divorcio, pensión alimenticia o la acreditación de algún documento de identificación oficial.

Poco fue lo que obtuve de mis colegas. No me quedó más remedio que hacer lo que mi intuición e incipiente formación me permitía: dirigirme a la agencia del Ministerio Público ${ }^{23}$ a dar fe de los hechos ocurridos en contra de la víctima menor de edad, mismo que fue vinculado con el delito de maltrato y diagnosticado por el médico legista como paciente con "síndrome de Kempe". ${ }^{24}$ Muchas fueron las horas que pasé al lado del niño y su familia (las suficientes para sumergirme en su mundo, en sus dolores, en sus miedos y carencias, todos enmarcados en una profunda desigualdad social, pobreza y marginalidad). Ahí a la espera,

\footnotetext{
${ }^{22}$ Término utilizado por Freud para designar la forma en cómo se inscriben los acontecimientos en la memoria, recuerdos inscritos que sólo emergen en relación con otras huellas.

${ }^{23}$ El Ministerio Público es un organismo autónomo y jerarquizado, cuya función es dirigir en forma exclusiva la investigación de los hechos constitutivos de delito, los que determinen la participación punible y los que acrediten la inocencia del imputado y, en su caso, ejercer la acción penal pública en la forma prevista por la ley. De igual manera, le corresponderá la adopción de medidas para proteger a las víctimas y a los testigos. No podrá ejercer funciones jurisdiccionales (Ley orgánica constitucional del Ministerio Público, 1999: artículo $1^{\circ}$ ). ${ }^{24}$ En el año 1946 el médico John Caffey inició la descripción del Síndrome del Niño Maltratado (SNM) -también conocido como Síndrome de Kempe- a partir de sus hallazgos de fracturas múltiples y hematomas en seis niños. Este hecho es el antecedente para que en 1953 Silverman y Kempe introdujeran el término del Síndrome del Niño Kempe o Golpeado (Ruíz, 2019).
}

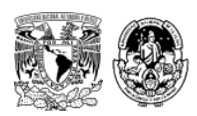


entre trámites jurídico-administrativos y médicos que pretendían derivar en la atención hospitalaria del niño pero, ante todo, en una detención oportuna del violador. Yo era muy joven e inexperta por aquel entonces. Sentir que no era así, que la atención médica llegaba tardíamente y el proceso jurídico sería largo y tortuoso, me llenó de rabia e impotencia; para todos se trataba nada menos que de una "víctima menor de edad, un paciente con "síndrome de Kempe", una averiguación previa...” ojalá alguien hubiera advertido que se trataba de Mario, me hubiera pedido que les hablara de él y no de su sintomatología, los hechos ocurridos o el número de expediente asignado.

Mario fue el primer niño sobreviviente de maltrato infantil a quien tuve la responsabilidad de acompañar desde el Trabajo Social. Yo contaba con apenas 14 años y estaba realizando mi servicio social como parte de mi formación técnica profesional ${ }^{25}$ en un Centro de Salud en ciudad Nezahualcóyotl en el Estado de México.

Hoy es doloroso recordarle. Su cuerpo tembloroso, su desconexión con el mundo, su llanto tímido que se sintonizaba con el mío y al que no me quedaba más remedio que callar.

\section{Prefacio}

La episteme en Foucault (1979) hace referencia al "conjunto de figuras epistemológicas que dan formalidad a un conocimiento determinado y consensuado por la comunidad científica, de carácter dinámico que responde a construcciones discursivas, congruentes con el momento histórico en que es validada".

Dado que se trata de una forma de legitimación respecto de un saber, colocaremos las percepciones y construcciones en torno a la niñez como resultado de un devenir histórico, lo que nos permitirá comprender el lugar que ocupa en la sociedad contemporánea y su reconocimiento desde una perspectiva multidisciplinar, para con ello, profundizar en las diversas formas de "intervenirle" desde el Trabajo Social.

\footnotetext{
${ }^{25}$ En México la formación en Trabajo Social cuenta con tres niveles: Técnico profesional, Licenciatura y Maestría. 
El capítulo que se expone a continuación se encuentra dividido en cuatro apartados: en el primero se desarrollan las epistemes de la niñez a partir del proceso de historización, sobre la base de los supuestos enmarcados en la mirada de la Europa occidental, resaltando los preceptos descritos para la edad antigua, media y moderna; después habremos de situarnos particularmente en México, acercándonos a la geografía de los pueblos mesoamericanos, enfatizando en las contradicciones de cara a los discursos hegemónicos que conciben a las niñas y los niños como seres humanos "a la espera de la vida adulta, pasivos y maleables" (perspectiva eurocéntrica, ampliamente difundida) y en lo que ocupa a nuestro país, se discute cómo fue para las culturas maya y azteca la percepción de niñas y niños era de divinidad y prosperidad; posteriormente se expone el momento de ruptura a partir de "la colonización" (1519), el movimiento independentista (1821), la Revolución (1910) y de ahí en adelante, se desarrollan los diversos momentos históricos hasta la época Cardenista (1934-1940) con la instauración del Estado benefactor.

Después se recuperan los conocimientos y saberes multidisciplinares en torno a la infancia, colocando énfasis en la psicología del siglo XIX, particularmente en lo trabajado en la década de los 80, dada la reciprocidad de este campo disciplinar respecto de los marcos jurídicos de protección de niñas y niños a nivel internacional y nacional. Aquí se profundiza en la actual visión enmarcada en la Convención Internacional de los Derechos del Niño (CIDN) y la construcción del paradigma "el niño como sujeto de derecho", referente de enorme influencia en México y el mundo.

Seguidamente las y los lectores encontraran un planteamiento que se centra en comprender el papel que juega la niñez en el modelo económico capitalista en su fase neoliberal, tensionada con el establecimiento del paradigma mencionado ("el niño como sujeto de derecho"), desvelando la multiplicidad de expresiones que emergen frente a este sistema voraz, planteando dos polos: una niñez automatizada a merced del mercado que se edifica como consumidora en contraste con aquella que carece de capacidad de consumo y se convierte entonces en la niñez consumible. 
Para concluir con la recuperación de la niñez, nos centraremos en el abordaje de las propuestas epistemológicas y de enfoque, de reconocimiento de la infancia como categoría de análisis, a partir de la recuperación de propuestas desarrolladas en el contexto latinoamericano, cuyo posicionamiento crítico, apuntado por la sociología y la antropología de la infancia, nos llevan a reconocer en la "niñez situada" una propuesta de enfoque para la comprensión de esta categoría como precepto histórico, contextual y relacional, que permeara en adelante el documento de tesis.

\subsection{Epistemes de la niñez: categoría conceptual, resultado de un devenir histórico}

Pensar la niñez como constructo histórico social, representa hoy día un desafío que nos distancia de la idea de que se trata sólo de una etapa de desarrollo con ciertas características biopsicosociales y nos obliga a ubicarla en una realidad situada que responde a las condicionantes sociales, económicas, políticas y culturales, reconociendo en su construcción ontológica, un entramado de elementos múltiples y complejos que le ubican como sujeto trascendente y determinante del tejido y estructura social.

Reducirla a un momento etario de ciertas características biopsicosociales, configura una episteme ampliamente difundida hasta el siglo XX por la medicina, la psicología y la pedagogía, cuyos significantes bordean, casi hegemónicamente, los constructos epistemológicos contemporáneos que se expresan en las ciencias jurídicas, pedagógicas y psicosociales, determinando la manera en cómo se mira y aborda la niñez.

En las siguientes líneas habremos de desentrañar algunas propuestas de historicidad de la episteme de "niñez", colocadas desde la categoría de "infancia"26, en un recorrido epocal a nivel mundial y nacional, desvelando la episteme ampliamente difundida hasta el siglo XX, empezando con un acercamiento a la recuperación desde la perspectiva occidentalizada que describe la edad: antigua, media y moderna y posteriormente, recorrer los campos

\footnotetext{
${ }^{26}$ La etimología desvela: infancia viene del latín infantia que significa "incapacidad de hablar" (Stavchansky y Untoiglich 2019:28). 
epistemológicos en México a partir de la época Prehispánica, la Colonia, el México Posrevolucionario y hasta el llamado Estado benefactor.

\subsubsection{Historización de la niñez desde la mirada de la Europa occidental}

Recuperar el recorrido histórico en torno a los imaginarios de la niñez en el mundo ha sido una ardua tarea realizada por distintos estudiosos, en donde la litografía, literatura y periodismo se configuran como fuentes indispensables de análisis ante la carencia de textos publicados.

Imagen 2 La niñez en la Edad Antigua

Imagen 3 La niñez en la Edad Antigua
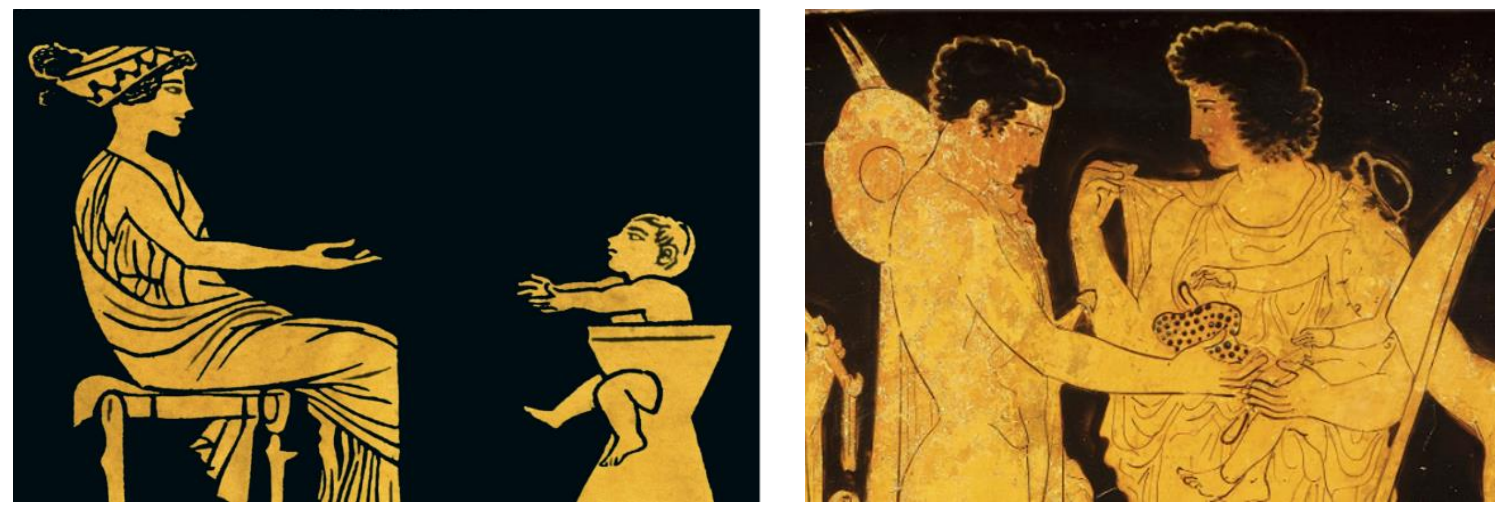

Fuente: Curso "País llamado infancia. La infancia en el siglo XIX” (1 Sesión). El Colegio

Nacional.

La "infancia”, para algunos estudiosos como Ariès (1987), es una invención moderna que aparece a finales del siglo XVII y sigue vigente hasta nuestros días; resultado de una profunda transformación de las creencias culturales y estructuras mentales asociadas al concepto de familia nuclear moderna, colocándola como una construcción simbólica vinculada al contexto y sus determinantes sociales. La "infancia" aparece en intrínseca relación con el mundo adulto, como se observa en las iconografías de las imágenes 2 y 3 , fortaleciendo un imaginario de dependencia. 
El libro del francés Philippe Ariès, El niño y la vida familiar en el Antiguo Régimen, publicado en 1960, es considerado como el pionero sobre el estudio de la historia de la infancia. En su trabajo se propone descubrir cómo la actitud de los adultos respecto a la infancia se ha transformado a través del tiempo, estableciendo una relación entre la historia de la educación, la historia social y el papel de la familia, destacando que el concepto de infancia emerge como una consideración que va más allá de la diferenciación con el mundo adulto, contemporáneamente.

En su recorrido histórico Ariès se vale de iconografías, litografías y pinturas que le ayudan a interpretar a las niñas y los niños como "hombres en miniatura", con nula afectividad en su relación paterno-filial y una infancia fuertemente vinculada a concepciones religiosas que se expresan a través de ángeles y santas infancias. El desarrollo iconográfico de la Europa occidental resulta de utilidad para el historiador, ante la falta de textos con datos precisos sobre la infancia. En su trabajo expone que la aparición de la escuela, de origen no favoreció la diferenciación del niño con la vida adulta, sino hasta el siglo XIX, en donde la influencia de la pedagogía y la psicología provoca la construcción de esta como un espacio etario y con ello propio (por lo menos simbólicamente).

Por su parte, los estudios realizados por María de Jesús Pérez (2009) respecto de los antecedentes históricos discursivos y simbólicos, se sitúan en la Europa occidental y sugieren etapas de historización que pretenden contribuir a la comprensión de las distintas representaciones que la sociedad le ha asignado a la infancia. En la tabla 1 se describe la edad: antigua, media y moderna.

Tabla 1 Cronología epocal de la niñez en Europa Occidental

\section{Edad Antigua}

Ausencia de reconocimiento del niño como sujeto social. Su preparación educativa se centraba en la formación adulta. En el caso de Grecia, los padres eran los que tenían poder sobre los menores a través de la figura de patria potestad.

En Roma el titular de los menores era denominado paterfamilias, el cual tenía el poder de decidir sobre la vida o muerte de los recién nacidos, expulsarlos del hogar y decidir con quién debían casarse. Las niñas eran educadas para ser madres (practicaban diversos deportes que implicaban un gran esfuerzo físico, con la finalidad de engendrar hijos

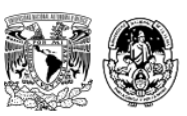


robustos) y los niños para ser guerreros, oradores, políticos (educados en una fuerte disciplina militar, golpeados y puestos en disputas entre ellos).

La condición de la infancia en Grecia y Roma está íntimamente vinculada con la condición de hijo, de manera que resulta difícil establecer si el trato obedecía a la cualidad de infante o a la filiación. Sin embargo, las potestades del jefe de familia nos dan una idea de la situación de los descendientes mientras estos eran pequeños y reflejan una imagen del hijo prácticamente como propiedad de la familia, completamente sometido a la voluntad de sus progenitores o de la comunidad, y consecuente ausencia de derechos.

El niño era considerado como un proyecto de adulto, al cual le faltaban diversas cualidades que había de desarrollar para llegar a ser persona o ciudadano completo; se le percibía como un ser completamente moldeable y con grandes carencias de voluntad y de carácter, al que era necesario enseñar el dominio de la razón. Platón propone en la República y las leyes separar a los niños de sus padres para convertirlos en ciudadanos virtuosos, pues estos son considerados "propiedad" de la comunidad.

\section{Edad Media}

Durante esta época ya se hace uso del término infancia, sin que se experimentara una real diferenciación con el mundo adulto, pues los niños y niñas iban a la guerra y trabajaban, los hijos de los nobles y la naciente burguesía podían acceder a la educación infantil, en tanto los hijos de campesinos, artesanos y demás grupos con ese nivel recibían educación en el hogar. En lo que respecta a las niñas, independientemente del estatus social, se les educaba para servir en los hogares.

En la interpretación de De Mause, a partir del siglo IV comienza una etapa que se prolonga hasta el siglo XIII caracterizada por el "abandono", durante la cual los padres reconocen al hijo como poseedor de un alma, pero al mismo tiempo le ven lleno de maldad, lo que hace necesario azotarle. Se les envía lejos, a la casa de la nodriza (para el caso de los hijos de nobles), al monasterio, o a otro hogar, o se le abandona afectivamente en el propio seno de su familia. La elección de la niñera se vuelve un asunto de gran importancia, pues se considera que la formación comienza desde los primeros meses de vida.

\section{Edad Moderna}

Gracias al surgimiento de pensamientos filosóficos enmarcados en la ilustración, los tratos hacia los menores "mejoraron", aun cuando el abandono se practicaba como una legítima costumbre. Es en el siglo XVII cuando los padres asumen nuevos deberes con relación a su crianza: alimentación, vestido, religión. Se ubica su reconocimiento social en el descubrimiento de la infancia, adquiriendo una concepción de dependencia.

Los cambios operados durante esta época tuvieron como consecuencia el surgimiento de una incipiente literatura sobre la infancia, en la que moralistas y educadores se pronunciaban a favor o en contra de algunas prácticas de crianza y daban consejos para la formación durante los primeros años de vida.

El niño conquista un lugar junto a sus padres, deja de confiarse a personas extrañas y se convierte en un elemento indispensable de la vida cotidiana, todos se preocupan de su educación, de su porvenir, aunque todavía no es un personaje relevante.

En otros ámbitos se incrementa también la intervención estatal y eclesiástica y surge toda una serie de disposiciones y de ética religiosa.

Los niños eran vistos como las "esperanzas del futuro", se les dedicaba mucho tiempo y comienzan a aparecer en ciertas regiones algunos análisis de conceptos abstractos de niñez,

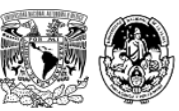


así como de sus aspectos indeseables y referencias a la cantidad de tiempo, de incomodidades y de dinero necesarios para criar a los descendientes.

Fuente: Elaboración propia a partir de Pérez (2009) y el Instituto de Investigaciones Jurídicas de la UNAM

Profundizando en la Edad Antigua (descrita en la primera parte de la tabla 1), podemos observar un marco de invisibilidad de la niñez como ente individual, se trata de una propiedad más de la familia, en donde se les reconoce en una calidad de esclavos que habitan con el "señor de la casa" (nombrado el patriarca) y misma que habría de desaparecer en la Edad Media.

La familia es la forma de organización social que aparece en el surgimiento de la propiedad privada y el Estado; es una de las primeras formas institucionalizadas de organización social en el inicio de la civilización. El término familia proviene del vocablo famulus que se refiere al siervo, al esclavo. La familia se conforma inicialmente como el conjunto de personas y esclavos que habitan con el señor de la casa, denominado pater/patriarca, que es el responsable de la potestad y dominio legal del hogar, y en consecuencia de todos quienes lo habitan [...] es un poder de vida y muerte hacia los hijos, la esposa y los esclavos (Chávez y Hernández, 2019:9).

Adentrandonos en la sociedad de la Edad Media, tampoco existía la idea de niñez, sin embargo, dice Ariès (1987) que la idea de la niñez no se debe confundir con el afecto a los niños: corresponde a una conciencia de la naturaleza particular que distingue al niño del adulto. Se trataba entonces de pequeños adultos sin una propia identidad (imagen 4 y 5 ). Y aunque las transformaciones epocales del Renacimiento y la Ilustración provocaron una nueva mirada, esta no lograba consistentemente reconocerles como sujetos sociales. 


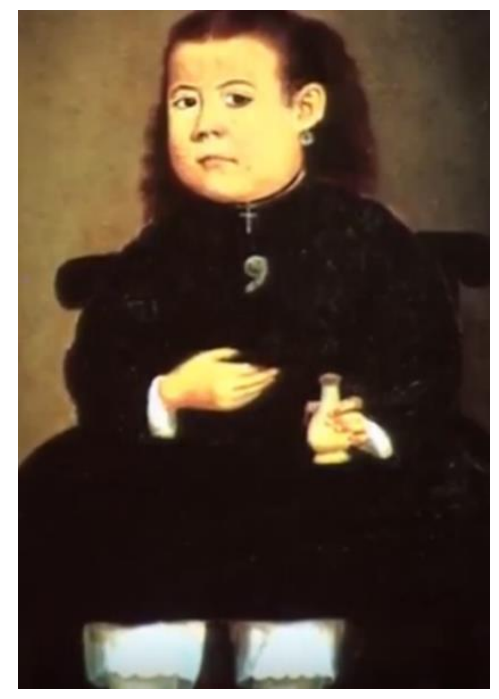

Imagen 4 La niñez en la Edad Antigua

Fuente: Curso "País llamado infancia. La infancia en el siglo XIX” (1 Sesión). El Colegio Nacional.

Imagen 5 La niñez en la Edad Antigua

Fuente: Curso "País llamado infancia. La infancia en el siglo XIX” (1 Sesión). El Colegio Nacional.

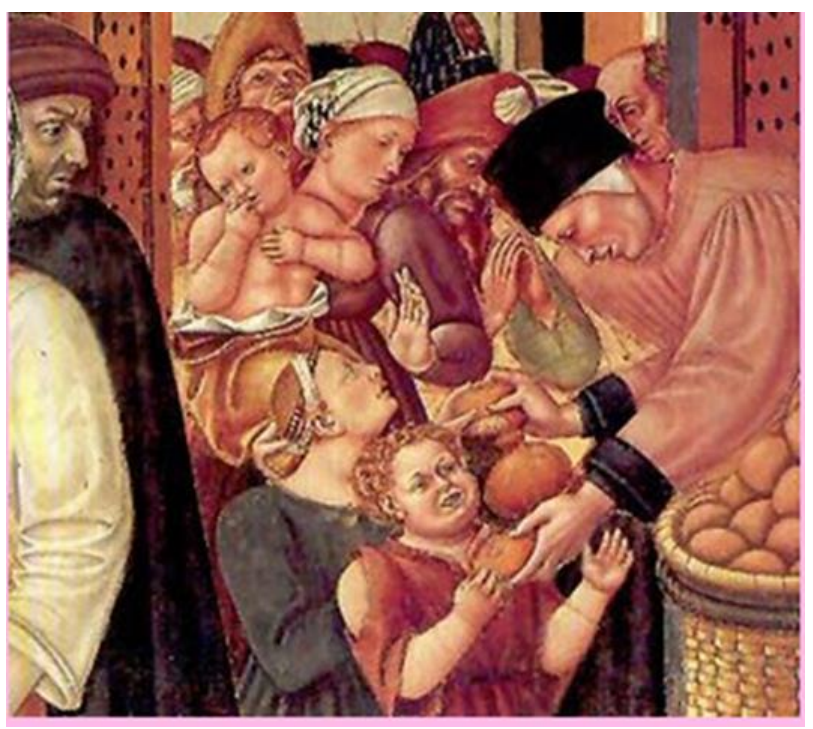

"Chartier ha estudiado el proceso a través del cual la imprenta fue creando un mundo simbólico que enriquecía y modificaba el mundo de los adultos al cambiar hábitos de lectura y producir las condiciones para el surgimiento del lector moderno" (Del Castillo, 2006: 20), lo que impactó en la manera de concebir a los infantes aproximándose a un cambio de paradigma hasta entrado el siglo XIX. Es en este período histórico que se desarrolla:

La difusión de la escolarización y la separación del mundo infantil respecto de los adultos; la investigación psicológica y pedagógica que diseñó y confirió atributos y características a la niñez inéditas hasta ese momento; y finalmente el saber y la práctica de la medicina pediátrica que desembocó en el siglo XIX en la proyección de una mirada clínica especializada. Aquí se construyeron las bases epistemológicas para un nuevo paradigma de la niñez, en conexión con otros saberes y disciplinas surgidos en Europa durante la segunda mitad del siglo XVIII; la pediatría, la pedagogía, la psicología social y la antropología (Del Castillo, 2006: 20). 
Es gracias al impulso de estas disciplinas que la percepción de la niñez como sujeto con identidad y con características propias, comienza a incidir y se ve reflejado en las currículas de la educación formal y la atención médica infantil. Tanto la pediatría como la pedagogía de fines del siglo XIX formaron parte de una episteme; esto es de una sistematización de conocimiento, que en este caso estaba organizado alrededor de la necesidad de gestionar y generar los aparatos administrativos y discursivos que crearon las condiciones para la percepción de la diferencia entre la vida infantil y la vida adulta.

Es así como el recorrido hasta ahora expuesto y colocado en la visión eurocentrista, exhibe a las niñas y los niños, como seres inferiores de poca valía a merced de un mundo patriarcal y adultista, que logra reconocerle como persona con características y necesidades propias, hasta la Edad Moderna.

Por otra parte, el acercamiento a otros saberes ancestrales como los documentados en los pueblos originarios de nuestro país o culturas como "las andino-amazónicas [...] que solían asignar a los niños [...] autoridad ("el kamayoq") en su propio entorno o como predictores [...]" (Rengifo, 2003), posibilita el reconocimiento de otras percepciones con relación al rol y función social fundamental de niñas y niños. A continuación, se describe lo relativo a México.

\subsubsection{Historización de la niñez en México}

En las últimas décadas y gracias a los aportes de disciplinas como la arqueología y la antropología, sabemos que las niñas y los niños en el México prehispánico ocupaban un lugar central, eran reconocidos como parte fundamental de la comunidad, con identidad propia y protagonismo social, protegidos y cuidados de manera colectiva al considerarles "seres de luz"; dando énfasis a estos elementos abrimos el siguiente apartado, en el que nos adentraremos en el momento disruptivo que transforma la mirada hacia la niñez e instaura prácticas culturales de profunda violencia enmarcadas en la época virreinal. Posteriormente abordaremos lo concerniente al México Posrevolucionario y el Estado benefactor, culminando en el siglo XX con la entrada en vigor de la CIDN.

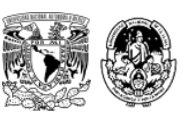




\subsubsection{El México prehispánico: entre el Tepochcalli y el Calmécac}

En el mundo mesoamericano la información acerca de lo infantil desde una división etaria es escasa y lo que se ha logrado recuperar a partir de estudios antropológicos e historiográficos, se centra fundamentalmente en la sociedad azteca por su protagonismo y hegemonía cultural, en donde "gracias al Códice Mendocino, se conoce del nacimiento del niño o de la niña en un entorno preordenado, cuyo equilibrio cósmico y social está sostenido por un complicado ritual, destinado a apaciguar la cólera de los dioses, en donde los niños desempeñaban una importante función: ser sacrificados para evitar catástrofes y el fin del universo" (De Parres, 2001:89).

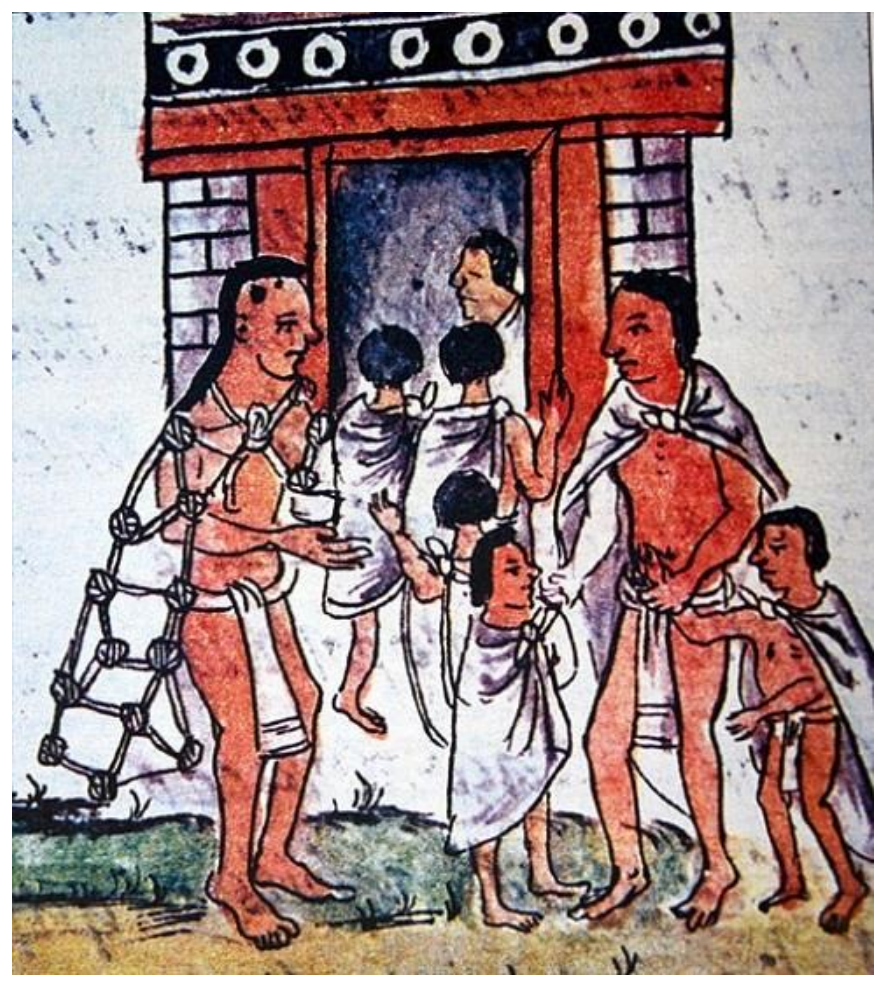

Imagen 6 La niñez en el México prehispánico Fuente: Almomento, 2015.

Para el caso del México prehispánico, con base en los estudios de Díaz Barriga (cronista estudioso de las diversas manifestaciones culturales como el lenguaje, registros gráficos y 
códices), se sabe que en la sociedad mexica ${ }^{27}$ las niñas y los niños eran vistos como "un regalo enviado del cielo" en donde las madres durante el proceso de gestación eran cuidadas en espacios especiales y aunque la educación era severa, esta respondía a la necesidad por fortalecer el carácter. A diferencia de otras sociedades prehispánicas, en la mexica (Díaz, 2015) desde los seis años, los niños eran empleados en labores que eran realizadas por los adultos y también, al mismo tiempo, recibían educación. En la sociedad azteca jugaban un papel fundamental, puesto que eran considerados seres que atraían la lluvia y el crecimiento y en términos generales, eran vistos como seres que generaban prosperidad.

[...] niños y niñas eran vitales para la cosmovisión mexica. Se les consideraba "un regalo de los dioses, comparados con los mayores bienes y objetos valiosos, y se creía que habían sido formados en el más alto de los cielos". Eran vistos como "intermediarios entre los hombres y las deidades de la lluvia y los mantenimientos, así como regeneradores del tiempo cíclico"; por ello, al sacrificarlos se ofrecía lo más preciado que aseguraría "la continuidad de la vida y la regeneración del grupo" (Díaz, 2015:47).

La visión colonialista y occidentalizada de la niñez ha reproducido ideas belicosas y fundado la crianza de los niños y niñas en el mundo prehispánico en prácticas coercitivas, rígidas y de estratificación social arbitraria. Si bien es cierto que los estudios respecto del mundo infantil en esta época no son tan robustos, se cuenta con hallazgos que sugieren una forma contraria y colocan en el cuidado prácticas culturales que responden a su cosmovisión.

La educación especializada más importante se llevaba a cabo de los seis años hasta los doce. Los padres internaban a sus hijos en el Tepochcalli, si querían ser guerreros, o en el Calmécac, si iban a dedicarse a las ciencias. En este mismo recinto había un anexo destinado para las niñas, a quienes se les impartía una educación fundamentalmente moral y se le preparaba a fin de que pudieran cumplir con todas sus obligaciones en el matrimonio.

Ninguna cosa más me ha admirado, más digna de alabanza que el cuidado y orden que en criar a sus hijos tenían los mexicanos. Porque entendiendo bien que en la crianza e institución

\footnotetext{
${ }^{27}$ Los mexicas (también conocidos como aztecas) fueron un pueblo mesoamericano de filiación nahua que fundó México-Tenochtitlan.

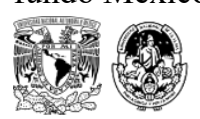


de la niñez y juventud consiste toda la buena esperanza de la república, dieron en aportar a sus hijos de regalo y libertad que son dos partes de aquella edad y ocuparlos en ejercicios provechosos y honestos (Díaz, 2015:47).

Como podemos observar, la niñez era fundamental y de enorme protagonismo social, relevante para la configuración comunitaria al incluirles en actividades productivas de acuerdo con su identidad y posición social.

\subsubsection{La época colonial: un nuevo ordenamiento}

La Conquista (1519) trajo consigo una nueva forma de estratificación social. La religión y la Iglesia desempeñaron un papel determinante impactando en las estructuras sociales, políticas y económicas de los pueblos originarios y dieron pauta a una nueva generación de niños acorde a su condición.

En lo que respecta a la Colonia y a los primeros años de la República, resuenan en las elaboraciones historiográficas los asuntos referidos a la enfermedad y mortalidad de los niños en América Latina. De este modo, se perfilan las instituciones para tramitar algunos asuntos relacionados con el control y la protección de la vida infantil, en cuyo seno se propicia la configuración de regímenes de crianza tales como las casas de expósitos y los hospicios. En los registros de estas instituciones se encuentran huellas de los problemas sobre los cuales se buscaba elucidación, como el abandono, el infanticidio, la ilegitimidad y la pobreza, entre otros (Herrera y Cárdenas, 2013: 9).

Es de esta manera que la definición de la niñez indígena se rehízo siguiendo los patrones evangelizadores que es necesario deslindar de los autóctonos, reconociendo la marcada diferencia entre la niñez indígena y la mestiza; para el caso de niñas y niños nativos, la incorporación en actividades laborales incluía prácticas en condición de esclavitud, como en las y los adultos, al representar mano de obra a merced de la corona española (Gonzalbo Rabel, 1994).

En la élite social las niñas y los niños eran educados en colegios, seminarios, conventos y escuelas. La educación infantil deja de ser edificada en el seno familiar para ser impartida

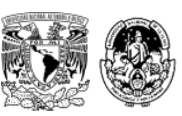


por las diferentes órdenes religiosas. Sosenski (citado en Herrera, Cárdenas, 2013:293) documenta que, al colocar "a los niños en los campos de cultivo, en los talleres de las correccionales y en las escuelas industriales, más que una estrategia proteccionista -se trataba- de una intervención institucional para controlar la incorporación de los sectores populares al proyecto económico".

\subsubsection{Los movimientos independentista y revolucionario en México: entre segregación, violencia y abandono}

Ante el movimiento armado del México independiente (1821) se experimenta un recurrente abandono de los menores, frente a las condiciones adversas por las que transitaba la sociedad mexicana. Marcilio (citado en Zoila, 2017) relaciona el aumento de las niñas y niños abandonados con los cambios desarrollados en la esclavitud, lo que propició que muchos hijos de madres esclavas fueran libres desde su nacimiento y las madres, al no tener qué ofrecerles, decidían abandonarlos.

[...] las primeras instituciones creadas especialmente para el resguardamiento de estos niños estaban a cargo de la Iglesia, no porque la Iglesia se interesará realmente por el futuro de estos niños, sino que los expósitos fueron criados por cuestiones éticas y morales. Durante la independencia el Estado será quien se encargue de estas instituciones y las reformas sociales, sus reglamentaciones y la creación de instituciones, las cuales ayudaron a definir al niño marginal, dotándolo de un contenido social, cultural y político (Zoila, 20017:41-42). 
Imagen 7 La niñez en el México revolucionario

Fuente: Garnica, 2018.

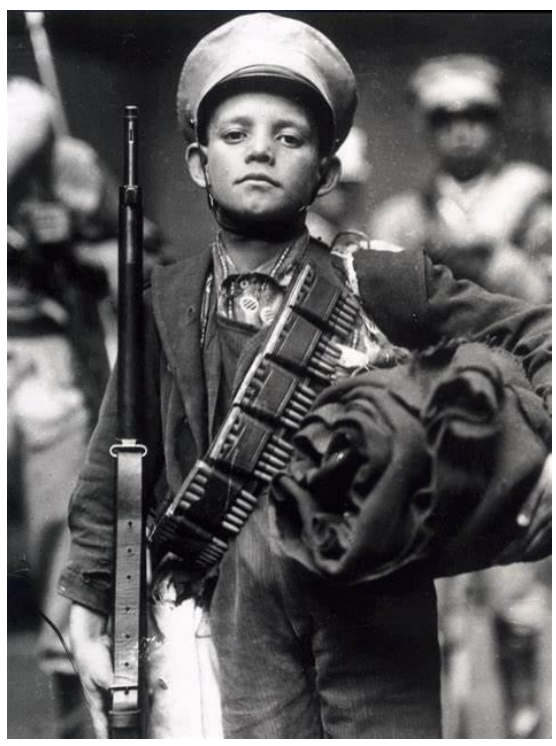

Y en lo que ocupa al movimiento Revolucionario (1910), se vive una marcada transformación en relación con el papel que juegan niños y niñas en la participación del México naciente (véase imagen 7). La Revolución Mexicana representó un momento de enormes cambios en lo que toca a la representación y realidad de la niñez. Las demandas revolucionarias que iluminaron las injusticas sociales, pusieron a la vista de todos la realidad de los niños trabajadores, niños que con el desarrollo de la lucha armada tomaron las calles participando en huelgas y otros movimientos sociales de la mano de los adultos (Del Castillo, 2006).

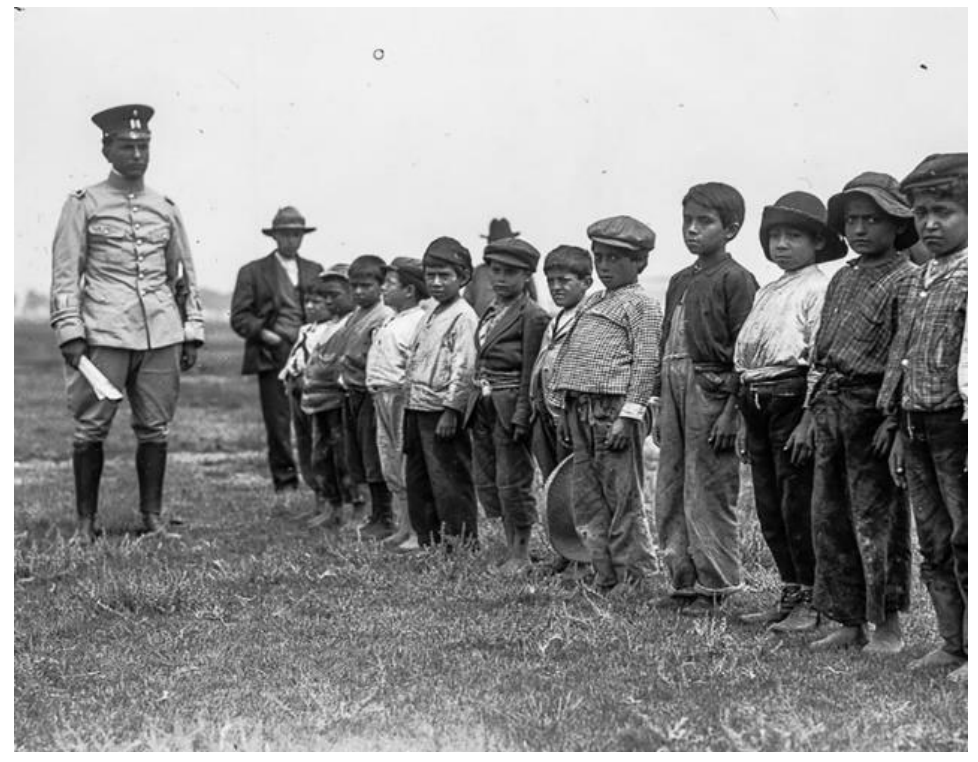

Imagen 8 La niñez en el México revolucionario Fuente: "Los niños que participaron en la revolución mexicana", México Desconocido, 2018. 
La imagen del niño guerrero prevaleciente durante la época revolucionaria confunde las ideas de inocencia y agresión, muchas veces dentro de la misma representación. El niño militarizado posando en las fotos con su escopeta y sus balas, representa a la vez la naturaleza omnipresente de la violencia que llegaba a la niñez y justifica la lucha armada como una causa pura y moral en la que los niños participaban (véase imagen 8). Es decir, por una parte, la guerra y la violencia revolucionaron el concepto de infancia creando un nuevo espacio de participación que pocas veces se había relacionado con la cultura infantil (Jackson, 2007: 127).

Es evidente el papel protagónico de la niñez en este momento histórico, sólo que dicho protagonismo emerge del reconocimiento de su fuerza de trabajo, su participación en el movimiento armado y para el caso de las niñas, su subsecuente uso y abuso en el ámbito sexual.

\subsubsection{EI nuevo Estado-nación: el nuevo ciudadano}

A nivel internacional, en el ámbito jurídico, los grandes cambios producidos durante el siglo XIX tienen una gran influencia sobre la consideración del niño. "Se va desarrollando la idea de que el Estado debía protegerlo pues la prosperidad y la seguridad dependían de la existencia de una clase de ciudadanos sanos; es así como se extienden los medios de enseñanza, se introduce la escolarización obligatoria y diversos servicios sanitarios públicos" (IIJ, 2019).

En nuestro país, durante la época Cardenista (1934-1940) se institucionaliza la atención de la niñez frente a la necesidad de atender las demandas sociales y con la responsabilidad de consolidar un nuevo ordenamiento social. Esto permitió a su vez, que el Estado encontrara en ello, un espacio de legitimidad y la consecuente edificación de ciudadanos fieles a la nación y con un encarnado sentimiento nacionalista.

En esta época un gran número de niñas y niños en México carecían de cuidados parentales, como resultado de los movimientos armados. Se observa una inminente necesidad por ejecutar un nuevo reajuste y reordenamiento de las estructuras sociales y en consecuencia se 
configuran instituciones de atención a la niñez, a manera de hospicios e internados, mismas que pretenden responder a la efervescencia y exigibilidad social por el acceso a los derechos civiles, políticos, económicos, sociales y culturales (como la educación, la salud y la protección de los menores). Es importante recordar que, hasta este momento de la historia nacional, la atención de los niños huérfanos y desvalidos era una tarea que recaía casi exclusivamente en las órdenes religiosas en una filosofía aparentemente caritativafilantrópica frente a la incapacidad del Estado por asumir una responsabilidad respecto a estos.

La protección a la infancia en México (Muñozcano, 2004: 44) "surgió alrededor de la ayuda y la caridad principalmente a través de congregaciones religiosas que tenían la intención de brindar asilo a niñas y niños huérfanos o en situación de pobreza extrema, en esta época la asistencia giraba en torno a la ayuda económica o material para satisfacer necesidades básicas”. Es por el año 1937 que:

[...] se trabajó el problema de la infancia con un enfoque socialista y se pretendió que para que las niñas y niños pudieran crecer como seres productivos y con condiciones para lograrlo, era necesario brindarles acceso a la salud, higiene, vestido, educación, hogar y alimentación. Para ello se crea el Departamento Autónomo de Asistencia Infantil del que pasarían a depender todas las instituciones de beneficencia pública (Cardoso, 2013: 46). 


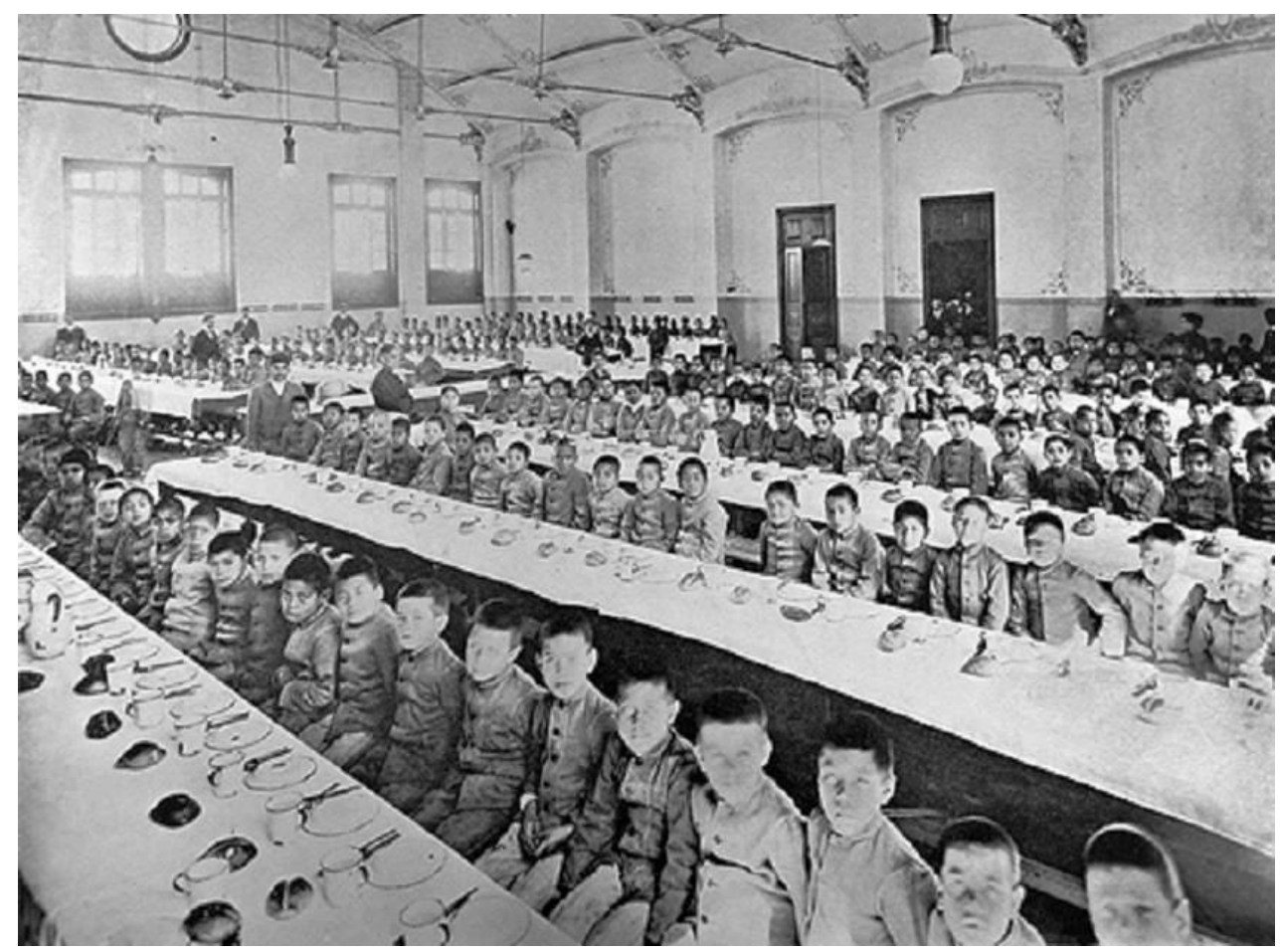

Imagen 9 La niñez en el Porfiriato

Fuente: “Así era el impresionante hospicio para pobres de Porfirio Díaz” (2019), México

Desconocido.

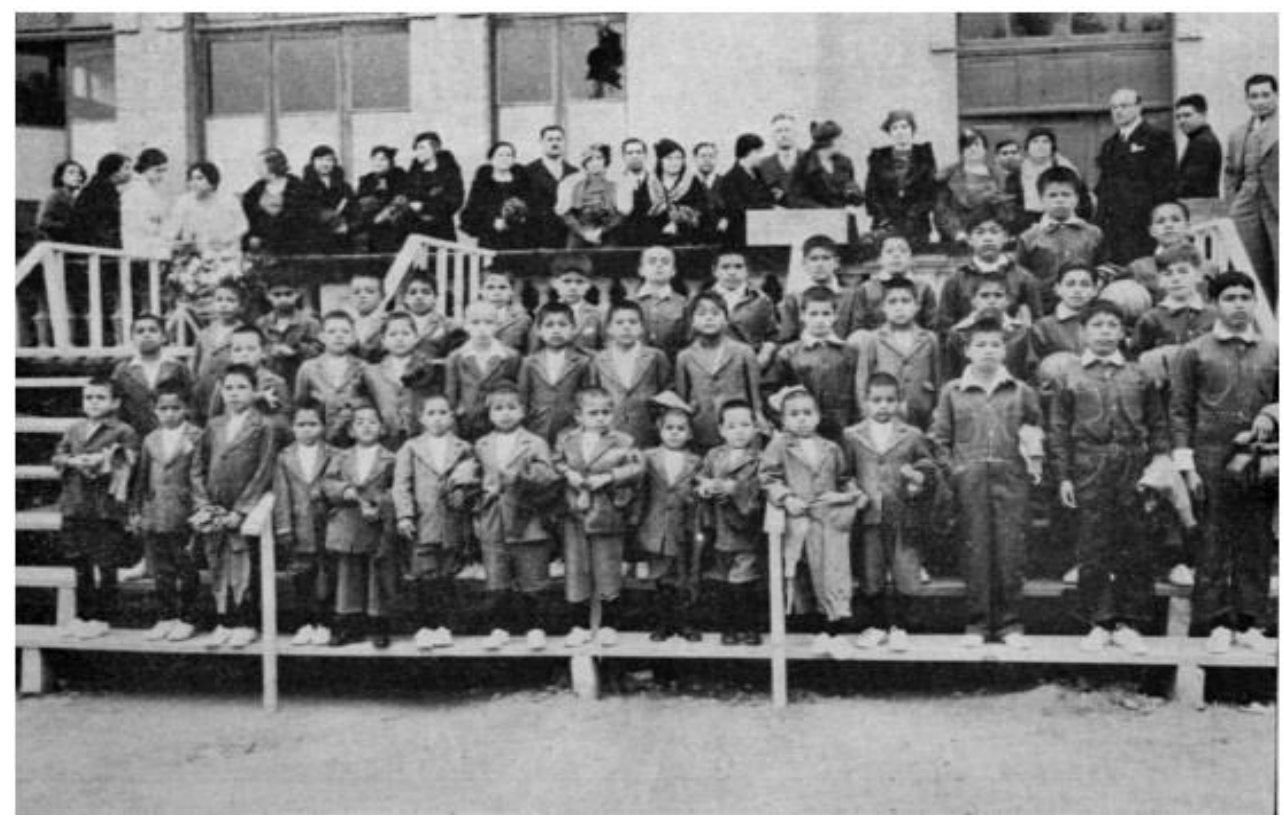

Imagen 10 La niñez en el Cardenismo

Fuente: "Los niños y jóvenes infractores de la Ciudad de México, 1920-1937. Campaña contra la mendicidad. Grupo de niños ex mendigos en un festival dedicado a ellos por otros niños de la beneficencia, 1935". 
Si bien Jacques Donzelot (1977) hace una severa crítica a la forma en cómo espacios de estas características (hospicios y orfanatos) advirtieron una suerte de encarcelamiento de la niñez, habrá que colocarse en el análisis contextual, determinado en este momento histórico por la disputa entre dos sistemas político-económico: socialismo versus capitalismo, en donde el proyecto nacional apuntaba a la incorporación de un modelo capitalista humanizado, es decir, en México el Estado benefactor impulsado por Lázaro Cárdenas, si bien, se caracterizó por la intervención del Estado en la economía, también dio importante realce al beneficio social en materia de salud, empleo, asistencia social, dirigido a todas las personas, independientemente de su clase social, ocupando grandes inversiones de gasto público.

En esta etapa nacional, la niñez se asume a la espera de la vida adulta y aspira ejercer a plenitud sus derechos, al convertirse en ciudadano. Es en el Estado benefactor que se configura como grupo poblacional de atención gubernamental y que vio hasta la década de los 80 , cierta estabilidad en cuanto a la atención institucionalizada.

Sin embargo, dicha estabilidad se ve irrumpida ante la entrada y consolidación del modelo económico neoliberal; los dispositivos se transforman y materializan en instituciones, leyes, políticas, disciplinas, declaraciones científicas y filosóficas, conceptos y posiciones morales, que tienen la función específica de mantener el poder (Foucault, 1976).

En el marco internacional que promueve declaraciones y convenios internacionales de protección (CIDN), con la ausencia de aparatos estatales que logren cristalizar un verdadero reconocimiento del niño como sujeto de Derecho y que en este predominar de las leyes del mercado impuesto por el hegemónico modelo económico la figura del niño se desdibuja haciendo de él un cuerpo mercantil. Un aparato jurídico de protección se tensa frente a escenarios sociales de profunda desigualdad, precarización y pobreza. 
Tabla 2 Cronología epocal de la niñez en México

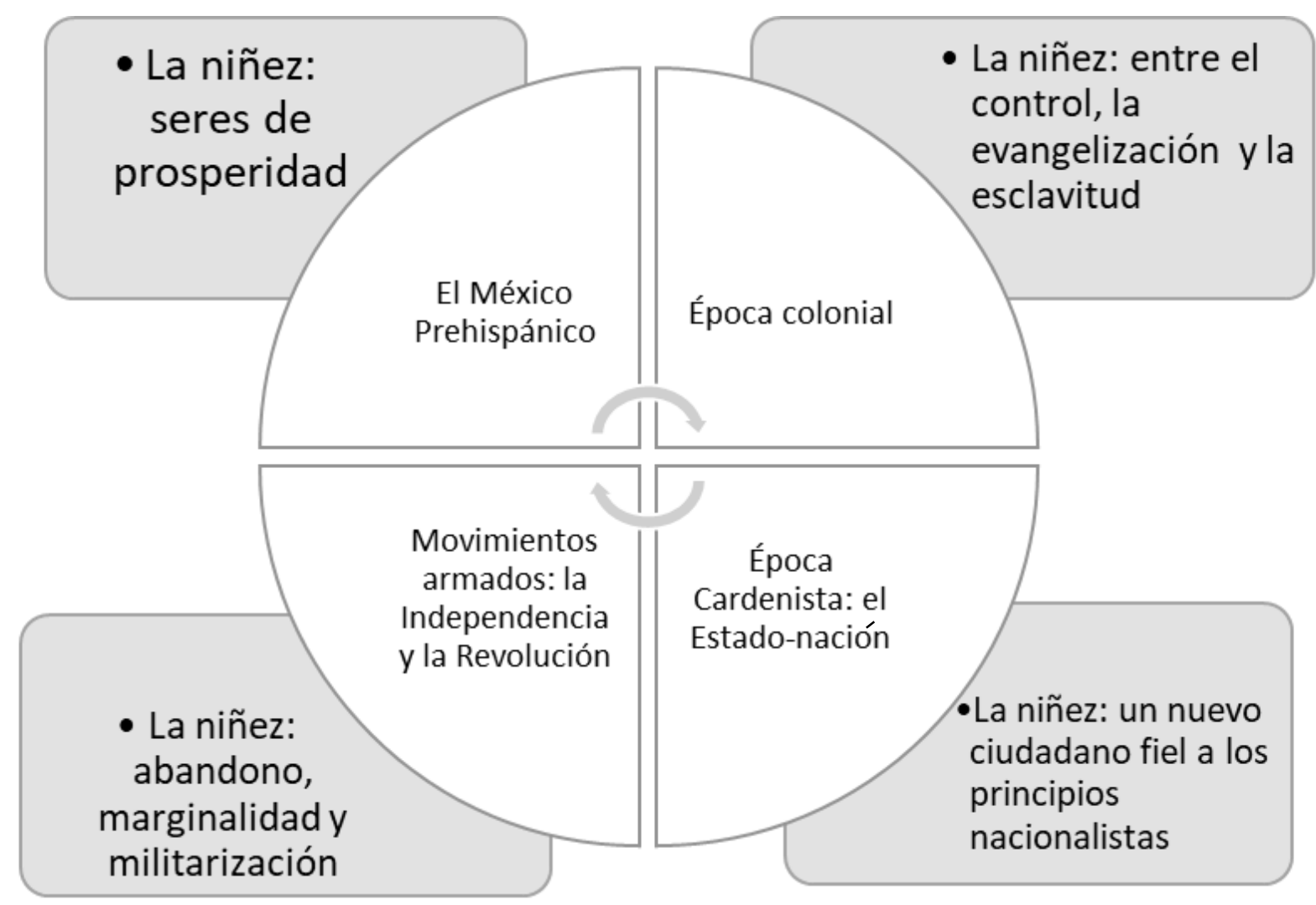

Fuente: Elaboración propia con base en la historización desarrollada en el capítulo.

Lo descrito hasta este momento, permite identificar los momentos históricos nacionales por los que ha transitado el mundo infantil (ver tabla 2) y las percepciones construidas en función al rol social que ha ocupado en nuestro país, partiendo de la realidad prehispánica y hasta la década de los ochenta con la entrada en vigor de la CIDN a la que nos adherimos y ratificamos como Estado-parte (1990). A continuación, realizaremos un recorrido que ocupa el entendimiento de la niñez sobre este marco jurídico-conceptual y su intersección con la construcción epistemológica, desentrañada desde perspectivas multidisciplinares, en donde áreas como la psicología, la pedagogía y la antropología, han jugado un papel determinante. 


\title{
3.2 Conocimientos y saberes en torno a la niñez en una perspectiva contemporánea: construyendo una episteme en el contexto de los derechos del Niño
}

A partir de la década de los ochenta, la visión en torno a la niñez como una etapa determinante en la vida humana, se fortalece gracias al interés de diversas disciplinas, que colocan a las niñas y los niños, como personas activas, con voz y características propias, incitando no sólo el robustecimiento de una construcción epistémica, sino impactando en el reconocimiento de estos como sujetos de derecho y protección.

\begin{abstract}
A pesar de las divergencias en relación con el trato a los niños en las distintas épocas, parece haber un acuerdo mínimo en que la categoría de infancia fue construyéndose a través de la historia, ya sea mediante una revolución o a través de un cambio paulatino. No queda claro si el maltrato fue generalizado o una práctica aislada ${ }^{28}$, pero ciertamente las características y necesidades específicas de cada una de las etapas de la niñez eran desconocidas y, por lo tanto, había un alto riesgo de que no fueran atendidas adecuadamente.

La importancia de la figura del niño como actor social en la actualidad es indiscutible y el intento por comprender su historia, forma parte de la tendencia a reconocer su singularidad (IIJ, 2019:20).
\end{abstract}

\subsubsection{De los diversos campos en el estudio de la niñez}

El siglo XX es considerado por algunos autores como De Mause, el siglo del niño. Los trabajos del siglo XIX se continúan en investigaciones en todos los campos de la infancia, la tasa de mortalidad infantil se reduce dramáticamente gracias a la mejora de la higiene, a los avances de la medicina preventiva y curativa, así como a la atención de los servicios públicos (IIJ, 2019).

\footnotetext{
${ }^{28}$ Para Loredo (2017) "los malos tratos deben ser con la intencionalidad de causar daño o por lo menos de no atender adecuadamente al niño. Sin embargo, algunas teorías estarían de acuerdo en que, aunque no intervenga la voluntad puede haber maltrato". 
A continuación, abordaremos algunos preceptos teóricos en torno a la infancia, durante la década de los ochenta y la influencia que han tenido en la construcción de un aparato jurídico de protección respecto de las niñas y los niños a nivel internacional y nacional.

Delval resalta tres hechos que influyen en la profundización y robustecimiento de estudios en torno a la infancia en la época contemporánea:

a) El movimiento psicoanalítico: Freud escribe sobre la importancia de las experiencias vividas en la niñez para la personalidad del adulto; posteriormente se hicieron trabajos de psicoanálisis directamente con niños.

b) La extensión de la escolarización obligatoria: muchos autores insistieron en que la educación debía diseñarse sobre la base del conocimiento del niño.

c) La introducción de los test mentales: los cuales se crearon con la idea de elaborar un instrumento que permitiera conocer el nivel de cada niño para que pudiera seguir la enseñanza con éxito (Delval, 1994:45-48).

Por otra parte, el ámbito pedagógico juega un papel fundamental en la transición y cambio de paradigma en la percepción de la niñez en la época moderna. Los primeros escritos en los que se menciona a la infancia fueron dedicados a la educación, la cual para Ariès (1987):

Constituye la gran diferencia entre la civilización medieval y la moderna y se encuentra en el centro de la concepción de niño: “el hecho esencial es el siguiente: la civilización medieval no tenía idea de la educación. Nuestra sociedad depende hoy día (y lo sabe) del éxito de su sistema educativo. Tienen un sistema de educación, una concepción de la educación, una conciencia de su importancia" (1987: 539-540).

Para Bustelo los saberes relacionados con la infancia son muchos, lo que configura un espacio interdisciplinario que debería incorporar muchos esfuerzos convergentes.

Añade la ciencia jurídica y expone, entre otras, la sociología, la filosofía, la historia, la ciencia política, la economía, la geografía, el psicoanálisis, la antropología, los saberes asociados a la educación, etc. Afirmó que hay que avanzar ahora en estos saberes y explorar otras

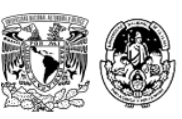


direcciones que no necesariamente, excluyen la anterior, pues la tarea del momento implica la resignificación de las luchas y la renovación de los lenguajes asociados a la infancia (2012:288).

Otras estudiosas como Sandra Carli (2011), han dado seguimiento en la profundización de la infancia. En ella, el campo de estudios en América Latina se viene configurando desde los años noventa, en buena parte por dos grandes matrices de problematización. En una matriz académica —o si quiere más teórica-, la infancia se constituye como un objeto paradigmático en las ciencias sociales y humanas que invita a ser trabajado en las fronteras de las disciplinas, colocando en un papel central la perspectiva histórica para desencializar la infancia como categoría y dar cuenta siempre de su construcción social.

Reconocer las epistemes de la niñez en diferentes épocas y contextos culturales nos ayuda a desvelar con claridad su protagonismo político, económico y social contemporáneo, es decir, que en cada momento las niñas y los niños ocupan un rol derivado de las condiciones contextuales, y es gracias a su reconocimiento, que es posible comprender la manera en cómo es vista y estudiada hoy: la niñez se concibe en una relación individual-colectiva que le permite existir y emerger como actor político-social.

\subsubsection{Los derechos de niñas y niños en el marco internacional y nacional: dispositivo en el ordenamiento jurídico}

En el proceso evolutivo que experimentan los derechos humanos en el siglo XX ocurre una particular especificación, que consiste en el paso gradual hacia una determinación o concreción de los sujetos titulares de esos derechos,

... la vinculación de los derechos a las personas concretas de sus titulares, que es una respuesta a problemas concretos derivados de su condición social, cultural o física. Así, si bien los niños son, al igual que el resto de las personas, los destinatarios de todas las disposiciones que protegen los derechos humanos, en ese proceso de vinculación de los derechos a sus titulares, se hizo evidente la necesidad de reconocer a la niñez como un grupo humano que por su condición de inferioridad en las relaciones sociales requiere para su debida

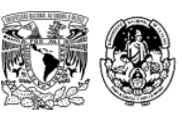


protección de normas específicas que de manera general tiendan al reconocimiento, promoción y amparo de sus derechos... en ese proceso de especificación, para que esa normativa a favor de la infancia que a nivel internacional se ha producido se trasforme en una realidad, requiere de su efectiva recepción en el derecho positivo mexicano y de su aplicación coercitiva, como una de las vías para romper con los esquemas culturales tan arraigados en nuestra sociedad, por los cuales a los niños no se les concede la titularidad de derechos (Álvarez, 2011: 2).

En 1924 se reconocen, a nivel mundial, por primera vez los Derechos del niño. La Declaración de Ginebra, se configura como un instrumento y quizá el parteaguas más importante de reconocimiento de la niñez en sus necesidades fundamentales de protección, asistencia y cuidado, definidos por la comunidad internacional y de ahí se desprenden dos más, consolidándose lo que hoy es, el instrumento más importante con adherencia y ratificación por parte del Estado Mexicano en el año 1990: La Convención sobre los Derechos del Niño (véase Tabla 3).

Dichos avances jurídicos respondieron en gran medida a los estragos, que la Primera y Segunda Guerra Mundial, dejaron en las sociedades de su época, impactando directamente en la niñez. Niñas y niños experimentaron escenarios de violencia y orfandad que les colocaron en altas condiciones de vulnerabilidad y con ello, aparecen organismos internacionales enfocados a su protección.

La Segunda Guerra Mundial dejó entre sus víctimas a miles de niñas y niños en una situación desesperada. Como consecuencia -entre las acciones más relevantes se destaca- en 1947 la creación del Fondo de las Naciones Unidas para la Infancia (conocido como UNICEF) -agencia del sistema de organización de las Naciones Unidas, enfocado a promover los derechos de niñas, niños y adolescentes en el mundo- al cual se le concedió el estatus de organización internacional permanente en 1953 (Humanium, 2019).

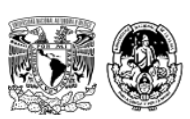


Tabla 3 Cronología de los instrumentos internacionales de protección a la niñez

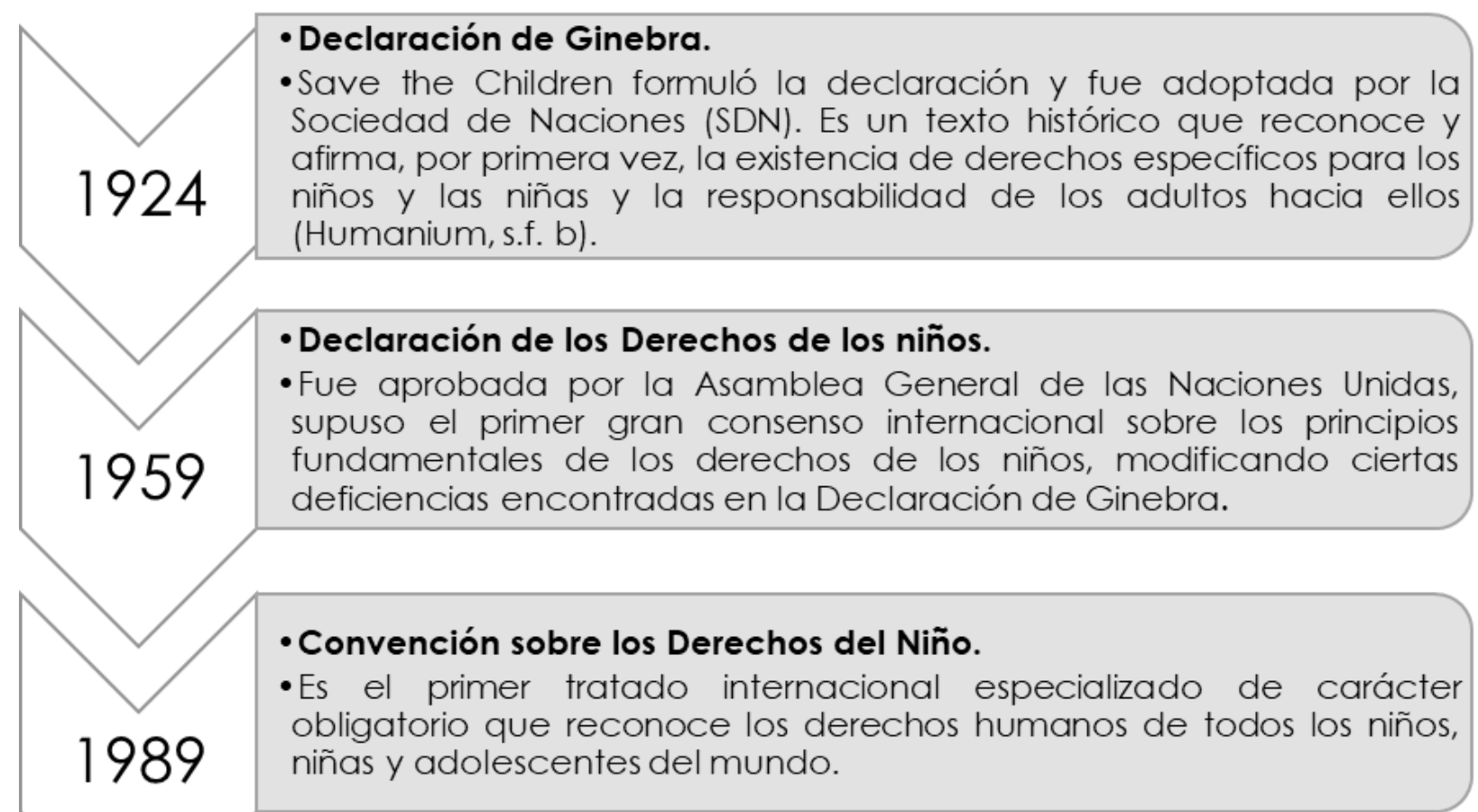

Fuente: Recuperado de Ruíz (2019: 34).

"Estos instrumentos legislativos y los organismos promotores -resultado de un aparente consenso internacional- dan cuenta de la expresión del rol social, de la ubicación del niño en sociedad, es decir, en la división del poder en un determinado ámbito, sea en la familia, la escuela o la sociedad en general" (Cussiánovich, 2019), y por tanto, aunque intentan acercarse al reconocimiento del mundo infantil diferenciándolo del mundo adulto, la apuesta por este reconocimiento se constriñe a marcos jurídicos, lo que le hace ser insuficiente.

En ese hiato es donde habita el aparataje burocrático-administrativo-jurídico-políticoeconómico-corporativo, que cobra forma en las instituciones, pero no necesariamente asumen su función de instituir la infancia. En ese sentido, las instituciones están en falta y en la distancia entre la norma y su aplicación -por el complejo aparataje de dispositivos institucionales, educativos, sociales, judiciales- los principios de la Convención Internacional por los Derechos de Niñas, Niños y Adolescentes pierden su posibilidad de oficiar como límite; es decir pierden la posibilidad de oficiar como marco simbólico de referencia social (Zelmanovich y Minicelli, 2012: 41). 
Tardíamente han llegado los marcos jurídico-normativos a nuestro país. Es en 1990 que México se adhiere y ratifica la Convención sobre los Derechos del Niño, comprometiéndose con ello a incluir en la agenda nacional, estrategias de política pública tendientes a dar cumplimiento con sus principios.

En todas las decisiones y actuaciones del Estado se velará y cumplirá con el principio del interés superior de la niñez, garantizando de manera plena sus derechos. Los niños y las niñas tienen derecho a la satisfacción de sus necesidades de alimentación, salud, educación y sano esparcimiento para su desarrollo integral. Este principio deberá guiar el diseño, ejecución, seguimiento y evaluación de las políticas públicas dirigidas a la niñez. Los ascendientes, tutores y custodios tienen la obligación de preservar y exigir el cumplimiento de estos derechos y principios (Artículo $4^{\circ}$, Constitución Política de los Estados Unidos Mexicanos).

Y aun cuando hay algunos marcos jurídicos antecedentes, es la Ley General de los Derechos de Niñas, Niños y Adolescentes, la que supone uno de los hitos más importantes en nuestro país en materia de derechos de Niñas, Niños y Adolescentes, publicado en el Diario Oficial de la Federación el 5 de diciembre del año 2014. 
Tabla 4 Tratados, protocolos y declaraciones de derechos humanos a los que México se ha adherido

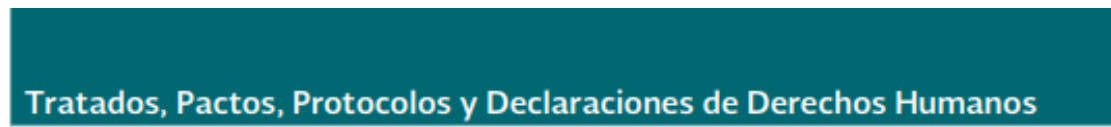

8o Protocolo Facultativo de la Convención sobre los Derechos del Niño, relativo a la venta de niñas y niños, la prostitución infantil, y la pornografía infantil Adopción: 25 mayo 2000

8o Protocolo para Prevenir, Reprimir y Sancionar la Trata de Personas, especialmente Mujeres y Niños, que complementa la Convención de las Naciones Unidas contra la Delincuencia Organizada Transnacional Adopción: 15 noviembre 2000

Art. 3, inciso d

\&o Convención sobre la Eliminación de Todas las Formas de Discriminación contra la Mujer Adopción: 18 diciembre 1979

so Protocolo Facultativo de la Convención sobre la Eliminación de Todas las Formas de Discriminación contra la Mujer Adopción: 10 octubre 1999

\&o Convención Internacional para la Represión de la Trata de Mujeres y Menores Adopción: 30 septiembre 1921

80 Convención contra la Tortura y Otros Tratos o Penas Crueles, Inhumanos o Degradantes Adopción: 10 diciembre 1984

so Protocolo Facultativo de la Convención contra la Tortura y Otros tratos o Penas Crueles, Inhumanos o Degradantes Adopción: 18 diciembre 2002

\&o Convención Internacional sobre la Protección de los Derechos de Todos los Trabajadores Migratorios y de sus Familias Adopción: 18 diciembre 1990

\&o Convenio Internacional del Trabajo No. 182 sobre la Prohibición de las Peores Formas de Trabajo Infantil y la Acción Inmediata para su Eliminación Adopción: 17 junio 1999

80 Convención sobre los Derechos de las Personas con Discapacidad Adopción: 13 diciembre 2006

8o Protocolo Facultativo de la Convención sobre los Derechos de las Personas con Discapacidad Adopción: 13 diciembre 2006
(R) Ratificación

(A) Adhesión

Publicación en DOF

(R) 15 marzo 2002

DOF: 22 abril 2002

(R) 3 febrero 2003

DOF: 10 abril 2003

\section{(R) 23 marzo 1981}

DOF: 12 mayo 1981

Fe de erratas DOF: 18 junio 1981

(R) 15 marzo 2002

DOF: 3 mayo 2002

(A) 10 mayo 1932

DOF: 25 enero 1936

(R) 17 enero 1986

DOF: 6 marzo 1986

(R) 15 marzo 2005

DOF: 15 junio 2006

(R) 8 marzo 1999

DOF: 13 agosto 1999

(R) 30 junio 2000

DOF: 7 marzo 2001

(R) 26 octubre 2007

DOF: 2 mayo 2008

(R) 26 octubre 2007

DOF: 2 mayo 2008

${ }^{1}$ Como antecedentes a la Convención sobre los Derechos del Niño de Nueva York, se tiene la Declaración de Ginebra de 1924 sobre los derechos del niño y la Declaración de los Derechos del Niño de 1959.

Fuente: Modelo Tipo de Atención y Protección Integral de Centros de Asistencia Social para Niñas, Niños y

Adolescentes (2018:15).

A menor estado de derecho mayor legislación. En la actualidad se cuentan innumerables marcos jurídicos de protección de Niñas, Niños y Adolescentes (ver tabla 4), a los que nuestro 
país se ha adherido, y al mismo tiempo -como veremos más adelante-, se expresan condiciones económicas, sociales y culturales, que inhiben el tácito ejercicio de estos para NNA en el territorio nacional.

Estas reglamentaciones estructurales configuran una tecnología de biopoder, es decir de administración de la vida, "aquel que se centra en los procesos que son específicos de la propia vida, como el nacimiento, la muerte, la reproducción, la migración y la enfermedad, el cuidado, así que también son diferentes la racionalidad, dispositivos, estrategias y luchas o resistencia que genera. En la biopolítica, el objetivo ya no es el cuerpo, sino la regulación de la población como cuerpo político" (Sandoval, 2018). Se instituye el cuidado desde la norma y la jurisdicción (ejemplo de ello los espacios de cuidado alternativo CAS), vigilando e institucionalizando una práctica de cuidado y protección.

Las investigaciones antropológicas han relacionado los estilos de crianza de las comunidades con sus sistemas de organización social. En la época de los recolectores y los cazadores, los sistemas de crianza no se limitaban sólo a la madre, sino que incluían a todos los miembros de la tribu [...] hace falta toda una tribu para criar a un niño [...] Ese estilo de crianza responsabiliza a toda la comunidad del bienestar de cada niño y a la vez cría niños y niñas con una gran seguridad básica que desarrollan sentimientos de confianza en los demás y forman grupos humanos en que las emociones que circulan son las de confianza, solidaridad y respeto (Barudy \& Dantagnan, 2005: 14).

El reconocimiento, adherencia y construcción de marcos jurídicos de protección, desvela entonces la "judicialización" del cuidado de la niñez, controlando desde este dispositivo, acciones de cuidado -que han sido el principio fundamental de preservación de la especie-. Siguiendo los planteamientos de Colangelo (2020) la crianza infantil es resultado de la intersección entre "diversidad y desigualdad, en donde cada grupo social pone en práctica una serie de pautas a través de las cuales el niño o niña internaliza los modos de actuar, pensar y sentir propios de su grupo de pertenencia, a la vez que adquiere su identidad como sujeto", pero esta práctica es situada, contextual y relacional, por tanto, se conjuga con dispositivos en donde el Estado y el modelo económico irrumpen el mundo privado e instauran formas predeterminadas y homogenizantes del “deber ser” en el cuidado de niñas y niños.

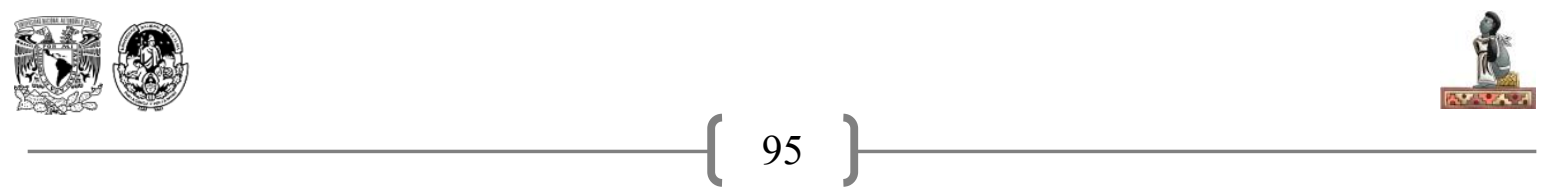




\section{Para Zelmanovich:}

[...] institucionalizar la infancia, responderá a las formas en que lo singular y colectivo se reflejan, se solidaricen, diferencien y distancien. De ahí que instituir la infancia en el discurso contemporáneo con relación a la legalidad de la cultura, por la inscripción de la ley fundante del sujeto en el orden social que es marca de la diferencia entre lo prohibido y lo permitido. Ante la renuncia de los adultos a efectuar estas operaciones de diferenciación, que son operaciones de inscripción subjetiva, la deriva a la que quedan expuestos precipita a los niños a un estado de desamparo simbólico (2011: 98).

El reconocimiento y bordeo conceptual definido por los marcos jurídicos de actuación a nivel internacional, ha instaurado la forma en cómo hoy día se concibe la niñez, direccionando la episteme y encaminando acciones de política social, además de la investigación científica respecto a él desde diversas disciplinas como la pedagogía, psicología y obviamente la ciencia jurídica.

La infancia y su asimetría colocan en el centro la cuestión de los atributos que a ella se le atribuyen y que sirven para construir los dispositivos jurídicos y culturales que la sujetan a su "pequeñez". Se trata entonces de decodificar el discurso hegemónico de la infancia y de establecer una posición crítica frontal contra las teorías que celebran la dependencia infantil. La infancia es devenir abierto, tiene una historicidad que coloca el pasado no como lo que fue sino en función de futuro como re-encantamiento del mundo (Bustelo, 2012: 290).

De acuerdo con la Convención de los Derechos del niño, se entiende por niño "todo ser humano menor de dieciocho años, salvo que, en virtud de la ley que le sea aplicable, haya alcanzado antes la mayoría de edad" (UNICEF, 2006: 10).

Como vemos, en las sociedades contemporáneas y desde el punto de vista sociojurídico, la infancia corresponde a un grupo social, determinado por un rango de edad que va del nacimiento a los 18 años. Para Rodríguez (2002) el tema de los límites etarios de la infancia resulta especialmente polémico, no sólo en el mundo académico, sino en las conversaciones cotidianas, toda vez que los niños parecen adelantarse y dejar muy pronto de ser y hacer

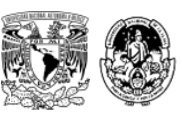


aquello que realmente les corresponde" para acomodarse a la expectativa adulta que les asigna características homogenizantes en un mundo ideal.

\subsection{La niñez en el contexto capitalista-neoliberal}

Colocar la niñez como una etapa del desarrollo del ser humano en un rango de edad específico, ha cobijado y definido los estudios de las disciplinas mencionadas en la época moderna resultando conveniente al modelo económico capitalista; sumergirse en su estudio desde la dimensión individual, dando poca o casi nula importancia a los elementos contextuales que hacen de la categoría de niñez un precepto sociocomunitario; estas disciplinas han dedicado numerosos y amplios estudios relacionados a sus características etarias.

\subsubsection{La psicología promovente de una episteme individualizante: ritmos y modalidades convenientes al capitalismo}

En lo que ocupa a la psicología y desde principios del siglo XX se han sucedido distintas hipótesis acerca del desarrollo de la mente infantil. Dichas teorías han intentado explicar de qué manera se van adquiriendo las nuevas conductas, especialmente durante los primeros años de vida, en lo que el ser humano tiene que aprender prácticamente todas las habilidades necesarias para vivir y relacionarse en la sociedad a la que pertenece (IIJ, 2019: 75) y, al mismo tiempo, dichos planteamientos robustecen un modelo económico individualizante: el capitalista-neoliberal.

Lo que habremos de revisar a continuación, recupera aportes de la psicología en lo relativo a las características individuales de la experiencia infantil (ver tabla 5), Egle Becchi (1980) señala que "el propósito de la psicología científica de base positivista será, a partir de la segunda mitad del siglo XIX, explicar la conducta de los niños a través de reglas que trasciendan cada caso individual y permitan dar cuenta de los ritmos y modalidades de crecimiento de todos los niños”, de ahí el énfasis y protagonismo de esta disciplina. 
La episteme contemporánea fortalecida por la psicología alude a nociones de desarrollo funcionalistas, como veremos a continuación, fortaleciendo la idea de que el/la niño/a es un ente individual en donde "los rangos de edad utilizados van a variar según los criterios que se destaquen (madurez sexual, responsabilidad penal, facultad para trabajar, etc.) en el marco de una sociedad que ha querido pensar a la infancia como un período definido por límites naturales, olvidando el carácter social y político de estas delimitaciones”(Vergara, 2015: 57). Aquí algunos ejemplos:

Tabla 5 Características de la infancia desde las distintas escuelas de la psicología del

desarrollo

\begin{tabular}{|c|c|}
\hline ESCUELA & APORTACIONES \\
\hline $\begin{array}{c}\text { ETOLOGÍA } \\
\text { (Bowlby) }\end{array}$ & $\begin{array}{l}\text { La etología explica el comportamiento humano como un conjunto } \\
\text { de capacidades innatas con las que llegan al mundo los seres } \\
\text { humanos y que les permiten sobrevivir. Hay un paralelismo entre } \\
\text { la conducta animal y la conducta del hombre y señala que toda } \\
\text { conducta instintiva debe contribuir a la supervivencia y } \\
\text { propagación de la especie, pero es necesario que el organismo } \\
\text { cuente con el entorno apropiado para que se pongan en marcha } \\
\text { los sistemas que integran el comportamiento instintivo. }\end{array}$ \\
\hline $\begin{array}{l}\text { TEORIAS DEL } \\
\text { APRENDIZAJE } \\
\text { (Pavlov, Skinner, } \\
\text { Bandura, Walters) }\end{array}$ & $\begin{array}{l}\text { Esta aproximación teórica estudia la evolución del individuo } \\
\text { desde la perspectiva del aprendizaje, entendido como el proceso } \\
\text { básico del desarrollo en que el individuo cambia por la } \\
\text { experiencia o la práctica. En este sentido el estudio de la infancia } \\
\text { resulta fundamental por ser la etapa de la vida humana en que la } \\
\text { adquisición de nuevas conductas se produce de manera más } \\
\text { acelerada. } \\
\text { Las teorías del aprendizaje ponen el énfasis del desarrollo en las } \\
\text { respuestas que el niño va adquiriendo a través de los } \\
\text { condicionamientos o de la imitación para el desarrollo de su } \\
\text { personalidad. }\end{array}$ \\
\hline $\begin{array}{c}\text { PIAGET Y OTRAS } \\
\text { TEORÍAS } \\
\text { COGNITIVAS } \\
\text { (Piaget, Vigotsky) }\end{array}$ & $\begin{array}{l}\text { El desarrollo psíquico se inicia con el nacimiento y termina en la } \\
\text { edad adulta, y al igual que el desarrollo orgánico es un proceso en } \\
\text { el que va alcanzando estados de equilibrio cada vez más } \\
\text { avanzados. } \\
\text { El niño evoluciona de la incoherencia y la inestabilidad hacia la } \\
\text { sistematicidad de la vida adulta atravesando por varias etapas que } \\
\text { se caracterizan por la aparición de estructuras originales distintas } \\
\text { de las etapas anteriores y se definen por una forma particular de } \\
\text { equilibrio: }\end{array}$ \\
\hline
\end{tabular}




\begin{tabular}{|c|c|}
\hline & $\begin{array}{l}\text { - Etapa sensoriomotríz } \\
\text { - Etapa preoperacional } \\
\text { - Etapa de las operaciones concretas } \\
\text { - Etapa de operaciones formales } \\
\text { Las consideraciones del individuo como sujeto activo de su } \\
\text { propio desarrollo y el descubrimiento de la particularidad de los } \\
\text { procesos mentales en el niño han sido importantes en el estudio } \\
\text { de la infancia. }\end{array}$ \\
\hline $\begin{array}{c}\text { TEORÍAS } \\
\text { PSCOANÁLITICAS } \\
\text { (Freud, Erikson) }\end{array}$ & $\begin{array}{l}\text { Propone que todo comportamiento se encuentra motivado por } \\
\text { determinantes inconscientes que buscan reducir la tensión } \\
\text { provocada por los estímulos a través de dos mecanismos: } \\
\text { exteriores, que resuelven por medio de movimientos musculares, } \\
\text { e interiores o pulsiones, que son las exigencias que plantea el } \\
\text { cuerpo a la vida psíquica y cuya satisfacción es más difícil. } \\
\text { Freud atribuye una gran importancia a las experiencias infantiles } \\
\text { en la formación de la personalidad y sitúa el origen de la neurosis } \\
\text { adulta en acontecimientos de la niñez. }\end{array}$ \\
\hline $\begin{array}{c}\text { TEORÍAS } \\
\text { CONTEXTUALISTAS } \\
\text { (Bronfenbrenner) }\end{array}$ & $\begin{array}{l}\text { Los primeros años de la vida se caracterizan por la necesidad de } \\
\text { ir asumiendo roles en cortos períodos de tiempo y aprendiendo las } \\
\text { conductas asociadas con cada uno de ellos. } \\
\text { Los primeros roles que la niña o el niño asume son los } \\
\text { relacionados con el parentesco: hijo/a, nieto/a, sobrino/a, primo,a, } \\
\text { etc. También es probable que se produzcan cambios en esta etapa, } \\
\text { como la llegada de un nuevo hermano, la incorporación a la edad } \\
\text { escolarizada, etc. } \\
\text { Las transiciones se realizarán con éxito en la medida en que el } \\
\text { individuo pueda contar con un vínculo del entorno originario y } \\
\text { exista una buena comunicación y coordinación entre los distintos } \\
\text { ambientes en los que se desenvuelve. } \\
\text { La gran crítica que se ha hecho a esta construcción teórica es el } \\
\text { peso excesivo que se atribuye al medio ambiente y la poca } \\
\text { atención al individuo dentro de los estudios sobre el desarrollo. }\end{array}$ \\
\hline
\end{tabular}

Fuente: Elaboración propia a partir del Instituto de Investigaciones Jurídicas de la UNAM (2019).

Una niñez situada, como perspectiva de abordaje, supone entenderla en los contextos sociopolíticos, geográficos, culturales y no sólo como un listado de características de desarrollo que pretenden universalizar la experiencia infantil. Hoy día, en México se vive un contexto de pobreza, marginalidad y desigualdad, resultado del hegemónico modelo económico capitalista neoliberal en su fase más perversa, en donde la vida humana se intercambia y mercantiliza. 
Se trata de la asimetría que, en la dimensión de la cultura, expresa la relación de la infancia con la adultez predominante en la actualidad. Aquí la infancia no se refiere al niño o la niña singularizados ni a las categorías de hijo/a, sino al colectivo infancia que expresa el lugar que en la cultura tienen nuevas generaciones respecto a los adultos. Esta asignación en la cultura es histórica y discursiva. La infancia es situada incuestionablemente en una relación de dependencia y subordinación (Bustelo, 2012: 289).

A continuación, situaremos la niñez en un contexto que define relaciones económicas, sociales y culturales, a partir del modelo capitalista-neoliberal.

\subsubsection{La niñez como sujeto relacional en un contexto económico capitalista neoliberal}

El individualismo en el sistema capitalista emerge a manera de principio que rige la organización social, pone en riesgo la cohesión comunitaria y reconocimiento de interdependencia de los sujetos -o bien la relación se constriñe a la dependencia y subordinación como plantea Bustelo (2012)-, dado que uno de los ingredientes de los que se alimenta el poder para ejercer el control sobre la población es intentar inculcar una conciencia individualista; el objetivo final que mueve al poder es hacer que los individuos de una sociedad sean lo más productivos posibles, pero al mismo tiempo, que sean lo más dóciles y obedientes.

El neoliberalismo, más que una comunidad, fábrica cuerpos agrupados en serie ¿pero apuesta por el lazo social? Los discursos de poder acusan, acosan y a-cosan. Clasificaciones, evaluaciones y diagnósticos que segregan y fracturan vínculos. Ruptura de voz convocante, silencio acallado ante el dolor epocal: “consume, con-súmete, so-métete”, imperativos que exigen la indiferenciación, la seriación de lo mismo, del UNO. Inmersos en el olvido mediático, ignoran que el malestar necesario, es producto fértil, reproductor de cultura [...] promotor de con-vivencia social (Stavchansky y Untoiglich 2019:28).

Es así como pensar la niñez distanciada de su protagonismo social reduce su necesaria complejidad conceptual. En contraposición: 
[...] el análisis sociológico enfatiza que la categoría infancia es una construcción histórica y social y no un mero registro de la naturaleza. Se diferencia claramente por su antagonismo con la adultez, así como de otras categorías sociales como clase, género, etnia, etc., aun cuando, como se dijo, es atravesada por ellas. Este análisis se aleja epistemológicamente de las concepciones biologizantes y desarrollistas de base individualista y abstracta, como las formuladas por otras tradiciones analíticas como la psicología, particularmente la piagetiana. En este contexto, los niños, las niñas y los adolescentes son analizados y clasificados de acuerdo con distintos saberes, pero se les niega el carácter de actores. Sin embargo, son sujetos que tienen una representación histórica específica y diferente de su localización en la cultura de los adultos. La infancia resiste la imposición de normas y valores verticalmente impuestos por el mundo de los adultos. Esta perspectiva se diferencia también de la visión sociopsicopedagógica que coloca a la infancia en el contexto de la relación social maestroalumno, de la "formación" áulica y el ámbito pedagógico reducido a la escuela (Sarmento, 2008: 17-39).

Se construyen y fortalecen prácticas que atentan en contra de la niña/el niño como sujeto, que le mercantilizan y cosifican. De ahí la urgencia por reconocerle como sujeto colectivo, desafiando la episteme que le reduce a un ente individual e individualizante, que se arranca del contexto para analizar de forma independiente negando la interdependencia y la interrelación que no significa subordinación.

\subsubsection{Los dos polos de la infancia en el capitalismo: consumidor y consumible}

Barudy y Dantagnan (2005:48) han advertido sobre los riesgos que implica para la infancia un modelo económico neoliberal globalizante, impuesto por las clases dominantes en todos los países. Las consecuencias de este modelo basado en el libre mercado se hacen notar de manera diferente en los países ricos en contraste con los países pobres y establecen una categorización de la infancia a partir del lugar que ocupan en dicho sistema:

Tabla 6 Infancia y modelos de dominación 


\section{Infancia y modelos de dominación}

El modelo de la modernidad

Autoritario

Clerical

Militar

Adultista

Patriarcal

Explotación de la fuerza de trabajo

Control social por represión

Hipertrofia de la

"función paternante"

Represión infantil

NIÑO COMO FUERZA DE

TRABAJO

(futura mano de obra explotada)

\section{El modelo de la posmodernidad}

Manipulador

Individualista

Materialista

Basado en el deseo

Indiferencia

Consumismo

Control social mediante la alienación

Pensamiento único

Hipertrofia de la

"función maternante" (alimenticia)

Libertinaje infantil

NIÑO COMO OBJETO DE

CONSUMO

(consumistas precoces)

Fuente: Barudy \& Dantagnan (2005: 49).

En el modelo de la modernidad y como revisamos anteriormente, en lo concerniente a la época poscolonial, independiente y revolucionaria, las niñas y los niños fueron utilizados como importante fuerza de trabajo e incluso como manos belicosas implicadas en los movimientos armados, cobrando un papel protagónico. Hoy día en la posmodernidad, ellas y ellos juegan un papel de fortalecimiento del sistema económico, en donde suponen fuerza consumidora que mantiene la homeostasis y les construye como consumistas "precoces" (ver tabla 6).

El análisis que se centra en comprender también el papel que juega nuestra niñez en el modelo económico hegemónico, que incorpora su rol de consumidor y emerge para preservar el status quo y engrosar las ganancias que sostienen el capitalismo, configurando así, una crisis 
de la infancia en donde la televisión, revistas, diarios, constituyen una red por cuanto imponen las mismas operaciones de recepción a los destinatarios.

Las prácticas dominantes actuales, el consumo y la comunicación, no detentan la diferencia moderna entre el mundo infantil y el mundo adulto que instituyó simbólicamente la niñez. En relación con estas prácticas, hay dos figuras que detentan la subjetividad actual del niño: la del consumidor y la del sujeto de derecho, que en el universo mediático aparece bajo la figura de sujeto de opinión (Corea, Lewkowics, 99:53-54).

Si partimos del complejo análisis de la niñez situada y reconocemos el papel de consumidor que se instituye a la infancia ¿es posible pensar en una niñez que se consume?: la niñez contemporánea "se constituye en la lógica del consumo de los mercados, y ello nos interpela como un síntoma del lazo social. Como constituyente del discurso de los mercados, aparece como objeto de adicción. Acción misma de un "capitalismo infantil" como un biopoder que mercantiliza a los niños como consumidores, dinamizadores y objetos de consumo" (Pippi de Medeiros, 2009: 37).

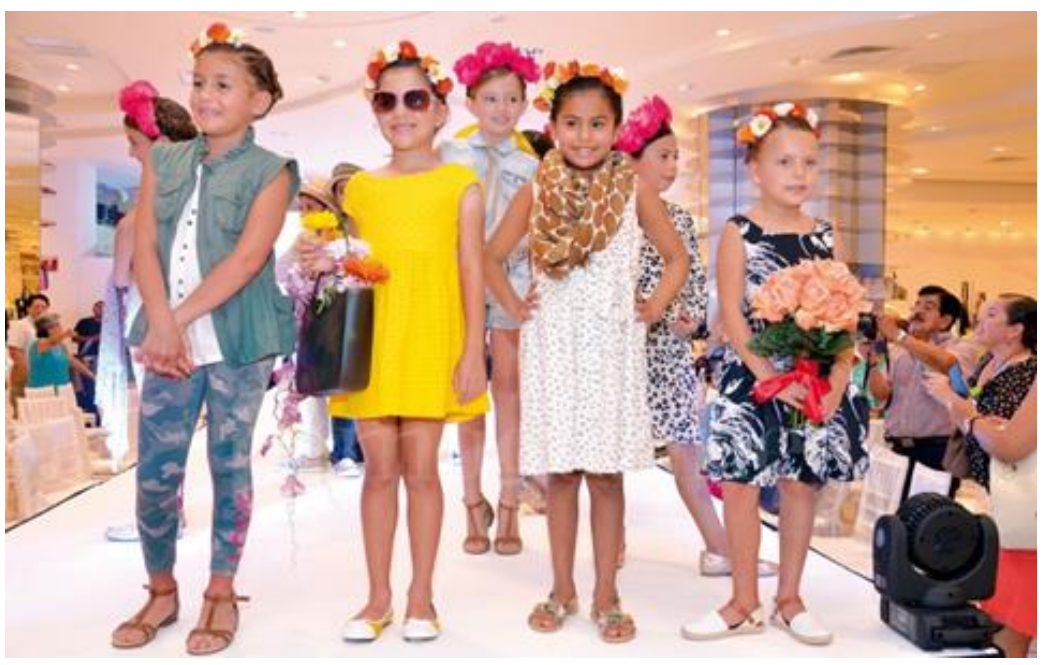

Imagen 11 Desfile de moda infantil en Liverpool El Dorado Fuente: Casting Desfile para Niños y Mamás. La Casita de Martina 
Los niños felices, aquellos que tienen cabida en el sistema como consumidores, son nuestra imagen de inocencia, de pasividad y un nulo protagonismo, al reducirles como depositarios a merced del mundo "adultista". Pero los niños que, por muchas razones, no pueden corresponder a un ideal ¿se convierten en los reusables, desechables, mercantilizables?

Es decir, las niñas y los niños cuyos contextos inhiben una capacidad de consumo son transformados por el sistema como consumibles; aquellos que sirven para satisfacer otras "necesidades adultas": están los que se explotan en el ámbito sexual y/o laboral, los que se comercian ilegalmente en la adopción y satisfacen una necesidad parental, los que son implicados en actividades delictivas como el crimen organizado e incluso aquellos que se mercadean antes de nacer a través de actividades como la subrogación de vientres. Lo que para Narodowski (1999), se configura como una expresión en "dos polos: infancia hiperrealizada (la de la realidad virtual) y la infancia desrealizada (la de la realidad real)".

Ante un escenario tan complejo, resulta insuficiente reducir las expresiones de lo infantil a versiones dicotómicas: consumidores-consumibles, aunque dicha polaridad, ofrece al mismo tiempo un abanico de posibilidades para analizar "cómo en el actual régimen global de producción de la infancia tiene lugar la reorganización discursiva que produce, en distintos lugares del mundo, bajo distintas condiciones sociales y en diferentes universos culturales, una multiplicidad de infancias" (Diker, 2009: 30); la expresión subjetiva que incluye al niño abusado, abandonado, maltratado, al sometido a la pantalla y la internet, al que se vive en la inmediatez y el consumo y también, al niño peligroso, al sicario y al mendigo. Todas estas manifestaciones en la simetría instituyente del dispositivo jurídico en una concepción moderna: "el niño como sujeto de derecho". 


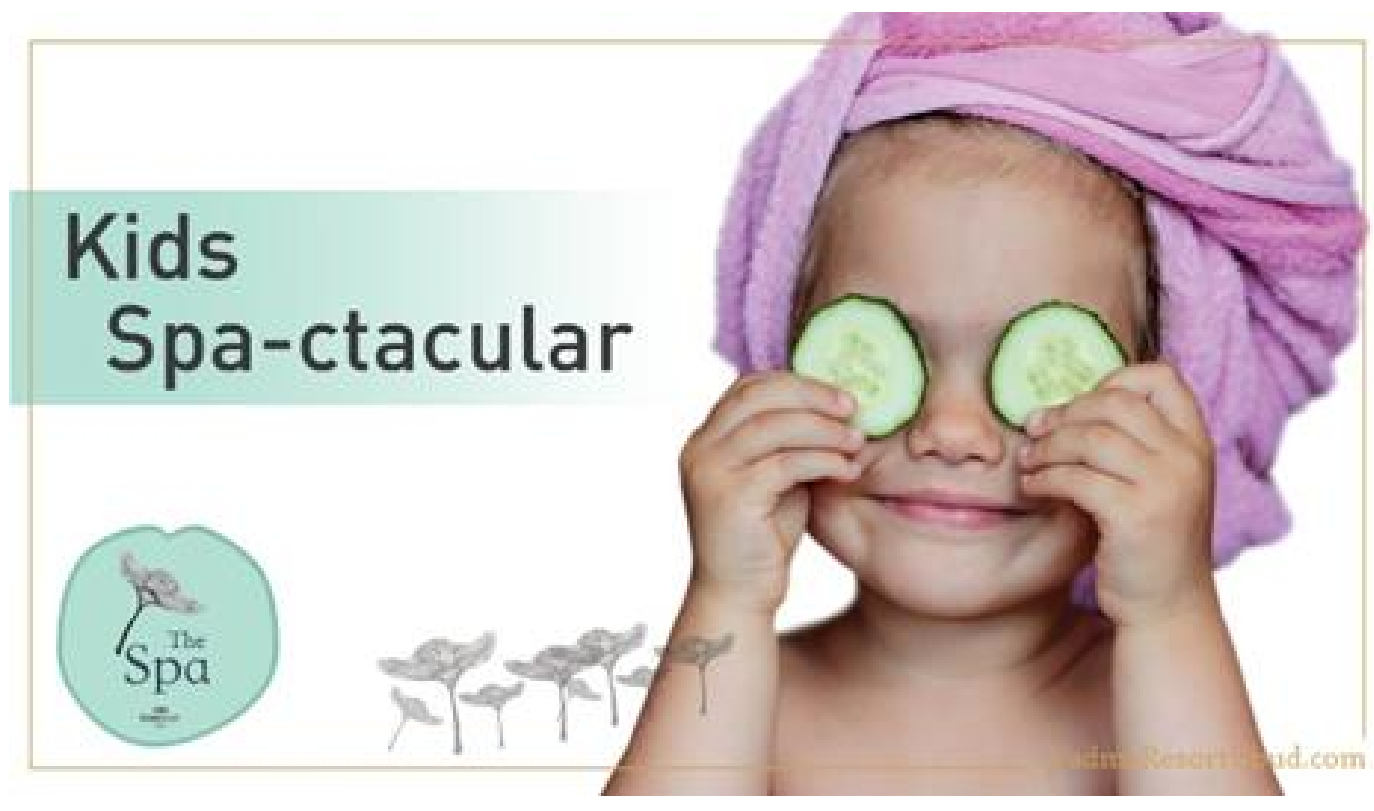

Imagen 12 Spas para niñas en la Ciudad de México

Fuente: Time Out México, 2017.
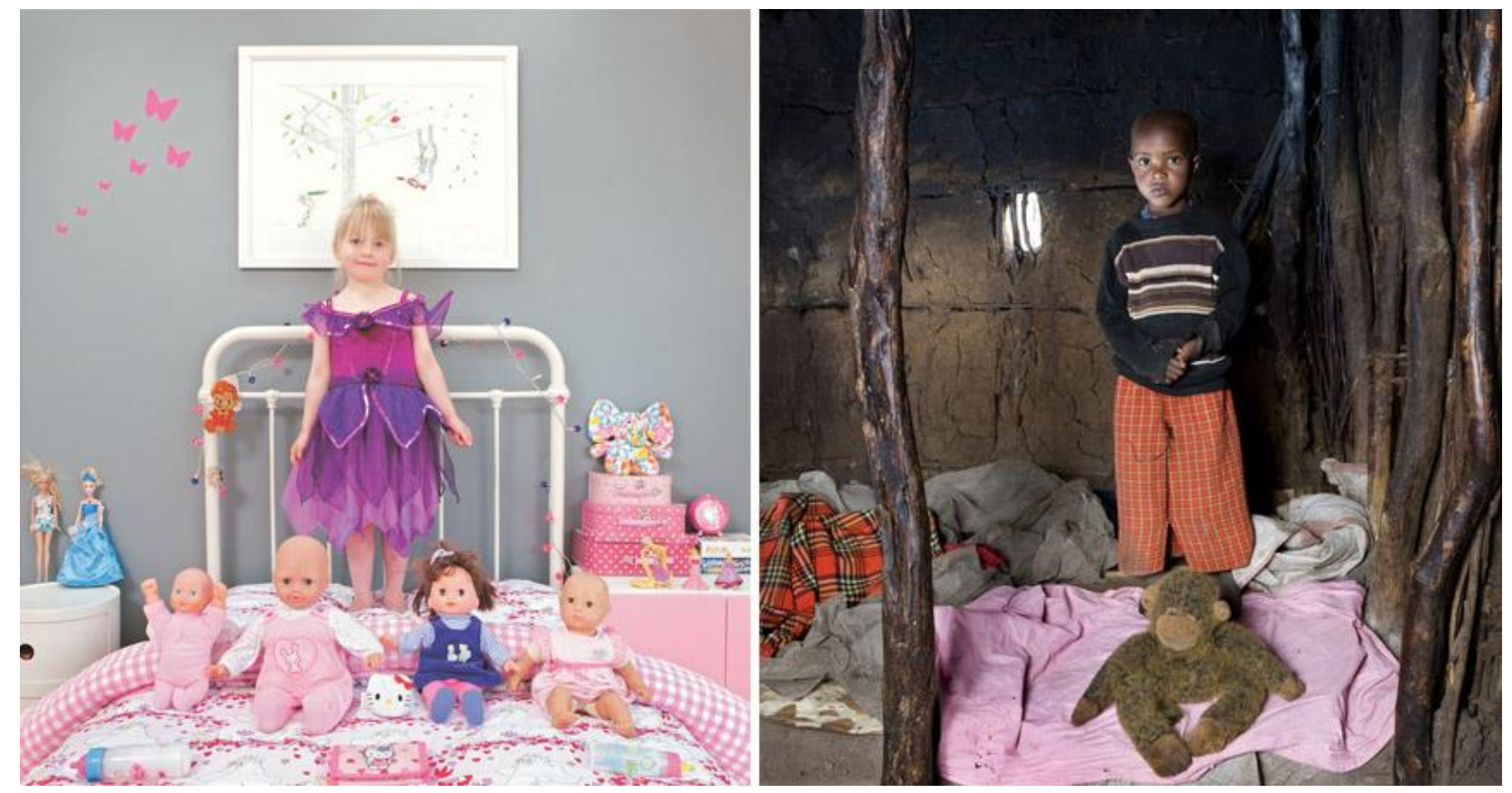

Imagen 13 Los dos mundos

Fuente: Ayayay, 2019.

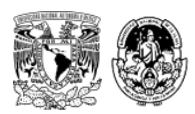




\subsection{Propuestas epistemológicas y de enfoque para la comprensión de la niñez}

Definir un enfoque de reconocimiento de la niñez como categoría de análisis en la sociedad contemporánea, debe ocupar una obligada discusión si se aspira a trascender de su reconocimiento como un rango etario de ciertas características biopsicosociales.

Agamben (2007) expone que es necesario "reconsiderar la infancia: ésta no es un momento cronológico sino una relación con el lenguaje; por esta razón, hay siempre un niño o niña en cada uno de nosotros. La infancia es una experiencia pura trascendental, liberada del sujeto. No hay niño, no hay niña: hay infancia, es decir, comprender la infancia más allá del universo individual de ciertas características y definirla como un entramado complejo que implica, una perspectiva conceptual, colectiva y relacional”.

Complejizar la infancia, permite deconstruir el precepto e implica reconocerla en su infinidad de expresiones y contextos, no como categoría individual sino en relación con el contexto, renunciar a la falsa idea lineal y unidireccional de que se trata de una etapa necesaria que está a la espera de la vida adulta, una vida futura que ofrecerá plenitud; y teniendo como elementos comunes un protagonismo: político-social, cultural y ético, que le distancie de una mirada reduccionista en cuanto a sus características, propias de una etapa del desarrollo humano, para entenderla desde la forma en cómo lo singular se vuelve colectivo y esa colectividad determina su desarrollo, es decir, cómo su experiencia cotidiana en el ámbito privado (la familia), se intersecciona con el rol social y público (la escuela, las instituciones), a través del cual, no sólo recibe sino produce cultura, se interrelaciona y emerge activo.

Desde la perspectiva de Mayall (2002) "la infancia no alude a un sujeto particular, sino que es un concepto relacional, similar al de género, ya que da cuenta de las relaciones históricamente configuradas entre los niños y el mundo adulto”.

A continuación, se recuperan algunas consideraciones hechas por estudiosos contemporáneos, que no necesariamente articulan una misma línea de pensamiento en términos ontológicos del ser niño, pero que aportan desde miradas distintas, elementos de

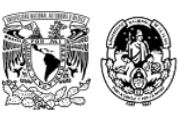


proximidad social para su reconocimiento, configurando así, un enfoque para el estudio de la niñez. Estas propuestas, han sido recuperadas a la luz del enfoque teórico de esta investigación, debido a sus reflexiones que ubican el reconocimiento de la niñez como categoría relacional, contextual e histórica, distantes de la propagación de un enfoque adultocéntrico y homogenizante y cuyos postulados presentan avances importantes respecto de los "nuevos" estudios de la infancia hacia el contexto latinoamericano.

\subsubsection{Nueva mirada de la infancia: por una categoría relacional ${ }^{29}$}

Entender la infancia como campo sociohistórico, ha ocupado en las últimas décadas un análisis profundo y se sitúa en reflexionar la manera en cómo el mundo infantil se experimenta en una relación dialógica con el contexto, su papel activo y de protagonismo social. Para Bustelo:

La niñez se constituye como una figuración no sólo cronológica en donde las experiencias del ser en el mundo se manifiestan subjetiva e intersubjetivamente y en donde cabría pensarse como personas en estado de niñez (así como valdría, re-pensar personas en estado de adultez). La infancia es entonces una categoría relacional en la que se pone en juego el poder; relación que se devela históricamente en las prácticas (discursivas o no) y en las luchas que la atraviesan. La infancia no es un sujeto a priori o un sujeto jurídico abstracto formal sino una construcción histórica y relacional (2012: 292).

Estos posicionamientos epistemológicos de la niñez, co-existen y apuestan a una "nueva mirada de la infancia"; algunos rasgos del pensamiento latinoamericano, son resumidos en Bustelo en el punteo señalado a continuación (2012: 294), para este autor:

1) La infancia es una categoría antagónica con la adultez que es su exterior constitutivo. Pero la relación adultez-infancia es una relación de dominación. Opera, principalmente, vía el

${ }^{29}$ Eduardo Bustelo. Licenciado en Ciencias Políticas y Sociales en la Universidad Nacional de Cuyo, Mendoza, Argentina. Fundador y primer director (1989 y 1993) de la Oficina de UNICEF en Argentina, asesor en Desarrollo Humano para la Oficina Regional de UNICEF para América Latina y el Caribe hasta 1997.

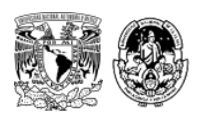


concepto de sociedades de control. La maduración y la socialización son dispositivos conceptuales centrales que son profundamente cuestionados en este proceso.

2) La infancia es una categoría estructural y no transitoria. Pero estructural en el contexto de una relación de dominación. Perspectiva crítica hacia la clásica teoría del desarrollo infantil que concibe a la infancia con un telos definitivo que culmina en la adultez.

3) La infancia es una categoría intercultural y de fuerte contenido contra el paternalismo adulto. La infancia no es principalmente una teoría protectiva pues mientras más protección hay menos autonomía y menos actoralidad.

4) La infancia es una autonomía en el contexto de una heteronomía social planteada como proyecto y construcción política. Se trata de autonomía con partencia social y no la autonomía pensada como proyecto individual.

5) La infancia es una diacronía, es una discontinuidad con el orden del status quo. La infancia no es una fotocopia de la generación adulta. Se trata de un proceso diacrónico y no una sincronía con el orden adulto.

6) La infancia es una categoría emancipatoria y como tal implica una teoría del cambio social. El devenir de la infancia, en tanto que transporta lo nuevo, coincide con la construcción de una sociedad justa. Y aquí se junta con la actitud utópica como principio crítico-regulativo de la práctica política.

Siguiendo las ideas de Bustelo (2012) la niñez debe entenderse más allá de una temporalidad diacrónica, transformándola en una categoría de carácter emancipatoria y construcción cultural, apuntando hacia una nueva visión de lo infantil. 


\subsubsection{Por una Cultura de la infancia ${ }^{30}$}

"La construcción de una cultura de la infancia radica en reconocer en niñas y niños a un agente político-social en tanto su esencia pública, ningún ser es privatizable o refundible fuera del ámbito de la sociedad, responsabilidad común que no se reduce al ámbito doméstico, relaciones intrafamiliares o de tutelaje; ético en tanto se trata de construir humanidad y sostener procesos de humanización; y cultural como resultado de un recuento subyacente a lo largo de la historia" (Cussianovich, 2010: 6-10).

En conversación con Morsolin (2015), el peruano destaca su aportación pedagógica, que ha llamado "Pedagogía de la ternura":

Hablar de pedagogía de la ternura corre el riesgo, como todo en la vida, de devenir una banalidad, un eslogan, una tarjeta de presentación aceptable. Tanto más buscada cuanto que puede funcionar como un mecanismo de compensación a la cultura de la modernidad heredada y que en nombre de la razón terminó relegando la subjetividad y en su combate contra el romanticismo, instaurando cierto neoestoicismo, o como señaló en 1919 el II Congreso Panamericano del Niño, el ideal de niño es que sea "robusto, sano y viril".

Sin embargo, la ternura para nada es apenas un refugio ante sociedades de la violencia institucionalizada; la ternura, en particular en el ámbito familiar, está llamada a convocarnos en torno a otros paradigmas de las relaciones sociales, de la vida interpersonal. Pero muy en especial, la ternura debe ser entendida como una virtud política, como un componente insoslayable de nuestra práctica educativa familiar, profesional sea cual fuere ésta. Ciertamente que de ello dependerá que con menos desgarramientos logremos que la vida familiar, escolar, comunitaria exprese el eros pedagógico y el agape convivial, necesarios para construir sin pausa identidad, responsabilidad social y solidaridad. La solidaridad es la ternura de los pueblos dijo

\footnotetext{
${ }^{30}$ Desarrollada por Alejandro Cussiánovich. Sacerdote, maestro y filósofo peruano, promueve la creación de la primera organización autónoma en manos de los propios niños, niñas y adolescentes trabajadores en su país, germen de un proceso de organización latinoamericano e internacional de niños, niñas y adolescentes trabajadores. 
con razón Tomás Borges y añadiríamos, de las parejas, de las familias, de las colectividades societales (Morsolin, 2015:1).

"Pensar en una cultura de la infancia nos debe advertir cómo los niños y niñas ensamblan sentidos de pertenencia que se les presentan como incompatibles, al apropiarse, reformular o refuncionalizar los mensajes identitarios dirigidos por sus familias, iglesias, escuelas y organizaciones, mediante sus acciones y perspectivas. Esto los muestra como activos partícipes de los conflictos político-culturales en curso” (Szulc, 2018: 60).

Es decir, los niños y las niñas, no son exclusivamente receptores de una cultura, sino creadores de esta.

\subsubsection{Una mirada sociológica y antropológica deconstructiva de la infancia}

En los últimos años se coloca la necesidad por recuperar saberes de múltiples disciplinas para lograr categorizar la infancia, saberes que cuestionen las consideraciones históricas en el pensamiento occidentalizado que datan del pater-familias en la época antigua, el abandono de niñas y niños en la Edad Media que le adjudican autonomía y no una percepción de entes pasivos a la espera de la vida adulta. En esta línea de pensamiento Casas Ferrán (1998:2340) advierte que no se deben ignorar la serie de ideas y múltiples acepciones de las niñas y niños, que han referenciado el universo de lo infantil. Indica entre ellas que:

a) La infancia como representación positiva: es idílica y feliz, simboliza la inocencia, la pureza, la vulnerabilidad. Actualmente esta imagen es utilizada y manipulada por la publicidad.

b) La infancia como representación negativa: conlleva la necesidad de "corregir" la maldad o rebeldía inherente a la infancia. Acostumbra a ir asociada a una desvalorización de lo infantil y a la justificación del control.

c) La infancia como representación ambivalente y cambiante: etimológicamente, el origen del concepto "infancia" viene del latín in-fale, el que no habla, por lo tanto, el que no tiene algo valioso que decir, no vale la pena escucharlo.

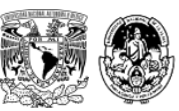


Casas Ferrán (1998:16) sostiene que el concepto infancia se refiere más a un consenso social sobre una realidad, que a una realidad social objetiva y universal.

En el caso de la sociología deconstructiva de la infancia, las nociones sobre niño, niños o infancia son tratadas como formaciones discursivas socialmente construidas, a través de las cuales las ideas, imágenes y conocimiento de los niños y la infancia se comunican en la vida social; también se les ve como agentes sociales activos que moldean las estructuras y los procesos sociales que dan a su alrededor (Calderón, 2015: 132).

En el campo de la antropología se han planteado enfáticamente estos "nuevos preceptos". Para Vergara (2015: 57): "Desde hace poco tiempo, ha empezado a reconocerse un campo definido como los nuevos estudios sociales de la infancia, surgido inicialmente como "nueva antropología" o "nueva sociología de la infancia", pero luego entendido como un ámbito interdisciplinario al que se ha incorporado la historia, la geografía, la literatura, la psicología, el trabajo social, las ciencias jurídicas y otras disciplinas”.

Esta implicación multidisciplinar ha posibilitado la reformulación y el entendimiento de la niñez en el contexto latinoamericano, perfilando un campo de estudio de relevancia, que sugiere la exigencia por comprenderle de forma contextual, interrelacionando con otros componentes como el sistema económico, político, social y cultural en donde es posible identificar relaciones de poder atravesadas por las instituciones del Estado, los medios de comunicación, la familia y demás espacios de la vida pública y privada en los que se desarrollan niñas y niños.

Lo desarrollado hasta este punto del capítulo aborda algunos de los planteamientos que han envuelto a la categoría de niñez en el mundo y México, el conjunto de configuraciones construidas en contextos históricos particulares que condicionan los modos de entender a este grupo poblacional y eso, cobra relevancia cuando reconocemos la influencia de las epistemes de sujetos sociales y su encuentro con las epistemes de la intervención disciplinar, cuya convergencia construye entramados complejos que se retroalimentan, resultando imposible, verles de forma separada.

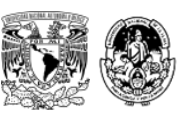


A partir del recorrido histórico en torno a la percepción de la niñez en México y el mundo, se ofrecen elementos para su comprensión y consecuente categorización de la infancia y/o niñez, esta se ha colocado discursivamente en la idea de que se trata de dos conceptos sinónimo, aún en la época contemporánea y en los aportes de los estudiosos en la actualidad, no se logra vislumbrar una diferenciación exacta entre ambos y aunque la psicología ha contribuido en marcar alguna diferencia, está la coloca nuevamente en lo concerniente a rangos de edad (sugiriendo que la infancia se atribuye a niñas y niños en edad preescolar, en tanto los escolares serán "niños", universalizando con ello el desarrollo humano).

\section{5 ¿Qué es la niñez? Una propuesta de enfoque para su comprensión}

Hacer esta puntualización y en seguimiento a la pregunta ¿qué es la niñez?, no resulta menor, dado el esfuerzo que ocupa el tratar de comprenderla como categoría de análisis, sin que esto signifique construirla hegemónicamente.

La presente investigación, habrá de colocarse en la afinidad por el uso de la categoría niñez discriminando así el uso de infancia (y en lo subsecuente el lector lo identificará de esta manera). Lo anterior en congruencia con el planteamiento de renunciar a la idea de que se trata de sujetos pasivos y sin voz propia. Por otra parte, tampoco se retomará al niño o niña sólo como persona individual, sino como resultado de una construcción colectiva, histórica y determinada por su contexto, constituirle como sujeto del lenguaje, entrar en el universo de los semántico abriendo así la posibilidad de la historia, la posibilidad de otra episteme de la niñez (siguiendo a Agamben).

Propongo un enfoque que entienda a la niñez como la experiencia humana dinámica, relacional y contextual de los primeros años de vida, resultante de un trayecto histórico situado que supone un proceso de humanización que se construye subjetiva e intersubjetivamente en relación con los otros, en el entendido de una interseccionalidad en donde lo individual y colectivo convergen, lo íntimo y lo público se encuentran.

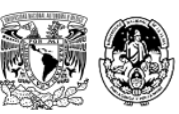


Esta perspectiva permitirá reconocer a los niños y las niñas, como sujetos activos en un espacio social, contribuyendo así, a una lectura interpretativa, que para efectos de la llamada “intervención social” les reconozca desde otro campo epistemológico y con ello, suscitar una transformación en el escenario y construcción del conocimiento.

\section{Epílogo}

Al inicio del capítulo, he relatado mi encuentro con Mario -por la década del noventa-, en aquella época los aparatos jurídicos no eran un referente consistente para la atención de los sistemas familiares, en muchos hogares se repetían patrones de abuso (situación que desafortunadamente no ha cambiado sustancialmente) soportados en la idea de que el mundo íntimo familiar se gobierna solo y el "padecer" es un asunto individual y de exclusiva responsabilidad de quien lo vive, discurso promovido por un sistema económico altamente individualista y meritocrático, que instituye en la familia la "célula de la sociedad" independiente del escenario social, además del constructo epistemológico, promovido -entre otras tecnologías- por el conocimiento científico de la psicología funcionalista del siglo XIX, que como vimos a lo largo del capítulo, generó la idea de que el desarrollo infantil es meramente individual e independiente del contexto.

Ese referente de carácter individual constriñe el maltrato infantil, su prevención e intervención profesional, a un trámite administrativo competencia del dispositivo jurídico que se registra en instrumentos como las "carpetas de investigación" y a su vez, robustecen el brazo operario del Estado que se soporta en epistemes separadas del entorno.

Mario fue un número de expediente, un número de averiguación previa (hoy "carpeta de investigación), un niño con "síndrome de Kempe" atrapado en la categoría del "sujeto de derecho", proveniente de una "familia disfuncional" en donde los convenios internacionales y las reglamentaciones nacionales le invisibilizan cuando se privatiza el maltrato y se justifica la intervención profesional desde la indispensable "objetividad", que construye relaciones entre "extraños", es decir, relaciones distantes y despersonalizadas, que se rigen por manuales de procedimientos y marcos jurídicos, indicativos del hacer profesional, imposibilitando el

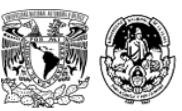


encuentro y reconocimiento del "otro", operando así el dispositivo que inhibe trascender hacia la transformación de trayectorias.

En este capítulo, iniciamos exponiendo la construcción histórica, cultural y social respecto de la comprensión de la niñez desde la Europa occidental, y de ahí en adelante, se reconoce la permanente transformación resultado del proceso que le define y asigna ciertos atributos, características y roles congruentes a la época. Una categoría conceptual que obedece a condicionantes de orden estructural que implican elementos políticos, culturales, económicos y, por ende, íntimamente sociales.

Se identifica el recorrido epistémico de la categoría de niñez, en el transitar desde una mirada occidentalizada que plantea a las niñas y los niños como seres humanos "inferiores", "a la espera de la vida adulta" y "de poca valía” que, hacia la década del ochenta, construye el reconocimiento del niño como "sujeto de derecho". Al mismo tiempo ha sido posible identificar otras formas de relación en nuestras culturas mesoamericanas. Particularmente en la cultura mexicana se parte de la información documentada que reconoce entre los mexicas, una idea de que el "infante" es signo de prosperidad y luz, que se transforma durante la Conquista (1519), sufriendo una importante segregación en todos los ámbitos. Son los movimientos independentistas (1821) y revolucionarios (1910), los que le dan un lugar y protagonismo a la "infancia" debido a su incorporación como "guerrilleros" y para el caso de las mujeres como sustitutas del sostenimiento familiar.

Las ideas nacionalistas instauradas en el Cardenismo (1934-1940) son definitorias para la niñez mexicana, pues es en esta época que se institucionaliza como una responsabilidad estatal la atención de la "niñez en riesgo" (ver nota 11), inscribiendo políticas sociales específicas de atención a los desposeídos y vulnerables.

A nivel internacional, hay un reconocimiento generalizado de que el siglo XX resulta ser donde se plantea con mayor consistencia el cambio de paradigma hacia la "infancia". La preocupación por proporcionarle a los niños y las niñas mejores condiciones para su adecuado desarrollo en cuanto a educación, salud, alimentación y protección jurídica han

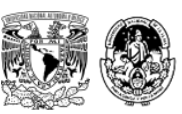


sido asuntos que permanentemente se colocan en las agendas internacionales desde el inicio del siglo y que se han materializado en convenios y tratados internacionales, y legislaciones nacionales.

Pese al intento de materializar un marco jurídico de protección a nivel internacional que apunte hacia la construcción de un concepto de niñez más amplio y garante de sus DH y de su reconocimiento como actor político, social y económico, no se puede soslayar que la hegemonía del modelo económico capitalista en su fase neoliberal y globalizada representa una serie de contradicciones que, para efectos prácticos, colocan a la niñez en un papel protagónico desde su rol en la economía global ya sea como fuerza de trabajo, como consumidor o consumible.

Es gracias a algunos saberes disciplinares emanados de la sociología y la antropología contemporánea que se posibilitan otros caminos epistémicos de reconocimiento de la niñez como experiencia humana dinámica y contextual de los primeros años de vida, resultante de un proceso histórico situado que supone un ejercicio humanizante y se construye subjetiva e intersubjetivamente en relación con los otros, en el entendido de una interseccionalidad en dónde lo individual y colectivo convergen, lo íntimo y lo público se encuentran.

De esta forma, se agrieta la episteme "infancia" y su consecuente percepción funcionalista que alude al silencio, "a la persona que no habla", al que se encuentra "a la espera de la vida adulta", para dejar entrar un conocimiento "otro", el que humaniza y entiende a la niñez en un papel dinámico, activo y de protagonismo social, a partir del cual se produce humanidad. 


\section{LAS EPISTEMES DE LA INTERVENCIÓN DESDE EL TRABAJO SOCIAL FRENTE A UNA NIÑEZ SITUADA}

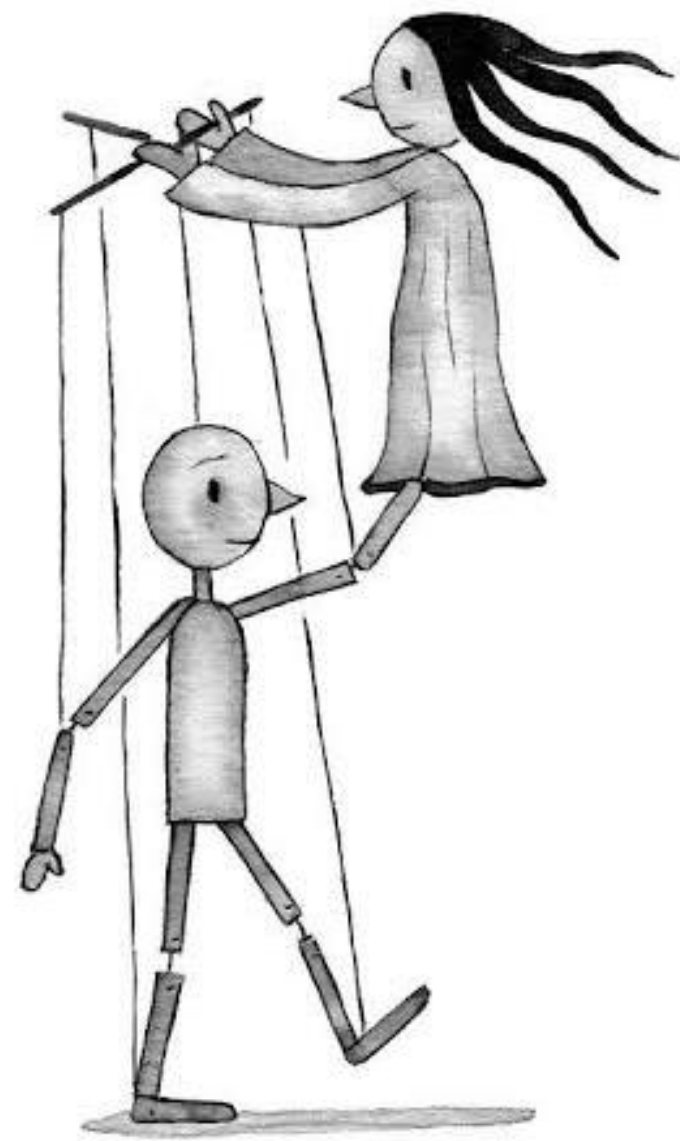

TROCHE

Troche, G. (2016). [Ilustración]. Recuperada de: https://culturainquieta.com/es/inspiring/item/8859-laspoeticas-e-inspiradoras-ilustraciones-de-troche.html 
La empatía como la capacidad de comprensión, que garantiza el suministro adecuado (calor, alimento, arrullo, palabra). Y el miramiento, como el mirar con amoroso interés a quien se reconoce como sujeto ajeno y distinto a uno mismo.

(Ulloa, 1995)

Gabriela

(2020)

Mi historia viene de un árbol dolorido. La violencia y el maltrato experimentado en mi niñez influyeron la manera en cómo me coloco hoy en el mundo. Cuando niña mi futuro lo percibía muy claro: repetir el maltrato como consecuencia de la experiencia pueril. Provengo de una familia precarizada social, cultural y económicamente, con una madre cuyas condiciones de negligencia y maltrato en su niñez se instauraron en mente y cuerpo y contribuyeron -de alguna forma y en algunos pasajes de su marentalidad para ser poco receptiva y distante en el terreno emocional.

En mis primeros años de vida y frente a los discursos que me envolvían, no encontraba posibilidades para escapar de esas geografías de dolor, la probabilidad de transformación la anulaba casi de facto, como si el camino trazado no dejara muchos campos para revelarse. Discursos aprendidos en mi formación profesional y retomados de algunas corrientes de la psicología: "las profecías autocumplidoras" (Vargas, 2015¹), las "violencias transgeneracionales" (Del Valle, 2014 ${ }^{32}$ ), "el proyecto sentido" e incluso "las lealtades familiares" (Bonomi, 2014 ${ }^{33}$ ), construían una cartografía teórica que se instauraba en mi

31 "La profecía tiene estructura de destino: se da una predicción sobre algo que está por venir y de lo que es inevitable sustraerse. Lo que el psicoanálisis nos enseña es que no es necesario que dicha predicción sea proferida por una suerte de profeta o adivino -ni por una madre-, sino que es el lugar del Otro el que tiene ese lugar oracular inicial para el sujeto" (Vargas, 2015: 73).

32 "La consideración de las huellas mnémicas referidas a lo vivido por generaciones anteriores le añade amplitud e importancia a la herencia arcaica y se amplía la dimensión ontogenética a la filogenética. Podemos considerar la transmisión generacional el modo natural en que los saberes, los bagajes emocionales y los legados se traspasan a los herederos" (Del Valle: 2014: 7).

33 "Un evento específico de la historia de la persona, el cual se repite de una manera cíclica e inconscientemente, por ejemplo, una muerte, un nacimiento, un accidente, entre muchos otros más casos. Allí el inconsciente se encarga de marcar los acontecimientos o nexos significativos y trascendentales para que se repitan en una o más generaciones" (Bonomi, 2014:15).

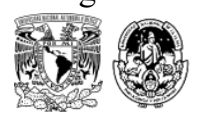


mente, y tras las cuales, aspiraba comprender mi propia realidad. Elementos que no se restringieron a un campo personal y se cristalizaban -sin que yo cobrara conciencia de elloen las formas de intervenir desde mi rol como trabajadora social.

Aproximarme a algunos de los cánones establecidos por las neurociencias que enlistan la serie de consecuencias neurobiológicas del maltrato y su trascendencia en la vida adulta me distanciaban de comprender la manera en cómo las condicionantes sociales, económicas y simbólicas, influyen para su aparición y persistencia. Asumía que las experiencias personales, la identidad y la historización propia, moldean un "catálogo cerebral” y dan sustento a la conducta que va más allá de la conciencia, invisibilizando los elementos familiares y sociales que coadyuvaron para que, ese dogma, cobrará otros matices y que hoy, me lleva a profundizar en los componentes de la intervención social situados en las relaciones y los contextos sobre la comprensión de los fenómenos que les incitan.

Si bien es cierto que las diversas experiencias con quienes nos rodean en los primeros años de vida dan forma a las concepciones y representaciones que tenemos del mundo, son las relaciones con los otros y las otras y los factores contextuales y sociales, los elementos más importantes en la configuración de la realidad social.

Mi trayectoria profesional se ha centrado en gran medida en intentar comprender la manera en cómo la violencia y el maltrato influye en lo individual, familiar y colectivo, a partir del acompañamiento de seres humanos cuyas historias de vida se cuentan desde territorios de abuso y maltrato extraordinarios. Identificar aquello que me motivaba a sumergirme en la intervención con una particular niñez: "la receptora de maltrato" me ha llevado años de trabajo intelectual y emocional que, de primer momento, recupera un pensamiento biologicista y después trasciende al terreno de lo social.

Mis primeras experiencias profesionales como trabajadora social se sitúan en la atención de familias cuya violencia doméstica determinaba las relaciones internas y los llevaba al ámbito legal.

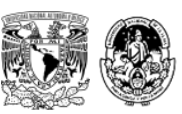


Por el año 1997 y laborando en el Centro de Terapia de Apoyo a Víctimas de Delitos Sexuales $^{34}$ (CTA), pude atestiguar el maltrato hacia decenas de niñas que constantemente se escondían tras discursos incoherentes de la experiencia familiar, testimonios que, por un lado, denunciaban el abuso sexual vívido y por el otro, justificaban con discursos como "yo lo provoqué", "no es tan importante" "mi papá nada más estaba jugando conmigo"; agravios cometidos por padrastros, primos, abuelos, tíos, esos cercanos que perpetraban el abuso sexual y en donde el resto de las figuras adultas no lograban consolidarse como agentes disponibles y protectores. Es así que ellas, sin mucha opción, protegían el universo familiar ofreciendo sus propios cuerpos sexuados a temprana edad en aras de conservar lo casi único y más valioso que tenían: la estabilidad familiar.

\section{Prefacio}

El maltrato infantil que se ejerce dentro de la familia tiene diversas expresiones que se cristalizan en: maltrato físico, psicológico, sexual y/o emocional. Son producto de ambientes hostiles que permean y establecen relaciones asimétricas de abuso al interior, repercutiendo especialmente en las niñas y los niños. Es así como muchos menores de edad que lo experimentan son desprendidos, por indicación del Estado, de sus sistemas de cuidado primario para ser atendidos en espacios de cuidado alternativo: los CAS, lugares construidos desde la política pública en donde se busca la restitución de los derechos de la niñez receptora de maltrato.

A lo largo del presente capítulo, centraremos el foco en la intervención desde el Trabajo Social con esta singular niñez, para ello recupera su historicidad a través de algunas etapas de relevancia en interconexión con las propuestas concretas de atención a la niñez en condición de institucionalización en nuestro país, expone el tránsito de las y los menores de

\footnotetext{
${ }^{34}$ El Centro de Terapia de Apoyo a víctimas de delitos sexuales depende de la Fiscalía General de Justicia de la Ciudad de México (antes procuraduría General de Justicia), tienen como objetivo la atención y asistencia multidisciplinaria (médica, jurídica, psicológica y de Trabajo Social) a las víctimas directas e indirectas de los delitos contra la libertad y la seguridad sexual; y el normal desarrollo psicosexual sobre sus derechos como víctimas del delito, con la finalidad de empoderarlas con respecto a las esferas que se vieron afectadas por la comisión del hecho violento.
}

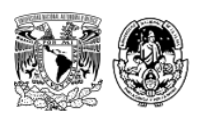


edad como "sujetos de protección" y su tensión paradigmática ante el reconocimiento de "sujetos de derecho".

Se divide en cuatro apartados, inicia con la época Cardenista (1934-1940) que constituye un momento parteaguas para la nación y para la disciplina del $\mathrm{TS}$, pues representa el deslizamiento del acto de la "caridad" y la "beneficencia", a la acción gubernamental a través de la profesión (cuyo nivel formativo para aquel entonces era de nivel técnico (ver nota 24). Aquí la aparición del Estado benefactor determina el auxilio a la niñez como una obligación, transitando de una acción filantrópica (predominante hasta entonces) a la de una obligación estatal, que derivó en una hegemonía que avaló la intervención del Estado en las familias y en donde las y los trabajadores sociales, jugaron un papel protagónico.

Posteriormente se revisa la década del sesenta y la influencia del movimiento de Reconceptualización en América Latina, que colocó al TS en un importante ejercicio de reflexión y emancipación profesional.

Se continúa con la discusión respecto de la intervención, pero ahora en un contexto neoliberal, en donde la niñez experimenta una tensión en tanto es reconocida por los marcos jurídicos de protección nacional e internacional como "sujeto de derecho", al tiempo que se vive en un escenario de violencia estructural y familiar en donde la pobreza y la desigualdad son fenómenos multidimensionales de alto impacto que inhiben el cabal cumplimiento de derechos; se advierte una dicotomía construida por el modelo económico: "el niño consumidor-el niño consumible".

Finalmente, y tras los desafíos que esta niñez representa para la profesión, se hace una revisión latinoamericana respecto de las propuestas de intervención en el TS contemporáneo, destacando aquellas que se consideraron relevantes en función del tema que ocupa este documento. 


\subsection{Las epistemes de la intervención: de la filantropía vigilante a la operación institucionalizada}

Los DH y las garantías de igualdad social en México se construyen en el período posrevolucionario en la época Cardenista, momento histórico de consolidación de las instituciones y la asistencia social.

[...] el esfuerzo más profundo e integrador de todo este periodo de gobiernos, emanados de la revolución, tiene lugar durante el régimen de Lázaro Cárdenas del Río (1934-1940). Para entonces, la beneficencia pública, desde la óptica de la justicia y la igualdad social, se convierte en Asistencia Social. Es decir, el auxilio de los pobres no sólo era una buena acción sino una obligación estatal, se trataba de una responsabilidad social (Huerta, 2006:7).

El Estado comenzaba a intervenir en "regular la economía y llevar a cabo un proceso de institucionalización y nacionalización, reflejo del desarrollo económico que experimentaba nuestra nación y que, al mismo tiempo, reclamaba el control público de servicios esenciales" (Arteaga, Campos, Piña, 2007:287).

La transformación hacia el Estado benefactor obliga un tránsito de la beneficencia al ejercicio de los derechos e impacta directamente en la intervención social practicada hasta el momento por las y los trabajadores sociales, quienes encontraban en la filantropía un sentido, una identidad e incluso para muchos, una génesis disciplinar. En ese sentido, "las normas de carácter religioso fueron un componente importante en la configuración de la intervención profesional" (Rozas, 2000: 15). Para Carballeda (2002: 21) "la filantropía construye un otro sobre el cuál intervenir; lentamente lo clasifica y logra incluirlo en una determinada estructura de la sociedad, para él, la intervención en lo social se presenta como una vía de ingreso a la modernidad dirigida a aquellos que cada época construye como portadores de problemas que pueden disolver al todo social".

"La nueva realidad nacional, enmarcada en las luchas obreras de la segunda mitad del siglo XIX que actúan en esta génesis de la profesión con una fuerte perspectiva anti romántica

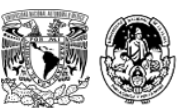


defensora de valores y principios" (Siqueira, 2016: 6) -ahí se acomodan valores humanitarios-, marcan un parteaguas disciplinar que empieza a distanciarse de las acciones caritativas para intentar configurarse como intervenciones intencionadas basadas en la construcción de la política pública y en la aspiración de desencadenar conocimiento científico. En México, es a partir de este momento que las acciones de perfil religioso y filosófico "se adensan y se mezclan con las acciones mantenidas por los Estados nacionales orgánicamente capturados por la dinámica monopólica del capital y comprometidos con la gestión responsable del pauperismo" (Siqueira, 2016: 5).

E1 Trabajo Social en México tiene un desarrollo histórico complejo, variado y contradictorio. $\mathrm{Su}$ accionar debe ser analizado y contextualizado a partir de las acciones del Estado ya que no se trata de un quehacer autónomo o independiente, sino de una profesión ligada íntimamente al accionar del aparato estatal y es necesario tomar en cuenta las connotaciones políticas que ello implica (Evangelista, 98:79).

En la época Cardenista (1934-1940), se da una suerte de administración de la pobreza y la desigualdad a partir de la asistencia; paralelamente el TS pretende tomar distancia de las prácticas tradicionales asociadas a la caridad y la filantropía, enfocándose hacia una práctica social en aproximación al reconocimiento de los DH.

Sin embargo, con relación a las niñas y los niños desvalidos, los DH llegaron muchos años después. En esta época el Estado ofreció un modelo de institucionalización que "buscaba disciplinarlos, los gobiernos posrevolucionarios articularon una estructura institucional por medio de la cual podían ejercer métodos coercitivos para someter con el fin de "regenerar" a la población que, de acuerdo con los criterios de la época, se consideraba una carga económica o potencialmente peligrosa, por la asociación que se daba entre pobreza y delincuencia” (Alanis, 2014:71).

El tratamiento de los llamados "niños en riesgo" (ver apartado 3.1.2.4) se soportaba fundamentalmente en el internamiento de niñas y niños en casas hogar u orfanatos, espacios administrados por el Estado, que los albergaba indistintamente, lo mismo valía el niño

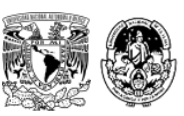


vagabundo, que el huérfano, que el discapacitado, todos compartían un factor común: la anomia $^{35}$, estaban fuera de la normalidad e imposibilitados de integrarse en la sociedad, representaban un riesgo presente y futuro, por lo que había que limitar todo acceso a una vida en sociedad.

Las instituciones asistenciales trataron de manejar posturas incluyentes, aunque no universalistas, en sus acciones. Es decir, posturas que dieran cabida al recogimiento de varios niños sin importar sus condiciones, lo que generó que la mayoría de ellas terminaran por constituirse en espacios masivos, en cuyo interior albergaban a diferentes grupos de niños: desde callejeros hasta indígenas, pasando por huérfanos, explotados y abandonados. Lo anotado aquí, a su vez, provocó que terminaran por recibir una atención igualmente indiferenciada y hasta autoritaria como lo mencionan algunos autores (Griesbach y Sauri, 1997).

Para controlar, administrar y regular la asistencia a esta población, el Estado se valió de técnicos profesionales operarios de los programas: las y los trabajadores sociales.

Un trabajador social acudía directamente a sus domicilios para concientizar a los padres, según los discursos oficiales, de los peligros que implicaban las calles para sus hijos, así como para convencerlos de regularizar su situación familiar, si así lo necesitaban (como formalizar los matrimonios) e inculcarles algunos cursos de valores e higiene. Todo bajo una racionalidad ciertamente funcionalista e higienista que en ese momento planteaba que la desintegración podía solucionarse acudiendo a especialistas que llevaran el orden en donde no lo había, tanto que en las pláticas que manejaba el trabajador social, normalmente utilizaba criterios de normalidad familiar (Osorio, Arteaga, 2012:220).

Esta práctica de las y los trabajadores sociales, encomendados en desprender a las niñas y los niños de sus sistemas familiares en respuesta a las condiciones de pobreza, ha sufrido severas e inflexibles críticas a la profesión que la instalan al servicio de los intereses del Estado, y

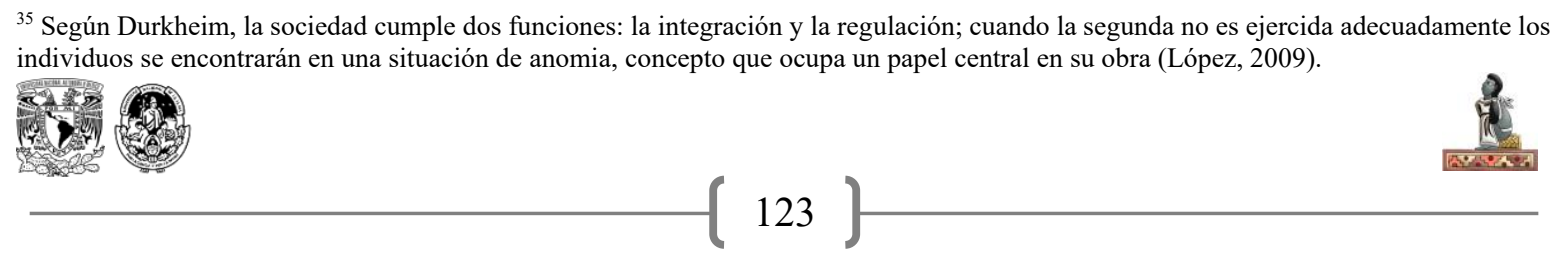


resulta fortalecida a partir de la legitimación otorgada por éste: la intervención en lo social será planteada entonces como un instrumento.

"La intervención avanzaría sobre la vida cotidiana, imponiendo un orden, además de construir y ratificar ese otro en el lugar de la exclusión" (Carballeda, 2002:29). Ese lugar, que aparece bajo el manto de un discurso de protección con reglas, infraestructura y condiciones, en donde el individuo y sus necesidades se homogenizan para ser intervenidos como sujetos anómicos y pasivos sobre los que se debe actuar y decidir.

"En el transcurso del siglo XX se puede observar, además, que las instituciones de encierro para los niños y niñas bajo las diferentes denominaciones que fueron adoptando, no se escapan de los modelos penitenciarios en cuanto a su operatividad concreta" (Schmukler, Campos 2009: 156). Si bien, discursivamente la niña y el niño se vuelven entes de cuidado y protección, el modelo de intervención diseñado para ellos es muy cercano a un modelo carcelario de encierro y disciplina.

Las instituciones ejercen un control directo y visible sobre aquellos calificados criminales o locos a través del encierro y de tratamientos de rehabilitación, pero también delimitan los alcances de las nociones de delito (y su contracara, la legalidad), y de locura (y por tanto de normalidad). Este segundo efecto es expansivo a toda la sociedad, define que es (a) normal y cuáles son los desvíos y desviados que merecen la represión e instituyen prácticas disciplinarias que atraviesan toda la sociedad. Las instituciones dirigidas a la infancia desde fines del siglo XIX pueden interpretarse con esta perspectiva de análisis (Schmukler y Campos, 2009: 147).

Es así como el origen del TS asociado predominantemente a las acciones de caridad, beneficencia y filantropía comienza -a partir del emerger del Estado benefactor y en adelantea expresar cierto distanciamiento de dichas prácticas, justificar su hacer en intervenciones de conocimiento científico y a desencadenar una labor funcionalista-enajenante. Al respecto es necesario destacar que esta enajenación disciplinar puesta al servicio de los intereses del Estado y al capital (binomio que en el modelo neoliberal se consolida), es resultado de un proceso histórico y no ha sido privativo del TS. Gramsci (1963) a finales del siglo XIX ya
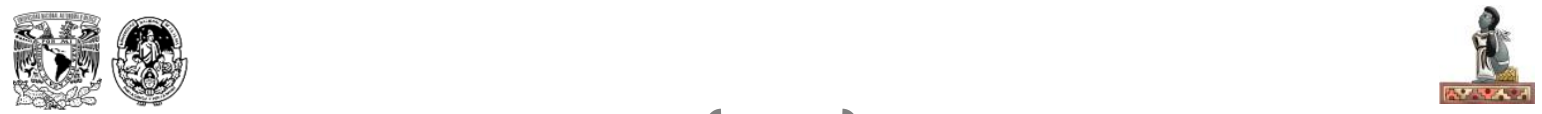
analiza el papel de lo que llamó «el intelectual orgánico», aquel que emerge sobre el terreno a exigencias de una función necesaria en el campo de la producción económica ligado orgánicamente al desarrollo de la organización política.

En este antecedente se funda una episteme de la intervención, que no trasciende en nuestros días y se encuentra fortalecida en el contexto económico actual, que otorga agencia disciplinar y ejerce el poder del Estado a través de profesionistas que operan acciones concretas tendientes a mermar el tejido social y fracturar la estructura familiar, sobre el discurso de la "protección".

Los intelectuales orgánicos desarrollados en Gramsci (1963) se ven robustecidos en el modelo capitalista en su fase neoliberal, motivando que gran parte de las intervenciones se encaminen a dar respuesta a las exigencias del mercado, en donde para efectos del Trabajo Social, se espera un profesional capaz de administrar la pobreza y paliar sus efectos, constriñendo el ejercicio profesional a acciones concretas sin una transformación consistente -que amenace las estructuras del Estado- y en donde la desigualdad y acumulación de desventajas no desparece, sólo se gestiona (discusión que será abordada más adelante).

\subsubsection{La Reconceptualización: entre la encomienda funcionalista y el principio emancipador}

Siguiendo la trayectoria de historicidad, es en 1961, en la administración del presidente Adolfo López Mateos, que en México se decreta la creación del Instituto Nacional de Protección a la Infancia (INPI). Este nuevo organismo descentralizado con personalidad jurídica y patrimonio propio tendría como principal propósito el proteger a la niñez así como suministrar a los escolares servicios asistenciales complementarios (actualmente es el SNDIF).

La atención en albergues de cuidado prevaleció como una política asistencial.

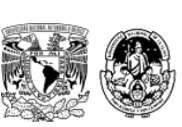


Lo cual forma parte de una racionalidad ciertamente paternalista de la época, en donde el Estado con características omnímodas atendía, como reprendía, a diferentes grupos sociales, aun cuando ello fuera de forma limitada, indiferenciada y hasta autoritaria, utilizaba una idea tutelar propia de las instituciones cerradas de la época, como los tutelares y los psiquiátricos, en tanto que a los niños se les concebía propiamente como objetos de protección, lo que permitía que los trabajadores sociales de las instituciones, así como otras autoridades civiles, pudieran abordarlos y trasladarlos a los establecimientos asistenciales o de otro tipo, si así lo creían conveniente. Todo bajo el discurso legitimador del bienestar de estos (Osorio, Arteaga, 2012:220-221).

En lo referente al TS, “en el transcurso de este periodo es notoria la transformación del quehacer político que se encamina hacia los marcos de una labor auxiliar aséptica e instrumentalista" (Evangelista, 98:95), a la vez que en el ámbito académico, se hace evidente un tránsito que intenta dejar atrás las pautas paternalistas que usaban al profesional para adaptar al inadaptado, conservando así la homeostasis del sistema. "La década del sesenta trajo al trabajo social otros discursos y nuevas construcciones de la intervención en lo social. Diferentes visiones y explicaciones de lo social implicaron la posibilidad de tener una serie de vías de entrada al tema de las desigualdades, la dependencia o la expresión de los problemas sociales y sus posibilidades de intervención" (Carballeda, 2006:88).

Y aunque a México los principios del Movimiento de Reconceptualización ${ }^{36}$ lo permean tardíamente (1969) con respecto al resto de América Latina, se inscriben consecuentemente en una política pública que pone la mirada en la atención de algunos grupos en desventaja social, en dónde la infancia se visibiliza y se configura como una población potencialmente asistencial.

En 1968, la profesión eleva su nivel de formación técnica a licenciatura reflejándose en el Plan de Estudios que ofrecía la UNAM. Se trataba de una formación multidisciplinaria que incluía conocimientos psicológicos, sociales, jurídicos, teoría y metodología propia del

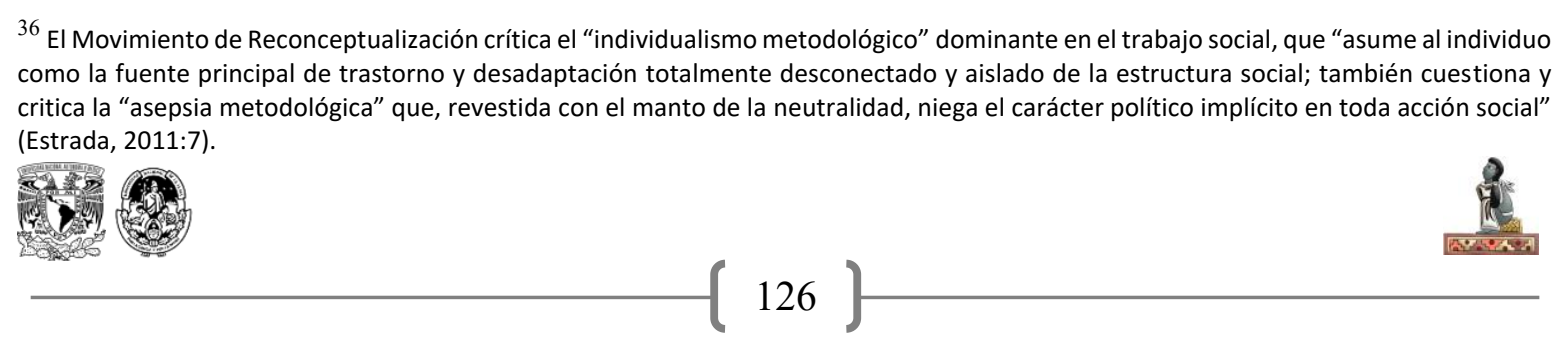


Trabajo Social; esto se interpretaba como la búsqueda por consolidar y desarrollar una intervención de carácter científico.

Es aquí donde la y el trabajador social, influenciados por las ideas críticas de las y los colegas latinoamericanos y la efervescencia de la época en el país, recupera los principios de la doctrina Marxista; se cuestiona su hacer y se ve claramente acorralado entre los valores y principios emancipadores que una praxis exige y las expectativas estatales. A manera de hipótesis, es probable que en realidad este fortalecimiento disciplinar obedeciera a la necesidad por transformar los servicios asistenciales recurriendo a formas de intervención menos coercitivas y al mismo tiempo más efectivas, algo que sólo un profesionista integral lograría hacer consistentemente. De ahí que se pueda interpretar la agencia disciplinar como un elemento más de la tecnología del poder.

Los dispositivos disciplinarios han secretado una "penalidad de la norma", que es irreductible en sus principios y su funcionamiento a la penalidad tradicional de la ley. El pequeño tribunal que parece actuar permanentemente en los edificios de la disciplina, y que a veces adopta la forma teatral del gran aparato judicial, no debe engañar: no prolonga, excepto por algunas continuidades formales, los mecanismos de la justicia criminal hasta la trama de la existencia cotidiana, o al menos no es lo esencial; las disciplinas han fabricado — apoyándose en toda una serie de procedimientos, por lo demás muy antiguos - un nuevo funcionamiento punitivo y es éste el que poco a poco ha revestido el gran aparato exterior que parecía reproducir modesta o irónicamente (Foucault, 1976:214).

Otro factor que pudo haber influido para que la tendencia revolucionaria y emancipadora que apremiaba en las y los trabajadores sociales de la época, no lograra consolidarse en los servicios asistenciales (además de los determinantes socio-políticos que buscaban a toda costa callar las nuevas orientaciones de las ciencias sociales), es que en el gremio "la reconfiguración profesional se enfocó fuertemente en la praxis desde escenarios comunitarios, convencidos de que la organización social y por ende el cambio de las estructuras sociales, económicas y políticas, tenían que darse desde los contextos populares y comunales. Estas ideas se fortalecían con los principios del movimiento indigenista, que en 
ese momento se caracterizó por un reforzamiento y ampliación de la acción a partir de la organización de la estructura corporativa de las y los indígenas" (Sánchez 99:94).

E1 Trabajo Social localizado en este período de reconceptualización y su contexto situacional, responde a situaciones tales como el período de expansión del capitalismo, sistema segregador y excluyente que provocaba y provoca sentimientos de injusticia y desigualdad en la población [...] la figura del sujeto ${ }^{37}$ surge como garante de intervención en tanto que es él quien puede contribuir a esta nueva sociedad. Para ello se implementan nuevas formas de trabajo basados en modelos socioeducativos promocionales con la aspiración de ampliar las bases de participación social desde las organizaciones populares mediante el intento de fortalecer la identidad profesional (Castellanos 2013:31-32).

Es así como la disputa entre la construcción identitaria de la profesión y los intereses del Estado, develan una inquietud que se debate hasta nuestros días, que lidia entre una encomienda profesional funcionalista y un principio emancipador. Estos elementos ocuparon la reflexión de Foucault, Donzelot y otros estudiosos y se plantearon en la mesa de la discusión: “¿Qué es el Trabajo Social?” (2001) -como se describió en el primer capítulo de esta investigación-.

Para las décadas del setenta y ochenta, en lo competente a la atención de la niñez, confluyen importantes factores que empujan hacia una nueva forma de atenderla: "la crisis económica que empezaba a azotar en el país, la ampliación de las instituciones de asistencia privada y la definición de algunos efectos nocivos derivados del internamiento" (Osorio, Arteaga, 2012: 221), llevaron a replantear la intervención social y a requerir ahora una participación más activa de las y los trabajadores sociales, quienes se veían ante la encomienda de salir a las calles y generar procesos de sensibilización enfocados hacia una transformación autogestiva, dirigida a potenciar las habilidades productivas del niño/a y su familia. Esta exigencia, resultaba coherente con respecto a las aptitudes y habilidades promoventes en la formación disciplinar y aparentemente congruentes con una práctica emancipadora del ser humano.

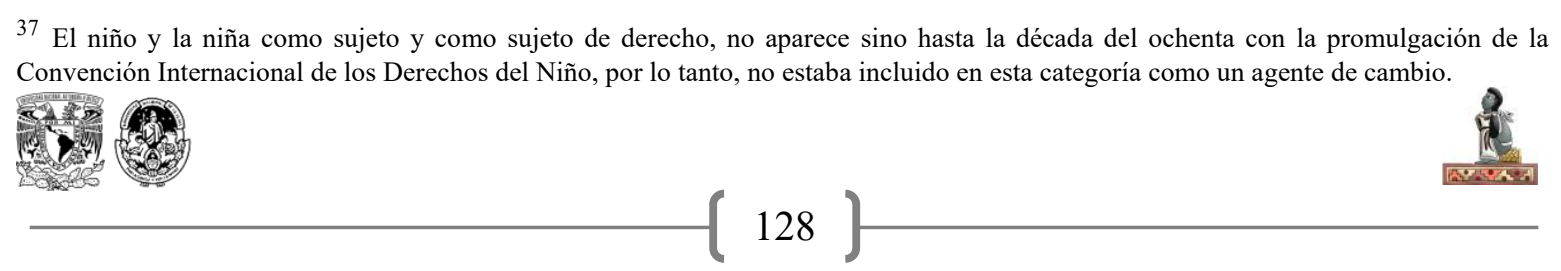


Desafortunadamente estas posibilidades disciplinares se enfrentan, al mismo tiempo, al fortalecimiento del modelo capitalista en su fase neoliberal (ver apartado 3.3.2 y 3.3.3), que requiere operarios al servicio del mercado, en donde las niñas y los niños, se cosifican y mercadean. El TS inserto en la gubernamentalidad o en la sociedad civil, encuentra tensiones que confrontan un pensamiento crítico, emanado del movimiento de Reconceptualización y los planteamientos desde el escenario académico con una encomienda institucional, que define procesos de gestión de las pobrezas, exigiéndole acciones concretas de incipiente transformación social.

De igual forma, no hay que olvidar que en realidad el grado de licenciatura de la profesión era de reciente creación y el campo de actuación estaba engrosado por técnicos en TS (situación que no dista sustancialmente de lo que hoy se experimenta y que habremos de encontrar en el apartado de resultados, más adelante), cuya formación académica, no abarcaba los contenidos de la licenciatura y su participación predominantemente operaria y procedimental resultaba moldeable, haciendo -por parte del Estado- de la intervención una herramienta de control.

Esta intervención estaba definitivamente determinada por el adelgazamiento y el inicio de la pérdida del Estado benefactor, que se resistía en continuar con políticas sociales asistencialistas y comienza a aparecer en escena el discurso de la "familia" como el mejor escenario de desarrollo infantil.

Entre los menores abandonados y, de manera más particular, entre los que permanecían en calidad de resguardo, en los albergues temporales, fue muy común que se les exhibiera el discurso de "lo familiar", para tratar de regresarlos a sus familias y evitar la internación o permanencia prolongada en las instituciones públicas... éstas empezaron a limitar sus acciones y a delegar parte de sus responsabilidades a las comunidades (Osorio, Arteaga, 2012: 225). 


\subsubsection{El reconocimiento de la niñez como sujeto de intervención social en el capitalismo neoliberal}

"La política de no internamiento correspondiente con el naciente discurso de los derechos de niñas, niños y adolescentes y la mutación en las representaciones sociales en torno a este grupo poblacional, se dan asociadas a cambios en las prácticas sociales y en las instituciones dirigidas a su atención" (Schmukler, Campos 2009:147). La figura de la institución se ve como "una red simbólica socialmente sancionada, en la que se combinan en proporción y relación variables, un componente funcional y un componente imaginario [...] la sociedad vive sus relaciones con sus instituciones a la manera de lo imaginario, dicho de otra forma, no reconoce en el imaginario de las instituciones su propio producto" (Castoriadis, 1983:3).

La institucionalización vinculada con la noción de niñez como construcción social, se pone en el centro del debate entre las naciones dando como resultado, la Convención Internacional de los Derechos del niño, a fines del siglo XX. Este documento es quizá el hito más importante en relación con la niñez y sienta, en definitiva, un antes y un después respecto de la manera en cómo se construye la percepción de esta en el mundo entero, pues se reconoce discursivamente al niño como sujeto de derecho, atribuyéndole así un carácter protagónico y activo frente al entonces secundario y pasivo rol.

Las prácticas asistencialistas no desaparecieron y de alguna manera vigorizan la atención a la niñez receptora de maltrato que deriva en la institucionalización como medio de protección, hecho que determinó en gran medida la aparición de nuevas instituciones de asistencia privada y el espacio que había recuperado el Estado, respecto a este grupo poblacional y poco a poco lo vuelve a retomar la Iglesia.

Ahora bien, si en la década anterior las instituciones públicas trataron de alentar una especie de secuencia de los dispositivos asistenciales implementados desde la década de los ochenta, en la que acababa de terminar no fue la excepción, solo que ahora los trataron de complementar con otros elementos propios de la actualidad como: la profesionalización, la 
corresponsabilidad y la sistematización tecnológica, que devienen de las ideas de eficiencia y efectividad (Osorio y Arteaga, 2012: 228).

En los albores del año 2000 la intervención social se enfrenta a estos retos y a los que la misma realidad social, cambiante y dinámica, le ofrecen. Aparecen en la escena reflexiones disciplinares que cuestionan la intervención hasta entonces próxima al funcionalismo. Para Carballeda (2002: 32):

En el contexto actual, la intervención en lo social se nos presenta como un espacio de libertad, ya que se construye en pequeños hiatos, intersticios, lugares, donde es posible reconstruir historicidad, entender a ese otro, no como sujeto a moldear, sino como un portador de historia social, de cultura, de relaciones interpersonales. La intervención probablemente implicó fragmentación, aunque se presentara como dispositivo de integración. Es por eso por lo que intervenir en lo social puede significar o no, unir aquello que una vez se fracturó, recuperar las sociabilidades pérdidas, que sumadas conducen a la reconstrucción de la sociedad.

\subsubsection{La niñez en condición de institucionalización y la intervención desde el Trabajo Social: tensiones e imprecisiones}

En convergencia con estos planteamientos académicos y de cara a la realidad social, los desafíos disciplinares exigen una trascendencia y reflexión profunda respecto del ejercicio profesional, colocados en una honda discusión de los planteamientos, no sólo de carácter metodológico, sino epistemológico y por ende ontológico, que revelen un posicionamiento crítico y político situado, es decir, en diálogo con las expresiones de la compleja expresión de lo social.

En seguimiento a la reflexión de la niñez y su intersección con la intervención desde el TS frente a la realidad concreta, habremos de reconocer que, hoy día, en México se experimentan una serie de contradicciones en lo relativo a la atención de las personas niñas, siendo evidente el fracaso para dotar de condiciones adecuadas para su desarrollo, al situarles en condiciones de pobreza y violencias tanto estructurales como de maltrato al interior del ámbito doméstico.

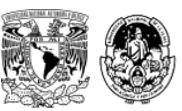


Sólo por mencionar algunas de las condiciones sociales que les envuelven y de acuerdo con datos ofrecidos por UNICEF (2019), se sabe que: en México hay 40 millones de NNA, de estos, más de la mitad viven en condiciones de pobreza y 4.7 millones en pobreza extrema; 2.5 millones trabajan; dos de cada diez desapariciones en el país son de menores de edad y se cuenta con un registro de 30,000 vinculados al crimen organizado.

En lo concerniente a la niñez albergada en CAS, no se cuenta con una cifra exacta de cuántos son, cuáles son los motivos de ingreso y/o las condiciones familiares que les atraviesan, es decir, de la caracterización de este grupo poblacional y, por ende, de las exigencias profesionales que implica la restitución de sus derechos.

Hay una relación directa entre el modelo económico capitalista en su fase neoliberal y la situación de la infancia, su voraz instauración promueve condiciones de pobreza y desigualdad como resultado de la inequidad y la acumulación del capital en reducidas manos, que impacta a la sociedad en general, inhibiendo el adecuado desarrollo económico, social y cultural a nivel comunitario y familiar. Sólo por ejemplificar, en un reciente estudio interregional realizado por el Banco Mundial (2010) y documentado por UNICEF sobre las variables correlacionadas con violencia, se demuestra claramente la relación entre la pronunciada desigualdad de ingresos y el comportamiento violento fuera y dentro de los sistemas de familia, aumentando la frustración de los individuos, lo que puede constituir fuertes antecedentes del comportamiento violento. Con fundamento en lo documentado por diferentes fuentes académicas y gubernamentales, se sabe que la violencia puede provocar secuelas importantes entre las que se encuentran: dificultades en el aprendizaje, abuso de sustancias adictivas, precocidad en la iniciación sexual, depresión, suicidio y comportamiento violento.

Con la finalidad de construir marcos jurídicos de protección a la niñez en México, el pasado 4 de diciembre de 2014 se expide mediante decreto publicado en el Diario oficial de la Nación, la Ley General de los Derechos de Niñas, Niños y Adolescentes, que toma al interés superior de la niñez como criterio orientador para toda acción del Estado.

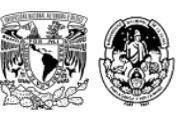


Como parte de las acciones para atender los preceptos enmarcados en dicha Ley, en abril de 2016, en la Ciudad de México se llevó a cabo el Encuentro Nacional de Centros de Asistencia Social, el cual no fue presidido ni organizado por el Sistema Nacional para el Desarrollo Integral de la Familia (SNDIF) -a pesar de ser la institución rectora en esta materia-, sino por el Instituto de Desarrollo Social (INDESOL) ${ }^{38}$. El Encuentro tuvo como objetivo, generar un espacio de diálogo que propiciara la sensibilización, la revisión, retroalimentación y acercamiento entre los actores esenciales que deben participar de manera coordinada para la regulación en el funcionamiento de los Centros de Asistencia Social (CAS) públicos y privados, y que esto refleje en resultados efectivos en la protección integral de los derechos de niñas, niños y adolescentes (NNA). La Titular en turno del SNDIF señaló que, con la legislación sobre niñas, niños y adolescentes, se amplían las atribuciones de esta institución, así como sus compromisos con este sector de la sociedad; destacó la labor de las instituciones privadas y dijo que solo, el Estado "no podría atender a miles de menores que hoy están desprotegidos y sin ninguna red familiar”.

En dicho encuentro se habló de un aproximado de 30,000 niñas y niños en condición de institucionalización (cifra que no ha variado con respecto a la que se documenta hoy día) que son atendidos por organismos gubernamentales y de la sociedad civil, en dónde los últimos se estiman en 879 y la presencia religiosa permea significativamente, esta última referencia no es menor, dado que en estos espacios de corte religioso se han documentado significativos casos de maltrato y abuso en contra de la niñez: abusos sexuales, adopciones ilegales, explotación laboral e incluso adopciones ilegales.

\footnotetext{
${ }^{38}$ El Instituto de Desarrollo Social, es la instancia gubernamental que tiene como misión fomentar la participación ciudadana y la organización social y comunitaria a través de la capacitación, el intercambio de experiencias y la articulación a nivel regional y temático entre los diversos actores sociales con el apoyo de recursos físicos, materiales, financieros y humanos para generar sinergias que propicien mayores vínculos y lazos sociales a fin de avanzar en proyectos que incidan en el desarrollo social y productivo a través de la interacción entre la sociedad civil organizada y las instancias gubernamentales para consolidar la cohesión social.
}

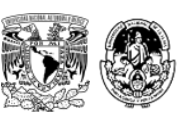


Se plantea que hay un desconocimiento respecto al total de albergues existentes y sus padrones de población y aunque el SNDIF es el responsable de la regulación de los Centros de Asistencia Social, su población y los servicios que estos proporcionan, a la fecha, no cuenta con estándares establecidos tanto de acreditación como de seguimiento de estos.

Recuperar esta experiencia nacional, no sólo da cuenta de la falta de regulación en materia de institucionalización de la niñez, sino de la debilidad rectora del SNDIF a fin de concretar acciones de política pública de cuidado y protección de menores de edad que han sido desprendidos de sus sistemas familiares y se encuentran a cargo del Estado mexicano.

Con base en el Informe especial sobre la situación de los Derechos de Niñas, Niños y Adolescentes en Centros de Asistencia Social y Albergues Públicos y Privados de la República mexicana (CNDH, 2019: 123), y pese a los marcos jurídicos de actuación, la cuantificación de menores de edad albergados en CAS no ha variado significativamente en nuestro país, recrudeciéndose las condiciones de violencia hacia este grupo poblacional.

La sociedad mexicana ha atestiguado en los últimos años, evidentes transgresiones a niñas y niños en condición de institucionalización, objeto de abusos y maltratos en los Centros Asistenciales que les albergan. Casos como Casitas del Sur, asociación civil que en el año 2009 desveló la red de tráfico de menores en donde 11 de ellos fueron sustraídos y cuya presidente era líder de la organización religiosa la Iglesia Cristiana Restaurada (Milenio, 2014); o el Albergue La Gran Familia, presidido por Rosa Verduzco Verduzco, una mujer a quien las autoridades acusaron de secuestrar y maltratar a los niños que alojaba (BBC, 2014) y que ante el operativo policíaco, motivó el pronunciamiento de intelectuales mexicanos quienes en una carta en su defensa destacaron: "La humillación escandalosa de una gran trabajadora social es inmerecida y atenta contra sus derechos más elementales”, mismos que serán abordados con mayor profundidad y detalle en el capítulo siguiente.

El pronunciamiento de que una directora, nombrada trabajadora social, maltrataba a niñas y niños al interior de un CAS no es menor para la profesión, pues acorta en el imaginario la brecha que el trabajo disciplinar ha venido construyendo respecto a su distancia con la

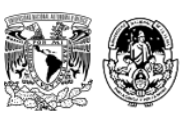


filantropía y el hacer científico de la profesión, lo que obliga a repensar y deconstruir la percepción que se tiene de la intervención en el escenario asistencial.

Aunque hoy día el Estado sigue proporcionando servicios de alojamiento, ha sido evidente la tendencia a la privatización de los servicios que se otorgan -regresemos a párrafos anteriores, en donde las autoridades del SNDIF expresan su incapacidad para atender a las niñas y los niños que requieren la institucionalización-, delegando en gran medida su responsabilidad a organizaciones de la sociedad civil que financian sus proyectos desde la iniciativa privada y/o programas gubernamentales, situación que responde efectivamente al modelo económico neoliberal que deja en manos de los privados la responsabilidad del Estado.

Esta circunstancia lleva a las y los trabajadores sociales a insertarse en escenarios laborales distantes de la escena gubernamental y a desarrollar una práctica teniendo como contexto ese alejamiento del aparato gubernamental como órgano rector. Profesionistas del Trabajo Social que se incorporan a la iniciativa privada cumpliendo con los criterios, procedimientos y manuales definidos por estas instancias y en donde la niñez se administra a través de programas y proyectos que no necesariamente responden al adecuado cuidado, protección y asistencia de sus sistemas familiares, sobre todo si consideramos que muchas de estas organizaciones son de corte religioso promovientes del regreso a prácticas caritativas y filantrópicas, que en apariencia habían sido superadas.

El desmoronamiento del Estado y las problemáticas que aquejan a la infancia en México, desafían el ejercicio profesional de los trabajadores sociales, quienes desde los años setenta acarrean una deuda respecto a la intervención que se debate entre el ser humano y sus derechos y el funcionalismo del Estado. Aquí "la complejidad de las problemáticas actuales da cuenta de la necesidad de profundizar el conocimiento y la discusión acerca de las prácticas que intervienen en este campo. Es decir, sobresale la importancia de reflexionar y analizar críticamente lo que se hace, en tanto la intervención con la finalidad de revisar y observar desde dónde y para qué se interviene en lo social” (Carballeda, 2010:48).

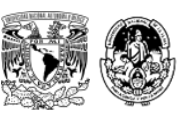


Estudiosos como Foucault, Donzelot y otros han descrito puntualmente el papel punitivo de las instituciones y su configuración como dispositivos de control. Frente a eso, trabajadores sociales como Carballeda (2010:1), abordan a partir de la utilización de la noción de dispositivo "una forma de aproximación a esa complejidad, y desde una perspectiva que permite pensar la intervención en lo social no sólo como la continuidad de una práctica punitiva, sino también como una posibilidad de resistencia o construcción de libertad".

En este sentido la episteme de la intervención desde el TS ofrece otros campos para la comprensión e implicación en campo, confrontando las prácticas enmarcadas en un funcionalismo, brazo operario del Estado, y permitiendo identificar los intersticios que coadyuven en la transformación social.

A continuación, y para cerrar el capítulo, se recuperan algunas propuestas latinoamericanas desarrolladas en la dimensión metodológica con relación a la intervención del Trabajo Social.

\subsection{La intervención desde el Trabajo Social contemporáneo: algunas proposiciones latinoamericanas}

Como se revisó en el capítulo anterior, al igual que las epistemes de la niñez, las epistemes de la intervención desde el TS son resultado de un proceso histórico en donde las transformaciones disciplinares se reconfiguran, resignifican y replantean. Hoy día disciplinarmente se afirma que no se trata del operar de un manual institucional, sino de la incorporación de saberes que permiten una acción racional, intencional y fundada en el conocimiento (Tello, 2015). En este sentido y desde diversos ámbitos (entre ellos el académico), se han realizado esfuerzos por deconstruir las premisas establecidas para el hacer profesional como un mero intermediario Estado-sociedad o de carácter filantrópico, y coloca un posicionamiento crítico, ético e incluso ontológico, en donde diversos colegas nacionales y latinoamericanos se sumergen y envuelven en formas diferenciadas del hacer tradicional disciplinar, sosteniendo que: 
[...] el trabajo con el otro debe implicarnos y transformar nuestras posiciones, la de todas y todos quienes estamos en juego durante la investigación e intervención [...] apuestan por el despliegue de procesos de simbolización intersubjetivos, que apuntan, al menos, a tres elementos: respeto por los tiempos del sujeto con quien se da el encuentro; espejeamiento, traducción y transformación de nuestras vivencias afectivas; y, apertura a la palabra bajo el en-tendido de una mirada tercera (Pérez, 2018: 11-12).

Estas maneras de concebir el TS permiten intuir y construir nuevas formas de resistencia disciplinar que resultan la contracara del ejercicio de poder que aprisiona los cuerpos de esos otros: "los sujetos institucionales", "los huérfanos" ,"de las familias negligentes", que son atendidos por las instituciones y desde un modelo o manual de procedimientos se intervienen excluyendo sus características y demandas individuales y familiares, ubicándolos en moldes normativos que se limitan a atender necesidades físicas, distanciándose del padecer íntimo y la implicación con la familia que somatiza las condicionantes sociales -las que en poco o nada- han favorecido su dinámica para configurarse como espacios seguros de desarrollo para los integrantes que le conforman.

La intervención profesional en la atención de la niñez en condición de institucionalización se realiza frecuentemente recurriendo a la Metodología de intervención individualizada (o de caso), referente que aporta: fases, funciones, actividades, técnicas e instrumentos específicos para la inmersión al campo individual y familiar de la niña o el niño en condición de institucionalización.

A partir de una revisión exploratoria se recuperan algunas propuestas a nivel latinoamericano de referente metodológico (en donde lo epistemológico y ontológico no se desvela explícitamente, pero en la ejecución arroja elementos de comprensión de estas dos dimensiones y en donde la intersección de lo método-epistémico-ontológico, expresan en sí, parte de la episteme disciplinar) que involucran la atención del sujeto y su familia que dependiendo del contexto se denominan: Trabajo Social Individualizado; de caso; familia e incluso acompañamiento psicosocial individual, cada uno con sus propias características, que 
comparten la influencia de Mary Richmond (1922) en el tratamiento de caso y su propuesta en tres fases: Estudio, Diagnóstico y Tratamiento.

En la tabla (7) expuesta a continuación, se reflejan algunas propuestas metodológicas desarrolladas por algunas teóricas y teóricos del TS en países como: Argentina, Chile, Brasil Colombia y México, revisión que se hace sin considerar condiciones particulares que se recuperan sólo con la intención de indagar las propuestas metodológicas hasta hoy desarrolladas y a fin de explorar los referentes teórico-metodológicos, dada su recurrencia en la atención de la niñez en condición de institucionalización y las familias de éstos. 
Tabla 7 Metodología de intervención individualizada. Una revisión latinoamericana

\begin{tabular}{|c|c|}
\hline $\begin{array}{c}\text { País, autoras (es) y } \\
\text { concepción }\end{array}$ & Fase metodológica y descripción \\
\hline $\begin{array}{c}\text { Argentina } \\
\text { Robertis, } 1988 \\
\text { Método } \\
\text { psicosocial } \\
\text { individualizado }\end{array}$ & $\begin{array}{l}\text { Solicitud o Problema social. ¿Qué se está solicitando? ¿Para quién? ¿Y cuál es la dirección de la solicitud? Este punto } \\
\text { es de suma relevancia, puesto que es de dónde partimos para llegar a los objetivos y estrategias de intervención. } \\
\text { Evaluación preliminar y operativa. Dinámica del sujeto, que sí hay y qué no, puesto que de aquí se parte para la } \\
\text { intervención -entender al sujeto desde su contexto-. } \\
\text { Elaboración del proyecto social y contrato. La realización de objetivos, para que la intervención tenga direccionalidad } \\
\text { en cuanto a lo que se está realizando. } \\
\text { El nivel de intervención. Poner el accionar en la persona, la familia, un grupo o en la comunidad, puesto que se habla de } \\
\text { una postura universal de la metodología de intervención. } \\
\text { Puesta en práctica de las intervenciones. Es el accionar del trabajador o trabajadora social. } \\
\text { Evaluación de los resultados. Consiste en evaluar los cambios producidos en la situación, al comienzo, en el transcurso } \\
\text { y al finalizar la intervención, con la intención de saber si debe de realizarse un ajuste o no. } \\
\text { Finalización. Dentro de la cual se pone en la mesa el cierre de la intervención. }\end{array}$ \\
\hline
\end{tabular}




\begin{tabular}{|c|c|}
\hline $\begin{array}{c}\text { Brasil } \\
\text { Ramírez y } \\
\text { Castañeda, } 2011 \\
\text { Servicio Social } \\
\text { de Casos }\end{array}$ & $\begin{array}{l}\text { Formas de entrada. Búsqueda activa, demanda espontánea, derivados de otros centros. } \\
\text { Inicio de atención. Asignación de un profesional de referencia, apertura de expediente. } \\
\text { Organización del centro. Las funciones son distribuidas de acuerdo con la titulación de los profesionales. } \\
\text { Intervención. Predominio de visitas domiciliarias y trabajo grupal. } \\
\text { Duración/ acompañamiento familiar. La intervención en los grupos es indeterminada. }\end{array}$ \\
\hline $\begin{array}{c}\text { Colombia } \\
\text { Barreto, } 2003 \\
\text { Caso Social }\end{array}$ & $\begin{array}{l}\text { Se da el nombre de "caso social" a un individuo o familia afectados por un problema material o inmaterial que no estén } \\
\text { en capacidad de resolver por sí solos. Método específico por medio del cual se trabaja en la dualidad de la persona humana } \\
\text { haciendo énfasis en sus fenómenos psico-sociales y afectivos, con el fin de extinguir el problema individual mediante un } \\
\text { proceso de educación que permita la nueva re-adaptación del hombre o de la familia a una vida normal dentro de su } \\
\text { ambiente social. }\end{array}$ \\
\hline $\begin{array}{c}\text { México } \\
\text { Julieta Flores } \\
2012 \\
\text { Trabajo Social } \\
\text { Individualizado }\end{array}$ & $\begin{array}{l}\text { Definir el problema y sus características. Esta actividad implica un esfuerzo del profesional por precisar los aspectos } \\
\text { esenciales que caracterizan o identifican la situación problema y la diferencian de otras situaciones parecidas o } \\
\text { relacionadas. } \\
\text { Ubicar y relacionar el problema con la problemática central que lo engloba y determina sus características y su } \\
\text { comportamiento. Es muy importante tener presente que un problema no se comporta de la misma manera en personas o } \\
\text { en situaciones diferentes. Las estrategias de acción exigirán tener en cuenta el contexto al momento de proponer las } \\
\text { soluciones. } \\
\text { Diagnóstico del Problema. Analizar las causas y consecuencias del problema, lo que implica actividades que conllevan } \\
\text { a construir el diagnóstico. Priorizar los factores causales y sus interrelaciones para comparar la importancia relativa que } \\
\text { pueda tener cada una de las causas identificadas en el diagnóstico y en el comportamiento del problema. A través de estos } \\
\text { análisis, el profesional hace un inventario de las situaciones desfavorables identificadas, diferenciadas y reagrupadas con } \\
\text { criterios operativos. El producto del análisis es una relación de problemas de intereses para la persona e institución, } \\
\text { agrupados por categorías. } \\
\text { Estrategia de Acción. La estrategia describe las acciones concretas de la Intervención Individualizada que el profesional } \\
\text { recomienda para el logro de esos resultados. Por esta razón, la estrategia tiene que estar rodeada de teorías, métodos, } \\
\text { técnicas, herramientas e instrumentos de Trabajo Social. El empleo creativo de estos es lo que generalmente determina la } \\
\text { efectividad de las estrategias de acción. }\end{array}$ \\
\hline
\end{tabular}




\begin{tabular}{|l|l|}
\hline & Ejecución. En esta etapa se concretiza el cumplimiento de las estrategias de acción previamente evaluadas. Si al llegar a \\
esta etapa falta información se deberá revisar las etapas anteriores. Uno de los aspectos básicos es la asesoría por parte del \\
profesional de Trabajo Social para que la persona participe activamente en las estrategias de acción previamente trazadas. \\
Evaluación de las acciones. Las primeras actividades dirigidas a formular cualquier tipo de evaluación deben centrarse \\
en precisar por qué y para qué realizar este análisis, y establecer si dicha intención es claramente compartida por las \\
personas involucradas en la situación. Del propósito de la evaluación dependen otras decisiones, como el contenido de \\
esta, la metodología a utilizar, los recursos requeridos, el tiempo previsto para realizarla y el tipo de evaluador más \\
conveniente.
\end{tabular}

Fuente: Elaboración propia con base en las propuestas metodológicas latinoamericanas, 2020.

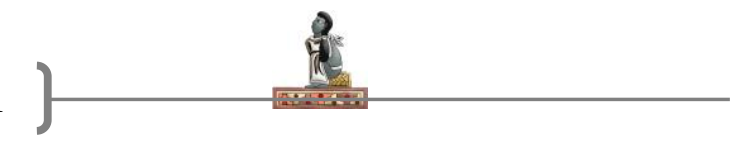


Como podemos observar en el breve recorrido de las propuestas a nivel metodológico que contemplan algunas experiencias latinoamericanas, la tendencia generalizada en el abordaje de casos inicia con la construcción de un diagnóstico, mismo que se diseña con base en el proceso de investigación, para con ello generar acciones de intervención, ejecutarlas y evaluar el impacto. Estas fases de actuación se sitúan específicamente en el individuo y/o la familia, en la recurrencia del enfoque teórico sistémico que habrá de servir para una superficial comprensión de los elementos estructurales que después se invisibilizarán. La definición metodológica, a nivel operativo, regresa a comprimir a la familia y coloca sus esfuerzos en el ajuste de las relaciones internas que dan forma a su dinámica, depositando la responsabilidad de transformación, a sus capacidades internas, respondiendo congruentemente a la episteme que difunde el imaginario de que las condiciones familiares son de asunto íntimo y privativo, que compete únicamente a quienes componen su estructura.

Esta forma de intervenir disciplinarmente -en esencia- fue propuesta y desarrollada por Mary Richmond en 1917, con fundamento en la experiencia obtenida de su implicación en el ámbito médico, de ahí, que las fases metodológicas sean enunciadas desde planteamientos como el diagnóstico y la intervención y aun cuando ha pasado más de un siglo, las propuestas no han variado sustancialmente.

Pensar desde la intervención, sugiere la generación de acciones que irrumpen y transgreden. Intervención que generalmente se reproduce sobre la base de una concepción "normativofuncionalista" de la familia y se diseña desde una posición jerárquica -en donde el profesional es el poseedor del "saber"-, que en poco considera la capacidad de conocimiento y reconstrucción social que los sujetos, familias y comunidades poseen.

Cuando se trata de niñez receptora de maltrato y en condición de institucionalización, el agenciamiento disciplinar, la episteme profesional, la construcción de sujetos institucionales y el proceso de subjetivación, apunta hacia suponer y adjudicar la facultad de invisibilizar y ajustar seres pasivos y anómalos, sobre ellos la tecnología del poder opera aprisionando y limitando la transformación de sus trayectorias, es aquí donde el dispositivo aplica y responde

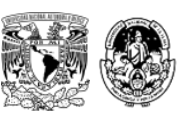


a un modelo económico capitalista en su fase neoliberal alienante que construye cuerpos desechables, que no importan.

Sin embargo, ¿es posible pensar otras formas? La experiencia obtenida hasta hoy ¿proporciona elementos para la deconstrucción del ejercicio profesional y nos permite identificar otras maneras de implicarnos con la niñez receptora de maltrato y sus sistemas familiares y comunitarios? ¿Cómo resignificar esta intervención y pensarla como procesos de acompañamiento insertos en un contexto social y en el reconocimiento de la niñez y sus familias como los expertos de su realidad, capaces de tomar las decisiones que habrán de transformar sus trayectorias? Más adelante el lector encontrará la propuesta generada del proceso que ocupa esta tesis, misma que plantea más adelante.

\section{Epílogo}

Al inicio del capítulo, he colocado la experiencia personal-profesional a partir del relato Gabriela, mismo que pretende evidenciar la manera en cómo tras la formación técnica en TS se instauró en mí una episteme de la intervención, con una proximidad a la mirada funcionalista que me habilitaba a desencadenar acciones concretas, enmarcadas en los manuales de procedimientos institucionales, generando al mismo tiempo una insatisfacción frente a la evidente inoperancia e impacto que dicho mecanicismos derivaba. Dispositivos jurídicos y médicos se privilegiaban de mí, invisibilizando las condicionantes sociales y económicas como potentes marcadores de contexto que determinan las trayectorias.

Otro elemento imbricado era la propia historia de maltrato que se alojaba en mí y me interconectaba frecuentemente con las niñas y los niños cuyas trayectorias me resonaban, y al pasar de los años, pude cobrar conciencia de que no sólo las experiencias personales, la identidad y la historización propia construyen la manera en cómo vivimos el mundo, también las relaciones y el contexto social. 
Cobrar conciencia de mis motivos para sumergirme en una particular niñez: la receptora de violencias me ha llevado años de trabajo intelectual y emocional. Entender cómo las epistemes disciplinares actúan como una tecnología más del poder, pues nos empuja a una ansiada "objetividad" y nos reduce a ser agentes operarios, que al estar colocados en la implementación acrítica conducen a caminos fallidos que se experimentan como intervenciones ineficientes, que al mismo tiempo cuestionan y merman la percepción de nuestro ejercicio profesional, operando así eficientemente el proceso de subjetivación, el cual se monta y justifica en la operacionalización de metodologías y manuales desarticulados de la realidad social.

A lo largo de este capítulo se recuperaron algunos momentos históricos de relevancia en torno a la atención de la infancia en México, tejiendo un entramado con el ejercicio disciplinar de la y el trabajador social atravesado por la política pública definida para cada etapa, consecuente al imaginario social del niño como "sujeto de asistencia, protección y derecho".

El primer período abordado es el pos-revolucionario, situado en la época Cardenista en donde la aparición del Estado benefactor determina el auxilio a la niñez como una obligación, transitando de una acción filantrópica (predominante hasta entonces) a la de una obligación estatal, que derivó en una hegemonía que avaló la intervención del Estado en las familias y en donde los trabajadores sociales jugaron un papel protagónico.

Posteriormente se revisó la década del sesenta y la influencia del movimiento de Reconceptualización en América Latina, que colocó al profesional en TS en un importante ejercicio de reflexión y emancipación profesional. Este, inserto en las instituciones gubernamentales, experimenta una tensión que se debate entre los principios emancipadores inspirados en el movimiento de Reconceptualización (que a su vez se vio influido por el materialismo histórico) y la encomienda funcionalista exigida por el Estado.

Seguidamente se colocó la discusión en lo relativo a la niñez y su reconocimiento como "sujeto de intervención social”, que se vive tensionado por los marcos jurídicos de protección

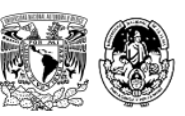


definidos a nivel nacional e internacional para su cuidado -desde la década del ochenta- y un escenario en donde la violencia, la pobreza y la marginalidad que se vive en México le construyen con un carácter de "niño consumidor o niño consumible", insertos en el contexto capitalista-neoliberal. Después se describen brevemente algunas tensiones e imprecisiones relativas a la situación nacional de niñas y niños en condición de institucionalización, que desvelan el profundo desconocimiento de la condición actual de este grupo poblacional ante la carencia de referencias y registros de cuidado alternativo.

Para finalizar el capítulo se revisaron algunas propuestas latinoamericanas a nivel metodológico, que evidencian las propuestas de intervención del TS contemporáneo situados en el vigente escenario social. 
- Capítulo

\section{CUIDADO ALTERNATIVO: ESTRATEGIA PARA LA ATENCIÓN DE LA NIÑEZ RECEPTORA DE MALTRATO}

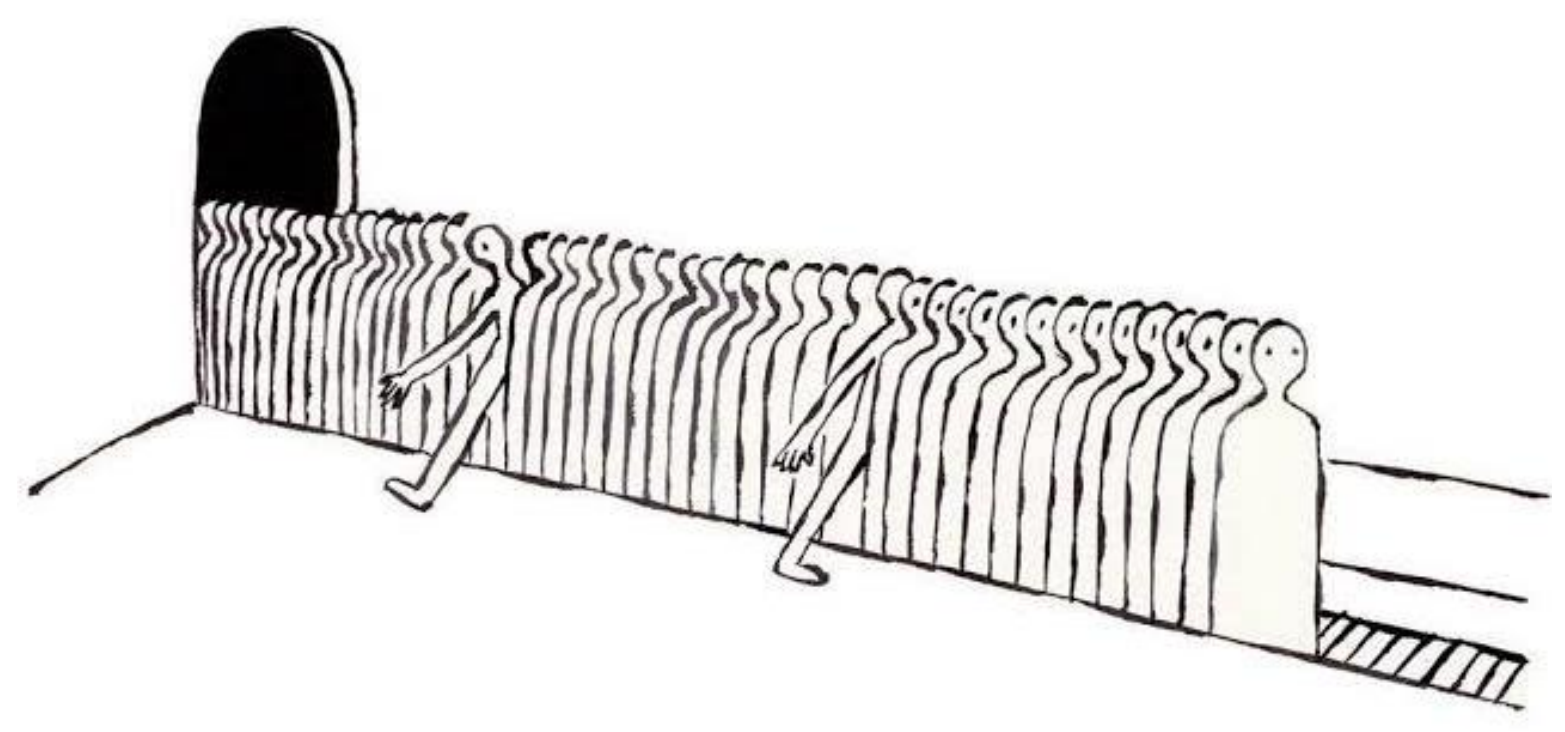

TRocHE 
[...] Sea como objeto de mercancía o de eliminación, la niñez contemporánea se constituye en la lógica del consumo de los mercados, y ello nos interpela como un sintoma del lazo social. Como constituyente del discurso de los mercados, aparece como un objeto de adicción. Su cuerpo puede ser, así, un objeto sexual, pero no sexuado. Encontramos ahi una diferenciación radical entre el objeto de la toxicomanía y el objeto de pulsión o del fantasma. La falta en ser o parece ser provocada por un objeto innominado e irrecuperable sino por una mercancía que se compra en el mercado. Acción misma de un "capitalismo infantil" como un biopoder que mercantiliza a los niños como consumidores, dinamizadores y objeto del consumo...

(Pippi de Medeiros, 2009)

Margarita

(2004)

Cursaba el último semestre de mi formación como licenciada en TS. Me encontraba muy inquieta por hallar mi lugar profesional, que para ese entonces creía tener muy claro: involucrarme en los procesos de desarrollo comunitario desde las geografías de los pueblos originarios de nuestro país.

Realizaba mis Prácticas de Especialización en la Comisión Nacional para el Desarrollo de los Pueblos Indígenas. El Lic. Francisco Pérez (un abogado mixteco de gran trayectoria en la defensa de los pueblos originarios), se acercó para darme una especial encomienda: “entraremos en un rato más al Centro de Readaptación Femenil, estando allí debes buscar a Margarita y realizar una entrevista abierta que considere los elementos que la llevaron a reclusión. Es muy importante que cuides cada detalle del encuentro". En ese momento, como pasante de la carrera de Trabajo Social adscrita al programa especial de atención a mujeres indígenas, me vi asaltada por preguntas que no me atreví a formular: ¿por qué la encomienda hacia mí?, ¿cuáles eran los antecedentes?, ¿cómo es que me delegaba algo que parecía -por su tono de voz- de tanta relevancia y al mismo tiempo, no me ofrecía los datos de la (38

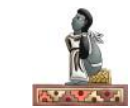


averiguación previa como en otros casos? Inundada de incógnitas nos adentramos al espacio que en sí mismo era frío y agresivo. Aún recuerdo el olor a orines, mariguana, desechos putrefactos en un ambiente surrealista que cobijaba la convivencia familiar de las mujeres internas con sus hijos y familiares.

Me acerqué a una mujer añosa que estaba en el centro del espacio vigilante del espectáculo: “busco a Margarita -le dije- ¿podría decirme en qué celda la encuentro?” La respuesta no se dejó esperar: "ella no está aquí niña, salió, pero si la esperas, seguro en un par de horas estará de regreso.” Extrañada me dejó tal respuesta ¿cómo era posible que si se trataba de una cárcel me dijera que no se encontraba? Supongo que mi mirada atónita le dio elementos para continuar la conversación: "no es raro, Margarita pertenece a la estudiantina del penal y ha salido en grupo a dar un concierto." De ahí seguimos conversando de la mujer que me ocupaba: “¿sabes?, -me dijo la anciana- ella llegó a la cárcel hace como diez años. Cuando ingresó no hablaba español porque es mazahua y nadie la visitaba. Comenzó por estudiar la primaria, luego la secundaria y así hasta la preparatoria. Hace unas semanas le avisaron que podrá cursar la universidad. Ha sido un ejemplo para muchas de las que estamos aquí adentro, nos ayuda, nos cuida y siempre tiene una palabra de aliento para todas nosotras."

Escuchar este relato y el ímpetu con el que me era contado incrementaba mi curiosidad y me ponía ansiosa frente a la entrevista que debía realizar. ¿Cómo podía ser que una mujer de tales características estuviera en la cárcel?, ¿qué la había llevado a cometer un delito?, ¿qué la había hecho permanecer por más de diez años en cautiverio, alejada de su familia?, ¿por qué nadie la visitaba? Así pasaron los minutos y las horas hasta que apareció frente a mí, el personaje tan finamente descrito:

"Hola Margarita -le dije-, mi nombre es Gabriela, vengo del Instituto de para la Atención Indígena y me gustaría que me regalarás un rato. Deseo hacerte una entrevista". Recuerdo con mucha claridad esas primeras palabras, las cuales pronuncié tímida y temblorosa. Me sentía tan pequeña frente a una mujer de clara fisonomía indígena: piel morena, extrema delgadez, cabello largo y negro, cara redonda y una profunda mirada. “¿Qué deseas saber?” Su trato tan familiar me tranquilizó e incitó a preguntar con mayor fluidez: “Cuéntame, ¿qué

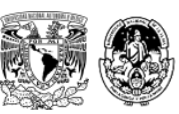


te ha traído a la cárcel?" Debo confesar que me sentía un poco ridícula haciendo esta pregunta, pero no encontraba otra manera de iniciar la conversación, se hizo un largo silencio que nos preparó a ambas para el intercambio: "como seguramente sabes, mi nombre es Margarita y llevo en la cárcel más de 10 años. Estoy acusada de privación ilegal de la libertad, "secuestro", con una condena de 28 años sin posibilidad de fianza."

Su discurso, su manera de hablar, su temple, eran definitivamente incongruentes con lo que había imaginado. Se expresaba con tanta claridad, tecnicismos y sobriedad, que cualquiera hubiera dudado que se trataba de una indígena llegada a la ciudad, sin instrucción académica y hablante sólo de su lengua materna.

Continuó. "Te contaré mi historia. Yo nací en San Felipe del Progreso, en el Estado de México en una comunidad indígena mazahua en donde se vivía mucha pobreza, mucha hambre, muchas carencias; mi padre era alcohólico y nos maltrataba a mi madre, hermanos y a mí y el único sueño al que podíamos aspirar las mujeres era a venir a la ciudad y trabajar como sirvientas en "Las Lomas"; yo la verdad no quería eso, no me veía barriendo y trapeando pisos en casas de "ricachones", pero no podía aspirar a algo distinto, porque ni siquiera sabía que podía estudiar, ser una profesional, trabajar y ganar mi propio dinero. Cuando tenía como 14 años, una prima me dijo que se iría "a los Estados Unidos", que ahí había muchas oportunidades y que podíamos trabajar piscando fresa o en un McDonald's o cuidando niños de mujeres gringas, y que se ganaba muy bien. No tenía mucha idea de lo que me hablaba, pero imaginar simplemente estar fuera de la comunidad, me llenaba de ilusión, y entonces, sin avisarle a nadie, un día agarré mis cosas y me vine a la ciudad. Ya estando aquí, conocí a Roberto, el padre de mi hijo.

Trabajábamos los dos en una casa rica y como yo necesitaba dinero para irme a la frontera, trabajaba como sirvienta en esa casa, en donde él era jardinero. Mi prima pasados unos meses se fue a Tijuana, pero como yo ya estaba muy enamorada no quise irme y preferí quedarme con Roberto. Empezamos a vivir juntos y yo me embaracé. Aunque él era alcohólico como mi padre y me golpeaba, aguanté un par de años, pero después me di cuenta de que le estaba 
haciendo mucho daño a mi hijo y decidí que lo mejor era la separación, así se lo dije y aunque no le gustó nada, pues nos dejamos.

De cualquier manera, me seguía buscando y me amenazaba todo el tiempo con quitarme a mi niño, me violaba cuando quería, me pegaba y me robaba el dinero que yo ganaba. Logré conseguir un cuarto en un terreno baldío, los dueños me dejaban vivir ahí a cambio de que lo cuidara, pero un día llegó Roberto en la madrugada y nos sacó a patadas a Toñito (mi hijo) y a mí, teniendo que quedarnos por días en el baño que estaba a un costado del cuarto mientras él se quedaba adentro sin saber por qué o para qué.

Entonces, había pasado como una semana, le dije a Toñito que se asomará por una ventana aprovechando que él había salido. Mi hijo me contó que había un niño "chiquito" amarrado adentro y que tenía platos de comida y muchas moscas alrededor, que lloraba mucho.

Me asusté de lo que me dijo, no entendía qué hacía un niño amarrado en mi cuarto y por qué Roberto lo tenía allí, así que salí corriendo a la delegación y con señas les dije a los policías que fueran conmigo a mi casa, pues yo no hablaba español, en realidad no es que lo necesitara para lavar o planchar ropa ajena; lo único que recuerdo es que cuando llegamos, la policía entró y empezaron a gritar "ella es la maldita secuestradora".

Los recuerdos que tengo después de eso no son muy claros, me asignaron un abogado que casi nunca venía a verme y con el que además ni siquiera podía hablar porque él no sabía mazahua, un día vinieron unas trabajadoras sociales del DIF, se llevaron a mi hijo y me dijeron que me iba a quedar aquí por muchos años”.

\section{Prefacio}

El capítulo que se desarrolla en las siguientes líneas, inicia ofreciendo a las y los lectores la descripción del contexto actual mexicano, que advierte condiciones de pobreza, marginalidad y violencias, afectando a gran parte de la sociedad mexicana. Describe cómo y cuándo dichas condicionantes estructurales atraviesan el mundo íntimo familiar que ponen a la niñez en un

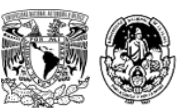


escenario de hostilidad y transgresión de sus derechos fundamentales, haciéndose proclive la intervención del Estado a partir del cuidado alternativo mediante la institucionalización en CAS como estrategia de política pública. El antecedente histórico de los CAS se funda en la década del cuarenta (ver apartado 3.1.2.4), en donde se atendía a los niños en riesgo. Continua vigente hasta nuestros días a través del SNDIF y la PFPNNA.

Posteriormente se expondrán los motivos de ingreso a un CAS desde la perspectiva jurídica nacional y en congruencia con las directrices de organismos internacionales -como el Fondo de las Naciones Unidas para la Infancia (UNICEF)-, indicando las afectaciones documentadas respecto de esta medida de cuidado que, ante el desprendimiento de la familia de origen, impacta al desarrollo integral de las y los menores de edad.

\subsection{Niñez y violencias estructurales: cuando el afuera determina el adentro}

Como ya he explicado antes -en la parte introductoria de esta tesis- la recuperación conceptual de la "niñez receptora de maltrato, sin cuidados parentales y en condición de institucionalización" no es casual e intenta responder congruentemente al bordeo teórico de la "niñez situada". Alude al reconocimiento de que el lenguaje construye realidad y que hay ciertas particularidades que hacen de estas personas niñas, un entramado complejo determinado por condiciones adversas en sus contextos sociofamiliares, institucionales y personales.

En esta primera parte del capítulo habremos de problematizar la niñez, pero no cualquiera: se trata de aquella colocada en un modelo capitalista neoliberal y globalizador que construye cuerpos residuales y que no puede ser concebida aisladamente, esa que emana de una construcción social y obedece a componentes estructurales, en donde la historización edifica un andamiaje cultural adyacente: la niñez receptora de maltrato, sin cuidados parentales y en condición de institucionalización que supone un grupo tendiente al cuidado alternativo, sin olvidar que "no existe, ni es pensable, un pueblo o grupo humano sin relato, sin leyenda constituyente. Es este collage de relatos y leyendas que forman el patrimonio colectivo, lo que llamamos "memoria social" y que constituye nuestra identidad, zona conflictiva y controversial entre diferentes

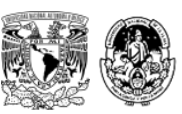


estamentos sociales, entre diferentes grupos de afinidad e intereses. Lo pasado y lo actual están allí, en permanente tensión" (Calvi, 2005: 118).

Las condiciones de pobreza, violencia y desigualdad que hoy aquejan a la sociedad mexicana agudizan las problemáticas sociales y representan en sí mismas violaciones estructurales a los DH. Según estimaciones del CONEVAL (2014), "sólo 2 de cada 10 mexicanos no son pobres o vulnerables por alguna carencia social"; "7 de cada 10 personas perciben que su entorno comunitario es inseguro" (INEGI, 2017); y "las mujeres y los niños siguen siendo grupos poblacionales altamente discriminados" (CONAPRED, 2012).

Nuestro país transita así por una ola de violencia, pobreza y desigualdad, que se expresa en la vida familiar, en los espacios íntimos de desarrollo individual y comunitario, en donde las condicionantes económicas inhiben el adecuado desarrollo de las niñas, los niños, sus familias y afecta determinantemente en el tejido social. Para (2014:1) "los decapitados, descuartizados, los asesinatos y los feminicidios enmarcan un lamentable escenario para México, no son hechos que han de verse aislados, bien por el contrario, parecieran ser un conjunto de síntomas ligados entre sí, que forman un síndrome social difícil de comprender y aún más difícil de atender. En su etiología la violencia se estructura en primera instancia en el encuentro de un niño con el mundo que lo rodea" 
Tabla 8 Niñez y violencias estructurales

\section{3 menores de edad}

- son asesinados al día

\section{De 2006 a 2016}

- se han reportado un aproximado de 7 mil niñas y niños desaparecidos que no han sido localizados.

\section{1 de cada 3}

- menores de edad dice sufrir agresiones dentro de la escuela.

\section{México: Primer lugar}

- en casos de violencia y abuso sexual a niñas entre los países de la Organización para la Cooperación y Desarrollo Económico.

Fuente: Elaboración propia con base en La Jornada, 2018.

En México la mitad de las niñas y los niños (y en consecuencia sus familias) viven en condición de pobreza, lo que significa que no logran satisfacer a cabalidad sus necesidades fundamentales; si son indígenas 8 de cada 10 viven en pobreza extrema. Dese el año 2000 y al cierre de 2019, cerca de 21 mil niñas, niños y jóvenes fueron víctimas de homicidio doloso, 7 mil casos de desaparición se documentaron y 30,000 han sido reclutados por el crimen organizado (REDIM, 2019) como ya hemos mencionado.

Estos datos dan cuenta de las hostiles condiciones estructurales que se ofrecen a la niñez en el territorio nacional -resultado de un sistema económico capitalista voraz que agudiza las desigualdades y encrudece la falta de oportunidades-, que les colocan en una evidente segregación y determina en mucho la vida futura: decrementando sus capacidades y destinando a la perpetuación social de condiciones de maltrato y violencia que atraviesan el mundo íntimo familiar, que es su espacio de construcción primigenia. 
El sistema económico que es defendido a ultranza por los políticos en turno, provoca desintegración familiar, el aspecto económico deviene en trabajo de ambos progenitores, descuido de los hijos y estados alterados de comportamiento derivados de las fuertes presiones monetarias a las que se ven sometidos los padres; se rompen las estructuras familiares, en muchas ocasiones aparece la violencia física y psicológica, en el mejor de los casos esta violencia es neurótica, en el peor de los casos, esta violencia se ejerce de forma sociopática (Lara, 2014:1).

\subsection{Niñez y violencias domésticas: cuando el adentro determina el afuera}

Cuando las condiciones de maltrato se experimentan al interior del sistema familiar e impiden que el menor de edad permanezca en él, el Estado tiene la obligación de velar por su restauración y reparación en derechos con fundamento en la Ley General de los Derechos de Niñas, Niños y Adolescentes (LGDNNA, 2014) generando como último recurso su institucionalización en Centros de Acogimiento Residencial. Con fundamento en la LGDNNA (2014:83), es obligación del Estado "proteger los derechos de niñas, niños y adolescentes, cuando los mismos se encuentren restringidos o vulnerados, en términos de esta Ley y las demás disposiciones aplicables. La institucionalización procederá como último recurso y por el menor tiempo posible, priorizando las opciones de cuidado en un entorno familiar."

De acuerdo con los estudios más recientes relacionados al desarrollo comunitario y familiar de la niñez mexicana, se sabe que "la escuela y la vía pública son dos entornos donde suceden 8 de cada 10 agresiones contra niñas, niños y adolescentes entre 10 y 17 años"; "el hogar es el tercer lugar en donde los niños están expuestos a la violencia” (UNICEF, 2017), además de que: 
Tabla 9 Niñez y violencia doméstica

\section{7 de cada 10}

- han sido víctimas de agresión en sus hogares.

\section{6 de cada 10}

- niñas, niños y adolescentes entre 1 y 14 años han experimentado algún método violento de disciplina infantil en sus hogares.

\section{1 de cada 2}

- niñas, niños y adolescentes ha sufrido alguna agresión psicológica por un algún miembro de su familia.

\section{1 de cada 15}

- niños y niñas ha recibido alguna forma de castigo físico severo (jalones de orejas, bofetadas, manotazos o golpes fuertes) como método de disciplina.

\section{1 de cada 10}

- niñas, niños y adolescentes entre los 10 y 17 años ha sufrido algún tipo de agresión en el hogar.

En lo relativo a NNA en condición de institucionalización, en junio de 2015 el Estado Mexicano recibió por parte del Comité de los Derechos del Niño de las Naciones Unidas (CDNNU) algunas recomendaciones que destacan la inexistencia de políticas públicas suficientes para apoyar a las familias en el cumplimiento de sus responsabilidades parentales, y enfatizó en la falta de documentación para identificar el número total de niñas y niños privados de un entorno familiar incluyendo la carencia de acciones respecto del cuidado en instituciones de la sociedad civil. 


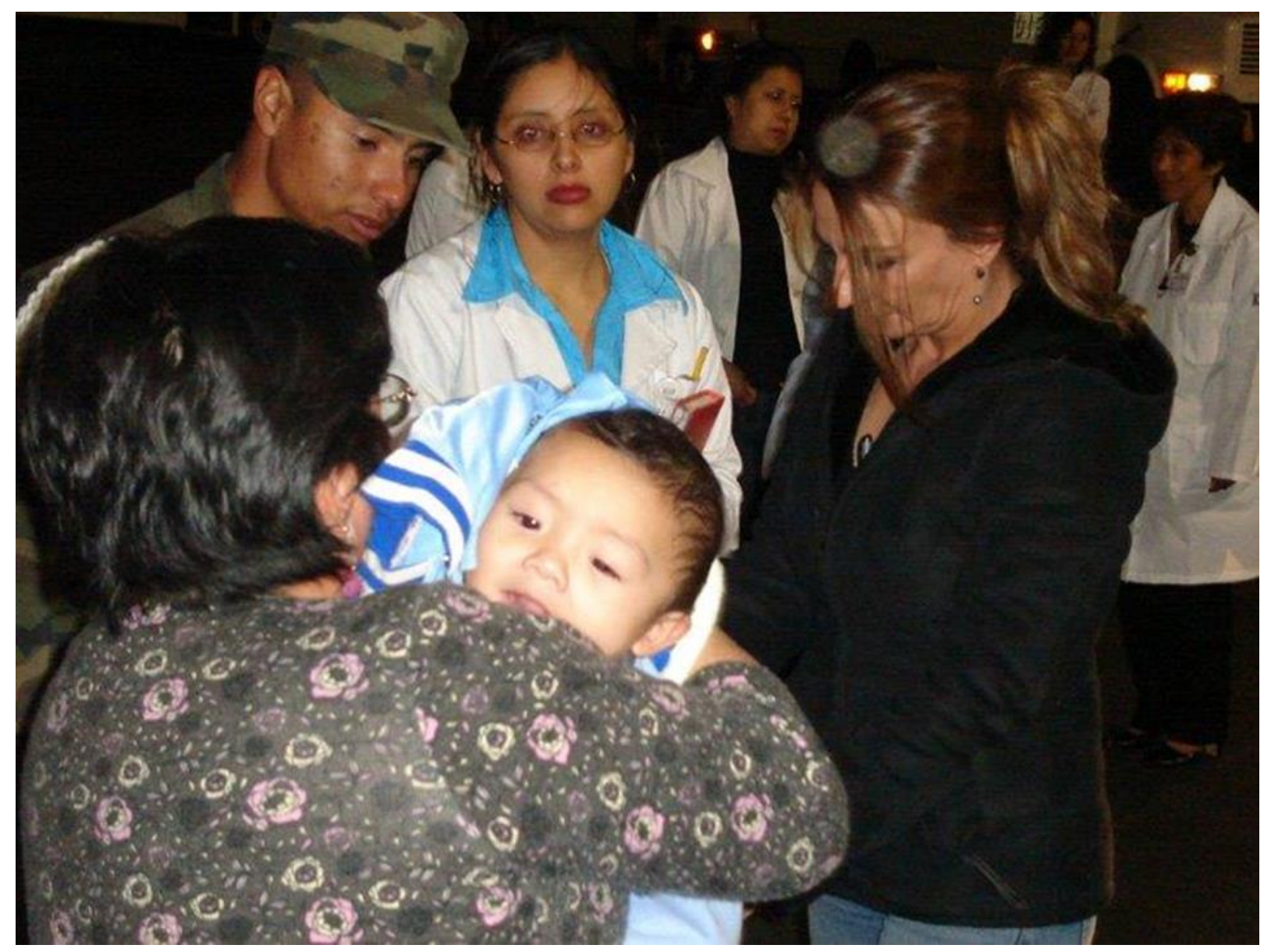

Imagen 14 Recibimiento de niñas y niños provenientes del DIF Tabasco, afectados por Huracán Dean, 2007

Fuente: Archivo personal, Ruíz Gabriela 2014.

Las niñas y los niños que sufren maltrato al interior del ámbito doméstico y cuya permanencia en el sistema de origen no son posible, son susceptibles del cuidado alternativo que ofrecen las instituciones gubernamentales o los organismos de la sociedad civil al tratarse de una estrategia de política pública, que aspira a la restitución de sus derechos. Estas condiciones adversas pueden ser provocadas -entre otras cosas- por una condición de pobreza extrema, negligencia o maltrato, que atenta contra su integridad biopsicosocial. 


\subsection{Acogimiento residencial: la institucionalización como estrategia de restitución de derechos de la niñez receptora de maltrato}

Se entiende por cuidado alternativo, al acogimiento residencial o institucionalización que provee el Estado frente a la privación del cuidado parental de niñas, niños y adolescentes, por parte de su familia de origen; vinculado frecuentemente a condiciones de violencia, negligencia o maltrato.

Cuando la propia familia del niño no puede, ni siquiera con un apoyo apropiado, proveer al debido cuidado del niño, o cuando lo abandona o renuncia a su guarda, el Estado es responsable de proteger los derechos del niño y de procurarle un acogimiento alternativo adecuado, con las entidades públicas locales competentes o las organizaciones debidamente habilitadas de la sociedad civil, o a través de ellas. Corresponde al Estado, por medio de sus autoridades competentes, velar por la supervisión de la seguridad, el bienestar y el desarrollo de todo niño en acogimiento alternativo y la revisión periódica de la idoneidad de la modalidad de acogimiento adoptada (Asamblea General de las Naciones Unidas, 2010: 3).

La Asamblea General de las Naciones Unidas, organismo internacional encargado de velar por la restitución de Derechos de Niñas, Niños y Adolescentes, a través del instrumento Directrices sobre las modalidades alternativas de cuidado (2010:6), define como Modalidades de Acogimiento alternativo:

1.- Acogimiento informal. Solución privada adoptada en un entorno familiar, en virtud de la cual el cuidado del niño es asumido con carácter permanente o indefinido por parientes o allegados (acogimiento informal por familiares) o por otras personas a título particular, por iniciativa del niño, de cualquiera de sus padres o de otra persona sin que esa solución haya sido ordenada por un órgano judicial o administrativo o por una entidad debidamente acreditada.

2.- Acogimiento formal. Todo acogimiento en un entorno familiar que haya sido ordenado por la autoridad judicial o un órgano administrativo competente y todo acogimiento en un entorno residencial, incluidos los centros de acogida privados, resultante o no de medidas judiciales o administrativas. 
Según el entorno en que se ejerce y en relación con la modalidad formal, el acogimiento residencial (formal) es el que se lleva a cabo en un entorno colectivo no familiar: como lugares seguros para la atención de emergencia, los centros de tránsito en casos de emergencia y todos los demás centros de acogimiento residencial a plazo corto y largo (UNICEF, 2010).

En lo concerniente a los marcos nacionales de protección a la niñez, la LGDNNA (2014) establece como "acogimiento residencial" a aquél brindado por CAS como una medida especial de protección de carácter subsidiario que será de último recurso y por el menor tiempo posible, priorizando las opciones de cuidado en un entorno familiar.

Finalmente, La Ley de Cuidados Alternativos para Niñas, Niños y Adolescentes en el Distrito Federal (2015) estipula que por ningún motivo la pobreza será una causa para separar a niñas y niños de sus familias y que deben emplearse medidas para su apoyo y acompañamiento; define el acogimiento o cuidado alternativo como la institución o figura jurídica mediante la cual una persona asume, de manera temporal, el cuidado y atención integral de un niño, niña o adolescente en situación de desamparo, en estricto respeto a sus derechos. Define como modalidades de cuidado alternativo:

1.- Acogimiento por familia extensa. Se entiende por acogimiento de familia extensa el que se da cuando niñas, niños y adolescentes se encuentran bajo el cuidado de su familia consanguínea o por afinidad hasta el cuarto grado.

2.- Acogimiento por familia ajena. El acogimiento por familia ajena es el cuidado que reciben niñas, niños o adolescentes por parte de una familia alternativa con la cual no tienen vínculos de parentesco.

3.- Acogimiento residencial. El acogimiento residencial es el que brindan las instituciones públicas, sociales o privadas a la niña, niño o adolescente en situación de desamparo. Su objetivo es dar temporalmente acogida a las niñas, niños y adolescentes y contribuir activamente a su reintegración familiar o, si ello no fuera posible, preparar su tránsito hacia una familia ajena o a obtener los beneficios de la adopción.

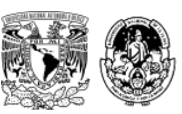


Este instrumento jurídico determina que el acogimiento residencial es autorizado preferentemente por el Comité Técnico del Sistema de Desarrollo Integral de la Familia o la autoridad judicial competente según sea el caso.

A su vez, los espacios designados como de acogimiento residencial de acuerdo con la LGDNNA (2014) son los Centros de Asistencia Social en donde se atiende a niñas y niños sin cuidados parentales o familiares. Pueden ser de orden público, privados o asociaciones.

Algunas de las exigencias que se solicitan en las Directrices sobre las Modalidades Alternativas de Cuidado de los Niños, realizadas por UNICEF (2010) en torno al acogimiento residencial son: que las autoridades competentes nacionales o locales deben establecer procedimientos que sean rigurosos para el ingreso a los Centros y que sólo se contemplen casos en los que la última opción sea el acogimiento residencial. De la misma forma, se debe contar con cuidadores que puedan brindar atenciones personalizadas que permitan a niñas y niños crear vínculos con un cuidador determinado y se establezcan apegos seguros al tener adultos disponibles, cumpliendo así las funciones de protección que se requieren.

Para lo concerniente a esta investigación, nos colocaremos en el cuidado alternativo que se brinda a la niñez mediante la modalidad residencial, frecuentemente conocida como “institucionalización” (como hemos referido).

Para ello, iniciaremos con un breve recorrido histórico con relación a la configuración del SNDIF, esfuerzo del Estado mexicano por contar con una institución rectora en materia de atención a la niñez en condición de vulnerabilidad y sus sistemas de familia (por la década del setenta) y hasta la entrada en vigor de la PFPNNA en virtud de la reciente LGDNNA (2014).

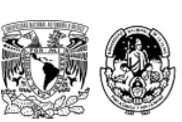




\subsection{La asistencia social en México en materia de protección a la niñez: responsabilidad}

del SNDIF

El Sistema Nacional para el Desarrollo Integral de la Familia se crea en enero de 1977 por Decreto Presidencial (ver imagen 15) en el sexenio de José López Portillo (D.O.F. 1977:26), teniendo como más antiguo antecedente el Programa Gota de Leche (que desde 1929 aglutinaba a un sector de mujeres mexicanas, quienes se encargaban de proporcionar alimento a niñas y niños de la periferia de la Ciudad de México).

Imagen 15 Decreto presidencial a través del cual se crea el SNDIF

\section{SECRETARIA DE SALUBRIDAD Y ASISTENCIA}

DECRETO por el que se crea un organismo público descentralizado con personalidad jurídica y patri. monio propio, que se denominará Sistema Nacio. ual para el Desarrollo Integral de la Familia.

Al margen un sello con el Escudo Nacional, qué lice: Estados Unidos Mexicanos-Presidencia de la zepública..

JOSE LOPEZ PORTILLO, Presidente Constituciotal de los Estados Unidos Mexicanos, en ejercicio de a facultad que me confiere la traccion I del articu, 89 de la Constitución Polf́tica de los Estados Uni. os Mexicanos y con fundamento en el artículo 13 de I Ley para el Control, por parte del Gobierno Fedeal, de los Organismos Descentralizados y Empresas e Participación Estatal; y en los artículos 27 frac. ones XXV y XXIX; 32 fracciones XII; 35 fracción III; 37 fracciones I, III $\mathrm{y} X V I ; 38$ fracciones $I$ inc1. , d); 39 fracciones I, VII. VIII y XVI; y 45 de la Lev rgánica de la Administración Pública Federal, y

\section{CONSIDERANDO}

Que la Institución Mexicana de Asistencia a la Ni. $z$ y el Instituto Mexicano para la Infancia y la $\mathrm{Fa}$. lia, son organismos públicos descentralizados que han nentado el bienestar social en el país, coadyuvando a satisfacción de ingentes necesidades de la población;

$$
=\ldots
$$

Que dada la afinidad en los objetivos de la Ins. ición Mexicana de Asistencia a la Niñez e Instituto xicano para la Infancia y la Familia, se ha estimado veniente que sus funciones se realicen, sin dupliiones ni interferencias, a través de una sola adminis. zión, lo que permitirá además una mejor utilización los recarsos y mayores beneficios para la cnlectiad; he tenido a bien expedir el siguiente

\section{DECRETO}

ARTICULO 10.-Se crea un organismo público des. centralizado con personalidad jurídica y patrimonio propio, que se denominará Sistema Nacional para el Desarrollo Integral de la Familia, con domicilio en la ciudad de México.

ARTICULO 20.-Los objetivos del Sistema serán:

I-Promover en el pais el bienestar social.

II.-Promover el desarrollo de la comunidad y fo mentar el bienestar familiar;

III.-Apoyar y fomentar la nutrición y las acciones de medicina preventiva dirigidas a los lactantes y en general a la infancia, así como a las madres ges. tantes;

IV.-Fomentar la educación para la integración social. a través de la enseñanza preescolar y extra. escolar:

V.-Fomentar el sano crecimiento físico y mental de la niñez y la formación de su conciencia crítica:

VI.-Investigar la problemática del niño, la madre y la familia, a fin de proponer las soluciones ade. cuadas;

VII-Establecer y operar de manera complementaria hospitales, unidades de investigación y docencia y centros relacionados con el bienestar social;

VIII.-Fomentar, y en su cașo, proporcionar servicios asistenciales a los menores en estado de aban dono;

IX.-Prestar organizada y permanentemente servicios de asistencia juridica a los menores $\mathbf{v}$ a las fa.

Fuente: Diario Oficial de la Federación de fecha 13 de enero de 1977 (DOF, 1977: 26).

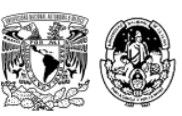


Las instituciones que antecedieron a lo que hoy conocemos como el SNDIF, fueron el Instituto Nacional de Protección a la Infancia (INPI-1961), centrado también en la distribución de desayunos escolares, y el Instituto Mexicano de Asistencia a la Niñez (IMAN1968) creado con el objeto de ampliar la cobertura asistencial y acercarla a otros sectores más vulnerables, mediante la implementación de programas de asistencia especializada en atender a menores abandonados, huérfanos, en condiciones de marginación y/o pobreza, y en general, en situaciones que representan un riesgo en su salud física o emocional (SNDIF, 2018:7-8). A partir de su creación la atención de la niñez se fortalece y gubernamentaliza, materializándose estrategias de política pública para este sector poblacional y sus sistemas de familia.

En 1975 se crea el Instituto Mexicano de la Infancia y la Familia, enfocado a la promoción del bienestar social. Este último, debido a la concordancia de objetivos, se fusiona con el IMAN y dan paso a la fundación del Sistema Nacional para el Desarrollo Integral de la Familia (Ruíz, 2019:47).

El SNDIF, desde su creación en 1977 y a la fecha, ha sufrido transformaciones internas como resultado de las dinámicas sociales que experimenta la sociedad mexicana. En cuanto a la población albergada, por la década de los setenta y hasta el año 2010, el alojamiento de menores de edad rebasaba los 500 niños y niñas, quienes se vinculaban principalmente con condiciones de pobreza extrema, abandono o el ingreso voluntario a solicitud de la familia.

Hoy día, derivado del contexto de violencia que se vive en el territorio nacional, los motivos de ingreso han sufrido una importante transformación y se expresan en el alojamiento de NNA vinculados con fenómenos como la niñez migrante no acompañada (proveniente fundamentalmente del triángulo norte de América Central), la trata de personas (en fines como la explotación sexual y/o laboral, las adopciones ilegales) e incluso el maltrato institucional experimentado en otros CAS de carácter privado. En cuanto a la cantidad de menores de edad asistidos, no se rebasan los 150 NNA, a pesar de que las instalaciones arquitectónicas, siguen siendo las mismas, con la misma capacidad instrumental. 
Los perfiles profesionales también han variado sustancialmente en cantidad y nivel académico. En lo competente al Trabajo Social, hasta el año 2000 las profesionales eran de nivel técnico y hoy se requiere el nivel de licenciatura y se experimenta una disminución en las contrataciones de nuevo personal. Con relación a los marcos normativos de actuación y frente a la entrada en vigor de la LGDNNA (2014), el SNDIF se vio obligado a reestructurar los manuales de procedimientos, a fin de armonizar con los marcos normativos internos y las vinculaciones interinstitucionales. La PFPNNA creada en 2016 por mandato de LGDNNA (2014), ha sido quizá la transformación más importante, y es el vehículo a través del cual se realizan y gestionan los ingresos y egresos de la población albergada.

En lo concerniente a la atención por parte de los CAS de carácter privado, se observa un robustecimiento de estos. Para 2020 se contabilizan en un aproximado de 758 a lo largo de todo el territorio nacional bajo diversas figuras que van desde Asociaciones Civiles, Albergues, Fundaciones e Instituciones de Asistencia Privada, en contraste con sólo 119 CAS de naturaleza pública, lo que nos da un total de 877 (CNDH, 2019: 3) como detallaré con mayor profundidad en el siguiente apartado (5.5). Con base en la estimación de REDIM (2020) "9 de cada 10 niñas y niños en condición de institucionalización, son atendidos por Organizaciones de la Sociedad Civil”, como ya se mencionó al inicio de esta tesis (OSC).

El SNDIF como lo conocemos hoy, resultado del proceso histórico expuesto, es una institución:

[...] de gobierno federal descentralizada, encargada de conducir políticas públicas en materia de asistencia social que promueven la integración de la familia. También, promueven acciones encaminadas para mejorar la situación vulnerable de niños, adolescentes, adultos mayores y personas con discapacidad [...] Combate las causas, así como los efectos de vulnerabilidad en coordinación con los sistemas estatales, municipales y organizaciones civiles; entre los objetivos de la institución está la promoción de la asistencia social y la prestación de servicios en ese campo (SNDIF, 2018: 8). 
ORGANIGRAMA SISTEMA NACIONAL PARA EL DESARROLLO INTEGRAL DE LA FAMILIA

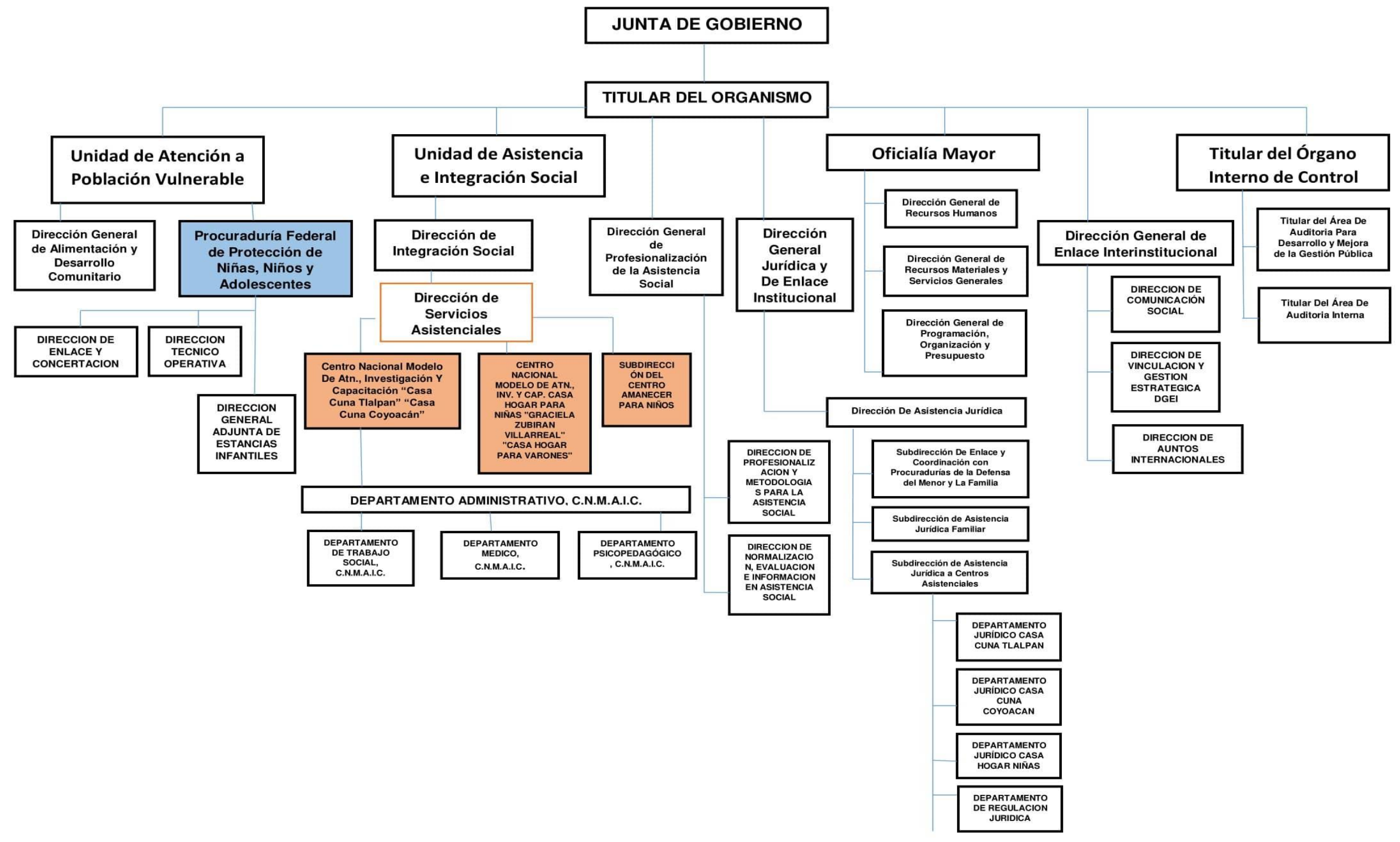

Tabla 10. Fuente: Elaboración propia con base al Estatuto Orgánico del Sistema Nacional para el Desarrollo Integral de la Familia y el Manual General de Organización del institucional, ubicados en la página oficial (Normateca).

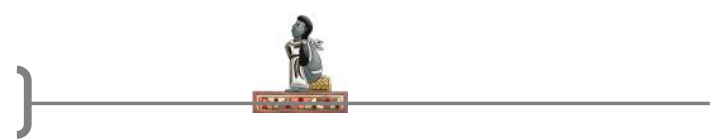


Como vemos en la imagen 25, se encuentra integrado por una Junta de Gobierno, un área Titular, dos Unidades de Atención y Asistencia, una Oficialía Mayor y un Órgano Interno de Control, que a su vez cuentan con diversas Direcciones Generales.

La atención que se brinda en los CAS del SNDIF en cuanto a las gestiones de ingreso, plan de restitución de derechos y egreso, son determinadas por la Procuraduría Federal de Protección de Niñas, Niños y Adolescentes (PFPNNA), órgano que forma parte de la institución. Nos detendremos para exponer su vinculación con los CAS, sus funciones y Procedimiento Interno para la Restitución de Derechos y Medidas de Protección a Niñas, Niños y Adolescentes, que establece los mecanismos internos a seguir por parte de los servidores públicos adscritos a este órgano y encargados de la restitución de derechos de menores de edad cuando hayan sido restringidos o vulnerados, y de la determinación de medidas especiales de protección (PFPNNA, 2016: 1).

\subsubsection{De la Procuraduría Federal de Protección de Niñas, Niños y Adolescentes}

La PFPNNA (2016) depende de la Unidad de Atención a Población Vulnerable (tal como se observa en la tabla 11) que, a su vez, depende de la Unidad de Asistencia e Integración Social. Es de reciente creación en nuestro país y entró en funciones en el año 2016. Su constitución es determinada en la LGDNNA en diciembre de 2014, formando parte del SNDIF; es creada para una efectiva protección y restitución de los derechos de niñas, niños y adolescentes, y sus funciones primordiales en relación con la restitución de derechos de la niñez en el territorio nacional son:

I. Representar a niñas, niños y adolescentes en procedimientos judiciales y administrativos.

II. Solicitar y ordenar medidas de protección para este grupo poblacional.

III. Brindar protección y restitución integral de derechos de menores de edad.

IV. Elaborar Plan de Restitución de Derechos de NNA.

V. Dar seguimiento a las acciones contenidas en el Plan de Restitución de Derechos.

VI. Realizar denuncias ante el Ministerio Público ante probables delitos, en contra de menores de edad y solicitar medidas urgentes de protección especial.

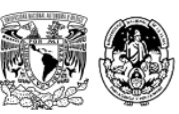


VII. El área de asesoría y representación jurídica tendrá que solicitar la ratificación y dar seguimiento a las mismas.

VIII. Articula y gestiona las acciones de los actores del Estado, la familia y la comunidad.

IX. Da seguimiento hasta que todos los derechos estén garantizados, en todos los casos atendidos.

Tiene una estrecha relación con los CAS del SNDIF, al tratarse de la instancia jurídica que determina las medidas Especiales de Protección, es decir las acciones y servicios, incluidas las medidas urgentes dirigidas a la protección de derechos de NNA en situación de vulnerabilidad por circunstancias específicas de carácter socioeconómico, alimentario, psicológico, físico, discapacidad, situación migratoria, apátrida u otros donde se les restrinjan o limiten el ejercicio de sus derechos (PNMC, 2019). ${ }^{39}$

Este vínculo tensa al mismo tiempo las acciones que se generan en los menores de edad albergados y sus familias, al tratarse de una instancia representativa y jurídico-administrativa, frente al papel operativo de cuidado alternativo que reposa en los CAS y su equipo multidisciplinario. Elementos que abordemos más adelante y se expresan tácitamente en los hallazgos obtenidos del trabajo de campo.

En lo competente al ingreso de NNA a los CAS del SNDIF, se cuenta con un Procedimiento Interno para la Restitución de Derechos y Medidas de Protección a Niñas, Niños y Adolescentes (PFPNNA, 2016: 1-42), que se resume en la imagen 26. Inicia cuando la PFPNNA toma conocimiento de algún delito cometido en contra de menores de edad mediante denuncia, información remitida por la Dirección General de Regulación de los Centros de Asistencia Social o a través de un medio de comunicación, y deriva en un consecuente análisis de caso mediante las valoraciones sociales, psicológicas y médicas. Esto determina el grado de afectación, y de proceder, se construye un Plan de restitución de derechos consecuente a las características de cada caso.

39 Información obtenida del conversatorio: Elementos jurídicos de protección a la infancia en México, organizado y coordinado en el marco del proyecto PNMC 2019, mismo que cuenta con una memoria digital, Seminario Problemáticas de la niñez en el México contemporáneo. La niñez vinculada a la Trata de personas: un abordaje multidisciplinar que aloja las videograbaciones de las conferencias y conversatorios realizados. 
Tabla 11 Procedimiento Interno para la Restitución de Derechos y Medidas de Protección a Niñas, Niños y Adolescentes

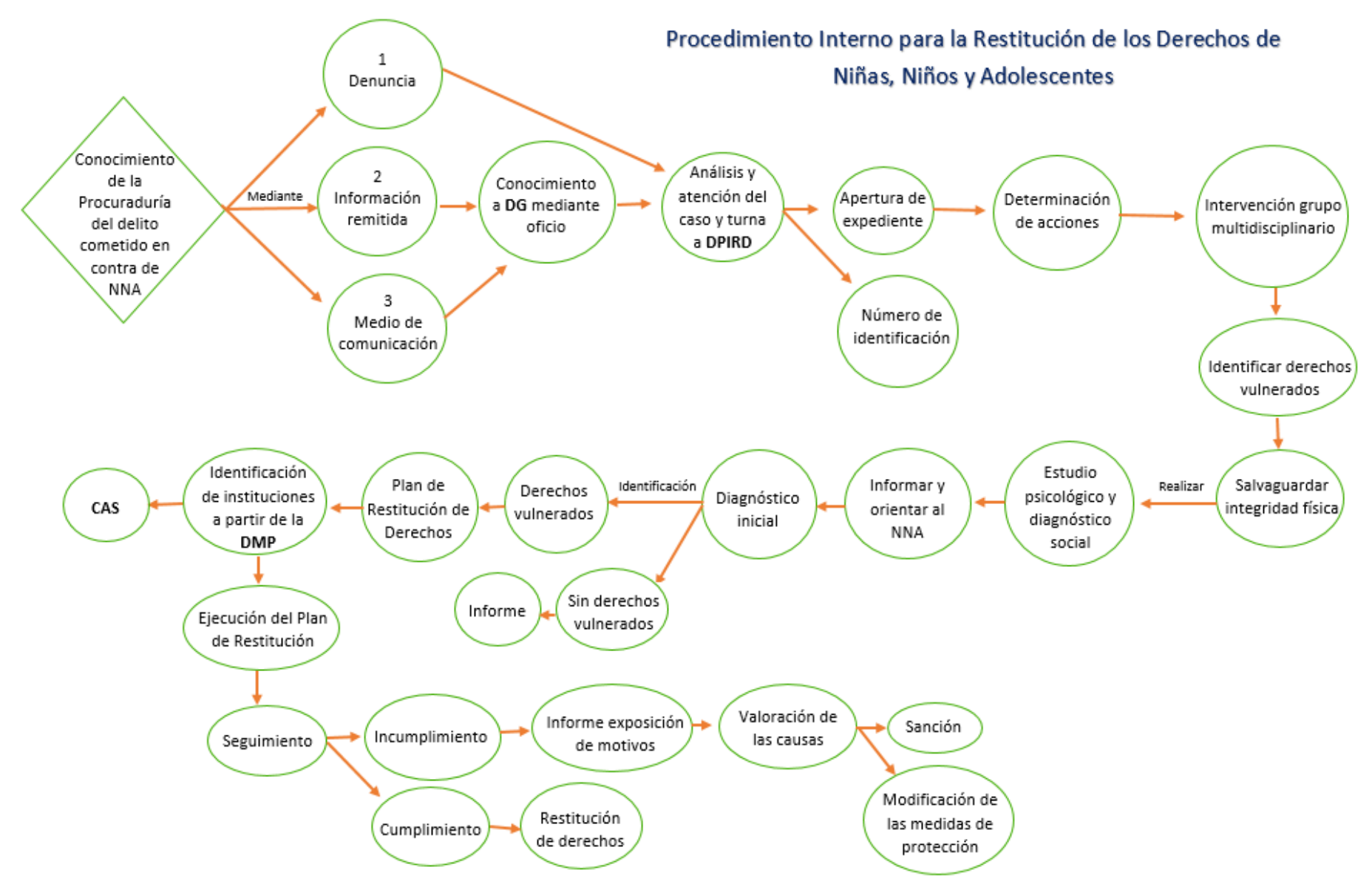

- DG: Dirección General

- DPIRD: Dirección de Protección Integral y Restitución de Derechos

- DMP: Dirección de Medidas de Protección

- CAS: Centros de Asistencia Social

Fuente: Elaboración propia con base al procedimiento establecido por la PFPNNA, 2016.

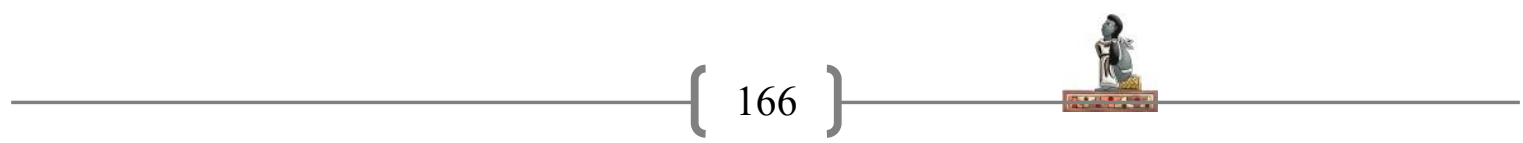


Se define -en caso de ser necesario- el ingreso institucional (CAS) remitiéndoles dicho Plan, a efecto de que el equipo multidisciplinar accione lo pertinente, hasta la modificación que motivo el ingreso, generando condiciones favorables de egreso.

Los descrito expone que los CAS del SNDIF no trabajan de forma aislada, en realidad se constituyen como los espacios de cuidado alternativo en términos operativos al ser quienes se encargan de operacionalizar el plan de restitución de derechos frente a la violación de la que pudieron ser objeto NNA, aunque estas determinantes provienen de la PFPNNA.

\subsection{Niñas, niños y adolescentes en condición de institucionalización: cifras, motivos y afectaciones}

Como se ha señalado en párrafos anteriores, los marcos jurídicos de carácter internacional y nacional definen que es responsabilidad del Estado generar acciones tendientes a la supervisión, vigilancia y acompañamiento de los CAS, de carácter público y privado, encargados del cuidado de niñas y niños sin cuidados parentales y receptores de maltrato. Desafortunadamente desde hace años se han venido realizando una serie de cuestionamientos y recomendaciones a las autoridades mexicanas con relación a las estrategias implementadas, mismas que se expresan ineficientes.

Se sabe, con base en la información emitida por el Instituto Nacional de Estadística y Geografía 2015 (INEGI, 2015), que alrededor de 33,118 niñas, niños y adolescentes se encuentran bajo la protección del Estado, albergados en 877 casas hogar, albergues, refugios y otras modalidades de cuidado institucional, públicos y privados en todo el país (CNDH, 2019: 3). De acuerdo con el Informe especial sobre la situación de los Derechos de Niñas, Niños y Adolescentes en Centros de Asistencia Social y Albergues Públicos y Privados de la República mexicana:

[...] tales cifras alertan al Estado mexicano sobre la magnitud de un problema social registrado y documentado desde hace al menos dos décadas: la situación especial de vulnerabilidad en la que se encuentran las niñas, niños y adolescentes que -por diversas causas- carecen de un entorno familiar. No son pocos los casos de violencia, abuso, 
negligencia y omisiones contra la población menor de edad residente en centros de asistencia social, cuyo origen ha radicado, generalmente, en la falta de regulación, supervisión y control estatal, y en el no reconocimiento del carácter de sujetos de derechos de niñas, niños y adolescentes (CNDH, 2019: 4).

En el mismo informe, la Comisión Nacional contabilizó un total de 26,372 niñas, niños y adolescentes albergados en CAS durante el periodo solicitado en los cuestionarios -que va de enero 2014 a febrero 2016- (ver imagen 16) (CNDH, 2019:120).

Como se puede claramente advertir, hay una diferencia de 6,746 mil menores de edad albergados en los CAS y Albergues públicos y privados si se comparan las cifras ofrecidas por INEGI y los datos recabados por la CNDH, lo que representa poco más del $25 \%$ del universo documentado. Este dato no es menor y evidencia la falta de padrones de población en condición de institucionalización, señalamiento que desde 2015 se ha realizado a las autoridades mexicanas y a la fecha sigue sin resolverse (esta situación se hace manifiesta nuevamente en el informe de referencia). 
Imagen 16 Mapa niñas y niños residentes en los CAS y albergues públicos y privados

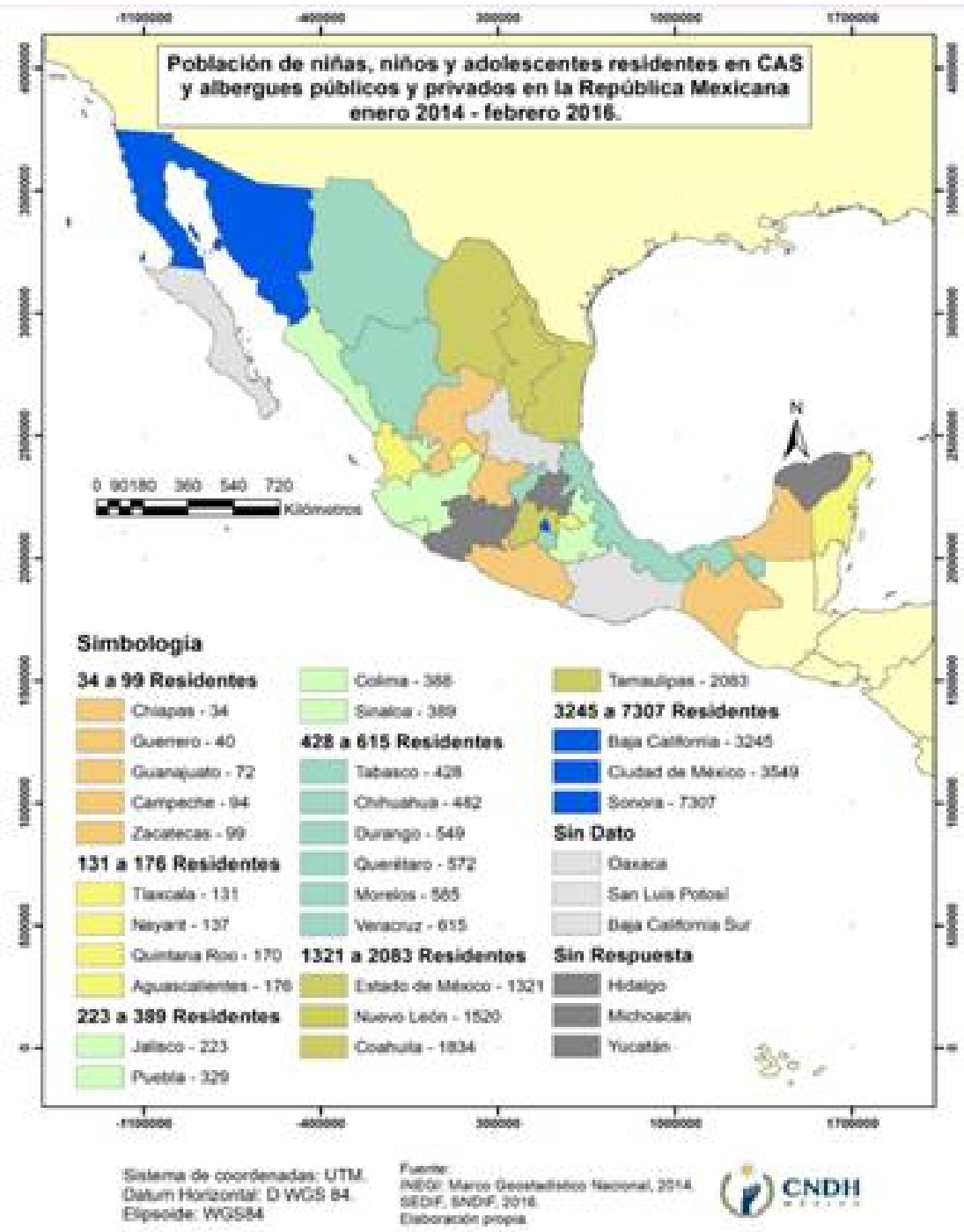

Fuente: Informe especial sobre la situación de los Derechos de Niñas, Niños y Adolescentes en Centros de Asistencia Social y Albergues Públicos y Privados de la República mexicana (CNDH, 2019:123).

Con relación a la información de los centros que atienden a la población, el informe expresa que se contabilizaron 877 CAS en todo el país, de los cuales 119 son de naturaleza pública y 562 privada; empero, por falta de datos de las autoridades no fue posible determinar la naturaleza jurídica de 196 CAS, siendo estos de los Estados de Chihuahua (193), Jalisco (1) y Colima (2) respectivamente (ver imagen 17) (CNDH, 2019:115). 
Imagen 17 Mapa número de CAS y albergues públicos y privados

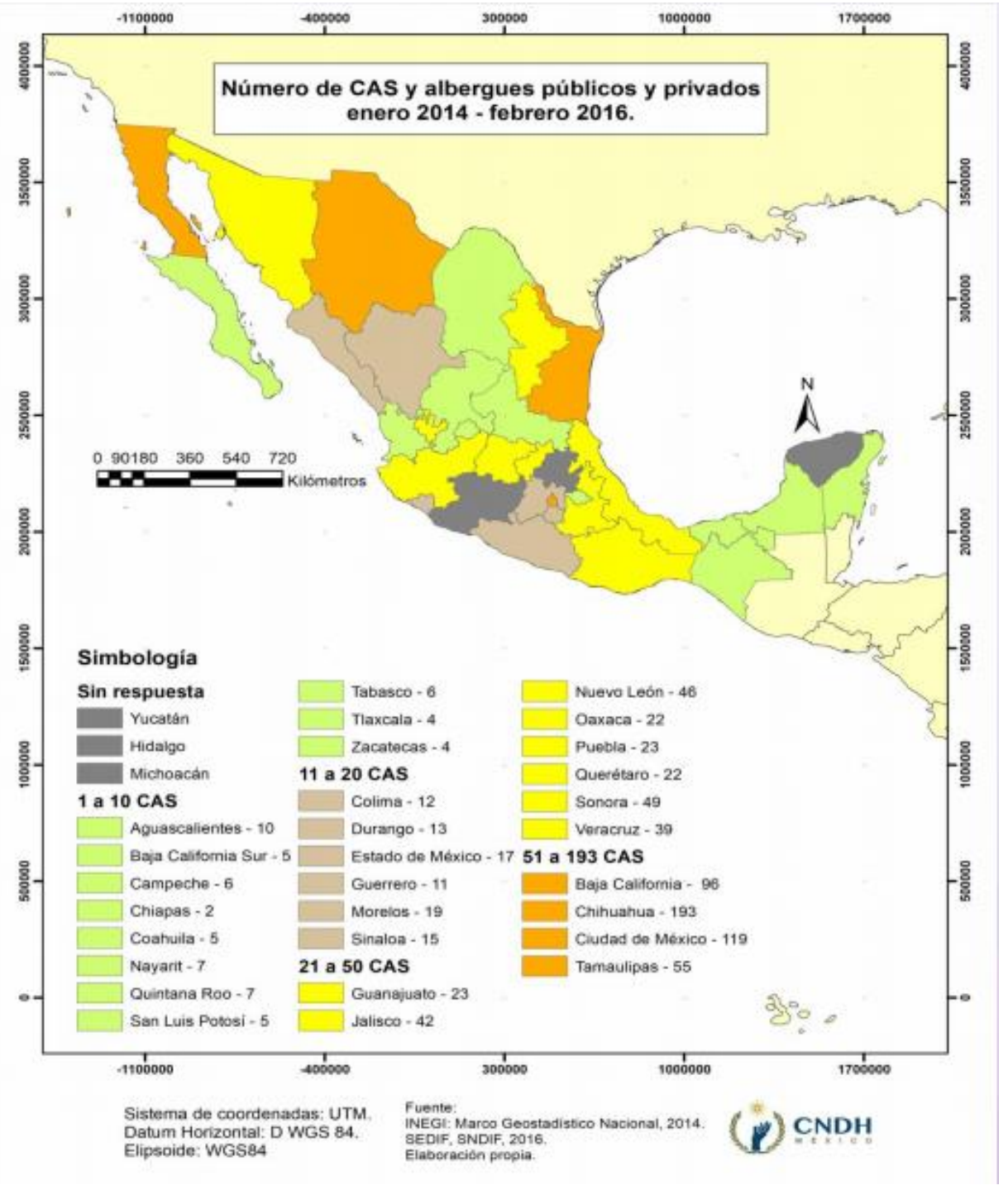

Fuente: Informe especial sobre la situación de los Derechos de Niñas, Niños y Adolescentes en Centros de Asistencia Social y Albergues Públicos y Privados de la República mexicana (CNDH, 2019:118).

Los CAS de carácter privado están contemplados en la LGDNNA (2014), son OSC que proveen de cuidado alternativo o acogimiento residencial a NNA bajo las figuras de: Asociación Civil (A.C.), Fundaciones o Instituciones de Asistencia Privada (IAP) -que no están obligadas a atender las disposiciones normativas del SNDIF, pues no dependen del presupuesto gubernamental (o son apoyados de forma parcial)-. Generalmente obtienen

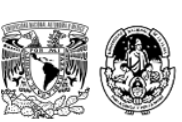


recursos económicos proporcionados por particulares: la mayoría de las veces se reciben de empresas, fideicomisos o fondeadoras bajo el concepto de "donativos" que, dicho sea de paso, son deducibles de impuestos.

El SNDIF, a pesar de contar enunciativamente con la rectoría de la asistencia social de NNA en nuestro país, no tiene potestad jurídica que le permita sancionar irregularidades detectadas en los diversos CAS privados (ver imagen 18) y tampoco tiene injerencia en la administración de los recursos económicos, materiales o humanos.

Imagen 18. Financiamiento CAS

\section{- 431 albergues y centros reportaron funcionar con recursos privados y públicos \\ - 376 sólo con recursos privados \\ - 68 exclusivamente con recursos públicos.}

Fuente: Elaboración propia con base en el Informe especial sobre la situación de los Derechos de Niñas, Niños y Adolescentes en Centros de Asistencia Social y Albergues Públicos y Privados de la República mexicana (CNDH, 2019:12). ${ }^{40}$

El día 5 de diciembre de 2019, participé de la $5^{\text {a }}$ Conferencia Nacional de Procuradoras y Procuradores de Protección de Niñas, Niños y Adolescentes en la mesa "Regulación de los Centros de Asistencia Social" (ver imagen 19), a propósito del informe recientemente emitido en dicho encuentro, autoridades estatales manifestaron una serie de dificultades que no permiten acceder y dar seguimiento puntual. La persona responsable de la Procuraduría Estatal de Morelos expresó: “sabemos muy bien cuál es nuestra responsabilidad, pero también deben entendernos, tenemos muchas organizaciones que no nos quieren ni abrir la puerta, cuando yo me acerco, lo primero que me dicen es que nunca había ido alguien a

\footnotetext{
${ }^{40}$ La imagen expone información de 875 centros, en tanto el informe manifestó 877; este faltante de 2 Centros es una imprecisión del informe de referencia. 
vigilarlos. No me dejan revisar expedientes ni nada; además cómo se los vamos a exigir, si el gobierno no les da nada". Añadió, "las personas trabajan por un sueldo de $\$ 4000$ mensuales, luego hasta la gasolina tienen que poner ellos. La gente que trabaja en las casas hogar, lo hace porque son muy filantrópicas". 41

Imagen 19 Oficio invitación como ponente $5^{\text {a }}$ Conferencia Nacional de Procuradoras y Procuradores de Protección de Niñas, Niños y Adolescentes

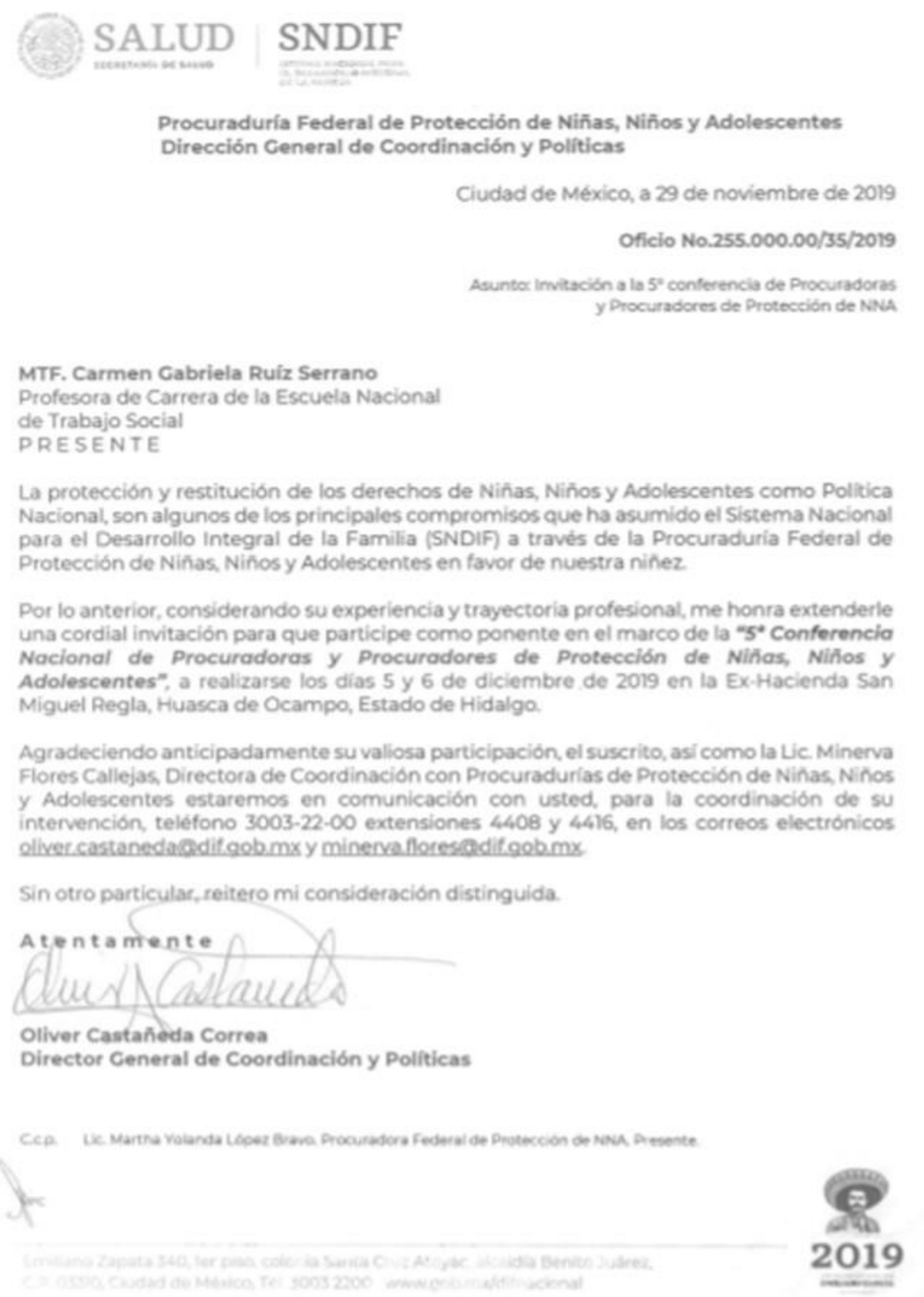

Fuente: Archivo personal, Ruíz Gabriela 2019.

${ }^{41}$ Nota de diario de campo personal: 06 de diciembre de 2019.

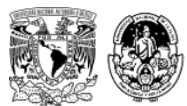


En las Observaciones finales sobre los informes periódicos cuarto y quinto consolidados de México (2015), el Comité de los Derechos del Niño se congratuló de la aprobación de la Ley General de la Niñez, no obstante, externó su preocupación por la situación de las personas menores de 18 años privadas de cuidados parentales al señalar la falta de políticas suficientes para apoyar a las familias en el cumplimiento de sus responsabilidades parentales; el hecho de que se desconoce el número de quienes se encuentran privados de cuidado familiar; y que el internamiento continúa siendo la opción prioritaria como medida alternativa de cuidado y la prevalencia de una supervisión inadecuada en CAS privados, factores que han propiciado casos graves de abuso y negligencia (CNDH, 2019: 64).

\subsubsection{Motivos de ingreso de la niñez a los espacios de cuidado alternativo}

Diversos son los motivos que logran documentarse respecto de las causas que separan a un menor de edad de su sistema familiar, todos ellos vinculados a condiciones de marginalidad y pobreza.

Se observa que la amplitud del concepto "protección o resguardo" impide identificar de manera precisa las causas por las que se recurre a esa medida de cuidado alternativo, ya que, por ejemplo, esta puede solicitarse durante el trámite de una averiguación previa o carpeta de investigación por la comisión de delitos en su contra; por abandono de la familia; incapacidad de los padres o familiares para proporcionarles cuidados y atenciones, o incluso, por ingreso voluntario por falta de recursos económicos. De ahí que, aunque significativos, los datos que proporcionaron los Sistemas DIF no son suficientes para generar un mapeo puntual que sea de utilidad para prevenir los factores de riesgo que conllevan a la institucionalización (CNDH, 2019:132).

Hasta hace algunos años, antes de 2013, los motivos de ingreso de la niñez a CAS públicos y privados enlistaban (ver tabla 12): omisión de cuidados, abuso sexual, maltrato físico y psicológico. Sin embargo, de 2014 a la fecha, cada vez más NNA son vinculados con fenómenos como: la trata de personas, la niñez migrante no acompañada, los padres privados de la libertad entre otros. 
Tabla 12 Motivos de institucionalización de niñas y niños según UNICEF

\section{De acuerdo a UNICEF los motivos que se han considerado jurídicamente para asignar que las niñas o niños sean institucionalizados son:}
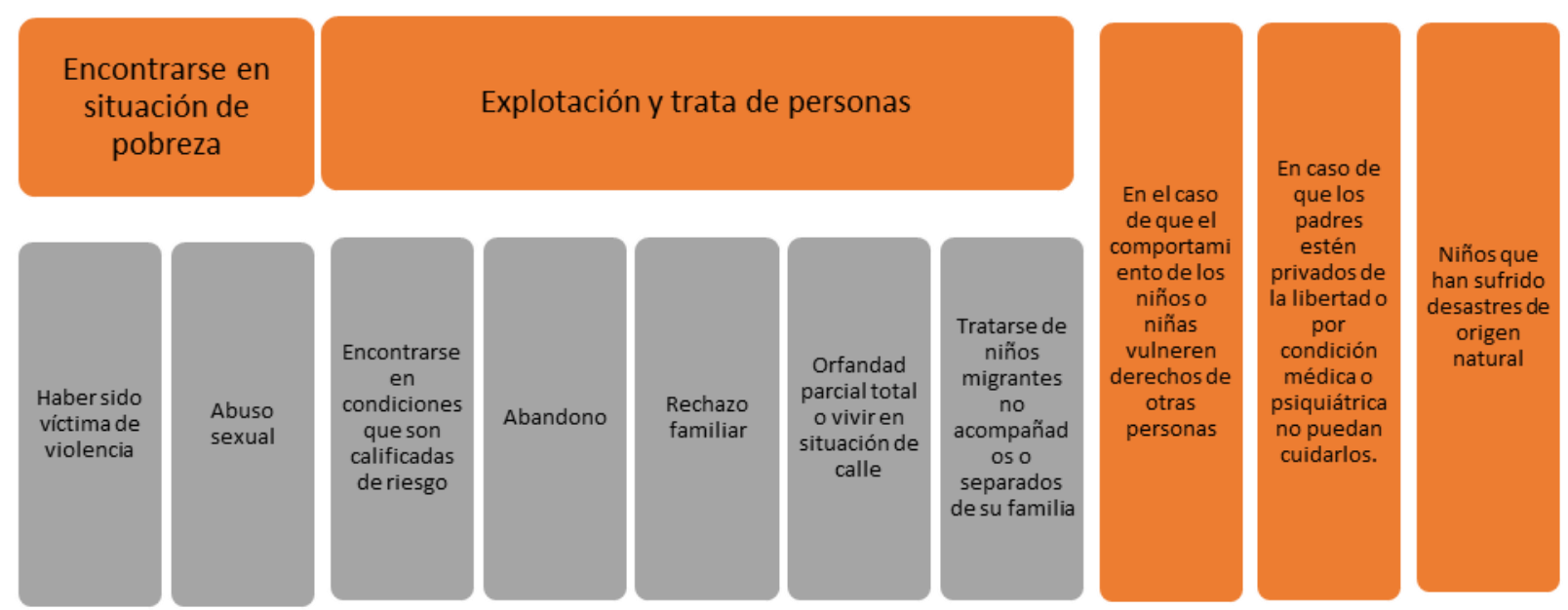

Fuente: La intervención del trabajador social en la atención de la infancia en condición institucionalizada. ENTS-UNAM (Ruíz, 2018).

Hoy día las problemáticas que aquejan a la niñez se han complejizado, dado que involucran fenómenos de orden estructural como el migratorio. Al mismo tiempo hay una prevalencia que implica la violencia ejercida en el ámbito doméstico como el motivo de ingreso más recurrente, que como se ha planteando ya, no es más que una expresión de las deficiencias y violencias estructurales, en donde la pobreza es esa primera violencia que coloca en desventaja y tensión a las familias y los contextos sociales más próximos como la escuela y la comunidad (ver tabla 13). Usualmente los sistemas de familia que presentan relaciones de violencia también exhiben condiciones de pobreza extrema y falta de oportunidades para el desarrollo integral de sus miembros. 
Tabla 13 Motivos de ingreso de NNA a CAS de carácter público, social y privado

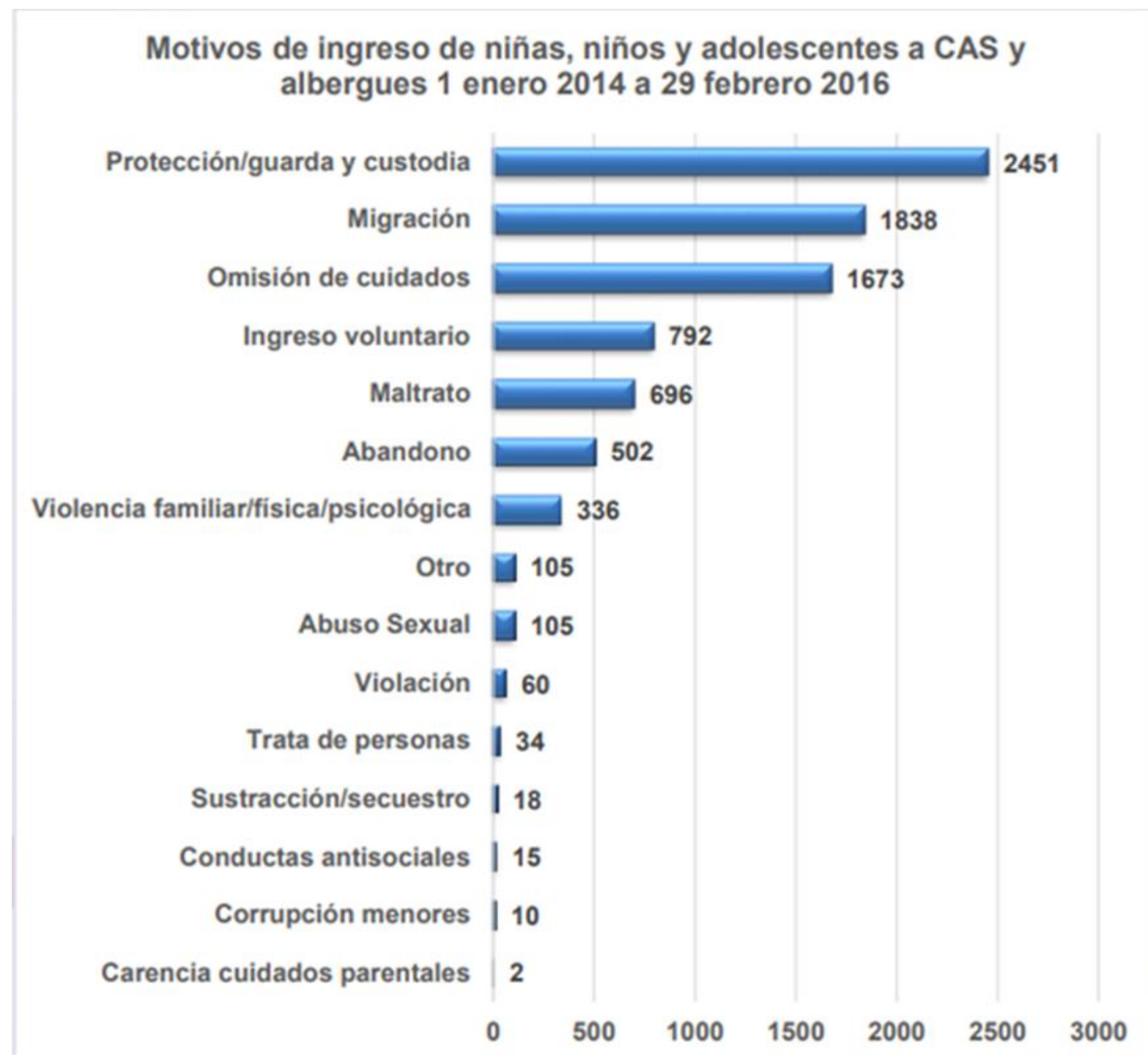

Fuente: Informe especial sobre la situación de los Derechos de Niñas, Niños y Adolescentes en Centros de Asistencia Social y Albergues Públicos y Privados de la República mexicana (CNDH, 2019:131).

Como se puede identificar, la violencia familiar se constituye como el elemento preponderante de ingreso y residencia institucional que coloca en estado de vulnerabilidad al niño y en donde el maltrato transgeneracional del sistema familiar es la constante: 
Cuando la intensidad de las fluctuaciones familiares es demasiado grande, y faltan en el tejido social los recursos materiales y/o psicosociales que permitan el manejo de la crisis, aumenta la tensión familiar con el peligro de que los niños, los elementos más débiles del sistema, sean usados como chivos expiatorios (Barudy, 2016:74).

Para Barudy estudioso de la psicología, estos sistemas familiares se engloban en la categoría de "familia negligente", y las entiende como:

"aquellas que corresponden a un sistema donde los adultos, especialmente los padres, presentan de una manera permanente comportamientos que se expresan por una omisión o una insuficiencia de los niños que tienen a cargo. Un contexto de pobreza y/o aislamiento social rodea a menudo al sistema familiar; este contexto coincide muy fuertemente con una historia de carencias múltiples en la biografía de los padres" (2016:88).

Madres, padres, abuelos, se viven en un espiral de pobreza y violencia que les ubica en una dicotomía inclusión-exclusión, etiquetándolos como incompetentes para el cuidado y crianza. Necesario advertir que el uso de la categoría "familia negligente" es comúnmente utilizado por los dispositivos jurídicos (leyes, reglamentos, instancias ministeriales y judiciales). Desde el Trabajo Social, me detengo a precisar esta categoría: cuando se quiere describir a los sistemas familiares que no logran ofrecer a sus miembros condiciones adecuadas para su desarrollo, generando dinámicas en donde emerge la violencia física, emocional, psicológica y sexual, como formas de relación. Persistente el uso de "familia negligente" en peritajes e informes sociales elaborados por las y los profesionales encargados de la atención de la violencia doméstica y la niñez en condición de institucionalización.

Tengo la intención de ejemplificar la manera en cómo los discursos influyen en la intervención dejando claro que desde la perspectiva de esta tesis, dicha categoría atrapa y etiqueta a los sistemas de familia. Se configura como una episteme de tendencia criminalizante y carácter hegemónico que justifica -muchas veces- la separación de niñas y niños de los sistemas de origen, y frente a la cual debemos colocarnos críticamente y cuestionar su frecuencia y constancia, dada la franca recuperación categórica desde la disciplina del Trabajo Social y otras como la psicología, la medicina y el ámbito jurídico.

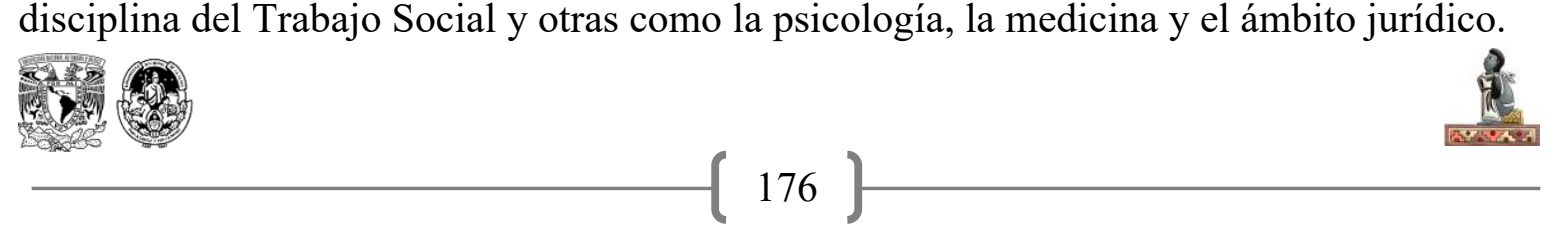


Algunos detalles que al respecto se describen:

Tabla 14 La Familia negligente

Tipos de negligencia
1.- Negligencia biológica por trastorno del apego.
a) Factores dependientes de la madre:
- Depresión.
- Enfermedad mental.
- Toxicomanía y alcoholismo.
- Trastorno del apego como consecuencia de traumatismos infantiles (madres pasivas-
indolentes, madres activas-impulsivas).
b) Factores dependientes del niño.
c) Factores dependientes del padre.
2.- Negligencia cultural.
- Trastornos del apego biológico por modelos de crianza inadecuados y violentos.
- Carencias educativas.
3.- Negligencia contextual.
a) La pobreza como medio ambiente:
- Ausencia de estructuración espaciotemporal.
- Funcionamiento familiar caótico y predador.
- Trastornos de la percepción y la discriminación sensorial (frío, calor, hambre, saciedad,
agresividad y violencia, ternura, sexo).
b) Aislamiento social:
- Marginalidad.
- Familias monoparentales.

Fuente: Recuperado de Barudy, 2016: 88.

Aún y cuando hemos descrito algunos factores estructurales que motivan condiciones adversas para las familias de las niñas y los niños en condición de institucionalización, los marcos jurídicos y procedimentales de atención a esta población en poco consideran la 
responsabilidad del Estado respecto de los motivos que la generan, atribuyendo esencialmente al sistema familiar la responsabilidad y diagnostican categorías como: familia disfuncional, generadora de violencia, desestructurada. ${ }^{42}$

Stavchansky y Untoiglich destacan, en relación con las problemáticas que viven las familias, que:

Vivimos en un tiempo en el cual cada uno se queda a solas con sus sufrimientos y sus miedos, pensando cada quien, que es el único que siente temor o soledad. El sufrimiento pasa a ser privado y responsabilidad personal que cada sujeto tendrá que resolver por sí mismo. Cada ser humano considera que tiene que salvarse solo, y si no lo consigue, entonces es por su propia falta de mérito, es porque no lo intentó lo suficiente o porque eventualmente su cerebro tiene algunas fallas que no se lo permiten. Se borra así la dimensión política del sufrimiento, lo público se disuelve en múltiples privados, que privan al sujeto de las luchas colectivas por mejores condiciones de vida (2019:40).

Por su parte Jaramillo sostiene que:

La relación entre la responsabilidad individual y el destino es complicada, pero explicar la pobreza, la marginalidad y la criminalidad con el argumento de la cultura de la pobreza (es decir, la transmisión intergeneracional de las normas y comportamientos culturales patológicos y destructivos dentro de los hogares pobres, o a los referentes culturales violentos en el entorno de los jóvenes de familias pobres) equivale a ignorar toda una serie de condiciones y restricciones estructurales que moldean la trayectoria de vida de los individuos y la sociedad (2016: 1).

Es decir, la sociedad contemporánea en el sistema capitalista neoliberal coloca en la experiencia individual la responsabilidad de la pobreza, la violencia, la anomía y por ende atribuye a quienes son incapaces de evolucionar, una serie de etiquetas y diagnósticos que le atrapan. Es en esta percepción individualizante que la niñez y sus familias se advierten en una suerte de disfuncionalidad que les excluye y ubica como seres desechables.

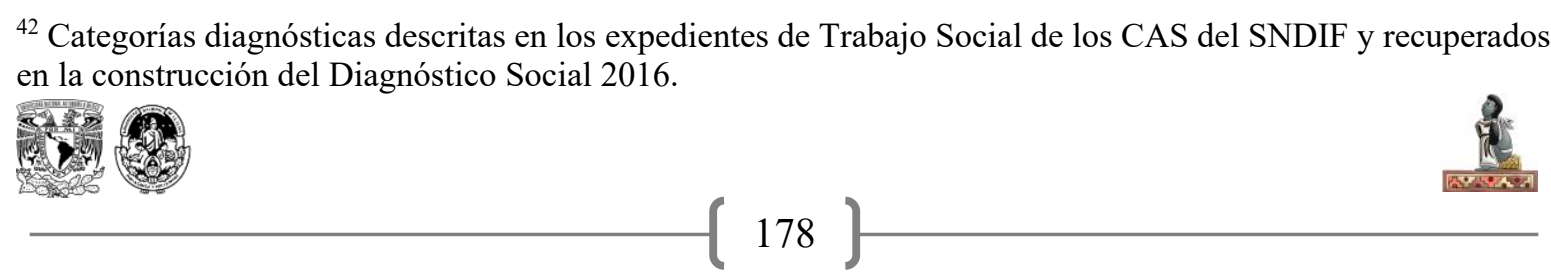


La producción de "residuos humanos" o para ser más exactos de seres humanos residuales ("los excedentes y superfluos" es decir la población de aquellos que o bien no querían ser reconocidos, o bien no se deseaba que lo fuesen o que se les permitiese la permanencia) es una consecuencia inevitable de la modernización y una compañera inseparable de la modernidad [...] los problemas de los residuos (humanos) y la eliminación de residuos (humanos) pesan mucho y para siempre en la líquida, moderna y consumista cultura de la individualización. Saturan todos los sectores más relevantes de la vida social y tienden a dominar las estrategias vitales y alterar las más importantes actividades de la vida, alentándolas a generar sus propios desechos sui generis: relaciones humanas malogradas, incapaces, inválidas o inviables, nacidas con la marca del residuo inminente (Bauman, 2015:18).

Es necesario considerar que la institucionalización de una niña o niño a un CAS que resulta de la imposibilidad de sus padres o familiares para proveerle del cuidado y atención familiar genera en él un impacto difícil de resarcir al experimentar una sensación de pérdida o abandono. Usualmente la institucionalización se encuentra vinculada a experiencias de violencia doméstica y estructural, vivencias que representan en el niño "eventos traumáticos, que lo alteran profundamente en todas las dimensiones de su persona: la forma en que piensa, en que aprende, en que recuerda y en cómo se percibe a sí mismo y al mundo que le rodea" (Bloom, 1999:1).

Al mismo tiempo para Osorio y Arteaga (2013:217) "la atención otorgada en las instituciones públicas asistenciales a los niños en riesgo en el centro de México ha transitado de una forma de atención disciplinaria (representada por dispositivos masivos, indistintos y asistencialistas) a otra de control (simbolizada por dispositivos gerenciales y menos terapéutica) sin que la primera haya desaparecido del todo”. Lo señalado ha ido generando una suerte de desamparo estatal hacia ellos, al tiempo que criminaliza a algunos grupos.

El Fondo de las Naciones Unidas para la Infancia (UNICEF, 2011:21): sugiere que el cuidado alternativo que se les provee en estos centros de acogimiento debe garantizar al niño, niña y adolescente un hogar estable que le brinde la seguridad de un vínculo continuo y seguro con 
sus acogedores, favoreciendo el establecimiento de relaciones significativas con los adultos y con sus pares mientras dure la medida.

Este énfasis que el organismo internacional pone en la relación vincular, se asocia con investigaciones que demuestran la importancia de las relaciones afectivas y de los cuidados mutuos en la conservación de la salud psíquica. De acuerdo con la propuesta de Barudy, la constitución biológica y las experiencias relacionales son fundamentales para las personas, pues influyen, se complementan y se perturban mutuamente. Uno de los componentes más importantes de las relaciones afectivas que forjan a una persona sana es el hecho de haber sido atendido, cuidado, protegido y educado en períodos tan cruciales de la vida como la infancia (Barudy, 2005:23-52).

Dichos posicionamientos se tensan en México frente a las condicionantes institucionales que privilegian supuestos jurídicos que en poco favorecen dicha relación vincular y norman la vida a partir de temporalidades y acciones de cuidado fundadas en la restitución de Derechos de Niñas, Niños y Adolescentes como entes individuales. "Los escenarios judiciales -en tanto instancia simbólica clave de la sociedad democrática- requieren ser analizados en sus discursos, prácticas y formas ceremoniales, incluso administrativas, cuando allí mismo la decidía y la in-dolencia se vienen convirtiendo en norma. Frente a esta se plantea otra: la diferencia entre la lectura del mundo desde la perspectiva infantil y la de aquel cuya infancia ya se fue" (Zelmanovich, 2012: 42).

\subsubsection{Del desprendimiento familiar al encierro institucional: efectos, implicaciones y grietas}

Hoy día a nivel internacional y nacional se cuenta con diversos sistemas de protección a la infancia, ${ }^{43}$ cuya encomienda es la protección de niñas, niños y adolescentes entre los que se

\footnotetext{
43 Conjunto de órganos, entidades, mecanismos, instancias, leyes, normas, políticas, servicios y presupuestos a nivel nacional, local y municipal orientados a respetar, promover, proteger, restituir y restablecer los derechos de los niños y niñas y reparar el daño ante la vulneración de estos, establecidos por las legislaciones nacionales de infancia (Morlachetti, 2013: 12).
} 
cuentan a nivel internacional: el Fondo de las Naciones Unidas para la Infancia (UNICEF), Save the Children, y en el espectro nacional: el Sistema de Protección Integral de los Derechos de Niñas, Niños y Adolescentes (SIPINNA), la Procuraduría Federal de Protección de Niñas, Niños y Adolescentes y el Sistema Nacional para el Desarrollo Integral de la Familia. Estos organismos internacionales y nacionales han sugerido en distintos momentos la erradicación de la institucionalización como medida de cuidado alternativo al identificar en esta estrategia serias implicaciones y consecuencias biopsicosociales, como resultado de los modelos de internamiento que en poco favorecen la individualidad y construcción vincular del sujeto. Se considera que en:

[...] el momento en que un niño o niña ingresa a una institución es despojado de su cultura, de su presentación, en muchas ocasiones debe renunciar a su historia, su estilo de hablar, su cultura, en definitiva, despojado de sí mismo. Pues se espera que el niño o niña se adapte a su nuevo hogar, donde habrá reglas, actividades ya establecidas y además tendrá que apegarse a las costumbres de dicho lugar que le dará hospitalidad (Goffman, 1972:20).

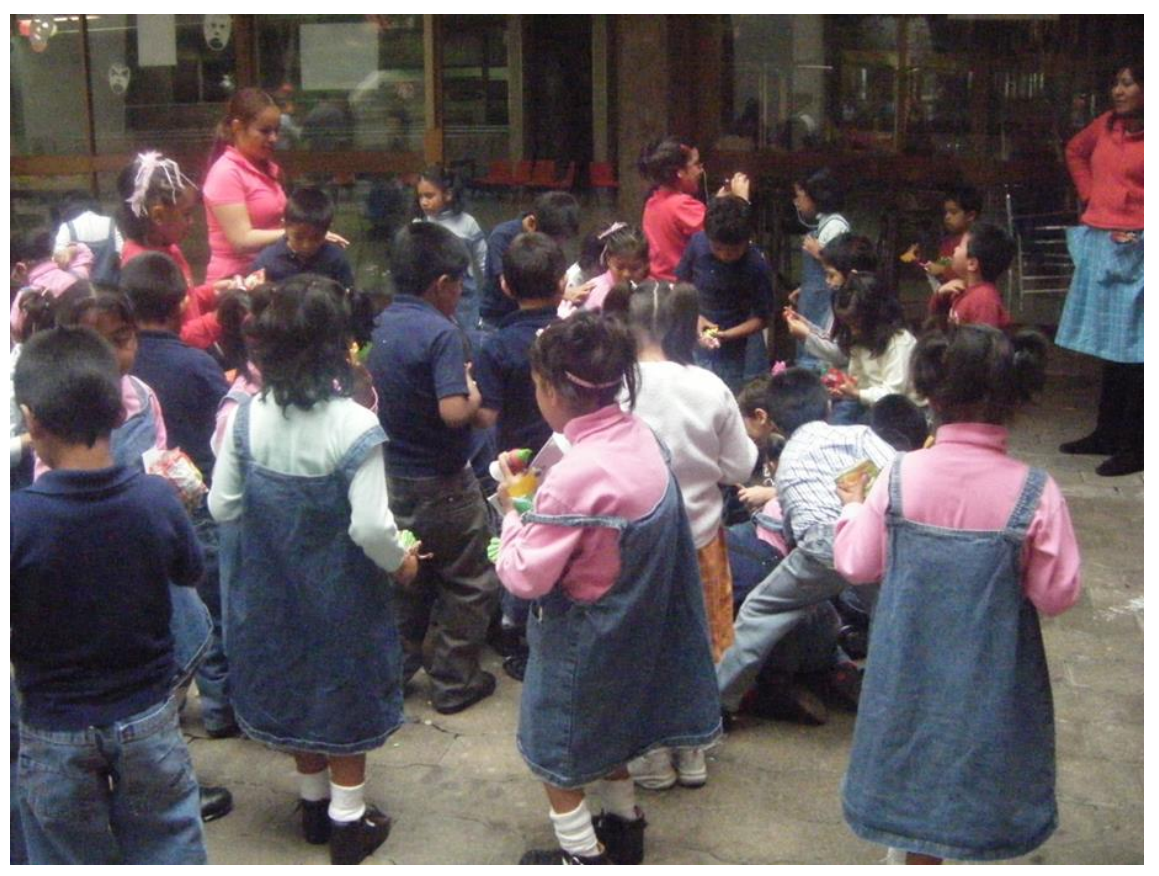

Imagen 20 Festividad en Casa Cuna Coyoacán Fuente: Archivo personal, Ruíz Gabriela 2009. 
Distintos autores han planteado que niñas y niños en instituciones con estas características, tienden a una vida que en el modelo institucionalizado se determina con normas, reglas internas y condicionantes que homogenizan el comportamiento y que en gran medida masifican a la población (ver imagen 20 y 21). Horarios de rutinas tales como: el desayuno, la comida, el baño, son previamente definidos por las y los cuidadores formales y profesionistas encargados del funcionamiento institucional; vestimenta, calzado, alimentos, son adquiridos en cantidades mayores y sin una diferenciación. Incluso niñas y niños comparten juguetes, ropa de cama, entre otros.

Imagen 21 Reglamento ubicado a la entrada del dormitorio: Sala Preescolar Niñas, Casa Cuna Coyoacán

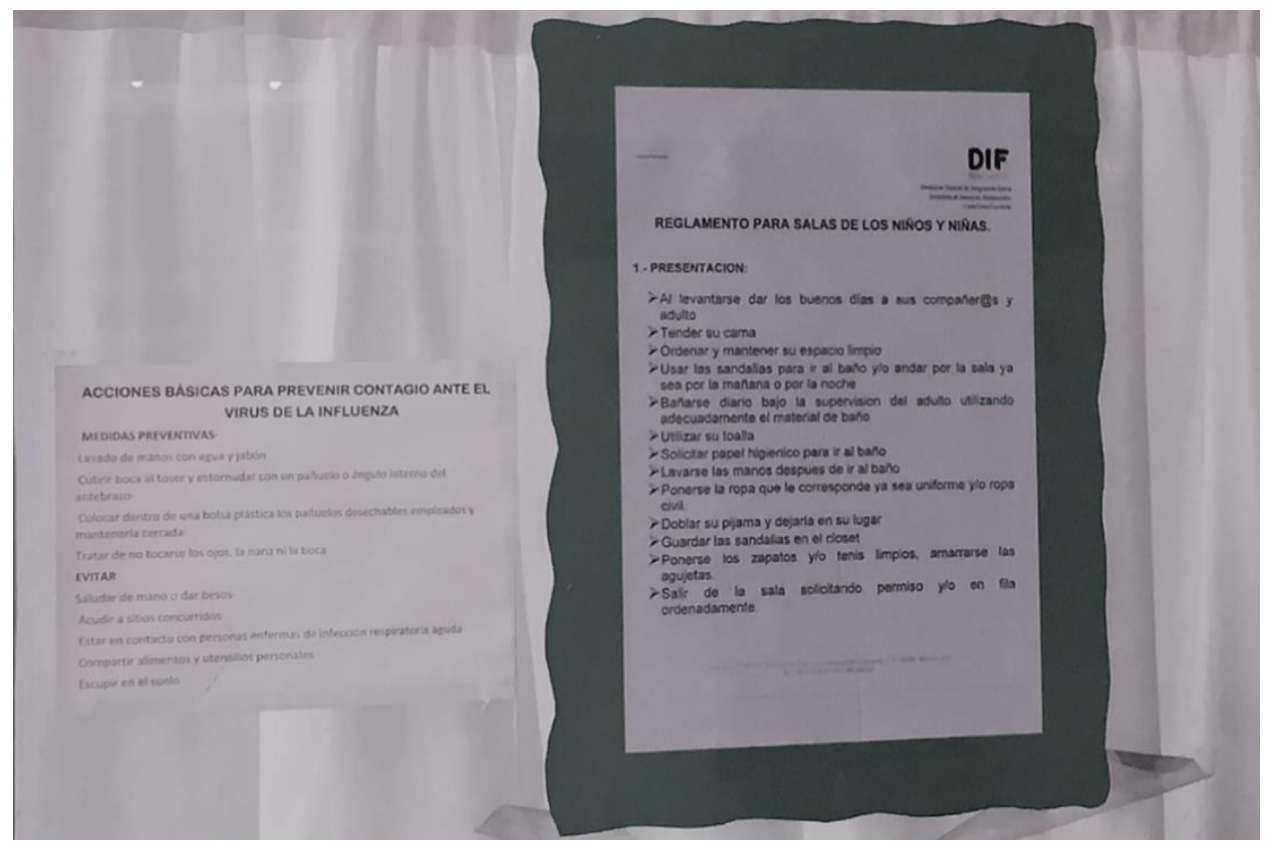

Fuente: Archivo personal, Ruíz Gabriela 2007. 
Imagen 22 Sala de aislamiento que aloja a las niñas y niños de reciente ingreso en Casa Cuna Coyoacán

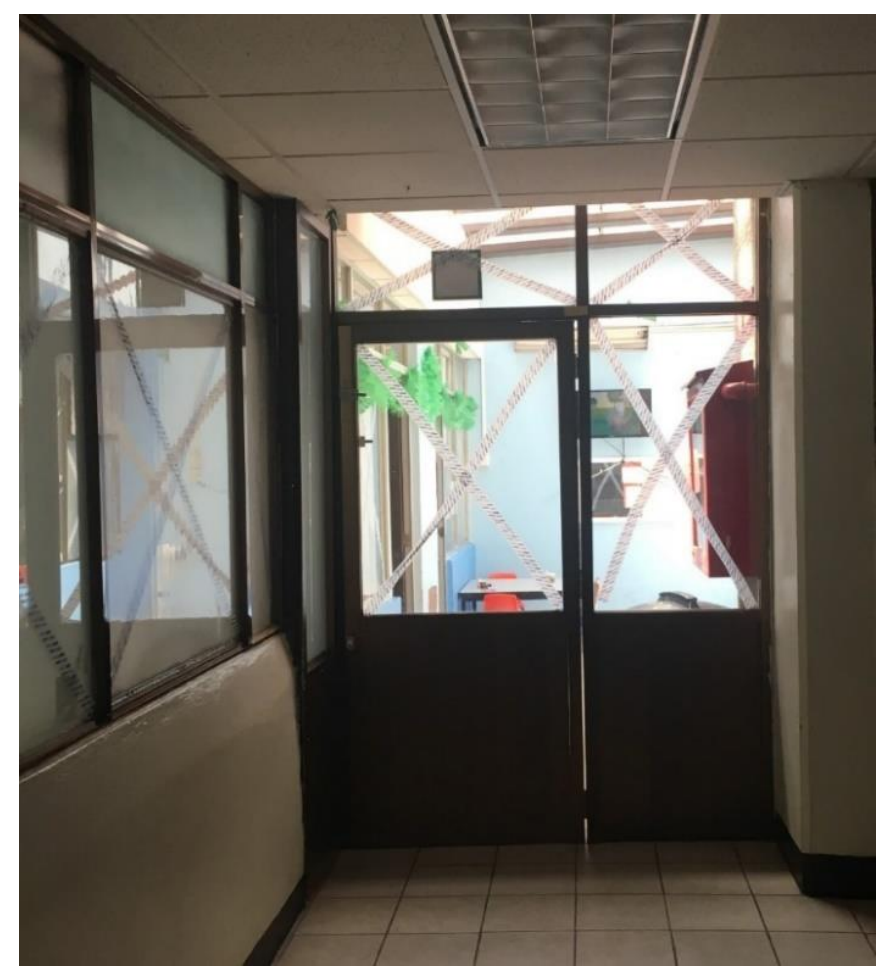

Fuente: Archivo personal, Ruíz Gabriela 2007.

Respecto a la vida en condiciones de institucionalización, Rene Spitz, psiquiatra y psicoanalista austriaco nacido en Viena, dirigió investigaciones extensas acerca del hospitalismo, un diagnóstico pediátrico utilizado para describir a niños pequeños que no se desarrollan o prosperan en un entorno hospitalario o de casas hogar (ver imagen 22) cuando viven allí por periodos largos sin sus madres (la tasa de mortalidad en estas casas es notablemente más alta) (Chanin, 2018: XXV).

Organismos como UNICEF (2020) atribuyen a niñas y niños en condición de institucionalización: rendimiento escolar por debajo de su edad, limitaciones de orden cognitivo, incapacidad para vincularse afectivamente, problemas para relacionarse en ámbitos sociales de forma adecuada e incluso comportamientos violentos. Se caracterizan por reacciones emocionales impulsivas que oscilan entre un desapego afectivo hasta las dependencias masivas. Los niños y niñas más pequeños frecuentemente presentan retraso del desarrollo, alteraciones del sueño, enuresis, desmotivación expresada en forma de 
aburrimiento y conducta pasivo-agresiva; con relación a las y los adolescentes, problemas de adaptación y desafiantes.

También se han asociado ciertas afectaciones a la salud mental, como el "trastorno reactivo de la vinculación de la niñez", que incluye síntomas relativos a la conducta de apego y los liga a una causa concreta (maltrato o crianza en ambientes que limitan la oportunidad de formar apegos selectivos). "Al basarse en la conducta social en contextos muy determinados (niños maltratados e institucionalizados), el trastorno reactivo de la vinculación se ha apoyado en la observación de una población muy determinada, es de esperar un sobrediagnóstico de esta" (Galán, 2010:587).

Por otra parte, la psicología ha denominado a muchas de ellas y ellos como "niños velcro", quienes buscarán evitar cualquier tipo de interacción con alguna persona. Mientras que los llamados "niños pegajosos" buscarán el contacto todo el tiempo con cualquier persona para sentirse seguros. Ambos pueden demostrar una extensión amplia de problemas emocionales tales como síntomas depresivos y de ansiedad o comportamientos que buscan la seguridad.

Otra característica de los niños en esta condición tiene que ver con la desvalorización que se refiere al concepto de sí mismo debido a angustias de la infancia, a errores y fracasos, al temor y a la responsabilidad, ya que esta exige compromiso y supone para él un lazo afectivo positivo o negativo. No arriesga lo que supondría crear este lazo por temor a la frustración y el temor al abandono (Bowlby, 1967 citado en López, 2016).

\subsubsection{Trastornos psicológicos y psiquiátricos asociados con la institucionalización de niñas y niños en CAS}

Diversas expertas y expertos han resaltado que la vida en los CAS, sumada a la violencia vívida frecuentemente en la primera infancia, construye cuerpos altamente traumatizados. Comúnmente la niñez que permanece en institucionalización puede vivir situaciones económicas, familiares y sociales muy distintas a la de los niños que viven en familias convencionales. "La ocurrencia de acontecimientos estresantes es uno de los factores de riesgo para el ajuste infantil, existiendo una amplia evidencia empírica sobre el aumento del

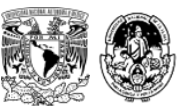


riesgo de desarrollar problemas emocionales y depresivos" (Oliva, Jiménez, Parra y SánchezQueija, 2008: 53-62).

Con frecuencia se construyen a su alrededor una serie de trastornos de orden psicológico y/o psiquiátrico que les constriñe y atribuye dificultades en todas las áreas, entre ellas, las habilidades de socialización:

Tabla 15 Trastornos vinculados con la niñez en condición de institucionalización

\begin{tabular}{|l|l|l|l|l|}
\hline Autismo & $\begin{array}{l}\text { Trastorno } \\
\text { de Déficit } \\
\text { de }\end{array}$ & $\begin{array}{l}\text { Trastorno } \\
\text { del } \\
\text { Atención }\end{array}$ & $\begin{array}{l}\text { Trastorno } \\
\text { Espectro } \\
\text { Autista }\end{array}$ & $\begin{array}{l}\text { Trastorno } \\
\text { do del } \\
\text { Desarrollo }\end{array}$ \\
\hline Oposición \\
Desafiante
\end{tabular}

Fuente: Elaboración propia, 2019.

Es común que niñas y niños sean medicados para controlar su comportamiento y regular sus relaciones sociales.

Cuando características como la tristeza, la inquietud infantil, la timidez, la rebeldía adolescente, que son inherentes a lo humano, se transforman en patología nos encontramos ante un proceso de patologización de la vida. Este proceso lleva a concebir como enfermas ciertas particularidades de los sujetos, lo cual implica un conjunto de operaciones políticas, programas, estrategias y dispositivos; intervenciones puntuales; campos argumentales; cuyos efectos ubican en un lugar de enfermo/a, o de potencialmente enfermo o anormal o pasible de traumatización o desubjetivización, a aquellos individuos que quedan por fuera de los criterios de normalidad de su época (Untoiglich, 2014: 25). 
De acuerdo con la información proporcionada a partir de las "preguntas ciudadanas"44 que realicé en 2018, supe que hay un porcentaje significativo de niñas y niños que viven en los CAS del SNDIF vinculados con un diagnóstico psiquiátrico.

Tabla 16 Número de población albergada en los CAS del SNDIF diagnosticada con un trastorno psicológico y/o psiquiátrico para 2018

\begin{tabular}{|c|c|}
\hline $\begin{array}{c}\text { CAS DEL SNDIF Y } \\
\text { PORCENTAJE DE } \\
\text { POBLACIÓN MEDICADA }\end{array}$ & DIAGNÓSTICOS \\
\hline $\begin{array}{c}\text { CNMAIC CCT } \\
7.3 \%\end{array}$ & $\begin{array}{l}\text { TDAH vs Oposicionista desafiante. } \\
\text { TDAH }\end{array}$ \\
\hline $\begin{array}{c}\text { CNMAIC CCC } \\
\mathbf{3 1 . 8 1 \%}\end{array}$ & $\begin{array}{l}\text { Trastorno por Desregulación Disruptiva de las Emociones y TDAH. } \\
\text { Limítrofe vs Discapacidad leve TDAH, Trastorno de Conducta, } \\
\text { Trastorno Mental y del Comportamiento Secundario A Disfunción } \\
\text { Cerebral. } \\
\text { Trastorno adaptativo Enuresis, Trastorno de Conducta, } \\
\text { Discapacidad intelectual leve, Trastorno de Conducta TDAH, } \\
\text { Trastorno de lenguaje, Enuresis, Trastorno Adaptativo. }\end{array}$ \\
\hline $\begin{array}{c}\text { Subdirección del Centro } \\
\text { Amanecer para Niños } \\
62.9 \%\end{array}$ & $\begin{array}{l}\text { Trastorno Mental y del Comportamiento Secundario A, Síndrome } \\
\text { Congénito de Angelman, Trastorno Disocial Severo con Escasas } \\
\text { Emociones Prosociales, TDAH. } \\
\text { Trastorno de Conducta, TDAH, Trastorno del Espectro Autista, } \\
\text { Síndrome de Asperger, Discapacidad Intelectual vs Inteligencia } \\
\text { Limítrofe. } \\
\text { Trastorno Disocial con Escasas Emociones Prosociales, TDAH } \\
\text { Moderado, Trastorno de Desregulación Disruptiva de las } \\
\text { Emociones y Rasgos Acentuados de Personalidad Limítrofe, } \\
\text { Trastorno Disocial con Escasas Emociones Prosociales, TDAH sin } \\
\text { ansiedad en el presente, Trastorno adaptativo, Enuresis Primaria } \\
\text { Nocturna, Ansiedad infantil en tratamiento, Reacción Adaptativa } \\
\text { con Síntomas de Ansiedad y Conducta, Trastorno por Ansiedad de } \\
\text { Separación, Discapacidad Intelectual, Trastornos de Aprendizaje. } \\
\text { Trastorno de Déficit de Atención con Hiperactividad, Trastorno } \\
\text { Depresivo, Trastorno de Estrés Postraumático, Trastorno }\end{array}$ \\
\hline
\end{tabular}

${ }^{44}$ Las "preguntas ciudadanas" son un mecanismo de acceso a la información del que cualquier ciudadano mexicano puede echar mano y obtener información relativa a un tema en particular de competencia gubernamental. Su acceso se gestiona a través de Instituto Nacional de Acceso a la Información (INAI). 


\begin{tabular}{|c|l|}
\hline & $\begin{array}{l}\text { Adaptativo, Trastorno Mental y del Comportamiento Secundario A, } \\
\text { Disfunción Cerebral, Retraso Mental Leve. }\end{array}$ \\
\hline CNMAIC-CAHONI & $\begin{array}{l}\text { Trastorno oposicionista desafiante, Trastorno hipercinético } \\
\text { Disocial, Trastorno por déficit de atención con Hiperactividad, } \\
\text { Trastorno oposicionista desafiante, Discapacidad Intelectual, } \\
\text { Trastorno depresivo mayor, Trastorno de estrés postraumático, } \\
\text { Discapacidad intelectual con compromiso del comportamiento, } \\
\text { Trastorno adaptativo, Trastorno oposicionista desafiante, Trastorno } \\
\text { adaptativo son síntomas de ansiedad, Discapacidad intelectual, } \\
\text { rasgos acentuados de personalidad limítrofe, Distimia. Trastorno } \\
\text { mental orgánico, Discapacidad intelectual con compromiso del } \\
\text { comportamiento, Trastorno mixto ansioso depresivo. Trastorno } \\
\text { adaptativo, Trastorno de estrés postraumático, Atención por } \\
\text { antecedente de uso de etanol. Trastorno de estrés postraumático, } \\
\text { Discapacidad Intelectual con compromiso del comportamiento. }\end{array}$ \\
\hline CNMAIC-CAHOVA & $\begin{array}{l}\text { TDHA, Depresión, Estrés Postraumático, Trastorno Antisocial } \\
\text { Oposicionista. Depresión, Trastorno Disocial con riesgo Psicótico, } \\
\text { Ansiedad por separación, Trastorno de ansiedad, Depresión, } \\
\text { TDHA, Retraso del Neurodesarrollo. Depresión, Retraso del } \\
\text { Neurodesarrollo, TDAH. }\end{array}$ \\
\hline
\end{tabular}

Fuente: Elaboración propia a partir de información obtenida en Preguntas Ciudadanas: 1236000034019/33919/34119/34219/37419, proporcionada por el SNDIF (2019).

La medicina social regula la vida a partir de estrategias de control sofisticadas que se relacionan con la creación de instituciones, procedimientos, saberes y marcos jurídicos que pretenden la optimización y el cumplimiento de ciertos objetivos respecto de la población como objeto de intervención (Salinas, 2014:34).

Foucault (2018) ve el proceso de la medicalización ligado a perspectivas normalizadoras. En realidad, la medicina de intervención autoritaria en un campo cada vez mayor de la existencia individual o colectiva es un hecho absolutamente característico. Hoy la medicina está dotada de un poder autoritario con funciones normalizadoras que van más allá de la existencia de las enfermedades y la demanda del enfermo (2018: 179). 


\subsubsection{Afectaciones al desarrollo derivadas de la institucionalización en la niñez}

Como hemos mencionado, organismos internacionales como UNICEF (2018) han documentado las afectaciones en las diversas dimensiones individuales, resultado de que un menor de edad experimente la vida en contextos de institucionalización -que no se limitan a la esfera psicológica o psiquiátrica-. A continuación, se exponen algunas afectaciones:

Tabla 17 Implicaciones y consecuencias de la institucionalización en la niñez

\begin{tabular}{|c|c|}
\hline Desarrollo físico & $\begin{array}{l}\text { Los niños que han permanecido en ambientes institucionales } \\
\text { presentan las siguientes características: estatura y peso menor al } \\
\text { promedio, problemas intestinales y de piel, voracidad de comer, } \\
\text { desnutrición, problemas bucales. }\end{array}$ \\
\hline $\begin{array}{l}\text { Desarrollo } \\
\text { cognoscitivo }\end{array}$ & $\begin{array}{l}\text { La niñez en condición de institucionalización puede mostrar } \\
\text { problemas de atención y de pensamiento y menor competencia } \\
\text { social, particularmente las niñas son las que frecuentemente repiten } \\
\text { años escolares. } \\
\text { Otras de las características son la hiperactividad/inatención y los } \\
\text { déficits cognitivos; retraso en la adquisición de vocabulario, } \\
\text { reducción en las habilidades de comunicación y conducta; procesos } \\
\text { sensoriales anormales, coeficiente intelectual más bajo, así como } \\
\text { menores habilidades de lectura y con frecuencia necesidad de } \\
\text { educación especializada. }\end{array}$ \\
\hline \multirow[t]{2}{*}{ Desarrollo afectivo } & $\begin{array}{l}\text { Con relación al desarrollo afectivo, los niños que han estado bajo } \\
\text { situación de institucionalización muestran trastornos o problemas } \\
\text { de apego; es común que muestran un apego no seguro. Cuando se } \\
\text { habla de la seguridad en el apego se refiere a la percepción que tiene } \\
\text { el individuo sobre sí mismo como agente competente para } \\
\text { promover una respuesta positiva a las figuras de apego. (Marrone, } \\
\text { 2001). Por lo tanto, algunas manifestaciones del apego inseguro } \\
\text { serán: enojo, conducta de oposición con relación a un adulto, evita } \\
\text { la proximidad o el contacto, conductas desconectadas, dificultad en } \\
\text { responder a gestos de consuelo, en comparación con niños que } \\
\text { viven en casa con sus padres biológicos. Este déficit en sus } \\
\text { relaciones con la gente y la debilidad en el vínculo emocional, son } \\
\text { anormales en su desarrollo y conducta. }\end{array}$ \\
\hline & $\begin{array}{l}\text { En lo concerniente al desarrollo social, los menores presentan } \\
\text { déficit en su competencia social, dificultad para hacer amistades y } \\
\text { para establecer relaciones con otros, presentan experiencias } \\
\text { constantes de rechazo, así como sentirse excluidos del grupo por }\end{array}$ \\
\hline
\end{tabular}




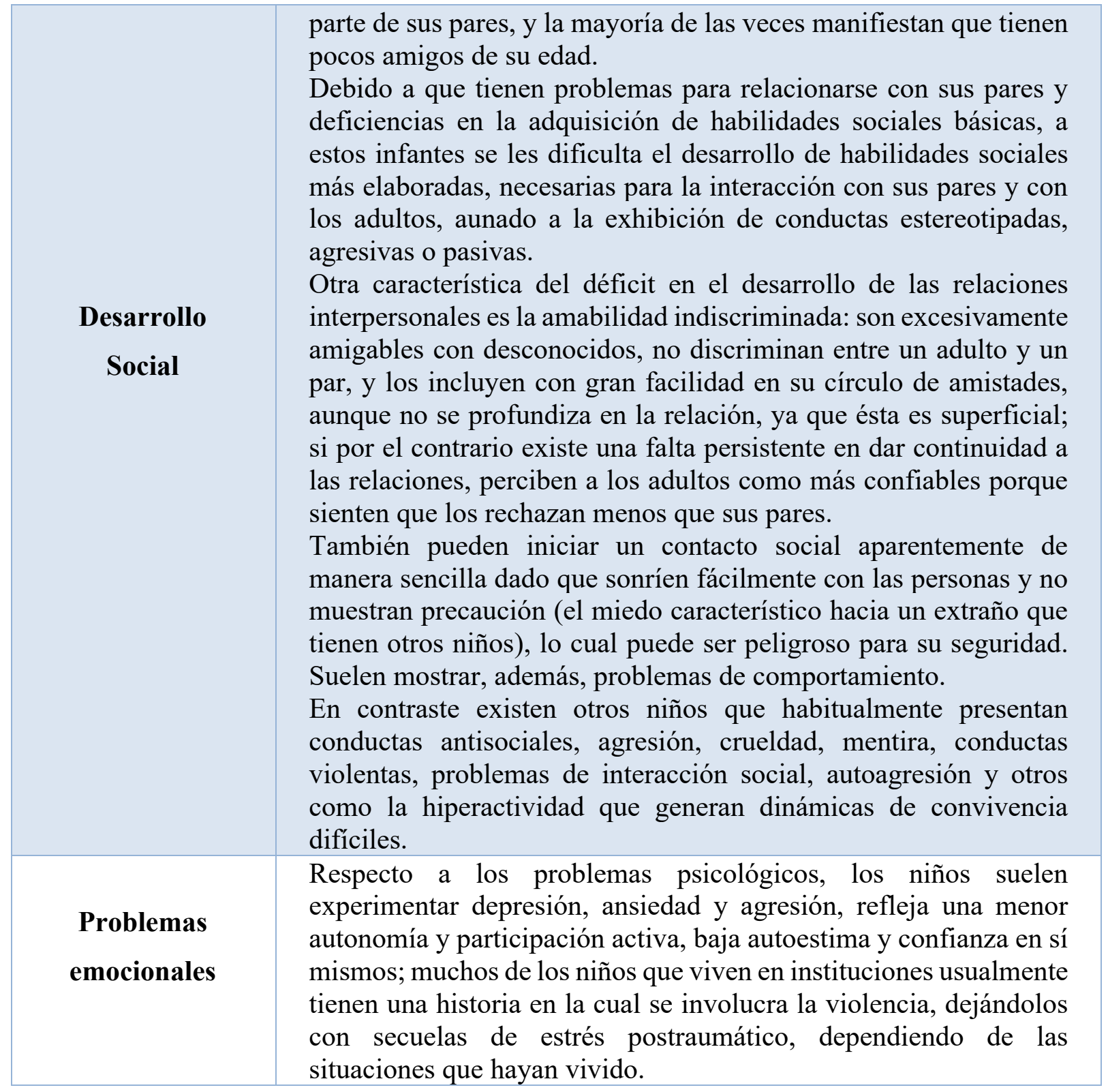

Fuente: Elaboración propia, a través de la recolección de información, 2017.

La opinión general que aún predomina es que las casas hogar son perjudiciales y que todas las niñas y los niños deben ser colocados en acogimiento familiar u otras alternativas de cuidado sustituto. ${ }^{45}$

${ }^{45}$ Chanin entiende por acogimiento familiar, lo que para el Estado mexicano es Familia de Acogida: aquélla
que cuente con la certificación de la autoridad competente y que brinde cuidado, protección, crianza positiva y
la promoción del bienestar social de niñas, niños y adolescentes por un tiempo limitado hasta que se pueda
asegurar una opción permanente con la familia de origen, extensa o adoptiva (LGDNNA, 2014: 3). Ella misma
manifiesta que la situación es compleja: el sistema de acogimiento familiar no garantiza que el menor sea 2. 
Hasta el momento se han planteado con detalle las implicaciones que la vida institucionalizada acarrea en niñas y niños y la manera en cómo afecta su desarrollo integral. Este impacto, se agudiza cuando el CAS -definido para su cuidado alternativo- contraviene la tarea de restitución de derechos, configurándose como un "espacio de riesgo" y perpetración del maltrato, condición que será profundizada en el capítulo siguiente.

\section{Epílogo}

La historia de Margarita, que abre este capítulo, pone en evidencia cómo las condicionantes estructurales de pobreza, marginalidad y violencia, inciden en las dinámicas familiares, favoreciendo la reproducción del maltrato, la negligencia y el abandono.

Toñito (su hijo) fue ingresado a un CAS, vinculado con uno de los motivos de ingreso descritos a lo largo del capítulo: “madre en condición de reclusión”, tras una determinación de orden judicial (que se deduce del relato) y sin posibilitar otras formas, destinando al niño a una vida en condición institucionalizada -que no dista sustancialmente de las estrategias gubernamentales de atención a los menores de edad previstas en la década del cuarenta-, que afecta en las dimensiones emocionales, sociales, psicológicas, pedagógicas, entre muchas otras.

La niñez en el territorio nacional experimenta cada vez y con mayor frecuencia este y otro tipo de realidades en un contexto determinado por las condicionantes derivadas de la presencia del crimen organizado; la niñez migrante que transita proveniente del Triángulo Norte de América Central, sin compañía y de forma irregular; la creciente orfandad vinculada con los feminicidios en México que reporta registros de 10 mujeres asesinadas al día en nuestro país; sin dejar de lado la enorme agudización de las desigualdades que coloca en contextos profundamente precarizados a NNA, inhibiendo la satisfacción de sus necesidades y derechos fundamentales.

entregado en el hogar correcto, o pase de familia en familia o logre sentirse parte de alguna (Chanin, 2018: $\mathrm{XXV})$.

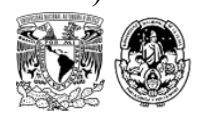


Este capítulo fue diseñado con la intención de contextualizar el cuidado alternativo a través de la institucionalización en nuestro país, desvelar la manera en cómo las condicionantes estructurales impactan en el tejido comunitario y familiar, determinando muchas veces el desprendimiento de niñas y niños de sus núcleos primarios y la consecuente intervención estatal para su ingreso a CAS, estrategia que no es nueva y deviene de un trayecto histórico cuya génesis gubernamental se coloca en el auge del Estado benefactor.

Es en el año 1977 que por Decreto Presidencial se constituye el SNDIF como lo conocemos hoy, teniendo como antecedente diversos programas e instituciones que atendían a las poblaciones más desfavorecidas.

De ahí en adelante, se han robustecido otras tecnologías de poder en donde las epistemes jurídicas se sobreponen. En 2016 inicia en funciones la PFPNNA tras la entrada en vigor de la LGDNNA (2014), confiriéndole atributos de representatividad de la niñez en México y, desde su creación, determina los ingresos y egresos a los CAS del SNDIF al mismo tiempo que los "planes de restitución de sus derechos", los cuales obedecen a motivos diversos enlistados en las legislaciones internacionales y nacionales como: la omisión de cuidados, el abuso sexual, físico y/o psicológico, la niñez migrante no acompañada, entre otras.

La vida en condición de institucionalización que se ofrece a esta niñez receptora de maltrato tiene afectaciones derivadas del abuso cometido en su contra en el ámbito familiar, el desprendimiento del sistema primario y la vida despersonalizada en los CAS, que suscitan -con base en lo documentado- trastornos psicológicos y/o psiquiátricos, y es así como se catalogan, diagnostican, evalúan y construyen epistemes que avalan tratamientos medicalizantes, exhibiendo importantes fisuras en su desarrollo integral. 


\section{- CAPítulo Vi •}

\section{CENTROS DE ASISTENCIA SOCIAL: \\ “ESPACIOS DE RIESGO", UNA INVISIBLE REALIDAD}

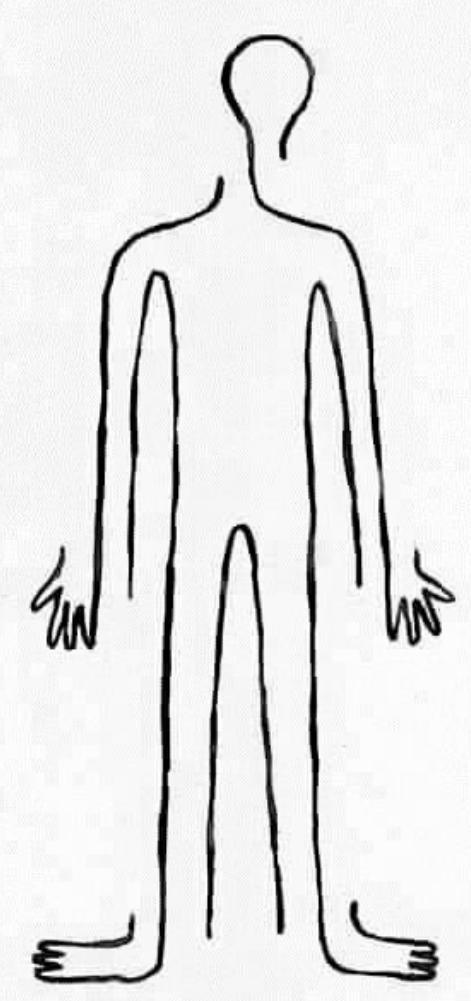

TROCHE

Troche, G. (2017). [Ilustración]. Recuperada de: https://www.facebook.com/PAingresARTE/photos/t.100047049700022/1362859240498096/?type=3 
La niñez es una construcción histórica, "una invención moderna". La pienso como un lugar constituido artificialmente, como un síntoma, como un lazo que nos defiende y nos posiciona frente a Otro. También en este sentido, como una singular expresión de lo que pasa con el lazo social.

(Pippi de Medeiros, 2009: 36)

JUAN

(2014)

El día 11 de julio de 2014, la Directora General de Integración Social ${ }^{46}$ del Sistema Nacional para el Desarrollo Integral de la Familia informó quiénes serían las coordinadoras responsables de las áreas de Psicología y Trabajo Social que participarían en un "operativo" con la Subprocuraduría Especializada en Investigación y Delincuencia Organizada (SEIDO), en coordinación con la Comisión Nacional de Derechos Humanos (CNDH): "la salida será el lunes 13 de julio en el vuelo 1416, destino Morelia Michoacán". No hubo detalles, el operativo era "secreto", tampoco hubo especificaciones respecto del rol profesional que habríamos de jugar, sólo una comisión oficial que inscribía fecha de salida sin especificar las condiciones del regreso.

Cuando me dieron la noticia de dicha encomienda (imagen 23) yo desconocía que la operación a la cual era enviada tenía como objetivo el rescate de 600 niñas y niños que presuntamente vivían en condiciones de hacinamiento y maltrato institucional: vejaciones ejercidas por las autoridades de un albergue de la sociedad civil que operaba hacía más de 40 años con el nombre La Gran Familia.

\footnotetext{
${ }^{46}$ La Dirección General de Integración Social cuenta con un manual operativo que define los procedimientos específicos y la secuencia de acciones de su quehacer a través de los Centros Asistenciales, con la finalidad de unificar criterios de operación para optimizar la prestación de los servicios de atención las niñas, los niños, las y los adolescentes y adultos mayores en situación de vulnerabilidad y que requieran de Asistencia Social (Manual de procedimientos, SNDIF, 2014).

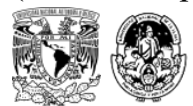


Imagen 23 Dictamen pericial del caso La Gran Familia, 2014

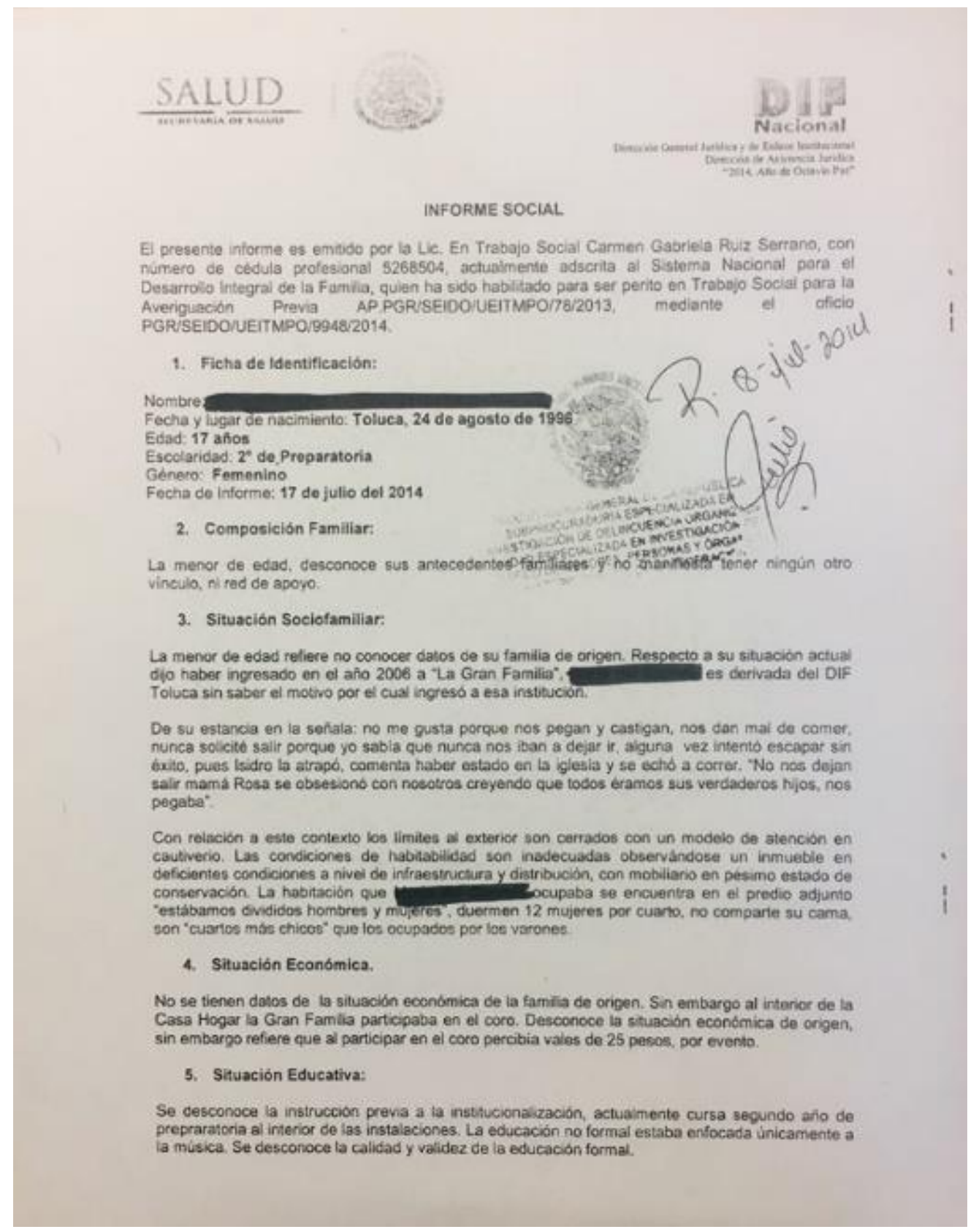

Fuente: Archivo personal, Ruíz Gabriela 2014.

El caso La Gran Familia ocupó los titulares de la prensa nacional en julio de 2014 al darse a conocer un operativo judicial llevado a cabo en el municipio de Zamora Michoacán que tenía como objetivo el rescate de niñas y niños albergados en la Asociación Civil del mismo nombre. Este se encontraba dirigido por una mujer de nombre Rosa Verduzco, quien era

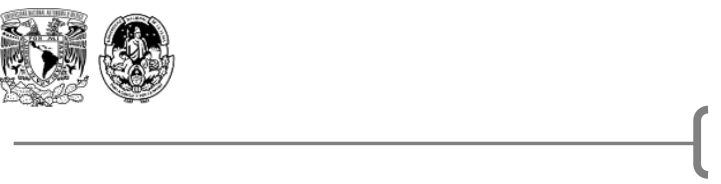


conocida por los residentes y la propia población del municipio de Zamora Michoacán como "la jefa".

También desconocía que años atrás, el área jurídica de la institución a la que yo pertenecía (SNDIF), había intentado ingresar al albergue (ya se sabía de las condiciones de violencia que en él se perpetraban) con un resultado infructuoso, pues al parecer había personas interesadas en que dicho espacio siguiera operando. Esto lo supe en una conversación con una compañera de trabajo y al respecto debo decir que dudaba de su versión. Sin embargo, el ver fotografías, donaciones e incluso cartas de protección de políticos, intelectuales y benefactores, hizo cuestionarme el alcance y veracidad del testimonio.

Veinticinco intelectuales defendieron a Rosa Verduzco y pidieron que se investigara a fondo este "nuevo michoacanazo", ya que "la humillación escandalosa de una gran trabajadora social es inmerecida y atenta contra sus derechos más elementales [...]Durante 66 años, Rosa Verduzco ha dedicado su vida a recoger, atender y educar niños abandonados para insertarlos en la sociedad, dándoles internado, educación básica, enseñanza de oficios y hasta una licenciatura en música", difundieron en una carta.

Los intelectuales mencionaron que "no es posible que en La Gran Familia haya habido irregularidades. Si las hubo, las autoridades deben investigarlas y sancionarlas". La carta fue firmada por Roger Bartra, Lydia Cacho, Miguel Carbonell, Lázaro Cárdenas, Christopher Domínguez, Malva Flores, Fernando García Ramírez, Hugo Hiriart, Enrique Krauze, Jean Marie Le Clezio, Andrés Lira, Jean Meyer y Verónica Murguía. Además de Fausto ZerónMedina, Gabriel Zaid, José Woldenberg, Isabel Turrent, Guillermo Soberón, Javier Sicilia, Guillermo Sheridan, Alberto Ruy Sánchez, Cristina Pacheco, Margarita de Orellana y Verónica Murguía (Animal político, 2014). ${ }^{47}$

En el año 2014 me encontraba a cargo de la supervisión del área de Trabajo Social de los CAS del SNDIF enfocados a la atención de niñas, niños y adolescentes sin cuidados parentales y tras haber estado 7 años al frente del departamento de Trabajo Social de una Casa Hogar. Mi experiencia profesional me había aproximado a la intervención social con

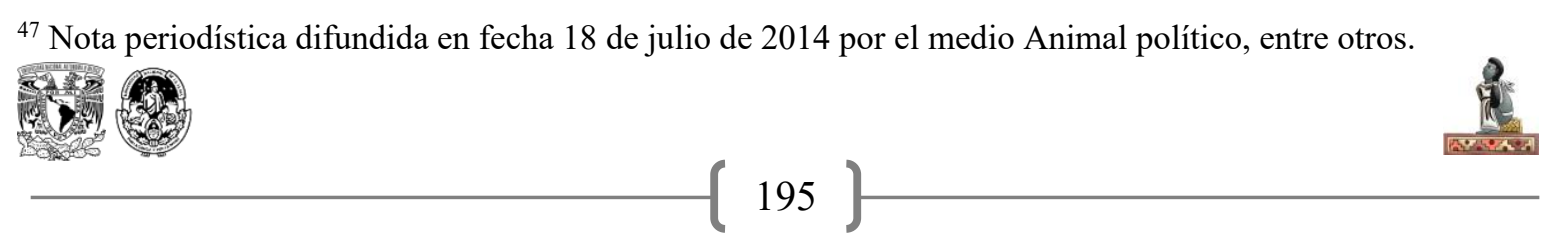


niñas y niños en condición de institucionalización y sus familias, en donde el factor común era la violencia familiar -en la mayoría de los casos ejercida al interior del ámbito domésticoque exigía, en definitiva, un conocimiento profundo de las características del maltrato y sus implicaciones.

Pero nunca me había enfrentado a violencias como las que descubrí en ese albergue: secuestros, torturas, violaciones, eventos que dejan un efecto traumático de alto impacto no sólo entre las víctimas directas, sino incluso en las víctimas potenciales ${ }^{48}$ (en las que nosotros nos implicamos sin saberlo explícitamente) y que además se tiñen de intereses políticos que desconocía -y a la fecha ignoro-.

Supe por una colega que mi designación para participar en el "operativo" se debía a mi experiencia en el acompañamiento de niñas y niños rescatados de una asociación civil en 2009 (Casitas del Sur), misma que se vinculó con adopciones ilegales y robo de infantes, ${ }^{49}$ y que este conocimiento me hacía idónea para participar. En aquella experiencia, mi intervención como trabajadora social se colocó en la atención directa de la niñez receptora de maltrato. Niñas y niños que fueron implicados en un determinante adoctrinamiento religioso que alienaba a la población albergada y sus familias, que compartían un factor común: condiciones de violencia al interior y extrema pobreza.

La noche que le antecedió al operativo de La Gran Familia fue de mucha angustia, no sólo para mí, sino para todas las personas asignadas a participar -esto lo supe tras las largas conversaciones que pudimos sostener durante los diez días que duró nuestra estadía en el albergue-. Lo poco que sabía me lo habían informado colegas con las que tenía una relación cercana y aparentemente contaban con más información respecto a la situación que nos ocupaba, nada certero en realidad.

Joison (1992) acuñó el término "trauma vicario", colocándolo como una categoría de estudio del agotamiento profesional que se experimenta cuando nos situamos en condiciones de alta

\footnotetext{
${ }^{48}$ Son víctimas potenciales las personas físicas cuya integridad física o derechos peligren por prestar asistencia a la víctima ya sea por impedir o detener la violación de derechos o la comisión de un delito (Ley General de Víctimas, 2017 Capítulo II, Art. 4).

${ }^{49}$ En el año 2009 en México y tras la denuncia por desaparición de la niña Ilse Michel, se intervienen las instalaciones del albergue Casitas del Sur, administrado por la Asociación Civil Reintegración Social, a la que se imputaron los delitos de tráfico de personas, adopciones ilegales y delincuencia organizada.

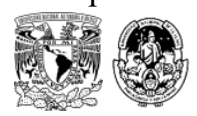


tensión, definiendo que trabajar en contextos de estrés permanente conlleva a las y los profesionistas a enfrentar con mayor intensidad las experiencias laborales, pues se agota la capacidad del organismo para enfrentar situaciones adversas. Un factor que aparece recurrentemente es la falta de información y predictibilidad. Para Ojeda (2006):

La traumatización vicaria es la presentación de síntomas relacionados con estrés postraumático en quienes apoyan a personas afectadas por una experiencia traumática, como en el caso de la violencia intrafamiliar. Se desarrolla como resultado de la exposición, breve o prolongada, a los traumatismos de la otra persona, combinada con la empatía que el trabajador siente hacia esta persona y con sus propias experiencias dolorosas aún no integradas en su vida (2006:23).

Saberme en un contexto tan incierto inhibió de primer momento mi capacidad cognitiva. El miedo, angustia y ansiedad me invadieron sin que pudiera hacer mucho al respecto.

Cuando nos encontramos frente a una amenaza la respuesta emocional se privilegia sobre la dimensión intelectual, igual que sucede con un niño o niña que ha sido sometido a escenarios hostiles y adversos. El aprendizaje depende de la habilidad para categorizar información. Podemos categorizar información y crear nuevas categorías sólo cuando estamos en un nivel de relativa calma y atención. Altos niveles de estrés apagan la habilidad normal. "Niñas y niños que han estado repetidamente ante situaciones de estrés abrumador se vuelve hipervigilantes, están expectantes y protegiendo la vida por encima de cualquier cosa" (Bloom, 2010:2).

El 14 de julio siendo las 10 de la mañana reunidos todos los profesionales en junta de trabajo, escuchamos: "[...] estas son las fotos aéreas del albergue, deberemos llegar mañana antes de las 8 para interrumpir a los niños antes de su salida a la escuela. Si durante el operativo alguien se desmaya o sale herido por alguna bala perdida, déjenlo en manos de los paramédicos, bajo ningún motivo intenten ayudarlo. Se les hará entrega de guantes, gorro, batas y zapatos especiales. No deben tocar a las personas que encontremos sin el equipo especializado y usarán repelente en todo momento. El primer lugar que habremos de intervenir es la celda de castigo "el Pinocho", sabemos que ahí hay niños con semanas de 
encierro y sin comida, es muy importante sacarlos a ellos primero [...]”. Estas fueron las indicaciones proporcionadas por el personal a cargo.

No dábamos crédito. ¿Acaso se trataba de una mala broma? La descripción del lugar y circunstancias no correspondían a un albergue infantil sino más bien a un centro de reclusión o un campo de concentración. Lo que en ese momento desconocíamos era que la representación hecha por los dirigentes del operativo en poco se acercaba a la realidad, lo que nos tocó atestiguar sobrepasó por mucho la primera descripción. La mirada de colegas, profesionales de otras disciplinas e instituciones, entre los que se contaban médicos, abogadas, psicólogas y defensores de derechos humanos, generaba una particular complicidad que se alimentaba de la expectativa, la incertidumbre y el compromiso profesional, mismo que se puso en juego una vez que estuvimos en la misma geografía de violencia y muerte que intuíamos, y al mismo tiempo no lográbamos dimensionar.

Así fue. El vuelo salió a las 6 de la tarde llegando a Morelia por la noche. En la madrugada del día siguiente nos encontrábamos reunidos: personal de la Procuraduría General de la República del Sistema Nacional para el Desarrollo Integral de la Familia y de la Comisión Nacional de Derechos Humanos, tres instituciones cuya responsabilidad era el rescate de niños y niñas albergados en La Gran Familia.

Los años de ejercicio y labor profesional en DIF Nacional habían traído consigo un trabajo colaborativo con trabajadoras sociales y otras profesionistas con quienes había compartido experiencias diversas. Eso facilitó la comunicación y el sentido de solidaridad, que no necesariamente se verbalizaba, sino que se comunicaba desde nuestra corporalidad y mensajes inscritos en la mirada.

Conforme nos íbamos acercando al lugar, el olor putrefacto, la imagen de un chiquero a la entrada y la tensión que se percibía en la penumbra de la madrugada, nos advertía que el momento tan temido se acercaba. Llegamos al lugar y como era esperado. La Policía Federal irrumpió sorpresivamente: rompió candados, ventanas, saltó bardas para abrir las puertas del lugar. El resto mirábamos asombrados aquel tenebroso escenario.

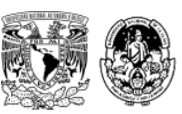




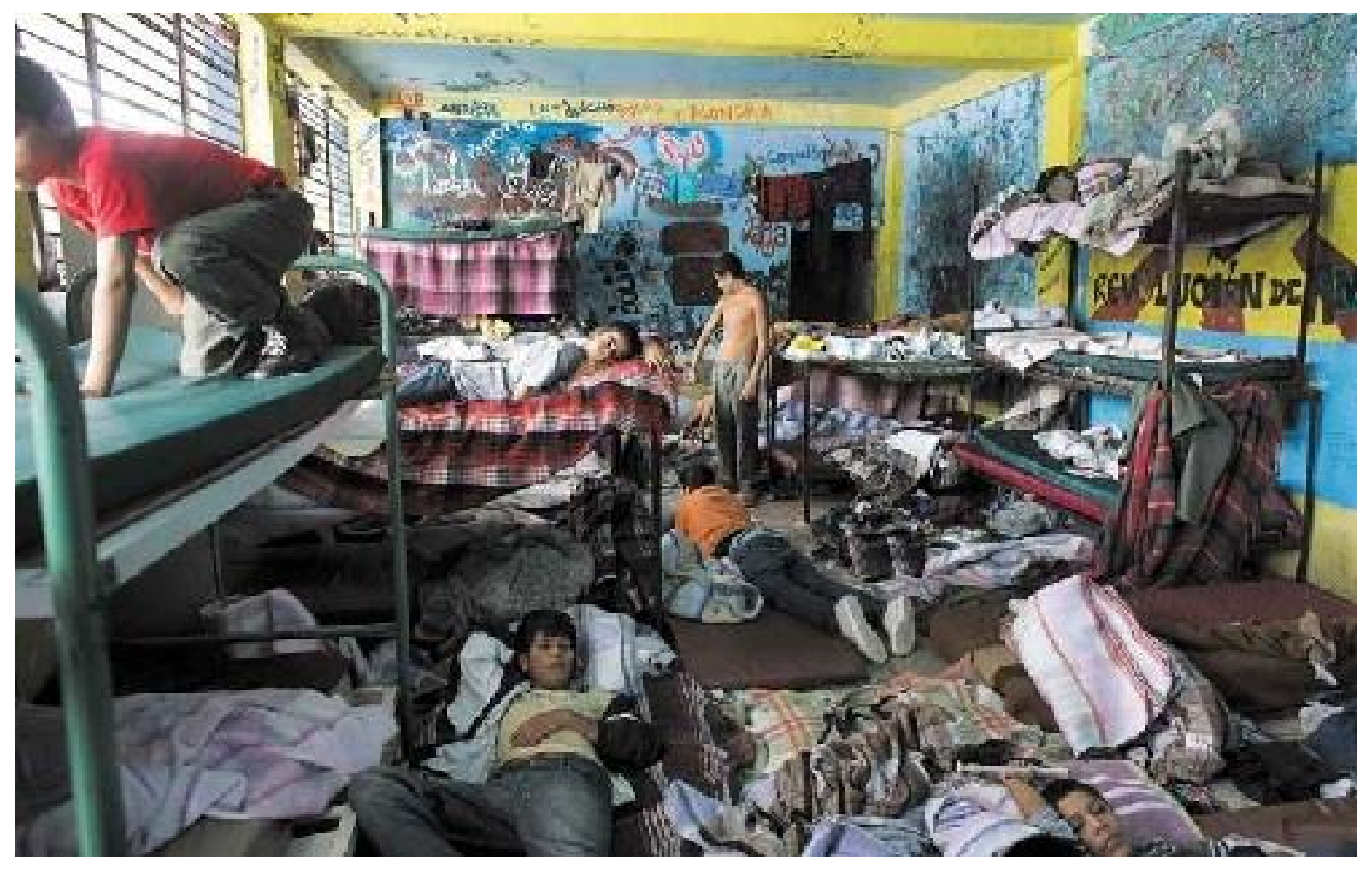

Imagen 24 Albergue La Gran Familia Fuente: La Gran Familia y sus demonios. Reconoce MX (2014).

Lentamente me acerqué sin mucho valor, debo reconocer; de inicio empujada por mi sentido de responsabilidad o quizá más bien acorralada por aquello que debía, pero no quería hacer. Entré sigilosamente al albergue, sabía que debía ir directo al "Pinocho", pero lo lento de mis pasos daba cuenta de mi resistencia. No había caminado un par de metros cuando él, Juan, un niño de aproximadamente 12 años me interceptó y sin más me dijo: “¿por qué no habían venido por nosotros?, por las noches gritábamos pidiendo auxilio. Se tardaron mucho".

¿Cuánto era mucho tiempo?, ¿por cuántas noches había gritado Juan? Días después supe que él había nacido en La Gran Familia, nunca había salido de ese lugar y no conocía más madre que "Mamá Rosa" que, de haberlo sido, lo habría engendrado a los casi 70 años, tal como se deducía por la información registrada en su acta de nacimiento. Su esbelta figura, las manchas y marcas en la piel, su cabello, su olor, su mirada, todo él era la evidente muestra de cómo la violencia, el maltrato y el dolor se viven, habitan y definen el cuerpo, y pese a eso hay algo que empuja y desafía.

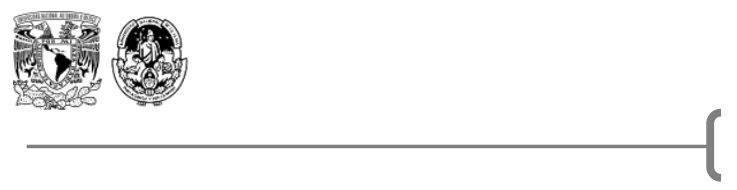


Es muy probable que Juan no supiera quiénes éramos o cuál era nuestra encomienda en ese "rescate" (creo que ni siquiera nosotros lo sabíamos claramente), pero algo dentro de él lo llevaba a resistir y reclamar la dignidad humana, esa que le había arrebatado autonomía, vida familiar y lo había situado en la estructura de un modelo indiferente a la vida de miles de niñas y niños cuya orfandad define en gran medida un camino hacia la desechabilidad.

Difícil en ese momento explicarme ¿cómo es que alguien que ha vivido preso intuye la libertad, aspira a ella y la reclama? ¿Cómo alguien cuya voz ha sido permanentemente silenciada, la alza y como un animal rabioso le escupe al mundo su existencia? ¿Cómo es que el sujeto institucional se niega a esa condición y se opone a la aniquilación?

Lo que mis colegas y compañeras vivieron no fue diferente. Recuerdo a la responsable del área de psicología en permanente contención de mujeres y niñas, quienes tras los relatos de abuso sexual y violaciones intentaban el suicidio; en la atención de niños y hombres que se golpeaban, atacaban y herían con todo lo que fuera posible: botellas, vidrios, tijeras. En ese holocausto todo se convertía en un arma, se respiraba el miedo, el dolor, la angustia y la incertidumbre.

Hubo momentos excepcionales, cierto. "islas de cuidado y armonía", acciones y actitudes que proveyeron de un sostenimiento emocional en aquel contexto que se configuraba violento y de riesgo, en donde las y los profesionales de las distintas disciplinas (Trabajo Social, Psicología, Derecho, entre otras) intentábamos tejer una red de fuerza frente a lo que experimentábamos al interior de nuestra mente y cuerpo, mismo que se veía atravesado por las historias que conocíamos. Algo que en mí se vivía como un "hospedar del otro" e incluso "a pesar del otro" y en donde frente a dicho acto, se hace imposible salir ileso. "Frente a la imposibilidad de disponer de un espacio para el otro, en tanto todo espacio se halla desde siempre contaminado por la alteridad, no obstante, es necesario insistir en la posibilidad de una apertura hospitalaria al otro en tanto compromiso con el otro, respeto de la diferencia, aun cuando la apertura solo pueda ser deficiente y provisional, o justamente por ello" (Derrida, 1998:54).

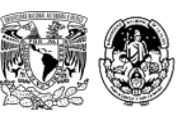


Tenía que ser así, de lo contrario hubiera sido imposible la estabilidad psíquica de profesionales, cuidadores y población en general. Yo cumplía 33 años, estaba lejos de casa y lo último que pasaba por mi mente era algún festejo por ello. Entré al comedor a una rutinaria inspección. Espacio que ya había sido habilitado con camas para las y los residentes que habían sido retirados de sus habitaciones con la finalidad de realizar la limpieza y fumigación de cada rincón del albergue. Con la batuta en la mano Marco indicaba la melodía: un grupo de aproximadamente 15 niños y niñas tocaron para mí las mañanitas. En un surrealista escenario emergía la música entre el olor a muerte, sexo, dolor, desesperanza. Ahí las lágrimas rodaron por mis mejillas, como si en ese llanto que me era permitido expulsara el dolor contenido frente a las vivencias acumuladas en esa realidad.

Lo que nuestros ojos, oídos y cuerpo presenciaron no cabía en la razón: cuerpos en descomposición carcomidos por piojos y liendres, ratas en los platos de comida, habitaciones llenas de excremento que alojaban a más de 50 personas entre los que se contaban mujeres, niñas, niños, hombres, adultos mayores. Un cuarto de perrera era más digno y limpio.

Fue el día 17 de julio que fuimos convocadas las trabajadoras sociales: debíamos realizar los peritajes para fundamentar los delitos encontrados, lo que significaba que en menos de 72 horas había que integrar las pruebas periciales, realizar la guía de entrevista, definir las categorías, metodología y enfoque. La noche que diseñamos la guía de entrevista, mis colegas se vivían colapsadas. Una de ellas se auto flagelaba enterrando sus uñas en la piel con una evidente dermatitis y una tos que no la dejaba articular una oración corrida.

Las narrativas que obtuvimos durante los diez días de estancia y las entrevistas realizadas describían venta de niños, órganos, mendicidad forzada, abusos sexuales, secuestros..., todo lo que necesitábamos para el Dictamen pericial en Trabajo social, ${ }^{50}$ mismo que documentaría

\footnotetext{
${ }^{50}$ El Dictamen Pericial articula el estudio del caso y del contexto desde la visión socio-jurídica y desde la teoría de la prueba. No es vinculante como tal, no ata al abogado en su valoración. Este es autónomo, pero debe tener en cuenta los aspectos antes mencionados para llegar a la conclusión de qué mérito probatorio asignar, es decir, libre valoración de la prueba. Es un medio de prueba que permite llevar al abogado a la convicción acerca de los hechos específicos, pues no es viable que él tenga competencias en todos los campos del saber (Quintero, 2014:32).

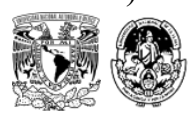


la averiguación previa por el delito de maltrato y trata de personas, informes que había que integrar antes de que se vencieran los tiempos procesales.

\section{Prefacio}

En el presente capítulo, nos sumergiremos en la devastadora realidad que México ha experimentado en materia de institucionalización de NNA, documentada y vinculada con algunos CAS de carácter social o privado (fundamentalmente) y que han sido denominados como "espacios de riesgo" expuestos gracias al periodismo de investigación y las observaciones de carácter nacional e internacional, en donde las violencias de tipo estructural han emergido: la trata de personas en sus fines de adopción ilegal, explotación sexual y/o laboral, la mendicidad forzada y el tráfico de órganos, además de abusos de orden físico, psicológico y sexual.

Se expone en una georreferencia que documenta lo relativo a la última década, haciendo una revisión por caso: año, ubicación geográfica y descripción, a través de la Recomendación ${ }^{51}$ o la documentación periodística.

Esta recuperación da rostro, describe escenarios y exhibe las dolorosas realidades del maltrato institucional que se perpetra en algunos CAS trascendiendo una estadística. Se construye frente a la necesidad de dimensionar la trascendencia del estudio de las características del cuidado alternativo a través de la institucionalización y referencia una cronología que parece no tener fin.

\footnotetext{
${ }^{51} \mathrm{La}$ Recomendación es la resolución mediante la cual la Comisión después de haber concluido las investigaciones del caso, determina de acuerdo con el análisis y evaluación de los hechos, argumentos y pruebas que constan en el expediente, que la autoridad o servidor público incurrió en violaciones a Derechos Humanos, al haber efectuado actos u omisiones ilegales, injustos, irrazonables, inadecuados o erróneos y señala las medidas procedentes para la afectiva restitución a los afectados de sus derechos fundamentales, y en su caso las sanciones susceptibles de ser aplicadas al responsable (CNDH, 2020). 


\subsection{Centros de Asistencia Social identificados en el territorio nacional como "espacios de riesgo"}

En agosto de 2019, se realizó el IV Seminario Internacional de Prácticas pedagógicas en contextos de encierro: perspectivas interdisciplinarias (Chile). Este espacio sirvió para colocar sobre la mesa de la discusión las condiciones que vive la infancia en los espacios de cuidado alternativo en América Latina y que se configuran como escenarios de encierro distantes de restituir los derechos de niñas y niños expulsados de sus sistemas de origen. Según un informe publicado por la Policía de Investigaciones (PDI) en 2019, en el 88 por ciento de los Centros en Chile se constató que se vulneraron los derechos de niños y niñas. Algunas de las reflexiones planteadas fueron que:

[...] en instituciones de protección existen circuitos de desprotección, los cuales están hechos de eso que es lo "insoportable" o experiencias negativas que marcan a niñas, niños y adolescentes. Lo que es insoportable para un niño quizás se aproxime a lo traumático. En esos casos, lo primero que se debe hacer al trabajar con infancias dañadas es devolverle lo enigmático a las experiencias insoportables que han vivido, porque se ha pensado que esos saberes instituidos en el lugar y señalados por Foucault, han llevado a creer que "estos niños ya tienen escrito todo su destino o futuro, la verdad es que no hay mentira más grande". Lo que si configura el circuito de lo insoportable es la manera regular que poseen las instituciones de responder ante estos menores (Escobar, 2019: 1).

Para el caso de México, las condiciones no son diferentes y se agudizan ante la falta de cercanía por parte de las autoridades para realizar un adecuado y oportuno acompañamiento y vigilancia de los CAS -de carácter privado-, lo que favorece la violación de los derechos de niñas y niños, configurándose como espacios de maltrato y los no lugares de la infancia.

El Comité de los Derechos del Niño de las Naciones Unidas en sus Observaciones Finales sobre los exámenes periódicos Cuarto y Quinto consolidados de México, adoptadas durante su sesión sexagésima novena del 18 de mayo al 5 de junio de 2015, a pesar de acoger con satisfacción que la Ley General de Derechos de Niñas, Niños y Adolescentes (LGDNNA) incluya la prohibición de la separación de niñas y niños de sus familias por situación de

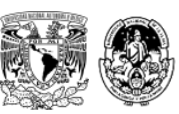


pobreza y que ordene el establecimiento de Procuradurías de Protección Especial para, entre otras cosas, proteger a niñas y niños privados de un entorno familiar, le preocupe sin embargo que:

(a) No existen políticas suficientes para apoyar a las familias en el cumplimiento de sus responsabilidades parentales;

(b) El número total de niñas y niños privados de un entorno familiar es desconocido;

(c) La institucionalización continúa siendo la opción priorizada sobre los hogares de acogida;

(d) Existe una supervisión inadecuada en las instituciones de cuidado alternativo, lo cual resulta en casos notorios de abuso y negligencia, como lo son "Casitas del Sur" y "La Gran Familia” (Mamá Rosa) (ONU, 2015:12).

Estas recomendaciones no son un asunto menor y ponen en tela de juicio la real eficacia estatal con respecto a las medidas de cuidado que se proveen a la niñez en estos espacios que se configuran a manera de escenarios hostiles, violentos y de encierro, en una estructura panóptica que determina la vida y las relaciones penetrando así los cuerpos, determinando su vida presente y futura desde una "nuda vida" y en una clara expresión de la microfísica del poder. "Basta entonces con situar a un vigilante en la torre central y en cada celda encerrar a un loco, un enfermo, un condenado, un obrero o un escolar" (Foucault, 1976: 218).

Homogenizar y desdibujar la realidad de los niños y niñas carentes de cuidados parentales y en condición de institucionalización, abraza la idea de la necesidad por categorizar sin que ello traiga consigo una profunda reflexión de sus vidas. "Desenlazar el vínculo conceptual entre infancia y cronología nos permite no solamente distinguir los conceptos niñez e infancia, sino también develar la construcción biopolítica -esto es, no sólo la construcción social - sobre el adulto y la adultez que subyace contenida en la forma de futuro y finalidad de ambas, niñez e infancia" (Mantilla, 2016). 
Para el caso de la niñez que ocupa el presente texto, es necesario reconocerla en un entramado de inclusión-exclusión, en donde el sistema produce cuerpos de desecho.

Observamos en el capítulo tres que la niñez se coloca como consumidor y consumible, en donde esta última nos abre interrogantes: ¿qué sucede cuando la niñez carece de un capital simbólico, cultural, económico y social que le excluye de esta opción? ¿De qué manera el carecer de un referente de familia les ubica en una orfandad real y simbólica en donde sus cuerpos pueden ser utilizados para infinidad de atrocidades en el manto de cuidado que aparentemente ofrecen los CAS?

[...] su vida puede ser suprimida impunemente. Miles de niños y niñas mueren cotidianamente y se transforman en niño sacer: son eliminables o desechables y la característica básica es que su muerte no entraña ninguna consecuencia jurídica. Nos dice así que, en términos biopolíticos, como categoría emancipatoria la niñez trae por condición lo más trágico: ser la primera en camino de la desaparición (Pippi de Medeiros, 2009: 37).

Perry y Szalavitz, aseguran que:

Aproximadamente un tercio de los niños que han sufrido abusos, padecerán algún problema psicológico evidente a consecuencia de estos malos tratos (y las investigaciones continúan demostrando cómo incluso problemas puramente "físicos", como las enfermedades cardiacas, la obesidad y el cáncer, tienen una mayor probabilidad de afectar a niños traumatizados más adelante). La atención adulta ofrecida a los niños durante y después de acontecimientos traumáticos puede suponer una diferencia abismal, en estos posibles desenlaces, tanto para bien como para mal (2016:12).

La recurrencia de experiencias de maltrato en nuestro país experimentadas en CAS de carácter social y privado (fundamentalmente) supone una cronología inagotable, en donde parece nula la intervención del Estado por generar condiciones que coadyuven en su desaparición. A continuación, se exponen algunos de los casos documentados en nuestro país que han sido resultado de investigaciones periodísticas y en donde se han reflejado condiciones de abuso y maltrato de alto impacto. 
Las autoridades demuestran su incapacidad, su desidia, su complicidad. Las historias se acumulan, se repiten con una regularidad escandalosa. Cada caso que nos persigue consagra la impunidad e invita a la repetición del abuso, en medio de la indiferencia general. Un país que renuncia a sus valores y abandona a los niños compromete su dignidad su futuro (Martínez, 2009: 15).

\subsubsection{Cronología de las geografías de violencia: violaciones a derechos de la niñez en Centros de Asistencia Social en México}

“Comité de los Derechos del Niño de las Naciones Unidas, en junio del 2015 a México: [...] y existe una supervisión inadecuada en las instituciones de cuidado alternativo, lo cual resulta en casos notorios de abuso y negligencia, como lo son "Casitas del Sur", "CAIFAC" y "La Gran Familia" (REDIM, 2018)".

A continuación, las y los lectores encontrarán la georreferencia del maltrato institucional documentado (ver imagen 25 y tabla 18), además de una serie de descripciones que detallan: año, estado de la República mexicana en donde se suscitó y nombre del CAS vinculado con el maltrato: 
Imagen 25 Mapa de la República mexicana donde se referencia el Maltrato institucional documentado de 2007 a 2019

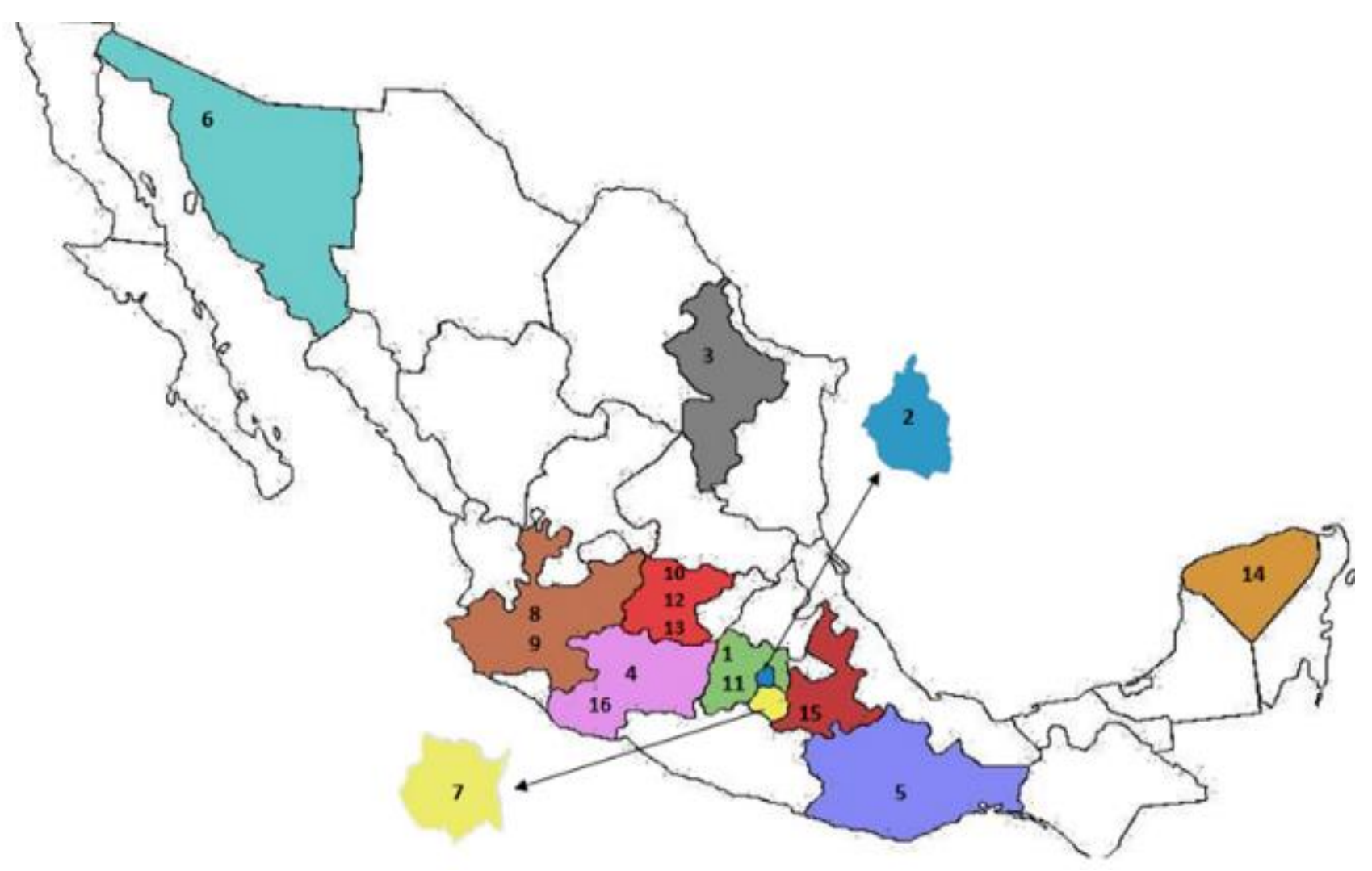

Fuente: Elaboración propia a partir de información recabada en el proyecto investigativo: Problemáticas de la niñez en el México contemporáneo (2016-2019, ENTS-UNAM).

Los casos de maltrato experimentados al interior de los CAS y en contra de niñas y niños albergados han sido documentados por diversas instancias y me han llevado a realizar un recorrido por otras fuentes, entre las que se cuentan: Diagnósticos nacionales como el Informe Especial sobre la situación de los Derechos de Niñas, Niños y Adolescentes en Centros de Asistencia Social y albergues públicos y privados de la República mexicana (2019); notas, periódicos y revistas nacionales (Proceso 2009, Colima noticias 2018, Aristegui 2016, Sin embargo 2019); y encuentros conversacionales en el marco del proyecto investigativo Problemáticas de la niñez en el México contemporáneo (2017), que además concentra la información recabada de las diversas fuentes. 
Tabla 18 Mapa de la República mexicana georeferencial del Maltrato institucional documentado de 2007 a 2019

\begin{tabular}{|c|c|c|c|}
\hline \multicolumn{4}{|c|}{ Acotaciones } \\
\hline & Año & Estado & CAS \\
\hline 1 & 2007 & Estado de México & Villa de las Niñas \\
\hline 2 & 2009 & Ciudad de México & Casitas del Sur \\
\hline 3 & 2009 & Monterrey, Nuevo León & $\begin{array}{l}\text { CAIFAC: Centro de Adaptación e } \\
\text { Integración Familiar }\end{array}$ \\
\hline 4 & 2014 & Michoacán & La Gran Familia \\
\hline 5 & 2015 & Oaxaca & Albergue Hijos de la Luna \\
\hline 6 & 2015 & Sonora & DIF Estatal \\
\hline 7 & 2016 & Morelos & Albergue Amor para Compartir \\
\hline 8 & 2016 & Jalisco & $\begin{array}{c}\text { Albergue Despertar Espiritual, Alcohólicos y } \\
\text { Drogadictos de Occidente A.C. }\end{array}$ \\
\hline 9 & 2016 & Jalisco & Villa de los Niños de Acatlán de Juárez \\
\hline 10 & 2017 & Guanajuato & Ciudad de Los Niños \\
\hline 11 & 2017 & Estado de México & La Divina Providencia \\
\hline 12 & 2018 & Guanajuato & Albergue Infantil de Irapuato, A.C \\
\hline 13 & 2019 & Guanajuato & Casa Hogar del Niño Pobre, Celaya \\
\hline 14 & 2019 & Mérida & $\begin{array}{l}\text { CAIMEDE: Centro de Atención Integral al } \\
\text { Menor en Desamparo }\end{array}$ \\
\hline 15 & 2019 & Puebla & DIF Estatal \\
\hline 16 & 2019 & Michoacán & Casa de mamá Rosita \\
\hline
\end{tabular}

Fuente: Elaboración propia a partir de información recabada en el proyecto investigativo: Problemáticas de la niñez en el México contemporáneo (2016-2019, ENTS-UNAM). 
La recuperación de la información ha sido sistematizada en una línea de tiempo que va del año 2007 al 2019 y organizada como se ejemplifica a continuación:

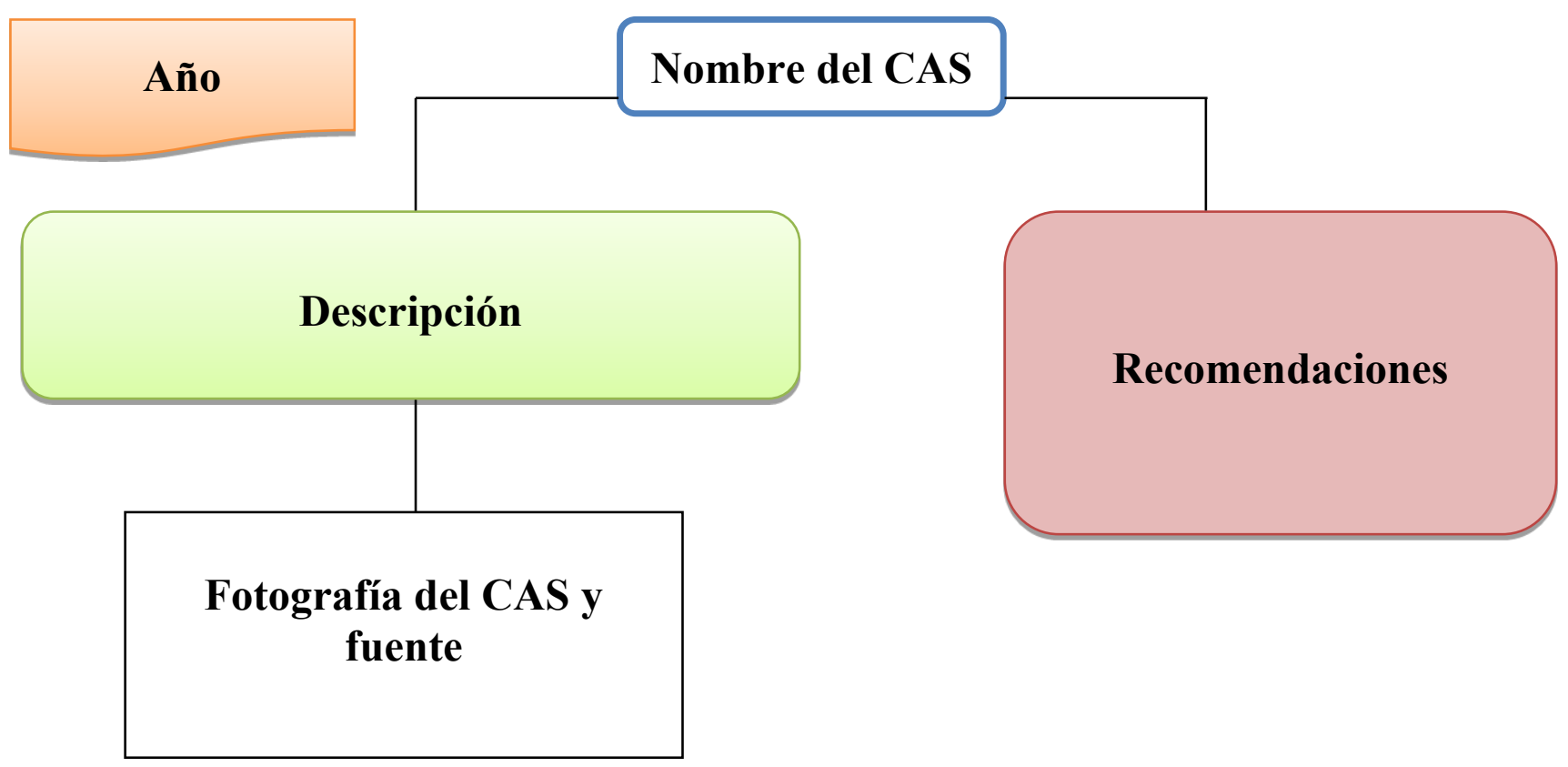

No omito mencionar que, aunque a continuación se describirán 19 casos (documentados de 2007 a 2019) de los cuales sólo se mapearon 16, para el caso de las Recomendaciones 22/2015 (Chihuahua) y 37/2015 (Michoacán) descritas en el Informe de la CNDH (2019: 1718), no se refiere a un CAS específico sino a la ausencia de protocolos y capacitación estatal por generar condiciones de cuidado alternativo para la población infantil en condición de vulnerabilidad. El que ocupa al Centro Nacional Modelo de Atención, Investigación y Capacitación Casa Hogar para Niñas "Graciela Zubirán Villareal”, se centra exclusivamente en observaciones de carácter infraestructural. Estos tres casos referidos han sido incluidos dado que obran en el Informe 2019 realizado por la Comisión Nacional de Derechos Humanos. 


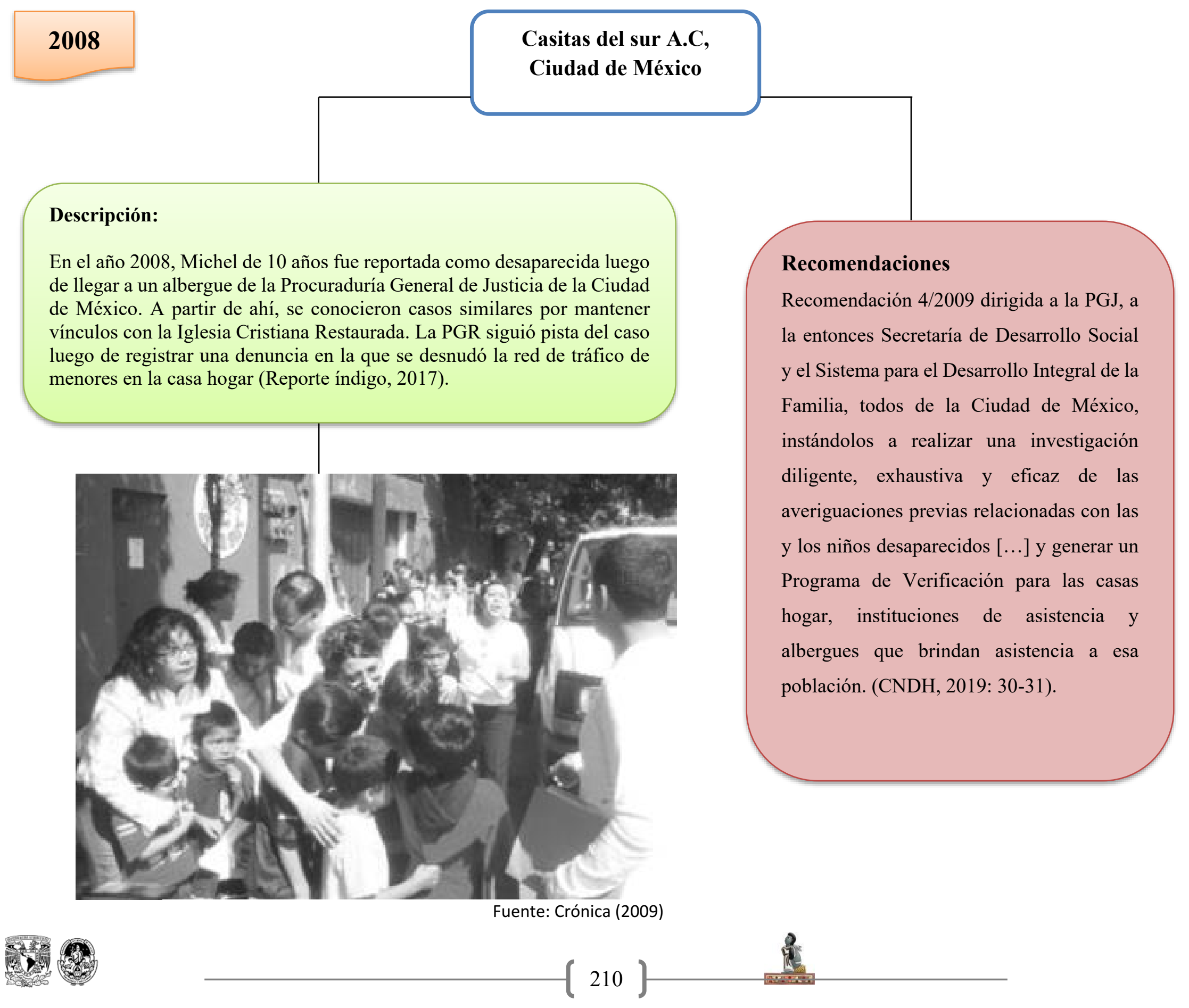


Caifac: Centro de Adaptación e Integración Familiar, A.C. Monterrey, Nuevo León

\section{Descripción:}

El refugio para menores en Monterrey presuntamente es administrado por la secta "Los Perfectos" de la Iglesia Restaurada Cristiana, que también dirige otros albergues, como "La Casita", en Cancún, Quintana Roo y "Casitas del Sur", en el Distrito Federal, y en los que también se han hecho señalamientos sobre una posible trata de menores de edad (Proceso, 2009).

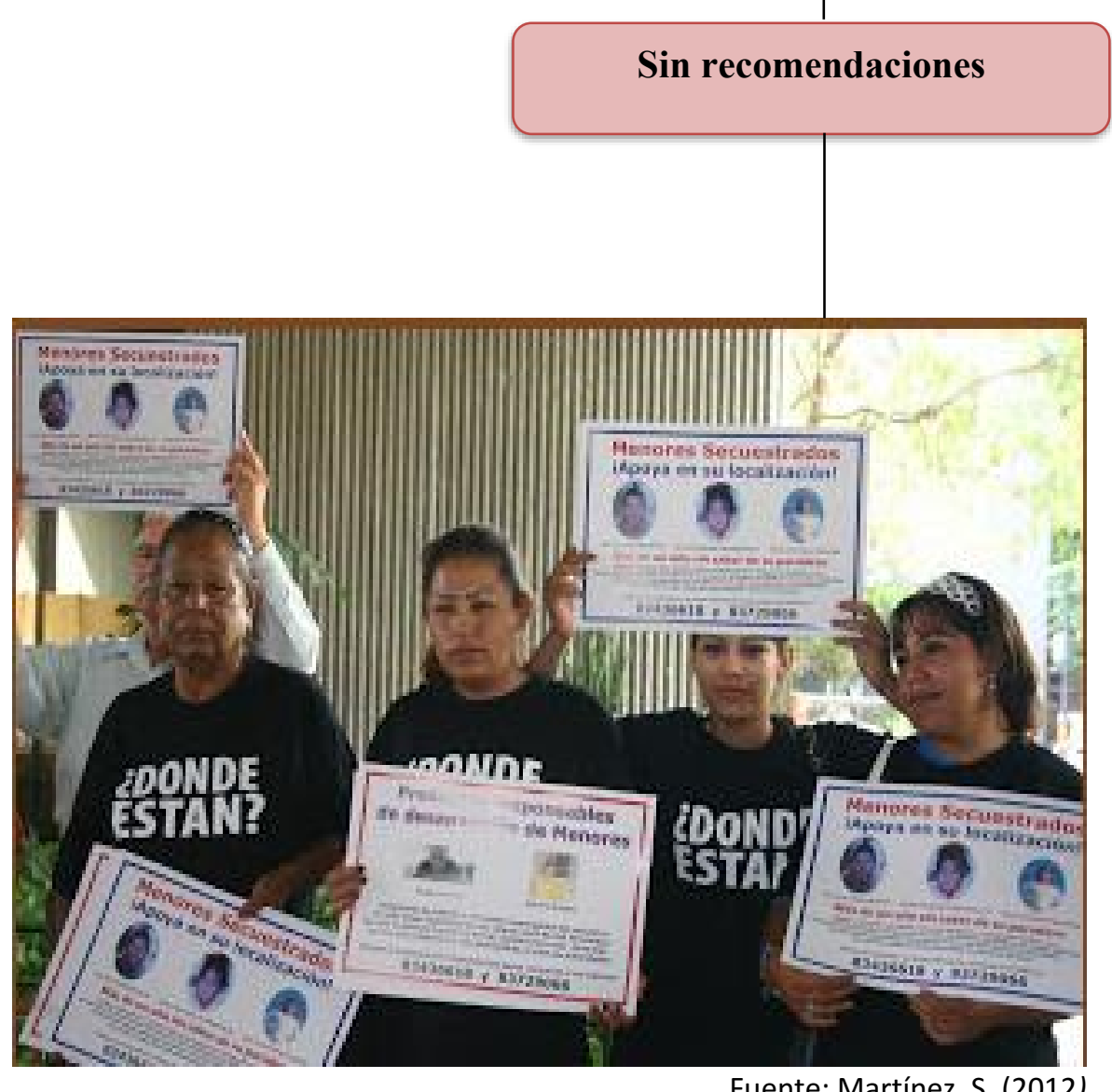

Fuente: Martínez, S. (2012)

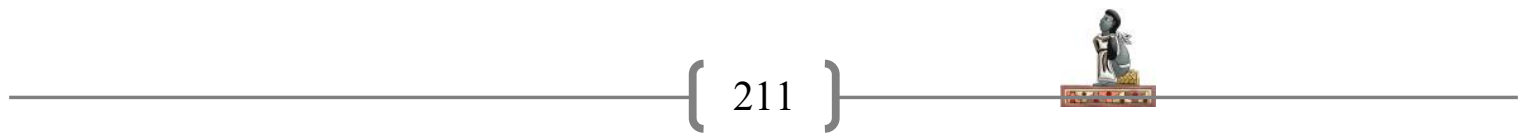



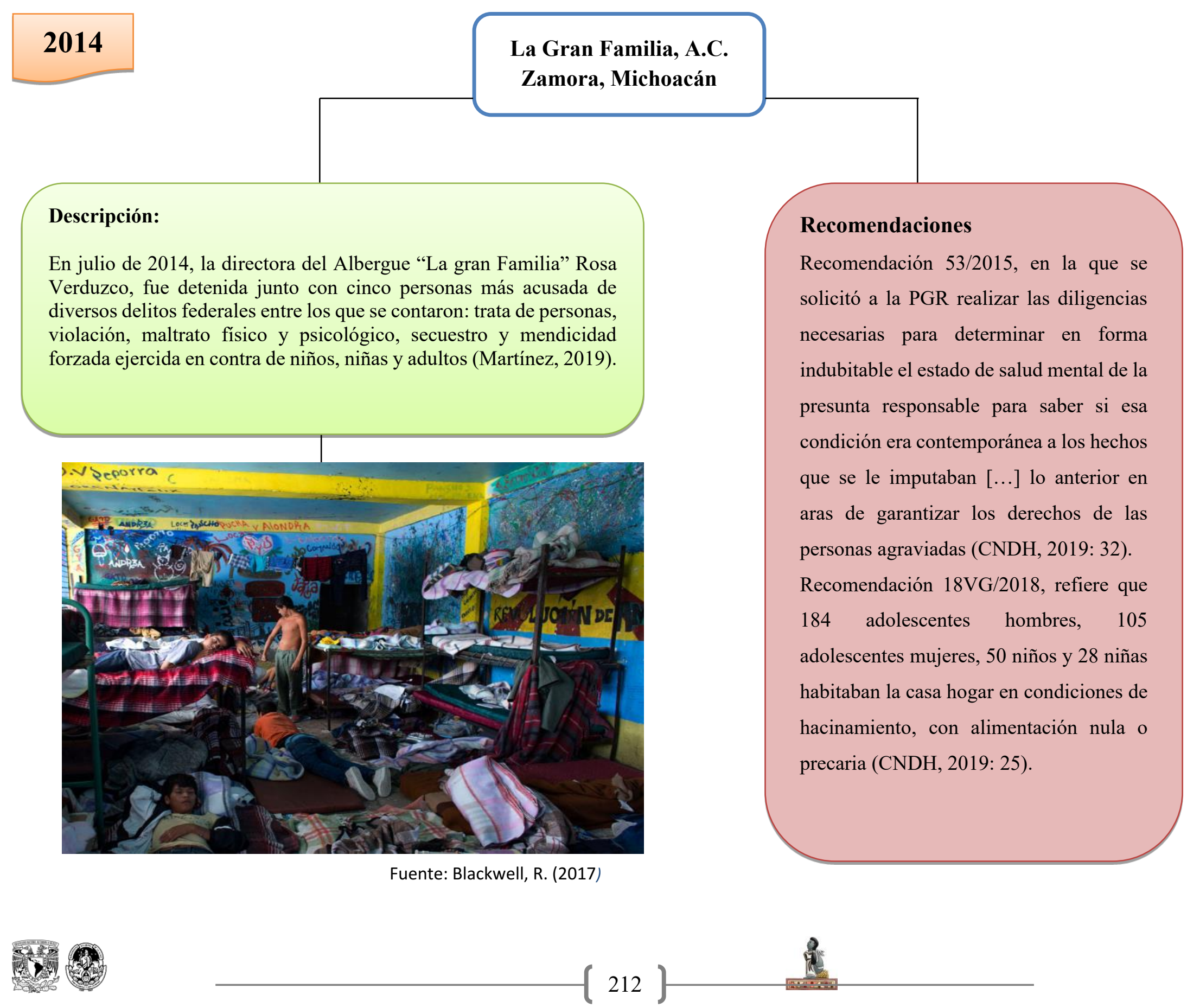


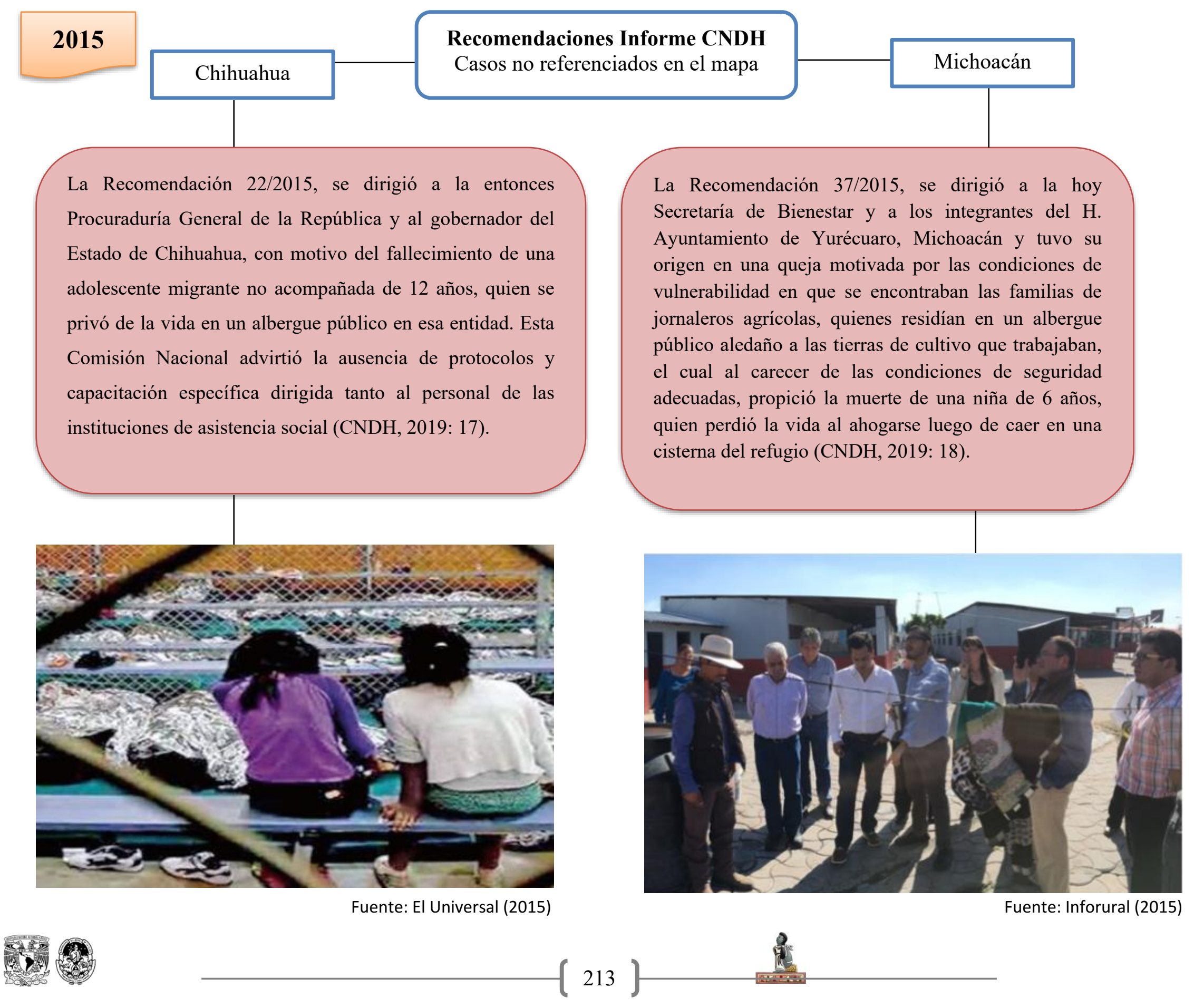




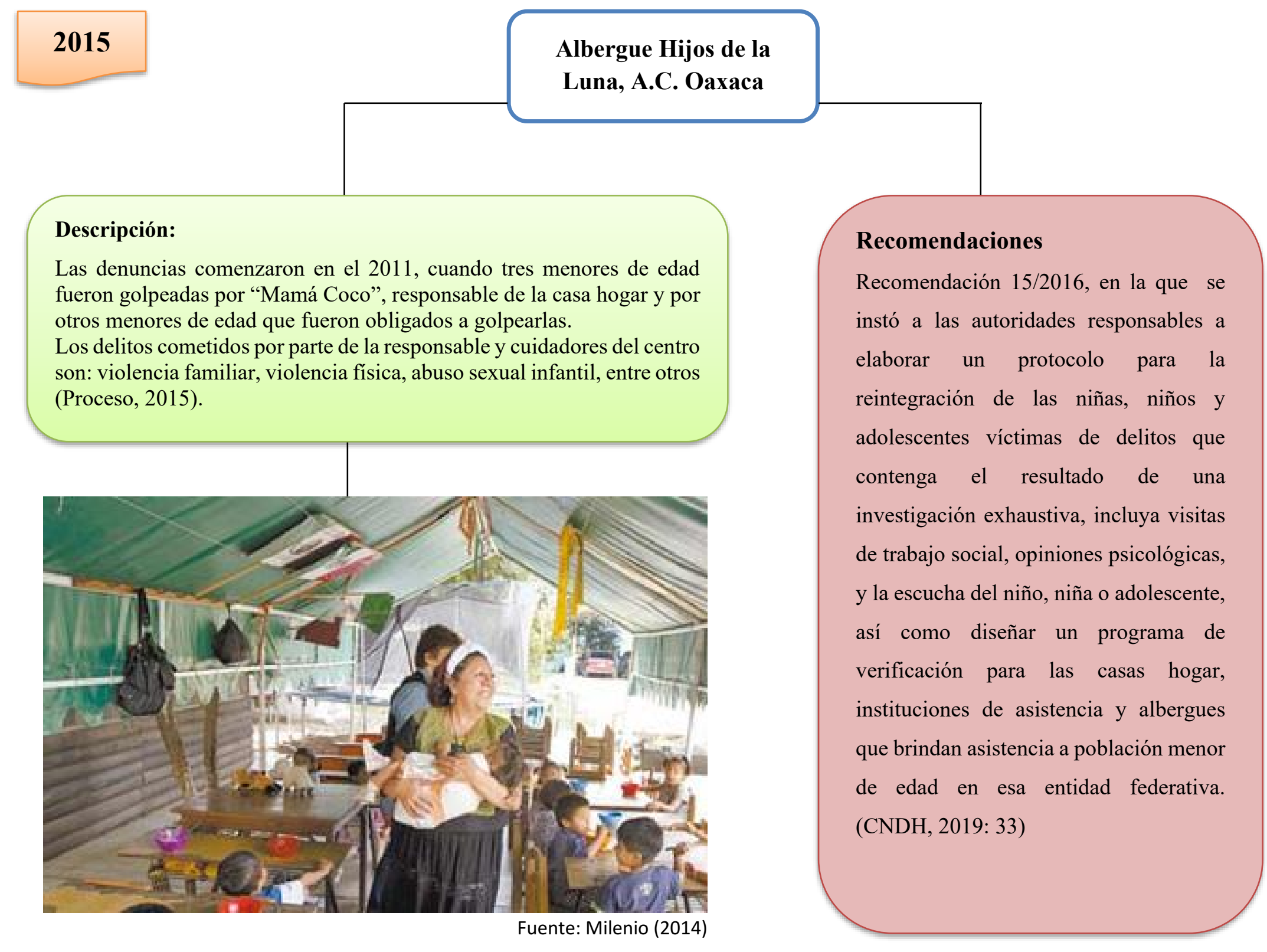




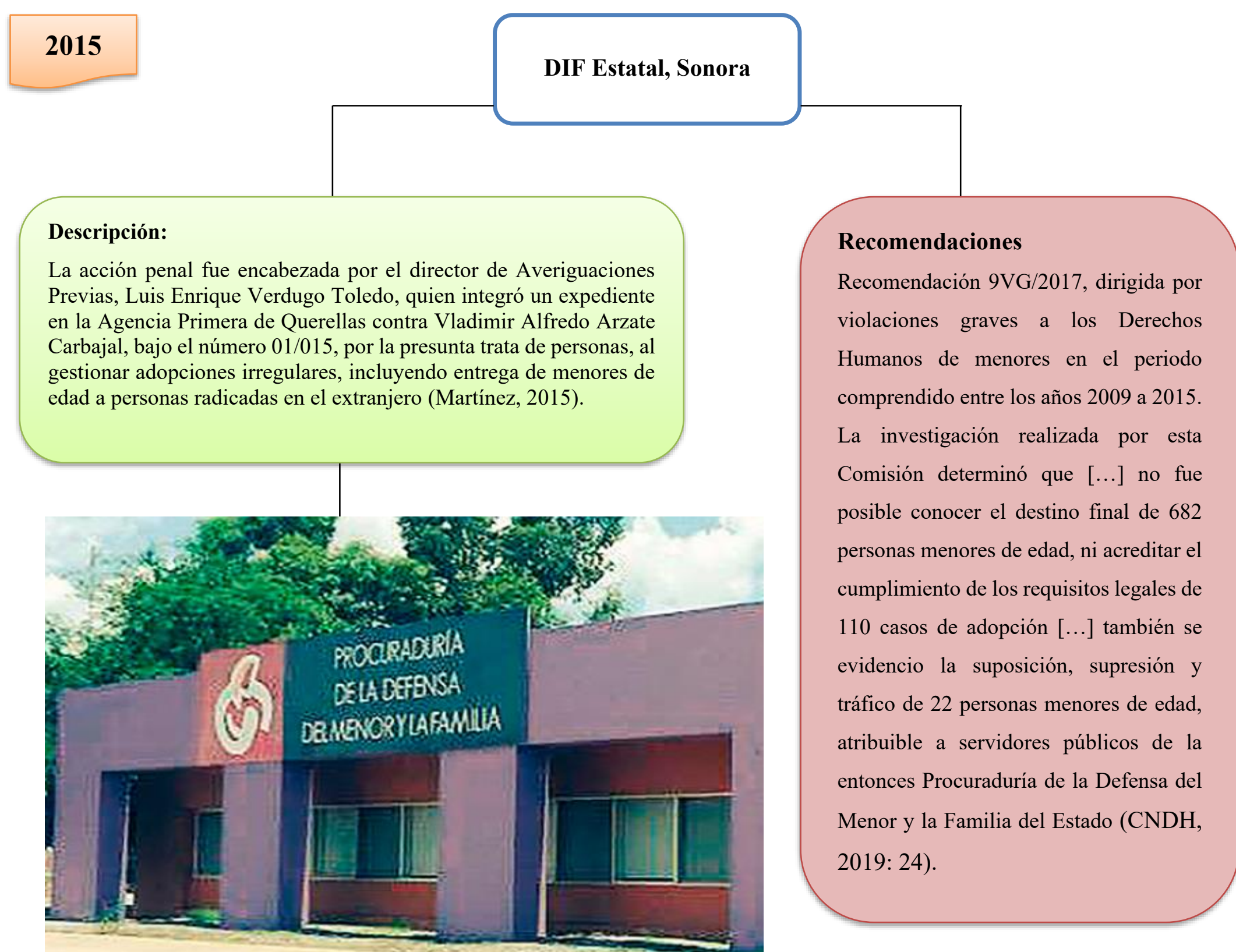

Fuente: Proceso (2015) 


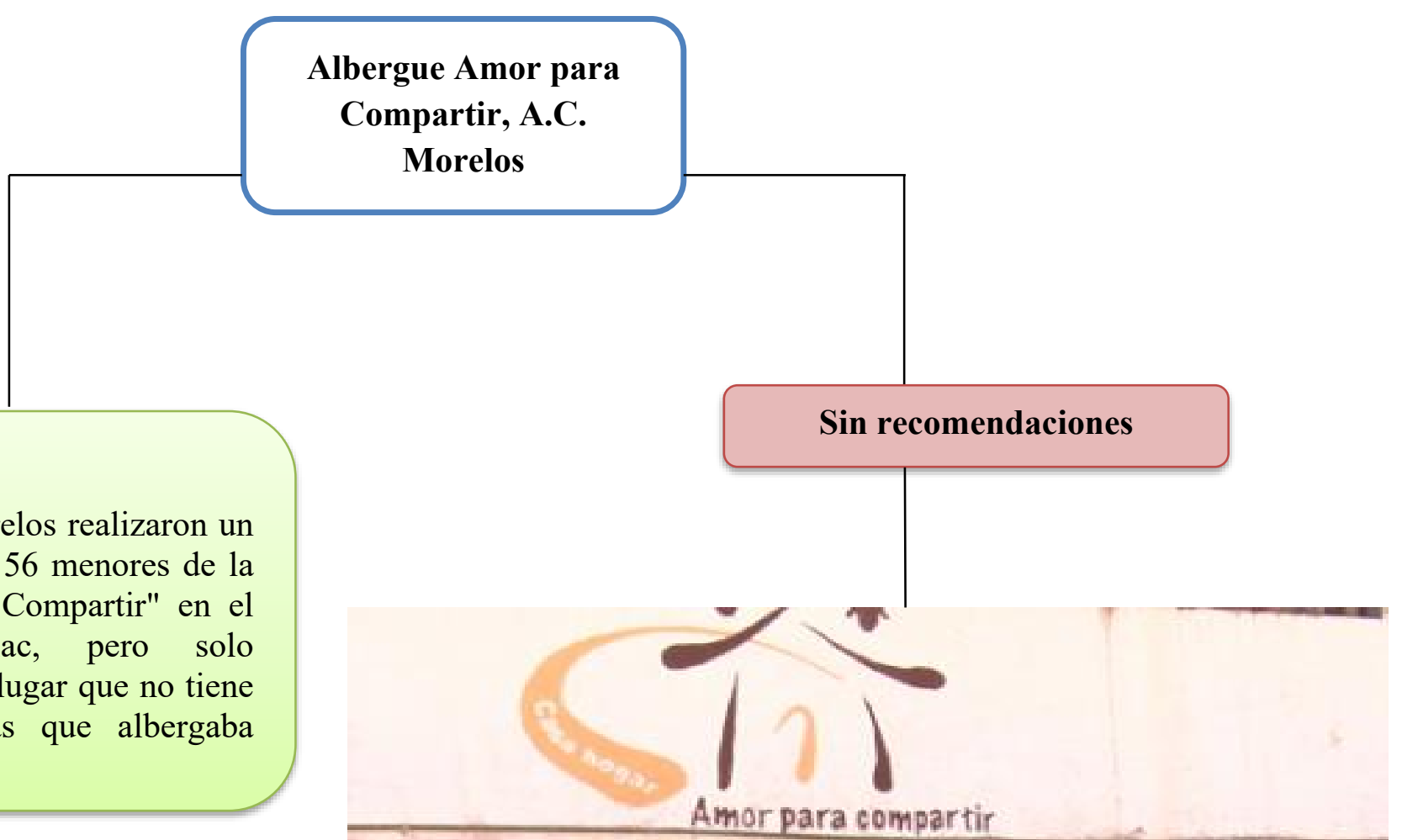

\section{Descripción:}

Autoridades del DIF Morelos realizaron un operativo para rescatar a 56 menores de la casa hogar "Amor para Compartir" en el municipio de Huitzilac, pero solo encontraron a 34 en este lugar que no tiene registro de las personas que albergaba (Cobos, 2016)

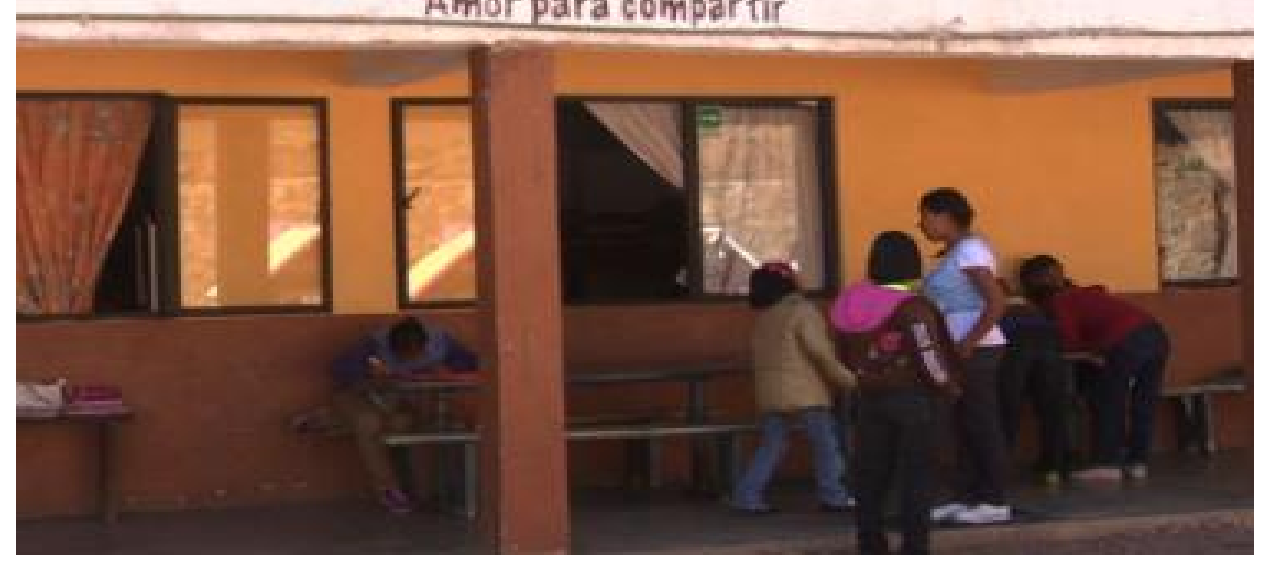

Fuente: Zona Centro Noticias (2016)

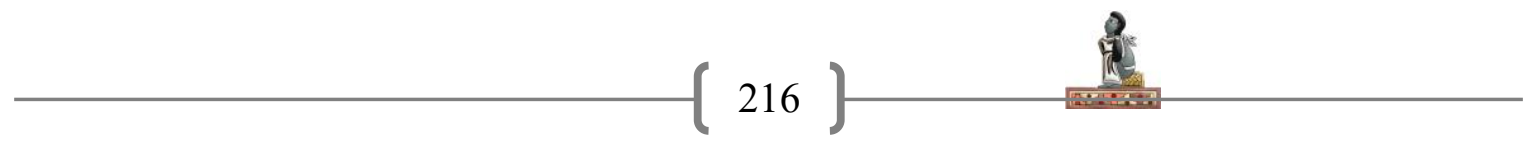



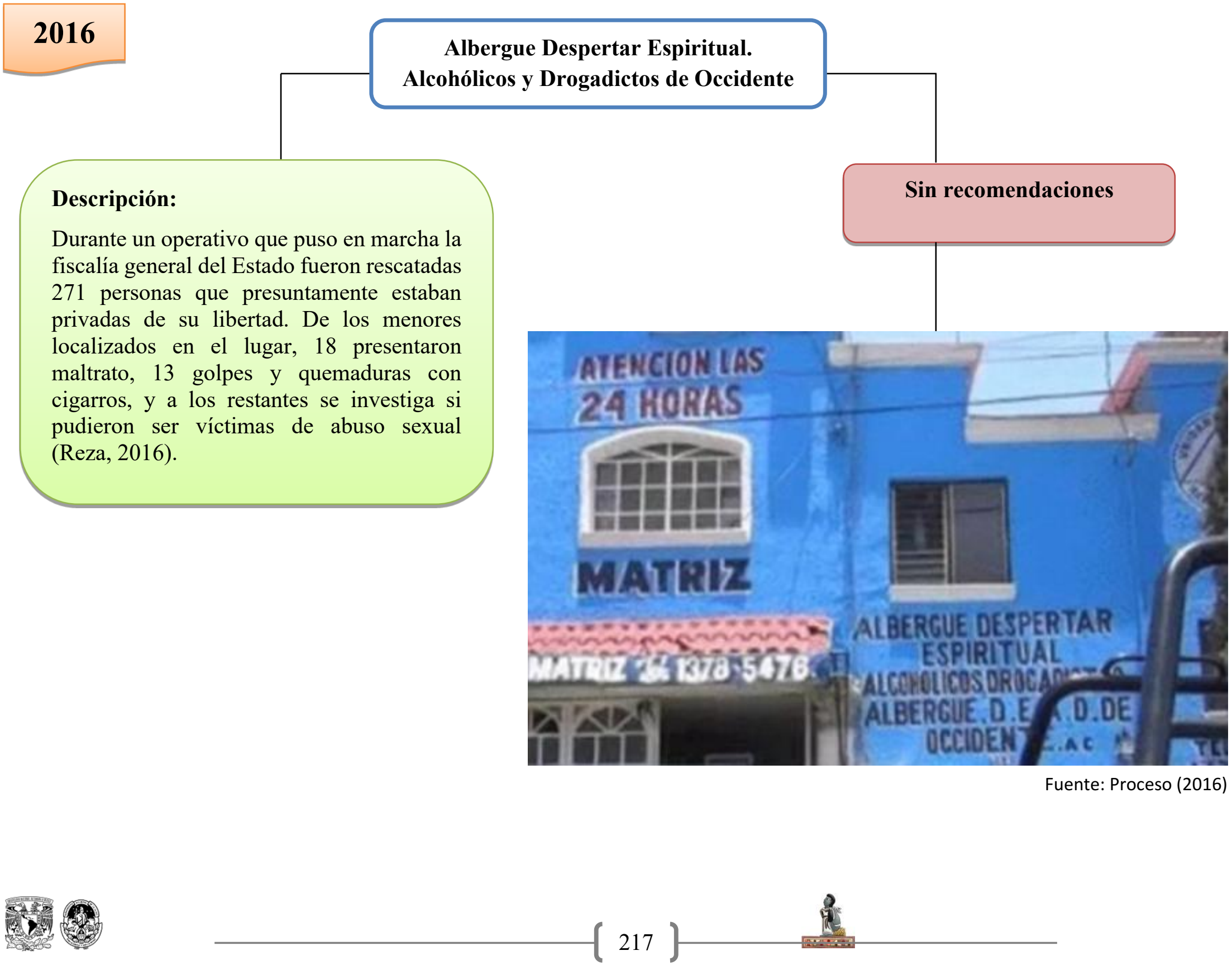


\section{6}

Villa de los Niños de Acatlán

de Juárez, A.C. Jalisco

\section{Descripción:}

El 23 de abril, cuatro alumnos recibieron 20 golpes con un cable y después fueron expulsados del plantel en Acatlán de Juárez, dirigido por la madre coreana Shin Soonyoung. Es la misma institución que Villa de las niñas en Chalco (Colima noticias, 2016).

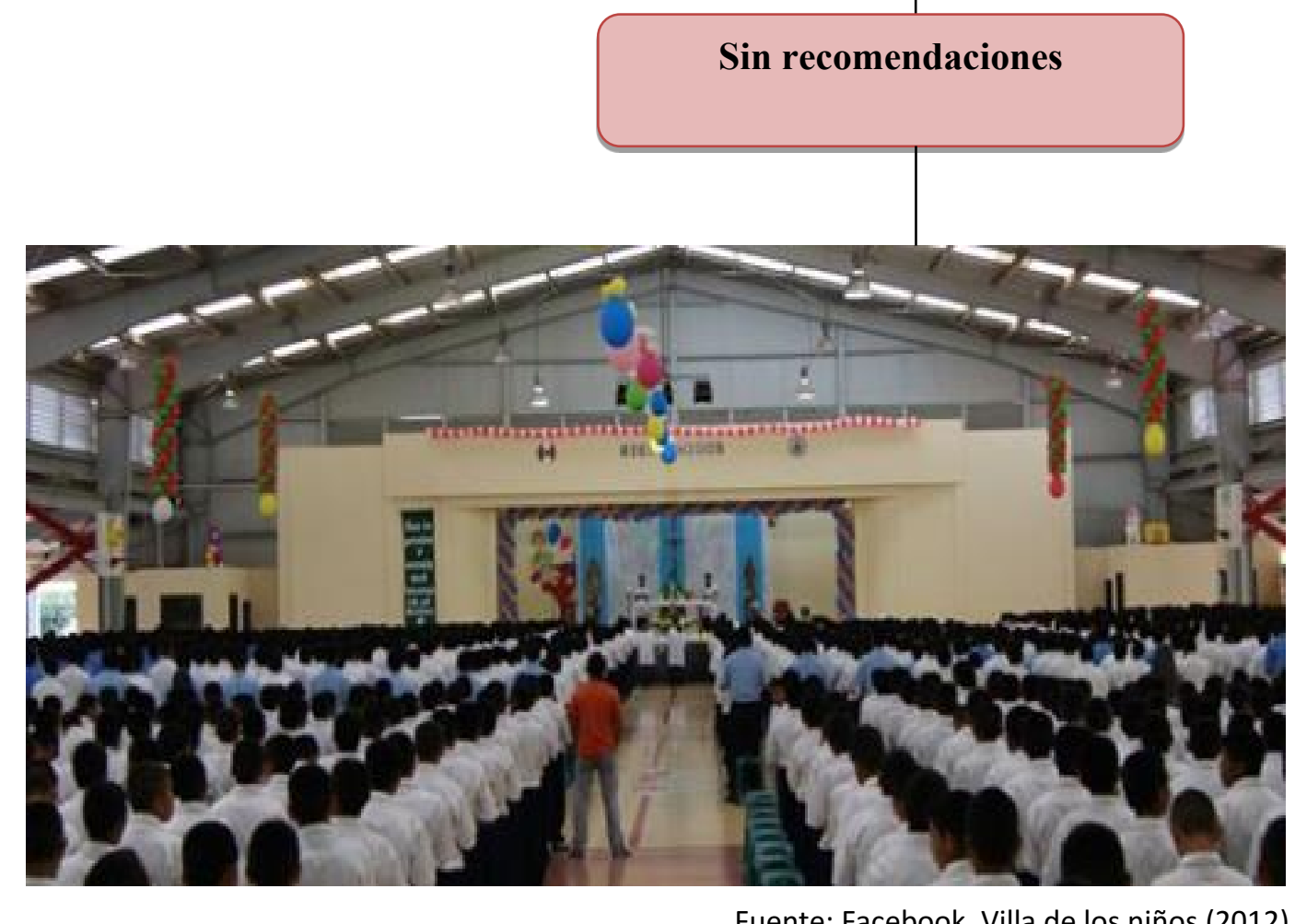

Fuente: Facebook, Villa de los niños (2012)

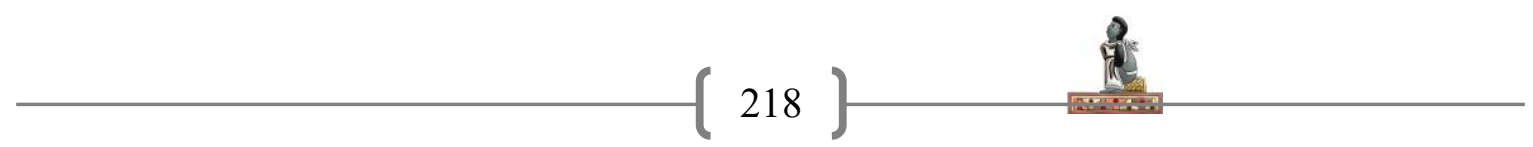


Ciudad de los Niños A.C.

Salamanca, Guanajuato

\section{Descripción:}

Había violencia física y sexual y se desviaban los recursos obtenidos por donativos. Funcionarios del Sistema para el Desarrollo Integral de la Familia (DIF) acudieron al albergue y encontraron menores de edad en mal estado, las instalaciones descuidadas y a una niña de siete años con las manos quemadas en una estufa, castigo de las cuidadoras (Velázquez, 2017).

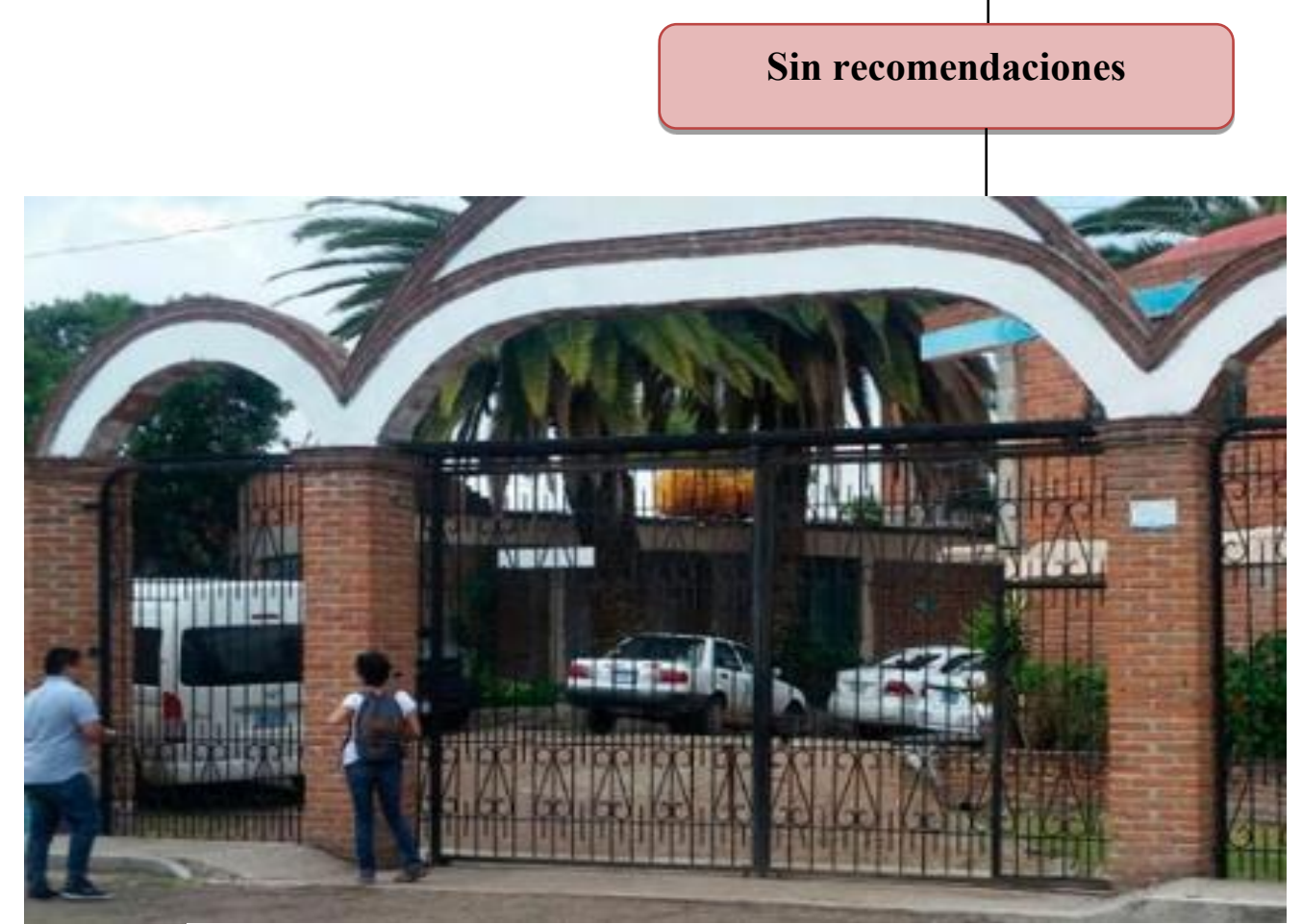

Fuente: Crónica de Xalapa (2017) 


\section{7}

\section{Descripción:}

A través de redes sociales, fue difundido un video en el que se muestran las precarias condiciones en las que se encuentran los internos de la Casa Hogar La Divina Providencia ubicado en el municipio de Chicoloapan, Estado de México (Díaz, 2017).

La Divina Providencia A.C. Estado de México

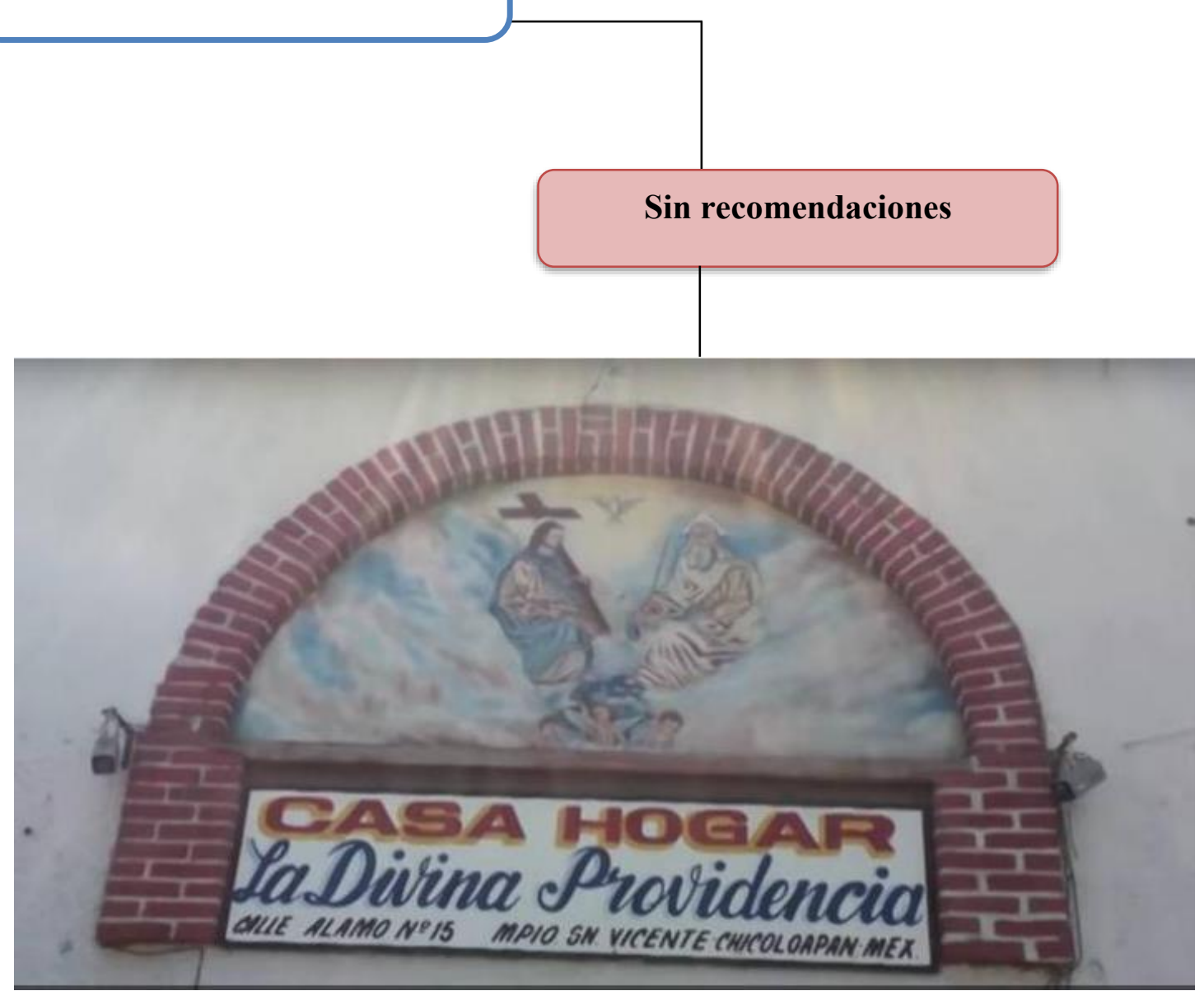

Fuente: SDP Noticias (2017)

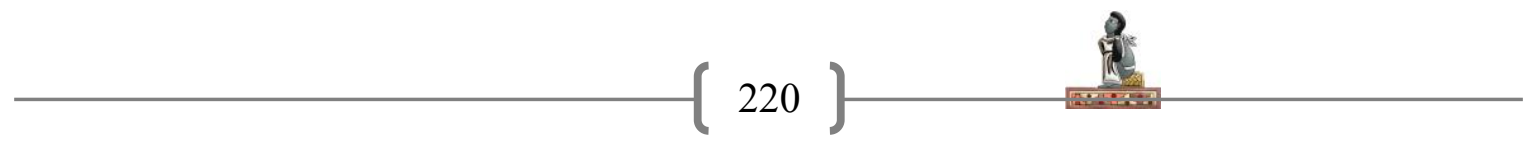




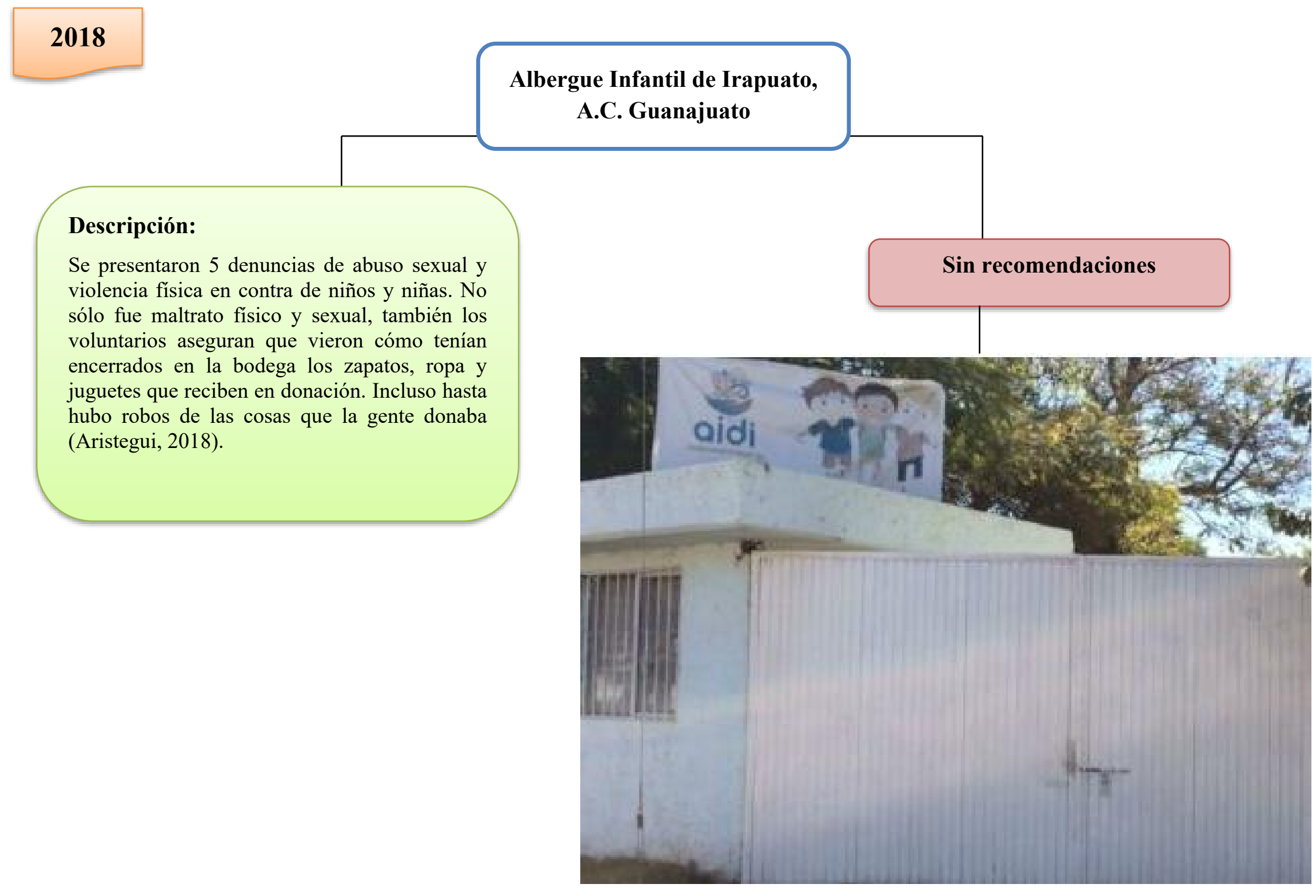

Fuente: Aristegui Noticias (2018) 
Informe de Supervisión ISP-11/2018 del Mecanismo Nacional de Prevención de la Tortura sobre el Centro Nacional Modelo de Atención, Investigación y Capacitación Casa Hogar para Niñas "Graciela Zubirán Villareal”

\section{Recomendaciones:}

El citado mecanismo publicó los resultados de las visitas de supervisión realizadas a este CAS en el cual se constatan diversas carencias en la infraestructura del centro. Entre ellas: deterioro de equipo sanitario, falta de luminarias en diversos lugares, instalaciones eléctricas expuestas, entre otras. Asimismo, se observó que las personas cuidadoras de las niñas y adolescentes que habitan en el centro no cuentan con capacitación para el manejo de personas adolescentes $[\ldots]$ de tal forma que algunas usuarias refirieron que las regañan sin razón aparente y utilizan palabras altisonantes (CNDH, 2019: 27).

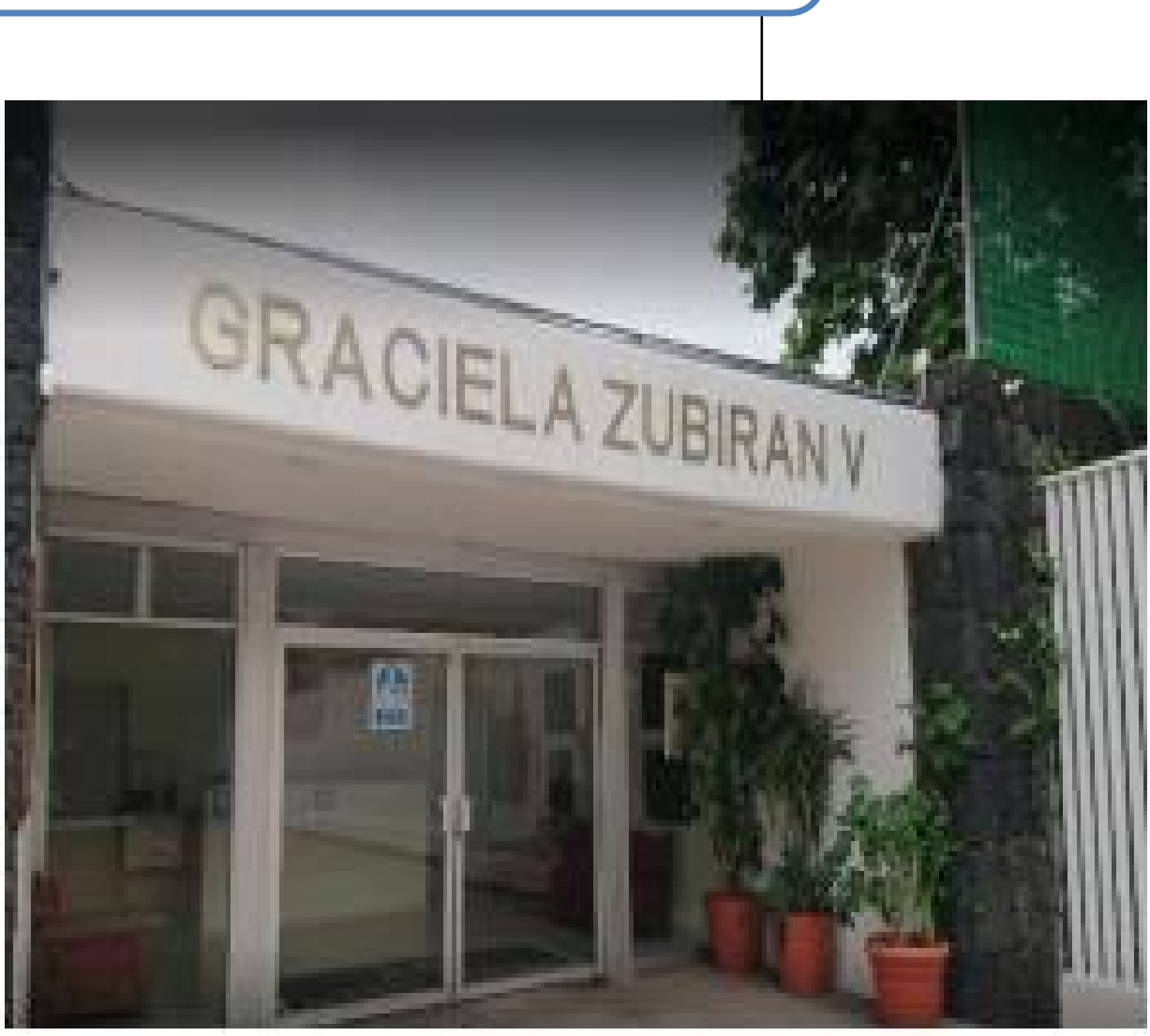

Fuente: CNDH (2018)
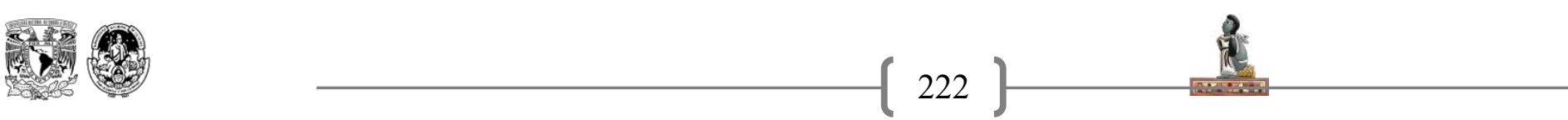


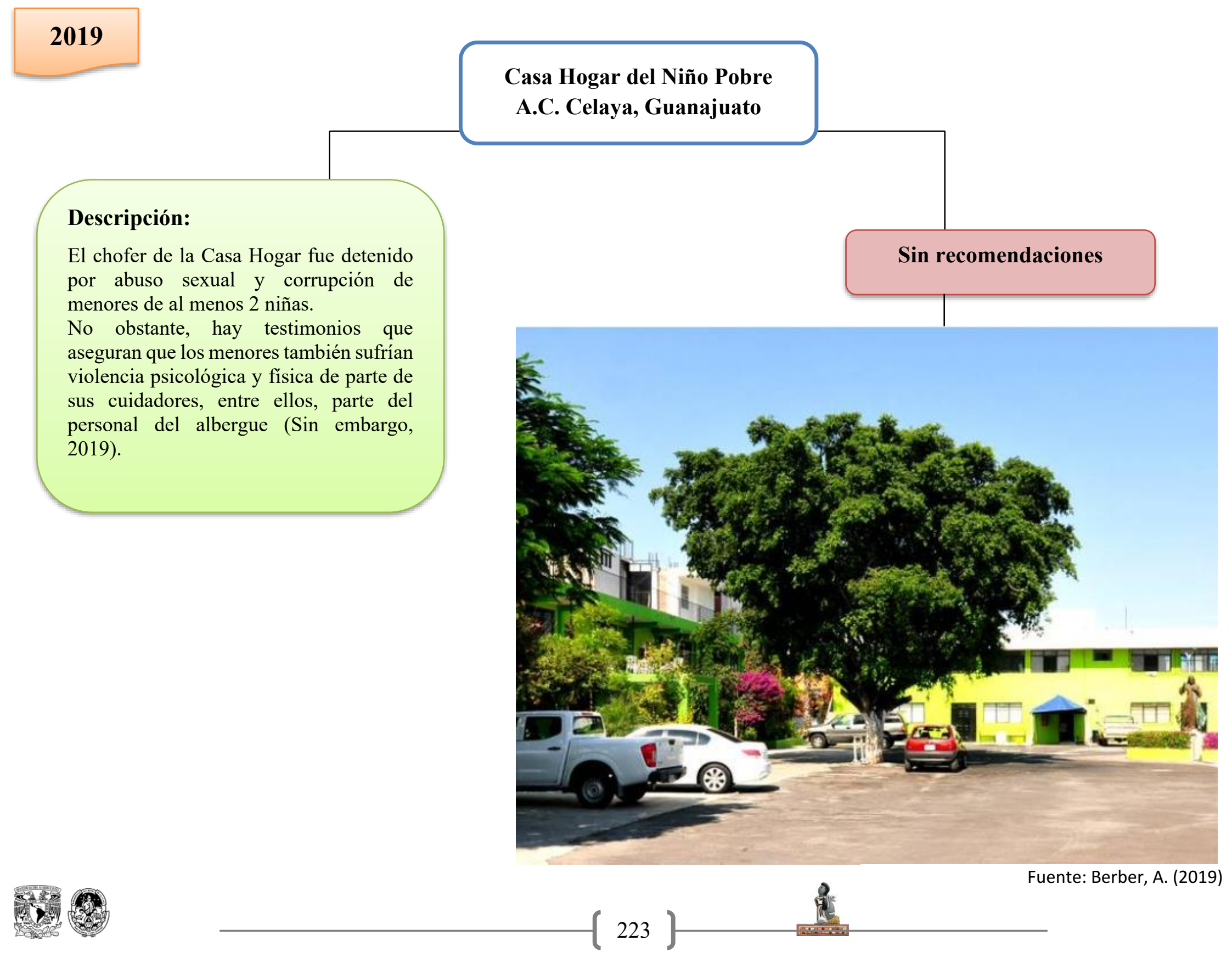




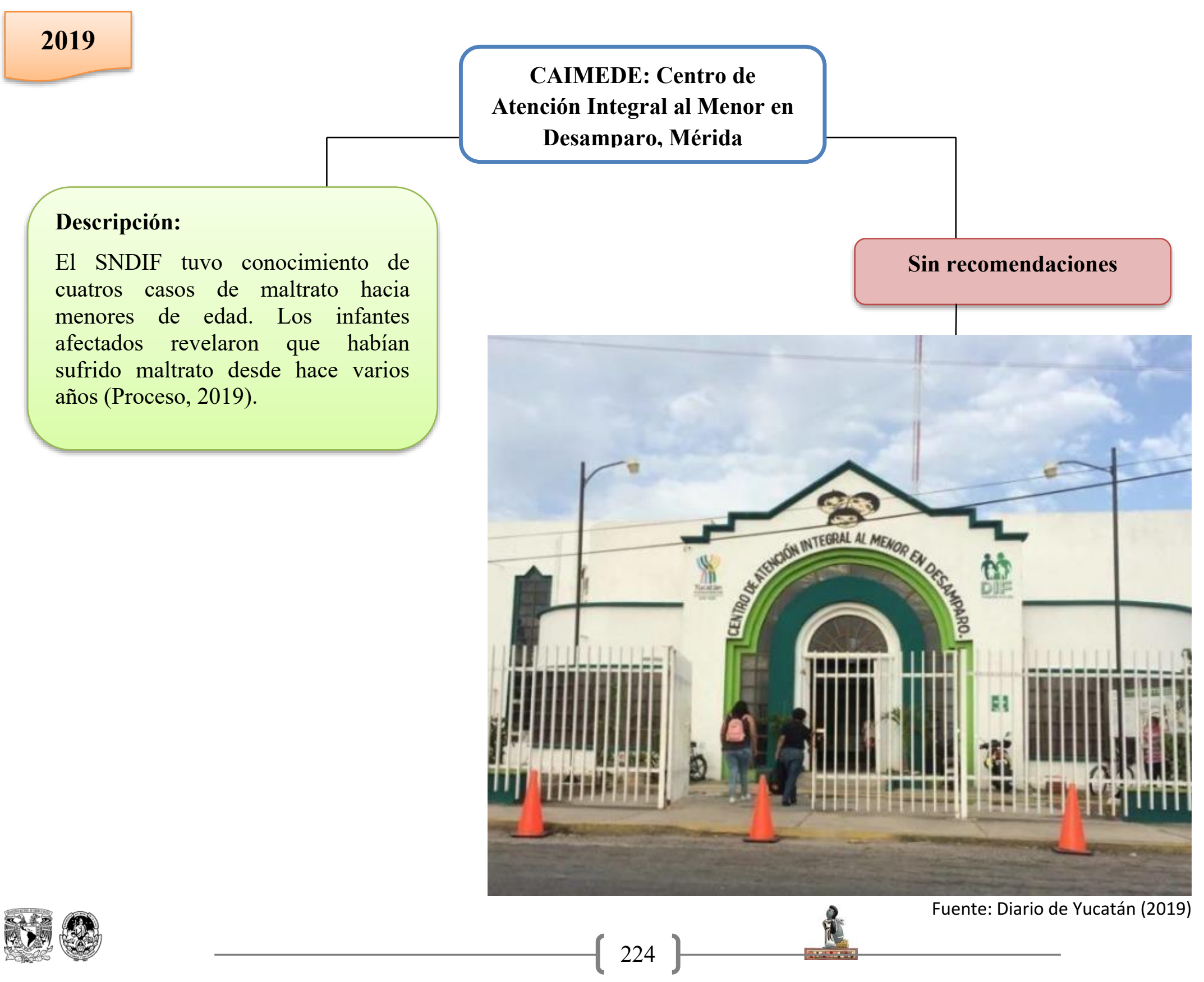




\section{Descripción:}

Desde el DIF estatal se detectó la venta de niños en Puebla. El gobernador Miguel Barbosa Huerta señaló que se fortalecerán áreas jurídicas del organismo y se reunirán elementos para presentar las denuncias penales contra quienes resulten responsables (Milenio, 2019).
DIF Estatal, Puebla

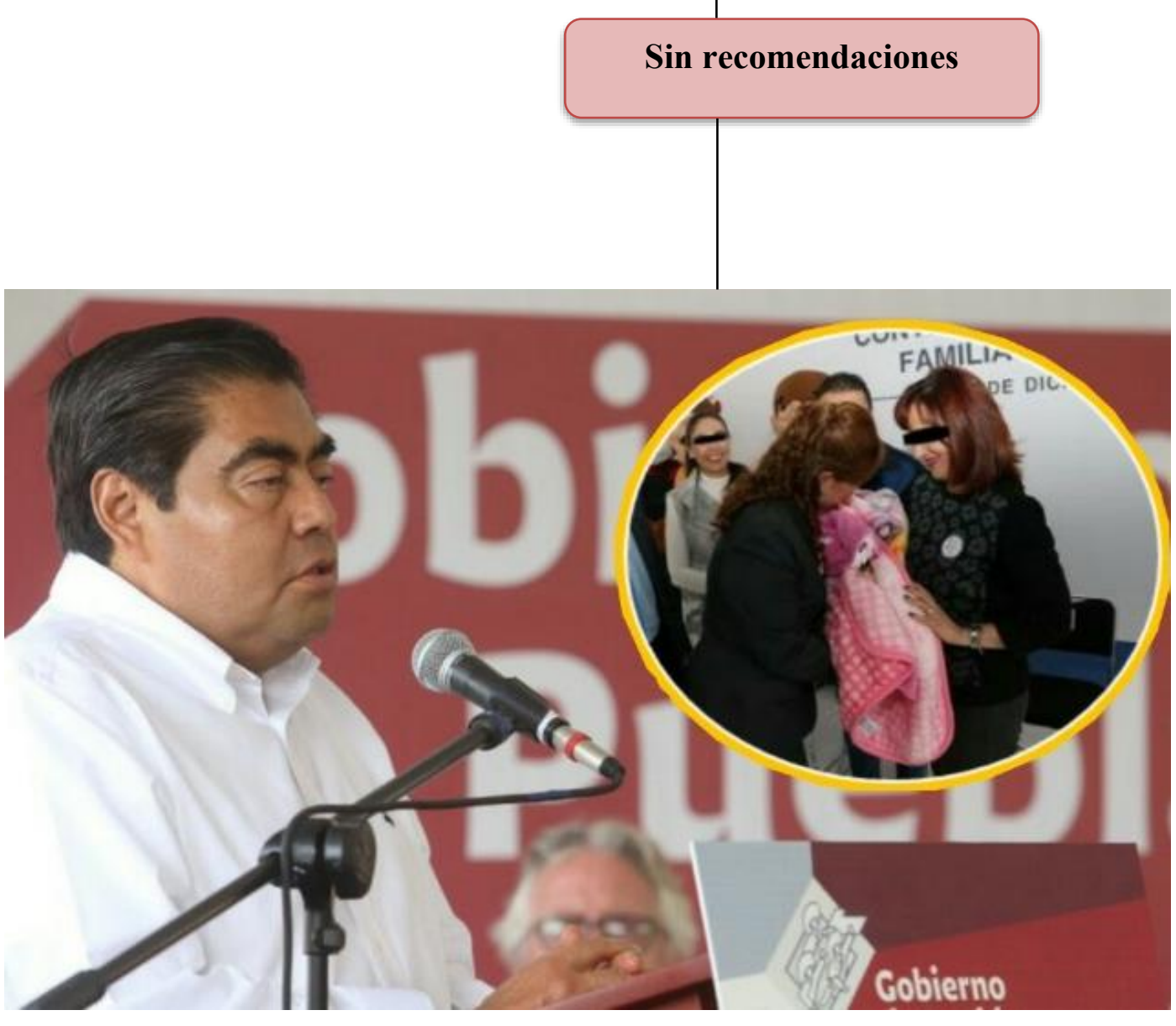

Fuente: MTP Noticias (2019)

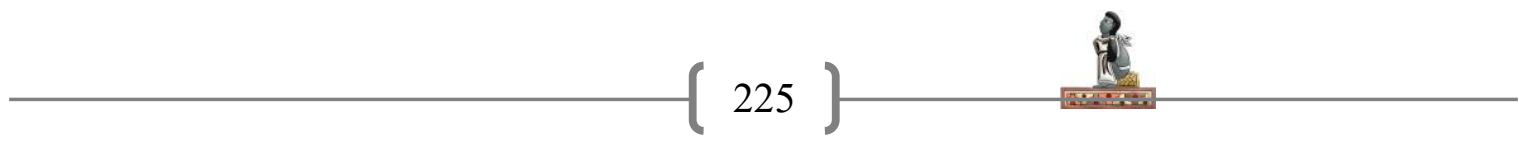




\section{Descripción:}

El lugar no tenía las condiciones para salvaguardar los derechos de salud e integridad de los menores, al existir carencias en servicios básicos. Además, se encontraron alimentos caducados, colchonetas sucias y las instalaciones en deplorables

(Quadratín, 2019).

condiciones

\section{Casa de mamá Rosita, Uruapan Michoacán}

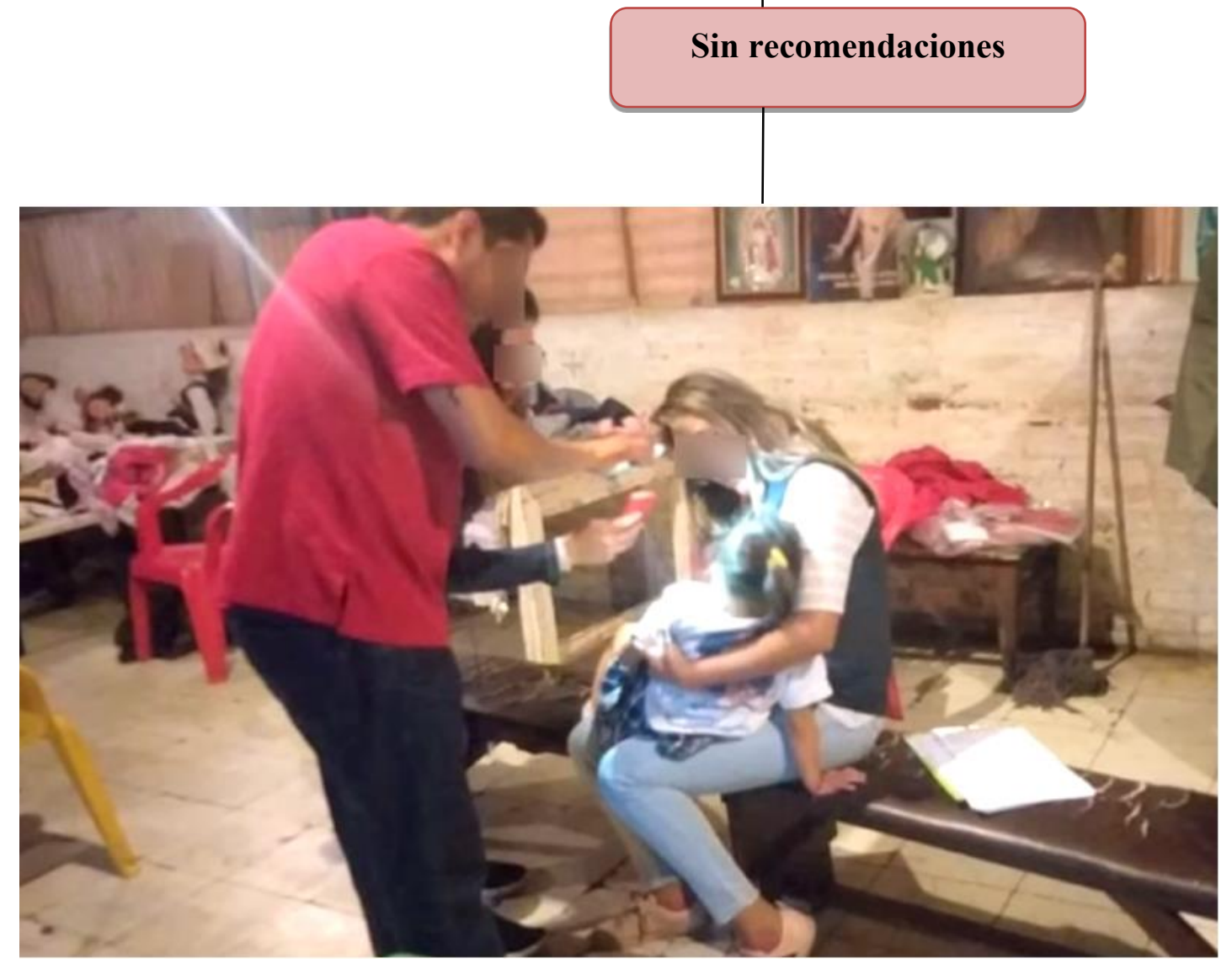

Fuente: Noticias Hoy (2019)

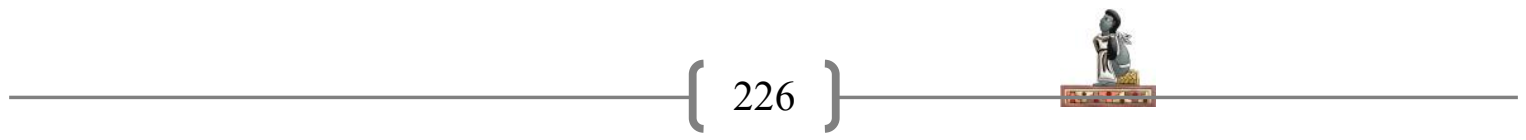




\subsubsection{El cuidado en CAS: una responsabilidad en tensión}

La cronología descrita en este capítulo pone en evidencia las serias debilidades del Estado mexicano en lo concerniente al seguimiento y vigilancia de los CAS de carácter social o privado que operan a través de figuras como: Asociación Civil (A.C.), Fundaciones o Instituciones de Asistencia Privada (IAP), entre otras. Como se mencionó en el capítulo IV (ver 4.1.3), a la fecha no se cuenta con un registro fidedigno de estas organizaciones, de la población que atienden, perfiles o mecanismos procedimentales para su cuidado; apenas tenemos un estimado de población albergada en el territorio nacional (30,000 NNA). Esta falta de información nos ha valido una serie de observancias de orden internacional (véase imagen 18: Financiamiento CAS).

El adelgazamiento de las responsabilidades estatales con relación al cuidado de niñas y niños en condición de institucionalización se expresa al dejar esta tarea en manos privadas. Actualmente sólo 1 de cada 10 menores de edad viven en un CAS de orden gubernamental y los 9 restantes lo hacen en espacios que funcionan con recursos económicos otorgados por particulares; la falta de registros y documentación de la población que atienden, revela la profunda opacidad y negligencia por parte de muchas organizaciones imposibilitando con ello que el Estado proporcione acompañamiento y vigilancia; y la hegemonía que tienen al administrar la vida de las y los menores de edad y sus familias. Es frecuente que la niñez albergada en estos espacios derive de sistemas de familia en donde padres, madres y/o cuidadores se han mostrado omisos, negligentes o bien la violencia ha estado presente, circunstancias que contribuye para que los sistemas de origen de NNA, tomen distancia e incluso les abandonen, lo que a su vez deriva en que las personas encargadas de estos espacios tengan potestad y autoridad para la toma de decisiones en relación a la vida presenta y futura de las y los albergados.

Es gracias al capital que ofrecen los privados a manera de donativos (ver 5.5) que estos CAS funcionan, ejerciendo su poder sobre la vida ajena y echando mano de profesionistas operarios que irrumpen el padecer íntimo y generan condiciones que legitiman el desprendimiento familiar (argumentando con "diagnósticos sociales" las etiquetas de: familias negligentes, omisión de cuidados, abandono), episteme que hemos revisado (ver 
5.5.1) y cuya rigidez encamina y legitima la cosificación de niñas y niños al hacer uso de ellos fuera de marcos procedimentales claros y alejados de planes de intervención social, tendientes a la transformación de trayectorias, en donde el maltrato se ha visibilizado.

Como se revisó en la georreferencia, estos CAS ha sido vinculados con violencias y delitos, que enlistan: adopciones ilegales, explotación sexual y/o laboral infantil, mendicidad forzosa e incluso tráfico de órganos; así como maltrato físico, psicológico, sexual, entre otros. Todo ello enmarcado en la corrupción e impunidad.

Las implicaciones y efectos del maltrato en la niñez se suman a las condiciones de impersonalidad y desubjetivación que se propicia al contar con modelos masificantes que homogenizan el comportamiento e invisibilizan a la población como sujeto individual, haciendo de él un sujeto institucional en una geografía específica.

Una realidad vigente es el acogimiento y la estadía de niñas y niños en CAS en el territorio nacional, por ende, voltear la mirada y situarnos en estos escenarios es profundamente necesario, urgente y relevante, dado que "mientras existan niños viviendo en instituciones, tendremos que trabajar para mejorar el cuidado que reciben en el ámbito institucional. Por esta razón debemos prestar atención al trato que reciben en las instituciones; al cambiar la manera en que estas cuidan a los niños en la cotidianidad, las casas hogar no serán dañinas" (Chanin, 2018: XXV).

\section{Epílogo}

La Gran Familia y mi consecuente participación como trabajadora social perito, marca en definitiva un parteaguas personal y disciplinar. Haberme situado en esa geografía de maltrato y perpetración de las más siniestras violencias transformó la manera en cómo me he colocado ante la implicación de niñas y niños, nunca me había enfrentado a violencias como las que descubrí en ese albergue: secuestros, torturas, violaciones, eventos que dejan un efecto traumático de alto impacto no sólo entre las víctimas directas, sino incluso en las víctimas potenciales.

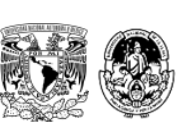


Esta experiencia me llevó a identificar de manera clara, la mercantilización de los cuerpos que están en el camino de la desechabilidad y a merced de un sistema económico que cosifica el ser, reduciéndolo a una mercancía que se explota, mercadea e intercambia a partir de la comisión de delitos como la explotación sexual y laboral, la mendicidad forzosa y las adopciones ilegales: atestiguados y documentados a partir de las entrevistas realizadas. Las narrativas que obtuvimos durante los diez días de estancia y las entrevistas elaboradas describían venta de niños, órganos, mendicidad forzada, abusos sexuales, secuestros... todo lo que necesitábamos para el "Dictamen pericial en Trabajo social".

Algo que no expliqué en el relato fue que la mujer llamada Rosa Verduzco, directora del albergue, fue declarada inimputable por las instancias jurídicas "al considerarla una mujer añosa que transitaba por una demencia senil que no le permitía diferenciar la violencia del cuidado". Esta declaración, hecha antes de que transcurrieran las 24 horas siguientes al operativo, es una muestra evidente de cómo el aparato jurídico es una tecnología del poder que no responde a la protección y cuidado de la niñez, sino al modelo económico que favorece la existencia de estos espacios que al mismo tiempo proveen de satisfactores $\sin$ importar si estos son la vida humana. No se trata de personas sino de un entramado estructural que ejerce el poder sobre quienes menos tienen.

Otro dato importante es que años atrás, el área jurídica de la institución a la que yo pertenecía (SNDIF), había intentado ingresar al albergue (ya se sabía de las condiciones de violencia que en él se perpetraban) y ese intento resultó infructuoso, pues al parecer había personas interesadas en que dicho espacio siguiera operando.

Esta inoperancia estatal, la falta de seguimiento con criterios claros de evaluación, la impunidad y complicidad política, se constituyeron en realidades profundamente contradictorias con lo que yo hasta ese momento concebía como una real protección de derechos de la niñez, misma que había aspirado y materializado como parte del equipo operativo en Casa Cuna Coyoacán, en donde cada caso se trataba de forma cuidadosa y artesanal, en donde mis colegas ponían sus conocimientos y subjetividades al intentar favorecer la transformación de trayectorias de "nuestros niños y sus familias".

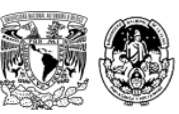


Este capítulo ha sido diseñado con la intención de dialogar con el capítulo siguiente y exponer las disimiles características y condicionantes que se manifiestan en diferentes espacios de cuidado alternativo a través de la institucionalización.

Los casos documentados a partir de la georreferencia expuesta dejan en claro la falta de vigilancia, seguimiento y acompañamiento por parte del Estado a los CAS de carácter privado. Incapacidad que propicia la construcción de "espacios de riesgo", en donde la vida tiene valor en tanto puede satisfacer una necesidad parental adulta: ser explotada sexual o laboralmente, dar en adopción de forma irregular e incluso mercantilizada en pedazos a partir de sus órganos. Ahí se expresa la necropolítica, la administración de la muerte psíquica y física. 


\section{- CAPítulo ViI •}

\section{SISTEMA NACIONAL PARA EL DESARROLLO INTEGRAL DE LA \\ FAMILIA, INSTITUCIÓN RECTORA EN MATERIA DE ASISTENCIA SOCIAL EN MÉXICO}

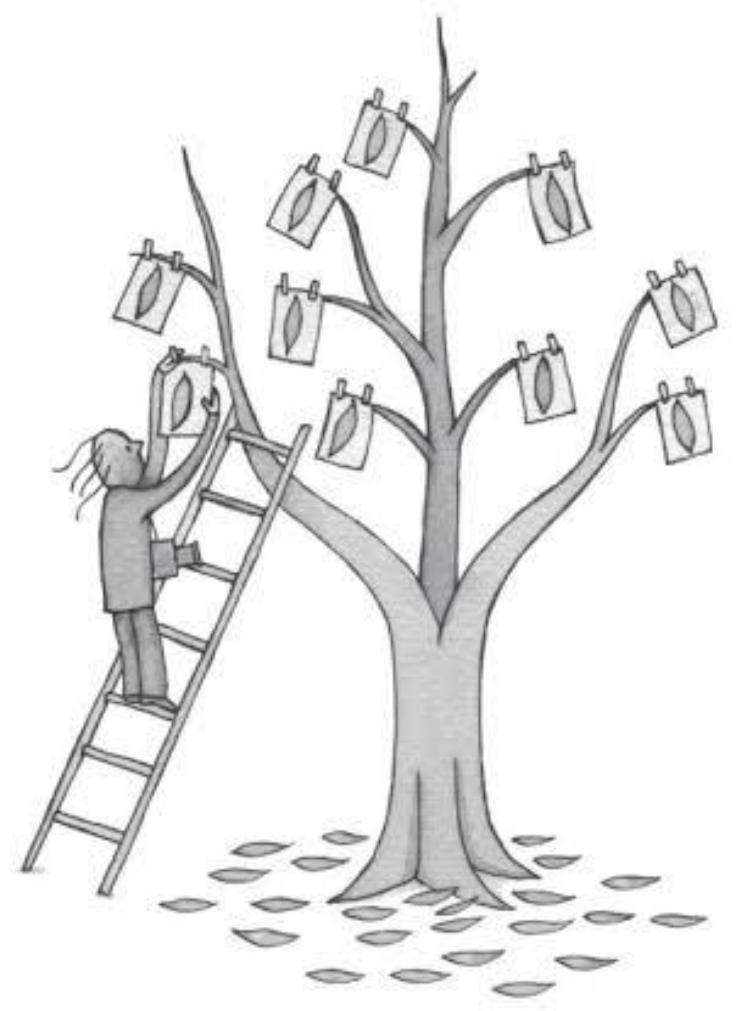

Troche, G. (2016). [Ilustración]. Recuperada de: https://elpais.com/elpais/2016/02/08/album/1454948052_654595.html\#ffoto_gal_2 
Dentro de cada niño existe una historia que necesita contarse, una historia que nadie más ha tenido tiempo de escuchar.

(Donald Winnicot)

Israel

(2013)

Cuando una niña o un niño son ingresados a un CAS, se inicia una trayectoria de vinculación numerológica. Su historia se ve determinada a partir del número de carpeta de investigación, el número de expediente, el número de dormitorio, el número de informe. En fin, el "número" es una identidad asignada que se tatúa de forma tan consistente como invisible.

Aquella tarde concentrada en mi escritorio, orgullosa de mi quehacer profesional, redactaba el reporte de algunas convivencias para el Ministerio Público cuando el teléfono sonó. "Quisiera hablar con la trabajadora social responsable del área por favor" -se escuchaba del otro lado del auricular-. "Sí, dígame” -contesté-. "Le llamo del Centro de Estancia transitoria para niños y el juez me ha requerido la búsqueda del expediente 112/97, necesitamos información valiosa con respecto a la averiguación previa de este caso". Esa solicitud era rutinaria, estaba acostumbrada a recibir este tipo de peticiones así que no me generaba problema alguno. Abrí mi base de datos y ubiqué el lugar donde obraba dicho expediente.

Me dirigí a la oficina que tiene por encima del marco de la puerta un rótulo que dice "archivo muerto". Me sumergí en ese espacio cuyo olor a humedad me era particularmente familiar. Registré los anaqueles y por un impulso que no podría explicar tomé un folder amarillo con la inscripción 11/65: pertenecía a un niño que había sido atendido en el Centro en el año 1965. Al hurgar entre los papeles que se deshacían por el paso del tiempo, resbaló de su interior una cadenita de oro con la imagen del Sagrado corazón de Jesús oxidada y empolvada por los años de encierro. En su interior se relataba la historia de un niño que había llegado vinculado con el "delito de abandono". No me resistí y ante mi curiosidad le di lectura a los informes que lo integraban. Se trataba de Israel, un niño cuya madre había llegado a la Ciudad de México por aquella época y le había dejado en las puertas de la Casa Hogar al no contar and (5) 
con nadie y vivirse sola en la inmensa ciudad. No había en el registro una descripción de violencia explícita, golpes u omisión de cuidados, sólo una madre sola que temía por la integridad de su hijo. El testimonio recurrentemente redactado: "prefiero que se quede aquí y le busquen una familia que le pueda dar lo que yo no puedo".

No había más detalles, ni direcciones, ni una descripción que arrojara elementos de identificación de la progenitora. ¿Será que alguien le había contado alguna vez a Israel que su madre lo había dejado en el CAS con -quizá- lo único valioso que tenía? ¿De qué manera ese amuleto representaba cuidado y amor de parte de su madre? ¿Cómo habría cambiado la vida del niño y tal vez la de su madre? ¿De qué modos habría significado o resignificado su estadía en el CAS?

Los "archivos muertos" son como cajas secretas que alojan historias de dolor, abandono, muerte y violencia; al mismo tiempo documentan historias de profundo amor y esperanza que usualmente no se abren y encierran subjetividades, que si lograran encontrar la luz seguramente abrirían también caminos de perdón y amor entre los niños que se hospedan en este particular territorio.

\section{Prefacio}

Este capítulo se divide en dos apartados: en la primera parte se expone otra geografía posible en el soporte y rectoría estatal y con una intervención intencionada, la que concierne a los CAS del SNDIF, que en su calidad de CNMAIC y Subdirección de Centro Amanecer para Niños, convocan a un ejercicio profesional congruente con las exigencias del México contemporáneo y en donde se enuncian enfoques y modelos diseñados para la atención de esta población.

Para iniciar se enuncian las características por CAS en cuanto a perfil etario y sectorial, motivos de ingreso con fundamento en la LGDNNA (2014), requisitos y directrices para la atención determinadas en el Modelo Tipo de Atención y Protección Integral de Centros de 
Asistencia Social para Niñas, Niños y Adolescentes $^{52}$ (2018), así como la propuesta de intervención metodológica para el TS suscrita en los instrumentos normativos, que dicho sea de paso, son instrumentos que definen el proceso de intervención y con base en la legislación vigente (LGDNNA, 2014) deberían ser aplicados en todos los CAS -ya sean públicos, sociales o privados-.

La segunda parte ocupa la exposición de los hallazgos del trabajo de campo organizada por: categoría de análisis, técnica, instrumentos y las subcategorías construidas con fundamento en el dato empírico.

\subsection{De los Centros de Asistencia Social del Sistema Nacional para el Desarrollo Integral de la Familia}

Para la atención de NNA, el SNDIF cuenta con cuatro Centros Nacionales Modelos de Atención Investigación y Capacitación (CNMAIC), además de una Subdirección de Centro. Todos ubicados en la Ciudad de México en la alcaldía de Coyoacán y con fundamento en el Modelo Tipo de Atención y Protección Integral de Centros de Asistencia Social para Niñas, Niños y Adolescentes, que abordaremos avanzado el capítulo.

Con base en el Reglamento Interno (SNDIF, 2014:7-8) artículo 8, para acceder a los servicios de atención que brindan los CAS se deberá cubrir invariablemente el siguiente perfil:

1. Tener la edad y sexo indicados para cada uno de los Centros.

2. Encontrarse en situación de riesgo o vulnerabilidad; y,

3. Contar con un estado de salud físico y psicológico que le permita incorporarse a los programas de la atención integral de los Centros y la vida comunitaria.

Cuando el niño o la niña, susceptible de institucionalización, no cubre con los requisitos antes descritos, la Dirección de cada CAS con fundamento en la evaluación hecha por el equipo

${ }^{52}$ El Modelo Tipo de Atención y Protección Integral de Centros de Asistencia Social para Niñas, Niños y Adolescentes del SNDIF, es el instrumento normativo con enfoque de derechos, que expone los lineamientos para la atención que se brinda a NNA en los CAS, considerando la atención multidisciplinar.

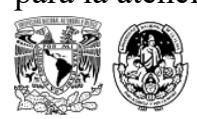


multidisciplinar (áreas psicológica, medica, pedagógica y Trabajo Social), argumenta los motivos a la PFPNNA para que ésta busque opciones de cuidado alternativo formal a través de organizaciones de carácter privado, atendiendo a la oportuna y eficaz atención de la o el candidato y con fundamento en el ejercicio de su derecho de asistencia, protección y cuidado.

A continuación, se describen los perfiles de atención y se expone la población albergada por sexo y edad, información que se recupera del Reporte al tercer trimestre 2019 de Atención Integral en Centros Asistenciales del SNDIF del portal oficial de la institución:

Centro Nacional Modelo de Atención, Investigación y Capacitación Casa Cuna Tlalpan

Imagen 26 CNMAIC Casa Cuna Tlalpan

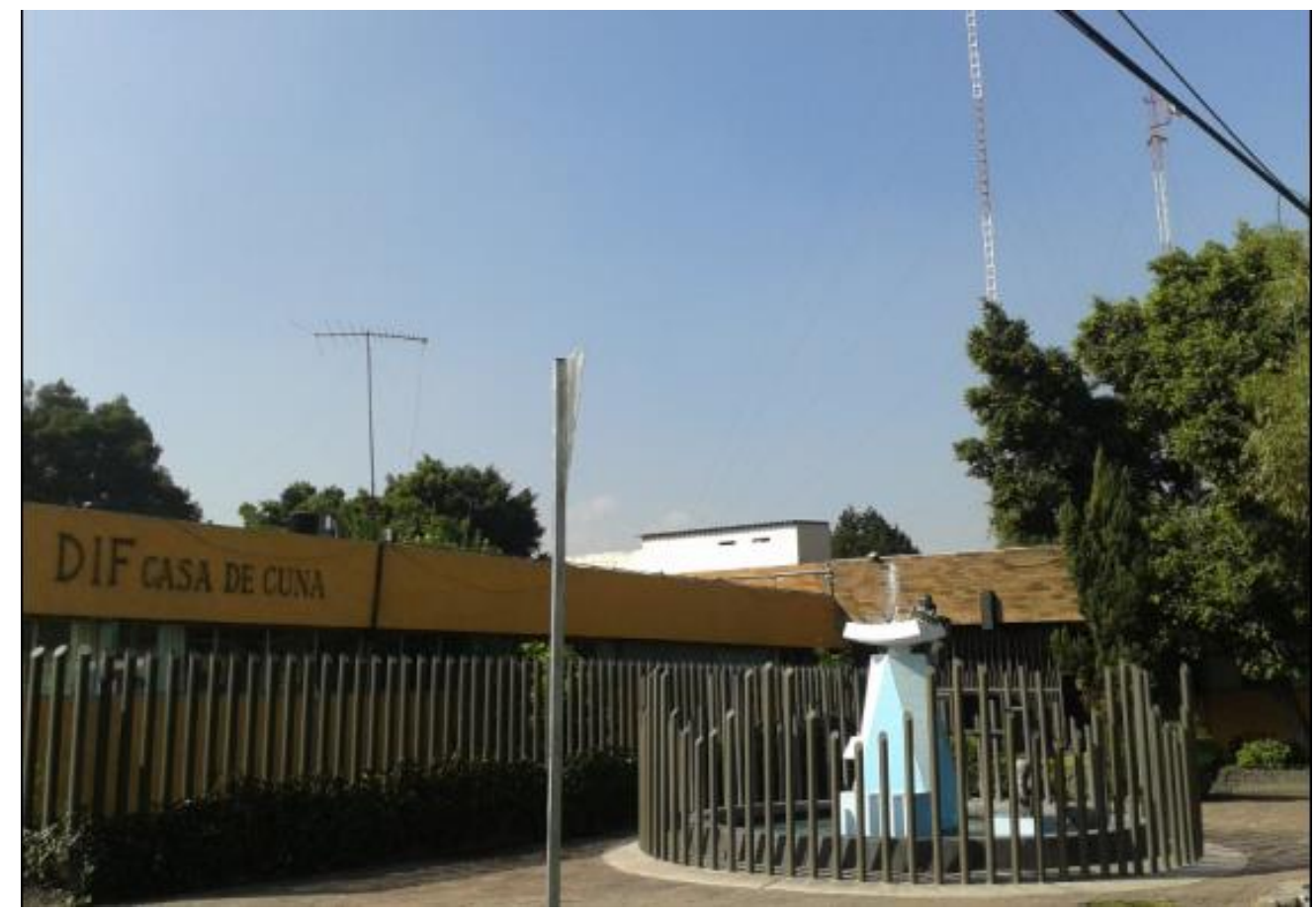

Fuente: Archivo personal, Ruíz Gabriela 2018.

Imagen 27 CNMAIC Casa Cuna Tlalpan: recorrido institucional en el marco de la Practica de Especialización 1907 


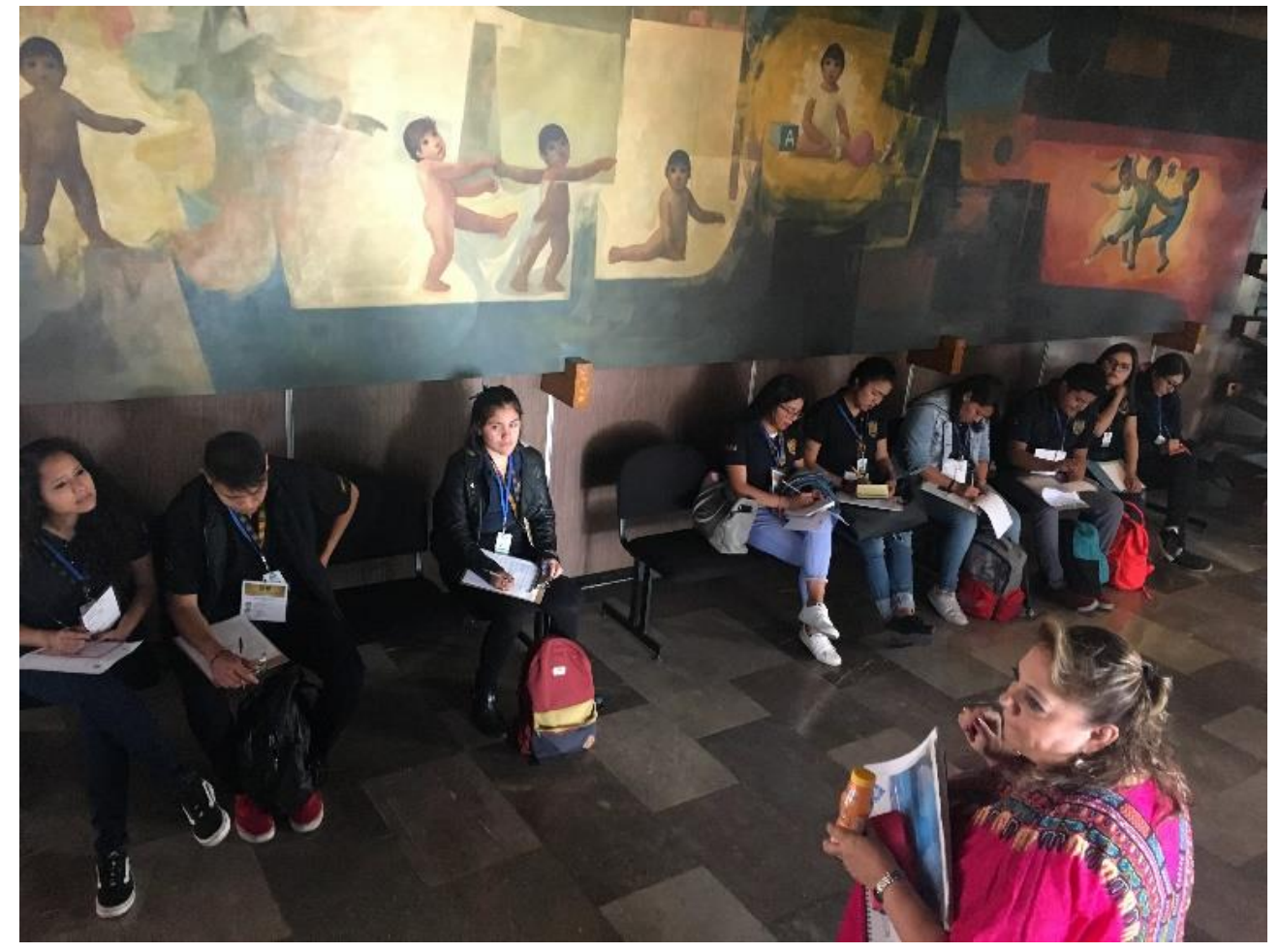

Fuente: Archivo personal, Ruíz Gabriela 2019.

Atiende niñas y niños de recién nacidos a 4 años 11 meses. Para septiembre de 2019 contaba con una población albergada de 34 residentes 20 mujeres y 14 hombres. 
Centro Nacional Modelo de Atención, Investigación y Capacitación Casa Cuna Coyoacán

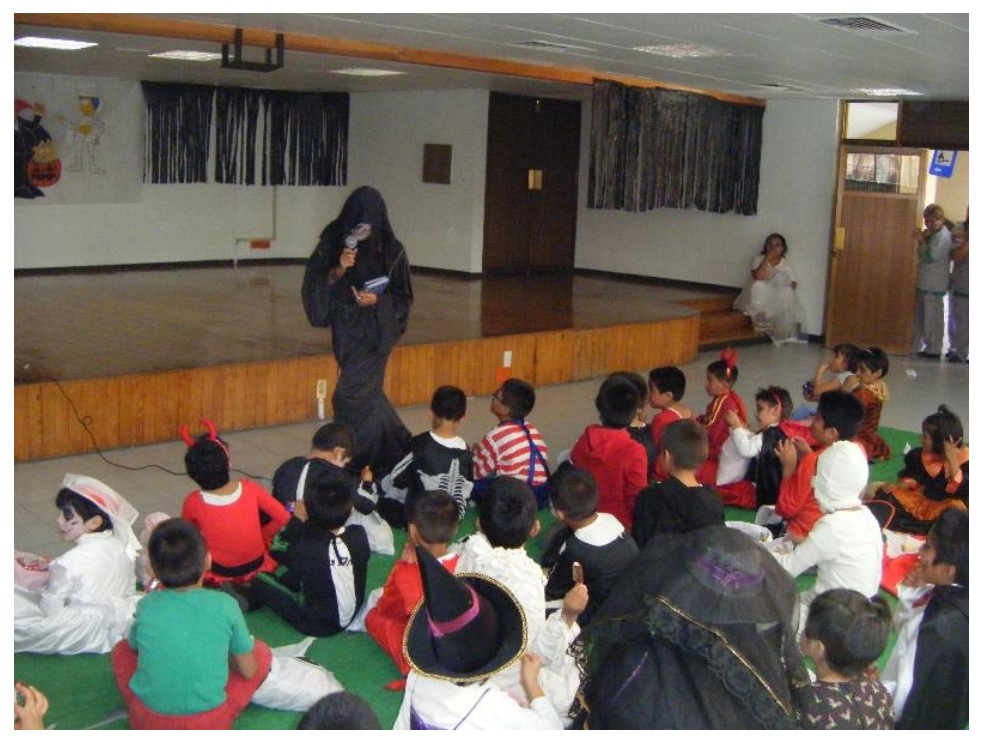

Imagen 28 CNMAIC Casa Cuna Coyoacán: Festividad día de muertos Fuente: Archivo personal, Ruíz Gabriela 2010.

\section{Imagen 29 CNMAIC Casa Cuna}

Coyoacán

Fuente: Archivo personal, Ruíz Gabriela 2018.

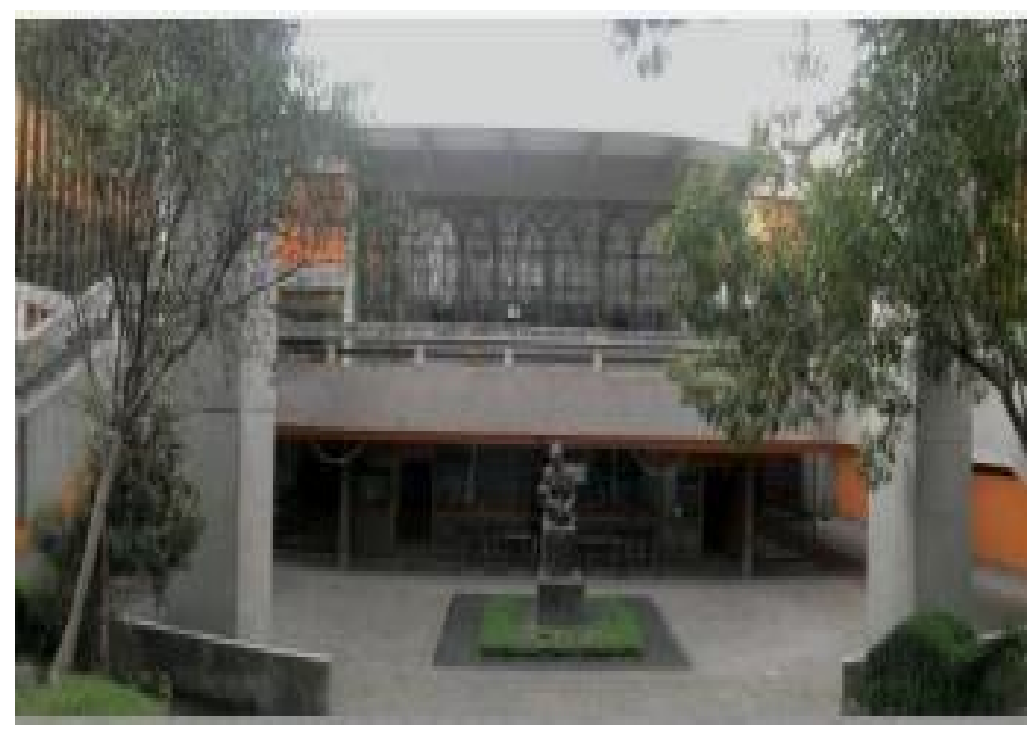

Atiende niñas y niños de 5 años a 8 años 11 meses. Para septiembre de 2019 contaba con una población albergada de 36 residentes 18 mujeres y 18 hombres. 


\section{Subdirección del Centro Amanecer para Niños}

Imagen 30 Subdirección del Centro Amanecer para Niños

Fuente: Archivo personal, Ruíz Gabriela 2018.
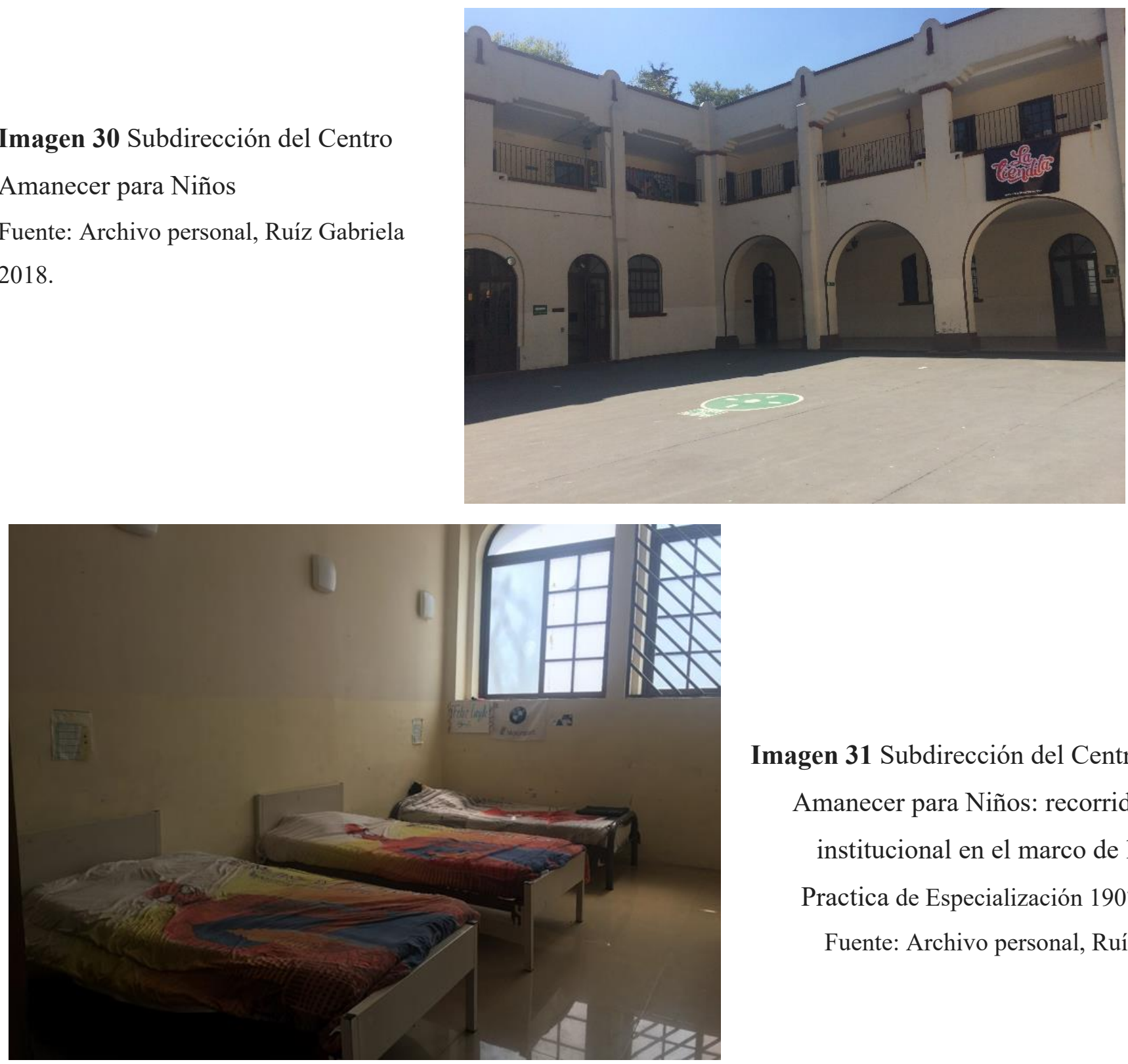

Imagen 31 Subdirección del Centro Amanecer para Niños: recorrido institucional en el marco de la Practica de Especialización 1907. Fuente: Archivo personal, Ruíz.

Atiende niños de 9 años a 12 años 11 meses. Para septiembre de 2019 contaba con una población albergada de 29 residentes. 


\section{Centro Nacional Modelo de Atención, Investigación y Capacitación Casa Hogar para Niñas}

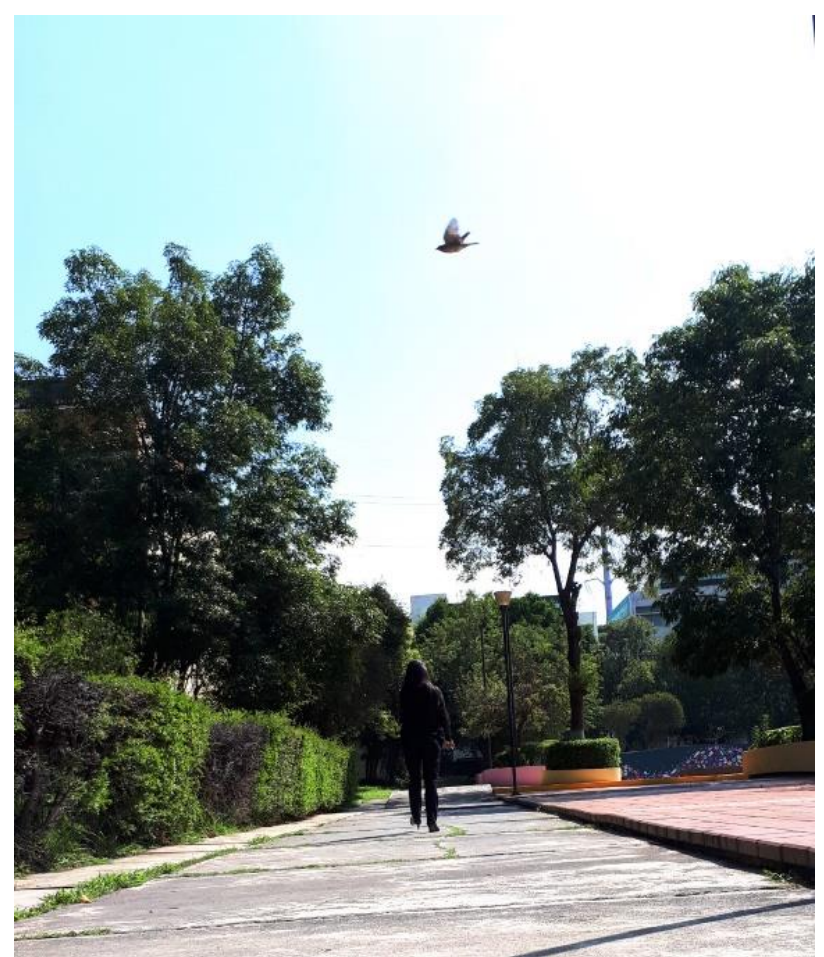

Imagen 32 CNMAIC CAHONI

Fuente: Archivo personal, Ruíz Gabriela 2018.

\section{Imagen 33 CNMAIC CAHONI:}

Recorrido institucional en el marco de la Practica de Especialización 1907.

Fuente: Archivo personal, Ruíz.

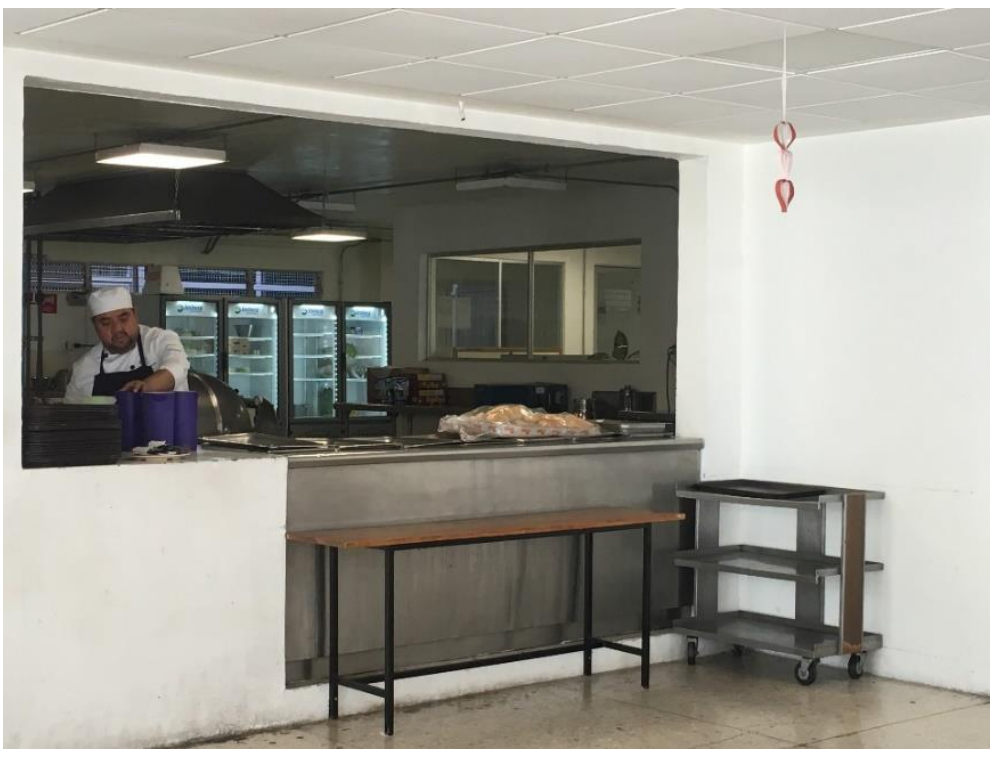

Atiende Niñas de 9 años a 18 años. Para septiembre de 2019 contaba con una población albergada de 40 residentes. 
Centro Nacional Modelo de Atención, Investigación y Capacitación Casa Hogar para Varones

Imagen 34 CNMAIC CAHOVA: Recorrido institucional en el marco de la Practica de Especialización 1907.

Fuente: Archivo personal, Ruíz.
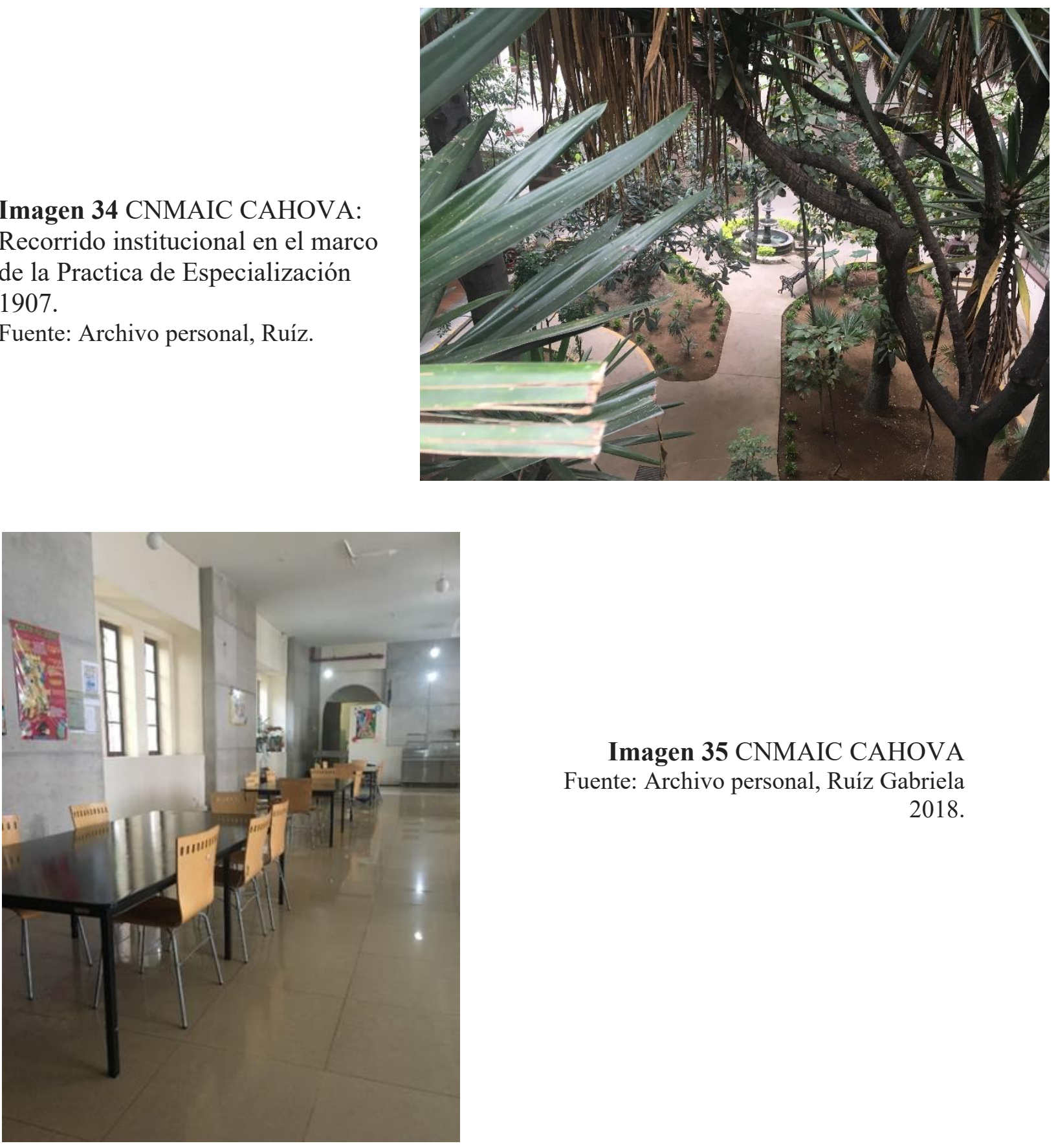

Imagen 35 CNMAIC CAHOVA Fuente: Archivo personal, Ruíz Gabriela 2018.

Atiende a niños de 13 años a 18 años. Para septiembre de 2019 contaba con una población albergada de 35 residentes. 
Los CNMAIC y la Subdirección de Centro Amanecer para Niños atendían una población total de 154 menores de edad a septiembre de 2019. Sustentan su atención en el Manual de Procedimientos de la Dirección General de Integración Social, que obra en la Normateca con fecha de última modificación el 11 de diciembre de 2014 (SNDIF, 2014), así como en el Modelo Tipo de Atención y Protección Integral de CAS para Niñas, Niños y Adolescentes (SNDIF, 2018). Ambos instrumentos tienen el objetivo de fungir como guía para un óptimo desempeño en los diversos departamentos que integran los Centros de Asistencia Social.

\subsubsection{Modelo Tipo de Atención y Protección Integral de CAS para Niñas, Niños y Adolescentes}

La intervención que se realiza en los Centros de Asistencia Social se soporta en las definiciones que se enmarcan en el Modelo Tipo de Atención y Protección Integral de CAS para NNA, como se mencionó anteriormente. Se trata del instrumento normativo que:

funge como una herramienta propositiva que orienta el desempeño, desarrollo, enfoque y procedimientos de atención en su diversidad, interdisciplinariedad y multipropósito con el fin de alinear las actividades e intervenciones del personal de los CAS en el enfoque de protección y restitución de derechos aplicando el principio del interés superior de la niñez y demás principios rectores reconocidos en la normatividad (Modelo Tipo de Atención y Protección Integral de Centros de Asistencia Social para Niñas, Niños y Adolescentes 2018:2).

Esta herramienta pretende ser la estrategia normativa que homologue la intervención de los CAS públicos y privados sobre la facultad de rectoría del SNDIF, aspiración que no ha sido concretada a pesar de los esfuerzos institucionales en materia de difusión y capacitación del Modelo.

Respecto el ingreso de las niñas y los niños a una CAS, este se detona cuando la autoridad ministerial toma conocimiento de algún acto delictivo en contra de un menor de edad, se 
inicia una carpeta de investigación agotando las posibilidades de cuidado en la familia de origen y estas se tornan imposibles.

Para la atención de NNA albergados en CAS del SNDIF, se cuenta con un equipo operativo que ejecuta el Modelo Tipo, mismo que toma como referencia la Ley General de los Derechos de Niñas, Niños y Adolescentes (específicamente en lo relativo al artículo 55 que establece los servicios mínimos con los que debe contar un CAS) (SNDIF, 2018:27-28).

Áreas de intervención:

- Atención Medica

- Psicología

- Nutrición

- Psicopedagogía

- Puericultura, y

- Trabajo Social

El Modelo Tipo servicios específicos (ver imagen 36) define para el área de Trabajo Social que deberá llevar a cabo los criterios de admisión y actividades que permitan integrar expediente administrativo de NNA (expediente que integra la documentación relativa al menor de edad: capeta de investigación jurídica, informes sociales, notas de seguimiento de caso, entre otros). 
Imagen 36 Servicios de los Centros de Asistencia Social

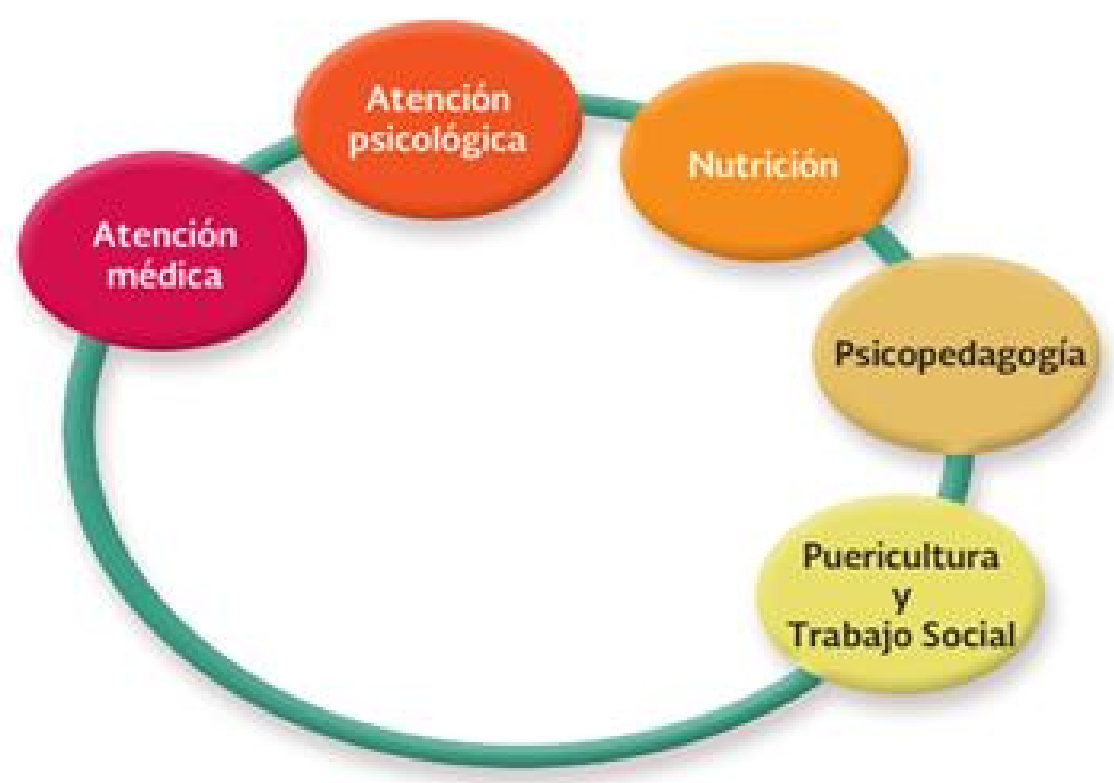

Fuente: Modelo tipo de Atención y Protección Integral de Centros de Asistencia Social para Niñas, Niños y Adolescentes, 2018: 35.

Cuando la institucionalización de las niñas y los niños es inminente, se desencadenan momentos de atención que inician en la etapa de ingreso y concluyen con un seguimiento institucional realizado por las áreas de Trabajo Social y psicología.

El egreso se lleva a cabo una vez que el equipo multidisciplinar considera haber coadyuvado en la transformación de las condiciones sociales, económicas y/o psicológicas que motivaron el ingreso. Para los CAS Casa Hogar Varones y Casa Hogar para Niñas, se suma el egreso por mayoría de edad, es decir cuando la o el adolescente llega a los 18 años. 
Imagen 37 Esquema general del Modelo Tipo de Atención en Centros de Asistencia Social

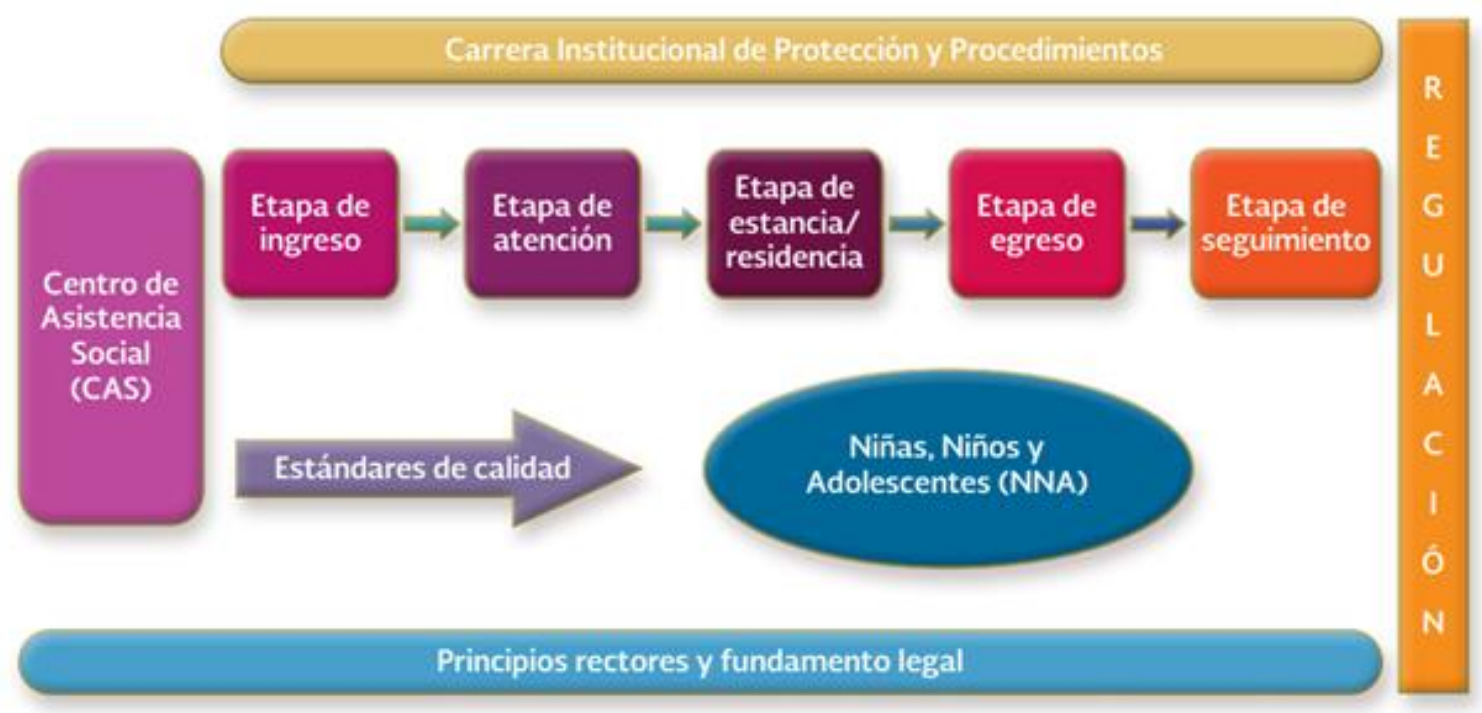

Vinculación interinstitucional

Vinculación interinstitucional

Fuente: Modelo tipo de Atención y Protección Integral de Centros de Asistencia Social para Niñas,

Niños y Adolescentes 2018: 36.

En la tabla 19 se describen las acciones que deben realizarse en cada etapa del Modelo de atención:

\section{Medidas de protección civil}

atencion: 
Tabla 19 Etapas del Modelo Tipo de Atención y Protección en los CAS. Adaptado de "Modelo de Atención y Protección Integral de Centros de Asistencia Social para Niñas, Niños y Adolescentes" de SNDIF, 2018

\section{Etapas del Modelo Tipo de Atención y Protección en los CAS}

\begin{tabular}{|c|c|c|c|c|c|}
\hline Etapa & I. Ingreso & $\begin{array}{l}\text { II. Atención y } \\
\text { restitución }\end{array}$ & $\begin{array}{l}\text { III. Estancia / } \\
\text { Residencia }\end{array}$ & IV. Egreso & V. Seguimiento \\
\hline Actividad & $\begin{array}{l}\text { Información y } \\
\text { orientación sobre los } \\
\text { servicios que brinda } \\
\text { el CAS: } \\
\text {-Detección y atención } \\
\text { de emergencias. } \\
\text {-Registro de vínculos } \\
\text { de confianza y } \\
\text { empatía con NNA. } \\
\text {-Entrevista } \\
\text { preliminar. } \\
\text {-Aplicación de } \\
\text { formato de primera } \\
\text { vez. } \\
\text {-Apertura } \\
\text { expediente. } \\
\text {-Valoración de la } \\
\text { situación individual } \\
\text { de cada NNA. } \\
\text {-Articulación } \\
\text { interinstitucional. } \\
\text {-Intervención } \\
\text { crisis en (si } \\
\text { necesaria). es } \\
\text {-Inicio de un plan de } \\
\text { intervención } \\
\text { centro del }\end{array}$ & $\begin{array}{l}\text { Diagnóstico social por } \\
\text { cada ingreso de NNA en } \\
\text { las siguientes áreas: } \\
\text { Trabajo social, médica, } \\
\text { psicología, legal y } \\
\text { pedagogía. } \\
\text {-Factores de riesgo. } \\
\text {-Gestiones. } \\
\text {-Referencias. } \\
\text {-Acompañamiento y } \\
\text { orientación a NNA sobre } \\
\text { su situación legal. } \\
\text {-Restitución de derechos } \\
\text { a NNA. } \\
\text {-Diseño de Plan de } \\
\text { restitución de derechos } \\
\text { en colaboración con cada } \\
\text { NNA, atendiendo sus } \\
\text { características } \\
\text { necesidades. y } \\
\text {-Contacto con algún } \\
\text { familiar o persona de } \\
\text { confianza de NNA. }\end{array}$ & $\begin{array}{l}\text { Cada NNA tendrá claro el } \\
\text { objetivo de su Plan de } \\
\text { acceso y desarrollo: } \\
\text {-Implementación del Plan } \\
\text { de acceso a derechos y } \\
\text { desarrollo, donde se } \\
\text { contemplarán algunas } \\
\text { actividades en: Trabajo } \\
\text { social, psicología infantil } \\
\text { y juvenil, pedagogía, } \\
\text { salud integral, área legal, } \\
\text { y esparcimiento (juego, } \\
\text { arte y cultura). } \\
\text {-Factores de protección. } \\
\text {-Regulación escolar. } \\
\text {-Desarrollo: para la } \\
\text { Habilidades para } \\
\text { vida (fundamental plan } \\
\text { de vida). } \\
\text { Habilidades para el } \\
\text { desarrollo económico, y } \\
\text {-Detectar las redes de } \\
\text { protección de NNA. }\end{array}$ & $\begin{array}{l}\text { Trabajo con la niña, niño o } \\
\text { adolescente para su egreso. } \\
\text {-Preparación de familiares, } \\
\text { tutorías e instituciones para su } \\
\text { recepción: } \\
\text {-Estrategias para acceso y } \\
\text { exigibilidad de derechos. } \\
\text {-Cartilla de los derechos de } \\
\text { NNA. } \\
\text {-Verificar las condiciones de } \\
\text { egreso, para salvaguardar el } \\
\text { interés superior de la niñez: } \\
\text {-Consolidación de acuerdos con } \\
\text { familia extensa, familia de } \\
\text { acogida, acogimiento pre- } \\
\text { adoptivo o adoptiva. } \\
\text {-Vinculación directa con quien } \\
\text { tendrá la guarda y custodia de } \\
\text { NNA. } \\
\text {-Evidencia administrativa del } \\
\text { egreso de NNA. } \\
\text {-Evaluación de calidad de los } \\
\text { servicios y del proceso de } \\
\text { atención y cuidado. }\end{array}$ & $\begin{array}{l}\text { Monitoreo de NNA } \\
\text { que ha egresado. } \\
\text {-Documentación. } \\
\text {-Evaluación de } \\
\text { visitas } \\
\text { domiciliarias, y } \\
\text { Sistematización de } \\
\text { las buenas } \\
\text { prácticas. }\end{array}$ \\
\hline
\end{tabular}

Fuente: Modelo Tipo de Atención SNDIF (2018). 


\subsubsection{Marco operacional de actuación de Trabajo Social}

El Modelo de referencia describe el perfil y las funciones de cada disciplina que integra el equipo multidisciplinario y para lo concerniente al servicio de Trabajo Social señala:

Tabla 20 Perfil y funciones del equipo de Trabajo Social. Adaptado de "Modelo de Atención y Protección Integral de Centros de Asistencia Social para Niñas, Niños y

Adolescentes" de SNDIF, 2018

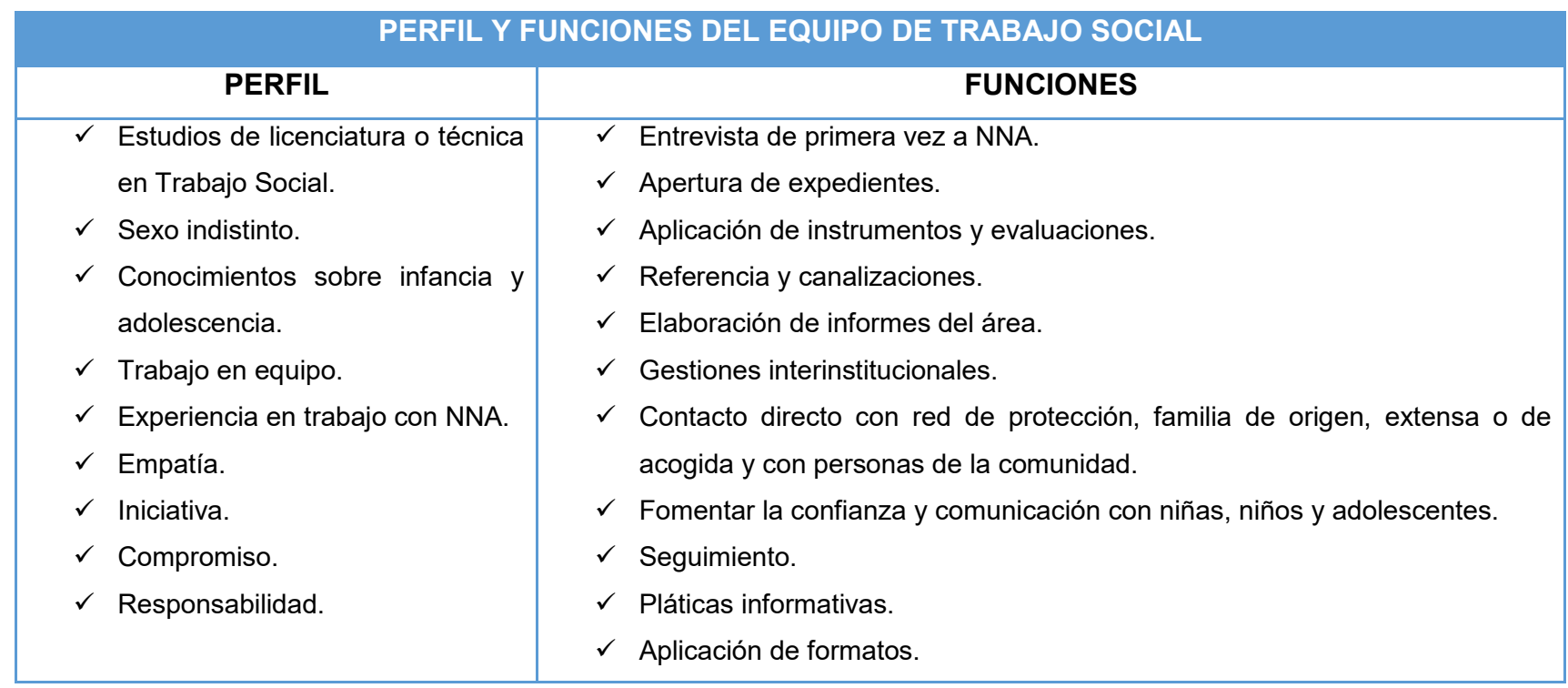

Fuente: Modelo tipo de Atención y Protección Integral de Centros de Asistencia Social para Niñas, Niños y Adolescentes 2018: 73.

Con base en el desarrollo del Modelo Tipo, Trabajo Social es la única área profesional que interviene durante todo el proceso desde el ingreso hasta el egreso del menor de edad y su consecuente seguimiento.

Hasta este momento hemos descrito las características y la base jurídico-normativa que regula la atención que se brinda al interior de los CAS del SNDIF, en donde como se ha revelado, el Trabajo Social se configura como una disciplina pilar en la atención al ser la responsable del diseño e implementación de planes de intervención social tendientes a la restitución de derechos de NNA receptores de violencia, sin cuidados parentales y en condición de institucionalización. La perspectiva disciplinar aspira a tener una

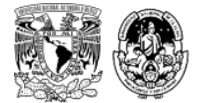


injerencia en las condiciones desfavorables que incitaron el ingreso, para con ello coadyuvar en la construcción de proyectos de vida que involucren a los sistemas familiares y rompan con el ciclo de violencia que ha vivido la niñez que en ellos se alberga.

\subsection{Subjetivación-episteme-institución y su expresión en el campo operativo (desarrollo, procesamiento y descripción de los resultados del trabajo de campo)}

En esta segunda parte del capítulo, se recuperan los hallazgos del trabajo de campo que se obtienen de la inmersión en los Centros Nacionales Modelo de Atención, Investigación y Capacitación (CNMAIC) y la Subdirección del Centro Amanecer para Niños definidos como la geografía investigativa, dado el carácter rector del SNDIF y como una posibilidad para identificar la intervención disciplinar descolocando la proposición de que todos los CAS reproducen violaciones a los derechos de la niñez. Se detallan las técnicas e instrumentos de investigación aplicados y se organizan con base en las tres categorías de análisis que se estipularon en el método: subjetivación-episteme-institución, así como las subcategorías construidas a partir del dato empírico.

Las técnicas de investigación utilizadas con las profesionistas fueron fundamentalmente desarrolladas en grupos focales (volver al capítulo 1 "Un enfoque cualitativo para comprender la intervención del Trabajo Social con la niñez receptora de maltrato, sin cuidados parentales y en condición de institucionalización: recorrido metodológico", si se desea recordar las precisiones). Se diseñan e implementan sobre la singularidad del espacio e informantes del estudio y la necesidad por obtener las características relativas al quehacer profesional, intentando dar respuesta a la pregunta ¿de qué manera el entramado subjetivación-episteme-institución configuran los elementos de un dispositivo que posibilita la intervención de las trabajadoras sociales dedicadas a la atención de la niñez receptora de maltrato, sin cuidados parentales y en condición de institucionalización?

Con respecto a las subcategorías -como ese elemento que surge a partir de una categoría y para profundizar en torno a la misma- que las y los lectores encontrarán: filantropía, empatía, apego, agencia, Trabajo Social, formación disciplinar, metodología, niñez, violencia, 
condiciones sociales, legislación, perspectiva adultocéntrica, marcos normativos de actuación institucional, autoridad, coordinaciones institucionales y políticas públicas, han sido construidas a partir de los datos del trabajo de campo y con fundamento en el enfoque teórico de la analítica del poder.

De igual manera se encontrará la información organizada:

a) Esquema referencial, que expone la categoría analítica y las subcategorías emanadas del dato empírico.

b) Técnica aplicada.

c) Herramienta, diseñada para efectuar en el formato de taller.

d) Descripción, que articula las categorías y subcategorías relativas al elemento que se deseaba explorar. 
Las técnicas aplicadas en los distintos talleres (3) contaron con la participación de 6 trabajadoras sociales adscritas al Sistema Nacional para el Desarrollo Integral de la Familia que laboran en el CNMAIC Casa Cuna Tlalpan. Se llevaron a cabo en las instalaciones del centro referido de agosto a octubre de 2017, en un horario matutino y con una duración de 4 horas. El intervalo para los encuentros fue de un mes.

\begin{tabular}{|c|c|c|c|c|c|c|}
\hline & $\begin{array}{l}\text { Trabajadora } \\
\text { social } 1\end{array}$ & $\begin{array}{c}\text { Trabajadora social } \\
2\end{array}$ & $\begin{array}{c}\text { Trabajadora } \\
\text { social } 3\end{array}$ & $\begin{array}{l}\text { Trabajadora } \\
\text { social } 4\end{array}$ & $\begin{array}{l}\text { Trabadora } \\
\text { social } 5\end{array}$ & $\begin{array}{l}\text { Trabajadora } \\
\text { social } 6\end{array}$ \\
\hline Edad & 54 años & 51 años & 49 años & 53 años & 55 años & 37 años \\
\hline Estado Civil & Casada & Casada & Unión libre & Soltera & Soltera & Soltera \\
\hline $\begin{array}{c}\text { Escuela de } \\
\text { procedencia }\end{array}$ & $\begin{array}{c}\text { Universidad } \\
\text { de } \\
\text { Guadalajara }\end{array}$ & $\begin{array}{c}\text { Instituto Nacional } \\
\text { de Psiquiatría } \\
\text { UNAM }\end{array}$ & CETIS 5 & $\begin{array}{c}\text { Escuela } \\
\text { Nacional de } \\
\text { Trabajo Social }\end{array}$ & $\begin{array}{c}\text { Escuela de } \\
\text { Trabajo } \\
\text { Social } \\
\text { Tampico }\end{array}$ & $\begin{array}{c}\text { Instituto } \\
\text { Mexicano de } \\
\text { Psico- } \\
\text { oncología }\end{array}$ \\
\hline $\begin{array}{l}\text { Grado de } \\
\text { estudios }\end{array}$ & Licenciatura & $\begin{array}{c}\text { Técnico con } \\
\text { Especialidad en } \\
\text { Psiquiatría }\end{array}$ & Nivel técnico & Licenciatura & Licenciatura & Licenciatura \\
\hline $\begin{array}{c}\text { Años } \\
\text { trabajando en } \\
\text { SNDIF }\end{array}$ & 25 años & 28 años & 24 años & 25 años & 30 años & 4 años \\
\hline $\begin{array}{l}\text { Años trabajando } \\
\text { con niñas y niños } \\
\text { institucionalizados }\end{array}$ & 6 años & 20 años & 15 años & 25 años & 5 años & 1 año \\
\hline
\end{tabular}




\subsubsection{La construcción del sujeto (categoría subjetivación)}

\section{a) Esquema referencial}

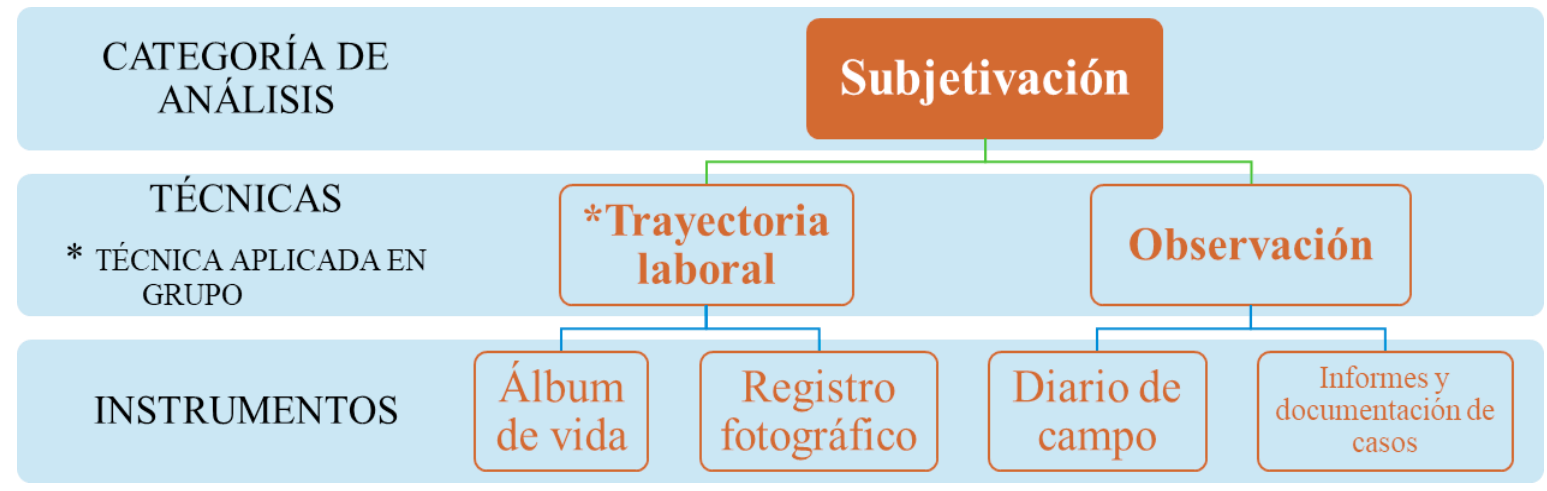

\section{b) Técnica: Trayectoria laboral}

Para poder reconstruir las trayectorias laborales de las trabajadoras sociales que participaron de la investigación se diseñó el taller Mis memorias, espacio de encuentro en donde cada informante recuperó su trayectoria profesional. Tenía la intención de recabar información para analizar el proceso de subjetivación respecto del ejercicio disciplinar y en convergencia con su historia de vida personal y en relación con las y los otros.

\section{c) Herramienta}

Álbum fotográfico (ver Anexo GFAF) que arroja información para identificar el proceso de subjetivación respecto del ejercicio profesional considerando: datos sociodemográficos (edad, género, lugar de residencia); formación académica (nivel); trayectoria profesional (dentro y fuera del SNDIF); Cursos de Profesionalización y consideraciones para la intervención desde el Trabajo Social.

Previo a la realización del taller, se solicitó a las participantes que recabaran fotografías que evidenciaran su trayectoria profesional en convergencia con sus vivencias personales (amigos, familia, relaciones de pareja). 
Una vez en el encuentro, tuvieron 2 horas para redactar las dimensiones del álbum y colocar las fotografías según correspondía. En plenaria se compartieron sus vivencias.

Imagen 38 Álbumes fotográficos de las trabajadoras sociales adscritas al CNMAIC CCT

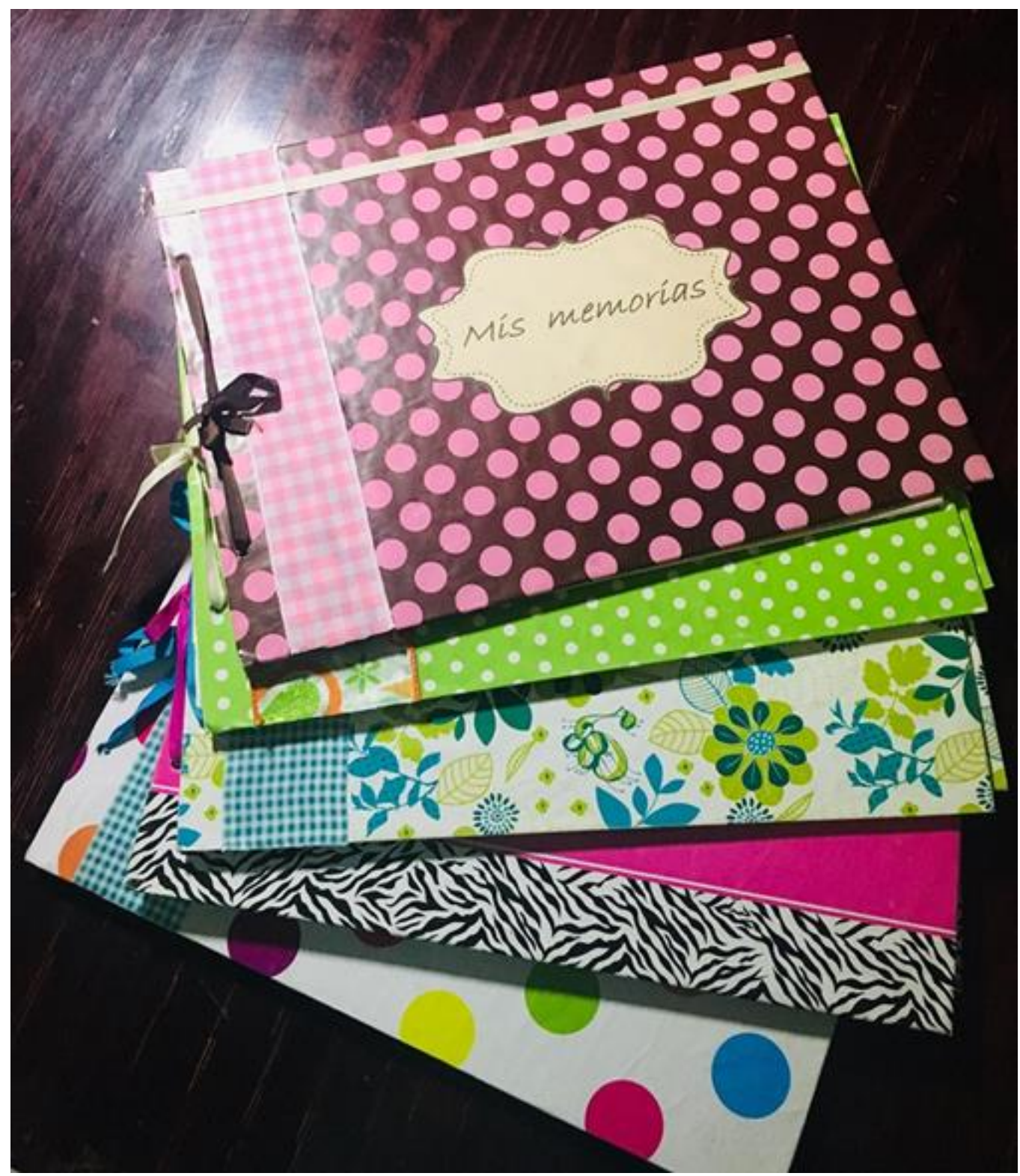

Fuente: Archivo personal, Ruíz Gabriela 2017. 
Imagen 39 Taller Mis memorias

Fuente: Archivo personal, Ruíz Gabriela 2017.
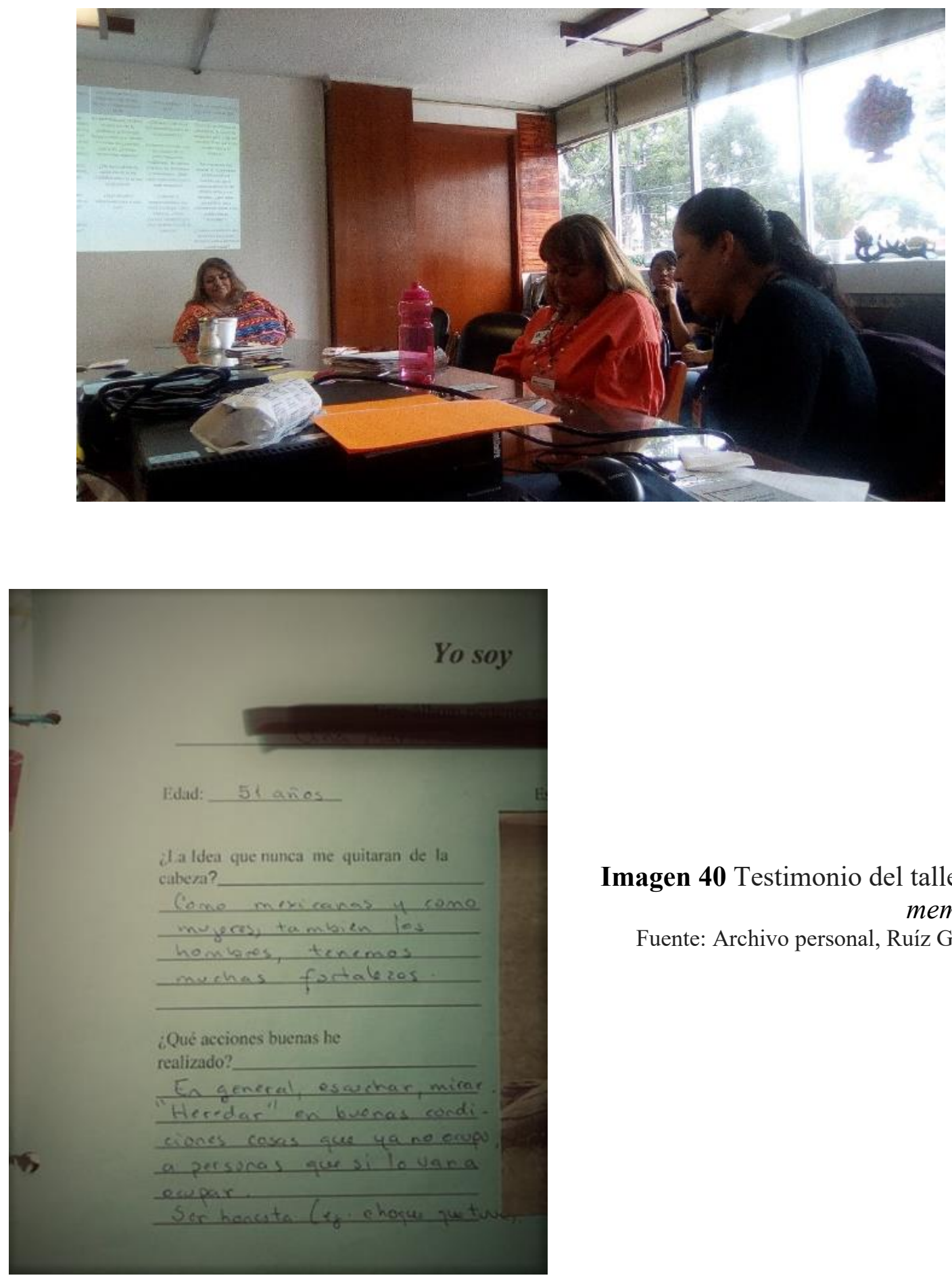

Imagen 40 Testimonio del taller Mis memorias

Fuente: Archivo personal, Ruíz Gabriela 2017.

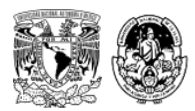




\section{d) Descripción}

\section{Categoría \\ Subjetivación \\ Subcategorías \\ Filantropía \\ Empatía \\ Apego \\ Agencia}

En consideración de la categoría de subjetivación en el trabajo de campo realizado, los esfuerzos se centraron en identificar las percepciones personales y del grupo que configuran la manera en cómo emerge y se sitúa el individuo en relación con los otros y las otras, teniendo como eje el propio ejercicio disciplinar.

Al respecto se construyeron subcategorías para dar cuenta de las maneras que esos vínculos adoptan, donde hay una fuerte recurrencia al concepto de "ayuda" a los demás y que se advertirá de forma constante en los discursos y prácticas narrativas. Este concepto está fuertemente articulado con las experiencias propias del maltrato vivido en la infancia dentro y fuera de los sistemas familiares de las informantes, lo que a su vez provoca sentimientos ambivalentes de cercanía y distancia al apreciar amor, cariño y cercanía con las niñas y los niños, mismos que se tensan con la frustración de no sentir que se impacta directamente en la transformación de trayectorias, en donde la agencia disciplinar ofrece una posibilidad al igual que una limitante, pues se identifican íntimamente como el mudo interno de las familias y los niños pero con una fractura clara en las contextos externos como la comunidad, la escuela y la propia institución. 


\subsubsection{De los constructos de la ciencia (categoría episteme)}

\section{a) Esquema referencial}

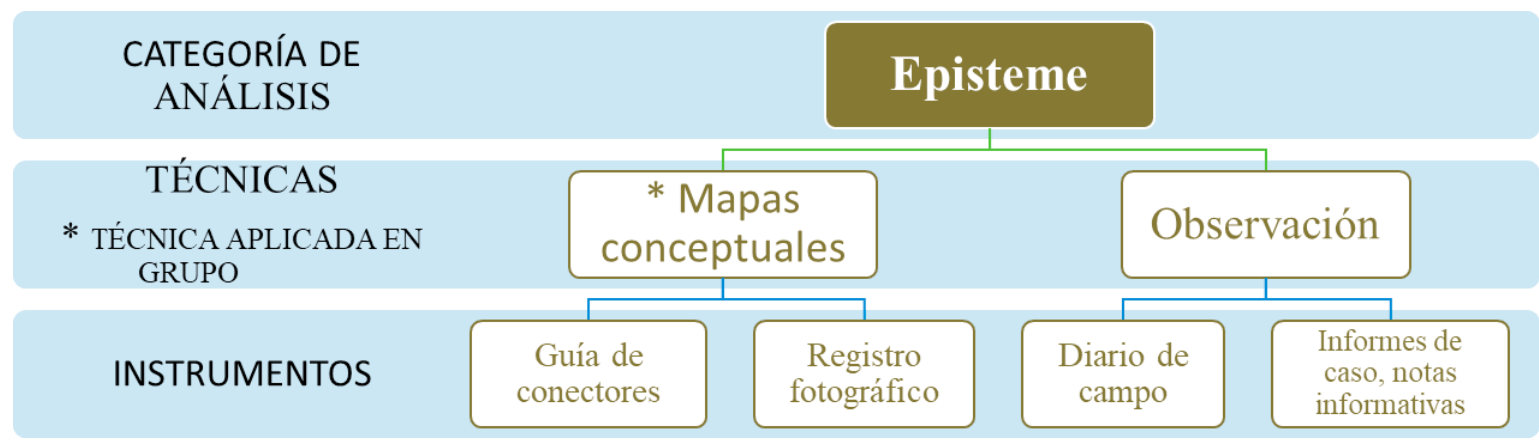

b) Técnica: Mapas conceptuales

\section{c) Herramientas.}

Se diseña e implementa el taller denominado: Enlazando mis saberes. Se trató de un espacio de encuentro en donde cada informante expuso sus referentes teórico-metodológicos de intervención y de la niñez receptora de maltrato, sin cuidados parentales y en condición de institucionalización a partir de una Guía de conectores (ver Anexo. GFGC) que permitirán la exploración de la categoría Episteme.

Al inicio del taller se entregaron de forma individual sobres rotulados con los conceptos: Niñez, Maltrato infantil, Intervención y Violencias, que en su interior contenían conectores (tabla 20) y se les indicó que deberían construir en un papel rotafolio 4 mapas que interconectarán cada concepto.

Al finalizar se discutieron grupalmente exponiendo con mayor detalle los criterios y conocimientos utilizados para su integración. 
Tabla 20 Guía de conectores

\begin{tabular}{|c|c|}
\hline Niñez & Maltrato infantil \\
- Perspectivas & - Se entiende \\
- Sujeto de derechos vs Sujeto de & - Tradicional \\
$\quad$ protección & - Contemporáneo \\
- Legislaciones & Violencias \\
\hline Intervención & $-\quad$ Factores propiciadores \\
- Maltrato infantil & - Tipologías y características \\
- Metodología de intervención & - Exigencia de la intervención \\
- Técnicas, instrumentos y enfoques & \\
- En el contexto contemporáneo & \\
\hline
\end{tabular}

Imagen 41 Portafolios del taller Enlazando mis saberes

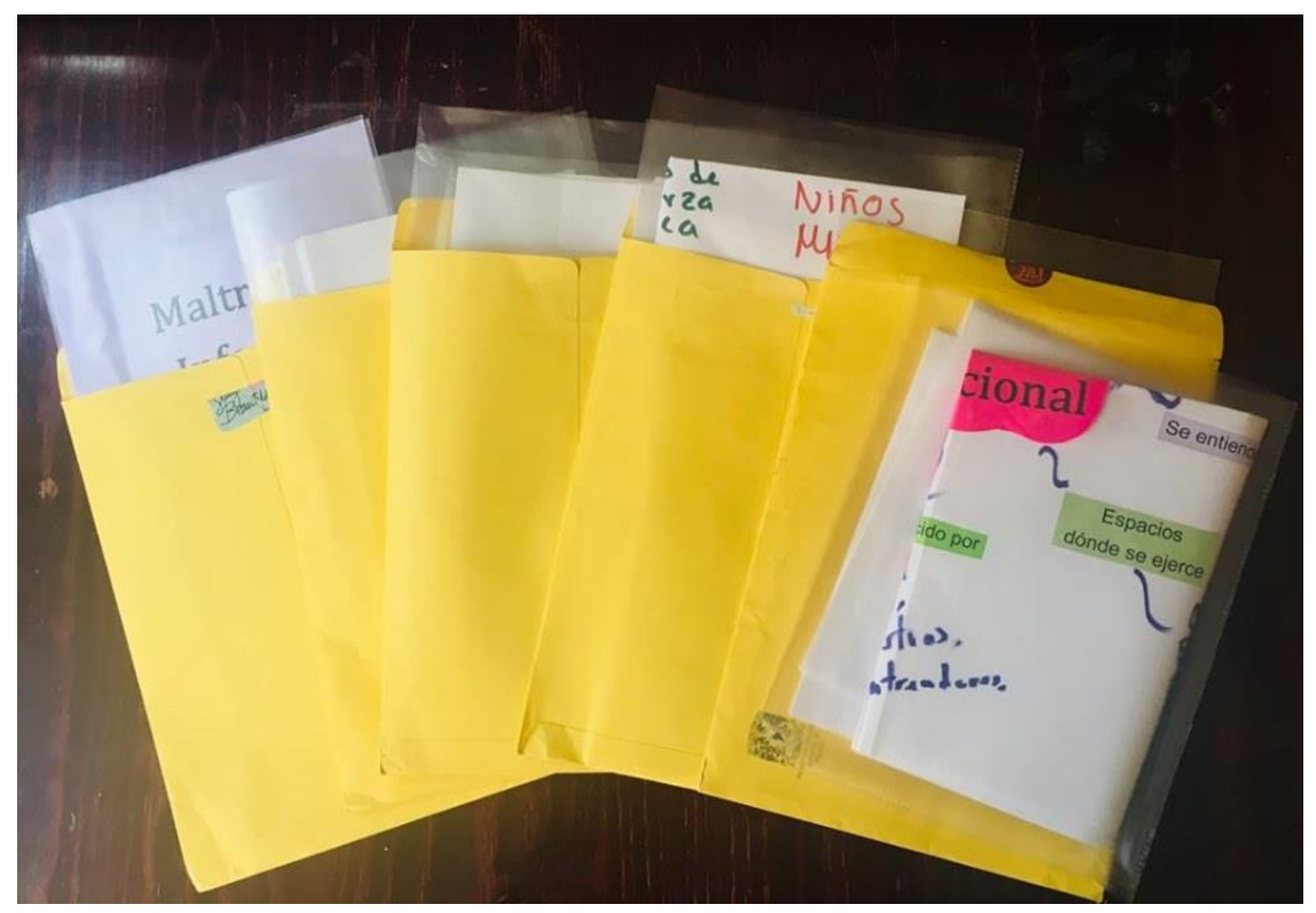

Fuente: Archivo personal, Ruíz Gabriela 2017. 
Imagen 42, 43, 44 Taller Enlazando mis saberes
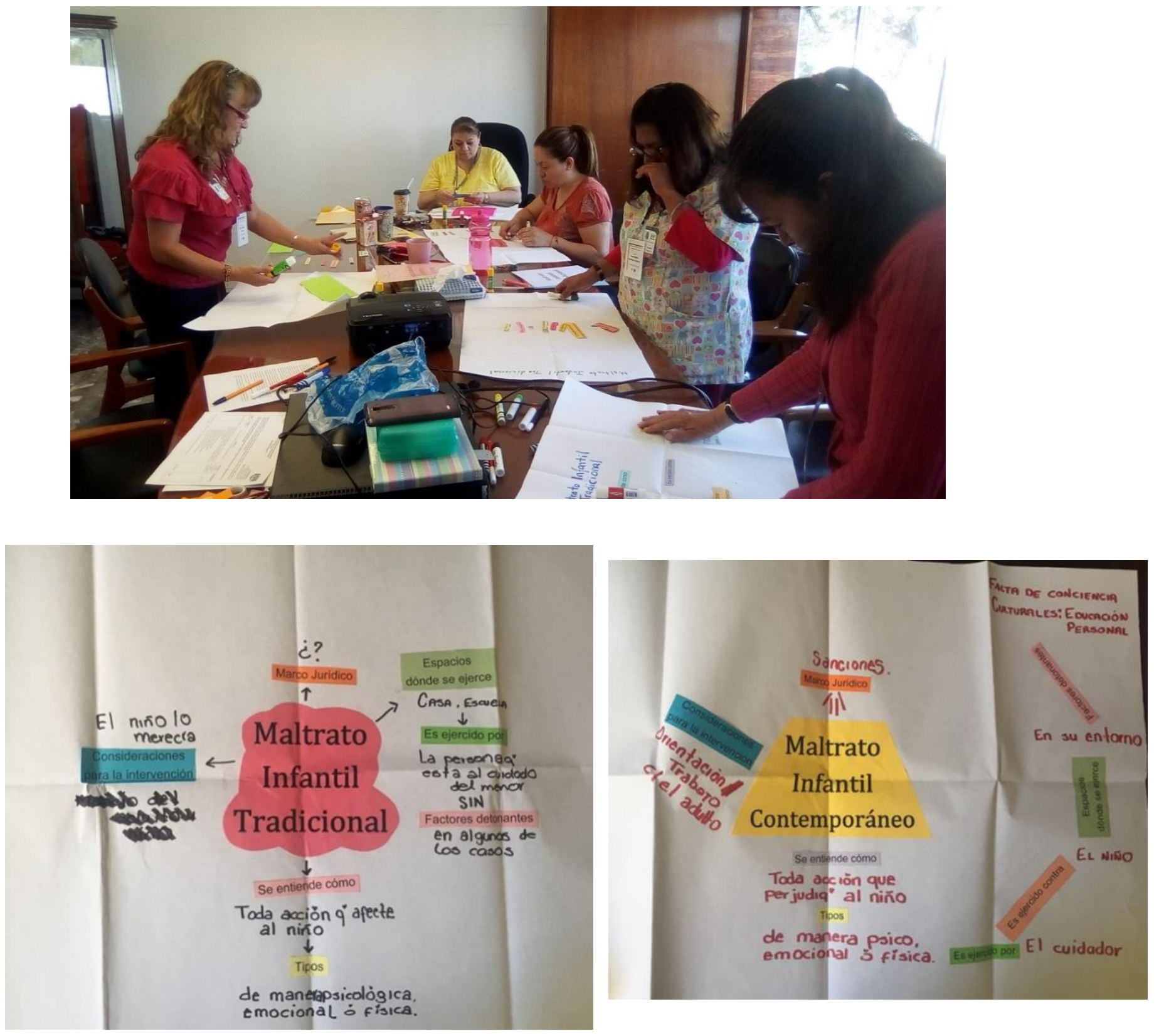

Fuente: Archivo personal, Ruíz Gabriela 2017.

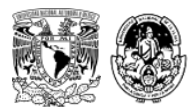




\section{d) Descripción}

\begin{tabular}{ll} 
Categoría & \multicolumn{1}{c}{ Subcategorías } \\
& Trabajo Social \\
& Formación disciplinar \\
& Metodología \\
& Niñez \\
Episteme & Violencia \\
& Condiciones sociales \\
& Legislación \\
& Perspectiva adultocéntrica
\end{tabular}

Para lo concerniente a la categoría de episteme, se exploraron los elementos que cobijan el ejercicio profesional desde la construcción disciplinar en donde hay una clara intersección de los elementos de subjetivación que se construyen en un puente que diferencia un hacer técnico con la forma de vivirse en el mundo, sólo por aquel que deriva del entramaje metodológico de la intervención social con las niñas y los niños.

De las narrativas expuestas, se observa que sigue permeando un imaginario de las niñas y los niños como "sujeto protección" que se fundan en los atributos que les colocan como "víctimas de maltrato" emanados de las condiciones adversas dentro y fuera del hogar. Vulneraciones que se instauran en un contexto de violencia que provoca un alto impacto de traumatización y para lo cual se recurre a los marcos jurídicos nacionales e internacionales, sin distanciarse significativamente de una perspectiva adulto-céntrica que coloca la toma de decisiones en el mundo adulto y que en sus prácticas tanto discusivas como operarias sigue considerando el estado de niñez como un estado de vulnerabilidad de necesaria intervención. 


\subsubsection{El rostro institucional (categoría institución)}

\section{a) Esquema referencial}

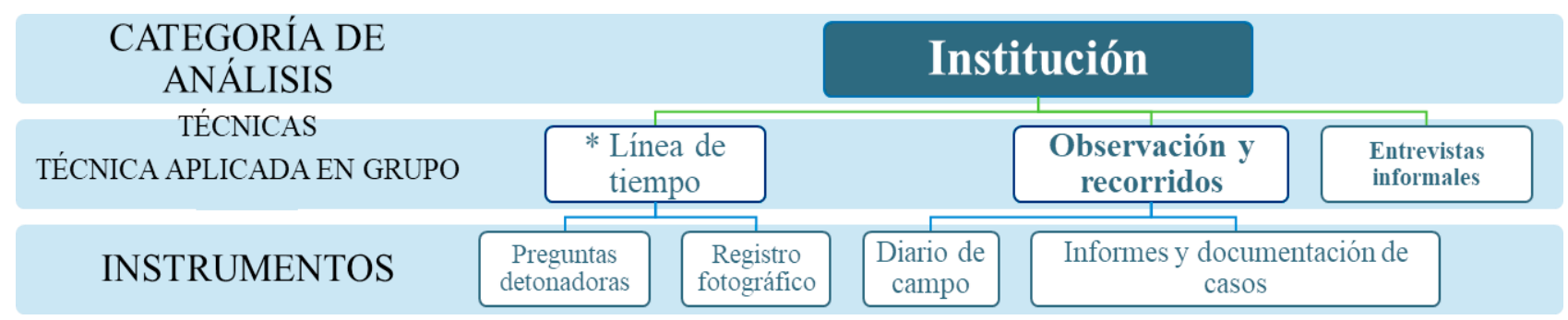

\section{b) Técnica: Línea de tiempo}

Para profundizar con relación a la Institución y la manera en cómo la perciben las trabajadoras sociales, se definieron cortes epocales (descritos en el apartado 5.3 y 5.3.1) con relación a las transformaciones institucionales y momentos que, de acuerdo con la información obtenida en campo, generó en ellas un impacto trascendental.

\section{c) Herramienta}

Se desarrolla el taller denominado: DIF a través del tiempo, espacio de encuentro en donde cada informante verbalizó y reflexionó sobre los cambios institucionales y su impacto en el ejercicio disciplinar a partir de la creación de preguntas detonadoras (ver Anexo. GFLT), diseñadas con cortes epocales que ellas mismas definieron.

Al inicio del taller se trabaja colectivamente la identificación de momentos de trasformación institucional que han impactado en el ejercicio profesional, que se sitúan de forma detallada en la dinámica interna y se plasman en una línea del tiempo.

Estos momentos de cambio incitan la formulación de preguntas (Anexo. GFLT) cuya intención fue profundizar en el impacto que dichos cambios tuvieron en términos de la intervención desde el Trabajo Social. 
En respuesta a dichas preguntas las participantes destacaron: Intervención hasta el año 2005, Cambio de Modelo institucional, Atención a solicitantes de adopción, entrada en vigor de la LGDNNA y la consecuente creación de la PFPNNA con un impacto relevante en función de los perfiles de atención. Transformaciones claramente identificadas y en congruencia con lo planteado en el capítulo 5 de esta tesis "Cuidado alternativo: estrategia para la atención de la niñez receptora de maltrato".

Se concluye con una plenaria de intercambio y discusión respecto de la percepción de las transformaciones institucionales.

Imagen 45 Taller DIF a través del tiempo

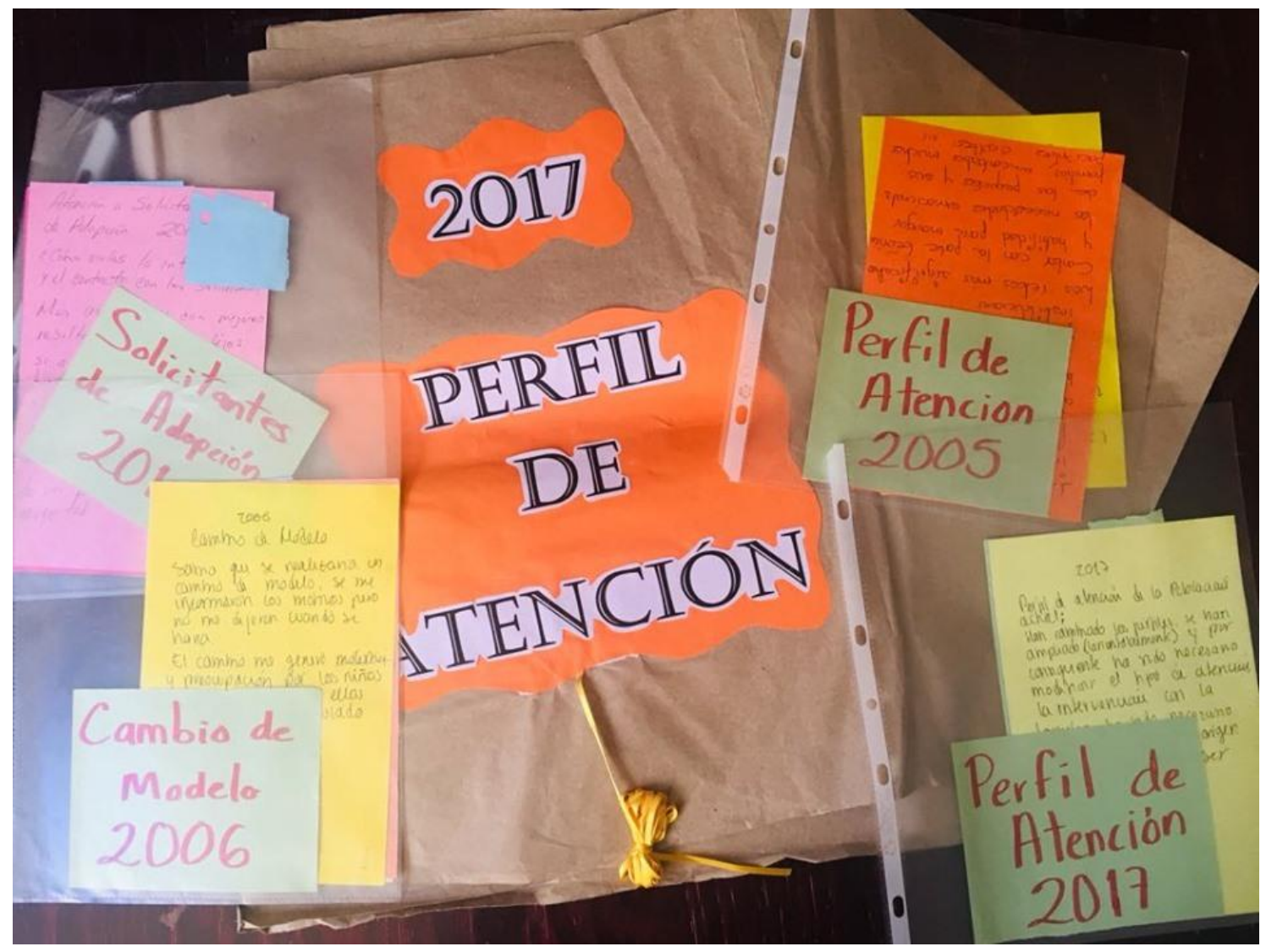

Fuente: Archivo personal, Ruíz Gabriela 2017. 
Imagen 46, 47 Taller DIF a través del tiempo
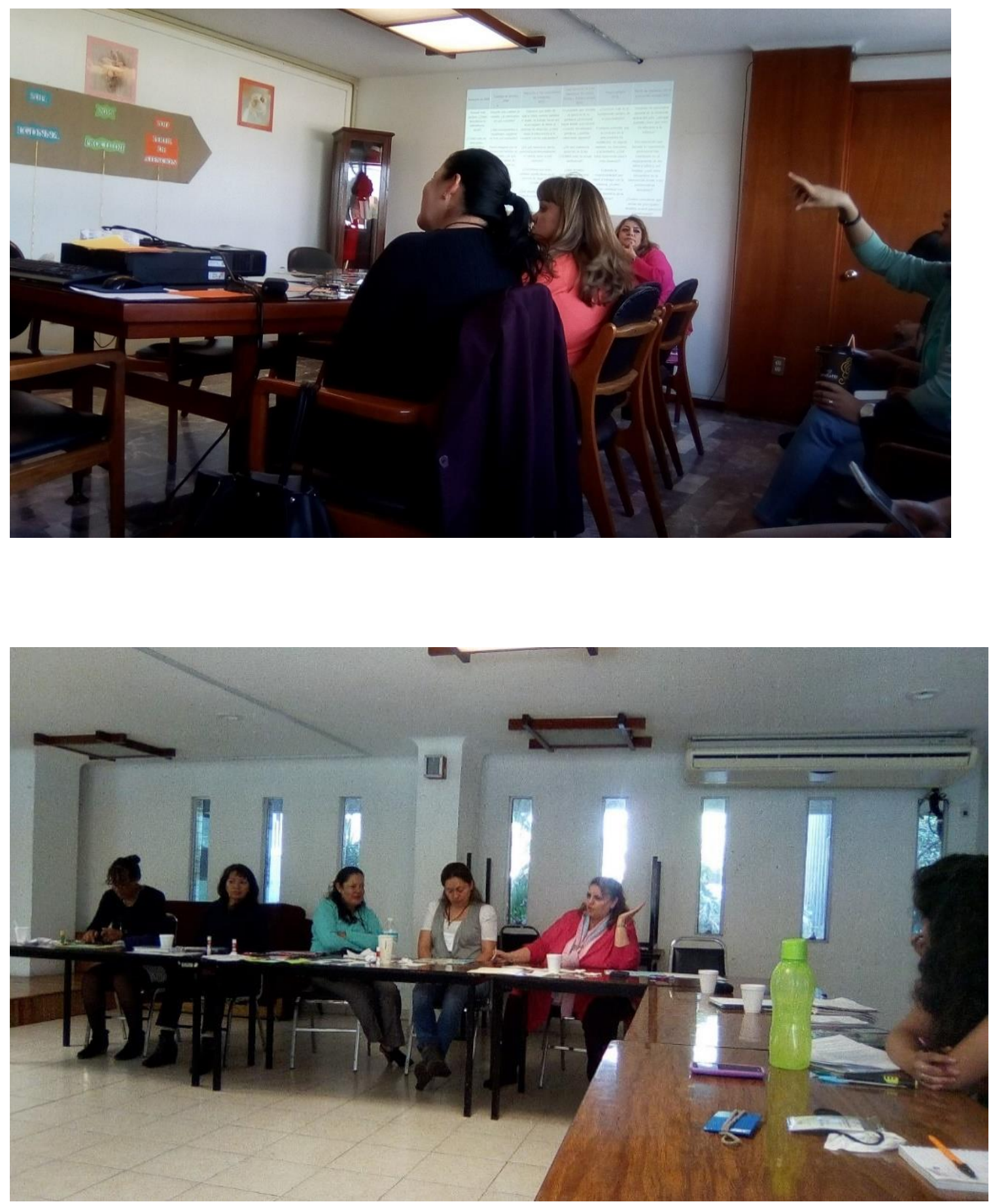

Fuente: Elaboración propia para el desarrollo del taller DIF a través del tiempo, 2017.

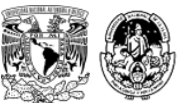




\section{d) Descripción}

\section{Categoría}

Institución

\section{Subcategorías}

Marcos normativos de actuación

institucional

Autoridad

Coordinaciones institucionales

Políticas públicas

La institución se configura entonces como la geografía de intervención que se implica en el mundo individual y familiar desde marcos normativos de actuación, que a manera de directrices delimita el ejercicio profesional y en donde autoridades administrativas y técnicas estipulan la manera en cómo habrá de realizarse dicha implicación.

Se desvela la convergencia con una red institucional más amplia que involucra otros actores (como la PFPNNA) que se definen para operar una política pública de cuidado alternativo: la institucionalización.

En síntesis, los hallazgos investigativos dan cuenta de la serie de elementos que emergen y se interrelacionan entre sí para orientar el ejercicio profesional, configurando el dispositivo de la intervención. 


\subsubsection{Categorías y subcategorías del dispositivo Intervención}

A partir de este esquema (tabla 21) se agrupan las categorías y subcategorías construidas a partir de los hallazgos del trabajo de campo a través del cual se aproxima, desde un análisis de la situación particular, hacia la respuesta a la pregunta ¿de qué manera el entramado subjetivación-episteme-institución configura los elementos de un dispositivo que posibilita la intervención de las trabajadoras sociales dedicadas a la atención de la niñez receptora de maltrato, sin cuidados parentales y en condición de institucionalización? Que será analizada y discutida en el apartado siguiente.

Tabla 21 Esquema de Categorías y subcategorías del dispositivo Intervención

Filantropía Empatía Apego Agencia

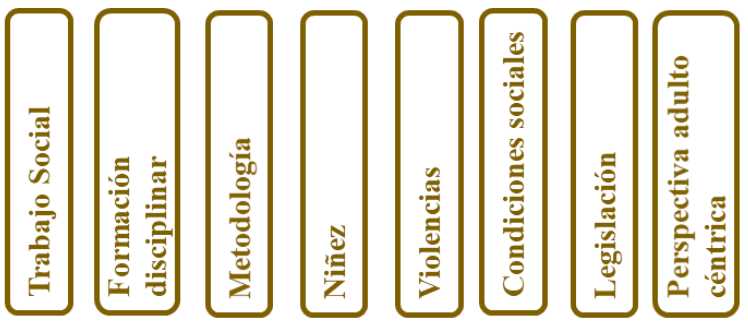

\section{EPISTEME}

INTERVENCIÓN

INSTITUCIÓN

\section{SUBJETIVACIÓN}

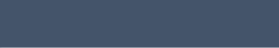
de actuación

Autoridad

Coordinación interinstitucional

Fuente: Elaboración propia con base en el trabajo de campo, 2019. 


\section{Epílogo}

El ingreso de una niña o un niño a un CAS deriva en una serie de impactos en su vida presente y futura. La vida se registra en archivos, notas e informes que documentan lo cotidiano, la vida íntima y los detalles de la existencia humana que al mismo tiempo pasan por el filtro de quien interpreta esa realidad. Frecuentemente estos registros pretenden dar cuenta de la trayectoria institucional, que para el caso de la niñez que nos ocupa, son redactados por el equipo de profesionistas que les atienden desde las diversas instituciones ya sean médicas, jurídicas y/o de asistencia social.

Esta herramienta de documentación, al mismo tiempo invisibiliza detalles singulares: los vínculos, los encuentros, las geografías de amor y esperanza, pues carecen de una narración en términos propios y usualmente registra patologías, carencias, deficiencias del sistema de origen, categorías que se soportan en las diversas epistemes disciplinares y dan cuenta de los motivos y características de la atención brindada.

Como vimos en la historia de Israel, el ingreso al CAS le permitió contar con un espacio que logro satisfacer sus necesidades fundamentales como alimentación, vivienda, educación, entre otras; al mismo tiempo fisuró su proceso de historicidad que de tomarse en cuenta, podría posibilitar la movilización, el entendimiento propio y la construcción de una identidad soportada en el conocimiento de la vida singular.

A lo largo de este capítulo, se recuperó información concerniente a los CAS del SNIDF que se encuentran en la CDMX, todos ubicados en la alcaldía de Coyoacán, mismos que configuraron el escenario investigativo central de esta tesis.

Se inicia detallando la ubicación geográfica por centro, características etarias y sectoriales y Modelo Tipo de Atención, instrumento normativo que otorga las directrices para la atención de las niñas y los niños albergados en los CAS del SNDIF y que pretende ser la estrategia para la atención en todos los espacios de cuidado alternativo de carácter público y privado, situación que a la fecha no ha logrado materializarse. 
El llevar a cabo esta revisión en términos normativo-institucionales, pone en evidencia la trascendencia de contar con referentes de actuación que dispongan enfoques y normas indicativas para el cuidado. El SNDIF para la operacionalización de sus 5 CAS define etapas: ingreso (momento en el que se evalúa la situación que motiva la institucionalización), atención y residencia (etapa en la que se pone en marcha el plan de restitución de derechos de NNA) y por último el egreso y seguimiento (que materializan la restitución de derechos y el acompañamiento institucional al salir del centro). Todas estas etapas son operadas por las áreas médica, psicología, nutrición, psicopedagogía puericultura y TS.

Se centra la atención en lo concerniente a las acciones definidas para la intervención del TS, identificándola como una de las áreas disciplinares de mayor impacto, la cual busca coadyuvar en la transformación de la realidad social que originó el ingreso a CAS y así participar activamente en la restitución de los derechos de la niñez albergada.

La segunda parte del capítulo recoge los hallazgos investigativos del trabajo de campo, mismos que a través de técnicas diferenciadas de enfoque cualitativo: trayectorias de vida, mapas conceptuales y línea del tiempo (implementadas en formato de taller con las TS del CNMAIC-CCC), permitieron obtener información y con ello construir los datos que se analizarán para dar respuesta a la pregunta ¿de qué manera el entramado subjetivaciónepisteme-institución configuran los elementos de un dispositivo que posibilita la intervención de las trabajadoras sociales dedicadas a la atención de la niñez receptora de maltrato, sin cuidados parentales y en condición de institucionalización?

Se concluye con la exposición del "Esquema de categorías y subcategorías del dispositivo Intervención", que interconecta las categorías y subcategorías identificadas y que serán discutidas y reflexionadas a la luz de la analítica del poder, en el apartado siguiente. 


\section{CAPÍTULO VIII}

\section{EL DISPOSITIVO DE LA INTERVENCIÓN}

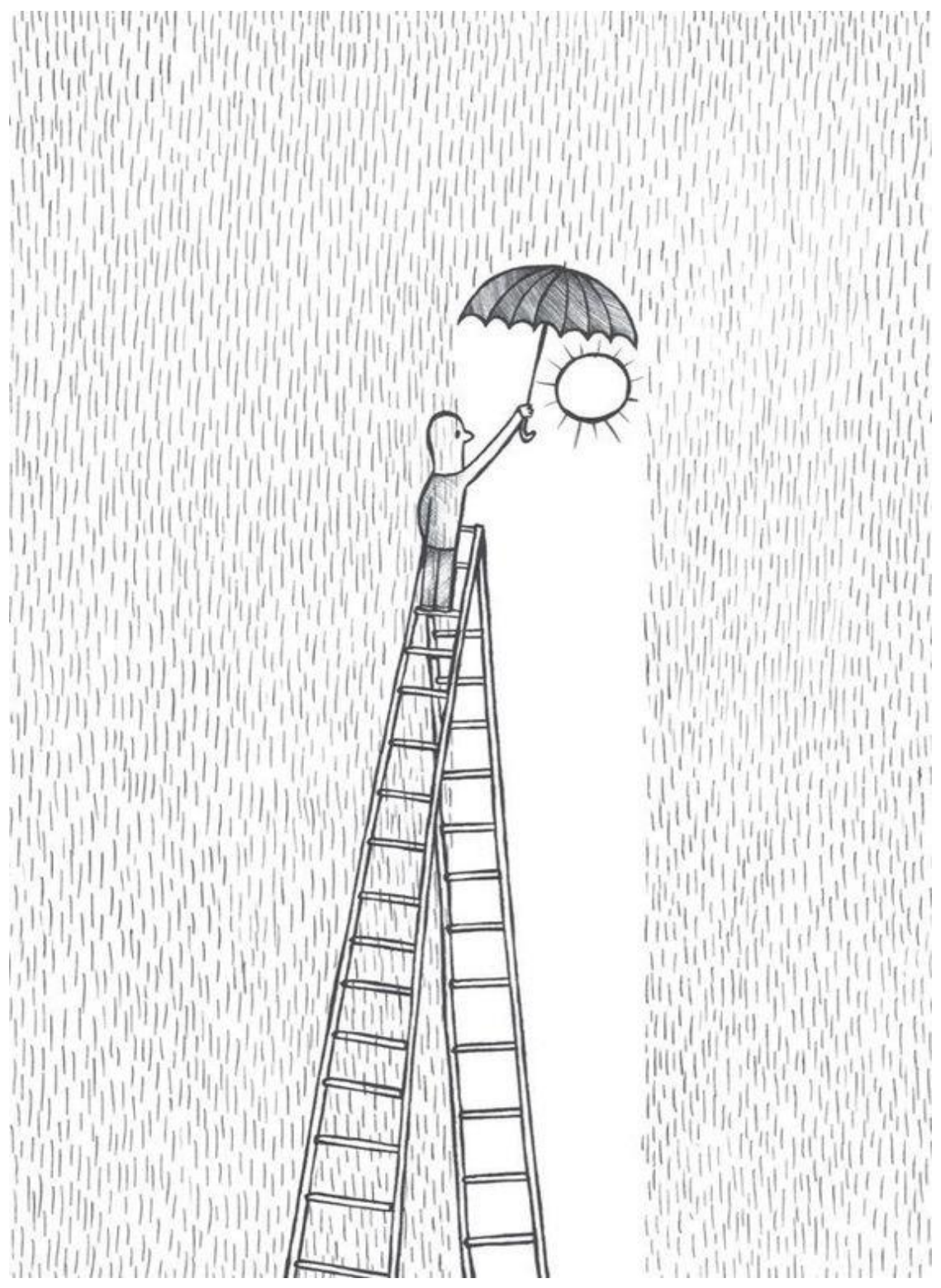

Troche, G. (2015). [llustración]. Recuperada de: http://portroche.blogspot.com/2015/ 
"No importa cómo salga la foto. Es

la mirada del otro el que dará valor".

(Jacques Derrida)

Donahí

(2020)

Uno de los peligros latentes y profundamente seductores que emergen tras la experiencia acumulada, los conocimientos teóricos y metodológicos incorporados y la vinculación desde una geografía académica, es la creencia de que estos elementos son suficientes para definir certeramente las intervenciones desde un lugar de autoridad. Sin embargo, esto nos coloca en una delgada cuerda floja, en donde perder el equilibrio es una amenaza con la cual hay que aprender a lidiar todos los días.

Comencé esta tesis compartiendo la historia de Mario, y de ahí en adelante las y los lectores se han topado con narraciones de algunos de los segmentos de las vidas de niñas y niños cuyas trayectorias han estado permeadas por los abusos, las violencias y la manera en cómo desde hace más de 25 años les he hospedado con mis propias fisuras.

En el quehacer investigativo y académico que hoy me toca desarrollar, he intentado situar mi lugar en el acompañamiento de equipos profesionales que se dedican a la atención de esta particular niñez, y es aquí donde Donahí, me devuelve a la realidad.

La cita fue en una reunión virtual -como se estila hoy en las condiciones de aislamiento social derivadas de la pandemia mundial-. Fui convocada por una organización de la sociedad civil con la que colaboro como asesora desde hace más de un año, misma que se encarga del cuidado de menores de edad vinculados con condiciones de maltrato en el escenario doméstico y separados de sus familias de origen. Nos encontramos para discutir la viabilidad de asignación de Donahí en una familia de condición adoptiva o la permanencia en el cuidado alternativo (ya fuera bajo la figura de familia de acogida o en el modelo de cuidado 
institucional) a la espera de determinar su proyecto de vida (atribución de la Fundación que le atiende).

Donahí tiene tres años y actualmente está en una familia de acogida por indicación judicial. Llegó a la fundación en cuestión tras el aparente abandono de su madre de origen tzotzil, un grupo indígena que se ubica en el sureste mexicano en un territorio de lucha que desde la década de los 90 ha sido fuertemente estigmatizado por algunos sectores conservadores de nuestra sociedad al implicarse en un movimiento político-militar que se disputa el territorio y promueve formas autonómicas de organización social, política y económica ante el descontento de un sistema económico profundamente desigual y un Estado inoperante en el ejercicio de los derechos de nuestros pueblos originarios.

Esta realidad atraviesa la percepción que se tiene de Donahí y su familia -particularmente la de los donantes de la fundación que le atiende-. Es muy poca la información que se tiene del dispositivo hospitalario -como suele suceder en este tipo de casos- y lo poco que se sabe descrito en "notas informativas" (informes que la autoridad judicial remite a la fundación): la madre adolescente, explicó al personal médico del nosocomio ubicado en la Ciudad de México, haber sido abusada en su contexto familiar.

Como describo en páginas anteriores, cuando es imposible el cuidado de las niñas y los niños por parte de sus progenitores el aparato jurídico define protocolos legales que advierten la responsabilidad de indagar las posibilidades de permanencia en el sistema de origen antes de asignar a una familia adoptiva. Esto último se hará sólo si se ha concretado un juicio de perdida de patria potestad, que se traduce en la desvinculación legal de las y los familiares consanguíneos y sobre la base de los Derechos del niño enmarcados en las reglamentaciones internacionales y nacionales, que reconoce el derecho de este a permanecer en la familia de origen.

La directora de la organización que atiende actualmente a Donahí y que funciona desde hace más de 40 años bajo la figura de Fundación, comienza la reunión explicando que "cuentan con una familia en lista de espera para adoptar a un niño pequeño". Relata con gran detalle y

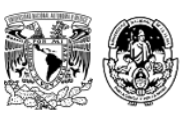


un claro entusiasmo de tono empático y seductor, que es una solicitud de carácter internacional: una pareja de origen español con muy buenos antecedentes y deseos de ser padres, que además ya tienen unos meses en espera y tras una serie de valoraciones han sido acreditados por sus equipos profesionales de Trabajo Social y Psicología para adoptar, pues cuentan con todos los recursos psicológicos y económicos para hacerse cargo de un niño y que dadas las características de Donahí es urgente la asignación. La descripción del matrimonio ocupa gran parte de la conversación, y en esta no se hace más que enaltecer los atributos y deseos de los solicitantes sin tocar en ningún momento la historia de quien se prevé adoptar.

No es menor decir que esta organización obtiene cuotas de recuperación de las personas que desean adoptar, que se traducen en pagos aproximados de $\$ 100,000$ por adopción realizada, recurso que no se obtiene obviamente con los niños acogidos en cuidado alternativo institucional y que tiene una clara tendencia de convencer a las y los integrantes que formamos parte del comité asesor de que este escenario es instrumental y materialmente óptimo.

Quienes conformamos el equipo especialista tenemos en nuestras manos la decisión de asignación y la tendencia es clara. Se colocan preguntas con relación a la familia adoptante: ¿cuánto ganan?, ¿en dónde viven?, ¿cómo son sus trabajos? Y es claro que se invisibiliza la condición de la que viene Donahí, pues la traducción es: entre mejores condiciones materiales, mejores condiciones de vida para él.

Parece que la decisión no tiene campos de salida alternos y las narrativas de las y los integrantes del Comité empiezan a emerger espontáneamente. El cuidador sustituto -quien se encuentra en la reunión- expresa: "es un peligro regresar a este niño con su familia de origen, imaginemos lo violenta que debe ser su comunidad en donde se encuentra en resistencia (...) hay mucha pobreza (...) los abuelos deben ser muy malos, ni siquiera pudieron cuidar de su hija”. Una de las especialistas añade: “yo ya tuve a un niño así hace años y ¿saben qué hice?, pues preguntarle a mi empleada doméstica qué costumbres tienen para poder ayudarlo a civilizarse". Concluye la directora del patronato (principal figura donante que otorga

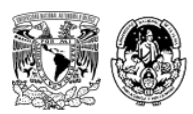


financiamiento económico para la actividad filantrópica de la institución): “¿no podemos hacer algo para que no sean notificados los abuelos y hacemos como que no nos damos cuenta? (...) esto ayudará a que el niño sea liberado muy pronto y esta familia pronto sea asignada. Obviamente lo digo pensando en el bienestar de todos”.

Estos relatos se hacían cada vez más robustos, con una expresa criminalización de la pobreza de la familia de Donahí fundada en percepciones personales y una ausencia de historización conveniente para satisfacer la necesidad adulta de una pareja que cuenta con el capital económico, social y cultural para tener un hijo que no tiene la familia tzotzil.

Tras un buen rato de presenciar el diálogo adulto y con una rabia que se experimentó en mi cuerpo, interrumpí para preguntar lo obvio: “¿cuál es la situación que guarda actualmente Donahí?” La directora se apresuró a responderme: “no tenemos liberación jurídica aún”. Ella percibió mi descontento y clara posición antagónica a la del resto del equipo. "Pero tú sabes Gaby, en estos casos la familia siempre es negligente y abandona a los niños, y pues entonces así podemos ir acelerando todos los trámites y ellos irán haciendo los pagos correspondientes".

Las niñas y los niños que provienen de familias altamente precarizadas y violentadas, en un sistema económico capitalista en su fase neoliberal más perversa, son transformados en mercancías, que sirven para satisfacer necesidades institucionales, parentales e incluso criminales. "Los más complejo es que en la relación de los adultos contra los niños, las peores atrocidades siempre se han cometido, mucho más en nombre del amor, la piedad y la compasión que en nombre de la propia represión" (García, 2004).

\section{Prefacio}

En este último apartado se discutirán y analizarán los principales hallazgos del trabajo de campo a la luz de la analítica del poder. Se hace necesario aclarar que a lo largo de la discusión se recuperan las narrativas de las y los informantes, mismas que se colocan en letras 
cursivas para su identificación y que se encuentran agrupadas en la "Tabla de procesamiento" que conforma el Anexo 7 al final de la tesis.

Tiene como finalidad articular los hallazgos del trabajo de campo con los elementos teóricos desarrollados en el documento a la luz de la analítica del poder, dando cuenta del cumplimiento del objetivo de la investigación: analizar subjetivación, episteme e institución como los elementos constituyentes del dispositivo de la intervención que posibilita el ejercicio profesional de las trabajadoras sociales dedicadas a la atención de la niñez receptora de maltrato, sin cuidados parentales y en condición de institucionalización, a partir de la recuperación de sus narrativas para con ello contribuir a la reflexión ontológica de la profesión.

\subsection{Entramado subjetivación-episteme-institución, elementos constitutivos del dispositivo intervención (discusión y análisis)}

Reflexionar la intervención del Trabajo Social en una geografía específica: los Centros de Asistencia Social que atienden a niñas y niños receptores de maltrato, sin cuidados parentales y en condición de institucionalización, implica el desafío de mirar la singularidad que se tensa y al mismo tiempo intersecciona con condicionantes, escenarios y significaciones sociales complejas.

No se trata sólo de situarse en la atención de un universo específico, el de las niñas y los niños en condición de institucionalización, cuyos contextos imposibilitan su permanencia en las familias de origen, exigiendo la intromisión estatal para el cuidado, reparación y restitución de sus derechos, en donde las y los trabajadores sociales nos implicamos y jugamos un rol profesional históricamente protagónico. Significa -al mismo tiempocomprender la forma en que nos atraviesa personal y profesionalmente el sumergirnos e implicarnos en el mundo íntimo de seres humanos altamente segregados, excluidos y expulsados que lidian con las contradicciones de una vida institucionalizada que trae consigo los efectos del maltrato e involucran a la familia de origen en su historia y proyección futura. 
La decisión de formarme como trabajadora social llego a mí a muy temprana edad. Inicié la formación técnica siendo una adolescente de apenas 14 años, con una escasa intuición y prácticamente nulos referentes disciplinares. Proveniente de una familia precarizada en la esfera social, económica y cultural, en donde las experiencias de maltrato se habían experimentado generacionalmente. De igual forma, encontrar mi espacio de actuación profesional no estaba claro de inicio, hubo experiencias que determinaron la ruta sin que yo lo supiera con claridad. Mi primer encuentro con Mario y su familia significaron una impronta al alojarse como la primera experiencia disciplinar; después el acompañamiento con sobrevivientes de abuso sexual y la niñez indígena definieron decisivamente la trayectoria que habría de seguir.

Comprender con mayor profundidad y consistencia las implicaciones del maltrato en la experiencia humana contextual de los primeros años de vida se desencadenó en la práctica, en el encuentro y en el acompañamiento de la niñez albergada en la Casa Cuna Coyoacán, en donde ingresé recién concluida la formación de licenciatura y convencida de que la construcción disciplinar me dotaría de los conocimientos teóricos para afrontar las exigencias de este grupo poblacional. Pronto me di cuenta que trabajar con una niñez marcada por las violencias más complejas y siniestras ocupaba de mí tanto el conocimiento teórico al tiempo que conectaba con mi propia historia. También se desarrollaba en un espacio concreto de intervención, un espacio determinado por lineamientos y marcos jurídicos de actuación que no siempre terminaban materializándose en la restitución de derechos de la niñez y sus contextos familiares y en donde los marcos jurídicos de actuación expresaban profundas contradicciones.

Para Carballeda (2010: 49) "si la configuración y constitución de la intervención social es ligada sólo a lo metodológico, termina elaborándose con criterios de otras prácticas interventivas que poseen un diferente tipo de desarrollo e inscripción histórica". Así pues y siguiendo esta línea de pensamiento, es que la presente investigación supuso un entramado de elementos a explorar para identificar la manera en cómo se constituye, configura y resignifica hoy la intervención: desde la singularidad de la subjetivación, en el 
reconocimiento de la construcción epistemológica disciplinar y colocada en un contexto situado que es la institución, en este caso los Centros de Asistencia Social.

Hoy día en nuestro país los contextos que expresan violencias, pobreza y desigualdad social atraviesan el mundo íntimo familiar estableciendo una relación dialéctica entre la experiencia en el ámbito doméstico y la experiencia del mundo social.

Tras algunos años de trabajo investigativo destinado a explorar la forma en cómo las violencias estructurales repercuten en la niñez y la experiencia del trabajo directo con familias en condición de vulnerabilidad, que derivaron en la institucionalización de los menores de edad, he comprendido que es imposible entender lo que pasa en el adentro, en la vida cotidiana, el espacio íntimo de las familias y sus integrantes, su padecer y necesidades, sin antes advertir que se trata de la expresión directa de las condiciones sociales y estructurales que, como observamos en el desarrollo de esta investigación, se vinculan con ambientes altamente precarizados, violentados y con prácticamente nulas redes de apoyo social que sostengan y ofrezcan otras alternativas.

Es así cuando las condiciones de violencia estructural impactan severamente el tejido familiar y este se configura como un espacio inseguro y hostil. Las problemáticas al interior se enuncian de formas múltiples: maltrato físico, psicológico o sexual, problemas vinculados con las adicciones, padecimientos emocionales e incluso actividades delictivas. Esto construye circunstancias de alto riesgo para las niñas y los niños exigiendo la intervención gubernamental para velar por el adecuado desarrollo de la niñez. Para ello una estrategia de política pública es el internamiento en espacios de cuidado alternativo: Centros de Asistencia Social.

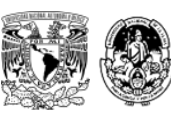




\subsubsection{Centros de Asistencia Social y cuidado alternativo, estrategia para la atención de la niñez receptora de maltrato, sin cuidados parentales y en condición de institucionalización, resultado de un proceso histórico}

La influencia y relación de las condiciones sociales y económicas desfavorables como factores que hacen proclive la institucionalización de niñas y niños en el territorio nacional, es claramente identificada por las trabajadoras sociales que participaron en la presente investigación, explica una de ellas: "actualmente los problemas son más agudos, desde mi óptica más porque ahora ya la mamá enfrenta, a lo mejor, retos mucho más complicados; los niños migrantes, ahora es un fenómeno evidente y recurrente; por otra parte lo esperado es que la persona que está a cargo del menor es quien maltrata, la violencia es ejercida por la persona que está al cuidado de él, y eso es lo que generalmente trae a las niñas y los niños a las Casas Hogar".

Esta estrategia de política pública enmarcada en el cuidado alternativo que se operacionaliza a través de la institucionalización, intenta dar respuesta a las directrices de cuidado y protección de la niñez sobre el reconocimiento de este grupo poblacional como "sujetos de derecho", precepto ampliamente promovido por los organismos internacionales y nacionales, resultado de un proceso histórico que inicialmente y por la década de los cuarenta reconocía en las y los menores de edad, un carácter de "sujetos de protección".

Desde la analítica del poder los dispositivos surgen primeramente "como respuesta a una urgencia, como tentativa de resolución pragmática, como forma política de solucionar lo que se percibe como un problema de orden práctico" (Heredia, 2012: 87). De ahí que la estrategia de institucionalización de niñas y niños en México puede interpretarse como el dispositivo creado para atender a la niñez sin cuidados parentales, que se desencadena en una época concreta: la Cardenista, ante la instauración del Estado benefactor (1934-1940). Define como una obligación estatal el internamiento de niños huérfanos o que se encontraban en riesgo social facultando a las y los trabajadores sociales a inmiscuirse en el ámbito familiar para mediante "la implementación de programas de asistencia especializada, atender a los menores abandonados, huérfanos, en condiciones de marginación y/o pobreza, y en general,

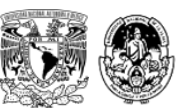


en situaciones, que representaban un riesgo en su salud física o emocional” (SNDIF, 2018:78).

Este momento histórico construye al niño "en riesgo", concibiéndolo como el sujeto que habrá de ser intervenido por el Estado (hasta entonces acogido por la Iglesia en el soporte de la caridad), en la aspiración de edificar ciudadanos fieles y con un encarnado sentimiento nacionalista. Se requerían sujetos institucionales que obedecieran normas, reglamentaciones y quienes en adelante se reconocerían como "niños institucionalizados" (las y los albergados en CAS). Desde una perspectiva individualizante poco se consideraban los contextos comunitarios y familiares, se les extraía del sistema familiar para su internación en una Casa Hogar y en tanto cumplían los dieciocho años se convertían en ciudadanos. Un claro proceso de subjetivación de la niñez congruente con las expectativas y necesidades de un Estado nacionalista en donde el niño dejaba de pertenecer a su sistema familiar para convertirse en “el hijo de la nación y al servicio de esta", resaltaba una trabajadora social con una trayectoria de más de 20 años de ejercicio profesional.

Este tipo de prácticas institucionales fueron severamente criticadas por Donzelot, quien en su texto La policía de las familias (1977) "analiza cómo el mercado de la infancia transita de técnicas conventuales y militares, conectadas con la autoridad familiar y religiosa, policial y judicial [...] a nuevos métodos en la medicina, la psiquiatría, la pedagogía, que tratan de aprovisionarse por sus propios medios la selección escolar y la prospección por los trabajadores sociales" (Donzelot, 1977). Aquí el Trabajo Social se destaca por el uso de técnicas profesionales como las visitas domiciliarias, los recorridos comunitarios, y en el desarrollo de funciones como la educación popular, que hacen que estas profesionistas (las trabajadoras sociales) se sitúen en el campo de una manera consistente y visible, y gesta en gran medida, una agencia disciplinar de identificación con los sectores populares y marginales.

El ejercicio disciplinar en la época pos-revolucionaria y la consecuente percepción de la niñez se sostuvo por décadas. Algunos de los espacios arquitectónicos de los Centros de Asistencia Social dan cuenta de ello: las instalaciones de Casa Hogar para Niñas datan de 1970 están

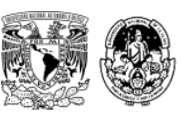


habilitadas para albergar a un aproximado de 500 niñas y hasta el año 2007 su población atendida, con base en la información proporcionada en los recorridos institucionales realizados durante 2019, era de un aproximado de 150. El testimonio de una de las informantes destaca: “cuando llegué a trabajar a Casa Hogar para Niñas en 1991, teníamos 6 Edificios con 12 departamentos para una capacidad de 71 niñas por edificio. Todos funcionaban y presentaban un modelo de internamiento al que las familias precarizadas recurrían para otorgar educación, alimento y vestido a sus hijas e hijos cuando las madres nos solicitaban el ingreso. Debían firmar una carta de aceptación para que la niña se quedara en la Casa Hogar hasta la mayoría de edad, aquí les enseñábamos oficios y si alguna quería estudiar, podía hacerlo".

Cuando me incorporé a Casa Cuna Coyoacán en el año 2007, los motivos de ingreso que derivaban en el desprendimiento de la niña o el niño de su sistema familiar de origen y concretaban la institucionalización en el CAS estaban fuertemente vinculados con procesos judiciales (carpetas de investigación), en donde los delitos de mayor recurrencia eran: el abuso físico, la negligencia y la omisión de cuidados. Para el año 2016 realicé el primer diagnóstico situacional de los Centros de Asistencia Social del SNDIF, logrando documentar que un importante porcentaje de solicitudes de ingreso, eran a petición del familiar (quien ante condiciones económicas precarias acudía a pedir ayuda institucional).

Las niñas y los niños eran internados en los CAS del SNDIF de manera indiferenciada e ingresaban por maltrato en el hogar, abuso sexual, negligencia o pobreza. Los motivos para la institucionalización no suponían una forma diferenciada de intervención y sumergirse en el trabajo con las familias de forma directa resultaba cada vez más complejo. El proyecto radicaba en alojar al menor de edad y satisfacerle sus necesidades básicas como alimentación, vestido, educación, atención médica, entre otras, sin que esto implicara necesariamente extender la intervención de Trabajo Social con los sistemas familiares de origen, a través de proyectos de reintegración familiar orientados hacia la transformación de trayectorias individuales y familiares.

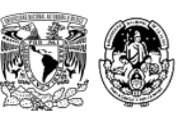


El niño y la niña carecían de voz, no se preguntaba su opinión, su tratamiento respondía al precepto del "niño como sujeto de protección" y todas las reglamentaciones se encontraban enfocadas a tratarlo de esa forma. Se ingresaba -con mucha frecuencia- a través de una carta solicitud de la madre y debía permanecer institucionalizado en aras de satisfacerle sus necesidades. Estas percepciones y formas de atenderle se encontraban íntimamente ligadas a la episteme histórica del niño como "ente pasivo", "maleable" y "a la espera de la vida adulta", interconectado con la histórica episteme de la intervención profesional como brazo operario del Estado, que de forma punitiva etiquetaba a las familias como "negligentes", robusteciéndose el ejercicio del poder del Estado frente a la vida familiar.

En Foucault (1991) el poder no se posee, se ejerce. Desde la década del ochenta, la instauración del niño como "sujeto de protección" cobra relevancia y los marcos jurídicos internacionales no sólo facultaban sino obligaban a los Estados a generar estrategias de atención a las niñas y los niños que pertenecían a dichas "familias negligentes", que se concebían como aquellas en donde los adultos, especialmente los padres, presentaban de una manera permanente comportamientos que se expresan por una omisión o una insuficiencia de cuidados a los niños y las niñas que tienen a cargo. "Un contexto de pobreza y/o aislamiento social rodea a menudo al sistema familiar, este contexto coincide muy frecuentemente con una historia de carencias múltiples en la biografía de los padres" (Barudy, 1998:87). Y es así como la biopolítica construye en la institucionalización los mecanismos, las técnicas, las tecnologías y los procedimientos por los cuales dirigir la conducta de los seres humanos mediante una tecnología gubernamental que hace uso de sus instituciones y profesionistas para controlar, retener y construir sujetos institucionales en el argumento de velar por la niñez y sus derechos, lo que trae implícito el ignorar las condiciones familiares y de esos padres, cuya negligencia emerge al estar insertos en un sistema que también ha ignorado sus necesidades fundamentales.

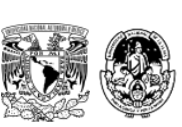




\subsubsection{La intervención del Trabajo Social frente a la niñez en condición de institucionalización: refuncionalización del dispositivo en el contexto neoliberal}

Estas epistemes, como el conjunto de prácticas discursivas que dan lugar a unas figuras epistemológicas tanto de la niñez como de la intervención desde el Trabajo Social, se instauran gracias al poder conferido por el Estado para acoger y atender a las niñas y los niños en condición de institucionalización, quienes para una de nuestras informantes deberían ser percibidos "como los hijos del Estado, los hijos del presidente, a los que no tiene por qué faltarles nada".

Estas percepciones, producto del proceso de historización que se consolidó durante el siglo XIX y principios del XX, prevalecen hoy día al tiempo que se tensan frente a la instauración y hegemonía de un modelo económico capitalista-neoliberal que desconoce el papel rector del Estado y se define al servicio de los intereses del mercado.

Insertos en este modelo, los Estados-nación despliegan prácticas encaminadas al fortalecimiento del sistema neoliberal. Para el caso de México y en relación al ejercicio y restitución de derechos de la niñez receptora de maltrato, sin cuidados parentales y en condición de institucionalización, dirigen una intervención asistencialista al tiempo que delegan la función de cuidado en instituciones y organizaciones de carácter privado, en donde hoy día sólo el 15\% del total de dichas instituciones son gubernamentales; contrario al proyecto del Estado benefactor que había construido una hegemonía respecto de la atención de este grupo poblacional. Según estimaciones de la REDIM (2020) "9 de cada 10 menores de edad, residen en CAS de carácter social o privado".

Aunado a la carencia de estrategias de coordinación, vigilancia y auditoría que se expresan en la ausencia de protocolos de evaluación y seguimiento de las instituciones sociales o privadas, la falta de un registro fidedigno que dé cuenta de la cantidad de niñas y niños en condición de institucionalización y la documentación certera de instituciones de cuidado alternativo que le ha valido a México observaciones internacionales de urgencia para atender estos rubros. 
Este elemento no es menor, en tanto la niñez sin cuidados parentales y en condición de institucionalización se vuelve un universo potencialmente vulnerable, que se estima en 30,000 personas y cuyo dato duro no da cuenta de las dimensiones del problema y tampoco expresa la complejidad en su atención. Una niñez que en el sistema neoliberal se muestra dicotómica: invisible frente a un Estado fallido, al tiempo que foco de programas de política pública paliativas que no logran extenderse a la transformación de las condiciones sociales que precipitan el ingreso a los CAS. "Niñas, niños y adolescentes se volvieron invisibles para esta nueva administración al no formar parte de ninguno de los 25 proyectos estratégicos" (REDIM, 2019:1). Lo que revela cómo las leyes y marcos normativos no son más que constructos enunciativos que forman parte de un dispositivo individualizante y congruente con el sistema económico cuyas características de acumulación de desventajas y precarización le fortalecen y hacen mantener el estatus quo.

Durante la última década y gracias al periodismo de investigación, se han documentado prácticas de administración del dolor de la niñez en Centros de Asistencia Social, en donde la corrupción y la impunidad han sido factores comunes. El caso La Gran Familia, Ciudad de los niños, Casitas del Sur, han dado cuenta de una niñez residual, la prevalencia de espacios de riesgo que tienen el "poder de dar muerte con tecnologías de explotación y destrucción de cuerpos tales como la masacre, el feminicidio, la ejecución, la esclavitud, el comercio sexual y la desaparición forzada, así como los dispositivos legal administrativos que ordenan y sistematizan los efectos o las causas de las políticas de muerte” (Estévez, 2019: 2).

“Por qué no habían venido? nosotros gritábamos por las noches”, fue el testimonio de Juan en La Gran Familia, y aunque este caso se configuró como uno de los eventos de mayor conmoción en los últimos años para la sociedad mexicana, a la fecha no se cuenta con una determinación jurídica e impresiona que no son las niñas y los niños lo más importante, pues lo que ocupa es el uso político del hecho. "Se trataba de capturar a Rosa Verduzco, Mamá Rosa, 80 años, la fundadora de la Gran Familia, inventándole una serie espeluznante de crímenes supuestamente cometidos contra sus niños y adolescentes, con la complicidad de varios de sus trabajadores. Todo este ejercicio fue acompañado de una cobertura mediática

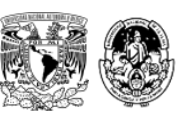


escandalosa" aseguraba el escritor Meyer en 2019 (idea que siguen sosteniendo, a más de seis años, algunos medios de la prensa nacional).

La recepción de niñas y niños por Centros de atención financiados con recurso privado y sin una vigilancia puntual es cada vez una práctica más frecuente. "Mandamos a los niños migrantes a las instituciones de convenio porque en los Centros de Asistencia Social del Sistema Nacional para el Desarrollo Integral de la Familia, no tenemos capacidad para atenderlos”, aseguró en 2019 el coordinador de los Planes de restitución de derechos de la Procuraduría Federal de Protección de Niñas, Niños y Adolescentes.

Sin embargo y con fundamento en las entrevistas y los recorridos institucionales, hechos a los Centros de Asistencia Social del Sistema Nacional para el Desarrollo Integral de la Familia, en el periodo 2016-2019 se pudo documentar que la capacidad instalada de Casa Cuna Coyoacán (por ejemplo) corresponde a 80 residentes y actualmente, con base en la información que obra en el portal institucional, es de 36 (a septiembre 2019). Al respecto los discursos de las profesionales que laboran en los Centros de Asistencia evidencian el descontento y la consternación por la disminución de niñas y niños albergados en los que se exhiben narrativas: "como ves está casa es muy grande, a mí me preocupa que ya no haya niñas, hasta nos quitaron ya algunos edificios para dárselos a la Dirección General de Rehabilitación. Antes llegábamos a tener hasta 120 niños en el Centro, cada vez hay menos, pero yo no creo que se deba a que ya no lo necesitan, sino a las nuevas políticas institucionales. No sé qué vamos a hacer sin niños, somos más trabajadores que población”, sostuvo en entrevista una trabajadora social. ¿Cómo explicar estas contradicciones; ¿la derivación de NNA a centros de cuidado alternativo de carácter social o privados, teniendo capacidad arquitectónica y humana para su acogimiento en el SNDIF?

El dispositivo se re-funcionaliza y transforma, inventando formas de permanencia y tecnologías para soportarse. Así como de origen el dispositivo de la intervención colocado en el internamiento respondía a la necesidad del Estado por generar ciudadanos, hoy se trata de subjetivar y construir sujetos institucionales que respondan a las necesidades de un mercado, en donde los centros sociales y/o privados administran la vida de niñas y niños sin

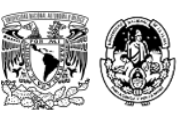


dar cuenta de los resultados y formas de atención. A través de una niñez aparentemente sin ningún capital: se recuperan sus cuerpos y en tanto conserve la minoría de edad, puede ser utilizable y re-utilizable.

En nuestro país hoy se enuncia al niño/a como "sujeto de derecho" inmerso en condiciones sociales que lo cosifican. Dependiendo de sus circunstancias y características se hace de él o ella: un/a niño/a fuerza de trabajo, un/a niño/a consumidor/a o un/a niño/a consumible. "El neoliberalismo, más que una comunidad, fábrica cuerpos agrupados en serie ¿pero apuesta por el lazo social? Los discursos de poder acusan, acosan y a-cosan. Clasificaciones, evaluaciones y diagnósticos que segregan y fracturan vínculos" (Stavchansky y Untoiglich 2019:28).

En los casos de maltrato institucional (perpetrados en Centros de Asistencia Social sociales o privados), las adopciones ilegales, la explotación laboral infantil y el tráfico de órganos, se revelaron como delitos perpetrados en contra de las y los residentes, documentado en lo tocante -por lo menos- a la última década. Por mi parte, recuerdo que cuando entramos a La Gran Familia encontramos ataúdes y a muchas adolescentes con marcas de cesárea, pero extrañamente no encontramos bebés. Los residentes decían que "por las noches sacaban a las embarazadas y luego las regresaban ya sin panza”. Por su parte en Guanajuato, explicaba un defensor de Derechos Humanos cuando hicimos la investigación en Ciudad de los Niños, que se intercambiaban niños con los de mamá Rosa y la amenaza era esa: "si te portas mal, te mandamos con la jefa".

Mi participación en el operativo de Casitas del sur, La Gran Familia, La Divina providencia y Ciudad de los Niños, me llevó a un universo desconocido que hizo cuestionarme el papel del Estado y sus tecnologías de poder frente a la atención de la niñez; cobrar conciencia de que su condición de orfandad y/o institucionalización no sólo representaba la ausencia de un referente familiar, sino que traía consigo la posibilidad de transgredirle y cosificarle en el anonimato e indiferencia social. 
La niñez en condición de institucionalización que se aloja en espacios de riesgo, brota para satisfacer la necesidad adulta desde una perspectiva adulto céntrica, ya sea para satisfacer la necesidad de ejercer el paternaje o maternaje, brindar atención en espacios de cuidado alternativo -obteniendo con ello recursos económicos- y justificar así la intromisión en el proyecto de vida, e incluso para realizar acciones filantrópicas que hagan del adulto una gran persona, atrapando y subjetivando así, sus cuerpos. "Entendemos que el niño no se quiera ir en adopción porque están sus otros hermanos, pero ya la psicóloga está trabajando con él, para convencerlo de que es el mejor proyecto para su vida"; afirmaba la directora de una fundación privada que se dedicaba a gestionar procesos adoptivos.

\subsubsection{Las epistemes de la niñez y la intervención, procesos tensionados en el escenario institucional: entre la práctica tradicional y la realidad contemporánea}

Uno de los elementos persistentes a lo largo de la investigación se coloca en el comportamiento adulto céntrico que invisibiliza los deseos y pensamientos de niñas y niños. Encontré narrativas como la de una niñera que aseguraba que (en 2006 se redefinen los rangos de edad para la atención en los CAS del SNDIF y deriva en una redistribución en los Centros por rango de edad): "cuando se hizo el cambio de modelo, se llevaron a los niños sin decir nada, ellos lloraban".

En esta misma percepción y tras el encuentro con una persona donante de dulces y juguetes a Casa Cuna Coyoacán que afirmaba: "yo traigo cosas a los niños pobrecitos y vine con mi hijo para que se las dé y se dé cuenta de lo afortunado que es, porque él lo tiene todo y ellos ni papás". Estas palabras revelan el imaginario colectivo de minusvalía respecto de la población albergada, que fortalece la conservación de prácticas asistencialistas paliativas confundiéndolas como ejercicio de derechos. Veamos otra forma de expresión en recorrido por Centro Amanecer al preguntarle a la enfermera responsable del área: ¿por qué se había decidido no incorporar al adolescente a la atención integral del centro (que implica educación, atención psicológica y actividades de recreación y esparcimiento colectivas) y

alrededor del mediodía este seguía con ropa para dormir? Respondió (en relación a la atención de un adolescente de condición migrante): “el niño anda en pijama porque está como

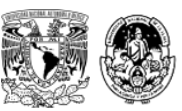


enojado, no nos hace caso. Como es migrante se irá pronto, así que lo atendemos en el área médica, no nos queda más que esperar".

La percepción de la niñez como "sujeto de protección” montada en el pensamiento adulto céntrico, se ve tensionada frente a su carácter de "sujeto de derecho", que implica la participación y el poder opinar sobre sus propias identidades, lo que influye en la manera en cómo se provee el cuidado, no sólo desde el Trabajo Social, sino en lo concerniente al resto de las áreas de atención descritas en el Modelo Tipo de atención.

Siguiendo esta línea, relativa a conducir las acciones con fundamento en los marcos procedimentales de actuación institucional, y para lo que ocupa a la intervención de las trabajadoras sociales respecto de la atención de NNA que debe involucrar al sistema familiar y comunitario con fundamento en la episteme disciplinar contemporánea, esta no ha logrado plasmarse de forma clara en los diversos manuales de procedimientos y lineamientos internos institucionales, lo que se tensa, frente a las propuestas de construcción metodológica disciplinar emanadas del ámbito académico contemporáneo, que en países como Argentina, Chile o Uruguay, destacan el carácter integral de la intervención en diversos niveles de actuación: individual, familiar y comunitario.

Para las chilenas Donozo y Saldias (1998:4-6) “el Trabajo Social basa su acción en tres premisas: reconocer a la familia como una unidad de estudio e intervención para el Trabajo Social, la cual no es equivalente al individuo, al grupo o a la comunidad, sino que posee una dinámica única y diferente, reconocer la necesidad que tiene la trabajadora social de capacitarse en el área de familia y revalidar al Trabajo Social como un profesional que, mejor capacitado, se encontraría en condiciones adecuadas y suficientes para realizar intervenciones a nivel familiar que no apunten tan solo a lo asistencial, sino que le permitan intervenir en las relaciones familiares".

Sin embargo, esta episteme disciplinar planteada desde el escenario académico, poco se materializa en la práctica. El agenciamiento que capta los procesos de individuación colectiva que moviliza potencias, se expresa e instaura a nivel profesional, una legitimidad que

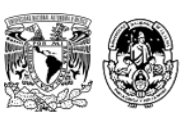


privilegia los manuales de procedimientos institucionales y los marcos jurídico-legislativos al momento de intervenir. Se ignora -muchas veces- la construcción metodológica disciplinar contemporánea para dar mayor peso a las determinantes normativas. Al respecto sostenía una trabajadora social: "al pasar el tiempo me he dado cuenta de que hay muchas cosas que podemos hacer, pero no siempre dependen de nosotros, pues los procedimientos dicen que estamos para resguardar, cuidar y proteger. Quien decide son los de allá arriba y las jerarquías institucionales. Las autoridades toman decisiones y nosotras somos las responsables de operar. Ellas definen el plan de restitución de derechos y ya nos marcan la ruta de trabajo con los niños y sus familias".

Es así como en la atención dentro de los CAS del SNDIF, se desvelan dos elementos importantes. Por un lado "la desarmonización de los marcos jurídicos en donde el Manual de procedimientos y el reglamento interno tienen fecha de última modificación en 2014" (según obra en la normateca institucional), en tanto la entrada en vigor de la Ley General de los Derechos de Niñas, Niños y Adolescentes es de diciembre de ese mismo año. Esto no es menor en tanto no se cuenta con una base jurídica homologada, que como ya vimos, es además el pilar que soporta la actuación profesional lo que provoca contradicciones que se manifiestan en la intervención (no sólo del área de Trabajo Social, sino del resto del equipo multidisciplinario encargado de la atención de niñas y niños en los CAS). Decía en la realización de un taller la trabajadora social: "conozco a algunos compañeros de la procuraduría y sé que ellos, al igual que nosotros también están sufriendo; quienes conocen las realidades de los niños somos los que estamos aquí en los Centros y ellos al pertenecer a una institución nueva, no saben".

En lo concerniente al Modelo Tipo de tención (2018) desarrollado por el Sistema Nacional para el Desarrollo Integral de la Familia para la operación de los Centros de Asistencia Social, este se encuentra planteado en función de las diversas "necesidades y decisiones progresivas durante el tiempo de estancia de niñas, niños y adolescentes” Enlista las etapas de atención dentro de las instalaciones (SNDIF, 2018:10-32): Ingreso, Atención, Residencia, Egreso y Seguimiento y sólo superficial e incipientemente se habla del sistema familiar de origen, como un foco importante de acompañamiento. 
Para Zelmanovich y Minicelli las instituciones que atienden a la niñez están en faltan de sus responsabilidades de cuidado, pues sobrevaloran las acciones burocráticas, y con ello “pierden la posibilidad de oficiar como marco simbólico de referencia social” (2012: 41) para la real atención de este grupo poblacional.

\subsubsection{Tecnologías del poder que subjetivan: diagnósticos, etiquetas y discursos}

Hemos destacado ya, el trascendente papel que juega el Trabajo Social como una de las disciplinas encargada de operacionalizar los marcos jurídico-normativos en la atención de la niñez albergada en CAS. Al respecto y en lo tocante a las metodologías específicas de intervención con conocimiento profundo en relación con el maltrato y las implicaciones que este tiene en el principio de la vida, son prácticamente nulas desde el ámbito académico.

Con fundamento en los testimonios de las trabajadoras sociales que participaron de la investigación, se identifica una percepción tradicional de la intervención frente al maltrato en contra de la niñez. No acotan una atención diferenciada frente al escenario de pobrezas y violencias que en México se vive. Exclamaba una colega: “trabajamos igual con ellos". Sin embargo, también destacaban que: "los casos son más complejos, ahora llegan por narcotráfico, trata y migración y con mayores exigencias en todos los ámbitos”.

Si estas narrativas las cruzamos con la cantidad de niñas y niños vinculados con trastornos psiquiátricos y medicados farmacológicamente en los Centros de Asistencia Social, el panorama es desalentador: "a partir de los 9 años, 6 de cada 10 niñas y niños albergados están vinculados con un diagnóstico psiquiátrico e ingresados por carpetas de investigación que los articulan con las violencias estructurales más perversas -trata de personas, migración, maltrato institucional-. De la revisión de un expediente con año de ingreso en 2016, se sabe que la madre abusaba sexualmente de su hija de 12 años. Filmaba los encuentros y luego los mandaba a los Estados Unidos. El material era para el padre de la adolescente, quien comercializaba en el mercado negro, situación que deja importantes impactos en el desarrollo psicoemocional. 
En un recorrido institucional señalaba la directora del CAS: "estoy pensando que deberíamos tener un edifico para atender a todas las niñas psiquiátricas, porque son un riesgo para las demás". "Cuando las problemáticas de orden social, educativo, político, económico e incluso emocional son abordadas como si fueran biológicas, estamos igualando el mundo de la vida humana al mundo de la naturaleza. Esto trae como consecuencia que se exceptúen de responsabilidad las instancias de poder, en cuyas entrañas son generadas y perpetuadas las más de las veces, tales dificultades" (Untoiglich 2013:26).

Durante el recorrido contextual que hicimos en la primera parte de esta investigación, se tocó lo concerniente a las violencias estructurales que aquejan el universo de niñas y niños que hoy se encuentra albergados en los Centros de Asistencia Social. Una niñez vinculada a problemáticas como la migración, el maltrato institucional e incluso la expresión de los fines de la trata de personas tales como el tráfico de órganos, las adopciones ilegales o la pornografía infantil; circunstancias de las que el periodismo de investigación ha dado cuenta y que exigen voltear la mirada a la manera en cómo atendemos a nuestra niñez.

Estas violencias estructurales en definitiva complejizan el actuar profesional y la intervención en la transformación de trayectorias es cada vez más difícil. En uno de los talleres realizados, me decía una informante: “Gaby, antes las mamás eran más fáciles de atender, ahora están vinculadas con el narcotráfico y los secuestros. Circunstancias que muchas veces derivan en procesos traumáticos de alto impacto, por ejemplo, el niño llegó de migración, ya estuvo albergado en el DIF de Neza, pero ahí lo violaron tumultuariamente". Cuando el ingreso al Centro Asistencial se encuentra vinculado a experiencias de violencia que representan en el niño eventos traumáticos (como la violación tumultuaria a la que se aludía en el testimonio), se vive profundamente alterado en todas las dimensiones, se transforma "la forma en que piensa, en que aprende, en que recuerda y en cómo se percibe a sí mismo y al mundo que le rodea" (Bloom, 1999:1).

La niñez que nos ocupa constituye un sujeto altamente complejo que expresa los efectos derivados del desprendimiento familiar, la violencia doméstica y la pérdida de la fuente principal de apego. Estas niñas y niños han sido expuestos al peligro en repetidas ocasiones,

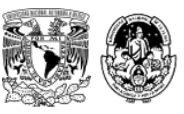


sus cuerpos se vuelven muy sensibles de manera que cualquier amenaza, por pequeña que esta sea, puede despertar esta secuencia de respuestas físicas, emocionales y cognitivas. Si estas implicaciones se suman a la masificación, impersonalización e indiferencia que pueden ofrecer algunos centros de cuidado alternativo, se incrementan los niveles de estrés, la incapacidad empática y potenciales dificultades para la socialización, aspectos derivados de la institucionalización que habrán de acompañar al individuo en su vida futura y en donde la repetición de la violencia es un fenómeno esperado.

De ahí que se requieran, para la atención de este grupo poblacional, profesionistas con una amplia episteme que incorpore el enfoque de comprensión de una niñez situada, el proceso tendiente a la transformación de trayectorias y la propia reflexividad, capaz de recuperar los elementos teórico-metodológicos y ponerlos al servicio de la transformación de trayectorias, no sólo soportada en la experiencia acumulada por años de ejercicio profesional que tiende a constreñir e inhibir formas nuevas y creativas capaces de hacer frente a la compleja realidad. Del mismo modo, la revisión latinoamericana realizada con relación a la metodología de intervención desde el Trabajo Social en el mundo contemporáneo es desafotunada, pues poco es lo que se logra documentar. En la dimensión metodológica, la producción científica de la disciplina se construye sobre la misma columna vertebral: investigación-diagnósticointervención, es decir, sobre la enunciación de fases, pero sin considerar a la niñez como un enfoque de comprensión para coadyuvar en las condiciones de adversidad que exhibe su realidad. No se identifican posicionamientos ontológicos e incluso de trascendencia política en nuestro país.

Al mismo tiempo, quiero destacar el importante aporte de Tello y Ornelas (2015), en tanto consideran consistentemente los elementos sociales, la construcción del sujeto de intervención, puntos de ruptura y potencialidades para la intervención. Sin embargo, es un referente que a pesar de ser contemporáneo y recuperar el contexto y cultura mexicana, no fue referido en ninguna de las informantes, quienes sólo recuperan los planteamientos de a Richmond y el Social work, que data de 1962, lo que pone en evidencia la distancia que hay entre el mundo académico y el mundo operativo. 
Las profesionales que participaron de los talleres (ver 7.2), cuentan con una importante trayectoria que se registra con 25 años de servicio institucional. Del grupo de seis sólo una cuenta con formación de licenciatura en Trabajo Social en la Universidad Nacional Autónoma de México, las 5 restantes obtuvieron el grado de licenciatura en escuelas de nivelación superior, obteniendo el título con materias cursadas a distancia en tan sólo 18 meses. Títulos que les permitieron subir en el escalafón laboral que se traduce por supuesto en un mejor ingreso salarial, comenta una informante: "yo llegué aquí siendo niñera, luego hice la carrera técnica en el CETIS y así fui escalando. Ahora soy jefa de departamento, sin que se traduzca necesariamente en una intervención robustecida teórica $\mathrm{y}$ metodológicamente".

Con fundamento en los hallazgos del trabajo de campo, se analiza que la carencia de referentes teórico-metodológicos son resultado de la obtención de un grado de licenciatura soportado fundamentalmente en la experiencia laboral dentro del SNDIF, mismo que como ya dimos cuenta, estaba diseñado para el internamiento y no para el proceso de acompañamiento de transformación de trayectorias individuales y/o familiares, tampoco en el robustecimiento teórico-metodológico disciplinar ofrecido por el escenario académico.

Al solicitarles que describieran algunas de las materias cursadas y a las que recurren durante su ejercicio profesional, el 80\% de las participantes no proporcionó información. Al solicitar la descripción de la intervención metodológica desde el Trabajo Social, lo que se enlista son los puntos definidos en el Manual de procedimientos, con instrumentos y técnicas desde en el marco jurídico-normativo de actuación institucional; hay una importante ausencia de descripción de la intervención metodológica del Trabajo Social y un fuerte discurso vinculado a la filantropía y el ejercicio profesional, que da cuenta al mismo tiempo de la manera en cómo se perciben en relación con los otros y las otras.

En Foucault (1984) un proceso de subjetivación es el modo en que el sujeto hace la experiencia de sí mismo al interior de un juego de verdad en el que está en relación consigo. De esa experiencia de sí mismo, de esa relación consigo, surge un "otro" que se inserta en relaciones de poder a la vez que reacciona ante ellas y las reformula. Se trata de la manera en

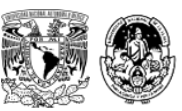


cómo emerge nuestra propia subjetividad como resultado de las prácticas discursivas que se instauran y determinan quiénes somos.

En mí, el reconocimiento del proceso de subjetivación me traslada a un momento coyuntural: tras haber atendido a una niña víctima de explotación sexual desde los seis meses y hasta los tres años de edad y experimentar mi propia incapacidad para intervenir (lo que hoy entiendo como acompañar) al sistema familiar e intentar responder a la expectativa que de mí se esperaba dentro de la Casa Hogar (como jefa de departamento), me lleva a formarme como terapeuta familiar. Esta profesionalización me redirecciona a la posibilidad de dialogar inter y transdisciplinarmente, cambiando radicalmente la manera en cómo me sumergía en el mundo familiar pero no con relación a las técnicas adquiridas exclusivamente, sino a partir de la deconstrucción que significó hacerme acompañar de voces de colegas que tenían experiencias laborales distintas pero compartíamos la misma necesidad de implicación con seres humanos profundamente maltratados; y entender la manera en cómo mi propia historia se atravesaba con la atención de este grupo poblacional, su familia y contextos comunitarios.

Al respecto, las trabajadoras sociales dedicadas a la atención de las niñas y los niños en los CAS manifiestan en la filantropía una manera implícita a la vez que determinante en las relaciones sociales y el ejercicio profesional. Al respecto el testimonio de una informante: "yo recuerdo que cuando decidí estudiar Trabajo Social yo decía: es que quiero ayudar a la gente para que cambie, para que digan, y no es fácil porque hay que mover muchas cosas, muchas emociones". Y esto se fortalece con la percepción que se tiene del hacer profesional con esta particular población. Exclama una abogada en un encuentro multidisciplinar al que asistí: "las personas que trabajan en las Casas Hogar son muy filantrópicas y esto influye en el ejercicio profesional, que pretende ser congruente con dicha percepción”.

Ellas saben que esta percepción de ayuda les permite entrar con mayor facilidad en el contexto familiar e incluso puede sugerir un elemento de resistencia frente al ejercicio de poder que constriñe desde los aparatos jurídico-administrativos. "Es cierto que muchas decisiones vienen de la Procuraduría, pero nosotras buscamos ya en el trabajo con los niños y las familias, implementar nuestras propias estrategias. Ahí nadie se puede meter”, exponen.

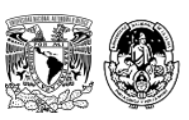


Se asumen como la parte más importante porque "son la puerta de entrada y salida de la institución", aunque este elemento en gran medida obedece a determinantes administrativas institucionales que se describen claramente en sus tareas enunciadas en el Modelo Tipo, en este instrumento se identifica que Trabajo Social es la única área profesional que interviene durante todo el proceso desde el "ingreso hasta el egreso" del menor de edad.

Importante destacar que además de puericultura, es la única profesión que no requiere el grado de licenciatura para ejercer dentro de los Centros de Asistencia Social, lo que tiene importantes implicaciones en términos de intervención, limitando el accionar y dejando nuevamente la intervención en un paliativo institucional que opera entonces como ese dispositivo de intervención-internamiento sin exigir de las trabajadoras sociales estrategias de impacto en el tejido social y constreñir su accionar a actividades administrativas, congruentes en los referentes normativos de actuación institucional.

Como ya se explicó, dicho Modelo define que Trabajo Social llevará a cabo los criterios de "admisión y actividades que permitan integrar expediente administrativo de niñas, niños y adolescentes" y cuya formación de nivel se interconecta vivenciando jerárquicamente inferior al resto de las áreas. Expone una colega: "aquí en la Casa Hogar me di cuenta de que quienes mandan, son las psicólogas".

En el acto de ayudar, que se mira permanentemente en sus discursos, se atraviesan sus propias historias, lo que provoca un proceso empático que emana de esas realidades que las espejean y marcan. Dicen: "yo siempre he vivido cerca de Casa Cuna y me acuerdo de que desde que era chiquita, me gustaba mucho y pensaba ¿qué habrá ahí adentro? En esa época yo no sabía que era adoptada y que salí de esta casa; en mí propia historia yo viví mucho maltrato, mi mamá nos llevaba al río cuando nos portábamos mal y ahí, con el agua helada nos bañaba como una forma de castigo".

Es ahí donde la intervención, en el encuentro sensible y en sintonía, cobra un sentido humanizante, que si se logra llevar al plano de la conciencia facilitaría procesos de desubjetivación y emancipatorios en niñas, niños y las propias profesionales, en el entendido

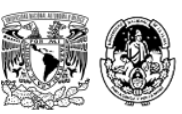


que la empatía no sólo es una técnica del Trabajo Social, es un proceso inherente al ser humano y gracias al cual construimos vínculos.

\subsubsection{Otras formas de situar y acompañar la realidad, procesos que favorecen la desubjetivación}

La experiencia internacional ha documentado que la única manera de transformar la historia de un niño que ha vivido procesos altamente traumatizantes es a partir de la construcción de una base segura y un adulto disponible que le ofrezca predectibilidad, permanencia y constancia. Las investigaciones realizadas por Barudy y Dantagnan (2005:60) sugieren como acciones preventivas y curativas en los modelos de resiliencia: ofrecer vinculaciones afectivas seguras, fiables y continuas, por lo menos con un adulto significativo, de preferencia de su red familiar o sino de la red social, incluyendo a los profesionales; facilitar los procesos relacionales que permitan dar un sentido o significado a las experiencias. Esto equivale a facilitar la toma de conciencia y simbolización de la red familiar y social por muy dura que sea y brindar apoyo social, es decir, facilitar la emergencia de redes psicosocioafectivas para los niños y sus padres.

De ahí que la construcción vincular que expresan las trabajadoras sociales debe promoverse desde la estrategia de afrontamiento de apego seguro. Comenta la informante: "no sé si será generalizado, pero yo no sabía, para mí fue muy fuerte el ver partir a los niños, verlos subirse a las camionetas, porque aquí tu aprendes a quererlos mucho y quieres lo mejor para ellos". Realizar una práctica de Trabajo Social con esta perspectiva sensible y empática, supone poner en marcha un proceso de transformación en el sentido de que se trata de la posibilidad de potenciar habilidades.

Desafortunadamente y tal como lo documenté en mi investigación de maestría en 2014, al trabajar con niñeras y niños albergados identifiqué que hay una constante ambivalencia en la construcción del Apego, lo que genera sistemas desorganizados que en poco favorecen el desarrollo psicosocial del niño. La percepción de una afectiva intervención se funda en la idea de un distanciamiento emocional: "por eso yo digo, no debemos vincularnos con los

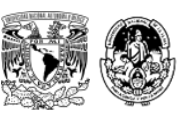


niños, yo desde chiquita fui muy despegada de mi mamá, así que ahora yo no me involucro, además así ellos no sufren con tantos cambios”. Estos hallazgos, exigen en definitiva una revisión respecto del posicionamiento profesional y de desencadenar procesos personales de reconocimiento y reflexión del papel que se juega en este entrar al mundo íntimo de las familias. Sus testimonios nos regresan a la experiencia de vida personal: "yo hablo desde mi sentir. Yo desde muy pequeñita no creé apegos ni de mi madre, yo me vi muy sola y los impactos que yo recibía los tenía que vivir yo sola, tuve que vivir la vida así. Y cuando llego aquí, y se dan este tipo de cambios así, los niños aquí viven tantos apegos y desapegos y tantos cambios que yo creo que como yo aprendí a salir sola en la vida y aquí estoy, que ellos también tienen que adaptarse a los cambios y por lo mismo ya no les afecta tanto".

Es imperante reconocer en ese acto de encuentro la posibilidad de construir formas diferenciadas y en resistencia al dispositivo instaurado en el sujeto institucional cuya subjetivación lo reduce a ser un "niño institucionalizado" o "una familia negligente y expulsora", "en donde el encuentro se abre al testimonio y puede hacer del dolor un estado de comprensión y al mismo tiempo entregar la palabra que implica entregar el cuerpo, volvernos cuerpo en la escucha asumiendo la entropía de un testimonio sin la brutalidad de la distancia" (Pippi de Medeiros, 2009: 54) con la que se envuelve la tan persistente objetividad de la intervención, que no hace más que inhibir el implicarse en la atención de estos grupos poblacionales que en sí mismos exigen el estar desde el lugar, la palabra, la mirada y la escucha.

En Carballeda (2018) el lugar, la palabra, la mirada y la escucha, se configuran como elementos de la intervención y que, en mí, se configuran como la ontología disciplinar, pues no se trata de un elemento exclusivo de la intervención, sino de la manera en cómo concebimos y nos colocamos frente al otro.

Sin duda, los hallazgos investigativos dan cuenta del proceso de subjetivación altamente influenciado por la idea de la trabajadora social como "la que ayuda", "la buena" y "la que escucha", atributos que construyen una agencia disciplinar y que al mismo tiempo puede 
ejercer el poder sobre la niñez y sus familias en el engranaje del dispositivo de la intervención social.

Al respecto habría que cuestionarnos: ¿qué escuchamos y desde dónde escuchamos?; luego ¿para qué? Hay una hoja de doble filo, pues en esta percepción se colocan una serie de prácticas asistenciales que ante la carencia de referentes teórico-metodológicos que abarquen la complejidad de la atención de niñas y niños en condición de institucionalización, receptores de maltrato y sin cuidados parentales, en poco se incide al intentar coadyuvar en la transformación de realidades, generando un alto sentido de frustración en donde se juegan muchos sentimientos. Decía una informante: “cuando yo llegué aquí lloraba al ver los expedientes y ver todo lo que viven los niños. He vivido con mucha frustración y coraje cuando no podemos hacer nada por ellos". Sin embargo, si le damos una vuelta de tuerca y reconocemos que la intervención con estos grupos poblacionales tiene per se una legitimidad, entonces habremos de entrar a realidades concretas y construir el lugar, que representa en sí mismo, un desafío.

Es posible pensar "el Trabajo Social como otro dispositivo que se inserta de una manera peculiar en cada espacio institucional, tal vez más grande o en una estructura que tiene la capacidad de contenerlo, y desde allí conforma, compone e instituye su lugar, también de manera dinámica, atravesada por el contexto, el clima de la época, la construcción de los problemas sociales, las condiciones de socialidad y el sistema de protección social vigente" (Carballeda, 2018:19).

Para efectos de esta investigación la institución no supone el dispositivo. Se trata de un elemento más de la tecnología del poder en donde este se ejerce sobre sujetos institucionales y crea subjetivación de todos los que en ella convergen. Cuenta con una serie de elementos para operar en donde los marcos jurídicos de actuación se instalan discursivamente definiendo las prácticas que al interior de la institución deben realizarse y esto muchas veces inhibe las prácticas profesionales (como ya se mencionó antes). Asegura la trabajadora social: "cuando las madres son omisas, violentas y no podemos trabajar con ellas, debemos estar cerca de los niños y tratar de subsanar los derechos que le fueron violentados en la medida

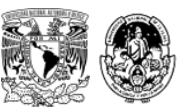


de lo posible. En algún momento te afecta el no poder intervenir como se quisiera, sin embargo, no puedes continuar así, te alineas y continuas; finalmente trabajamos para una institución.

Desde la aparición de la Ley General de los Derechos de Niñas, Niños y Adolescentes (2014), la intervención con menores de edad en CAS sufrió una importante transformación, dado que se configura la Procuraduría Federal de Protección de los Derechos de Niñas, Niños y Adolescentes, que funge como instancia representativa de los menores de edad cuyos derechos se han visto vulnerados. La creación de esta institución impresiona tener la intención de robustecer las instancias de cuidado de la niñez, sin embargo, a nivel operativo se ha vuelto un importante obstáculo según aseguran las informantes. "La creación de la Procuraduría ha sido más perjudicial en el ámbito operativo las valoraciones ahora son complicadas porque nosotras ya no tenemos contacto con los matrimonios, ver las diferencias en las valoraciones que hacíamos y hacen ahora; trabajamos con lo que hay".

Expresan también dificultades para la comunicación abierta y directa. En México hoy día contamos con organismos vigilantes y al mismo tiempo con la presencia más encrudecida de violaciones a derechos de los niños que en toda la historia. En uno de los talleres, aseguraba la trabajadora social: "escuché el mensaje de la titular y dije, ¡está todo resuelto!, pero pasa con las leyes. La tristeza es que son enunciativos y cuando vamos a la realidad, la realidad nos alcanza y no es que sea mala, sino que es escasa. Creo que tiene en intencionalidad algo fantástico que es tomar al niño como un sujeto de derechos.

A menor estado de derecho mayor legislación, "se ha institucionalizado en nuestro país la cultura de la militarización como solución de los problemas nacionales, en todos los niveles de gobierno" (REDIM, 2019), se ha colocado en la estrategia legislativa una responsabilidad humana: el cuidado de la niñez. Decía enfáticamente la trabajadora social en el desarrollo de uno de los talleres: "en la iglesia en el hospital y en las escuelas cuando se van a casar, es un requisito hacer los exámenes prenupciales. También puede ser un requisito presentar una constancia de escuela para padres, también que esté legislado”. 
Este testimonio, que coloca la resolución de los problemas en la aplicación punitiva de la ley, da cuenta de cómo la intervención resulta del entramado de los procesos de subjetivación, la intervención disciplinar y la construcción del sujeto institucional que atraviesa no sólo a la niñez sino a las profesionales que operan desde la institución.

Hasta aquí hemos analizado con los lentes de la analítica del poder la subjetivación, la episteme y la institución como los elementos constituyentes del dispositivo de la intervención que posibilita el ejercicio profesional de las trabajadoras sociales dedicadas a la atención de la niñez receptora de maltrato, sin cuidados parentales y en condición de institucionalización, desvelando las profundas contradicciones que se juegan en el campo a partir de este entramado y que al mismo tiempo, construyen posibilidades de re-significación y deconstrucción disciplinar; descubren en el hacer operativo y el encuentro con los otros, campos emancipatorios.

En el siguiente esquema, se sintetizan los hallazgos investigativos que han sido analizados, mismos que dan cuenta del entramando del dispositivo de la intervención y la manera en cómo se expresan en el campo operativo de actuación del Trabajo Social frente a la niñez en condición de institucionalización.

Tabla 22 Elementos constituyentes de la intervención: subjetivación-episteme-institución

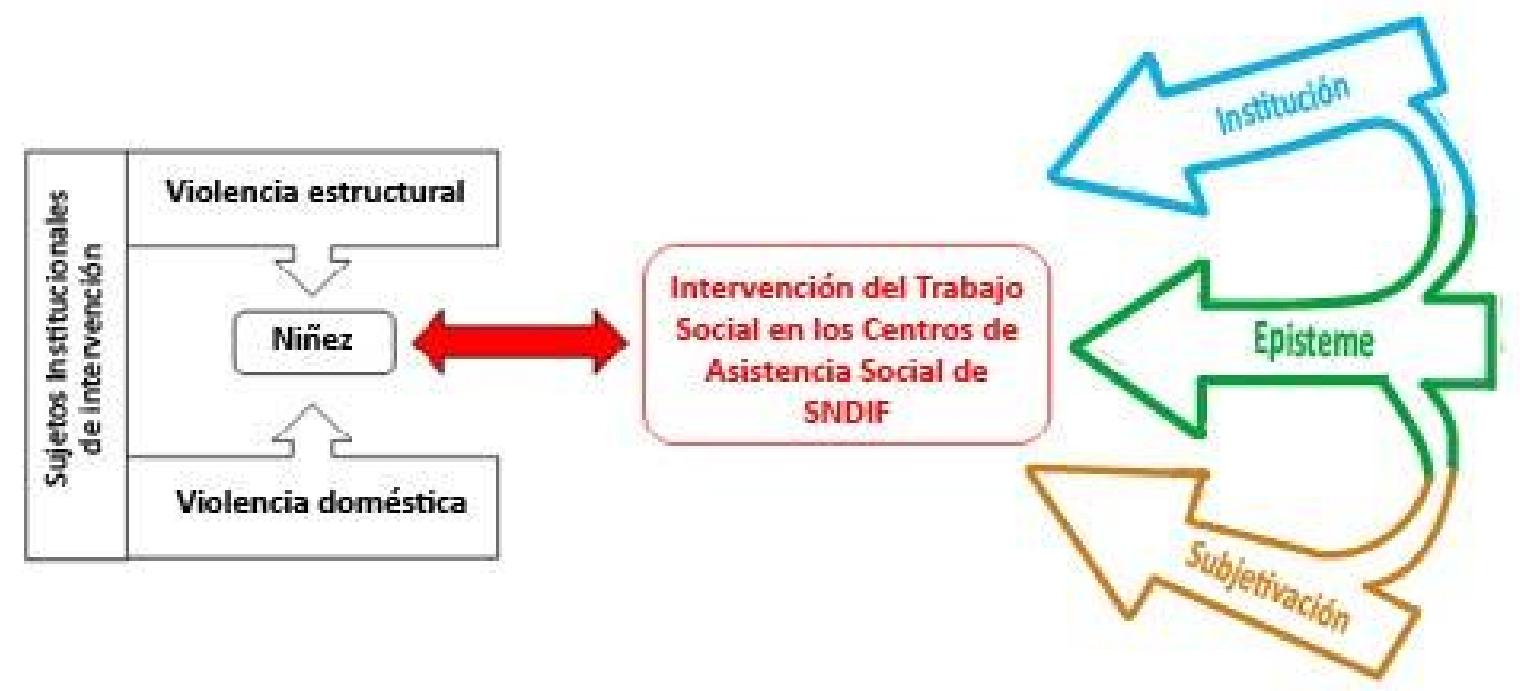

Fuente: Elaboración propia con base en el proceso de investigación, 2019.

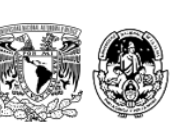




\section{2 "Enfoque de acompañamiento social": propuesta ruptura para la transformación de trayectorias}

Frente a las reflexiones expuestas, propongo desencadenar procesos diferenciados de atención a la niñez receptora de violencias, sin cuidados parentales y en condición de institucionalización desde el Trabajo Social. Para ello, expongo en las siguientes líneas las directrices a considerar en la propuesta de "acompañamiento social", misma que no es desarrollada con puntualidad, pues queda como tarea pendiente para un estudio próximo.

En el esquema que se adjunta a continuación (ver tabla 23) se sintetiza la propuesta, a través del cual se expresan formas singulares que apuntan hacia la deconstrucción del proceso de intervención, concibiendo en el acompañamiento social una configuración alternativa para la transformación de trayectorias.

Tabla 23 Proceso de acompañamiento social

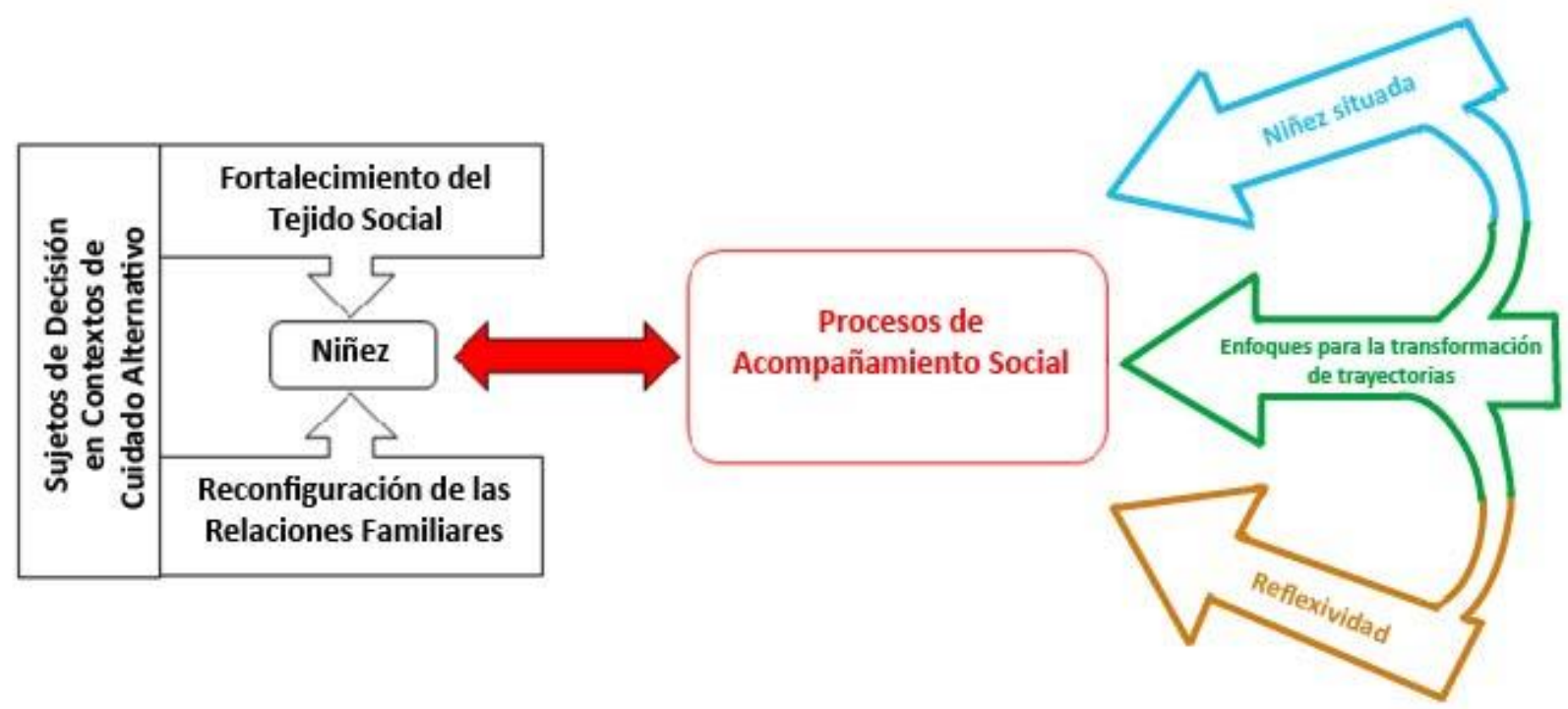

Fuente: Elaboración propia con base en el análisis del proceso de investigación, 2019.

Colocar sobre la mesa de la discusión el acompañamiento social con niñas y niños receptores de maltrato, sin cuidados parentales y en condición de institucionalización como proceso detonante para la transformación de trayectorias, se configura como una exploración-ruptura 
frente a la intervención social, ampliamente difundida en el Trabajo Social y sus consecuentes metodologías o modelos.

Si hacemos una revisión académica respecto del acompañamiento social como categoría, es frecuente encontrarla como sinónimo de intervención o como una forma en que esta última se expresa. Dicen Raya y Hernández (2014: 2) que "el acompañamiento como metodología de intervención social permite orientar la acción profesional hacia procesos de cambio, con la persona y con el entorno".

En mí y siguiendo los planteamientos de Funes y Raya (2001) acompañar es "mirar de otra manera a la persona y su historia, para que ella pueda verse de otra forma. Es creer en sus potencialidades, ayudarle a tomar conciencia y a desarrollarse, sea cual sea su estado actual. Acompañar es mediar entre las instituciones, más o menos burocratizadas de una sociedad y las personas que, por estar excluidas no puedan hacer valer sus derechos".

Desde una revisión detenida de estas narrativas, encontraremos elementos que pretenden contribuir a la diferenciación de las categorías: intervención-acompañamiento, sin embargo, no es difícil identificar la prevalencia de expresiones como: "ayudar a tomar conciencia", "hacer valer los derechos", "mediar entre las instituciones, más o menos burocratizadas de una sociedad y las personas". Al respecto, advertiré sobre el riesgo de emplear terminología novedosa que no necesariamente conlleva una modificación en la forma de abordar los fenómenos sociales, sino que reproduce una mirada filantrópica. Contrariamente pretendo encontrar en el proceso de acompañamiento social una posición crítica a la vez que sensible.

En torno a esta misma categoría, hay propuestas que emergen desde un posicionamiento más desafiante que se plantean -incluso- desde el "no método" y contravienen prácticas planificadas o intencionadas sobre sujetos concretos con perfiles específicos. Para Borja Aguirre (2013:128) el acompañamiento:

[...] aunque tiene un claro horizonte de autonomía y liberación de la persona, no parte de un esquema predeterminado, con etapas definidas, sino que se adecúa al momento presente y a

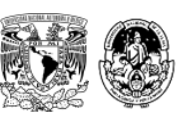


las necesidades cambiantes de las diversas circunstancias vitales. En ese sentido, podemos hablar de una "ausencia de proceso" (...) Se trata de un acompañamiento donde no existen tampoco unos perfiles definidos de personas a las que atender (...) El acompañamiento social personalizado como fórmula innovadora de respuesta, entre los diferentes diagnósticos médicos o sociales, entre diversas edades, sexos y orígenes geográficos. No hay compartimentos estancos, ni tampoco una predisposición previa a atender preferentemente unas características de la persona u otras.

En este aporte permea la personalización de quienes se acompaña, renunciando a la construcción de perfiles, circunstancias, problemáticas e incluso tiempos, sugiriendo darle una vuelta de tuerca a estas previas planificaciones y dejarnos sorprender por las singularidades de las personas que se hacen acompañar, para nuestro caso, desde el Trabajo Social.

Para efectos de esta exploración-ruptura, el acompañamiento social ocupa escarbar una forma de trabajo en el campo de la intervención que implique el reconocimiento de la relación dialógica, horizontal, de intercambio e implicación humana, en donde quien se acompaña no quede por fuera en una suerte de pasividad, objetivación y exclusión. Se trata de una "acción paraguas" que acoge sin distinción formas diversas de trabajar en lo social, implica ponerse junto al otro.

En el recorrido realizado en los capítulos anteriores he intentado documentar la experiencia del trabajo con una niñez situada, que inserta en las más terribles violencias se ha visto atrapada en una realidad que le revictimiza y en donde el actuar disciplinar se experimenta constreñido a los elementos de subjetivación, episteme e institución. Al mismo tiempo, he pretendido desvelar la urgente necesidad por desencadenar procesos que apunten hacia la transformación de trayectorias de la niñez, sus familias y contextos comunitarios en un ejercicio emancipatorio resultado del encuentro entre el sujeto de decisión (que se desplaza del sujeto de investigación y/o intervención, para reconocer su papel activo y transformador) y el profesional. 
Resignificar el modo en que nos colocamos desde nuestra expertíz, construyendo formas cobijadas por la proximidad, la afirmación del sujeto de decisión y el rol profesional -distanciado de la jerarquía que da la autoridad profesional- es una tarea tan compleja e incluso tan problemática como urgente.

En este sentido, resulta armónico recuperar planteamientos como el de Planella, quien asegura que acompañar es: "un acto de reconocimiento. Acompañar es acoger aquello que se presenta como dificultad en los sujetos y es origen de sus malestares, es bajar al pozo. Acompañar es confiar en los sujetos, es ejercer la dignidad de riesgo. Acompañar es sostener, es silenciar nuestras ideas, nuestros recuerdos, nuestros consejos, nuestras convicciones, Acompañar es estar presente, es recorrer el camino con alguien, pero no en su lugar (2016: 4)".

Este planteamiento teórico sirve como punto de partida para aproximarnos desde el Trabajo Social a procesos singulares de transformación de trayectorias. Al mismo tiempo planteo diferencias sustanciales -con tal posicionamiento- pues aseguro que el acto de acompañar, más que silenciar los propios pensamientos, posturas o ideas implica incitar para que las personas a quienes acompañamos dejen emerger los propios y se vuelvan la guía y el camino, esto como resultado de poner en juego las experiencias, conocimiento y lugares del acompañante y del que se hace acompañar, quienes se implican en el encuentro desde sus propios saberes, geografías, padeceres y esperanzas.

En lo que ocupa al Trabajo Social, es cierto que es una referencia disciplinar hasta hoy desarrollada y que ha logrado dar identidad al quehacer profesional se funda en la intervención social como objeto de estudio, con un soporte epistemológico consolidado y profundizado por investigadoras e investigadores, que han argumentado y construido esta propuesta. Para Tello (2016: 4) la intervención de Trabajo Social es una acción racional, intencional, fundada en el conocimiento científico, que tiene por objetivo desencadenar procesos de cambio social. Desde esta perspectiva la participación del sujeto es indispensable, para hablar de una acción de Trabajo Social.

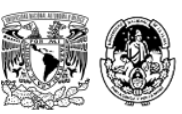


Este trazado de la intervención, deja claro que esta no es posible sin la participación del sujeto "al que se interviene" y en esencia sugiere la construcción misma del acompañamiento sin hacer un planteamiento explícito del mismo (en la reflexión de que responde a un momento histórico-social de nuestra disciplina, que exigía la especificidad profesional que a su vez fortaleció la identidad como trabajadoras y trabajadores sociales) y gracias a la cual hoy nos encontramos en la posibilidad de tomar a la intervención como un referente en vez de anularla, para la construcción de formas diferenciadas de actuación, congruentes a las condiciones económicas, sociales y culturales de la realidad.

Retomando a la misma Tello, la especificidad del Trabajo Social está justamente soportada en la mirada multidisciplinar, elementos fundamentales que el lector habrá de encontrar en la propuesta misma de acompañamiento planteada en este documento.

Por otra parte y sin la intención de desestimar que la intervención ha sido pilar fundamental para la disciplina -como ya lo he señalado- se hace necesario repensar sus supuestos y evidenciar que, colocada desde el ejercicio puramente científico y la consecuente episteme que le bordea, puede representar equívocos que inhiben la implicación humana al estar fuertemente influenciada por la objetividad como sinónimo de eficiencia, condiciones que se expresan en el campo operativo, limitando a los sujetos y llevándolos a dimensiones pasivas donde es el profesional quien desde un posicionamiento jerárquico diagnóstica, determina planes de tratamiento, evalúa e incluso recupera la experiencia del otro para generar conocimiento, invisibilizando los saberes y reduciendo a la persona a "sujeto de investigación y/o intervención".

Intervenir proviene del latín intervenīre, procede del verbo intervenio, intervenís, intervenire, interveni, interventum cuyo significado es sobrevenir, intervenir, entrometerse, interrumpir, impedir. En tanto que acompañar en su concepto puro, significa la existencia de una cosa al mismo tiempo que otra (RAE, 2020).

Lo latente y profundamente riesgoso de la intervención es precisamente la irrupción e invasión del otro desde una posición de superioridad profesional, en donde las y los

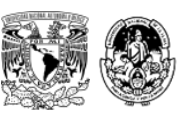


trabajadores sociales se adjudican -o le adjudican- la posesión del conocimiento y consecuentemente de la verdad. Esto homogeniza los procesos desde la implementación de modelos, metodologías, manuales de procedimientos -cuando se recuperan y ajustan acríticamente como recetarios-, borrando las particularidades y aspirando a la obtención de resultados inmediatos en la puesta en marcha del aparato técnico disciplinar que se ejerce a manera de listados, etapas y acciones concretas sobre quienes se trabaja.

La experiencia que hasta aquí hemos venido exponiendo, revela campos urgentes de deconstrucción en donde se dé cabida a las singularidades, el reconocimiento y respeto, tanto de las diferentes identidades como de los saberes que forman parte de la historia de aquellas personas adultas o en estado de infancia, con los que las y los trabajadores sociales nos implicamos. Desencadenar procesos de extrañamiento desde una posición que provoque a la pregunta, incite la duda como un camino para la construcción de nuevas posibilidades y, viabilice, por tanto, la identificación de las diferencias en lo que es nuestro al mismo tiempo que del otro.

Como expliqué al iniciar este apartado, no pretendo desarrollar la propuesta de acompañamiento social. Esto queda como una tarea pendiente para un estudio próximo, pero sí me gustaría colocar algunos supuestos que podrían intuir los caminos para los ya mencionados campos emancipatorios para la niñez y sus sistemas familiares y comunitarios, que apunten hacia la transformación de trayectorias y en el encuentro con los elementos constituyentes del dispositivo: subjetivación-episteme-institución, configurando una suerte de espejo a la vez que de quiebre.

Defino el acompañamiento social como una propuesta de enfoque para la transformación de trayectorias de la niñez receptora de maltrato, sin cuidados parentales y en condición de institucionalización, que implica el reconocimiento de un encuentro horizontal en donde convergen las voces del profesional que acompaña y el sujeto de decisión que se hace acompañar, en el reconocimiento de sus saberes e identidades y cuyo punto de intersección desencadena la posibilidad de transformar las trayectorias, ampliando los horizontes para la reconstrucción del tejido familiar y socio-comunitario. Este acompañamiento supone tres

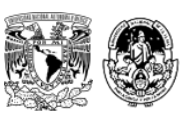


ejes: el sujeto situado (las personas niñas), la interseccionalidad con enfoques epistémicos y la deconstrucción sobre la base de los procesos de reflexividad de las y los profesionales en TS.

\subsubsection{Situar el territorio, situar los sujetos}

El proceso de acompañamiento social con la niñez en condición de institucionalización está determinado por una geografía específica: el espacio de cuidado alternativo (el CAS) y es ahí en donde lo individual y lo colectivo convergen; un espacio-territorio que delimita el lugar no sólo físico sino simbólico del niño y la niña en su cotidianidad, donde los lazos de consanguinidad no son los que determinan el vínculo sino el mismo encuentro y la compartición.

Esta niñez situada experimenta una doble realidad. La que está fuera del territorio institucional que ocupa generalmente a los suyos: la familia de origen que se ha visto permeada por la violencia y la omisión, condiciones que motivan la intervención estatal, el desprendimiento del clan y la vida dentro del territorio institucional que exige reconocer características, condicionantes y posibilidades intra y extramuros. En la dimensión familiar muchas veces ésta se ve sujeta a circunstancias jurídicas que la vinculan con delitos que no deben ser ignorados en el conocimiento profundo de los marcos legales de actuación, que en la gran mayoría de los casos fueron los detonantes de la institucionalización y en el mismo número de ocasiones, aluden a las y los familiares de la persona niña.

Por ende, la participación disciplinar habrá de considerar el adentro y el afuera; el pasado, presente y futuro del niño y sus sistemas próximos (familia, comunidad); la condición jurídica, las interrelaciones en su contexto, él como sujeto individual de decisión y colectivo como parte de ese núcleo que ha sido determinado generalmente por una historia de violencias, duelos y carencias, todas en un sistema estructural que reduce posibilidades frente a las condicionantes de marginalidad y pobreza que usualmente le han determinado. 
Trauma, Apego y Comunalidad desde el enfoque de la interseccionalidad: elementos triádicos indispensables en el acompañamiento de la niñez.

La evidencia documentada en cuanto a los procesos de reparación del trauma infantil, han dado cuenta de dos elementos fundamentales para lograr el resarcimiento: la construcción del Apego seguro a partir de la figura adulta disponible capaz de contener y acompañar al niño o la niña creando un espacio de seguridad que proporcione certeza, predictibilidad y constancia; la resiliencia como una capacidad de resignificación y crecimiento ante la adversidad, determinada por las relaciones sociales y el contexto.

Para Sandra Bloom (2013) "el trauma no se experimenta de igual forma en todos los seres humanos, este emerge cuando los recursos internos y externos son insuficientes para lidiar con la amenaza, se trata de un choque emocional que deja una impresión duradera en el subconsciente a causa de una experiencia negativa”. Lo esperado entre las niñas y los niños que se acogen en sistemas de cuidado alternativo, supone un necesario conocimiento y reconocimiento de los efectos que genera el desprendimiento de la familia de origen, además cuando esta primera ruptura se hace acompañar de violencias explicitas en las dimensiones psicológicas, sexuales o físicas, se hace proclive la presencia del trauma.

En esta misma línea de pensamiento, es indispensable incorporar una episteme profunda respecto de las características, impactos y efectos del maltrato en la niñez, para con ello cobrar conciencia de que esta exige un acompañamiento sensible. Las niñas y los niños requieren escenarios seguros, en donde las y los adultos, se comprometan a cuidar, proteger y reconocer su propio proceso, en el cual son activos y activas, lo que representa todo un reto disciplinar. Esta conexión con el mundo resulta del contacto humano, de las relaciones interpersonales que se desarrollen como base segura, en donde las relaciones de apego se entienden como:

[...] los vínculos afectivos que los niños entablan con sus padres y con otras figuras que cumplen las funciones parentales. Estas relaciones son cruciales para el bienestar del niño y para su desarrollo emocional y social (...) en la medida que el apego facilita el

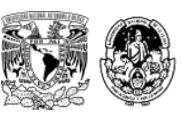


establecimiento de vínculos seguros, contribuye también al desarrollo en todas las áreas que requiere un niño en crecimiento. Se conoce que existe una relación positiva entre apego y estimulación hacia el niño, la que puede ser sensorial, afectiva y cognitiva (MECeP, 2014: 29)

De ahí que el rol de las y los cuidadores resulta trascendental, y la figura del adulto disponible debe contemplar: capacidad para dar afecto y sentirse comprendido, sostener y proporcionar seguridad para explorar.

Reconocer la relación vincular derivada del encuentro, desafiara la persistente idea de la objetividad como -casi- único camino para la eficiencia, colocar el vínculo como el mapa que nos hace funcionar en el mundo y que es imposible escapar a él. El infortunio emerge cuando la relación vincular se niega o se manifiesta de forma ambivalente, pues se hace proclive a la estrategia de afrontamiento insegura y eso no contribuye a romper con la cadena de violencia, destinando a su perpetuación intergeneracional.

Articulando con el eje anteriormente expuesto, es indispensable incorporar el elemento contextual, entendiendo que la idea del padecer no es un asunto personal y dimensionarlo en un escenario social en donde la geografía para que estas relaciones de base segura que promuevan el afecto y respeto se den, es indispensable. El escenario seguro debe contemplar: un ambiente libre de amenazas, que incluye aspectos relacionales y físicos, condiciones adecuadas para el desarrollo y la construcción de relaciones interpersonales de cuidado a nivel intra y extrainstitucional, además de fortalecer la perspectiva de comunalidad y la inclusión de redes de apoyo social recíprocas y con interacciones que trasciendan el tiempo, proporcionando protección y equilibrio.

Es ahí, en la interseccionalidad de la comprensión de las características de una niñez situada, donde los enfoques epistémicos y la reflexividad posibilitan procesos de transformación de las trayectorias. No se trata de empujar hacia anular, olvidar o romantizar la herida, sino construir condiciones desde el encuentro social para afrontar las adversidades y padeceres experimentados. Para Boris Cyrulnik (2014) el encuentro con los otros proporciona seguridad

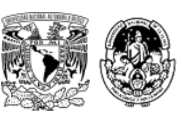


y eso detona procesos resilientes, coloca la posibilidad de resignificar la historia si coadyuvamos en el ámbito familiar para favorecer las relaciones libres de violencia y desde la base del cuidado.

En lo concerniente a la propuesta de reconstrucción del tejido social que logre cobijar el sistema de origen familiar y con ello impactar a la niña y el niño, resulta conveniente privilegiar la acción a escala comunitaria superando la percepción tan extendida de que las soluciones fundamentales se ubican en la escala del individuo y/o del gobierno, y evitando dos salidas en falso: el derrotismo y la supervivencia individual.

En el recorrido histórico ocupante a la época prehispánica e incluso en la práctica de muchos espacios de referente étnico, son las propias comunidades quienes se ocupan de la niñez sin cuidados parentales: asumiendo que el cuidado es un elemento fundamental de trascendencia social. Es valioso re-pensar que el cuidado y la crianza no son un asunto privativo de padres y madres, sino una tarea social que implica la participación activa de las sociedades a través de sus unidades básicas: la comunidad y la familia extensa.

\subsubsection{La reflexividad en el acto de hospedar}

Jacques Derrida (2017: 196) sostiene que "el acto de hospedar puede ser considerado como un nuevo nombre "espacial" de la esperanza. Su fuerza transfiguradora proviene de su capacidad de hospedar en la noche. En consecuencia, ante las serias dificultades actuales de nuestro mundo globalizado de recibir al diferente, al extranjero, al enemigo que altera nuestra mismidad sea en sentido personal, social, cultural o político”.

Hospedar al otro, al diferente, al extraño, es indispensable cuando se trata de acompañar desde un lugar claro y en sintonía con la realidad del otro, esto contribuye al proceso mismo de reflexividad, que en Guber (1988) se entiende como "indagar reflexivamente la manera en que se coproduce el conocimiento a través de sus nociones y sus actitudes y desarrollar la reflexión crítica acerca de sus supuestos, su sentido común, su lugar en el campo y las condiciones históricas y socioculturales en que el investigador lleva a cabo su labor”. Ambos

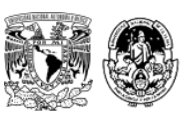


elementos se encuentran (el acto de hospedar y la reflexividad) configurando una intersección de cara al proceso de subjetivación, en donde la palabra, la mirada y la escucha, no son únicamente herramientas de intervención social, sino elementos constituyentes de un posicionamiento ético disciplinar.

\subsubsection{Enfoques para la transformación de trayectorias}

Carballeda (2018) nos ofrece una propuesta en este sentido (cuando recupera la palabra, la mirada, el lugar y la escucha, como componentes para la intervención). En vista del proceso de acompañamiento social que se propone, se vislumbra relevante profundizar además en los planteamientos psicológicos y filosóficos de Winnicot (1971), Derrida (2004) y Barthes (1980).

Acompañar a las niñas y niños en una geografía específica como es el cuidado alternativo a través de la institucionalización y tras su vinculación con el maltrato, exige dicho posicionamiento ético, reflexivo, profundo y comprensivo que, ante las realidades actuales, en un modelo económico neoliberal cada vez más perverso que encrudece e intensifica las desigualdades, desafía a las y los profesionales de lo social, y frente a lo cual nos obliga a actuar en consecuencia.

A partir de todo lo que se ha expuesto en esta tesis, se observa muy claramente la necesidad por resignificar los espacios de cuidado alternativo en el conocimiento de que hay innumerables niñas y niños en el territorio nacional cuyas familias requieren un sostén y la posibilidad de vivirse desde otro lugar -que no sea el maltrato-.

$\mathrm{Al}$ respecto y más allá de promover la desaparición de estos espacios, en la idea de que son innecesarios, caducos o de impacto negativo, valdría la pena preguntarnos ¿cuáles son las prácticas de cuidado al interior? ¿cómo promovemos procesos de acompañamiento familiar y comunitario que hagan de la estadía de la niña o el niño, una experiencia que abone a su desarrollo integral desde la proximidad y el reconocimiento de ellas y ellos como agentes activos y sujetos de decisión? O bien, ¿de qué manera configurar como espacios seguros la

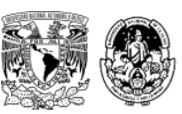


vida comunitaria en un modelo institucional desde la sensibilidad, el cobijo, el respeto y la esperanza?

\section{Epílogo Donahí}

El relato de Donahí es un botón de muestra de la condición de miles de niños y niñas que se ven imposibilitados de permanecer en sus familias de origen como resultado de la exclusión y la pobreza que inhiben las capacidades de sus sistemas de familia y contextos comunitarios para acogerlos, destinándolos a una vida en un contexto institucionalizado. El haber atestiguado la manera en cómo las y los profesionales toman distancia de la realidad social de un niño indígena y colocan sus propios referentes para decidir el proyecto de vida que habrá de tener, me confirma la necesidad por atravesar enfoques sensibles y en sintonía, coadyuvando para que su realidad se transforme.

Si bien es cierto que hay una serie de categorías convergentes que se implican en el proceso de intervención con la niñez en condición de institucionalización, que constriñen inhibiendo campos de emancipación al mismo tiempo se configuran como posibilidades para la transformación. Si logramos resignificarlas y disponernos a analizar las formas en que se implican podremos viabilizar a partir de la reflexividad y la comprensión de una niñez situada que se retroalimenta de los nuevos enfoques críticos ofrecidos por diversas disciplinas como la sociología, la antropología, la medicina y la ciencia jurídica.

Hasta aquí el capítulo recuperó los hallazgos del trabajo de campo resultado de la aplicación de las técnicas diferenciadas tras la implementación de una metodología de enfoque cualitativo, sobre la exploración de las categorías subjetivación-episteme-institución y las subcategorías filantropía, empatía, apego, agencia, Trabajo Social, formación disciplinar, metodología, niñez, violencia, condiciones sociales, legislación, perspectiva adultocéntrica, marcos normativos de actuación institucional, autoridad, coordinaciones institucionales y políticas públicas. 
Los datos empíricos se discutieron y analizaron para dar respuesta a la pregunta de investigación. ¿De qué manera el entramado subjetivación-episteme-institución configuran los elementos de un dispositivo que posibilita la intervención de las trabajadoras sociales dedicadas a la atención de la niñez receptora de maltrato, sin cuidados parentales y en condición de institucionalización?, a la luz del enfoque teórico de la analítica del poder, desvelando la manera en cómo esta niñez situada se vuelve un foco de intervención imbricada más allá del accionar de funciones y actividades específicas del TS, exhibiendo el entramado complejo, en donde las tecnologías del poder se ejercen.

A partir de lo expuesto, se logra documentar cómo el proceso de subjetivación actúa gracias a la convergencia de las ideas filantrópicas que fortalecen procesos de empatía entre la profesional y la niña o el niño, resultado de una interconexión con las vivencias personales y las trayectorias de vida permeadas por el abuso y el maltrato en ambos actores. Lo que a su vez favorece relaciones de apego, no sólo con la población albergada, sino con sus sistemas de familia y comunitarios, configurando así una agencia profesional de encuentro entre los mundos internos y externos.

Para lo tocante a la intervención que desde el Trabajo Social se realiza en este escenario de actuación profesional, se identifica una variedad de epistemes, que devienen de un proceso de historicidad en relación a las percepciones de la niñez vinculada con el maltrato como grupo poblacional de atención tradicional y sobre la base de la transversalidad que articula la política pública que institucionalizó la intervención en la década del cuarenta y la formación disciplinar, misma que experimentó una coyuntura al tecnificar su actuar impactando en las metodologías de inmersión con la niñez y otros sectores poblacionales.

La experiencia personal manifestada por las informantes entra en contacto con la experiencia de los otros y se tensa con los referentes teórico-metodológicos disciplinares exigiendo una intervención objetiva que se inhibe ante la carencia de elementos teórico-metodológicos que den respuesta a las demandas de las problemáticas actuales y exige la intromisión del Estado en el ejercicio del poder y la biopolítica construyendo cuerpos al servicio del mercado, en donde este grupo poblacional ha sido severamente violentado en espacios de cuidado

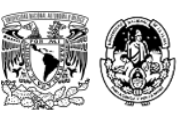


alternativo que se configuran, desde la necropolítca, como espacios de administración del dolor.

En nuestro país, derivado de las condiciones sociales de violencia, marginalidad y pobreza, se han encrudecido las expresiones del maltrato al interior del ámbito doméstico, inhibiendo el cabal cumplimiento de derechos de NNA, enmarcados en legislaciones tanto nacionales como internacionales tendientes a la protección de las personas niñas, quienes a su vez siguen siendo vistas como "sujetos de protección" en un discurso y accionar adultocéntrico, colocado en prácticas sociales que no logran visibilizarles consistentemente como actores sociales, políticos, productores de cultura y humanidad, lo que influye determinantemente en la implicación profesional.

Todo lo anterior situado en el escenario institucional de mayor impacto a nivel nacional en materia de asistencia y protección a la niñez: el Sistema Nacional para el Desarrollo Integral de la Familia. Institución que a través de sus marcos normativos de actuación determina las formas de cuidado y restitución de derechos de esta población, normado el ejercicio profesional en su calidad de autoridad y echando mano de diversas coordinaciones entre las instituciones vinculadas con la atención del fenómeno de la institucionalización de NNA receptores de maltrato y en condición de institucionalización.

El análisis realizado con fundamento en los hallazgos del trabajo de campo desvela la manera en cómo la intersección de los elementos subjetivación, episteme e institución, que dan cuerpo a la pregunta de investigación, presentan características que al interconectarse influyen en la intervención, se retroalimentan y entretejen dialécticamente mostrando cómo el dispositivo flexible muta y se transforma para permanecer al tiempo que ofrece otros campos posibles.

Esta realidad ocupa voltear la mirada a la intervención y en el reconocimiento de otras formas posibles construir los intersticios para el desplazamiento desde la intervención a procesos de acompañamiento social tendientes a la transformación de trayectorias que definan un entramado distinto en donde las niñas y los niños, así como sus contextos familiares y

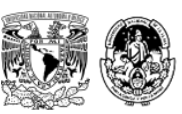


comunitarios, sean vistos como sujetos de decisión activos, en la comprensión de la singularidad de los contextos y en el encuentro con la construcción e identidad profesional que cobra conciencia del papel determinante que jugamos las y los trabajadores sociales en los procesos de esta niñez.

Y es así como se da fin a esta tesis, exponiendo la propuesta de exploración-ruptura denominada "Enfoque de acompañamiento social", misma que pretende ofrecer una resignificación y deconstrucción de la intervención, reconocida como una tecnología más del ejercicio de poder, desplazándonos hacia procesos emancipatorios de relación horizontal como proceso detonante para la transformación de trayectorias. Propuesta que abre la puerta para la continuidad del estudio y representa quizá, la tarea pendiente más significativa que se deriva de esta tesis. 


\section{CONCLUSIONES}

Cuidar del principio de la vida, significa cuidar de la humanidad.

Este último apartado, ofrecerá a las y los lectores algunas ideas concluyentes con relación al desarrollo de la tesis. Se inicia compartiendo aciertos y dificultades en el trabajo de campo, pertinencia del enfoque teórico y desafíos para su uso en el análisis e interpretación de los hallazgos empíricos. Posteriormente se destacan los aportes emanados a nivel teórico, metodológico y operativo. Seguidamente se regresa a la pregunta de investigación y al supuesto hipotético, dando respuesta a los mismos y enlazando con la propuesta: "enfoque de acompañamiento social". Se finaliza planteando las venas que abren el estudio y los elementos que se podrían considerar en futuras investigaciones.

La presente investigación tuvo como objetivo analizar subjetivación, episteme e institución como los elementos constituyentes del dispositivo de la intervención que posibilita el ejercicio profesional de las trabajadoras sociales dedicadas a la atención de la niñez receptora de maltrato, sin cuidados parentales y en condición de institucionalización.

Para alcanzar dicho objetivo, se recurrió al diseño metodológico de enfoque cualitativo a través del uso de técnicas diferenciadas, como entrevistas informales, formales, talleres grupales, observación de tipo participante y no participante, así como recorridos institucionales. De igual forma, se incorporó mi proceso de reflexividad. Para la construcción del capítulo seis, se realizó una revisión periodística tocante a la documentación de CAS reconocidos como "espacios de riesgo" a nivel nacional y en la última década.

Fueron especialmente relevantes para la realización de este estudio la identificación, descripción y análisis de las expresiones de las trabajadoras sociales en el campo operativo a la luz de la analítica del poder y en diálogo con el marco teórico. Se concluye que las categorías, emanadas del trabajo de campo, se interconectan, entrelazan y retroalimentan 
dialéctica y no linealmente, construyendo un entramado que precisa el dispositivo de la intervención.

Las técnicas utilizadas permitieron entrar al mundo íntimo de la intervención de las trabajadoras sociales adscritas a los CAS del SNDIF resultando complicado de principio, dado que emergía una "deseabilidad social" -que no se había previsto- inherente entre las colegas, con quienes años atrás sostuve una relación de autoridad (al haber coincidido como su supervisora). Esto evocaba una relación vertical y para su manejo se resuelve implementar talleres con herramientas que incitaran las narrativas desde un lugar genuino, inhibiendo la percepción de una evaluación. De ahí que el uso de talleres grupales fue un acierto metodológico. En lo tocante a la reflexividad que implicó cobrar conciencia de mi papel como trabajadora social e investigadora, ésta significó un desafío que me incitó a reflexionar sobre mi propia práctica y poner en juego mis tensiones y subjetivaciones. Al respecto destaco que aun cuando desde el inicio de la investigación se planteó que no se consideraba un estudio de carácter etnográfico, mi "estar ahí” (desde hace 15 años en diferentes roles) definió una forma de implicación particular.

Finalmente, en lo concerniente al recorrido teórico, un elemento que no fue considerando de inicio fue desarrollar el capítulo "Centros de Asistencia Social: espacios de riesgo". Una invisible realidad que se decide incorporar con la finalidad de evidenciar las disimiles expresiones que el cuidado alternativo -a través de la institucionalización- experimenta en nuestra sociedad, para con ello complejizar este escenario de actuación profesional. La realización de este apartado tuvo obstáculos, dado que la inmersión era de difícil acceso, por lo que decidí acudir al periodismo de investigación no sólo desde una revisión de gabinete, sino provocando encuentros con las y los periodistas involucrados cuyo acercamiento se dio a través de la observación participante incluyéndome en acciones de tipo operativo y académico que se documentaron en diario de campo y viabilizaron la obtención de fuentes de registros periodísticos, que de otra manera habría sido imposible retomar.

El enfoque teórico de la analítica del poder otorgó elementos para una reflexión crítica de la realidad social y congruente con el tema de estudio, sin embargo, implicó estudiarlo en

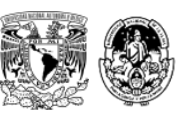


profundidad dada la falta de proximidad. Distanciarme de mi formación antecedente situada en el ámbito terapéutico representó un reto al verme fuertemente influenciada, por la psicología y las neurociencias.

En lo concerniente a la construcción del marco teórico, se estudiaron los referentes históricos en relación con los constructos de la niñez y la intervención desde el TS y se encaminó hacia su comprensión en el modelo neoliberal, que derivó en el entendimiento de las diversas fisuras, contradicciones y escenarios altamente complejos para la implicación profesional en la actualidad.

Esta revisión teórica en su interconexión con el trabajo de campo derivó en tres aportes:

1.- Desencadenar un deslizamiento de la categoría de "infancia" hacia el "enfoque de comprensión de la niñez" que la emplaza como la experiencia humana dinámica, relacional y contextual de los primeros años de vida, resultante de un trayecto histórico situado que supone un proceso de humanización, que se construye subjetiva e intersubjetivamente en relación con los otros en el entendido de una interseccionalidad en donde lo individual y colectivo convergen, lo íntimo y lo público se encuentran. Para así tomar distancia de la percepción históricamente difundida que la supone homogénea y limitada a un grupo poblacional en un rango de edad determinado.

2.- Replantear la "intervención" como el supuesto identitario del TS y desplazarnos hacia la construcción de procesos de "acompañamiento social", que defino como, el encuentro horizontal en donde convergen las voces del profesional que acompaña y el sujeto de decisión que se hace acompañar, la construcción de un espacio de reconocimiento de saberes e identidades y cuyo punto de intersección posibilita la transformación de trayectorias, ampliando los horizontes para la reconstrucción del tejido familiar y socio-comunitario.

3.- Resignificar el cuidado alternativo como una estrategia de política pública transitoria, de corta permanencia, que propone un distanciamiento emocional entre los actores que interactúan dentro de los CAS para deconstruirla y reconocerla como medida de cuidado que

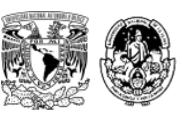


valide las relaciones vinculares, promueva la recuperación de la historicidad de la niñez albergada, y se configure a partir de ello como un escenario de cuidado capaz de dar identidad en la congruencia con las transformaciones de la realidad social contemporánea y en la tendencia de reconocer a la niñez como el proceso para construir humanidad.

En lo competente al papel de la institución, se sustenta la necesidad por fortalecer el carácter rector del SNDIF desde enfoques ontológicos, epistemológicos y metodológicos consistentes y críticos, que inhiban la permanencia de "espacios de riesgo" para la niñez, eliminando prácticas institucionales que vulneren y reproduzcan el maltrato hacia ella.

Con relación a la pregunta de investigación ¿de qué manera el entramado subjetivaciónepisteme-institución configura los elementos de un dispositivo que posibilita la intervención de las trabajadoras sociales dedicadas a la atención de la niñez receptora de maltrato, sin cuidados parentales y en condición de institucionalización? Ésta se logra contestar al analizar los hallazgos del trabajo de campo en diálogo con el marco teórico y a la luz de la analítica del poder.

Así se identifica que la subjetivación se desvela en este estudio en la medida que las trabajadoras sociales se encuentran con la niñez que se alberga en los CAS del SNDIF, poniendo en juego su propia experiencia de vida marcada por el maltrato y abandono en la niñez y, disponiéndose en una vinculación afectiva permeada por sentimientos de filantropía y una conexión empática que deriva en un agenciamiento disciplinar. La subjetivación también se nutre de las expectativas que se tiene de su actuar disciplinar por parte de la población beneficiaria, de las y los profesionistas que convergen en el escenario institucional y de las determinantes que se expresan en los marcos jurídico-normativos, estipulando acciones concretas para la profesión, el papel que se juega frente a la niñez y sus familias, las funciones y actividades profesionales, así como las metodologías y modelos a los que se recurre para la intervención desde el TS.

Este proceso se conecta con epistemes diversas que son el resultado de un proceso histórico en donde la niñez es entendida como un grupo poblacional ubicado en el rango cero-

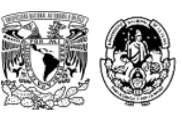


dieciocho años, necesitado de la protección adulta, y donde las perspectivas para su abordaje no han logrado desplazarse de la percepción del niño como sujeto de asistencia a la niñez sujeto de derecho. Esto en convergencia con las diversas metodologías que operan desde la formación disciplinar, que dan lugar a prácticas influenciadas por los preceptos enmarcados en el TS tradicional de intervención de caso (que emergió en la década del sesenta) y que no ha sido transformado sustancialmente pese a las problemáticas contemporáneas vinculadas con las violencias estructurales que recrudecen los maltratos al interior de los sistemas de familia, y cuyas repercusiones hacen de las niñas, los niños y sus contextos familiares y comunitarios, sujetos complejos.

La subjetivación y las epistemes en su intersección con los marcos normativos de actuación institucional configuran el dispositivo de la intervención.

Estos hallazgos confirman en gran medida el supuesto hipotético, que sostenía que la confluencia de las categorías subjetivación, episteme e institución constreñían la intervención social en el campo operativo. Se profundizó así el argumento de que, en efecto, no es la operacionalización mecánica de los procedimientos institucionales, los conocimientos científicos disciplinares y las metodologías sobre la base de la objetividad profesional lo que da cuerpo a la intervención, sino su intersección con otros ejes que emergieron en el trabajo de campo, como la historia de vida, la perspectiva filantrópica, los discursos y las prácticas profesionales, en el encuentro con diversas disciplinas, entre otras.

Al mismo tiempo, el supuesto hipotético limitaba la posibilidad de intervenir desde otro lugar. No ofrecía otros medios de transformación. Gracias a los hallazgos investigativos fue posible identificar intersticios, fisuras que abren venas para deconstruir y resignificar la implicación profesional desde el TS, derivando en la propuesta de exploración-ruptura llamada "Enfoque de acompañamiento social" que posibilita otras formas y ofrece reflexiones ontológicas disciplinares. De esta manera, este cierre incita la continuidad y define otros muchos caminos para la implicación investigativa y de definición de propuestas concretas para el acompañamiento social de la niñez, sus sistemas de familia y comunitarios.

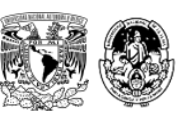


La tesis ha permitido dar cuenta de que, en el entramado de la intervención, las trabajadoras sociales también se configuran como potenciales sujetos de decisión, susceptibles de acompañamiento social, y para las cuales resulta urgente diseñar y ejecutar propuestas que faciliten la expresión de sus emociones, el acceso a conocimientos teórico-metodológicos del TS contemporáneo y la construcción de escenarios seguros que fortalezcan la identidad profesional. Por eso la continuidad del estudio para el desarrollo teórico-metodológico del "Enfoque de acompañamiento social”, se configura quizá como la consecuencia más evidente de esta tesis.

Finalmente, el "estar ahí", también ha posibilitado tener incidencia desde el ámbito académico, en estos años de implicación investigativa se logró la concreción de convenios de colaboración entre el SNDIF y la ENTS, promoviendo la incorporación de profesionistas en formación en este contexto situado, así también, el diseño y ejecución de escenarios académicos, de reflexión profesional y discusión, como el Seminario PNMC (que se realiza desde 2017 con la participación de las TS de los CAS), además de investigaciones de nivel licenciatura y maestría interesadas en la intervención del TS y la niñez.

En materia investigativa uno de los retos importantes es la realización de estudios de la niñez vinculada con el maltrato y en condición de institucionalización con enfoque inter y transdisciplinar que, tras el encuentro de las diversas miradas, favorezcan la comprensión del fenómeno de forma multidimensional. Al mismo tiempo, otro elemento a considerar es la realización de investigaciones que recuperen las voces multidisciplinares de las y los profesionales que interactúan frente a la atención de la niñez albergada en CAS, recuperando sus prácticas, vínculos y percepciones. Adicionalmente resulta relevante promover procesos de investigación con la niñez situada, ampliando el estudio a otras realidades que no necesariamente están siendo atendidas en escenarios institucionales y que se ve afectada por el maltrato y las violencias en la sociedad contemporánea, tales como, la niñez migrante no acompañada, la vinculada con el crimen organizado, la de referente étnico en condiciones altamente precarizadas e incluso la que se configura como "niñez consumidora". 
Para el abordaje de la niñez en los espacios académicos responsables de la formación de trabajadoras sociales, se vislumbra la necesidad por ampliar la relación y los convenios con organismos como el Fondo de las Naciones Unidas para la Infancia (UNICEF) -al tratarse del organismo internacional de mayor impacto en el abordaje de la niñez-, así como la construcción de una especialización en niñez, enfocada a trabajadoras y trabajadores sociales, que logre dotar de enfoques y modelos de pertinente utilización, para este grupo poblacional, en el convencimiento de que la academia no transforma nada, pero nada se transforma consistentemente sin la mano de la academia. 


\section{ÍNDICE DE IMÁGENES}

- Imagen 1. Taller DIF a través del tiempo. Elaboración propia para el desarrollo del Taller (2017)

- Imagen 2. La niñez en la Edad Antigua. Curso "Un país llamado infancia. La infancia en el siglo XIX" (1 sesión). El Colegio Nacional ....

- Imagen 3. La niñez en la Edad Antigua. Curso "Un país llamado infancia. La infancia en el siglo XIX" (1 sesión). El Colegio Nacional ...............................

- Imagen 4. La niñez en la Edad Antigua. Curso "Un país llamado infancia. La infancia en el siglo XIX" (1 sesión). El Colegio Nacional ................................... 75

- Imagen 5. La niñez en la Edad Antigua. Curso "Un país llamado infancia. La infancia en el siglo XIX" (1 sesión). El Colegio Nacional .................................... 75

- Imagen 6. La niñez en el México prehispánico. Almomento (2015) ................. 77

- Imagen 7. La niñez en el México revolucionario. Garnica (2018) ................... 81

- Imagen 8. La niñez en el México revolucionario. "Los niños que participaron en la revoluciónmexicana”. México Desconocido (2018) ................................ 81

- Imagen 9. La niñez en el Porfiriato. "Así era el impresionante hospicio para pobres de Porfirio Díaz. México Desconocido (2019)

- Imagen 10. La niñez en el Cardenismo. "Los niños y jóvenes infractores de la Ciudad de México, 1920-1937"

- Imagen 11. Desfile de moda infantil en Liverpool El Dorado. Casting desfile para Niños y mamás: La casita de Martina

- Imagen 12. Spas para niñas en la Ciudad de México. Time Out México (2017) ........

- Imagen 13. Los dos mundos. Ayayay (2019)

- Imagen 14. Recibimiento de niñas y niños provenientes del DIF Tabasco, afectados por Huracán Dean (2007). Archivo personal. Ruiz, Gabriela (2014) .

- Imagen 15. Decreto presidencial a través del cual se crea SNDIF. Diario Oficial de la Federación, (1977: 26)

- Imagen 16. Mapa niñas y niños residentes en los CAS y albergues públicos y privados Informe especial sobre la situación de los Derechos de NNA en CAS. CNDH (2019) .. 168

- Imagen 17. Mapa número de CAS y albergues públicos y privados. Informe especial sobre la situación de los Derechos de NNA en CAS. CNDH (2019) .

- Imagen 18. Financiamiento CAS. Elaboración propia. Informe especial sobre la situación de los Derechos de NNA en CAS y albergues públicos y privados de la República mexicana. CNDH (2019)

- Imagen 19. Oficio invitación como ponente $5^{\text {a }}$ Conferencia Nacional de Procuradoras y Procuradores de Protección de Niñas, Niños y Adolescentes. Archivo personal (2019) .. 171

- Imagen 20. Festividad en Casa Cuna Coyoacán. Archivo personal (2009) .............. 180

- Imagen 21. Reglamento ubicado a la entrada del dormitorio: sala preescolar niñas, Casa Cuna Coyoacán. Archivo personal (2007) 
- Imagen 22. Sala de aislamiento que aloja a las niñas y niños de reciente ingreso en Casa Cuna Coyoacán. Archivo personal (2009) ....................................... 182

- Imagen 23. Dictamen pericial del caso La Gran Familia. Archivo personal (2014) ...... 193

- Imagen 24. Albergue La Gran Familia. La Gran Familia y sus demonios. Reconoce

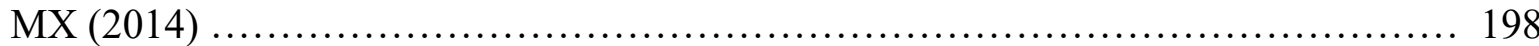

- Imagen 25. Mapa de la República mexicana donde se referencia el Maltrato institucional documentado de 2007 a 2019.

- Imagen 26. CNMAIC Casa Cuna Tlalpan. Archivo personal (2018) 234

- Imagen 27. CNMAIC Casa Cuna Tlalpan. Recorrido institucional en el marco de la Practica de Especialización 1907. Archivo personal (2019) .............................. 235

- Imagen 28. CNMAIC Casa Cuna Coyoacán. Festividad de día de muertos. Archivo

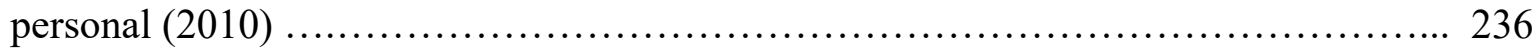

- Imagen 29. CNMAIC Casa Cuna Coyoacán. Archivo personal (2018) ................. 236

- Imagen 30. Subdirección del Centro Amanecer para Niños. Archivo personal (2018) .. 237

- Imagen 31. Subdirección del Centro Amanecer para Niños. Recorrido institucional en el marco de la Practica de Especialización 1907. Archivo personal ..................... 237

- Imagen 32. CNMAIC CAHONI. Archivo personal (2018) .......................... 238

- Imagen 33. CNMAIC CAHONI. Recorrido institucional en el marco de la Practica de Especialización 1907. Archivo personal ......................................... 238

- Imagen 34. CNMAIC CAHOVA. Recorrido institucional en el marco de la Practica de

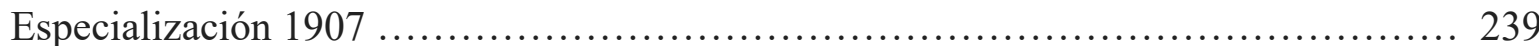

- Imagen 35. CNMAIC CAHOVA. Archivo personal (2018) ......................... 239

- Imagen 36. Servicios de los Centros de Asistencia Social. Modelo tipo de Atención y Protección Integral de Centros de Asistencia Social para Niñas, Niños y Adolescentes

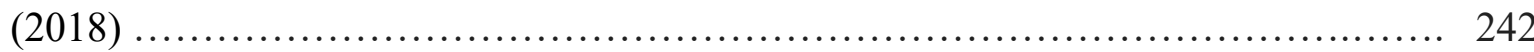

- Imagen 37. Esquema de, Modelo Tipo de Atención en Centros de Asistencia Social. Modelo tipo de Atención y Protección Integral de Centros de Asistencia Social para Niñas, Niños y Adolescentes (2018) ............................................ 243

- Imagen 38. Álbumes fotográficos de las trabajadoras sociales adscritas al CNMAIC

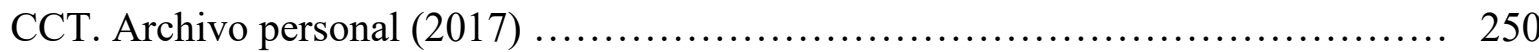

- Imagen 39. Taller Mis memorias. Archivo personal (2017) ......................... 251

- Imagen 40. Testimonio del taller Mis memorias. Archivo personal (2017) ............. 251

- Imagen 41. Portafolios del taller Enlazando mis saberes. Archivo personal (2017) ..... 254

- Imagen 42. Taller Enlazando mis saberes. Archivo personal (2017) .................. 255

- Imagen 43. Taller Enlazando mis saberes. Archivo personal (2017) ................... 255

- Imagen 44. Taller Enlazando mis saberes. Archivo personal (2017) .................. 255

- Imagen 45. Taller DIF a través del tiempo. Archivo personal (2017) .................. 258

- Imagen 46. Taller DIF a través del tiempo. Archivo personal (2017) .................... 259

- Imagen 47. Taller DIF a través del tiempo. Archivo personal (2017) .................. 259

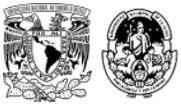




\section{ÍNDICE DE TABLAS}

\begin{tabular}{|c|c|c|c|c|}
\hline & Título & Año & Fuente & Página \\
\hline Tabla 1 & $\begin{array}{l}\text { Cronología epocal de la niñez en Europa } \\
\text { Occidental. }\end{array}$ & 2019 & Elaboración propia. & $72-74$ \\
\hline Tabla 2 & Cronología epocal de la niñez en México. & & Elaboración propia. & 86 \\
\hline Tabla 3 & $\begin{array}{l}\text { Cronología de los instrumentos internacionales de } \\
\text { protección a la niñez. }\end{array}$ & 2019 & Recuperado de Ruíz. (34) & 91 \\
\hline Tabla 4 & $\begin{array}{l}\text { Tratados, protocolos y declaraciones de derechos } \\
\text { humanos a los que México se ha adherido. }\end{array}$ & 2018 & $\begin{array}{l}\text { Modelo Tipo de Atención y } \\
\text { Protección Integral de Centros } \\
\text { de Asistencia Social para } \\
\text { Niñas, Niños y Adolescentes. } \\
\text { (15) }\end{array}$ & 93 \\
\hline Tabla 5 & $\begin{array}{l}\text { Características de la infancia desde las distintas } \\
\text { escuelas de la psicología del desarrollo. }\end{array}$ & 2019 & Elaboración propia. & $97-98$ \\
\hline Tabla 6 & Infancia y modelos de dominación. & 2005 & Barudy \& Dantagnan. (49) & 101 \\
\hline Tabla 7 & $\begin{array}{l}\text { Metodología de intervención individualizada. Una } \\
\text { revisión latinoamericana. }\end{array}$ & 2020 & $\begin{array}{l}\text { Elaboración propia con base } \\
\text { en las propuestas } \\
\text { metodológicas } \\
\text { latinoamericanas. }\end{array}$ & $138-140$ \\
\hline Tabla 8 & Niñez y violencia estructural. & 2018 & $\begin{array}{l}\text { Elaboración propia con base } \\
\text { en La Jornada. }\end{array}$ & 152 \\
\hline Tabla 9 & Niñez y violencia doméstica. & 2017 & $\begin{array}{l}\text { Elaboración propia con base } \\
\text { en UNICEF. }\end{array}$ & 154 \\
\hline Tabla 10 & $\begin{array}{l}\text { Organigrama Sistema Nacional para el Desarrollo } \\
\text { Integral de la Familia }\end{array}$ & & $\begin{array}{l}\text { Elaboración propia con base al } \\
\text { Estatuto Orgánico del Sistema } \\
\text { Nacional para el Desarrollo } \\
\text { Integral de la Familia y el } \\
\text { Manual General de } \\
\text { Organización del institucional. }\end{array}$ & 162 \\
\hline Tabla 11 & $\begin{array}{l}\text { Procedimiento Interno para la Restitución de } \\
\text { Derechos y Medidas de Protección a Niñas, Niños } \\
\text { y Adolescentes }\end{array}$ & 2016 & $\begin{array}{l}\text { Elaboración propia con base } \\
\text { en }\end{array}$ & 165 \\
\hline Tabla 12 & $\begin{array}{l}\text { Motivos de institucionalización de niñas y niños } \\
\text { según UNICEF. }\end{array}$ & 2018 & $\begin{array}{l}\text { La intervención del trabajador } \\
\text { social en la atención de la } \\
\text { infancia en condición } \\
\text { institucionalizada. ENTS- } \\
\text { UNAM. Ruíz, Gabriela (39) }\end{array}$ & 173 \\
\hline Tabla 13 & $\begin{array}{l}\text { Motivos de ingreso de NNA a CAS de carácter } \\
\text { público, social y privado. }\end{array}$ & 2019 & $\begin{array}{l}\text { Informe especial sobre la } \\
\text { situación de los Derechos de } \\
\text { Niñas, Niños y Adolescentes } \\
\text { en Centros de Asistencia } \\
\text { Social y Albergues Públicos y } \\
\text { Privados de la República } \\
\text { mexicana. CNDH. (131) }\end{array}$ & 174 \\
\hline Tabla 14 & La Familia negligente. & 2016 & Recuperado de Barudy. (88) & 176 \\
\hline Tabla 15 & $\begin{array}{l}\text { Trastornos vinculados con la niñez en condición } \\
\text { de institucionalización. }\end{array}$ & 2019 & Elaboración propia. & 184 \\
\hline Tabla 16 & $\begin{array}{l}\text { Número de población albergada en los CAS del } \\
\text { SNDIF diagnosticada con un trastorno } \\
\text { psicológico y/o psiquiátrico. }\end{array}$ & 2019 & $\begin{array}{l}\text { Elaboración propia a partir de } \\
\text { información obtenida en } \\
\text { Preguntas Ciudadana. } \\
\text { Proporcionada por el SNDI. }\end{array}$ & $185-186$ \\
\hline Tabla 17 & $\begin{array}{l}\text { Implicaciones y consecuencias de la } \\
\text { institucionalización en la niñez. }\end{array}$ & 2017 & $\begin{array}{l}\text { Elaboración propia, a través } \\
\text { de la recolección de } \\
\text { información. }\end{array}$ & $187-188$ \\
\hline
\end{tabular}




\begin{tabular}{|c|c|c|c|c|}
\hline Tabla 18 & $\begin{array}{l}\text { Mapa de la República mexicana geo-referencial } \\
\text { del Maltrato institucional documentado de } 2007 \text { a } \\
2019 \text {. }\end{array}$ & $2016-$ & $\begin{array}{l}\text { Elaboración propia a partir de } \\
\text { información recabada en el } \\
\text { proyecto investigativo: } \\
\text { Problemáticas de la niñez en } \\
\text { el México contemporáneo. }\end{array}$ & 207 \\
\hline Tabla 19 & $\begin{array}{l}\text { Etapas del Modelo Tipo de Atención y Protección } \\
\text { en los CAS. Adaptado de "Modelo de Atención y } \\
\text { Protección Integral de Centros de Asistencia } \\
\text { Social para Niñas, Niños y Adolescentes. }\end{array}$ & 2018 & $\begin{array}{l}\text { Modelo tipo de asistencia } \\
\text { SNDIF. }\end{array}$ & 244 \\
\hline Tabla 20 & Guía de conectores & & Elaboración propia. & 254 \\
\hline Tabla 21 & $\begin{array}{l}\text { Esquema de Categorías y Subcategorías del } \\
\text { dispositivo Intervención. }\end{array}$ & 2019 & $\begin{array}{l}\text { Elaboración propia con base } \\
\text { en el trabajo de campo. }\end{array}$ & 261 \\
\hline Tabla 22 & $\begin{array}{l}\text { Elementos constituyentes de la intervención: } \\
\text { Subjetivación-Episteme-Institución. }\end{array}$ & 2019 & $\begin{array}{l}\text { Elaboración propia con base } \\
\text { en el proceso de investigación. }\end{array}$ & 293 \\
\hline Tabla 23 & Proceso de acompañamiento social. & 2019 & $\begin{array}{l}\text { Elaboración propia con base } \\
\text { en el análisis del proceso de } \\
\text { investigación. }\end{array}$ & 294 \\
\hline
\end{tabular}




\section{REFERENCIAS}

Agamben, G. (2007). Infancia e historia. Destrucción de la experiencia y origen de la historia. Buenos Aires. Recuperado de: https://etsamdoctorado.files.wordpress.com/2012/12/agamben-giorgio-infancia-ehistoria.pdf

Agamben, G. (2009). Nuditá, Roma Nottetempo. Italia: valencia Pre-textos

Agamben, G. (2011). ¿Qué es un dispositivo? Sociología. Recuperado de: http://ayp.unia.es/r08/IMG/pdf/agamben-dispositivo.pdf

Al momento. (2015, 26 de abril). "Estudian niñez en épocas prehispánica y colonial”. Recuperado de: https://almomento.mx/estudian-la-ninez-en-epocas-prehispanica-y-colonial/

Alanis Rufino, C. (2014). La niñez desvalida y las campañas contra la mendicidad en la ciudad de México en la década de 1930. Recuperado de: https://revistas.inah.gob.mx/index.php/antropologia/article/view/5402/5508

Álvarez, R. M. (2011). El concepto de niñez en la Convención de los Derechos del Niño y en la legislación mexicana. México: Instituto de Investigaciones Jurídicas de la UNAM. Recuperado de: https://archivos.juridicas.unam.mx/www/bjv/libros/7/3011/4.pdf

Animal político. (2014, 18 de julio). "Intelectuales publican carta de apoyo a $<<$ Mamá Rosa $>>$ " Recuperado de: https://www.animalpolitico.com/2014/07/intelectuales-publican-carta-deapoyo-mama-rosa/

Aries, P. (1987). El niño y la vida familiar en el antiguo régimen. México: Tauro Ediciones

Aristegui, C. (18 de febrero de 2018) Abusan de niños en albergue infantil de Irapuato; presentan 5 denuncias ante Procuraduria, recuperado de Aristegui Noticias: https://aristeguinoticias.com/1802/mexico/abusan-de-ninos-en-albergue-infantil-deirapuato-presentan-5-denuncias-ante-procuraduria/ Consultado el día 2 de diciembre de 2019.

Aristegui Noticias: (18 de febrero de 2018) [Fotografía]. Recuperado de Aristegui Noticias: https://aristeguinoticias.com/1802/mexico/abusan-de-ninos-en-albergue-infantil-de-irapuatopresentan-5-denuncias-ante-procuraduria/

Arteaga Basurto, C; Campos y Covarrubias G. \& Piña Cano, M. (2007). Estado, economía y pobreza en México. México: Escuela Nacional de Trabajo Social-Plaza y Valdés Editores. 
Asamblea General de las Naciones Unidas (2010). Directrices sobre las modalidades alternativas de cuidado. Recuperado de: https://www.unicef.org/spanish/protection/files/100407-UNGARes-64-142.es.pdf

Asamblea Legislativa del Distrito Federal VI legislatura (2015). Ley de Cuidados Alternativos para Niñas, Niños y Adolescentes en el Distrito Federal. Recuperado de: https://data.consejeria.cdmx.gob.mx/images/leyes/leyes/LEY_DE_CUID_ALT_NINAS_NI NOS_Y_ADOL_EN_EL_DF_1.pdf

Augé, M. (1992). Los No lugares. Espacios del anonimato. Una Antropología de la sobre modernidad. México: Gedisa.

Ayayay. (s/f). Estas fotos muestran el impactante contraste de los niños del mundo y sus juguetes. [Ilustración]. Recuperado de: https://www.ayayay.tv/el-impactante-contraste-de-los-ninosdel-mundo-y-sus-juguetes/

Barreto, C., Benavides, J., Garavito, J. y Gordillo, N. (2003). Metodologías y métodos de Trabajo Social en 68 libros ubicados en bibliotecas de unidades académicas de Trabajo Social en Bogotá. Trabajo de grado. Facultad de Trabajo Social, Universidad de la Salle. Recuperado de: http://www.ts.ucr.ac.cr/binarios/pela/pl-000348.pdf

Barudy, J. \& Dantagnan, M. (2005). Los buenos tratos a la infancia. Parentalidad, apego y resiliencia. España: Gedisa.

Barudy, J. (2016). El dolor invisible de la infancia. Una lectura ecosistémica del maltrato infantil. Barcelona: Paidós.

Bauman, Z. \& Lyon D. (2013). Vigilancia líquida. México: Paidós. Recuperado de: http://www.ntic2012.yolasite.com/resources/10\%20Bauman.pdf

Bauman, Z. (2015). Vidas desperdiciadas. La modernidad y sus parias. México: Paidós.

Berber, A. (25 de abril de 2019) [Fotografía]. Recuperado de El Sol del Bajío: https://www.elsoldelbajio.com.mx/local/cierran-la-casa-hogar-del-nino-pobre-en-celaya3365834.html

Bing. (2019). Los niños en la historia: Historia de México. [Ilustración]. Recuperado de: https://www.bing.com/images/search?view=detailV2\&ccid=Kest\%2BBsC\&id=1934B92A AECA9229C06C1F457663A3C2F5706A7E\&thid=OIP.Kest-

BsC1R5JwacB5d_AeQHaJ7\&mediaurl=http\%3A\%2F\%2F1.bp.blogspot.com\%2F_tuyNqY Tx85g\%2FTQOjagUBH7I\%2FAAAAAAAAACo\%2FLq2E0aq-

X40\%2Fs1600\%2Fnino20revolucionario.jpg\&exph=1600\&expw=1193\&q=La+ni\%c3\%b1 ez + en + el + mexico + revolucionario + Del + Castillo\&simid $=608051124649594608 \&$ selectedin dex $=0$ \&ajaxhist $=0 \& v t=0$ 
Blancas, D. (8 de septiembre 2016) Amor de monja, recuperado de Crónica: http://www.cronica.com.mx/notas/2016/977218.html Consultado el día 29 de noviembre de 2019.

Blancas, D. (8 de octubre 2016) Monjas reciben $\$ 72$ millones al año y dan "sopa verdosa y pollo apestoso", recuperado de Crónica: http://www.cronica.com.mx/notas/2016/977415.html Consultado el día 29 de noviembre de 2019.

Blackwell, R (31 de julio de 2017). [Fotografía]. Recuperado de Proceso: https://www.proceso.com.mx/496905/politicos-curas-protectores-pederastia-trata\#\&gid=1\&pid=1 Bloom, S. (2010). Creating sanctuary: Toward the evolution of sane societies. E.U.A.: Routledge. Bloom, Sandra. El impacto del trauma en el desarrollo y el bienestar. Llegar a los adolescentes: la sabiduría de la medicina adolescente. Recuperado de: http://www.sanctuaryweb.com/Publications/PublicationsbyTopic.aspx

Bonomi, R. (2014). Basta de ... problemas de pareja. Argentina. Ed. Dr. Bonomi.

Borja Aguirre (2013). El acompañamiento social personalizado como fórmula innovadora de respuesta a personas con trastorno mental y en exclusión social. Recuperado de: http://repositoriocdpd.net:8080/bitstream/handle/123456789/1585/Art_AguirreBAcompana mientosocial_2013.pdf?sequence $=1$

Bowbly, J. (1986). Vínculos afectivos: Desarrollo y pérdida. Madrid: Ediciones Morata.

Bustelo Graffigna, E. (2012). Notas sobre infancia y teoria: un enfoque latinoamericano. Buenos Aires: Salud colectiva. Recuperado de: http://revistas.unla.edu.ar/saludcolectiva/article/view/168/147

Calderón Carrillo, D. (2015). Los niños como sujetos sociales. Notas sobre la antropología de la infancia. México. Recuperado de: http://www.scielo.org.mx/scielo.php?script=sci_arttext\&pid=S0185-06362015000100007

Calvi, B. (2005). Abuso sexual en la infancia: efectos psíquicos. Buenos Aires, Argentina: Lugar editorial.

Carballeda, A. (2002). La intervención en lo social. Exclusión e integración en los nuevos escenarios sociales. Buenos Aires: Paidós.

Carballeda, A. (2004). Del desorden de los cuerpos al orden de la sociedad. Buenos Aires: Espacio Editorial.

Carballeda, A. (2010). La intervención en lo social como dispositivo. Una mirada desde los escenarios actuales. México: Revista de trabajo social UNAM VI Época, No. 1. 
Carballeda, A. (2018). El lugar, la palabra, la mirada y la escucha. Entrevista e intervención social. Buenos Aires: Espacio Editorial.

Cardoso, A. (2013). Casas Hogar: ¿Maltrato o protección a la infancia? El caso Casitas del Sur. (Tesis de licenciatura). México, D.F: UNAM, Facultad de Ciencias Políticas y Sociales.

Carli, S. (2011). El campo de estudios sobre la infancia en las fronteras de las disciplinas. Notas para su caracterización e hipótesis sobre sus desafios. Argentina: Teseo.

Casas F. (1998). Infancia: perspectivas psicosociales. Barcelona: Paidós. Recuperado de: http://books.google.com.mx/books?id=0hNPIIpWm34C\&pg=PA218\&lpg=PA218\&dq=pap a + inocencio + III + el + torno + abandono + de + ni $\% C 3 \% B 1$ os\&source $=$ bl\&ots $=k c D j 3 n E I r d \& s i g$ $=6 h w f y F g U G b 6 v a D P 8 C i M d g V w w M R o \& h l=e s \& e i=s v E 5 T r H 8 G e a 1 s Q L 1 n c 0 p \& s a=X \& 13$ 9oi=book_result\&ct=result\&resnum $=4 \& v e d=0 C C 4 Q 6 A E w A w \# v=$ onepage $\& q=$ papa $\% 20 \mathrm{in}$ ocencio $\% 20 \mathrm{III} \% 20 \mathrm{el} \% 20$ torno $\% 20$ abandono $\% 20 \mathrm{de} \% 20 \mathrm{ni} \% \mathrm{C} 3 \% \mathrm{~B} 1$ os\& $\mathrm{f}=$ false

Castel, Donzelot, Focault, Gaudamar, Grignon y Muel. (1981). Espacios de poder. España: Técnicas gráficas. p. 22. Recuperado de: https://es.scribd.com/doc/35167035/Castel-R-Foucault-MEt-Al-Espacios-de-Poder-1981

Castellanos Huila, A. (2013). Trabajo Social: origen, métodos tradicionales, procesos y etapas históricas. Bogotá. Recuperado de: http://es.slideshare.net/darlynandreaariza/trabajo-socialorigen-mtodos-tradicionales-procesos-y-etapas-histricas

Castoriadis, C. (1975). La institución imaginaria de la sociedad 1. Recuperado de: http://www.terras.edu.ar/biblioteca/16/16TUT_Castoriadis_Unidad_2.pdf

Castro, E. (2004). El vocabulario de Michel Foucault. Un recorrido alfabético por sus temas, conceptos y autores. Bernal: Universidad Nacional de Quilmes.

Castro, H. (2004). El vocabulario de Michel Foucault. Un recorrido alfabético por sus temas, conceptos y autores. Bernal: Universidad Nacional de Quilmes.

CdEA. (2019, 09 de noviembre). "Sin registro 33 mil niños en albergues de México; no pueden ser adoptados". Recuperado de: http://www.cdea.org.mx/noticia/index.php?acc=mostrar\&idNoticia=1150

Chambon, A. S; Irving, A. \& Epstein. (2001). Foucaul y el trabajo social. Granada: editorial maristán/E.U.T.S. Linares (Univ. De Jaén).

Chanin E. \& Tardos A. (2018). En manos amorosas. Ecuador: Xlibris.

Chávez Carapia, J. C. \& Hernández Garnica, C. (2019). Familias y Vida cotidiana. México: Universidad Nacional Autónoma de México. 
Cobos, A. (26 de febrero de 2016) El albergue de Morelos del que desaparecieron 22 niños, recuperado de Milenio: https://www.milenio.com/estados/el-albergue-de-morelos-del-quedesaparecieron-22-ninos Consultado el día 29 de noviembre de 2019

Colángelo A. (2020) Crianza infantil y diversidad cultural. Aportes de la antropología a la práctica pediátrica. Recuperado de: https://www.sap.org.ar/docs/publicaciones/archivosarg/2020/v118n4a12.pdf

Colegio Nacional de México. (Productor). (2018). País llamado infancia: la infancia en el siglo XIX ( $1^{\circ}$ sesión). [Vídeo]. De: https://www.youtube.com/watch?v=CUzHx_rzl-o

Colima Noticias (9 de agosto de 2016) Madre superiora azota a niños internos en Acatlán de Juárez, recuperado de: https://www.colimanoticias.com/madre-superiora-azota-a-ninos-internos-enacatlan-de-juarez/ Consultado el día 29 de noviembre de 2019.

Comisión Nacional de Derechos Humanos. (2019). Informe especial sobre la situación de los Derechos de Niñas, Niños y Adolescentes en Centros de Asistencia Social y Albergues Públicos y Privados de la República mexicana. México. Recuperado de: https://www.cndh.org.mx/sites/default/files/documentos/2019-11/IE-ninas-ninosadolescentes-centros-albergues.pdf

CNDH (29 de octubre de 2018) [Fotografía]. Recuperado de CNDH: https://www.cndh.org.mx/sites/all/doc/PrevTortura/11_2018.pdf

Consejo Nacional de Evaluación de la Política de Desarrollo Social \& Fondo de las Naciones Unidas para la Infancia. Estudio: Pobreza y derechos sociales de niñas, niños y adolescentes en México 2014.

Consejo Nacional de Evaluación de la Política de Desarrollo Social \& Fondo de las Naciones Unidas para la Infancia. (2014). Pobreza y derechos sociales de niñas, niños y adolescentes en México. Recuperado de: https://www.unicef.org/mexico/spanish/MX_Pobreza_derechos.pdf

Corea, C. (1999). ¿Se acabó la infancia? Ensayo sobre la destitución de la niñez. México: Lumen/Humanitas, pp. 53-54.

Crónica (18 de octubre de 2009) [Fotografía]. Recuperado de Crónica: http://www.cronica.com.mx/notas/2009/463810.html

Crónica de Xalapa (3 de agosto de 2017) [Fotografía]. Recuperado de Crónica de Xalapa: http://cronicadexalapa.com/pgr-abre-investigacion-por-ciudad-de-los-ninos-enguanajuato/

Cyrulnik, Boris (2014). Nuevas miradas sobre la resiliencia. Editorial Gedisa, España. 
Cussianovich Villarán, A. (2010). Paradigmas de las culturas de infancia como formas de poder.

Perú. Recuperado de:

https://www.minjus.gob.pe/defensapublica/contenido/actividades/docs/449_20_paradigmas

_de_las_culturas_de_infancia_como_formas_de_poder.pdf

De la Cuesta-Benjumea, C. (2011). La reflexividad: un asunto crítico en la investigación cualitativa.

España: Departamento de Psicología de la Salud, Universidad de Alicante. Recuperado de: https://ps.ua.es/es/documentos/pdf/2011/la-reflexividad.pdf

De Parres, A. R. (2001). La niñez en el Código Mendocino. Recuperado de: https://www.medigraphic.com/pdfs/inper/ip-2001/ip011j.pdf

De Robertis, C. (1988). Metodología de la intervención en Trabajo Social. Buenos Aires-México: Lumen Hvmanitas.

Del Castillo, A. (2006). Conceptos, imágenes y representaciones de la niñez en la Ciudad de México 1880-1920. México: Colegio de México/Instituto Mora.

Derrida, Jacques (2017). La hosiptalidad como poética de la esperanza. Colombia, Universidad de San Buenaventura, Recuperado de: https://www.redalyc.org/pdf/3435/343554680007.pdf

Deleuze G, Guattari F. (2002). Mil mesetas. Capitalismo y esquizofrenia. Paris: Les Editions de Minuit.

Deleuze G, (2002). Diferencia y repetición. Buenos Aires, Argentina: Amorrortu.

Derrida, J. (1998). Adiós a Emmanuel Levinas seguido de Palabra de acogida. Madrid: Trotta.

Diario de Yucatán (16 de marzo de 2019) [Fotografía]. Recuperado de Diario de Yucatán:

https://www.yucatan.com.mx/merida/denuncian-en-la-fiscalia-a-dos-custodios-del-

caimede

Diario Oficial de la Federación. (D. O. F.) (1977). [Ilustración]. Recuperado de: http://dof.gob.mx/nota_to_imagen_fs.php?cod_diario=197493\&pagina $=26 \&$ seccion $=0$

Díaz Barriga Cuevas, A. (2015). La representación social de la infancia mexica a principios del siglo XVI. Recuperado de: http://www.historicas.unam.mx/publicaciones/publicadigital/libros/miradas/mirada003.pdf

Díaz, A. (2012). La representación social de la infancia mexica a principios del siglo XVI. En Sosenski, S. \& Jackson, E. Nuevas miradas a la historia de la infancia en América Latina: entre prácticas y representaciones. México: Instituto de Investigaciones históricas-UNAM.

Díaz, F. (2015). La educación de los aztecas. Cómo se formó el carácter del pueblo mexicano. México: Panorama editorial. 
Díaz, R. (16 de febrero de 2017) VIDEO: Denuncian presunto maltrato contra internos de casa hogar de la Madre Inés. Recuperado de:

SDP Noticias: https:/www.sdpnoticias.com/local/edomex/denuncian-internos-maltratopresunto-video.html Consultado el día 2 de diciembre de 2019

Diker, G. (2009). ¿Qué hay de nuevo en las infancias? Recuperado de: https://ediciones.ungs.edu.ar/wp-content/uploads/2018/04/9789876300506-completo.pdf

Del Valle, M. (2014). Transmisión transgeneracional y situaciones traumáticas. Recuperado de: https:/www.temasdepsicoanalisis.org/2014/01/28/transmision-transgeneracional-ysituaciones-traumaticas/

Domínguez, E. (2018, 18 de diciembre). Aristegui Noticias: “Abusan de niños en albergue infantil de Irapuato; presentan 5 denuncias ante Procuraduría". Recuperado de: https://aristeguinoticias.com/1802/mexico/abusan-de-ninos-en-albergue-infantil-deirapuato-presentan-5-denuncias-ante-procuraduria/

Donozo Díaz, M. D., \& Saldías Guerra, P. (1998). Modelo de intervención para el Trabajo Social Familiar. Escuela de Trabajo Social.

Recuperado de: http://www.ts.ucr.ac.cr/binarios/congresos/reg/slets/slets-016-059.pdf

Donzelot, J. (1977). La policía de las familias. España: Artes gráficas Soler.

El Universal (26 de septiembre de 2018) [Fotografía]. Recuperado de El Universal: https://www.eluniversal.com.mx/metropoli/edomex/investigan-muerte-de-alumna-de-villa-de-lasninas-en-chalco

El Universal (21 de octubre de 2015) [Fotografía]. Recuperado de El Universal: https://www.eluniversal.com.mx/articulo/estados/2015/10/21/ofrecen-disculpa-por-muerte-demigrante.

Escuela Nacional de Trabajo Social (2019). Memoria digital. Seminario Problemáticas de la niñez en el México contemporáneo La niñez vinculada a la Trata de personas: un abordaje multidisciplinar. Recuperado de:

https://view.joomag.com/seminario-problem $\% \mathrm{C} 3 \% \mathrm{~A} 1$ ticas-de-la-ni\%C3\%B1ez-en-elm\%C3\%A9xico-contempor\%C3\%A1neo-seminariopnmc/0544466001583788432?short\&fbclid=IwAR17f2_FgsVXq11UjjwrgBzGNq61A0FawFrU4clcjufU6n9ofrNMQkD2NU 
Escobar, C. (2019), IV Seminario Internacional de Prácticas Pedagógicas de Encierro, perspectivas Interdisciplinares. Chile: Facultad de Ciencias Sociales. Recuperado de: http://www.facso.uchile.cl/noticias/157287/infancias-invisibilizadas-ninos-en-contextos-deencierro

Estévez, A. (2018). Biopolitica y necropolitica: ¿Constitutivos u opuestos? Espiral, Estudios sobre Estado $y \quad$ Sociedad. 25(73), 9-43. Recuperado de: http://www.scielo.org.mx/pdf/espiral/v25n73/1665-0565-espiral-25-73-9.pdf

Estrada Ospina, V. M. (2011). Trabajo social, intervención en lo social y nuevos contextos. Recuperado de: http://bibliotecadigital.univalle.edu.co/bitstream/10893/6315/4/Prospectiva $\% 2016 \% 2 C \% 20$ 2011-2153\%20Trabajo\%20Social\%2C\%20intervenci\%C3\%B3n\%20en\%201o\%20social.pdf Fecha de consulta 16 de junio de 2016, p. 7

Evangelista Ramírez, E. (1998). Historia del Trabajo Social en México. México: Escuela Nacional de Trabajo Social-Plaza y Valdés Editores.

Fiscalía General de Justicia de la Ciudad de México (2020). Centro de Terapia de Apoyo a Víctimas de delitos sexuales. Recuperado de: https://www.fgjcdmx.gob.mx/nuestros-servicios/enlinea/mp-virtual/cta-centro-de-terapia-de-apoyo-victimas-de-delitos-sexuales

Flores, García, Ortega, Tellez, Volkers, García, Bernal, Zuñiga, García T. \& López. (2012). Intervención Individualizada. México: Yecolti.

Fondo de las Naciones Unidas para la Infancia. (2006). Convención sobre los Derechos del niño. Recuperado de: https://www.un.org/es/events/childrenday/pdf/derechos.pdf

Fondo de las Naciones Unidas para la Infancia. (2017). Informe Anual 2017 México. Recuperado de: https://www.unicef.org.mx/Informe2017/Informe-Anual-2017.pdf

Fondo de las Naciones Unidas para la Infancia. La violencia contra los niños, niñas y adolescentes. Magnitud y desafíos para América Latina. Resultados del estudio mundial de violencia 2010. Foucault, M. (1976). Saber y verdad. España: Las Ediciones de la Piqueta, p. 128.

Foucault, M. (1976). Vigilar y castigar. Nacimiento de la prisión. Francia: Siglo XXI Editores, p. 214.

Foucault, M. (1979). La Arqueología del saber. Francia: Siglo XXI Editores. pp. 322-324.

Foucault, M. (1981). «La gubernamentalidad», en Espacios de poder. Madrid: La Piqueta.

Foucault, M. (1984). “Foucault” en Denis Huisman. París: Dictionnaire des Philosophes.

Foucault, M. (1991). El Sujeto y el poder. Bogotá: Carpe Diem. 
Foucault, M. (2001). La naissance de la médicine sociale. En Dits et écrits II (pp. 207-228). Paris: Gallimard.

Foucault, M. (2001). Un diálogo sobre el poder y otras conversaciones. Madrid, España: Alianza.

Foucault, M. (2018). La crisis de la medicina o la crisis de la antimedicina. Recuperado de: http://scielo.sld.cu/pdf/rcsp/v44n1/1561-3127-rcsp-44-01-00172.pdf

Fuentes, M. L. La niñez frente a la crisis migratoria. Recuperado de: https://www.revistadelauniversidad.mx/download/b82e2259-1522-422c-a00f510e599f3c26?filename=la-ninez-frente-a-la-crisis-migratoria.

Funes, Jaume y Raya Esther (2001). El acompañamiento y los procesos de incorporación social. Guía para su práctica. Gobierno Vasco: Federación Sartu.

Galán Rodríguez, A. (2010). El apego. Más allá de un concepto inspirador. Recuperado de: http://scielo.isciii.es/pdf/neuropsiq/v30n4/03.pdf

Gallen, U. (2018). Universos paralelos. [Ilustración]. Recuperada de: https://www.facebook.com/meparecequenoesparatanto/posts/1173331599458418

Galtung, J. (2012). El triángulo de la violencia. Recuperado de: https://lizafleurdepeau.wordpress.com/2012/03/30/el-triangulo-de-la-violencia-segun-johangaltung/

García Canal, M. I. (1995). La desaparición del sujeto institucional. México: Universidad Autónoma Metropolitana. Recuperado en: https://www.redalyc.org/pdf/267/26700413.pdf

García Fanlo, L. (2011). ¿Qué es un dispositivo?: Foucault, Deleuze, Agamben. Revista de filosofía. Argentina. Recuperado de: http://serbal.pntic.mec.es/ cmunoz11/fanlo74.pdf

GB Magazine. (s/f). Desfile de moda infantil en Liverpool El Dorado. [Ilustración]. Recuperado de: http://gbmagazine.com/articulo/218/Desfile-de-moda-infantil-en-Liverpool-El-Dorado

Giddens, A. (1994). El capitalismo y la moderna Teoría Social. Barcelona: Editorial Labor, S. A.

Giraldo Diaz, R. (2006). Poder y resistencia en Michel Foucault. Colombia: UCEVA -Unidad Central del Valle del Cauca. Recuperado de: http://www.scielo.org.co/pdf/tara/n4/n4a06.pdf

Goffman, E. (1972). Internados. Ensayos sobre la situación social de los enfermos mentales. Argentina: Amorrortu.

Gómez-Mendoza, M. A. \& Alzate-Piedrahíta, M. V. (2014). La infancia contemporánea. Revista Latinoamericana de Ciencias Sociales, Niñez y Juventud, 12 (1), 77-89. Recuperado de: http://www.scielo.org.co/pdf/rlcs/v12n1/v12n1a04.pdf

Gonzalbo, P. \& Rabell C. (1994). La familia en el mundo iberoamericano, Instituto de Investigaciones Sociales. México: UNAM. Recuperado de: 
https://www.academia.edu/6822414/La_ninez_en_Mexico_e_Hispanoamerica_Rutas_de_e xploracion

Gramsci, A. (1967). La formación de los intelectuales. México: Grijalbo S.A.

Griesbach, M. y G. Sauri. (1997). Con la calle en las venas. México: Ednica-Foro de Apoyo Mutuo.

Guber, R. (2004). El trabajo de campo como instancia reflexiva del conocimiento. En El Salvaje Metropolitano. Buenos Aires: Paidos. Recuperado de: http://iidypca.homestead.com/Guber_El_Salvaje_Metropolitano.pdf

Guber Rosana (1988). El salvaje metropolitano. Colección Comunicación y Sociedad. Editorial Legasa. Buenos Aires.

Heredia, J. M. (2012). Dispositivos y/o agenciamientos. Revista Internacional de Filosofía, 19(1), 83101. Recuperado de: https://www.uma.es/contrastes/pdfs/019/5-Juan_Manuel_Heredia.pdf

Herrera, M. \& Cardenas, Y. (2013). Tendencias analiticas en la historiografía de la infancia en América Latina. Colombia: Universidad Nacional de Colombia.

Huerta Lara, M. (2006). La Asistencia Social en México. Recuperado de: http://s3.amazonaws.com/academia.edu.documents/40313228/huerta14.pdf?AWSAccessKe yId=AKIAJ56TQJRTWSMTNPEA\&Expires $=1479246262 \&$ Signature $=$ oltnTmDVtXktoY Mw77XUp2bDIjM\%3D\&response-contentdisposition=inline\%3B\%20filename\%3DLa_Asistencia_Social_en_Mxico.pdf

Humanium. (2019). Historia de los Derechos del niño. Perspectiva histórica de la evolución de los Derechos del niño. Recuperado de: https://www.humanium.org/es/historia/

Inforural (1 de diciembre de 2015) [Fotografía]. Recuperado de Inforural: https://www.inforural.com.mx/sedesol-inicio-atencion-a-recomendacion-emitida-por-la-cndh-enfavor-de-jornaleros-agricolas-en-yurecuaro-michoacan/

Instituto de Desarrollo Social. Recuperado de: http://indesol.gob.mx/indesol/

Itzhaky, H., \& Bustin, E. (2002). Strengths and Pathological Perspectives in Community Social Work. Journal of Community Practice.

Instituto de Investigaciones Jurídicas. (2019). El concepto de niño. Recuperado de: file://C:/Users/naata/AppData/Local/Packages/Microsoft.MicrosoftEdge_8wekyb3d8bbwe/ TempState/Downloads/5\%20(1).pdf

Instituto Nacional de Estadística y Geografía. (2015). Censo de Alojamientos de Asistencia Social. Recuperado de: https://www.inegi.org.mx/programas/caas/2015/

Jakson, E. (2007). Conceptos, imágenes y representaciones de la niñez en la Ciudad de México 18801920 de Alberto del Castillo Troncoso. México: Universidad Nacional Autónoma de México. Recuperado de: http://www.redalyc.org/pdf/941/94120261005.pdf 
Jaramillo Molina, M. (2016). La pobreza no es un problema individual sino estructural. Recuperado de: https:/horizontal.mx/la-pobreza-no-es-un-problema-individual-sino-estructural/

Joseph, N. \& Gowin, Bob. (1988). Aprendiendo a aprender. Barcelona. Recuperado de: http://www.terras.edu.ar/biblioteca/3/3EEDU_Novak-Gowin_Unidad_1(1).pdf

La Jornada. (2018, 23 de julio). México: primer lugar en violencia y abuso infantil. Recuperado de: https://www.jornada.com.mx/ultimas/sociedad/2018/07/23/mexico-primer-lugar-enviolencia-y-abuso-infantil-ocde-2832.html

La redacción. (2009, 05 de marzo). Proceso: "La "desaparición" de tres niños en Monterrey". Recuperado el 29 de marzo de 2019 de: https://www.proceso.com.mx/113345/ladesaparicion-de-tres-ninos-en-monterrey

Lara Peinado, J. A. (2014). Sobre la violencia. Letras del Norte: Blog de Análisis y Reflexión en torno a México y sus síntomas en el contexto de la posmodernidad. Recuperado de: https://letrasdelnorte.wordpress.com/2014/04/01/sobre-la-violencia/

Lemke, T. (2011). Biopolitical: An Advanced Introduction. New York: New York University Press.

Ley General de los Derechos de Niños, Niñas y Adolescentes. (2014). Diario Oficial de la federación. México. 04 de diciembre de 2014. p. 20.

Ley General de Víctimas. (2013). Diario Oficial de la federación. México. 03 de enero de 2017, p. 2 Longa, F. (2010). Trayectorias e historias de vida: perspectivas metodológicas para el estudio de las biografias militantes. Argentina: Universidad Nacional de La Plata. Recuperado de: https://www.aacademica.org/000-027/90.pdf

López Fernández, M. (2009). El concepto de anomia de Durkheim y las aportaciones teóricas posteriores. Recuperado de: http://www.redalyc.org/pdf/2110/211014822005.pdf

López, V. (2019, 23 de agosto). Milenio: "Desde el DIF se detectó venta de niños en Puebla: Barbosa”. Recuperado el 29 de agosto de 2019 de: https://www.milenio.com/politica/difdetecto-venta-ninos-puebla-barbosa

Loredo, A. (2017). Maltrato infantil: gravedad y prevención. México: Editores de textos mexicanos, S.A. de C.V.

Mancinas Espinoza, S. E. (2019). Intervención de Trabajo Social con familias. Interpelaciones y propuestas. Ponencia en el Primer Congreso nacional e Internacional de Investigación en Trabajo Social. Redes temáticas; dilemas y perspectivas. Durango, México.

Mantilla, L. (2013). Lo político, la política y la cultura política. Al margen del poder y de la comunidad: La “cultura política” del clientelismo. Guadalajara, Universidad de Guadalajara: Espiral. 
Márquez Rodríguez, J. (2009). Uso de la Tecnología como recurso para la enseñanza, "Las Líneas del Tiempo". Universidad Autónoma del Estado de Hidalgo. Recuperado de: https://www.uaeh.edu.mx/docencia/VI_Lectura/maestria/documentos/LECT50.pdf

Martínez, D. (3 de junio de 2019) Caso Mamá Rosa, las heridas abiertas. Recuperado de: El Sol de Zamora: https://www.elsoldezamora.com.mx/local/caso-mama-rosa-las-heridas-abiertas3710021.html Consultado el día 25 de noviembre de 2019

Martínez, M. (17 de agosto de 2015) Desmantelan red de tráfico de menores en Sonora dirigida por funcionarios. Recuperado de Proceso: https://www.proceso.com.mx/413104/desmantelanred-de-trafico-de-menores-en-sonora-dirigida-por-funcionarios Consultado el día 29 de noviembre de 2019

Martínez, S. (22 de abril de 2012) Persiste impunidad sobre secuestro de niños de los albergues conocidos como Las Casitas. Recuperado de La jornada: https://www.jornada.com.mx/2012/04/22/politica/015n1pol\# Consultado el día 29 de marzo de 2019

Martínez, S. (2009). Se venden niños. México: Planeta.

Martínez, S. (29 de abril de 2012) [Fotografía]. Recuperado de Periodismo de Investigación: http://sanjuanamar.blogspot.com/2012/04/la-historia-de-los-ninos-recuperados-de.html

Matías, P. (13 de octubre de 2015). Rescatan a 24 menores de albergue en Oaxaca; sufrían maltrato y abuso sexual. Recuperado de Proceso: https://www.proceso.com.mx/418069/rescatan-a24-ninos-de-albergue-en-oaxaca-sufrian-maltrato-y-abuso-sexual Consultado el día 29 de marzo de 2019

Mbembe, A. (2018). Necropolítica. Biopoder, soberanía, estado de excepción, política de muerte. Brasil: Biblioteca universitaria.

MECeP (2014). Modelo de Evaluación de Condiciones para la Parentalidad-MECeP en el marco de la Política de Protección de Derechos de la Infancia, Temuco. Recuperado de: http://www.fundacionlafrontera.cl/wpcontent/uploads/2016/05/MODELO_DE_EVALUACION_DE_CONDICIONES_PARA.pd $\mathrm{f}$

Mendoza, R. (1986). Una opción metodológica para los Trabajadores Sociales. México: Escuela Nacional de Trabajo Social UNAM.

Mercado, D. (2019, 24 de enero). La república: “Así era por dentro el albergue en S.J.L. donde encerraron a menores". Recuperado el 29 de marzo de 2019 de: https://larepublica.pe/sociedad/1400398-san-juan-lurigancho-albergue-encerraronmenores/12?ref=notagaleria 
Meyer J. Opinion (2020). Una turlupinatura al estilo mexicano. Recuperado de: https:/www.eluniversal.com.mx/opinion/jean-meyer/una-turlupinatura-al-estilomexicano?fbclid=IwAR1BpkHP3Q5_gjG2GlelpbaOzC4F4xvfODzloZOukCpIb7iHAlh1G3 1a8_s

México Desconocido. (2019). Ilustraciones de “Así era el impresionante Hospicio para pobres de Porfirio Díaz". [Ilustración]. Recuperado de: https://www.mexicodesconocido.com.mx/asiera-el-impresionante-hospicio-para-pobres-de-porfirio-diaz.html

México Desconocido. (30 de abril, 2018). Los niños que participaron en la revolución mexicana. [Ilustración]. Recuperado de: https://www.mexicodesconocido.com.mx/los-ninos-queparticiparon-en-la-revolucion-mexicana.html

Míguez, P. (2017). Genealogía, poder y disciplinamiento en el trabajo social: un análisis desde Foucault. Recuperado el 20 de febrero de 2020 de: https://www.colibri.udelar.edu.uy/jspui/bitstream/20.500.12008/10197/1/RF_Miguez_2017 n10.pdf

Milenio (23 de agosto de 2019) Desde el DIF se detectó venta de niños en Puebla: Barbosa. Recuperado de Milenio: https://www.milenio.com/politica/dif-detecto-venta-ninos-pueblabarbosa Consultado el día 29 de agosto de 2019.

Milenio. (2014, 08 de abril). El caso Casitas del Sur. Recuperado en octubre de 2016 de: http://www.milenio.com/policia/caso_Casitas_del_Sur-Casitas_del_Sur_0_277172831.html

Milenio (3 de noviembre de 2014) [Fotografía]. Recuperado de Milenio: https://www.milenio.com/estados/investigan-abusos-en-albergue-de-oaxaca

Morsolin, C. (2015). El aporte de Alejandro Cussianovich a la teología y a la pedagogía de Latinoamérica. Recuperado de: https://www.alainet.org/es/articulo/171697

MTP Noticias (26 de agosto de 2019) [Fotografía]. Recuperado de MTP Noticias: https://mtpnoticias.com/destacadas/si-hay-muchos-casos-de-adopciones-ilegales-desde-dif-pueblaconfirma-barbosa-video/

Muñozcano, M. D. (2004). Orfandad y abandono. Una política social y pública inconclusa en el marco de los Derechos Humanos. (Tesis doctoral). México, D.F, UNAM: Facultad de Ciencias Políticas y Sociales.

National Scientific Council on the Developing Child (2017). Arquitectura del cerebro. Recuperado de: https://developingchild.harvard.edu/science/key-concepts/brain-architecture/

Najar, A. (2014, 18 de julio). BBC: "Mamá Rosa, la mujer detrás del albergue del horror en México". Recuperado de: 
http://www.bbc.com/mundo/noticias/2014/07/140718_mama_rosa_michoacan_orfanato_m ujer_an

Narodowski, M. (1999). Después de clase, Buenos Aires, Novedades Educativas. — (2004) "De Oliver Twist a los pibes chorros. Cumbia villera e infancia desrealizada”, en Diker, Gabriela y Frigerio, Graciela. (comps), Una ética..., cit. supra.

Netto, J. P. (2004). Trabajo Social de cara a la realidad latinoamericana. Prospectiva, 9, 19-29. Recuperado de: http://hdl.handle.net/10893/1189 Fecha de consulta 16 de junio de 2016, p. 21.

Noticias Hoy (30 de noviembre de 2019) [Fotografía]. Recuperado de Noticias Hoy: http://noticiashoylp.com.mx/2019/11/30/21-ninos-son-rescatados-de-casa-de-mamarosita-en-uruapan/

Ojeda, T. E. (2006). "El autocuidado de los profesionales de la salud que atienden a víctimas de violencia sexual". Ginecología y Obstetricia de México, 52(1), 21-27. Recuperado de: http://sisbib.unmsm.edu.pe/bVrevistas/ginecologia/vol52_n1/pdf/a05v52n1.pdf

Oliva, Jiménez, Águeda y Sánchez Queija (2008). Acontecimientos vitales estresantes. Resiliencia y ajuste adolescente. Revista de Psicopatología y Psicología Clínica Vol. 13 No. 1, 53-62.

Recuperado de: http://aepcp.net/arc/(5)\%202008(1).Oliva\%20et\%20al.pdf

Organización Mundial de la Salud \& Oficina de las Naciones Unidas contra la Droga y el Delito. Informe sobre la situación mundial de la prevención de la violencia 2014.

Organización Mundial de la Salud. (2019). Maltrato de menores. Recuperado de: https://www.who.int/topics/child_abuse/es/

Organización Naciones Unidas. (2015). Comité de los Derechos del Niño de la Organización de las Naciones Unidas. Observaciones finales sobre los informes periódicos cuarto y quinto consolidados de México. Recuperado de: file://C:/Users/Proyecto\%20PAPIME\%203/Downloads/CRC_C_MEX_CO_45\%20SUB.pdf

Osorio, Ballesteros, A. \& Arteaga Botello N. (2012). De la disciplina al control: niños en riesgo y dispositivos asistenciales en el centro de México. México: Universidad Autonóma del Estado de México. Recuperado de: http://www.scielo.org.mx/scielo.php?script=sci_arttext\&pid=S0188-45572013000100009

Patricia Mesa-Gresa, Moya-Albio Luis (2011). Neurobiología del maltrato infantil: el "ciclo de la violencia". 
file://C:/Users/Proyecto\%20PAPIME\%203/Downloads/neurobiologadelmaltratoinfantilelc iclodelaviolencia.pdf

Pérez Ramírez, B. (coord.) (2017). La relevancia de la mirada y la palabra en las estrategias de intervención de Trabajo Social. México: UNAM. Recuperado de: https://drive.google.com/file/d/1_0bhyKcH8fxb1399a_0oqlX20Nupajz/view?fbclid=IwA R3jTWcDPuhAq0_nbKddsgT4t5ELkejI4Z8yO4Z6xXYr3iT8P2tg6MTcuJ8

Pérez, M. (2009). La relevancia de la participación infantil en la economía de México. México: Colegio de México.

Perry, B. \& Szalavitz, M. (2016). El chico al que criaron como perro. España: Capitanswing.

Pippi de Medeiros, M. (2009). Testimonios. Tráficos: cultura y subjetividad. Quinto Coloquio. 17. México: Instituto de estudios Críticos.

Planella, Jordi (2016). Acompañamiento social. Barcelona, editorial UOC. Recuperado de: https://books.google.com.mx/books?id=9qHqDQAAQBAJ\&pg=PT55\&source=gbs_selecte d_pages \&cad $=3 \# \mathrm{v}=$ onepage $\& \mathrm{q} \& \mathrm{f}=$ false

Proceso (5 de marzo de 2009) La “desaparición” de tres niños en Monterrey.

Recuperado de: https://www.proceso.com.mx/113345/la-desaparicion-de-tres-ninos-enmonterrey Consultado el día 29 de marzo de 2019

Proceso (17 de agosto de 2015) [Fotografía]. Recuperado de Proceso: https://www.proceso.com.mx/413104/desmantelan-red-de-trafico-de-menores-en-sonoradirigida-por-funcionarios

Procuraduría Federal de Protección de Niñas, Niños y Adolescentes (2016). Procedimiento Interno para la Restitución de Derechos y Medidas de Protección a Niñas, Niños y Adolescentes. Recuperado de: http://sitios.dif.gob.mx/normateca/wpcontent/Archivos/Procuraduria/proced_restitucion.pdf

Quadratín (30 de noviembre de 2019). Tras operativo en casa hogar de Uruapan aseguran a 21 menores. Recuperado de Quadratín: https://www.quadratin.com.mx/principal/tras-operativoen-casa-hogar-de-uruapan-aseguran-a-21-menores/ Consultado el día 2 de diciembre de 2019

Quintero Velázquez, A. M. (2014). Peritaje Social: contexto no clínico en la intervención sociofamiliar. Revista Facultad de Trabajo Social, 30. Recuperado de: https://revistas.upb.edu.co/index.php/trabajosocial/article/view/3319/2917

Ramírez, D y Castañeda, M. (2011). Encuentros y rupturas en la historia del Trabajo Social en Brasil $y$ Colombia. Revista de Trabajo Social, 13. Recuperado de: https://aprendeenlinea.udea.edu.co/revistas/index.php/revistraso/article/view/24186

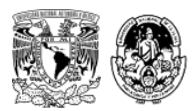


Raya Esther, Hernández Manuel (2014). Acompañar los procesos de inclusión social. Del análisis de la exclusión a la intervención social 1 . Recuperado de: file://C:/Users/Proyecto\%20PAPIME\%203/Downloads/DialnetAcompanarLosProcesosDeInclusionSocial-5234942\%20(2).pdf

Real Academia Española (2020). Recuperado de: https://www.rae.es/search/node/intervenir Reconoce MX (2014). La Gran Familia y sus demonios. [Ilustración]. Recuperado de: https://www.bing.com/images/search?view=detailV2\&ccid=YXC4ksu9\&id=A7F38CF4C8 A8872CCF34AE36A00CAF4B6037101E\&thid=OIP.YXC4ksu93GmFngMnNkqyXAHaD b\&mediaurl=http $\% 3 \mathrm{a} \% 2 \mathrm{f} \% 2 \mathrm{fwww}$.reconoce. $\mathrm{mx} \% 2$ fwp-content $\% 2$ fuploads $\% 2$ fmamarosa.png\&exph $=301 \&$ expw $=649 \& \mathrm{q}=\mathrm{La}+\mathrm{Gran}+$ Familia + mama + rosa $\& \operatorname{simid}=60802068632$ 9611104\&selectedIndex $=11 \&$ ajaxhist $=0$

REDIM (Red por los Derechos de la Infancia en México). (2014). Informe Alternativo sobre la situación de garantía de derechos de niñas, niños y adolescentes en México. Recuperado de: http://derechosinfancia.org.mx/documentos/Info_Alt_REDIM_Mexico.pdf

REDIM (Red por los Derechos de la Infancia en México). (2018). "Sistema DIF obligado a informar avances en certificación de Albergues y Centros de cuidado alternativo". Recuperado el 27 de marzo de 2019 de: http://derechosinfancia.org.mx/index.php?contenido=boletin\&id=133\&id_opcion=73:

REDIM (Red por los Derechos de la Infancia en México). (2019). Infancia y adolescencia en México. Entre la invisibilidad y la violencia. Desafios del nuevo gobierno para garantizar los derechos de niñas, niños y adolescentes. Recuperado de http://derechosinfancia.org.mx/documentos/REDIM_Balance_Anual_2019.pdf

Rengifo, G. (2003). Niñez y ayllu en la cosmovisión andina. Bolivia: Protagonistas.

Reporte Índigo (30 de julio de 2017) Explotación laboral en albergues de asistencia, una forma de trata de personas. Recuperado de Reporte Indigo: https://www.reporteindigo.com/reporte/trata-de-personas-albergues-de-asistencia/ Consultado el día 2 de diciembre de 2019

Revel, J. (2009). Diccionario Foucault. Buenos Aires, Nueva Visión.

Reza, M. (2016, 17 de enero). Proceso: "Rescatan a 271 personas cautivas en albergue de Tonalá". Recuperado el 29 de noviembre de 2019 de: https:/www.proceso.com.mx/440995/rescatana-271-personas-cautivas-en-albergue-tonala

Rodríguez, I. (2002). “Sociología de la infancia? Aproximaciones a un campo de estudio difuso”. Revista El Observador, 21 
Rodríguez J, G. (2016). Situación de los niños, niñas y adolescentes privados de cuidados parentales en México. Entre Textos, 8(22), 2-14. Recuperado de: http://entretextos.leon.uia.mx/num/22/PDF/ENT22-8.pdf

Rozas Pagaza, M. (2000). Trabajo social y compromiso ético. Asistencia o resistencia. Buenos Aires: Espacio Editorial.

Ruíz, C. (2014). Vínculo establecido entre niñeras de Casa Cuna Coyoacán y las niñas y niños asistidos. (Tesis de Maestría). México: Instituto de Terapia Familiar Cencalli.

Ruíz, C. (2015). Familia comunal institucionalizada: deconstruyendo la institucionalización. ENTSUNAM, Revista de Trabajo Social 9: Familias.

Ruíz, C. (2019). Maltrato infantil. De la violencia doméstica a la violencia estructural. México: UNAM-ENTS.

Ruíz, C. (Coord). (2016). Diagnóstico Social de los Centros de Asistencia Social del Sistema Nacional para el Desarrollo Integral de la Familia. México: UNAM - ENTS (mimeo).

Ruíz, C. (Coord). (2017). La intervención del trabajador social en la atención de la infancia en condición institucionalizada. México: UNAM - ENTS (mimeo).

Ruíz, C. (Coord). (2018). La trata de la niñez en México: mercantilización del cuerpo. México: UNAM - ENTS (mimeo).

Ruíz, C. (Coord). (2019). El cuidado: estrategia desde el Trabajo Social para la atención de la niñez frente al fenómeno de Trata de personas. México: UNAM - ENTS (mimeo).

Salinas Araya, A. (2014). La semántica biopolítica. Foucault y sus recepciones. Chile: EIRL.

Sánchez, C. (1999). Los pueblos indígenas: del indigenismo a la autonomía. México: Siglo XXI.

Sandoval, R. (2018). "El caso Ciudad de los Niños en Guanajuato: Necropolítica y violencia de género". Seminario Subjetividades, ética, género y justicia realizado por el Instituto de Investigaciones Jurídicas de la Universidad Nacional Autónoma de México, México.

Sandoval, R. (2018). "El caso Ciudad de los Niños en Guanajuato: necropolítica y violencia de género". Seminario Subjetividades, ética, género y justicia: reflexiones transdisciplinarias. México: Universidad pedagógica Nacional.

Santiago Antonio, Z. (2012). Ilustración de "Los niños y jóvenes infractores de la ciudad de México, 1920-1937”. [Ilustración]. Recuperado de: https://normasapa.com/como-referenciarimagenes-figuras-segun-las-normas-apa/

Schumkler Scornik, B. \& Campos, M. (2009). Las políticas de familia en México y su relación con las transformaciones sociales. México: Instituto Mora. 
SDP Noticias (16 de febrero de 2017) [Fotografía]. Recuperado de SDP Noticias: https://www.sdpnoticias.com/local/edomex/denuncian-internos-maltrato-presuntovideo.html

Siegel, Daniel y Pine, Tina (2014). Disciplina sin lágrimas: una guía imprescindible para orientar y alimentar el desarrollo mental de tu hijo. Recuperado de: https://books.google.com.mx/books/about/Disciplina_sin_1\%C3\%A1grimas.html?id=SPc $\mathrm{nBgAAQBAJ} \&$ printsec $=$ frontcover\&source $=\mathrm{kp} \_$read_button\&redir_esc $=\mathrm{y} \# \mathrm{v}=$ onepage $\& \mathrm{q}$ $\& \mathrm{f}=$ false

Sin Embargo (7 de mayo de 2019) El Estado mexicano mantiene una deuda con los niños y niñas que viven en albergues: especialista. Recuperado de Sin Embargo: https://www.sinembargo.mx/07-05-2019/3577104 Consultado el día 2 de diciembre de 2019

SIPSE.COM (2014, 18 de julio). Mamá Rosa no merece esta humillación: intelectuales. Recuperado de: https://sipse.com/mexico/michoacan-intelectuales-defienden-labor-de-mama-rosa102655.html

Siqueira da Silva, J. (2016). "Neoconservadurismo y Trabajo Social, apuntes para el debate". Clases del Doctorado en Trabajo Social.

Sistema Nacional para el Desarrollo Integral de la Familia. Estatuto Orgánico. Recuperado de: http://sitios.dif.gob.mx/normateca/?page_id=168;

Sistema Nacional para el Desarrollo Integral de la Familia. Manual General de Organización.

Recuperado de: http://www.dif.gob.mx/diftransparencia/media/ManualGralOrgSNDIF09Ago2012.pdf

Sistema Nacional para el Desarrollo Integral de la Familia (2014). Dirección General de Integración Social: Manual de procedimientos. México. Recuperado de: http://sitios.dif.gob.mx/normateca/normateca-interna/direccion-general-de-integracionsocial/

Sistema Nacional para el Desarrollo Integral de la Familia (2014). Reglamento Interno de Centros Nacionales Modelos de Atención Investigación y Capacitación Casa Cuna Tlalpan, Casa Cuna Coyoacán, Casa Hogar para Niñas, Casa Hogar para Varones y Subdirección del Centro Amanecer para Niños. Recuperado de: http://sitios.dif.gob.mx/normateca/wpcontent/uploads/2018/12/ReglamentoInternoInternoC NMAICs.pdf

Sistema Nacional para el Desarrollo Integral de la Familia (2014). Manual de Procedimientos DGIS. Recuperado de: http://sitios.dif.gob.mx/normateca/wpcontent/uploads/2015/09/ManualProcedimientosDGIS_Sep15.pdf 
Sistema Nacional para el Desarrollo Integral de la Familia (2018). Modelo tipo de atención y protección integral de centros de Asistencia Social para Niñas, Niños y Adolescentes. México. Recuperado de: https:/www.gob.mx/cms/uploads/attachment/file/315273/Modelo_tipo_de_atenci_n_y_prot ecci_n_integral_de_centros_de_asistencia_social_para_ni_as_ni_os_y_adolescentes.pdf

Sistema Nacional para el Desarrollo Integral de la Familia (2019). Reporte al tercer trimestre 2019 de Atención Integral en Centros Asistenciales del Sistema Nacional DIF. Recuperado de: https://datos.gob.mx/busca/dataset/atencion-integral-en-centros-asistenciales-del-sistemanacional-dif/resource/3d3c7cce-1dcf-40bf-b978-ea624db419cf?inner_span=True

Sistema Nacional para el Desarrollo Integral de la Familia. Encuentro Nacional de Centros de Asistencia Social. 25 y 26 de abril de 2016.

SNDIF (Sistema Nacional para el Desarrollo Integral de la Familia). Micrositio 2014.

Stavchansky, L. \& Untoiglich, G. (Coord) (2019). Infancias entre nos-otros. Clínica, biopolítica, ética de lo infantil y lo contemporáneo. México: El diván negro.

Szulc, A. (2018). Más allá de la agencia y las culturas infantiles. Reflexiones a partir de una investigación etnográfica con niños y niñas mapuche. Recuperado de: http://revistascientificas.filo.uba.ar/index.php/runa/article/view/5360

Tello, Nelia (2016). Apuntes de Trabajo Social. Trabajo Social, disciplina del conocimiento, México, UNAM. Recuperado de: http://neliatello.com/docs/apuntes-sobre-intervencion-social_neliatello.pdf

Tello \& Ornelas (2015). Estrategias y modelos de intervención de Trabajo Social. Ciudad de México: Estudios de Opinión y Participación Social A.C.

Tello, N. (2014). Trabajo Social Contemporáneo: tres grandes problemas. Murcia, España: Universitas. Recuperado de: http://neliatello.com/docs/trabajo-social-contemporaneo-tresgrandes-problemas.pdf

Tello, Peón, N. (2015). Apuntes de Trabajo Social. Ciudad de México: ENTS, UNAM.

Time Out México (30 de marzo de 2017). Spas para niñas en la Ciudad de México. [Ilustración]. Recuperado de: https://www.timeoutmexico.mx/ciudad-de-mexico/ninyos/spas-para-ninyas

Tinajero, C. (2019). Seis relatos sobre las vidas infames. México. Recuperado de: https://2018.reflexionesmarginales.com/seis-relatos-sobre-las-vidasinfames/?fbclid=IwAR1xWBiGlcdmaNabIHsT221H90cd4wutkv_PhWMIRLG6jhp4nzbw3 R1mzDQ 
Torres, A. (2007, 05 de abril). El Universal: "Solicitan ayuda en Villa de las Niñas, en Chalco". Recuperado el 25 de noviembre de 2019 de: https://archivo.eluniversal.com.mx/notas/416779.html

UNICEF (2018). Situación de niñas, niños y adolescentes sin cuidados parentales en la República de Argentina. Recuperados de: https://www.unicef.org/argentina/media/4196/file

Untoiglich, G. (2014). Medicalización y patologización de la vida: situación de las infancias en Latinoamérica. Buenos Aires. Recuperado de: file://C:/Users/Proyecto\%20PAPIME\%203/Downloads/2743-8837-3-PB\%20(1).pdf

Vargas, D. (2015). Profecía autocumplida o los dos tiempos de la verdad. Buenos Aires. Recuperado de: $\quad$ file://CC:/Users/naata/Downloads/DialnetProfeciaAutocumplidaOLosDosTiemposDeLaVerdad-5643996.pdf

Velázquez, K. (2017, 16 de diciembre). Proceso: “Ciudad de los Niños ¿sin Dios ni ley?” Recuperado el 01 de agosto de 2019 de: https://www.proceso.com.mx/515147/ciudad-de-los-ninos-sindios-ni-ley

Velázquez, K. (2019). PopLab: "Niños y niñas en albergues, olvidados, el estado actúa solo cuando la violencia llega al límite. Persisten olvido y omisiones oficiales para resguardar derechos de menores en instituciones de Guanajuato". Recuperado de: https://poplab.mx/article/Niosyniasenalberguesolvidadoselestadoactuasolocuandolaviolenci allegaallimite

Vélez, R. (2005). "Las técnicas de actuación profesional del Trabajo Social”. Actuación profesional e instrumentalidad de la acción. Buenos Aires, Argentina: Espacio Editorial.

Vergara A, Peña M, Chávez P, Vergara E. (2015). Los niños como sujetos sociales: El aporte de los Nuevos Estudios Sociales de la infancia y el Análisis Crítico del Discurso. Recuperado de: file:///C:/Users/PNMC/Downloads/artculo.pdf

Vignale, S. P. (2014). Politicas de la subjetividad: subjetivación, actitud crítica y ontología del presente en Michel Foucault. (Tesis Doctoral). Argentina: Universidad Nacional de Lanús. Recuperado de: http://www.repositoriojmr.unla.edu.ar/descarga/TE/DFilo/035009_Vignale.pdf?fbclid=Iw AR0iuiNigMZq0F4oIrjHmkTac15sGOmfegpP7Gp5mYAMikdObr0N_bDwtw

Villa De Los Niños Oficial (27 de agosto de 2012) [Fotografía]. Recuperado de Villa De Los Niños Oficial: https://www.facebook.com/VilladelosNinosOficial/photos/a.279165652196491/279165655 $529824 /$ type $=3 \&$ theater 
Villela Iamamoto, M. (2005). La investigación en servicio social en el contexto latinoamericano: la experiencia brasileña. Recuperado de: http://catedraparalela.com.ar/revistasoficial/revista2/investigacion.pdf fecha de consulta 16 de junio de 2016, pp. 11

Zelmanovich, P. \& Minnicelli, M. (2012). Instituciones de infancia y prácticas profesionales: entre figuras de segregación y dispositivos de inscripción simbólica. Argentina: Flacso.

Recuperado de: https://www.redalyc.org/articulo.oa?id=403041708005

Zelmanovich, P. (2011). "Violencia y desamparo", en Cátedra Abierta 2. Ciclo de Conferencias. Aportes para pensar la violencia en las escuelas, Observatorio Argentino de violencia en las Escuelas, Ministerio de Educación de la Nación-UNSAM, 2011.

Zona Centro Noticias (17 de febrero de 2016) [Fotografía]. Recuperado de Zona Centro Noticias: https://www.zonacentronoticias.com/2016/02/niega-albergue-amor-para-compartirmaltrato-de-ninos/

Zoila, A. (2007). Los niños en la historia. Los enfoques historiográficos de la infancia. México: Universidad Autónoma Metropolitana. Recuperado de: https://www.aacademica.org/zoila.santiago/6.pdf 
ANEXOS

Anexo 1: Cédula de Observación

\author{
Universidad Nacional Autónoma de México \\ Escuela Nacional de Trabajo Social \\ Cédula de observación
}

Práctica de Especialización I - Trata de Personas y Maltrato Infantil

Objetivo:

Que las y los integrantes del grupo de práctica de especialización 2807 "Trata de personas y Maltrato Infantil”, se aproximen a los Centros Nacionales Modelos de Atención, con el fin de conocer su funcionamiento.

Nombre de quien realiza:

Fecha:

Nombre de la institución:

\title{
Dirección:
}

Director/a:

Horario de inicio:

Hora de término:

Capacidad con la que cuenta el CNMAIC:

Numero de niñas y niños dentro del CNMAIC:

Rango de edad de niñas y niños en CNMAIC:

Ingreso de niñas y niños al CNMAIC:

Áreas laborales con las que cuenta el CNMAIC:

Total de Recurso humano:

Infraestructura (describir con lo que cuenta el centro: edificios, dormitorios, comedores, baños, etc.):

Servicios con los cuales cuenta el centro (luz, agua, drenaje, etc.):

Medidas de seguridad y vías de acceso con las que cuenta el centro en caso de sismo, incendio, o algún tipo de desastre natural:

Comentarios y/o impresiones personales: 
Anexo 2: Cédula de Registro de eventos académicos relativos a la niñez en condición de institucionalización

Universidad Nacional Autónoma de México

Escuela Nacional de Trabajo Social

Cédula

Práctica de Especialización I - Trata de Personas y Maltrato Infantil

Alumna/o:

Evento:

Lugar y fecha:

Tema:

Horario:

Modalidad:

Descripción:

Observaciones:

Comentarios: 
Anexo 3 (GFAF). Taller Mis memorias

Instrumento: Álbum de vida

Categoría: Subjetivación

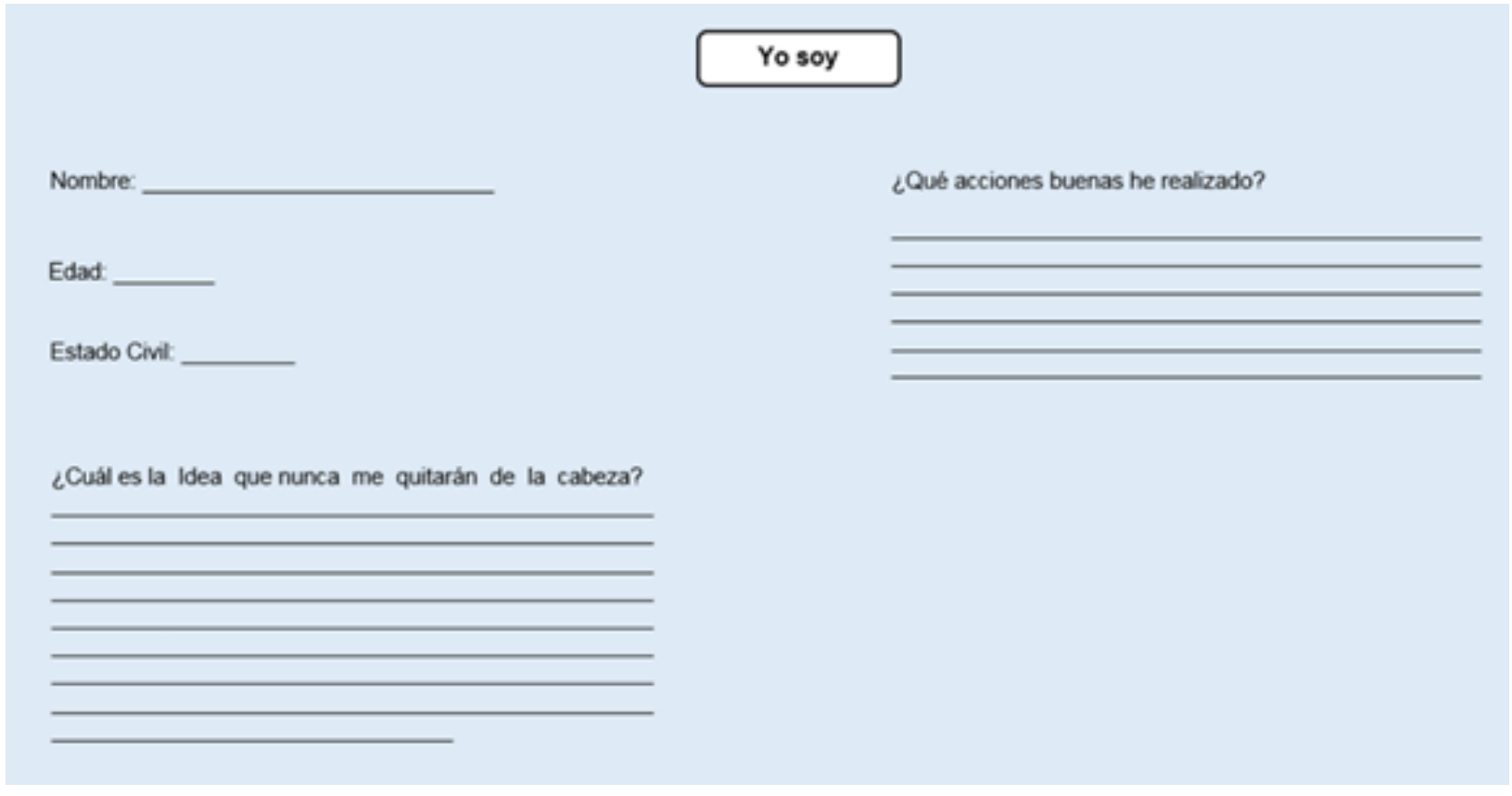

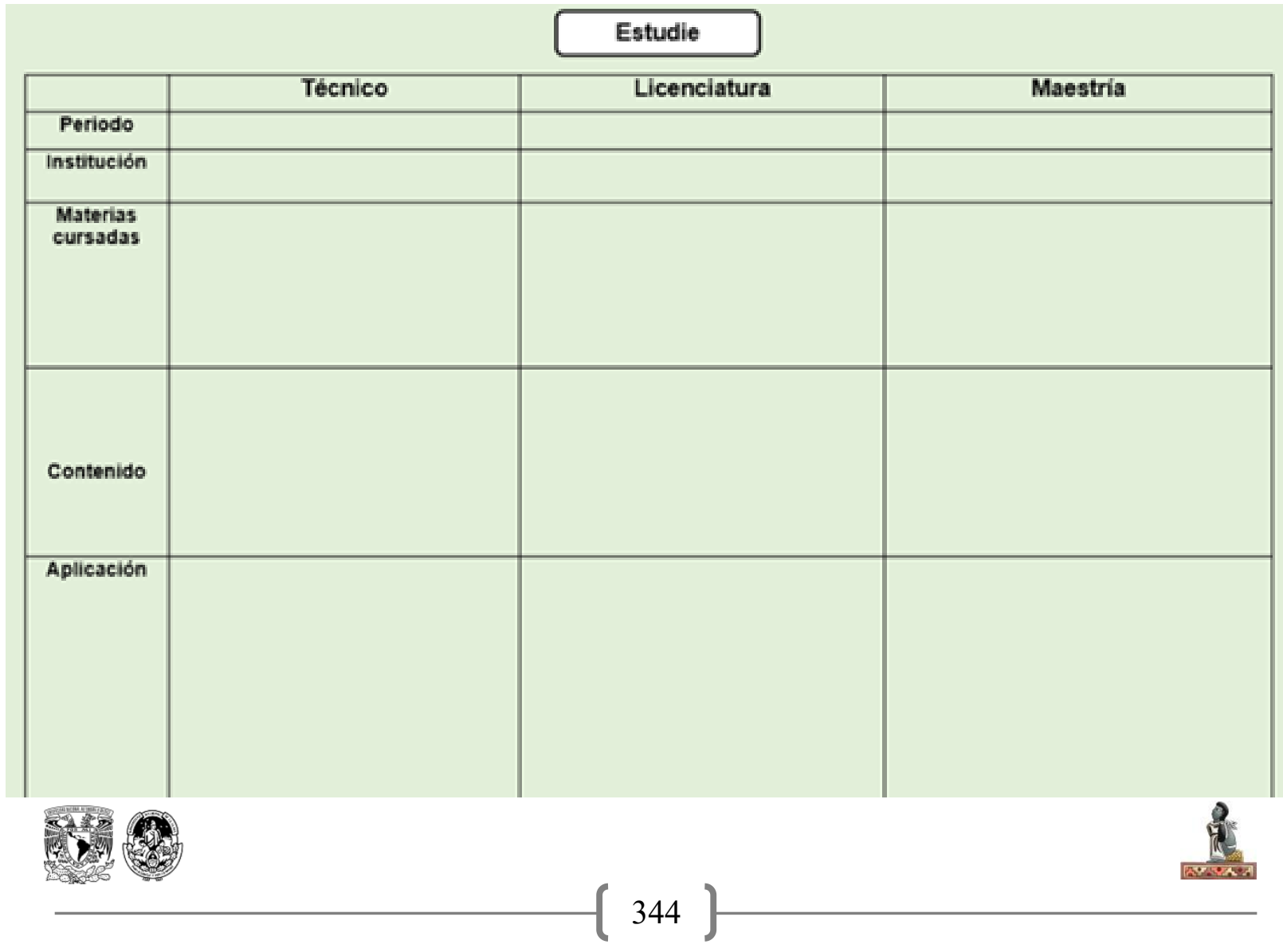




\begin{tabular}{|l|l|l|l|l|}
\hline \multicolumn{2}{c|}{ He trabajado en... } \\
\hline
\end{tabular}




\begin{tabular}{|c|c|c|c|}
\hline & & & \\
\hline Año & 2015 & 2016 & 2017 \\
\hline \multicolumn{4}{|l|}{ Contenido } \\
\hline \multicolumn{4}{|l|}{ Aplicación } \\
\hline & & & \\
\hline & & & \\
\hline & & & \\
\hline & & & \\
\hline & & & \\
\hline & & & \\
\hline
\end{tabular}


Actualmente en Dif hago..s

Viñeta narrativa.

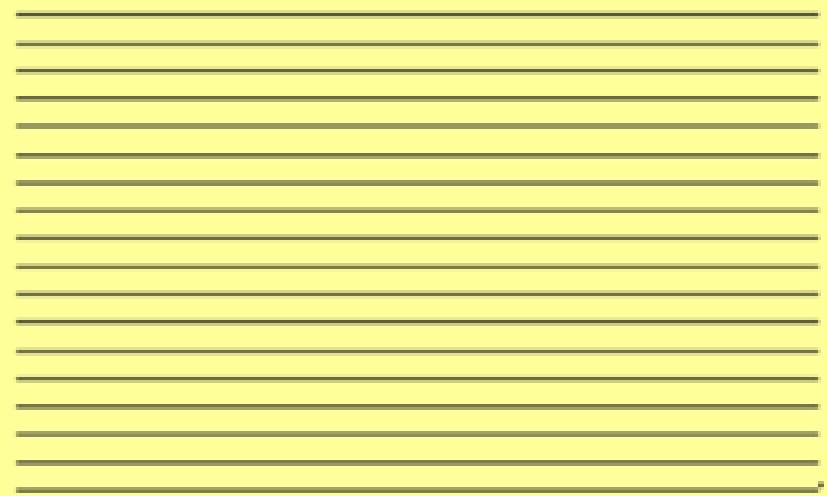

I
Intervención

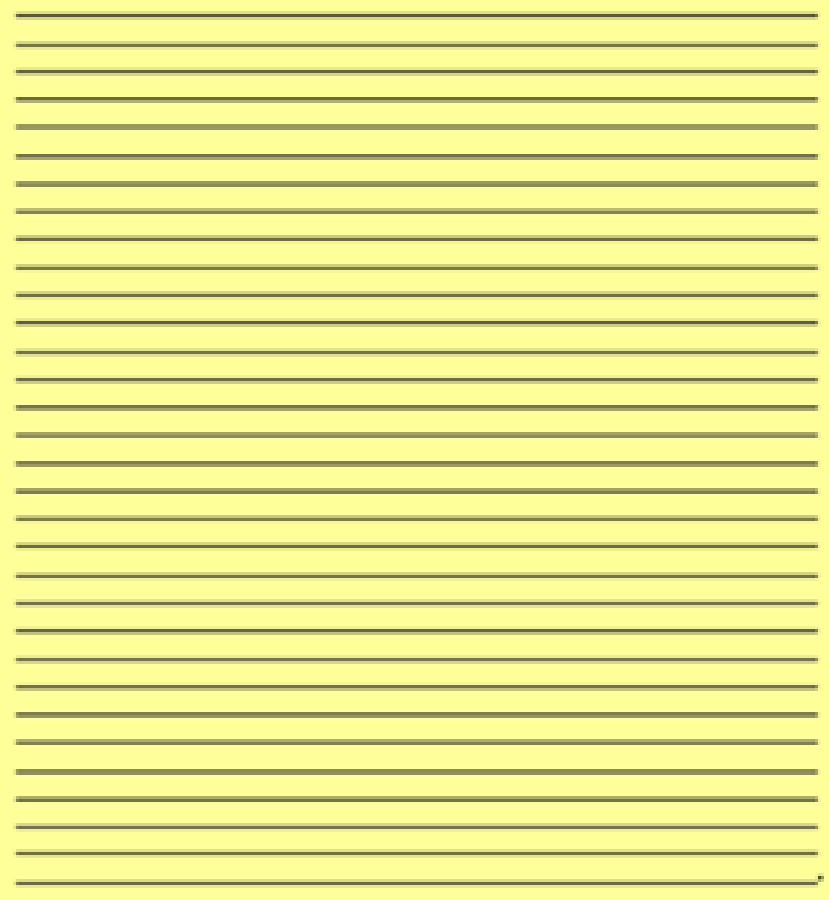


Anexo 4 (GFGC). Taller Enlazando mis saberes Instrumento: Guía de conectores Categoría: Episteme

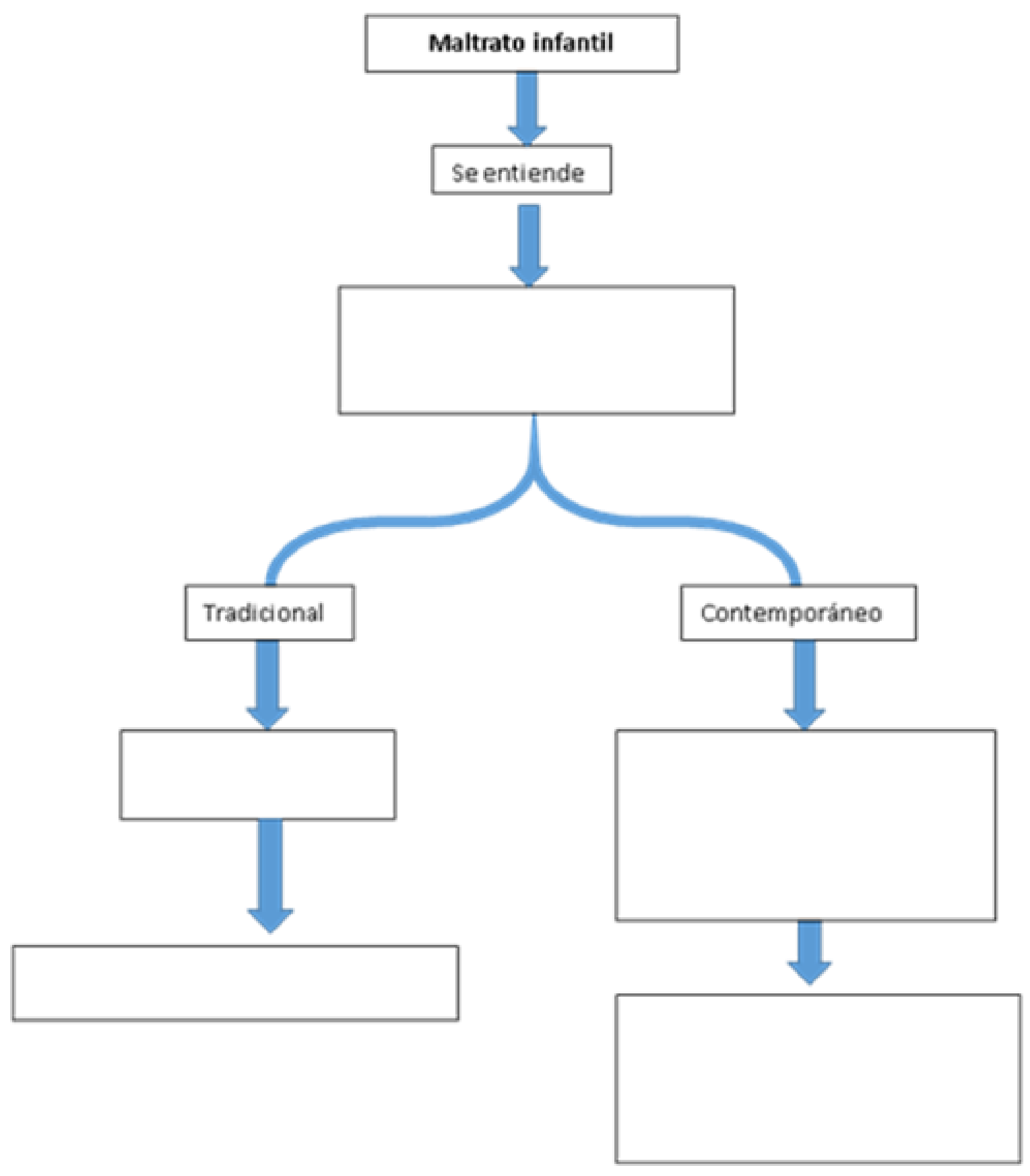




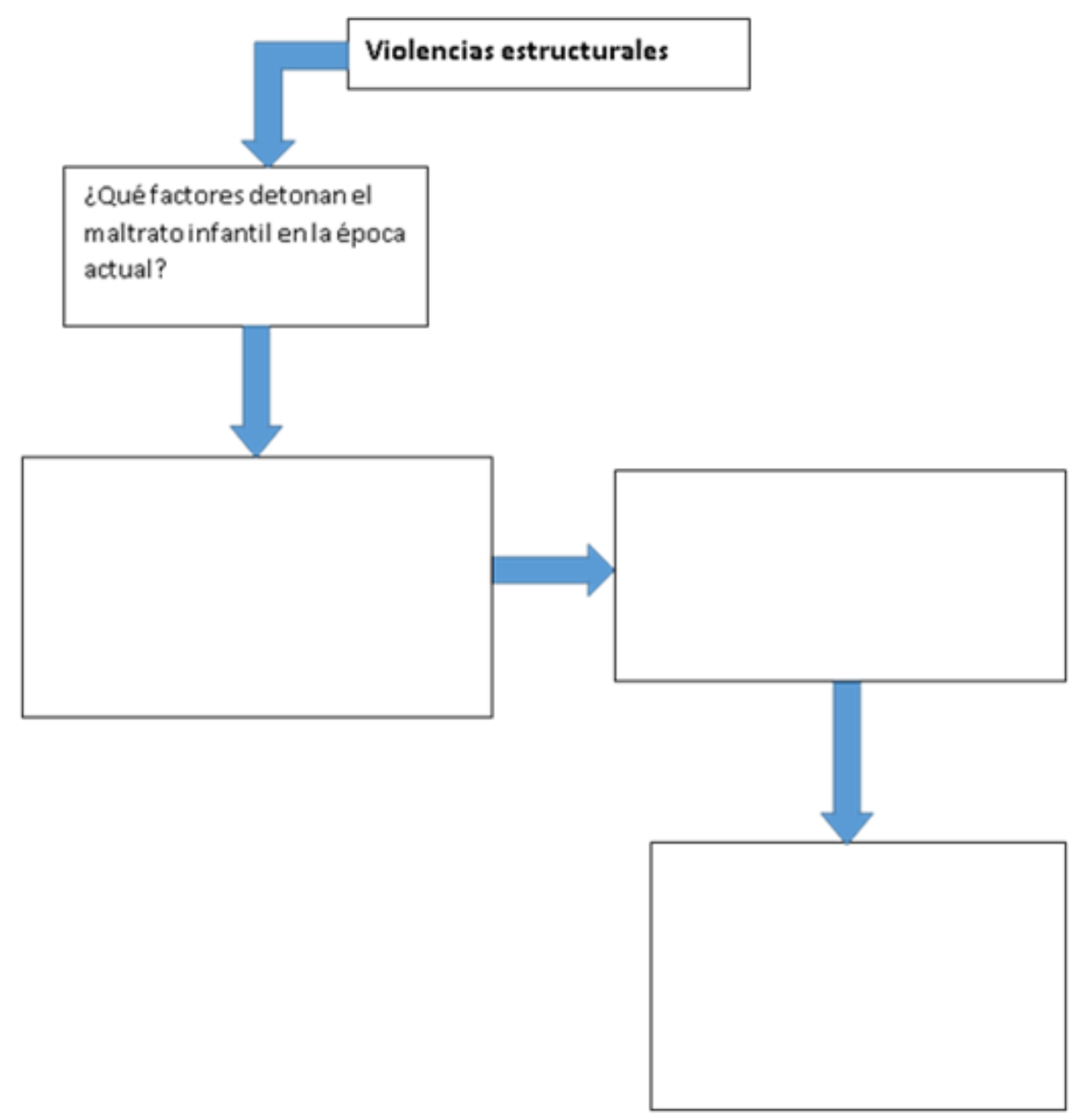




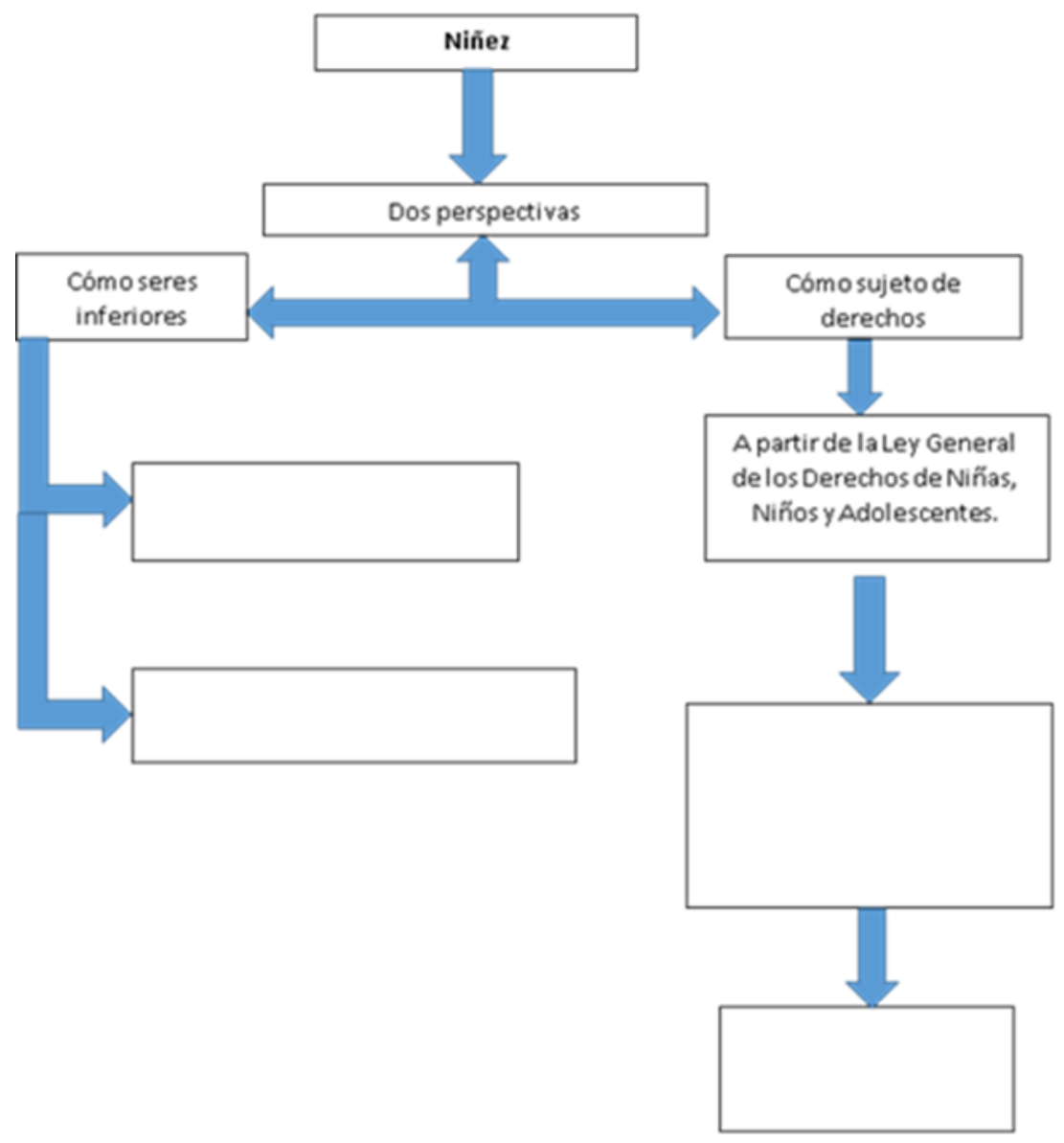




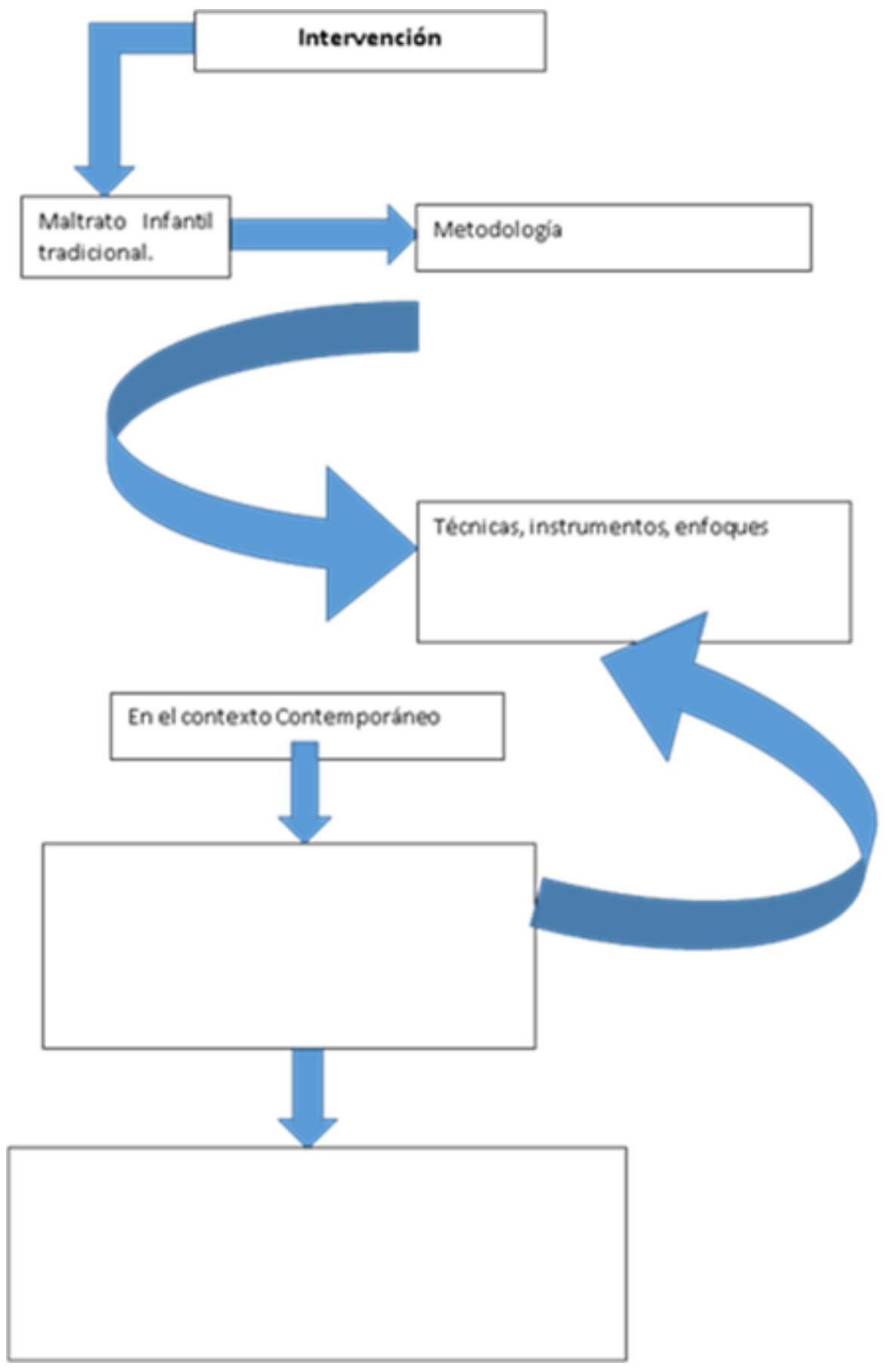




\section{Anexo 5 (GFLT). Taller DIF a través del tiempo}

\section{Instrumento: Línea del Tiempo \\ Categoría: Institución}

\begin{tabular}{|c|c|c|c|c|c|}
\hline Atención en 2005 & $\begin{array}{c}\text { Cambio de Modelo } \\
2006\end{array}$ & $\begin{array}{c}\text { Atención a los solicitantes } \\
\text { de Adopción } \\
2012\end{array}$ & $\begin{array}{l}\text { Ley General De Los } \\
\text { Derechos De Niñas, } \\
\text { Niños y Adolescentes. } \\
2014\end{array}$ & $\begin{array}{c}\text { Procuraduría } \\
2016\end{array}$ & $\begin{array}{l}\text { Perfil de atención de la } \\
\text { población actual } 2017\end{array}$ \\
\hline $\begin{array}{l}\text { Durante este } \\
\text { periodo, ¿Cómo } \\
\text { describirías la } \\
\text { intervención social? } \\
\text { ¿Cuáles eran las } \\
\text { principales } \\
\text { problemáticas } \\
\text { atendidas? } \\
\text { ¿Qué retos se te } \\
\text { presentaban en la } \\
\text { intervención social? } \\
\text { ¿Qué desafíos } \\
\text { representó para ti a } \\
\text { nivel profesional? }\end{array}$ & $\begin{array}{l}\text { Durante este cambio } \\
\text { de modelo, ¿te } \\
\text { informaron en qué } \\
\text { consistía? } \\
\text { ¿Qué pensamientos } \\
\text { e inquietudes } \\
\text { surgieron en ti en } \\
\text { ese momento? } \\
\text { Puedo imaginar que } \\
\text { la intervención } \\
\text { también se vio } \\
\text { afectada, ¿de qué } \\
\text { manera el cambio } \\
\text { de modelo influenció } \\
\text { en ella? } \\
\text { ¿Qué desafíos } \\
\text { representó para ti a } \\
\text { nivel profesional? }\end{array}$ & $\begin{array}{c}\text { Sabemos que antes de } \\
\text { aplicar estos nuevos } \\
\text { cambios el depto. de } \\
\text { trabajo social era el } \\
\text { encargado de llevar el } \\
\text { proceso de adopción, } \\
\text { ¿cómo vivías la } \\
\text { intervención y el con tacto } \\
\text { con los solicitantes? } \\
\text { ¿De qué manera te } \\
\text { afecto, personal y } \\
\text { profesionalmente, el } \\
\text { saberte ajeno a este } \\
\text { proceso? } \\
\text { ¿Consideras que hubo } \\
\text { cambios significativos en } \\
\text { el proceso de adopción?, } \\
\text { ¿Cuáles? } \\
\text { ¿Qué desafíos } \\
\text { representó para ti a este } \\
\text { proceso? }\end{array}$ & $\begin{array}{l}\text { Es probable que durante } \\
\text { el ejercicio de tu } \\
\text { quehacer profesional } \\
\text { hayas tenido que } \\
\text { recurrir a ciertos } \\
\text { documentos jurídicos, } \\
\text { ¿podrías mencionar } \\
\text { algunos? } \\
\text { ¿De qué manera la } \\
\text { aparición de la ley } \\
\text { LGDNNA nutre tu actuar } \\
\text { profesional? } \\
\text { ¿Qué desafíos } \\
\text { representa para ti esta } \\
\text { Ley? }\end{array}$ & $\begin{array}{l}\text { ¿Conoces cuál es el } \\
\text { fundamento jurídico de la } \\
\text { procuraduría? } \\
\text { Podemos entender que la } \\
\text { creación de la procuraduría } \\
\text { ha modificado, de alguna } \\
\text { manera, tus funciones y } \\
\text { actividades, ¿Qué retos } \\
\text { representa para ti esta } \\
\text { situación? } \\
\text { Entiendo la responsabilidad } \\
\text { que implica trabajar con la } \\
\text { infancia, ¿Cómo podrías } \\
\text { contribuir con ellos en } \\
\text { beneficio de la infancia? }\end{array}$ & $\begin{array}{l}\text { Teniendo un panorama } \\
\text { general de la situación } \\
\text { actual del país, ¿de qué } \\
\text { manera crees que esto ha } \\
\text { afectado a la infancia? } \\
\text { Reconociendo que } \\
\text { du rante tu experiencia } \\
\text { profesional has } \\
\text { con tribuido en el } \\
\text { mejoramiento de las niñas } \\
\text { y niños y sus familias, } \\
\text { ¿qué retos encuentras en } \\
\text { la intervención frente a las } \\
\text { problemáticas atendidas? } \\
\text { ¿Cuáles consideras que } \\
\text { serían tus principales } \\
\text { desafíos a nivel personal } \\
\text { y profesional? }\end{array}$ \\
\hline
\end{tabular}


Anexo 6: Formato de diario de campo

DIARIO DE CAMPO

FECHA:

HORA DE INCIO:

HORA DE TÉRMINO:

LUGAR:

OBJETIVO

ORDEN DEL DÍA

DESCRIPCIÓN

OBSERVACIONES

COMENTARIOS 
Anexo 7: Tablas de procesamiento.

Tabla de procesamiento 1. Categoría: Subjetivación y subcategorías: Filantropía, Empatía, Apego y Agencia

\begin{tabular}{|c|c|c|c|c|}
\hline Subcategoría & Viñeta narrativa & Técnica & Instrumento & Informante \\
\hline \multirow{5}{*}{ 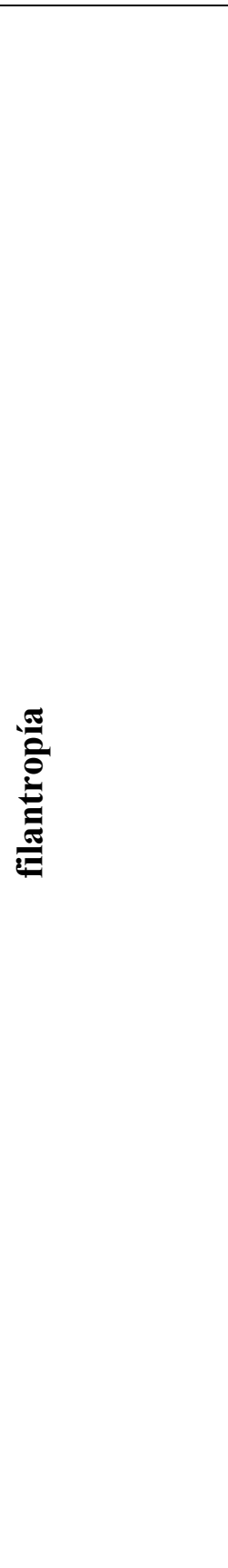 } & $\begin{array}{l}\text { Debo ser una buena } \\
\text { persona en todos los } \\
\text { sentidos, por eso me gusta } \\
\text { ser trabajadora social. }\end{array}$ & Trayectoria & $\begin{array}{l}\text { Álbum } \\
\text { fotográfico }\end{array}$ & TS 6 (GF) \\
\hline & $\begin{array}{l}\text { Ser trabajadora social es } \\
\text { apoyar en catástrofes, } \\
\text { donaciones a instituciones, } \\
\text { ayudar a mis vecinos de la } \\
\text { tercera edad. }\end{array}$ & Trayectoria & $\begin{array}{l}\text { Álbum } \\
\text { fotográfico }\end{array}$ & TS 3 (GF) \\
\hline & $\begin{array}{l}\text { Entender, apoyar e } \\
\text { impulsar al otro sin esperar } \\
\text { nada a cambio. Promover } \\
\text { el cambio, desarrollo social } \\
\text { y la liberación de las } \\
\text { personas. }\end{array}$ & Trayectoria & $\begin{array}{l}\text { Álbum } \\
\text { fotográfico }\end{array}$ & TS 1 (GF) \\
\hline & $\begin{array}{l}\text { Es la mejor forma de } \\
\text { ayudar a las personas a } \\
\text { entender que merecen una } \\
\text { mejor calidad de vida. }\end{array}$ & Trayectoria & $\begin{array}{l}\text { Álbum } \\
\text { fotográfico }\end{array}$ & TS 2 (GF) \\
\hline & $\begin{array}{l}\text { Las personas que trabajan } \\
\text { en las Casas Hogar son } \\
\text { muy filantrópicas, yo las } \\
\text { veo, tienen sueldos de } 4000 \\
\text { pesos y muchas veces, }\end{array}$ & $\begin{array}{l}\text { Encuentro } \\
\text { Nacional de } \\
\text { Procuradoras } \\
\text { y }\end{array}$ & $\begin{array}{l}\text { Diario de } \\
\text { campo }\end{array}$ & Procuradora \\
\hline
\end{tabular}




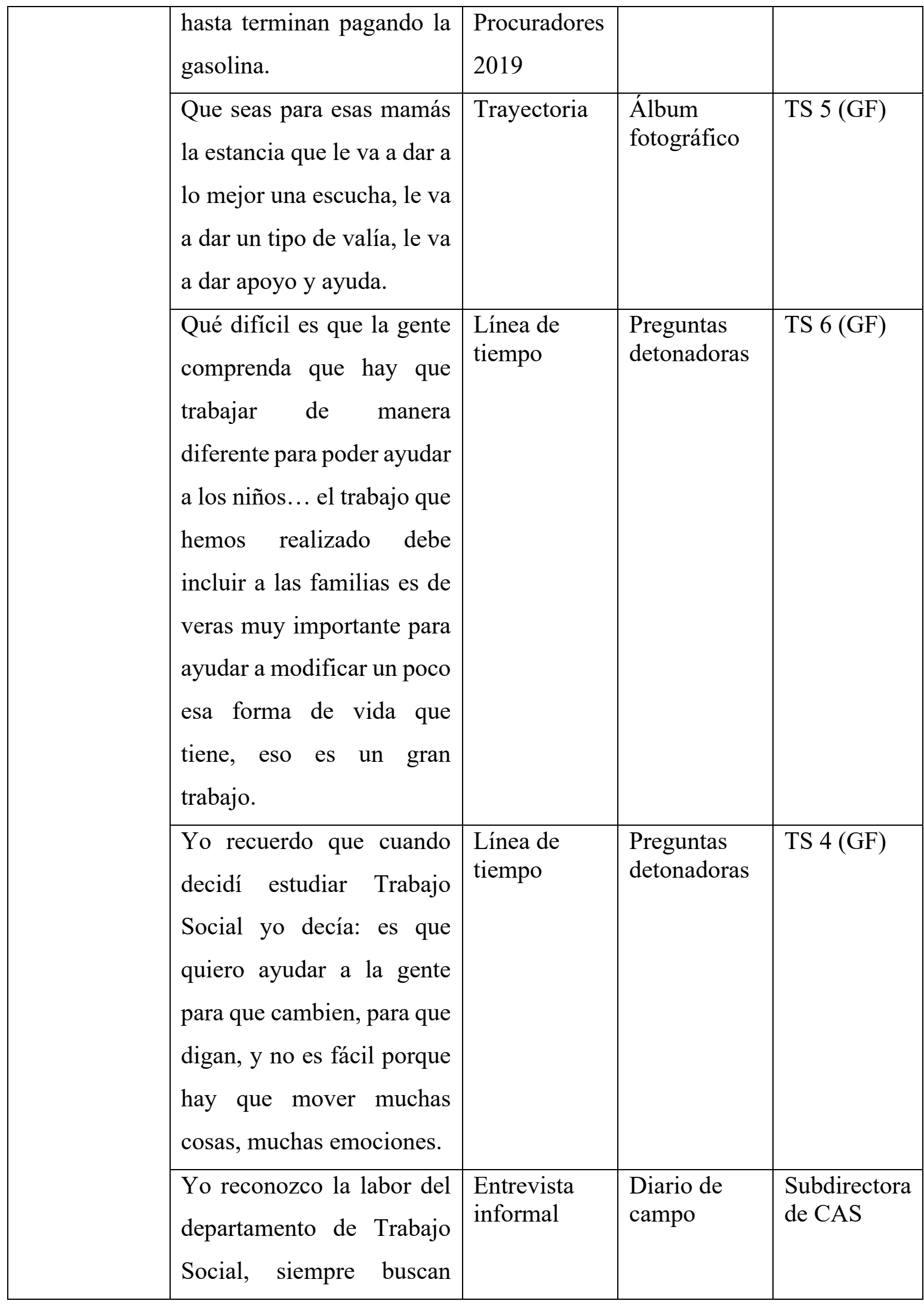




\begin{tabular}{|c|c|c|c|c|}
\hline & $\begin{array}{l}\text { como ayudar a la gente y } \\
\text { eso las personas lo } \\
\text { agradecen. }\end{array}$ & & & \\
\hline & $\begin{array}{l}\text { Yo traigo cosas a los niños } \\
\text { pobrecitos y vine con mi } \\
\text { hijo para que se las dé y se } \\
\text { dé cuenta de lo afortunado } \\
\text { que es él, porque lo tiene } \\
\text { todo. }\end{array}$ & $\begin{array}{l}\text { Entrevista } \\
\text { informal }\end{array}$ & $\begin{array}{l}\text { Diario de } \\
\text { campo }\end{array}$ & $\begin{array}{l}\text { Donante } \\
\text { CAS }\end{array}$ \\
\hline \multirow{3}{*}{ 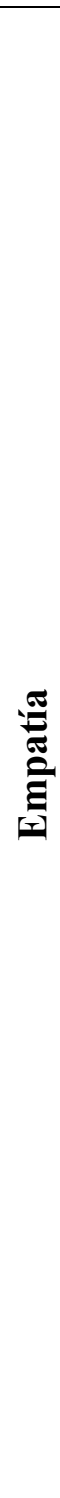 } & $\begin{array}{l}\text { Yo siempre he vivido cerca } \\
\text { de Casa Cuna, y me } \\
\text { acuerdo de que desde que } \\
\text { era chiquita, me gustaba } \\
\text { mucho y pensaba ¿qué } \\
\text { habrá ahí adentro? En esa } \\
\text { época yo no sabía que era } \\
\text { adoptada y que salí de esta } \\
\text { casa. }\end{array}$ & Trayectoria & $\begin{array}{l}\text { Álbum } \\
\text { fotográfico }\end{array}$ & TS 3 (GF) \\
\hline & $\begin{array}{l}\text { En mí propia historia yo } \\
\text { viví mucho maltrato, mi } \\
\text { mamá nos llevaba al río } \\
\text { cuando nos portábamos } \\
\text { mal y ahí, con el agua } \\
\text { helada nos bañaba como } \\
\text { una forma de castigo. }\end{array}$ & $\begin{array}{l}\text { Entrevista } \\
\text { informal }\end{array}$ & $\begin{array}{l}\text { Diario de } \\
\text { campo }\end{array}$ & TS \\
\hline & $\begin{array}{l}\text { Primero en la vida personal } \\
\text { la reflexión sobre mi } \\
\text { propia infancia y las } \\
\text { consecuencias y fortalezas } \\
\text { con las que cuento, después }\end{array}$ & Trayectoria & $\begin{array}{l}\text { Álbum } \\
\text { fotográfico }\end{array}$ & TS 1 (GF) \\
\hline
\end{tabular}




\begin{tabular}{|c|c|c|c|}
\hline $\begin{array}{l}\text { como madre de tres hijos } \\
\text { finalmente en mi quehacer } \\
\text { profesional para ser más } \\
\text { humana. }\end{array}$ & & & \\
\hline $\begin{array}{l}\text { Siento bonito porque yo } \\
\text { creo que no soy } \\
\text { obviamente la misma que } \\
\text { entró por la puerta de DIF } \\
\text { hace } 25 \text { años, con mucho } \\
\text { temor, mucho miedo, con } \\
\text { falta de mucho } \\
\text { conocimiento, y aquí lo he } \\
\text { aprendido; así también los } \\
\text { niños, tienen miedo. }\end{array}$ & $\begin{array}{l}\text { Entrevista } \\
\text { informal }\end{array}$ & $\begin{array}{l}\text { Diario de } \\
\text { campo }\end{array}$ & TS \\
\hline $\begin{array}{l}\text { De repente yo generalizo a } \\
\text { partir de la propia } \\
\text { experiencia en donde viví } \\
\text { violencia, son niños que } \\
\text { vienen de situaciones de } \\
\text { violencia y entonces } \\
\text { pareciera que todos vienen } \\
\text { en el mismo paquete. }\end{array}$ & $\begin{array}{l}\text { Entrevista } \\
\text { informal }\end{array}$ & $\begin{array}{l}\text { Diario de } \\
\text { campo }\end{array}$ & TS \\
\hline $\begin{array}{l}\text { Para abordar los casos yo } \\
\text { nunca pienso en cómo me } \\
\text { fue a mí, aquí los niños } \\
\text { tienen por lo menos que } \\
\text { comer, yo no. }\end{array}$ & Trayectoria & $\begin{array}{l}\text { Álbum } \\
\text { fotográfico }\end{array}$ & TS 5 (GF) \\
\hline $\begin{array}{l}\text { Ser siempre "yo" y } \\
\text { aprender de cada tropiezo } \\
\text { para mejorar mis acciones, }\end{array}$ & Trayectoria & $\begin{array}{l}\text { Álbum } \\
\text { fotográfico }\end{array}$ & TS 2 (GF) \\
\hline
\end{tabular}




\begin{tabular}{|c|c|c|c|}
\hline $\begin{array}{l}\text { así como ellos con sus } \\
\text { familias, me ayuda a } \\
\text { comprender a los niños y } \\
\text { su familia, } \\
\text { comprenderme a } \\
\text { misma. }\end{array}$ & & & \\
\hline $\begin{array}{l}\text { Tenemos que conocer el } \\
\text { contexto de la mamá, si no } \\
\text { tiene ella quien le ayude, } \\
\text { entonces no tiene mayor } \\
\text { capacidad } \\
\text { entendimiento, para ella } \\
\text { amarrar a este niño a la } \\
\text { cama es dejarlo seguro. }\end{array}$ & $\begin{array}{l}\text { Línea de } \\
\text { tiempo }\end{array}$ & $\begin{array}{l}\text { Preguntas } \\
\text { detonadoras }\end{array}$ & TS 6 (GF) \\
\hline $\begin{array}{l}\text { Yo siempre he dicho que la } \\
\text { llegada de los niños aquí } \\
\text { tiene dos caras; la fea } \\
\text { (cuando ingresan) y la } \\
\text { reintegración de un niño a } \\
\text { una familia adoptiva. Me } \\
\text { imagino siempre como se } \\
\text { sienten. }\end{array}$ & $\begin{array}{l}\text { Línea de } \\
\text { tiempo }\end{array}$ & $\begin{array}{l}\text { Preguntas } \\
\text { detonadoras }\end{array}$ & TS 1 (GF) \\
\hline $\begin{array}{l}\text { Se juegan muchos } \\
\text { sentimientos, cuando yo } \\
\text { llegué aquí lloraba al ver } \\
\text { los expedientes y ver todo } \\
\text { lo que viven los niños, } \\
\text { después llenarte de } \\
\text { felicidad al ver a ese niño }\end{array}$ & $\begin{array}{l}\text { Línea de } \\
\text { tiempo }\end{array}$ & $\begin{array}{l}\text { Preguntas } \\
\text { detonadoras }\end{array}$ & TS 4 (GF) \\
\hline
\end{tabular}




\begin{tabular}{|c|c|c|c|c|}
\hline & $\begin{array}{l}\text { que se va con una familia } \\
\text { adoptiva. }\end{array}$ & & & \\
\hline & $\begin{array}{l}\text { Deberíamos estar } \\
\text { preparadas } \\
\text { emocionalmente porque es } \\
\text { muy difícil tener los } \\
\text { elementos teóricos y la } \\
\text { experiencia para atender a } \\
\text { este tipo de población para } \\
\text { ser muy empáticos... falta } \\
\text { afectividad, falta amor. }\end{array}$ & $\begin{array}{l}\text { Línea de } \\
\text { tiempo }\end{array}$ & $\begin{array}{l}\text { Preguntas } \\
\text { detonadoras }\end{array}$ & TS 4 (GF) \\
\hline & $\begin{array}{l}\text { Cuando yo veo a Arturo no } \\
\text { sé qué me da, lo veo y } \\
\text { pienso, pero si es como mi } \\
\text { marido, seguro por eso nos } \\
\text { peleamos tanto. }\end{array}$ & $\begin{array}{l}\text { Entrevista } \\
\text { informal }\end{array}$ & $\begin{array}{l}\text { Diario de } \\
\text { campo }\end{array}$ & $\mathrm{TS}$ \\
\hline \multirow[t]{2}{*}{ 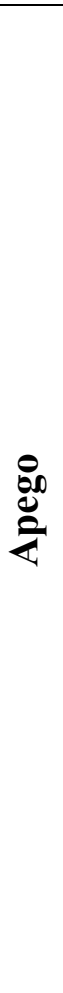 } & $\begin{array}{l}\text { Vivir de una forma más } \\
\text { humana, disfrutando el día } \\
\text { con lo que venga, sin tratar } \\
\text { de complicarme por lo } \\
\text { pasado o el futuro. De dos } \\
\text { años a la fecha he } \\
\text { aprendido más sobre } \\
\text { desapego y sólo buscar lo } \\
\text { indispensable en la vida. }\end{array}$ & Trayectoria & $\begin{array}{l}\text { Álbum } \\
\text { fotográfico }\end{array}$ & TS 3 (GF) \\
\hline & $\begin{array}{l}\text { Por eso yo digo, no } \\
\text { debemos vincularnos con } \\
\text { los niños, yo desde chiquita } \\
\text { fui muy despegada de mi } \\
\text { mamá, así que ahora yo no }\end{array}$ & Trayectoria & $\begin{array}{l}\text { Álbum } \\
\text { fotográfico }\end{array}$ & TS 4 (GF) \\
\hline
\end{tabular}




\begin{tabular}{|c|c|c|c|}
\hline $\begin{array}{l}\text { me involucro, además así } \\
\text { ellos no sufren con tantos } \\
\text { cambios. }\end{array}$ & & & \\
\hline $\begin{array}{l}\text { Si, estos cambios no } \\
\text { dependen de mí... no me } \\
\text { causa problema... no creo } \\
\text { apegos... los niños se } \\
\text { adaptan a los cambios... es } \\
\text { parte de su vida cotidiana. }\end{array}$ & $\begin{array}{l}\text { Línea de } \\
\text { tiempo }\end{array}$ & $\begin{array}{l}\text { Preguntas } \\
\text { detonadoras }\end{array}$ & TS 3 (GF) \\
\hline $\begin{array}{l}\text { Los cambios así se dan } \\
\text { aquí, pero yo no creo } \\
\text { muchos apegos, a mí el } \\
\text { cambio no me genera } \\
\text { conflicto, yo lo pensaba } \\
\text { por los niños, digo, que } \\
\text { duro lo viven, pero en } \\
\text { realidad si tú lo vives con } \\
\text { esa naturalidad el niño } \\
\text { también lo vivirá de esta } \\
\text { manera, y tienen que } \\
\text { adaptarse porque las cosas } \\
\text { así son, nosotros estamos } \\
\text { acá para acatar órdenes. }\end{array}$ & $\begin{array}{l}\text { Línea de } \\
\text { tiempo }\end{array}$ & $\begin{array}{l}\text { Preguntas } \\
\text { detonadoras }\end{array}$ & TS 4 (GF) \\
\hline $\begin{array}{l}\text { No sé si era generalizado, } \\
\text { pero yo no sabía, para mí } \\
\text { fue muy fuerte el ver partir } \\
\text { a los niños verlos subirse a } \\
\text { las camionetas, porque } \\
\text { aquí tu aprendes a a }\end{array}$ & $\begin{array}{l}\text { Línea de } \\
\text { tiempo }\end{array}$ & $\begin{array}{l}\text { Preguntas } \\
\text { detonadoras }\end{array}$ & TS 3 (GF) \\
\hline
\end{tabular}




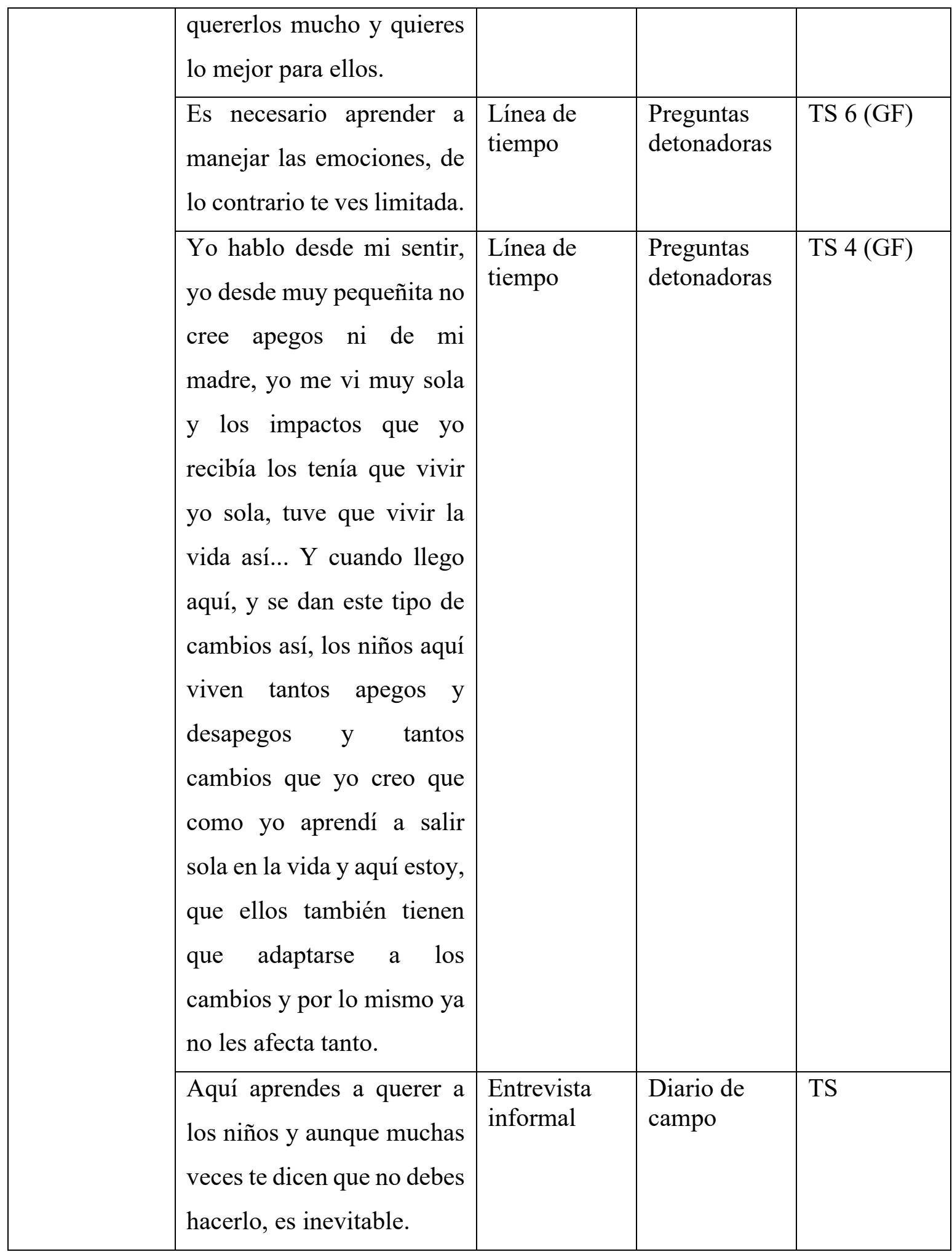




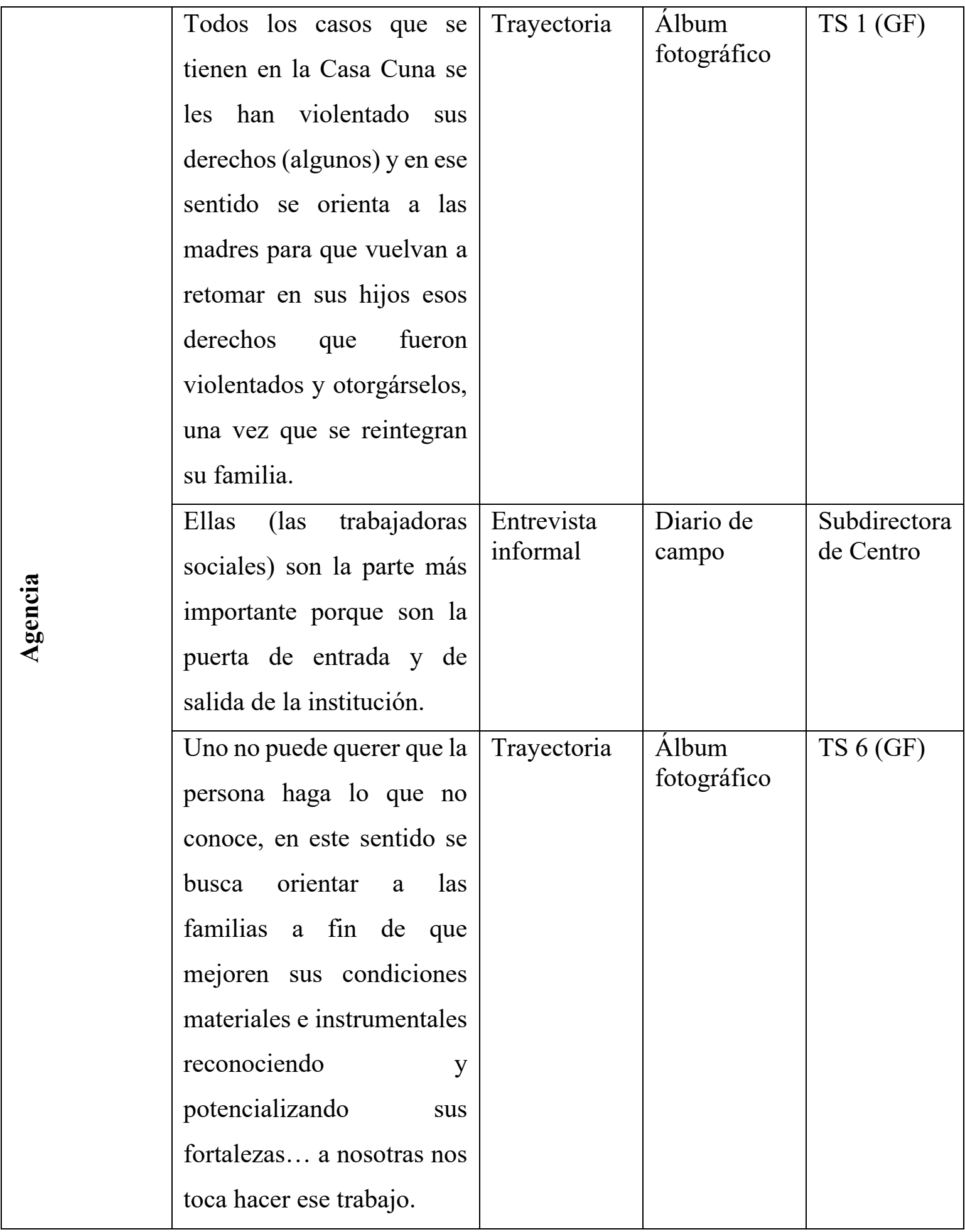




\begin{tabular}{|c|c|c|c|}
\hline $\begin{array}{l}\text { Es el lugar donde más } \\
\text { reconocimiento tiene el } \\
\text { trabajo social... ahí en las } \\
\text { juntas interdisciplinarias, } \\
\text { cuando llegué aquí y } \\
\text { participaba de las juntas } \\
\text { me di cuenta lo importante } \\
\text { que éramos, fue una etapa } \\
\text { muy bonita porque te das } \\
\text { cuenta que tú importas, tu } \\
\text { decisión. }\end{array}$ & $\begin{array}{l}\text { Línea de } \\
\text { tiempo }\end{array}$ & $\begin{array}{l}\text { Preguntas } \\
\text { detonadoras }\end{array}$ & TS 3 (GF) \\
\hline $\begin{array}{l}\text { Trabajo Social es la } \\
\text { disciplina más importante, } \\
\text { no hay otra; cuando se } \\
\text { trabaja en la Asistencia } \\
\text { Social, nosotras somos el } \\
\text { pilar. }\end{array}$ & $\begin{array}{l}\text { Entrevista } \\
\text { informal }\end{array}$ & $\begin{array}{l}\text { Diario de } \\
\text { campo }\end{array}$ & $\mathrm{TS}$ \\
\hline $\begin{array}{l}\text { Cuando "procu" nos } \\
\text { solicitaba a los niños, para } \\
\text { nosotros era frustrante el } \\
\text { saber que esos niños } \\
\text { podían regresar con sus } \\
\text { agresores; no podíamos } \\
\text { emitir ningún informe ni } \\
\text { opinar nada, ya no nos } \\
\text { preguntan. }\end{array}$ & $\begin{array}{l}\text { Línea de } \\
\text { tiempo }\end{array}$ & $\begin{array}{l}\text { Preguntas } \\
\text { detonadoras }\end{array}$ & TS 1 (GF) \\
\hline
\end{tabular}




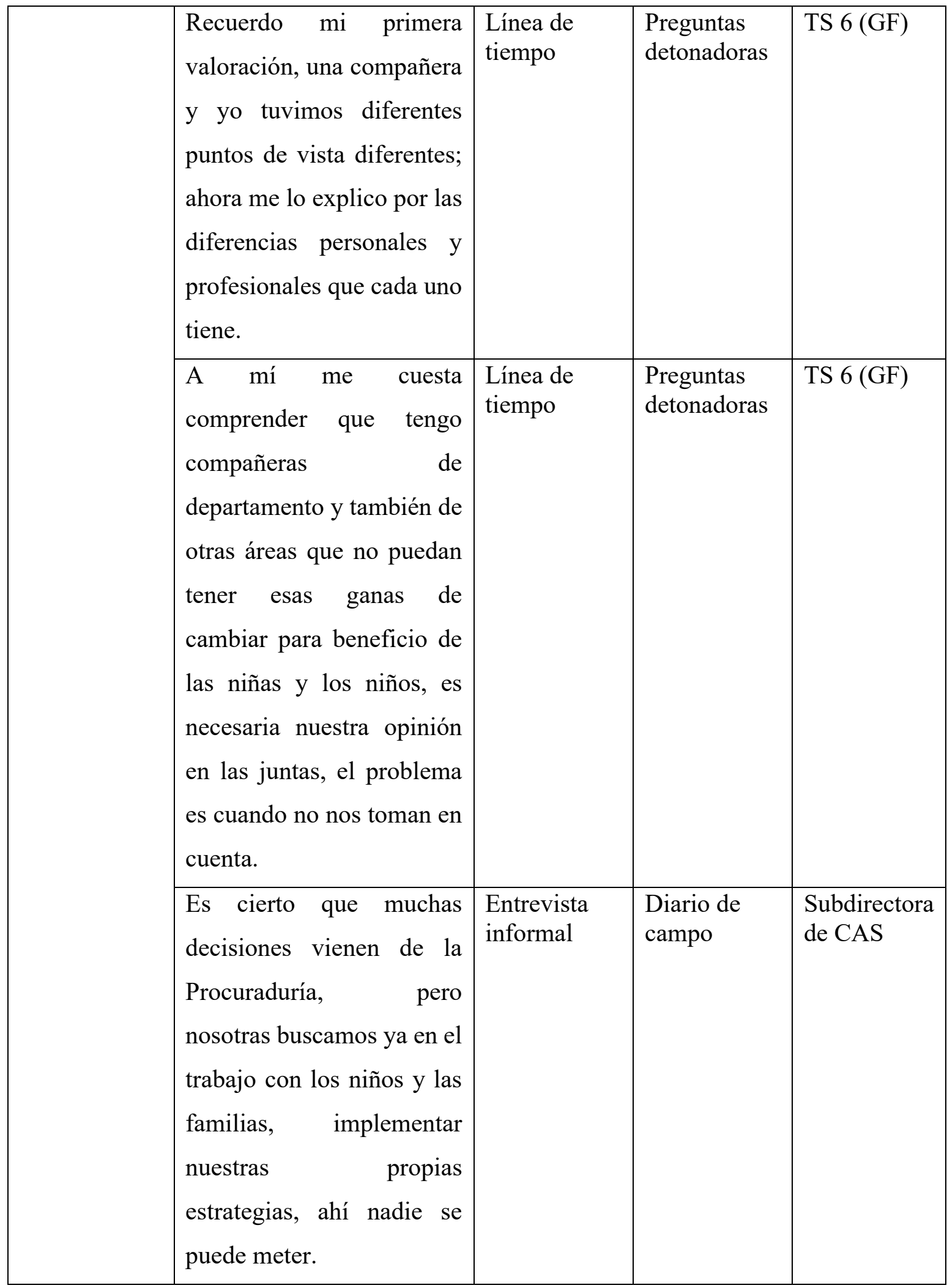




\begin{tabular}{|c|c|c|c|}
\hline $\begin{array}{l}\text { Antes nosotras } \\
\text { valorábamos a los } \\
\text { solicitantes de adopción, } \\
\text { hoy ya no lo hacemos, pero } \\
\text { con actividades como } \\
\text { Escuela para padres, } \\
\text { vamos orientando hacia } \\
\text { donde creemos que es lo } \\
\text { mejor para el niño y la } \\
\text { familia. }\end{array}$ & $\begin{array}{l}\text { Entrevista } \\
\text { informal }\end{array}$ & $\begin{array}{l}\text { Diario de } \\
\text { campo }\end{array}$ & $\begin{array}{l}\text { Subdirectora } \\
\text { de CAS }\end{array}$ \\
\hline $\begin{array}{l}\text { Trabajo Social es el que } \\
\text { ayuda, es el bueno y el que } \\
\text { escucha. }\end{array}$ & $\begin{array}{l}\text { Entrevista } \\
\text { informal }\end{array}$ & $\begin{array}{l}\text { Diario de } \\
\text { campo }\end{array}$ & $\begin{array}{l}\text { Subdirectora } \\
\text { de CAS }\end{array}$ \\
\hline $\begin{array}{l}\text { La llegada de la } \\
\text { Procuraduría nos quitó } \\
\text { presencia, ahora nos miran } \\
\text { como simples operarias. }\end{array}$ & $\begin{array}{l}\text { Entrevista } \\
\text { informal }\end{array}$ & $\begin{array}{l}\text { Diario de } \\
\text { campo }\end{array}$ & $\begin{array}{l}\text { Subdirectora } \\
\text { de CAS }\end{array}$ \\
\hline
\end{tabular}


Tabla de procesamiento 2. Categoría: Episteme y subcategorías: Trabajo Social, Formación disciplinar, Metodología, Niñez, Violencia, Condiciones sociales, Legislación y Perspectiva adultocéntrica

\begin{tabular}{|c|c|c|c|c|}
\hline Subcategoría & Viñeta narrativa & Técnica & Instrumento & Informante \\
\hline \multirow{3}{*}{ 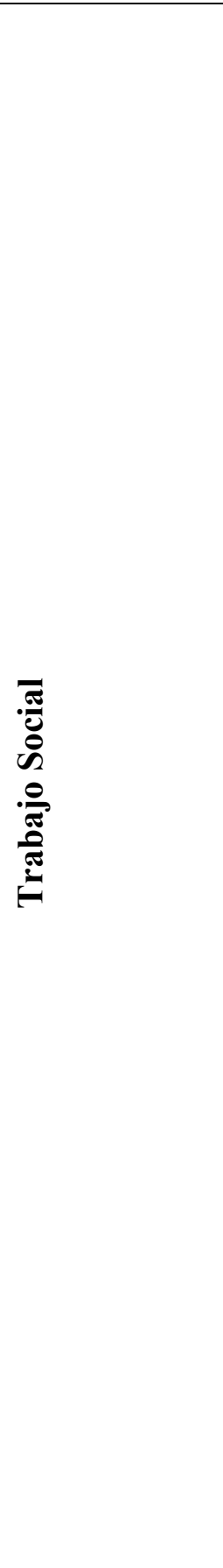 } & $\begin{array}{l}\text { La maravillosa } \\
\text { profesión que elegí } \\
\text { alguna vez y que superó } \\
\text { mis expectativas, al } \\
\text { permitir compartir mi } \\
\text { conocimiento teórico y } \\
\text { de vivencia con quienes } \\
\text { me permiten entrar en } \\
\text { sus vidas, buscando } \\
\text { alternativas de acción, } \\
\text { para una situación } \\
\text { determinada. }\end{array}$ & Trayectoria & $\begin{array}{l}\text { Álbum } \\
\text { fotográfico }\end{array}$ & TS 5 (GF) \\
\hline & $\begin{array}{l}\text { Es una carrera que nos } \\
\text { permite conocer de } \\
\text { cerca la problemática y } \\
\text { tratar de proyectar } \\
\text { confianza y apoyo a } \\
\text { quien lo solicita y } \\
\text { necesita, de una manera } \\
\text { cálida y afectiva. }\end{array}$ & Trayectoria & $\begin{array}{l}\text { Álbum } \\
\text { fotográfico }\end{array}$ & TS 3 (GF) \\
\hline & $\begin{array}{l}\text { Es una profesión que } \\
\text { tiene contacto con } \\
\text { personas en etapas de } \\
\text { conflicto y su atención } \\
\text { está enfocada en que }\end{array}$ & Trayectoria & $\begin{array}{l}\text { Álbum } \\
\text { fotográfico }\end{array}$ & TS 4 (GF) \\
\hline vin & & & & 最 \\
\hline
\end{tabular}




\begin{tabular}{|c|c|c|c|c|}
\hline & $\begin{array}{l}\text { puedan identificar sus } \\
\text { recursos } \\
\text { solucionar y } \\
\text { adelante. }\end{array}$ & & & \\
\hline & $\begin{array}{l}\text { Estilo de vida que se } \\
\text { ejerce en la vida } \\
\text { cotidiana y profesional } \\
\text { de acuerdo a sus } \\
\text { principios y ética. }\end{array}$ & Trayectoria & $\begin{array}{l}\text { Álbum } \\
\text { fotográfico }\end{array}$ & TS 4 (GF) \\
\hline & $\begin{array}{l}\text { Trabajo social brinda la } \\
\text { asistencia social con las } \\
\text { familias, incidir, hacer } \\
\text { un plan de trabajo y ver } \\
\text { al paciente oculto, que } \\
\text { muchas veces no era el } \\
\text { niño. }\end{array}$ & $\begin{array}{l}\text { Línea de } \\
\text { tiempo }\end{array}$ & $\begin{array}{l}\text { Preguntas } \\
\text { detonadoras }\end{array}$ & TS 6 (GF) \\
\hline & $\begin{array}{l}\text { Somos la cara que se da } \\
\text { para la atención al } \\
\text { público, somos las } \\
\text { primeras personas con } \\
\text { quien interactúa la } \\
\text { persona cuando llega a } \\
\text { la institución. }\end{array}$ & $\begin{array}{l}\text { Entrevista } \\
\text { informal }\end{array}$ & $\begin{array}{l}\text { Diario de } \\
\text { campo }\end{array}$ & $\mathrm{TS}$ \\
\hline & $\begin{array}{l}\text { Es esa profesión que } \\
\text { interviene con las } \\
\text { familias, con quienes } \\
\text { han vivido violencia, } \\
\text { somos el intermediario } \\
\text { entre la institución y la } \\
\text { persona para mejorar su }\end{array}$ & $\begin{array}{l}\text { Entrevista } \\
\text { informal }\end{array}$ & $\begin{array}{l}\text { Diario de } \\
\text { campo }\end{array}$ & $\mathrm{TS}$ \\
\hline (2) & & & & \\
\hline
\end{tabular}




\begin{tabular}{|c|c|c|c|c|}
\hline & $\begin{array}{l}\text { situación, intervenimos } \\
\text { con ellas. Somos el } \\
\text { eslabón más importante } \\
\text { de la cadena y con otras } \\
\text { áreas. }\end{array}$ & & & \\
\hline & $\begin{array}{l}\text { Tiene que ver con esas } \\
\text { estrategias } \\
\text { intervención para } \\
\text { transformar la realidad } \\
\text { del propio trabajador } \\
\text { social, acomodando tus } \\
\text { cosas a nivel personal y } \\
\text { con ello tener un } \\
\text { equilibrio e intervenir } \\
\text { con grupos de personas } \\
\text { y comunidades para } \\
\text { transformar su realidad. }\end{array}$ & $\begin{array}{l}\text { Entrevista } \\
\text { informal }\end{array}$ & $\begin{array}{l}\text { Diario de } \\
\text { campo }\end{array}$ & $\mathrm{TS}$ \\
\hline$\frac{\grave{\Xi}}{\stackrel{\Xi}{\Xi}}$ & $\begin{array}{l}\text { Nueva visión } \\
\text { institucional de lo que } \\
\text { se debía hacer, visión } \\
\text { más profesional, entran } \\
\text { ideas como } \\
\text { certificaciones. }\end{array}$ & $\begin{array}{l}\text { Línea de } \\
\text { tiempo }\end{array}$ & $\begin{array}{l}\text { Preguntas } \\
\text { detonadoras }\end{array}$ & TS 6 (GF) \\
\hline 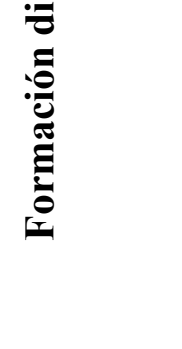 & $\begin{array}{l}\text { Yo como técnica } \\
\text { aprendí muchas cosas y } \\
\text { con eso me es suficiente } \\
\text { para trabajar con esta } \\
\text { población. }\end{array}$ & $\begin{array}{l}\text { Entrevista } \\
\text { informal }\end{array}$ & $\begin{array}{l}\text { Diario de } \\
\text { campo }\end{array}$ & $\mathrm{TS}$ \\
\hline & $\begin{array}{lll}\text { Trabajo } & \text { limitado } \\
\text { porque sólo el área }\end{array}$ & $\begin{array}{l}\text { Línea de } \\
\text { tiempo }\end{array}$ & $\begin{array}{l}\text { Preguntas } \\
\text { detonadoras }\end{array}$ & TS 4 (GF) \\
\hline 2. (4) & & & & \\
\hline
\end{tabular}




\begin{tabular}{|c|c|c|c|c|}
\hline & $\begin{array}{l}\text { psicológica trabaja en } \\
\text { las problemáticas. }\end{array}$ & & & \\
\hline & $\begin{array}{l}\text { Yo llegué aquí siendo } \\
\text { niñera, luego hice la } \\
\text { carrera técnica en el } \\
\text { CETis y así fui } \\
\text { escalando, ahora soy } \\
\text { jefa de departamento. }\end{array}$ & $\begin{array}{l}\text { Entrevista } \\
\text { informal }\end{array}$ & $\begin{array}{l}\text { Diario de } \\
\text { campo }\end{array}$ & $\mathrm{TS}$ \\
\hline & $\begin{array}{l}\text { No estaba segura de si } \\
\text { quería estudiar trabajo } \\
\text { social, pero cuando me } \\
\text { di cuenta de que con eso } \\
\text { podía ascender, pues } \\
\text { me animé. }\end{array}$ & $\begin{array}{l}\text { Entrevista } \\
\text { informal }\end{array}$ & $\begin{array}{l}\text { Diario de } \\
\text { campo }\end{array}$ & $\mathrm{TS}$ \\
\hline & $\begin{array}{l}\text { Estudié Trabajo Social } \\
\text { a nivel técnico y luego } \\
\text { la licenciatura en una } \\
\text { escuela privada, no ví } \\
\text { grandes diferencias, la } \\
\text { verdad. }\end{array}$ & $\begin{array}{l}\text { Entrevista } \\
\text { informal }\end{array}$ & $\begin{array}{l}\text { Diario de } \\
\text { campo }\end{array}$ & $\mathrm{TS}$ \\
\hline & $\begin{array}{l}\text { La intervención es cada } \\
\text { vez más difícil Gaby, } \\
\text { antes las mamás eran } \\
\text { más fáciles de atender, } \\
\text { ahora están vinculadas } \\
\text { con el narcotráfico y los } \\
\text { secuestros. }\end{array}$ & $\begin{array}{l}\text { Entrevista } \\
\text { informal }\end{array}$ & $\begin{array}{l}\text { Diario de } \\
\text { campo }\end{array}$ & TS 3 (GF) \\
\hline 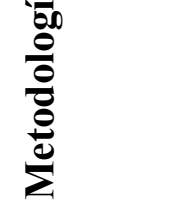 & $\begin{array}{l}\text { Trabajo con familia, } \\
\text { prevención y atención } \\
\text { para la intervención }\end{array}$ & $\begin{array}{l}\text { Mapas } \\
\text { conceptuales }\end{array}$ & $\begin{array}{l}\text { Guía de } \\
\text { conectores }\end{array}$ & TS 1 (GF) \\
\hline 2. (4) & & & & \\
\hline
\end{tabular}




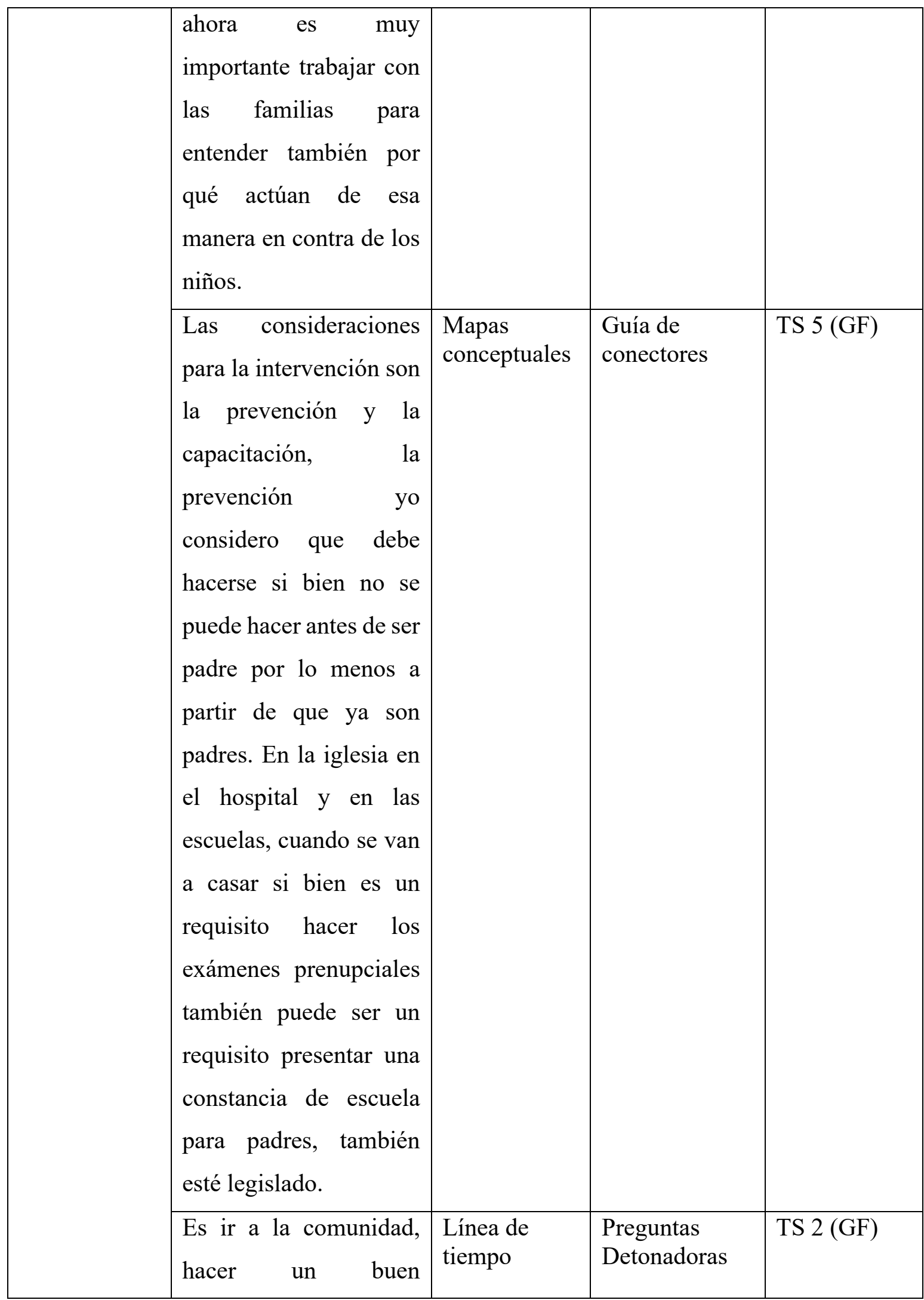




\begin{tabular}{|c|c|c|c|c|}
\hline & $\begin{array}{l}\text { diagnóstico no con base } \\
\text { a lo que tú creas desde } \\
\text { el escritorio. }\end{array}$ & & & \\
\hline & $\begin{array}{llll}\text { Contar con } & \text { parte } \\
\text { teórica, } & & \text { manejar } \\
\text { necesidades } & & \\
\text { emocionales } & \text { de } & \text { los } \\
\text { pequeños } & \text { y } & \text { sus } \\
\text { familias. } & & & \\
& & \end{array}$ & $\begin{array}{l}\text { Línea de } \\
\text { tiempo }\end{array}$ & $\begin{array}{l}\text { Preguntas } \\
\text { detonadoras }\end{array}$ & TS 5 (GF) \\
\hline & $\begin{array}{l}\text { Ahora es como hacer un } \\
\text { Frankenstein, todo el } \\
\text { mundo mete mano, uno } \\
\text { hace una cosa... yo } \\
\text { preguntaba oye pero yo } \\
\text { no entiendo quién va } \\
\text { hacer cada cosa y nadie } \\
\text { sabía nada y trabajamos } \\
\text { en el día, ahora vayan a } \\
\text { la calle y pregunten a } \\
\text { los usuarios que son } \\
\text { quienes nos deben } \\
\text { preocupar y dicen la } \\
\text { Procu la que dicen el } \\
\text { bunker o a cual". }\end{array}$ & $\begin{array}{l}\text { Línea de } \\
\text { tiempo }\end{array}$ & $\begin{array}{l}\text { Preguntas } \\
\text { detonadoras }\end{array}$ & TS 4 (GF) \\
\hline & $\begin{array}{l}\text { Actualmente los } \\
\text { problemas son más } \\
\text { agudos, más difíciles de } \\
\text { tratar, desde mi óptica } \\
\text { más porque ahora ya la } \\
\text { mamá enfrenta, a lo }\end{array}$ & $\begin{array}{l}\text { Línea de } \\
\text { tiempo }\end{array}$ & $\begin{array}{l}\text { Preguntas } \\
\text { detonadoras }\end{array}$ & TS 3 (GF) \\
\hline (2) & & & & \\
\hline
\end{tabular}




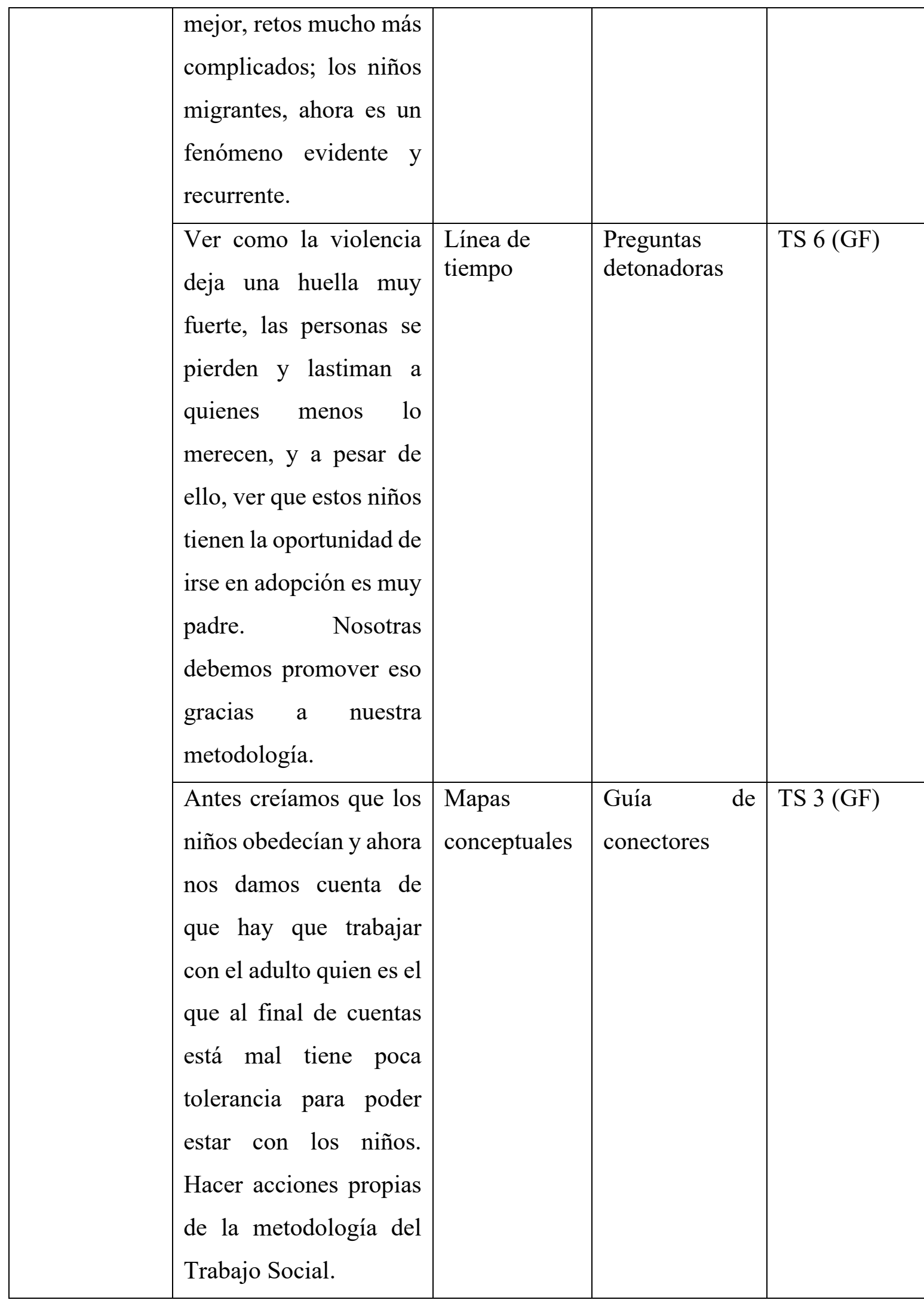




\begin{tabular}{|c|c|c|c|c|}
\hline \multirow{4}{*}{ : } & $\begin{array}{l}\text { Cuando las madres nos } \\
\text { solicitaban el ingreso, } \\
\text { debían firmar una carta } \\
\text { de aceptación para que } \\
\text { la niña se quedará en la } \\
\text { casa hogar hasta la } \\
\text { mayoría de edad, aquí } \\
\text { les enseñábamos oficios } \\
\text { y si alguna quería } \\
\text { estudiar, podía hacerlo. }\end{array}$ & $\begin{array}{l}\text { Entrevista } \\
\text { informal }\end{array}$ & $\begin{array}{l}\text { Diario de } \\
\text { campo }\end{array}$ & $\mathrm{TS}$ \\
\hline & $\begin{array}{l}\text { El niño anda en pijama } \\
\text { porque está cómo } \\
\text { enojado no nos hace } \\
\text { caso; como es migrante } \\
\text { se irá pronto, así que lo } \\
\text { atendemos en el área } \\
\text { médica, no nos queda } \\
\text { más que esperar. }\end{array}$ & $\begin{array}{l}\text { Entrevista } \\
\text { informal }\end{array}$ & $\begin{array}{l}\text { Diario de } \\
\text { campo }\end{array}$ & TS \\
\hline & $\begin{array}{l}\text { Cuando llegué a } \\
\text { trabajar a Casa Hogar } \\
\text { para Niñas, en } 1991 \\
\text { teníamos } 6 \text { edificios con } \\
12 \text { departamentos para } \\
\text { una capacidad de } 71 \\
\text { niñas por edificio, no } \\
\text { todos funcionaban. }\end{array}$ & $\begin{array}{l}\text { Entrevista } \\
\text { informal }\end{array}$ & $\begin{array}{l}\text { Diario de } \\
\text { campo }\end{array}$ & TS \\
\hline & $\begin{array}{l}\text { Cuando las madres nos } \\
\text { solicitaban el ingreso, } \\
\text { debían firmar una carta } \\
\text { de aceptación para que }\end{array}$ & $\begin{array}{c}\text { Entrevista } \\
\text { informal }\end{array}$ & $\begin{array}{l}\text { Diario de } \\
\text { campo }\end{array}$ & $\mathrm{TS}$ \\
\hline 4. & & & & \\
\hline
\end{tabular}




\begin{tabular}{|c|c|c|c|}
\hline $\begin{array}{l}\text { la niña se quedará en la } \\
\text { casa hogar hasta la } \\
\text { mayoría de edad, aquí } \\
\text { les enseñábamos. }\end{array}$ & & & \\
\hline $\begin{array}{l}\text { Desde siempre las niñas } \\
\text { ingresaban por maltrato } \\
\text { en el hogar, abuso } \\
\text { sexual o negligencia o } \\
\text { pobreza. }\end{array}$ & $\begin{array}{c}\text { Entrevista } \\
\text { informal }\end{array}$ & $\begin{array}{c}\text { Diario de } \\
\text { campo }\end{array}$ & $\mathrm{TS}$ \\
\hline $\begin{array}{l}\text { Los hijos del presidente } \\
\text { (los niños que viven en } \\
\text { las Casas Hogar), a } \\
\text { ellos no tienen por qué } \\
\text { faltarles nada. }\end{array}$ & $\begin{array}{c}\text { Entrevista } \\
\text { informal }\end{array}$ & $\begin{array}{l}\text { Diario de } \\
\text { campo }\end{array}$ & TS \\
\hline $\begin{array}{l}\text { Como ves está casa es } \\
\text { muy grande, a mí me } \\
\text { preocupa que ya haya } \\
\text { niños, hasta nos } \\
\text { quitaron ya algunos } \\
\text { edificios para dárselos a } \\
\text { la Dirección General de } \\
\text { Rehabilitación. }\end{array}$ & $\begin{array}{c}\text { Entrevista } \\
\text { informal }\end{array}$ & $\begin{array}{c}\text { Diario de } \\
\text { campo }\end{array}$ & $\mathrm{TS}$ \\
\hline $\begin{array}{l}\text { El niño llegó de } \\
\text { migración, ya estuvo } \\
\text { albergado en el DIF de } \\
\text { Neza, pero ahí lo } \\
\text { violaron } \\
\text { tumultuariamente entre } \\
\text { muchos chavos. }\end{array}$ & $\begin{array}{c}\text { Entrevista } \\
\text { informal }\end{array}$ & $\begin{array}{c}\text { Diario de } \\
\text { campo }\end{array}$ & Abogada \\
\hline
\end{tabular}




\begin{tabular}{|c|c|c|c|c|}
\hline & 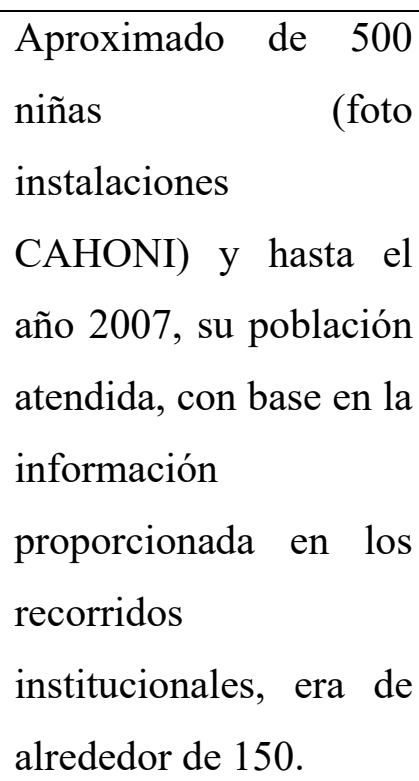 & $\begin{array}{c}\text { Entrevista } \\
\text { informal }\end{array}$ & $\begin{array}{l}\text { Diario de } \\
\text { campo }\end{array}$ & $\begin{array}{c}\text { Subdirectora } \\
\text { de centro }\end{array}$ \\
\hline \multirow{3}{*}{$\frac{\pi}{\frac{\pi}{2}}$} & $\begin{array}{l}\text { El maltrato infantil } \\
\text { tradicional son aquellos } \\
\text { actos que agreden y } \\
\text { lesionan: se entiende } \\
\text { como actos que agreden } \\
\text { y lesionan física y } \\
\text { emocionalmente a los } \\
\text { niños. }\end{array}$ & $\begin{array}{c}\text { Mapas } \\
\text { conceptuales }\end{array}$ & $\begin{array}{c}\text { Guía de } \\
\text { conectores }\end{array}$ & TS 5 (GF) \\
\hline & $\begin{array}{l}\text { Toda acción de omisión } \\
\text { descuido, negligencia, } \\
\text { golpes, insultos, gritos } \\
\text { que un adulto ejerce en } \\
\text { contra de un menor de } \\
\text { edad con el fin de } \\
\text { controlarlo o educarlo. }\end{array}$ & $\begin{array}{c}\text { Mapas } \\
\text { conceptuales }\end{array}$ & $\begin{array}{c}\text { Guía de } \\
\text { conectores }\end{array}$ & TS 2 (GF) \\
\hline & $\begin{array}{l}\text { El maltrato es físico, } \\
\text { emocional, sexual y } \\
\text { emocional. }\end{array}$ & $\begin{array}{c}\text { Mapas } \\
\text { conceptuales }\end{array}$ & $\begin{array}{c}\text { Guía de } \\
\text { conectores }\end{array}$ & TS 4 (GF) \\
\hline
\end{tabular}




\begin{tabular}{|c|c|c|c|}
\hline $\begin{array}{l}\text { El maltrato es ejercido } \\
\text { de los niños en contra } \\
\text { de los niños. }\end{array}$ & $\begin{array}{c}\text { Mapas } \\
\text { conceptuales }\end{array}$ & $\begin{array}{c}\text { Guía de } \\
\text { conectores }\end{array}$ & TS 3 (GF) \\
\hline $\begin{array}{l}\text { La violencia contra los } \\
\text { niños la ejerce el } \\
\text { (esposo) padre, hijo } \\
\text { mayor, jefe (trabajo } \\
\text { infantil) madre, } \\
\text { profesor, sacerdote "el } \\
\text { padre, el hijo mayor, la } \\
\text { madre, por el profesor o } \\
\text { el sacerdote. }\end{array}$ & $\begin{array}{c}\text { Mapas } \\
\text { conceptuales }\end{array}$ & $\begin{array}{c}\text { Guía de } \\
\text { conectores }\end{array}$ & TS 2 (GF) \\
\hline $\begin{array}{l}\text { La persona que está a } \\
\text { cargo del menor es } \\
\text { quien maltrata, la } \\
\text { violencia es ejercida por } \\
\text { la persona que está al } \\
\text { cuidado del menor. }\end{array}$ & $\begin{array}{c}\text { Mapas } \\
\text { conceptuales }\end{array}$ & $\begin{array}{c}\text { Guía de } \\
\text { conectores }\end{array}$ & TS 1 (GF) \\
\hline $\begin{array}{l}\text { Casa y escuela es el } \\
\text { espacio donde se ejerce } \\
\text { es en la casa o escuela. }\end{array}$ & $\begin{array}{c}\text { Mapas } \\
\text { conceptuales }\end{array}$ & $\begin{array}{c}\text { Guía de } \\
\text { conectores }\end{array}$ & TS 1 (GF) \\
\hline $\begin{array}{l}\text { En algunos casos sin } \\
\text { factores detonantes, } \\
\text { otras veces sin factores } \\
\text { detonantes, sólo en } \\
\text { algunos casos, sólo } \\
\text { porque si, lo merecía. }\end{array}$ & $\begin{array}{c}\text { Mapas } \\
\text { conceptuales }\end{array}$ & $\begin{array}{c}\text { Guía de } \\
\text { conectores }\end{array}$ & TS 4 (GF) \\
\hline $\begin{array}{l}\text { Las formas de violencia } \\
\text { en contra de niños y } \\
\text { niñas son las mismas, }\end{array}$ & $\begin{array}{c}\text { Mapas } \\
\text { conceptuales }\end{array}$ & $\begin{array}{c}\text { Guía de } \\
\text { conectores }\end{array}$ & TS 4 (GF) \\
\hline
\end{tabular}




\begin{tabular}{|c|c|c|c|c|}
\hline & $\begin{array}{l}\text { no han variado y por } \\
\text { tanto, trabajamos igual } \\
\text { con ellos. }\end{array}$ & & & \\
\hline & $\begin{array}{l}\text { Todo acto con la } \\
\text { intención de lastimar a } \\
\text { un niño, eso es el } \\
\text { maltrato } \\
\text { contemporáneo. }\end{array}$ & $\begin{array}{c}\text { Mapas } \\
\text { conceptuales }\end{array}$ & $\begin{array}{c}\text { Guía de } \\
\text { conectores }\end{array}$ & TS 1 (GF) \\
\hline & $\begin{array}{l}\text { Muchas de esas mamás } \\
\text { no saben que están } \\
\text { incurriendo en un delito } \\
\text { porque muchas veces } \\
\text { ellas aplican castigos o } \\
\text { cuidan a los niños de } \\
\text { cierta manera sin saber } \\
\text { que están incurriendo } \\
\text { en un delito porque } \\
\text { muchas veces a ellas así } \\
\text { las educaron, muchas } \\
\text { veces son cuestiones } \\
\text { culturales. }\end{array}$ & $\begin{array}{l}\text { Línea de } \\
\text { tiempo }\end{array}$ & $\begin{array}{c}\text { Preguntas } \\
\text { detonadoras }\end{array}$ & TS 6 (GF) \\
\hline & $\begin{array}{l}\text { Cuando entramos a la } \\
\text { Gran Familia, } \\
\text { encontramos ataúdes y } \\
\text { a muchas adolescentes } \\
\text { con marcas de cesárea, } \\
\text { pero extrañamente no } \\
\text { encontramos bebés, los } \\
\text { residentes decían que } \\
\text { por la noches sacaban a }\end{array}$ & $\begin{array}{l}\text { Recuperación } \\
\text { de } \\
\text { información } \\
\text { personal }\end{array}$ & $\begin{array}{l}\text { Diario de } \\
\text { campo }\end{array}$ & Investigadora \\
\hline 2. & & & & 总 \\
\hline
\end{tabular}




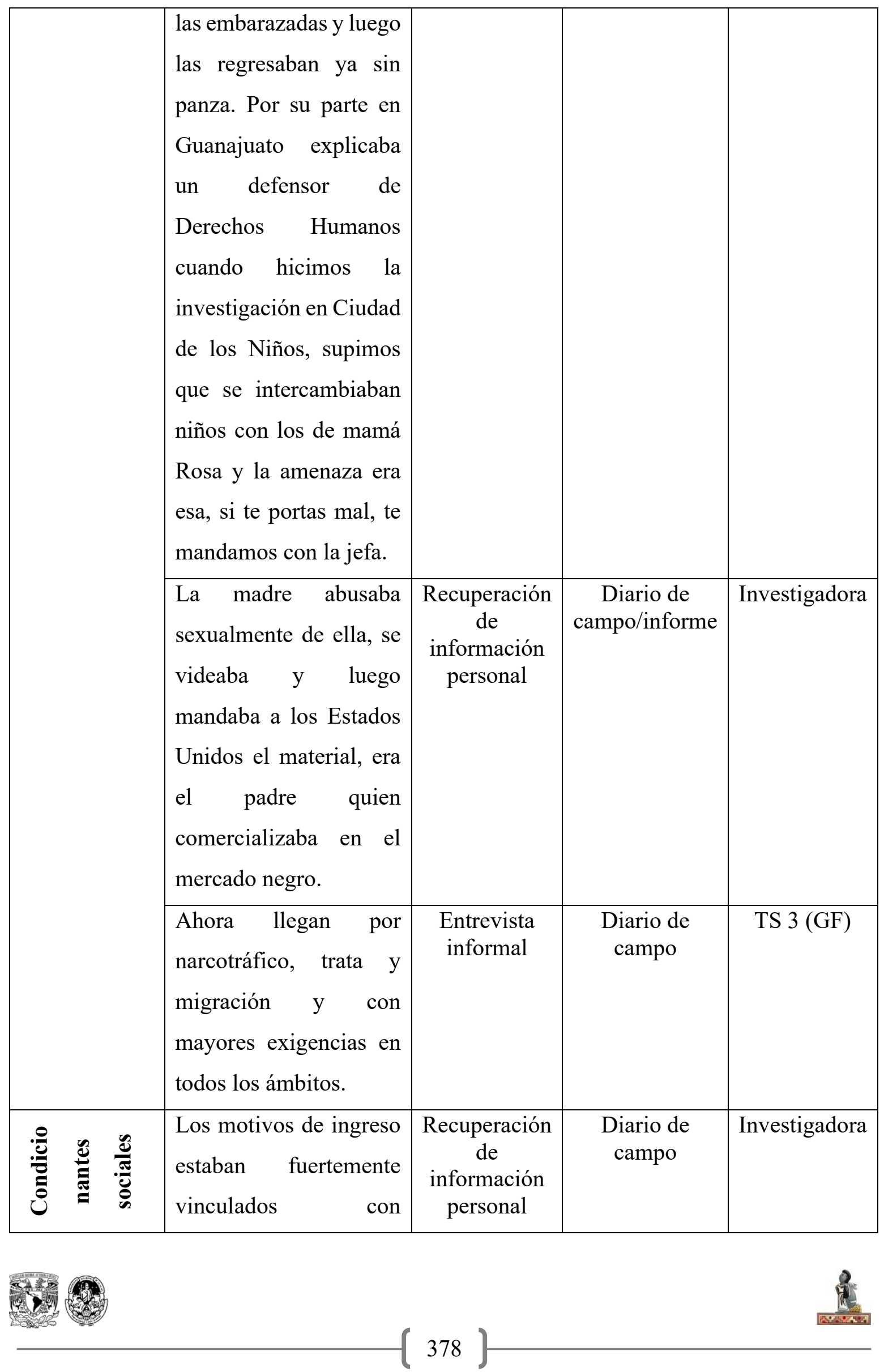




\begin{tabular}{|l|l|l|l|}
\hline $\begin{array}{r}\text { averiguaciones previas } \\
\text { que en pocas ocasiones } \\
\text { culminaban en ejercicio } \\
\text { de la acción penal y los } \\
\text { delitos más recurrentes } \\
\text { eran: el abuso físico, la } \\
\text { negligencia, la omisión } \\
\text { de cuidados. Para el año } \\
\text { 2016, que se realiza el } \\
\text { primer diagnóstico } \\
\text { situacional de los CAS, } \\
\text { los motivos de ingreso } \\
\text { documentados eran por } \\
\text { solicitud del familiar } \\
\text { ante } \\
\text { económicas precarias o } \\
\text { por alguna institución } \\
\text { que registraba violencia } \\
\text { física, sexual o } \\
\text { psicológica. }\end{array}$
\end{tabular}$|\quad| \quad \mid$




\begin{tabular}{|c|c|c|c|c|}
\hline & 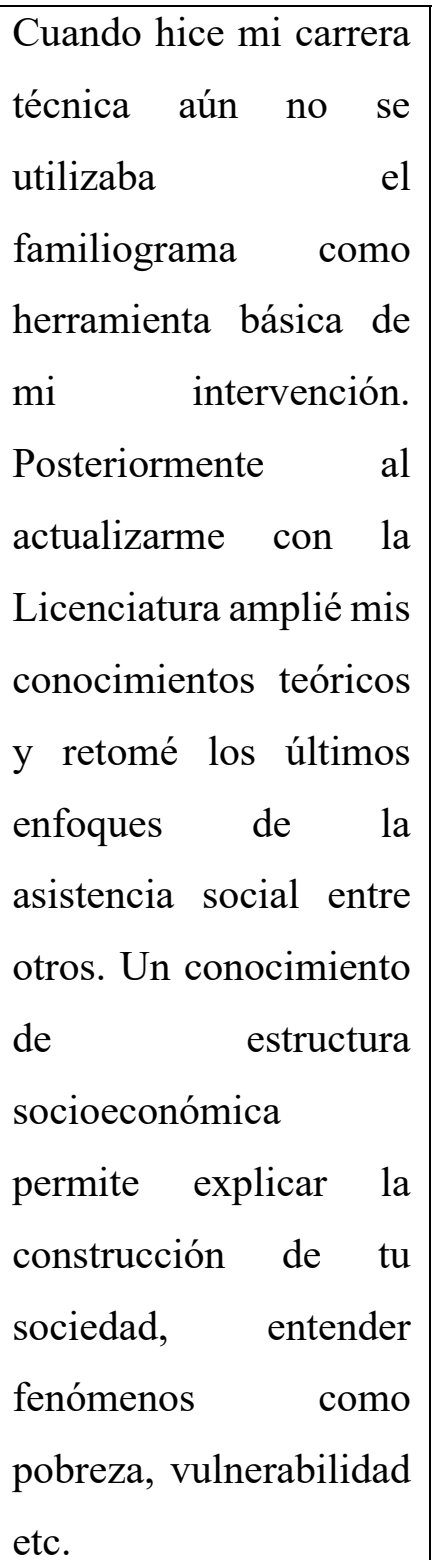 & $\begin{array}{c}\text { Mapas } \\
\text { conceptuales }\end{array}$ & $\begin{array}{c}\text { Guía de } \\
\text { conectores }\end{array}$ & TS 2 (GF) \\
\hline & $\begin{array}{l}\text { Desempleo, ignorancia, } \\
\text { pobreza, ira y } \\
\text { frustración } \\
\text { factores, } \\
\text { principales factores, es } \\
\text { el desempleo, la } \\
\text { pobreza la ignorancia, } \\
\text { la ira que conllevan a }\end{array}$ & $\begin{array}{c}\text { Mapas } \\
\text { conceptuales }\end{array}$ & $\begin{array}{c}\text { Guía de } \\
\text { conectores }\end{array}$ & TS 1 (GF) \\
\hline 2. & & & & 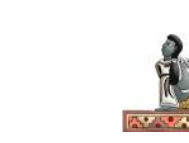 \\
\hline
\end{tabular}




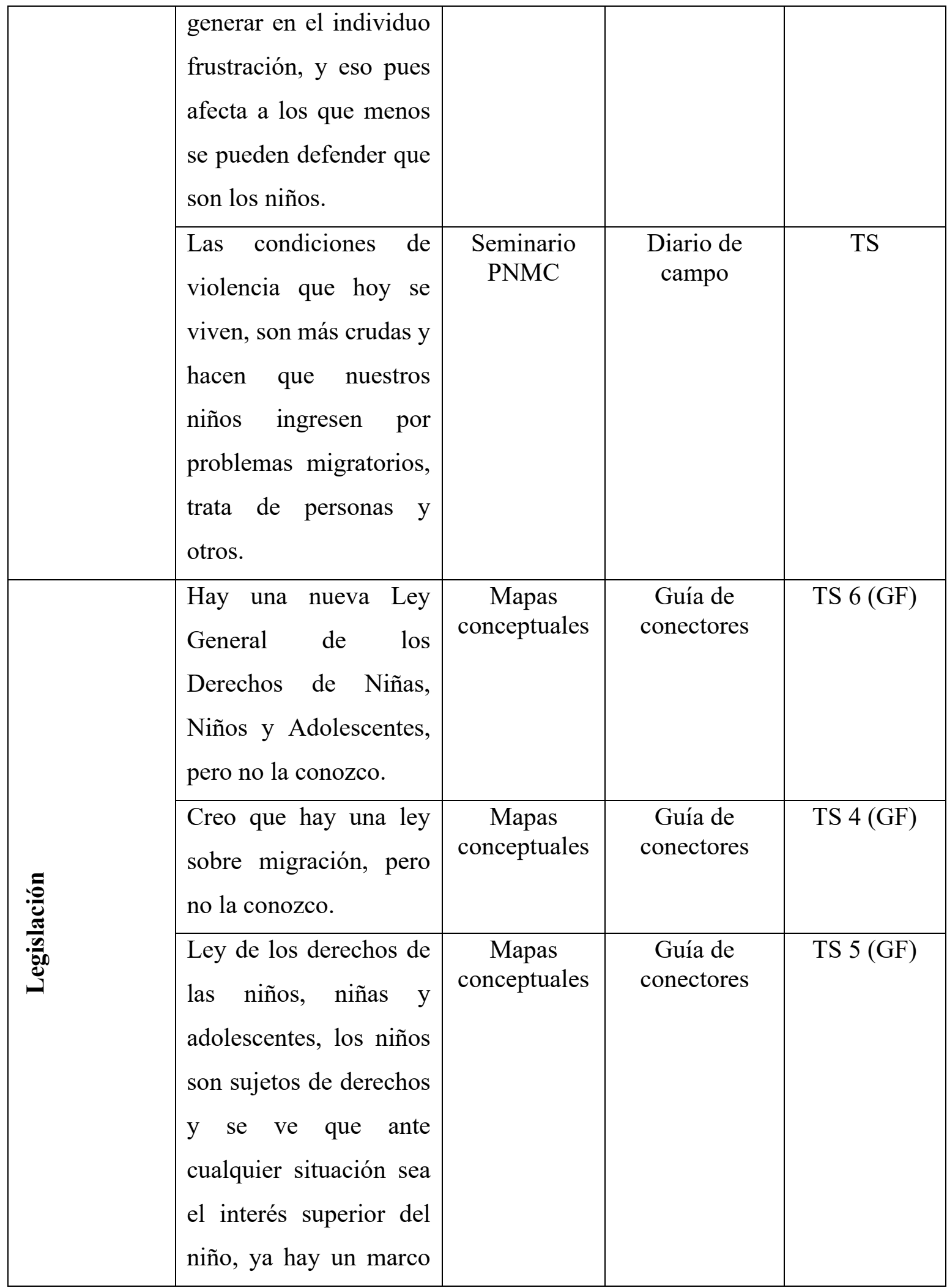




\begin{tabular}{|c|c|c|c|c|}
\hline & $\begin{array}{l}\text { jurídico que protege a } \\
\text { los niños, antes. }\end{array}$ & & & \\
\hline & $\begin{array}{l}\text { Hoy tenemos la Ley } \\
\text { General de los } \\
\text { Derechos de Niñas, } \\
\text { Niños y Adolescentes, } \\
\text { Ley Asistencia Social y } \\
\text { Derechos humanos. }\end{array}$ & $\begin{array}{c}\text { Mapas } \\
\text { conceptuales }\end{array}$ & $\begin{array}{l}\text { Guía de } \\
\text { conectores }\end{array}$ & TS 1 (GF) \\
\hline & $\begin{array}{l}\text { Ley general de los } \\
\text { derechos de las niñas, } \\
\text { niños y adolescentes. El } \\
\text { marco jurídico son } \\
\text { varios son los que nos } \\
\text { dan la línea para poder } \\
\text { intervenir. }\end{array}$ & $\begin{array}{c}\text { Mapas } \\
\text { conceptuales }\end{array}$ & $\begin{array}{l}\text { Guía de } \\
\text { conectores }\end{array}$ & TS 4 (GF) \\
\hline & $\begin{array}{l}\text { El trabajo que veníamos } \\
\text { haciendo antes de la ley } \\
\text { lo único que cambió fue } \\
\text { en regular y darnos } \\
\text { cuenta qué hacemos, } \\
\text { porque ya lo hacíamos, } \\
\text { pero no le dábamos } \\
\text { nombre... Nos ha } \\
\text { facilitado el trabajo, por } \\
\text { supuesto en la medida } \\
\text { que tu identificas lo que } \\
\text { estás haciendo, tienes } \\
\text { claro lo que vas a hacer } \\
\text { puedes ir dando } \\
\text { respuesta. }\end{array}$ & $\begin{array}{l}\text { Línea de } \\
\text { tiempo }\end{array}$ & $\begin{array}{c}\text { Preguntas } \\
\text { detonadoras }\end{array}$ & TS 2 (GF) \\
\hline (4) & & & & 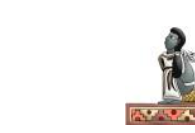 \\
\hline
\end{tabular}




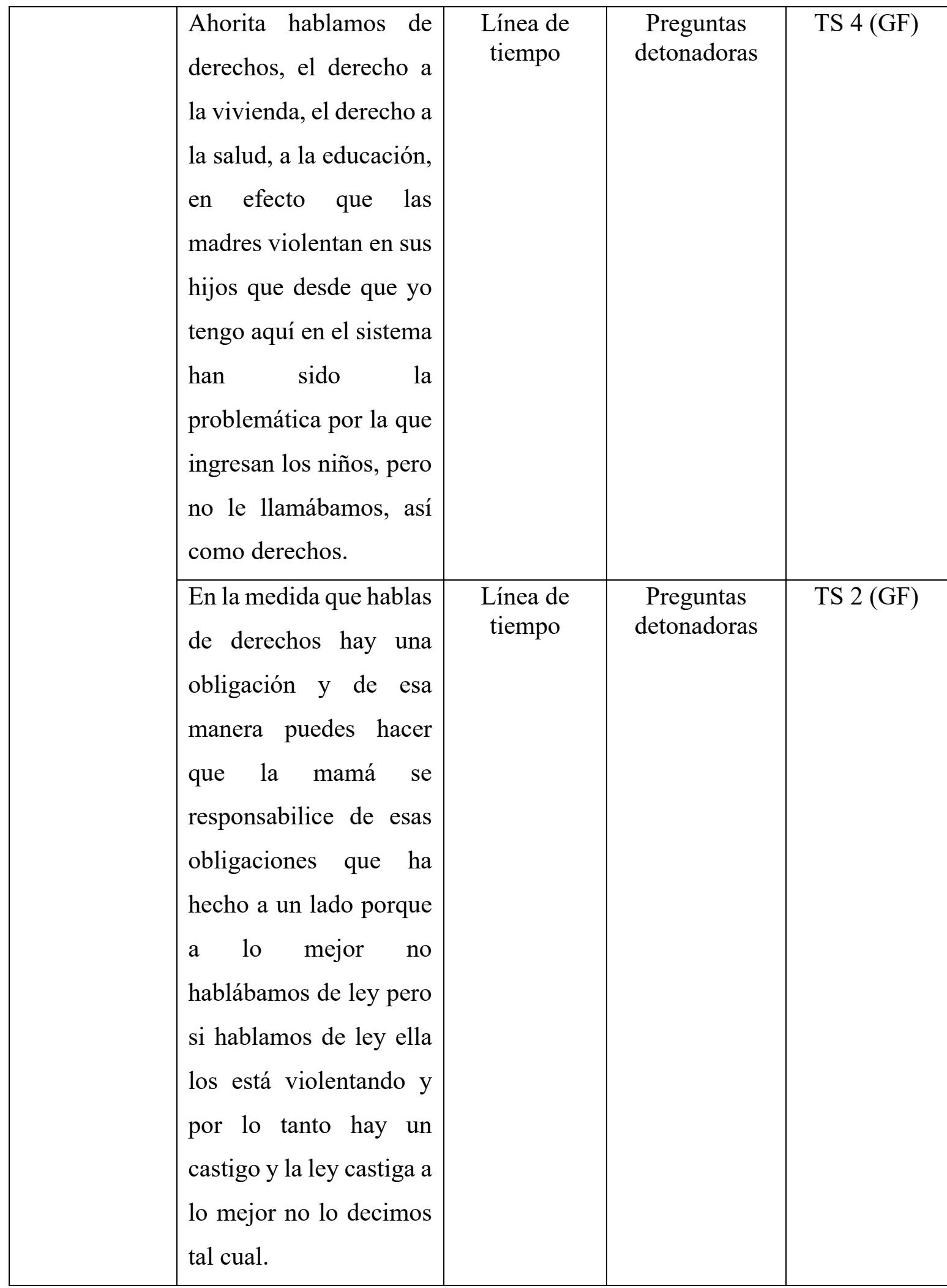




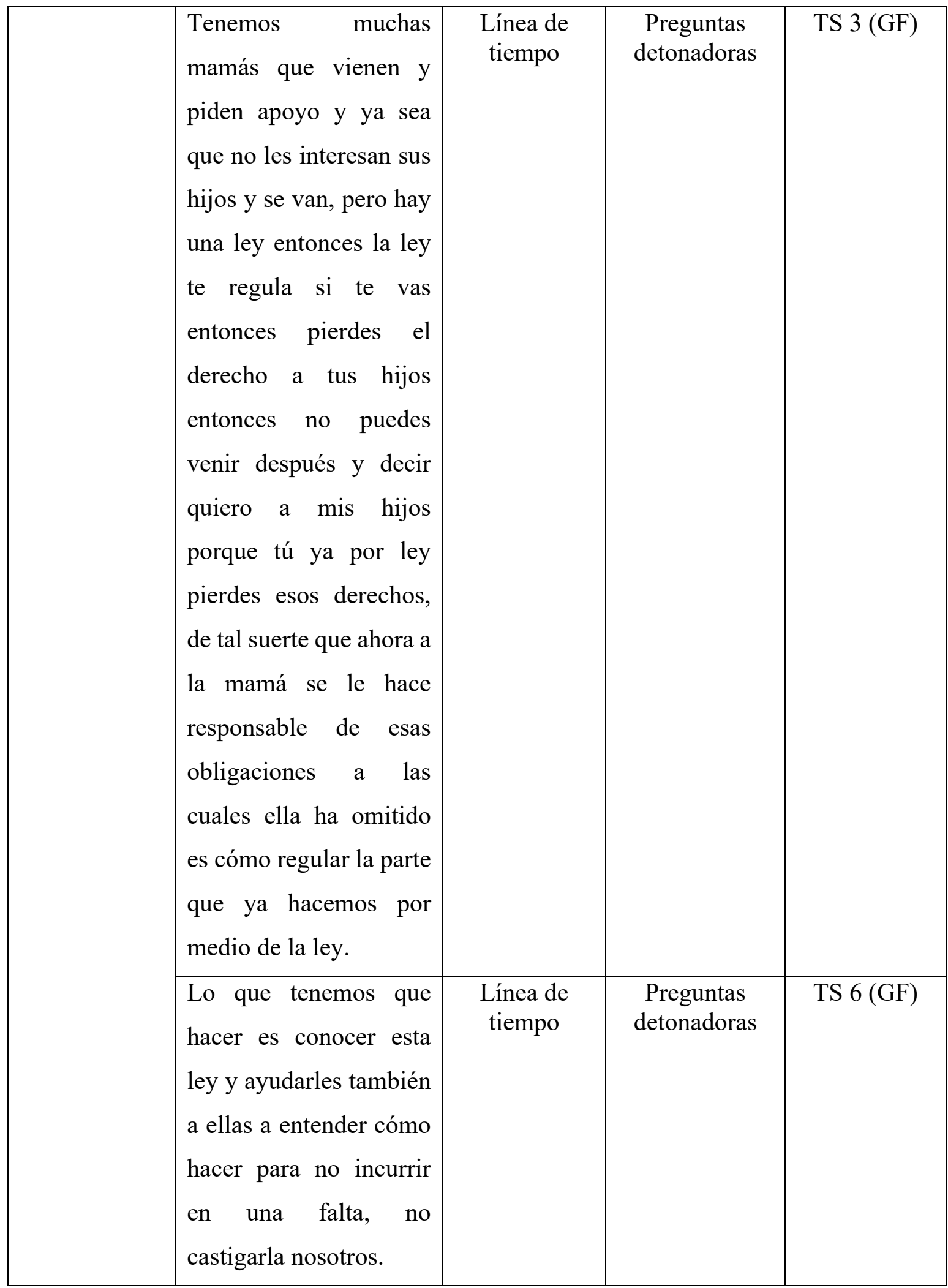




\begin{tabular}{|c|c|c|c|c|}
\hline \multirow[t]{2}{*}{ 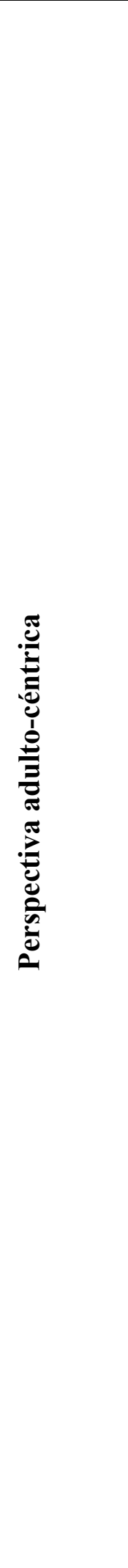 } & $\begin{array}{l}\text { Ahora hablamos los } \\
\text { derechos de los niños, y } \\
\text { te dicen los hijos es que } \\
\text { yo tengo derecho de } \\
\text { salir a jugar, sin } \\
\text { embargo, este derecho } \\
\text { viene pegado con } \\
\text { obligaciones, si tú no } \\
\text { puedes con esta } \\
\text { obligación no tienes } \\
\text { derecho y es } \\
\text { exactamente lo que pasa } \\
\text { con las mamás están } \\
\text { violentando los } \\
\text { derechos de sus hijos, } \\
\text { por lo tanto, que a su } \\
\text { vez esa responsabilidad } \\
\text { de tal manera que si } \\
\text { ellas están violentando } \\
\text { estos derechos no tienen } \\
\text { el derecho de a lo mejor } \\
\text { hasta reintegrarlo. }\end{array}$ & $\begin{array}{l}\text { Línea de } \\
\text { tiempo }\end{array}$ & $\begin{array}{c}\text { Preguntas } \\
\text { detonadoras }\end{array}$ & TS 4 (GF) \\
\hline & $\begin{array}{l}\text { Generó molestia y } \\
\text { preocupación por no } \\
\text { poder explicarles a los } \\
\text { niños el motivo de su } \\
\text { traslado. Yo recuerdo } \\
\text { muy bien, un lunes que } \\
\text { llegamos y ya se había } \\
\text { hecho el cambio, se }\end{array}$ & $\begin{array}{l}\text { Línea de } \\
\text { tiempo }\end{array}$ & $\begin{array}{c}\text { Preguntas } \\
\text { detonadoras }\end{array}$ & TS 3 (GF) \\
\hline (4) & & & & 䠞 \\
\hline
\end{tabular}




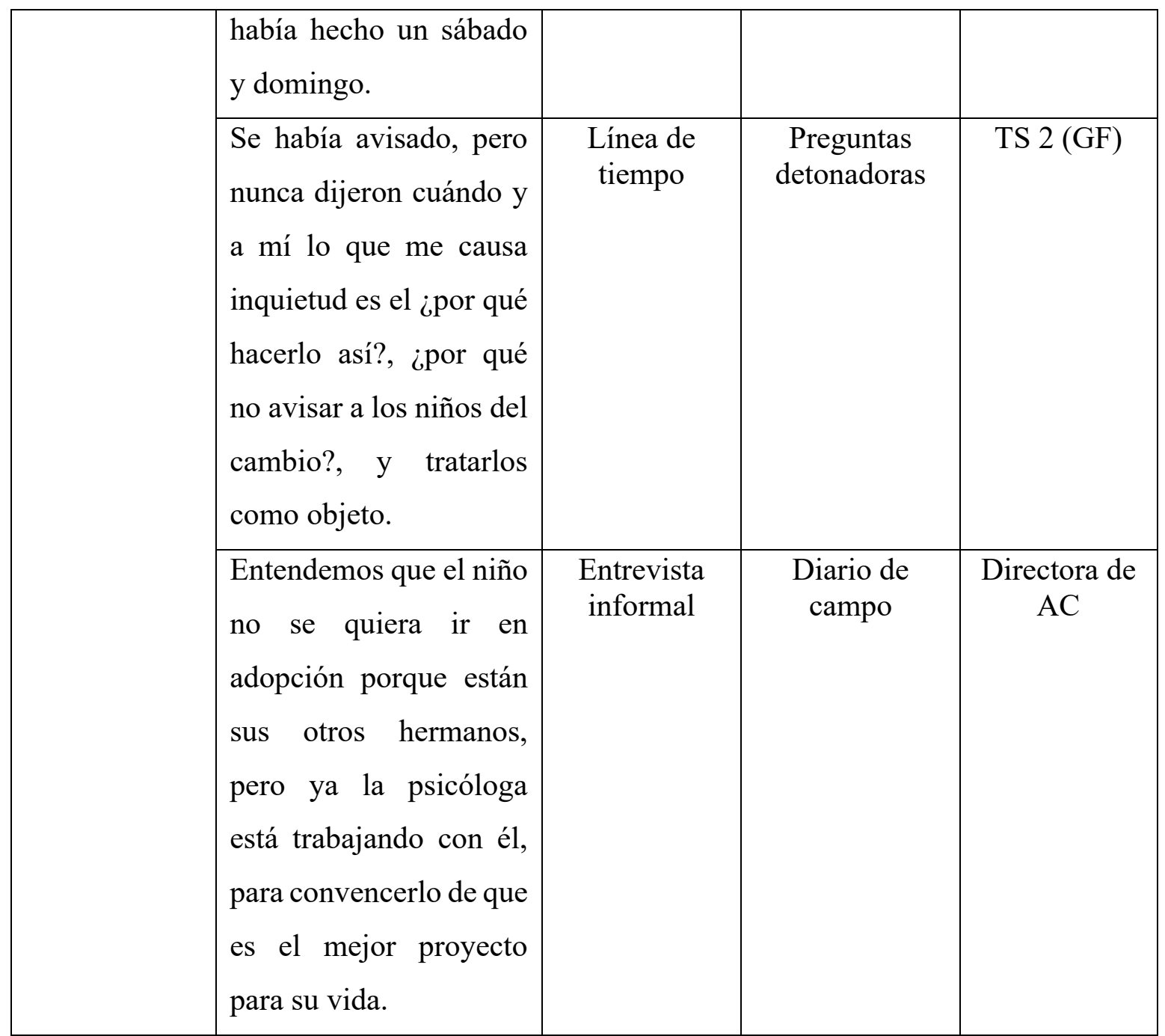


Tabla de procesamiento 3. Categoría: Institución y subcategorías: Marcos normativos de actuación institucional, Autoridad, Coordinaciones institucionales, Políticas públicas

\begin{tabular}{|c|c|c|c|c|}
\hline Subcategorías & Viñeta narrativa & Técnica & Instrumento & Informante \\
\hline \multirow[t]{2}{*}{ 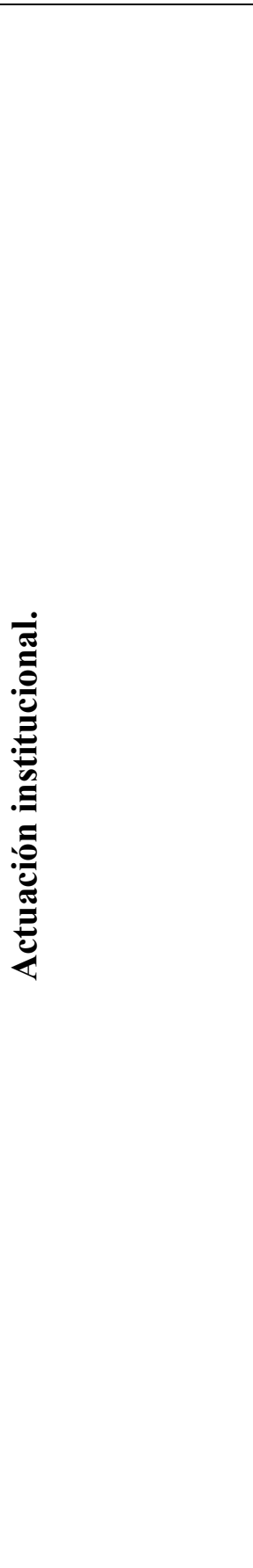 } & $\begin{array}{l}\text { Cuando las madres son } \\
\text { omisas, violentas y no } \\
\text { podemos trabajar con } \\
\text { ellas, debemos estar cerca } \\
\text { de los niños y tratar de } \\
\text { subsanar los derechos que } \\
\text { le fueron violentados en la } \\
\text { medida de lo posible. En } \\
\text { algún momento te afecta } \\
\text { el no poder intervenir } \\
\text { como se quisiera, sin } \\
\text { embargo, no puedes } \\
\text { continuar así, te alineas y } \\
\text { continuas; finalmente } \\
\text { trabajamos para una } \\
\text { institución. }\end{array}$ & $\begin{array}{l}\text { Línea del } \\
\text { tiempo }\end{array}$ & $\begin{array}{c}\text { Preguntas } \\
\text { detonadoras }\end{array}$ & TS 5 (GF) \\
\hline & $\begin{array}{l}\text { Al pasar el tiempo me he } \\
\text { dado cuenta de que } \\
\text { muchas cosas no siempre } \\
\text { dependen de nosotros, } \\
\text { pues los procedimientos } \\
\text { dicen que estamos para } \\
\text { resguardar, cuidar y } \\
\text { proteger, quien decide son } \\
\text { los de allá arriba. }\end{array}$ & $\begin{array}{l}\text { Línea del } \\
\text { tiempo }\end{array}$ & $\begin{array}{c}\text { Preguntas } \\
\text { detonadoras }\end{array}$ & TS 1 (GF) \\
\hline
\end{tabular}




\begin{tabular}{|c|c|c|c|c|}
\hline & $\begin{array}{l}\text { Es bastante frustrante y } \\
\text { angustiante que ellos no } \\
\text { entiendan que hay } \\
\text { necesidades humanas, } \\
\text { para ellos es más } \\
\text { importante cumplir con un } \\
\text { procedimiento } \\
\text { administrativo, que con la } \\
\text { atención a una necesidad } \\
\text { real. }\end{array}$ & $\begin{array}{l}\text { Línea del } \\
\text { tiempo }\end{array}$ & $\begin{array}{c}\text { Preguntas } \\
\text { detonadoras }\end{array}$ & TS 3 (GF) \\
\hline & $\begin{array}{l}\text { Tal vez no tenemos el } \\
\text { conocimiento, pero si la } \\
\text { experiencia profesional y } \\
\text { personal, sin embargo, no } \\
\text { podemos intervenir como } \\
\text { quisiéramos, } \\
\text { procedimiento nos limita. }\end{array}$ & $\begin{array}{l}\text { Línea del } \\
\text { tiempo }\end{array}$ & $\begin{array}{c}\text { Preguntas } \\
\text { detonadoras }\end{array}$ & TS 2 (GF) \\
\hline & $\begin{array}{l}\text { En algún momento te } \\
\text { afecta el no poder } \\
\text { intervenir como se } \\
\text { quisiera, sin embargo, no } \\
\text { puedes continuar así, te } \\
\text { alineas y continuas; } \\
\text { finalmente trabajamos } \\
\text { para una institución. }\end{array}$ & $\begin{array}{l}\text { Línea del } \\
\text { tiempo }\end{array}$ & $\begin{array}{c}\text { Preguntas } \\
\text { detonadoras }\end{array}$ & TS 1 (GF) \\
\hline & $\begin{array}{l}\text { Era muy bonito ver que ya } \\
\text { se podía } \\
\text { sistematizar yacer } \\
\text { realmente } \quad \text { que } \\
\text { procedimientos. }\end{array}$ & $\begin{array}{l}\text { Entrevista } \\
\text { informal }\end{array}$ & $\begin{array}{l}\text { Diario de } \\
\text { campo }\end{array}$ & $\mathrm{TS}$ \\
\hline (4) & & & & 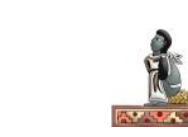 \\
\hline
\end{tabular}




\begin{tabular}{|c|c|c|c|c|}
\hline & $\begin{array}{l}\text { Estamos inmersas en una } \\
\text { institución que te marca tu } \\
\text { hacer, si ya no lo hacemos } \\
\text { ni modo, todo es } \\
\text { aprendizaje. }\end{array}$ & $\begin{array}{l}\text { Línea del } \\
\text { tiempo }\end{array}$ & $\begin{array}{c}\text { Preguntas } \\
\text { detonadoras }\end{array}$ & TS 4 (GF) \\
\hline 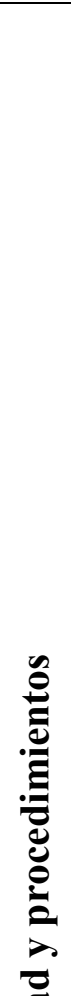 & $\begin{array}{l}\text { Escuche el mensaje de la } \\
\text { titular y dije: ¡está todo } \\
\text { resuelto!, pero pasa con } \\
\text { las leyes... la tristeza es } \\
\text { que son enunciativos y } \\
\text { cuando vamos a la } \\
\text { realidad la realidad nos } \\
\text { alcanza y no es que sea } \\
\text { mala, sino que es escasa, } \\
\text { creo que tiene en } \\
\text { intencionalidad algo } \\
\text { fantástico que es tomar al } \\
\text { niño como un sujeto de } \\
\text { derechos. }\end{array}$ & $\begin{array}{l}\text { Línea del } \\
\text { tiempo }\end{array}$ & $\begin{array}{c}\text { Preguntas } \\
\text { detonadoras }\end{array}$ & TS 2 (GF) \\
\hline 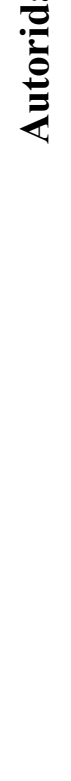 & $\begin{array}{l}\text { No, esto es algo } \\
\text { desatinado de hacer } \\
\text { programas hacer ideas... } \\
\text { ahora tenemos a la } \\
\text { licenciada Vargas que se } \\
\text { trajo todas las ideas de } \\
\text { Pachuca y decía: ¿por qué } \\
\text { se tardan tanto haciendo } \\
\text { procedimientos } \\
\text { adopción? Si allá tenemos } \\
\text { tres niños y tres }\end{array}$ & $\begin{array}{l}\text { Línea del } \\
\text { tiempo }\end{array}$ & $\begin{array}{c}\text { Preguntas } \\
\text { detonadoras }\end{array}$ & TS 1 (GF) \\
\hline
\end{tabular}




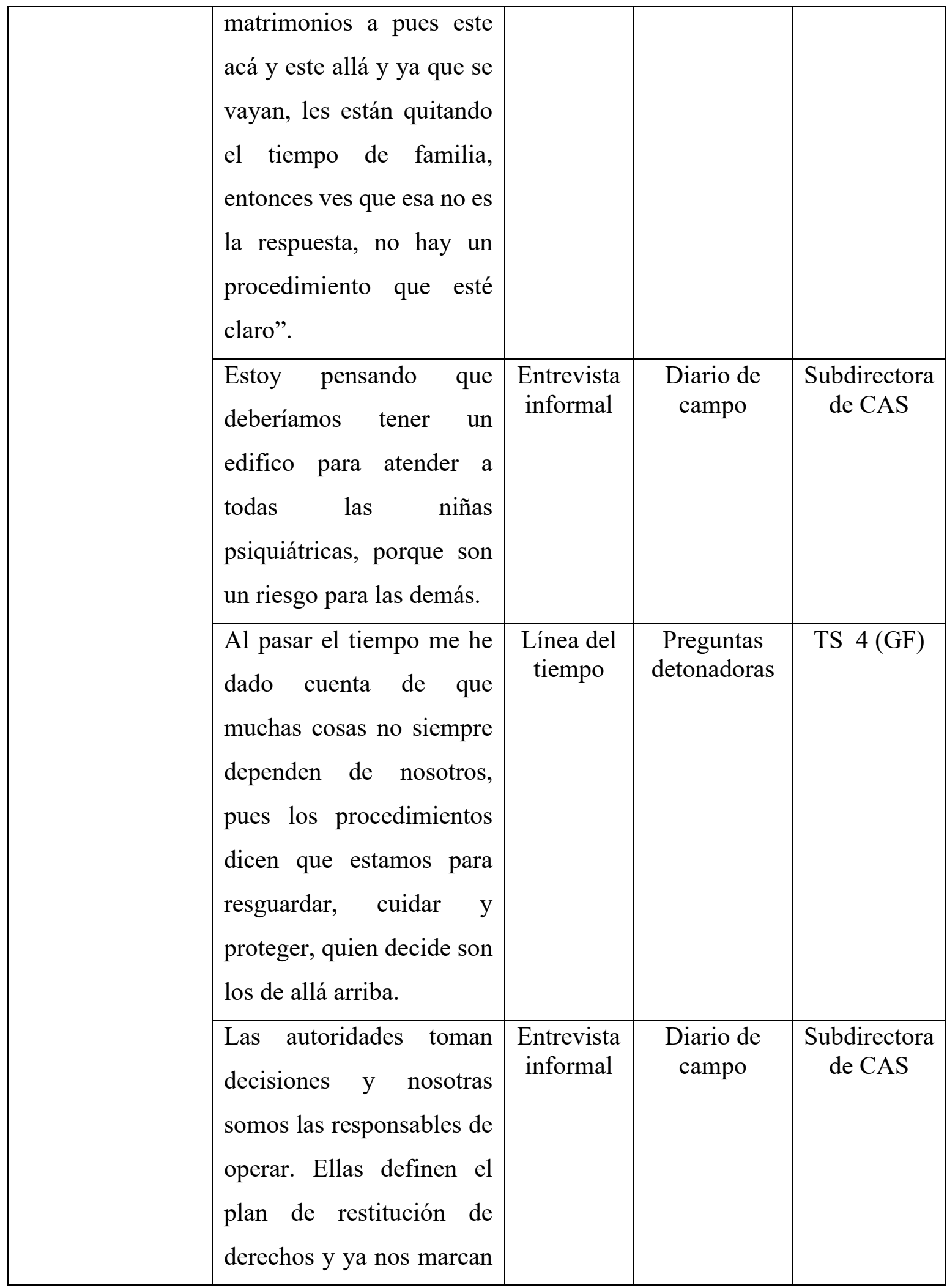




\begin{tabular}{|c|c|c|c|c|}
\hline & $\begin{array}{l}\text { la ruta de trabajo con los } \\
\text { niños y sus familias. }\end{array}$ & & & \\
\hline \multirow{4}{*}{ 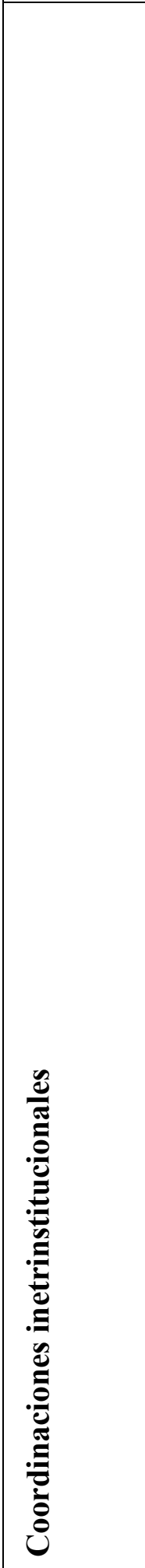 } & $\begin{array}{l}\text { Ahora, el proceso de } \\
\text { adopción, hecho desde lo } \\
\text { fragmentado, no llega a } \\
\text { tener éxito, cada uno } \\
\text { interviene desde su } \\
\text { opinión. }\end{array}$ & $\begin{array}{l}\text { Línea del } \\
\text { tiempo }\end{array}$ & $\begin{array}{l}\text { Preguntas } \\
\text { detonadoras }\end{array}$ & TS 6 (GF) \\
\hline & $\begin{array}{l}\text { Conozco a algunos } \\
\text { compañeros de la } \\
\text { procuraduría y sé que } \\
\text { ellos, al igual que nosotros } \\
\text { también están sufriendo; } \\
\text { quienes conocen las } \\
\text { realidades de los niños } \\
\text { somos los que estamos } \\
\text { aquí en los centros y ellos } \\
\text { al pertenecer a una } \\
\text { institución nueva, no } \\
\text { saben. }\end{array}$ & $\begin{array}{l}\text { Línea del } \\
\text { tiempo }\end{array}$ & $\begin{array}{l}\text { Preguntas } \\
\text { detonadoras }\end{array}$ & TS 1 (GF) \\
\hline & $\begin{array}{l}\text { Principales problemáticas: } \\
\text { ingresos por PGJDF, } \\
\text { solicitud de familiar y a } \\
\text { petición de otras } \\
\text { instituciones. }\end{array}$ & $\begin{array}{l}\text { Línea del } \\
\text { tiempo }\end{array}$ & $\begin{array}{c}\text { Preguntas } \\
\text { detonadoras }\end{array}$ & TS 3 (GF) \\
\hline & $\begin{array}{l}\text { Las valoraciones ahora } \\
\text { son complicadas porque } \\
\text { nosotras ya no tenemos } \\
\text { contacto con los } \\
\text { matrimonios, ver las }\end{array}$ & $\begin{array}{l}\text { Línea del } \\
\text { tiempo }\end{array}$ & $\begin{array}{c}\text { Preguntas } \\
\text { detonadoras }\end{array}$ & TS 2 (GF) \\
\hline (4) & & & & 量 \\
\hline
\end{tabular}




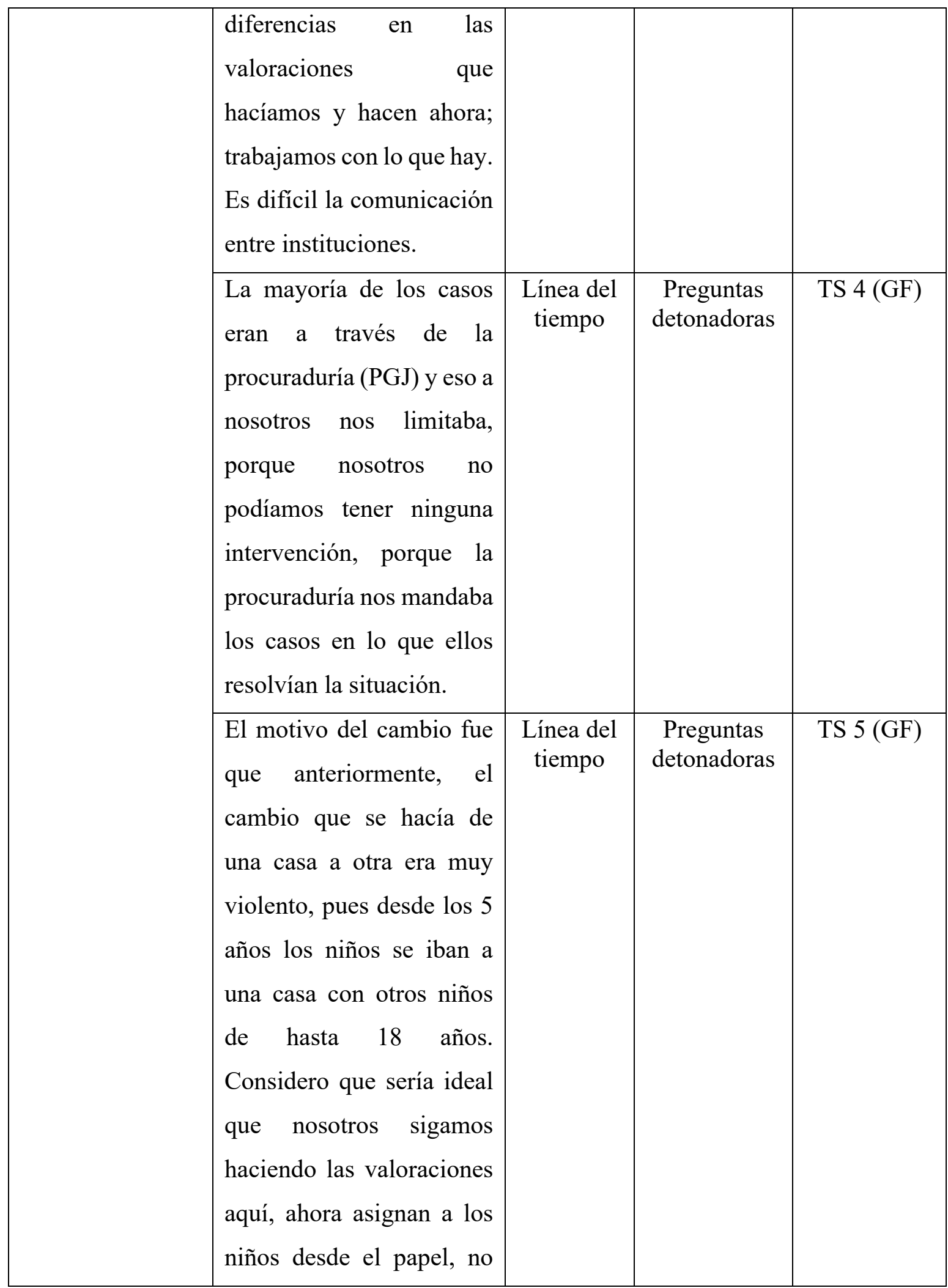




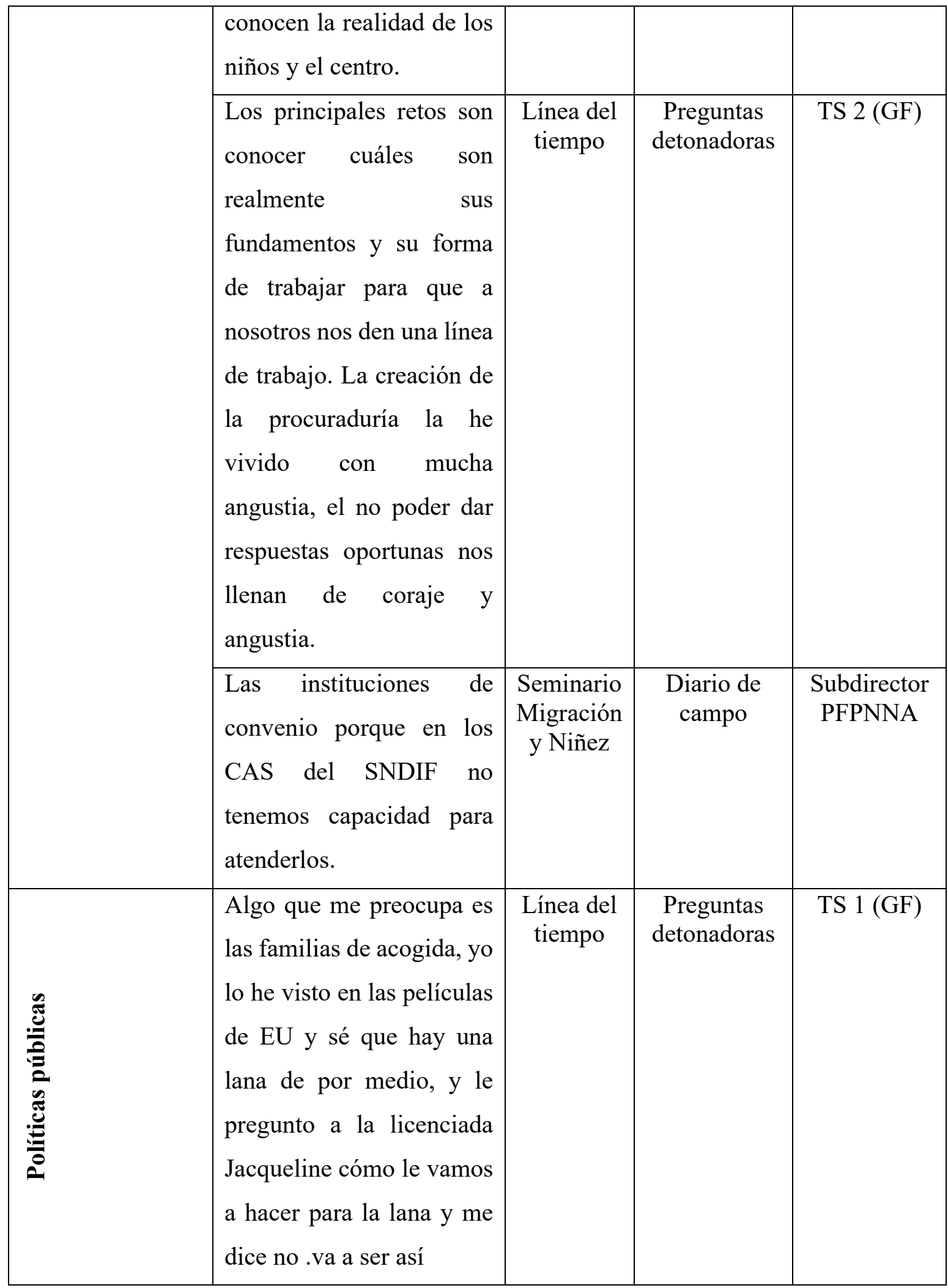




\begin{tabular}{|c|c|c|c|c|}
\hline & $\begin{array}{l}\text { La mayor parte de nuestro } \\
\text { trabajo se centraba en las } \\
\text { adopciones, desde la } \\
\text { entrevista filtro, } \\
\text { orientaciones, generar } \\
\text { solicitudes, valoración, } \\
\text { asignación de los niños y } \\
\text { convivencias. }\end{array}$ & $\begin{array}{l}\text { Línea del } \\
\text { tiempo }\end{array}$ & $\begin{array}{c}\text { Preguntas } \\
\text { detonadoras }\end{array}$ & TS 4 (GF) \\
\hline & $\begin{array}{l}\text { Con los nuevos cambios } \\
\text { ahora aparece la familia de } \\
\text { acogida, pero no sabemos } \\
\text { cómo va a funcionar. }\end{array}$ & $\begin{array}{l}\text { Entrevista } \\
\text { informal }\end{array}$ & $\begin{array}{l}\text { Diario de } \\
\text { campo }\end{array}$ & $\mathrm{TS}$ \\
\hline & $\begin{array}{l}\text { Yo me preguntó Gaby, la } \\
\text { mejor opción será } \\
\text { desaparecer los Centros de } \\
\text { Asistencia Social, hay } \\
\text { muchas personas que } \\
\text { dicen que ya no están } \\
\text { funcionando. Antes había } \\
\text { muchos niños, ahora ya } \\
\text { no. }\end{array}$ & $\begin{array}{l}\text { Entrevista } \\
\text { informal }\end{array}$ & $\begin{array}{l}\text { Diario de } \\
\text { campo }\end{array}$ & $\mathrm{TS}$ \\
\hline & $\begin{array}{l}\text { Antes llegábamos a tener } \\
\text { hasta } 120 \text { niños en el } \\
\text { Centro, cada vez hay } \\
\text { menos, pero yo no creo } \\
\text { que se deba a que ya no lo } \\
\text { necesitan, sino a las } \\
\text { nuevas políticas } \\
\text { institucionales. No sé qué } \\
\text { vamos a hacer sin niños, }\end{array}$ & $\begin{array}{l}\text { Entrevista } \\
\text { informal }\end{array}$ & $\begin{array}{l}\text { Diario de } \\
\text { campo }\end{array}$ & $\begin{array}{c}\text { Subdirectora } \\
\text { de CAS }\end{array}$ \\
\hline (4) & & & & 总 \\
\hline
\end{tabular}




\begin{tabular}{|l|l|l|l|c|}
\hline & $\begin{array}{l}\text { somos más trabajadores } \\
\text { que población. }\end{array}$ & & \\
\cline { 2 - 5 } & $\begin{array}{l}\text { Cuando se hizo el cambio } \\
\text { de modelo, se llevaron a } \\
\text { los niños sin decir nada, } \\
\text { ellos lloraban. }\end{array}$ & $\begin{array}{c}\text { Entrevista } \\
\text { informal }\end{array}$ & $\begin{array}{c}\text { Diario de } \\
\text { campo }\end{array}$ & TS \\
\hline
\end{tabular}

